\title{
Jean Meynaud
}

Professeur de science politique

Aux Universités de Genève et de Lausanne

\section{(1961)}

\section{Les groupes de pression internationaux}
Un document produit en version numérique par Mme Marcelle Bergeron, bénévole Professeure à la retraite de l’École Dominique-Racine de Chicoutimi, Québec et collaboratrice bénévole Courriel : Marcelle_Bergeron@uqac.ca

Dans le cadre de la collection : "Les classiques des sciences sociales" dirigée et fondée par Jean-Marie Tremblay, professeur de sociologie au Cégep de Chicoutimi Site web: http://classiques.uqac.ca/

Une collection développée en collaboration avec la Bibliothèque Paul-Émile-Boulet de l'Université du Québec à Chicoutimi Site web:_ http://bibliotheque.uqac.ca/ 


\section{Politique d'utilisation de la bibliothèque des Classiques}

Toute reproduction et rediffusion de nos fichiers est interdite, même avec la mention de leur provenance, sans l'autorisation formelle, écrite, du fondateur des Classiques des sciences sociales, Jean-Marie Tremblay, sociologue.

Les fichiers des Classiques des sciences sociales ne peuvent sans autorisation formelle:

- être hébergés (en fichier ou page web, en totalité ou en partie) sur un serveur autre que celui des Classiques.

- servir de base de travail à un autre fichier modifié ensuite par tout autre moyen (couleur, police, mise en page, extraits, support, etc...),

Les fichiers (.html, .doc, .pdf, .rtf, .jpg, .gif) disponibles sur le site Les Classiques des sciences sociales sont la propriété des Classiques des sciences sociales, un organisme à but non lucratif composé exclusivement de bénévoles.

Ils sont disponibles pour une utilisation intellectuelle et personnelle et, en aucun cas, commerciale. Toute utilisation à des fins commerciales des fichiers sur ce site est strictement interdite et toute rediffusion est également strictement interdite.

\section{L'accès à notre travail est libre et gratuit à tous les utilisateurs. C'est notre mission.}

Jean-Marie Tremblay, sociologue

Fondateur et Président-directeur général, LES CLASSIQUES DES SCIENCES SOCIALES. 
Un document produit en version numérique par Mme Marcelle Bergeron, bénévole, professeure à la retraite de l’École Dominique-Racine de Chicoutimi, Québec.

Courriel : marcelle_bergeron@uqac.ca

Jean MEYNAUD

Les groupes de pression internationaux.

Lausanne : Jean Meynaud, 1961, 560 pp. Collection : ÉTUDES DE SCIENCE POLITIQUE, ${ }^{\circ} 3$.

[Autorisation formelle accordée parles ayant-droit de l'œuvre de Jean Meynaud, son épouse, Mme Meynaud-Zogrphos, Michel Meynaud (fils) et Hélène-Yvonne Meynaud (fille) le 19 octobre 2008 de diffuser toutes les œuvres de Jean Meynaud dans Les Classiques des sciences sociales.]

8.f Courriels :

Mme Meynaud-Zographos (épouse) : meynaud-zographos@orange.fr

Hélène-Yvonne Meynaud (fille) : $\quad$ hymeynaud@free.fr.

Polices de caractères utilisés :

Pour le texte : Times New Roman, 12 points.

Pour les citations : Times New Roman 10 points.

Pour les notes de bas de page : Times New Roman, 10 points.

Mise en page sur papier format : LETTRE (US letter), 8.5’’ x 11'’)

Édition électronique réalisée avec le traitement de textes Microsoft Word 2007 pour Windows.

Édition réalisée le 15 juillet 2010 et complétée le 28 juillet 2010 à Chicoutimi, Ville de Saguenay, Québec. 


\section{Jean Meynaud}

(1961)

\section{Les groupes de pression internationaux.}

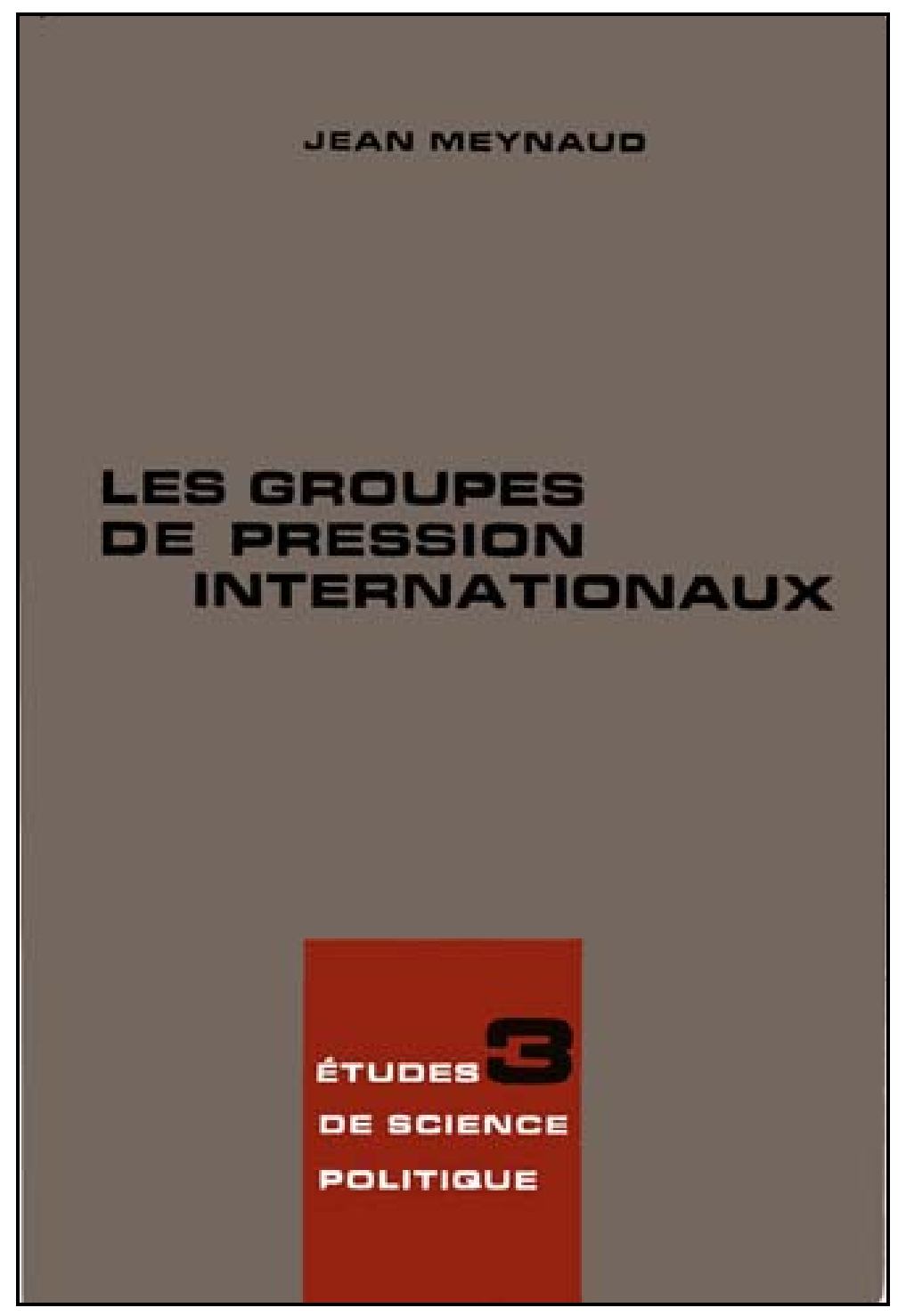

Lausanne: Jean Meynaud, 1961, 560 pp. Collection: ÉTUDES DE SCIENCE POLITIQUE, $\mathrm{n}^{\circ} 3$. 
[p. 2]*

\section{AUTRES OUVRAGES DE L'AUTEUR SUR LES GROUPES DE PRESSION}

Les groupes de pression. Paris, Presses Universitaires de France, 1960. (Que sais-je? 895.)

Les groupes de pression en France. Paris, Librairie Armand Colin, 1958. (Cahiers de la Fondation Nationale des Sciences Politiques. 95.)

\section{DANS LA MÊME COLLECTION \\ (Études de science politique, 6, Chemin de Mornex, Lausanne)}

1. La science politique : fondements et perspectives. 1960.

2. Technocratie et Politique. 1960.

* [Les numéros entre accolades réfèrent aux numéros de pages de l’édition de papier, MB.] 
[p. 557] *

\section{TABLE DES MATIÈRES}

\section{AVANT-PROPOS}

\section{CHAPITRE I : TABLEAU DES FORCES}

1. Internationales de partis

a) Rappel historique

b) Situation actuelle

c) Les sociétés secrètes

d) Autres formes de contact

2. Internationales syndicales

a) Rappel historique

b) Situation actuelle

c) Syndicalisme africain

d) Syndicalisme étudiant

3. Internationales d'affaires

a) Groupes et affaires capitalistes

b) Banquiers et financiers

c) Cartels internationaux

d) Associations professionnelles

e) Entreprises internationales

4. Internationales religieuses
a) Éléments du problème
b) Église catholique
c) Église orthodoxe
d) Protestantisme
e) Judaïsme
f) Islam

5. Mouvements de revendication nationale

a) La résurrection d'une nation : le sionisme

b) Un mouvement de rénovation nationale : l'arabisme

c) Mouvements pour l'indépendance

d) Les réfugiés

* [Les numéros entre accolades réfèrent aux numéros de pages de l'édition de papier, MB.] 
[p. 558]

6. Organismes d'inspiration humanitaire

a) Défense des victimes

b) Protection de la famille

c) Amélioration de l'existence

7. Mouvements de développement moral

a) Combat contre les préjugés raciaux

b) Promotion des droits de l'homme

c) Diffusion d'idéologies

8. Observations finales

\section{CHAPITRE II : ÉLABORATION DU SCHÉMA}

1. Incertitudes méthodologiques

a) Action publique et pression privée

b) Interventions individuelles et collectives

c) Activités organisées et tendances diffuses

2. À la recherche d'un critère : le statut de l'organisme

a) Cas des sociétés commerciales

b) Cas des associations

Éléments d'information, 179. Traits caractéristiques, 182. Statut des organismes, 186. Formules de regroupement, 189.

c) Nature du groupement et dimensions de l'activité

3. À la recherche d'un critère : la qualité de l'influence

a) Politique internationale et pression sur les gouvernements. Les acteurs, 197. Rôle des groupes nationaux, 200.

Critère de distinction, 206.

b) Politique intérieure et pression sur les gouvernements

\section{Esquisse dune typologie}

a) Utilisation indifférenciée de la notion de groupe

Bilan de l'extension, Application aux forces, Portée de la formule,

b) Une typologie dualiste : groupes nationaux et internationaux

Conception large. Proposition restrictive

c) Adaptation de la typologie aux analyses nationales

[p. 559]

\section{5. Éléments de classification}

Groupes de pression purs et occasionnels Groupes de pression durables et temporaires Organisations sans but lucratif et groupes à la recherche du profit. Groupements « intéressés » ou " désintéressés ». Groupements fondés sur des caractéristiques objectives ou sur des attitudes. Classification fondée sur l'agencement des structures. Capacité « autonome » et « dérivée » 


\section{CHAPITRE III : POINTS D'APPLICATION}

\section{Organisations intergouvernementales}

a) Introduction des groupes dans les organes dirigeants

b) Technique des arrangements consultatifs

Nations Unies (O.N.U.). Unesco. Autres organisations. Valeur du système.

c) Relations de fait

Conseil de l'Europe et O.E.C.E. Communauté Européenne du Charbon et de l'Acier. Communauté Économique Européenne. Appréciation globale.

\section{Institutions nationales}

a) Motifs du choix de ce niveau

b) Caractéristiques de l'intervention

3. Opinion publique
a) Aspects et nature de l'opinion mondiale

b) Modalités d'action des groupes

Techniques d'intervention sur l'opinion. Étude de quelques cas.

c) Dimensions de l'influence sur l'opinion,

\section{CHAPITRE IV : PREMIER BILAN}

1. Place dans la vie politique

a) Exigences d'une analyse scientifique

b) Intérêts économiques et pouvoir politique

Rappel de la thèse léniniste. Évaluation de cette thèse. Les transformations dans les rapports internationaux. De l' « exploitation » à la « domination ».

c) Poids des contraintes matérielles

[p. 560]

d) Rôle des organisations non gouvernementales

Groupements à buts économiques ou professionnels. Internationales religieuses et idéologiques. Internationales syndicales.

e) Développement de la compréhension internationale

f) Groupes internationaux et vie politique.

Groupes et politification. Groupes et politisation. Position propre des groupes.

\section{Intégration à la théorie}

a) Diversité des niveaux de l'analyse politique

b) Caractéristiques de l'approche suggérée

c) Suggestions pour une étude approfondie 


\section{CONCLUSION}

Notes bibliographiques

Appendice documentaire

Index des auteurs

Liste des organisations citées

Index des sujets

[p. 5] *

* [Les numéros entre accolades réfèrent aux numéros de pages de l'édition de papier, MB] 


\section{AVANT-PROPOS}

Retour à la table des matières

CE TRAVAIL trouve son fondement dans les efforts entrepris pour appliquer à l'étude des relations internationales la catégorie " groupes de pression ». D'un emploi courant dans l'examen de l'action gouvernementale intérieure, cette notion n'est pas encore pleinement utilisée pour l'explication des rapports entre les pays. Ce décalage, particulièrement sensible chez les spécialistes européens, ne semble pas imposé par la nature des choses: il résulte simplement de l'insuffisance les liaisons entre les diverses branches de la science politique. On forme l'espoir que ce livre contribuera à l'unification méthodologique de la discipline en incitant les chercheurs à se servir, pour l'analyse de la vie internationale, d'un schéma qui a fait ses preuves sur le plan des phénomènes internes et que l'on supposera connu du lecteur dans ses grandes lignes.

Cependant, l'objet propre de cet ouvrage n'est pas de plaider pour une extension dont le principe a déjà suscité de nombreuses réflexions théoriques et quelques applications pratiques. On s'efforcera d'établir qu'il est possible d'améliorer la connaissance du sujet en ayant recours au concept "groupe de pression international ». Il s'agit, en somme, non de découvrir des faits encore inconnus, mais de présenter un cadre spécifique d'interprétation permettant de tirer un meilleur parti des données disponibles et, notamment, de l'immense matériel assemblé par les historiens.

Le concept sur lequel on va raisonner est donc de nature empirique. Il a pour rôle de faciliter la classification et la compréhension d'un certain ordre de comportement. Il ne saurait avoir d'autre justification que l'utilité. Autrement dit, le critère auquel on entend soumettre cette recherche est la valeur opérationnelle de la formalisation énoncée.

Cette tentative n'est pas à l'abri de la controverse. Elle repose sur la [p. 6] certitude qu'il est souhaitable d'étendre aux rapports internationaux le schéma «forces de pression » (dont chacun sait qu'il est affecté de plusieurs imperfections théoriques). Mais l'acceptation de ce point de vue n'oblige pas à tomber d'accord sur l'opportunité d'instituer une différenciation à l'intérieur des groupements. Il est prudent et équitable de prévenir le lecteur que la sélection d'un ou plusieurs facteurs particularisant le « groupe de pression international » soulève des difficultés considérables et se heurte à de sérieuses objections. 
C'est au professeur Jacques Freymond que je suis redevable de l'inspiration initiale de cette étude. Le point de départ en a été un cours temporaire fait, en mai 1957, à l'Institut Universitaire de Hautes Études Internationales. On offre ici le résultat des recherches poursuivies depuis lors, sans songer à dissimuler les défauts et lacunes de ce premier essai. Il est aisé de remonter à leur source.

On n'aura pas besoin d'insister sur l'ampleur du thème abordé : l'exploration systématique de ses divers aspects dépasse la capacité d'un chercheur isolé. Mais, si l'on met à part le cas des États-Unis, rares sont encore les spécialistes en science politique qui peuvent s'appuyer sur une équipe d'enquêteurs expérimentés ou, plus modestement, disposent d'un bon service de documentation. Cette situation conduit à réaliser, à une échelle individuelle, des projets dont l'élaboration et l'exécution devraient être collectives. Ce travail n'a pas échappé à une telle servitude dont l'ultime conséquence est d'inciter à l'abstention ou d'obliger à prendre les risques intellectuels qui découlent inévitablement d'une investigation partielle.

Beaucoup en tirent la conclusion qu'il est préférable de se contenter de recherches d'allure monographique et de renvoyer à plus tard la formulation d'un cadre général. La suggestion n'est pas sans attrait et semble en harmonie avec les exigences de la méthode expérimentale. Cependant, pour une discipline aussi jeune que la science politique, sa Mise en œuvre aboutirait à une véritable capitulation.

Sans présentation d'ensemble, qui explicite et situe les phénomènes, il n'existe pas de stimulant pour l'établissement de telles monographies. Admettons que cet obstacle soit surmonté: le manque d'un schéma global, provoquant infailliblement une dispersion des efforts, conduirait [p. 7] à l'acquisition de résultats hétérogènes dont l'inutilité, pour la construction de la théorie, n'est plus à démontrer. Ces observations, aujourd'hui très banales, imposent la réalisation prioritaire d'un canevas de référence : elles obligent en même temps à le traiter comme une, hypothèse de travail.

La méthodologie de cette étude s'exprime dès lors en quelques mots : identifier les faits considérés et construire un schéma théorique qui permette de les rapprocher, de les classer, de les interpréter. Le propre de cette démarche est de postuler un constant va-et-vient entre les faits et la théorie. Position certes sans originalité : elle est effectivement celle de tous les spécialistes qui s'efforcent, avec des fortunes diverses, d'améliorer la connaissance positive des sociétés humaines.

Cette conception, en dépit de sa netteté, reste exclusive de tout aveuglement sur le sens et la portée des opérations effectuées ou des outils utilisés. Psychologues et sociologues ont depuis longtemps éclairé les chercheurs sur les infirmités du jugement humain ; ils ont établi le caractère utopique et l'aspect naïf des prétentions à une objectivité absolue. Le premier devoir du spécialiste est de faire preuve d'esprit critique à l'égard de ses propres exposés. Mais, ces réserves exprimées, la recherche positive reste l'instrument privilégié et en quelque sorte la seule voie disponible pour l'observation et l'explication des phénomènes de la vie sociale.

Difficile à pratiquer, cette méthode est souvent décevante dans ses résultats immédiats. Elle exige une longue patience qui risque d'indisposer, et parfois de décourager, les chercheurs. Il arrive souvent que l'exploitation d'une masse 
considérable de données permette tout au plus de dégager des constatations préliminaires ou des observations secondaires. Mais ce déblaiement progressif du terrain, représentatif du stade actuel de la science politique, est la condition nécessaire pour atteindre une connaissance complète ou, si l'on préfère, le prix à acquitter.

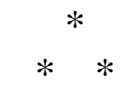

Cet ouvrage comporte une somme de notes bibliographiques assez considérable. Elle englobe les matériaux - disons plus franchement, une petite partie d'entre-eux sur lesquels il semble possible de se fonder pour la [p. 8] construction de la catégorie " groupe de pression international » (qui ne paraît pas encore avoir donné lieu ellemême à un examen systématique). Cette masse de références ne répond ni au souhait d'exposer une érudition qui reste fragmentaire, ni au désir de trouver une justification aux positions prises. Sur de très nombreux points ces notes prolongent le texte et ouvrent des perspectives supplémentaires. Un souci a présidé à leur établissement : celui de faciliter la tâche des étudiants qui seront parfois amenés à considérer ce livre comme un instrument de travail.

Un tel appareil provoque inévitablement une surcharge typographique s'il est distribué au bas des pages. Afin d'éviter l'incommodité qui en résulte pour le lecteur s'intéressant seulement au texte, on a décidé de le reporter en fin de volume * avec les index.

Lausanne, décembre 1960.

[Dans cette édition électronique les notes de fin ont été converties en notes de bas de page, MB.] 
[p. 9]

\section{CHAPITRE I}

\section{TABLEAU DES FORCES}

$\underline{\text { Retour à la table des matières }}$

L'ÉLABORATION du concept « groupe de pression international » est une tâche complexe. En tout état de cause, la discussion sera plus facile et significative, si elle s'appuie sur l'examen préalable d'un ensemble d'organismes concrets et de conduites effectives. Ce chapitre a précisément pour objet d'exposer l'activité des groupements capables ou désireux d'intervenir sur la scène internationale en vue d'influencer, directement et indirectement, les États ou institutions qui les rassemblent (et que, conformément à l'usage, on appellera " organisations intergouvernementales »). Le terme " groupement » est pris ici en un sens très large, l'effort de décomposition étant renvoyé au chapitre suivant.

Cette formule couvre, sans aucun doute, une matière très riche. Les travaux des savants, comme aussi les écrits des journalistes, se réfèrent constamment à des forces qui sont censées mener ou inspirer le jeu. Le sujet relève à la fois de l'argumentation scientifique et de l'imputation polémique. On note, certes, d'un plan de raisonnement à l'autre des différences importantes, sinon essentielles, dans le choix de la terminologie et l'appréciation de la puissance exercée ; mais l'existence de ces forces - cartels internationaux et internationales syndicales, sociétés religieuses et mouvement communiste... - n'est guère contestée. Dès lors, en présentant ces phénomènes, on ne risque pas, à condition d'éviter les stéréotypes et les mythes ainsi que les sélections partisanes, de s'écarter de la zone des comportements identifiables et observables.

[p. 10] Cette efficacité a toutefois une contre partie : si l'on se borne à exprimer le jugement commun ou quasi-universel, la formule n'apporte aucun élément de classification. Elle conduit presque fatalement à dresser un tableau sans lignes directrices. Mais ce danger est mineur si on le compare à celui de choix arbitraire qu'entraînerait un critère préconçu. Il est donc préférable, pour ainsi dire, d'étaler les cartes en suivant les orientations livrées par les conceptions courantes. Quand viendra la formulation théorique, cette documentation permettra d'en évaluer, avec une relative sécurité, la valeur heuristique. 
Ce tableau comporte deux particularités. Il n'est pas exhaustif et, d'ailleurs, ne saurait l'être à cause de la fluidité des rapports étudiés : pour des raisons évidentes, on a dû se borner à dégager des types et à illustrer chacun de quelques exemples. En second lieu, il est purement signalétique : la description analytique de la structure et de l'activité des multiples organismes, mentionnés sortirait du cadre, nécessairement restreint, de ce volume. Au surplus, sur de nombreux points, les données, scientifiquement établies ou vérifiées, manquent toujours.

Soulignons une dernière caractéristique : la juxtaposition de groupes dont on peut, légitimement marquer la grande inégalité de puissance. À côté de ceux « capables » d'influencer, on a aussi voulu accorder une place à ceux « désireux » de le faire. On peut accepter l'idée d'une hiérarchie de capacité sans oublier pourtant que l'absence encore totale d'outils de mesure (même en termes de classification ordinale) rend tout essai de pondération incertain et presque inévitablement subjectif. Il en va notamment ainsi quand il s'agit d'évaluer les conséquences de l'action de ces forces sur l'opinion publique. Or ce mode d'intervention aux résultats souvent diffus, constitue aujourd'hui l'objectif essentiel d'un grand nombre des organisations considérées

[p. 11]

\section{INTERNATIONALES DE PARTIS}

\section{$\underline{\text { Retour à la table des matières }}$}

Elles expriment et systématisent, de façon diverse, les relations instituées entre formations nationales dont l'objectif est, selon la définition classique, de conquérir et de conserver le pouvoir. On peut concevoir, pour le centre international, une mission d'aide matérielle et d'appui moral, mais aussi une fonction d'inspiration, de coordination et, à la limite, de direction. Encore que l'activité exercée ait été et demeure de portée fort variable, il est nécessaire d'analyser les conséquences de la création et du fonctionnement de tels organismes.

Ces internationales représentent l'essentiel du dispositif existant en matière de relations interpartisanes. Cependant, on ne saurait passer sous silence les sociétés secrètes auxquelles le public prête volontiers une puissance et une obstination considérables. Enfin, on évoquera brièvement quelques autres formes nouvelles de contact.

\section{a) RAPPEL HISTORIQUE}

La décision prise à Londres en septembre 1864 de fonder l'Association Internationale des Travailleurs, marque le point de départ de l'évolution. Pour Marx qui en fut le principal inspirateur, Cette $\mathrm{I}^{\text {re }}$ Internationale devait assurer la mobilisation des forces ouvrières en vue de réaliser la révolution prolétarienne. 
L'échec de la Commune, en dépit des avis et des appuis fournis par le Conseil général de l'organisation, allait bientôt établir le caractère prématuré de l'entreprise.

Tout en soulignant la faiblesse des résultats immédiats, les commentateurs sont, dans l'ensemble, d'accord pour marquer la répercussion à long terme de ce rassemblement. Évoquons en particulier le $\mathrm{V}^{\mathrm{e}}$ Congrès (La Haye, 2-7 septembre 1872) où les thèses marxistes finirent par triompher. Le congrès se prononça pour la constitution dans chaque pays d'un parti politique destiné à réunir les masses ouvrières contre les tenants de l'ordre établi et les organismes des classes dirigeantes. C'est sur de tels partis que Marx comptait pour « faire ressusciter l'Internationale sous une forme améliorée ${ }^{1}{ }^{1}$.

Cette vue s'est révélée juste en apparence. Durant les dix-sept ans qui vont s'écouler jusqu'à la création de la III $^{\mathrm{e}}$ Internationale (Paris, juillet 1889), l'encadrement des travailleurs a progressé dans de nom-[p. 12] breux pays. S'appuyant sur des partis socialistes, dont plusieurs (ainsi la social-démocratie allemande) constituent des forces déjà solides, cette nouvelle version de l'Internationale Ouvrière paraît devoir en obtenir la puissance et la cohésion qui avaient manqué à sa devancière. Mais, pour avoir surestimé le poids des solidarités de classe, elle était, elle aussi, appelée à connaître un effondrement complet ${ }^{2}$.

Retenons, comme très significative pour notre propos, la résolution votée au Congrès de Stuttgart (1907) en conclusion du débat sur « le militarisme et les conflits nationaux ». Dans ses stipulations essentielles, elle enjoignait aux travailleurs, en cas de menace de conflit, de « faire tous leurs efforts pour empêcher la guerre par tous les moyens qui leur paraissent les mieux appropriés » : cependant, si la guerre éclatait quand même, ils auraient le devoir «de s'entremettre pour la faire cesser promptement et d'utiliser de toutes leurs forces la crise économique et politique créée par la guerre pour agiter les couches populaires les plus profondes et précipiter la chute de la domination capitaliste ».

Ainsi l'Internationale acceptait-elle des obligations révolutionnaires, mais, en même temps, et par un curieux paradoxe, elle refusait d'envisager l'utilisation préfixée

1 Texte cité dans l'article sur la I In Internationale de la grande Encyclopédie soviétique (repris dans la brochure Les trois Internationales, Paris, 1955, p. 27). Sur le Congrès de La Haye, voir GERTH (Hans) (ed.), The First International Minutes of the Hague Congress of 1872 with related documents, Madison (Wisconsin), 1958. Il s'agit des notes d'un délégué allemand récemment découvertes et publiées pour la première fois. On trouvera une bibliographie complète des périodiques concernant la I ${ }^{\text {re }}$ Internationale in Répertoire international des sources pour l'étude des mouvements sociaux aux $\mathrm{XIX}^{\mathrm{e}}$ et $X X^{e}$ siècles, vol. 1, La Première Internationale. Périodiques, 1864-1877, Paris, 1958. Voir également BABEL (A.), « La première Internationale, ses débuts et son activité à Genève de 1864 à 1870 », in Mélanges d'études économiques et sociales offerts à William E. Rappard, Genève, 1944, pp. 225-364 : l'auteur fournit, en introduction, une liste des travaux les plus importants sur cette Internationale.

2 Voici les trois ouvrages les plus récents sur la $\mathrm{II}^{\mathrm{e}}$ Internationale: JOLL, (James), The Second International, 1899-1914, Londres, 1955 ; COLE (G.D.H.), A History of Socialist Thought, vol. III, The Second International, 1899-1914, Londres, 1956 (deux tomes); VAN DER ESCH (Patricia), La Deuxième Internationale, 1889-1923, Paris, 1957. 
de certains moyens, en réalité la grève générale, pour empêcher le déclenchement du conflit : le texte se bornait à préconiser l'emploi d'instruments variant " selon l'acuité de la lutte des classes et la situation politique générale »... Le Congrès de Bâle (1912), bien que s'en tenant à la plus pure phraséologie internationaliste, continua à se taire sur la nature et l'ampleur des moyens concrets à mettre en œuvre contre la guerre. Dès cette époque, il devenait possible de prévoir l'impuissance de la $\mathrm{II}^{\mathrm{e}}$ Internationale à l'heure des hostilités ${ }^{1}$.

Pour expliquer la défaite totale de juillet 1914, cette incapacité complète au combat, Lénine a mis en cause l'opportunisme du bureau dirigeant, «boîte aux lettres » à l'usage des éléments parlementaires, et non organe révolutionnaire capable de soulever les masses. Il est vrai que l'Internationale n'a jamais su faire de choix décisif entre les différentes tendances qui la composaient. Plus exactement, la majorité, pour voiler son esprit réformiste, était contrainte à une grande intransigeance doctrinale dans les proclamations. Ce verbalisme avait peut-être une excuse : la résistance de la solidarité nationale à toutes les campagnes propres à l'entamer. Seuls les forts peuvent se permettre un langage modéré, comme tant d'autres organismes qui devaient la suivre, l'Internationale laissait éclater sa fragilité par l'outrance de ses déclarations publiques.

[p. 13] Il n'apparaît que les diverses conférences socialistes tenues durant la première guerre mondiale aient eu une influence quelconque sur le déroulement des hostilités. Par contre, la Révolution russe de 1917 allait entraîner des conséquences profondes en suscitant la montée de nouvelles forces et en provoquant une rupture sur laquelle le monde des travailleurs n'a pu revenir.

À l'issue du conflit, des négociations intervinrent immédiatement pour la reconstitution de l'Internationale. En raison de diverses péripéties, elles ne purent aboutir définitivement qu'en 1923. Lors du congrès tenu à Hambourg en mai de cette année-là, le nouvel organisme prit le nom d'Internationale Socialiste Ouvrière. Se réclamant d'une idéologie marxiste rigoureuse, il devait lui aussi témoigner d'une modération certaine dans la pratique. On n'a pas le sentiment qu'il ait exercé une pesée notable sur les affaires internationales. L'expansion du fascisme, dont de nombreux socialistes sous-estimèrent le danger, lui porta de rudes coups. Mais, dès le début, un autre péril le guettait et, en une certaine mesure, le paralysait : la présence d'une Internationale Communiste, fondée à Moscou dans le sillage de la Révolution d'Octobre.

La III ${ }^{\mathrm{e}}$ Internationale (dont on peut faire remonter l'origine à l'action du noyau « de gauche » lors de la conférence tenue à Zimmerwald en septembre 1915) vit le jour à Moscou en mars 1919. Dès le congrès de l'année suivante (juillet-août 1920), les délégués présents, envoyés de 37 pays, acceptèrent les «vingt et une conditions d'admission » destinées à écarter de la nouvelle association aussi bien les

1 Sur ces problèmes, on pourra consulter DRACHKOVITCH (Milorad M.), Les socialismes français et allemand et le problème de la guerre 1870-1914, Genève, 1953. 
opportunistes de droite que les sectaires de gauche ${ }^{1}$. La mise en œuvre de ces conditions à l'échelon national, devait provoquer l'éclatement de plusieurs partis socialistes et marquer de façon durable la vie politique de divers pays (dont la France). Un accord s'étant révélé impossible avec l'Internationale Socialiste en voie de reconstitution, l'Internationale Communiste devenait une force politique spécifique.

On n'entreprendra pas de décrire ici les péripéties et vicissitudes de l'action engagée par le Komintern ${ }^{2}$. Durant une première phase, cet organisme, qui rassemblait les partis communistes du monde entier, eut une double fonction: coordonner la stratégie et assurer la direction du mouvement révolutionnaire mondial ; préserver l'État soviétique de la «contre-révolution » et de l'intervention étrangère. À cette époque, les membres du Komintern se comportaient entre eux comme des partenaires égaux: dans les quatre premiers congrès, la discussion s'engageait [p. 14] librement et certaines délégations ne craignaient pas de s'opposer aux directives venues du centre.

Cependant, dès le $\mathrm{V}^{\mathrm{e}}$ Congrès (Moscou, juin-juillet 1924), le système se transforme : l'emprise des dirigeants du Kremlin sur les partis étrangers s'étendant et s'approfondissant à mesure de l'ascension de Staline. Ce dernier, devenu maître de l'U.R.S.S., fait du Komintern un instrument de son pouvoir personnel : on observe alors - spécialement lors du dernier congrès, tenu en juillet-août 1935 — une interdépendance absolue entre l'Internationale Communiste et le gouvernement

1 La teneur de ces conditions doit être appréciée par rapport à l'ouvrage capital de LÉNINE (publié en avril 1920), La maladie infantile du communisme (le «gauchisme ») dont la dernière traduction en français remonte à 1953. Pour un commentaire général de la position léniniste, voir LAZITCH (Branko), Lénine et la IIIe Internationale, préface de Raymond Aron, Neuchâtel, 1951.

2 On en trouvera un résume rapide in LAZITCH (Branko), Les partis communistes d'Europe 19191955, Paris, 1956. On hésite à renvoyer le lecteur à la nouvelle Histoire du parti communiste de l'Union Soviétique, Moscou (Éditions en langues étrangères), 1960 : d'un conformisme absolu, elle n'apporte pratiquement rien sur ces problèmes. Pour une bonne étude de la question, se reporter à SCHAIPIRO (Leonard D.), The Communist Party of the Soviet Union. Londres, 1960. Pour les statuts du Komintern (initiaux et révisés) se reporter à FERLÉ (T.), Le communisme en France. Organisation, Paris, 1937, pp. 310-328. Pour une étude plus approfondie on se référera avant tout à SETON-WATSON (Hugh), The Pattern of Communist Revolution. A historical analysis, Londres, 1953, qui contient une riche bibliographie. Du même auteur, From Lenin to Khrushchev. The history of world communism, New York, 1960. Consulter aussi dans une autre perspective l'ouvrage partial, mais non sans intérêt, de HEILBRUNN (Otto), The Soviet Secret Service, Londres, 1956 (spécialement les chapitres V à IX). Sur la lutte entre socialisme et communisme, voir dans l'étude de COLE (G.D.H.), A History of Socialist Thought le volume V et dernier, Socialism and Fascism, 1931-1939, Londres, 1960 (spécialement le chapitre final où l'auteur compare la nature des deux mouvements). Voir aussi GIOLITTI (Antonio), Il comunismo in Europa, da Stalin à Krusciov, Milan, 1960. Mentionnons que Chatam House a entrepris la publication d'une série intitulée The Communist International 1919-1943. Documents. Deux volumes déjà parus : I, 1919-1922 ; II, 1923-1928 ; Londres, 1956-1960.

On pourra enfin utiliser l'étude bibliographique de R.N. CAIREW HUNT, Books on Communism, Londres, 1959, qui recense tous les ouvrages publiés en langue anglaise depuis une vingtaine d'années sur le mouvement communiste et l'U.R.S.S. 
soviétique. Finalement celui-ci, en juin 1943, dans le cadre de son alliance de guerre avec les nations occidentales, fait procéder à la dissolution de l'organisme.

Le Komintern s'est en définitive placé sur deux plans en vue d'influencer les affaires internationales : la fixation de la tactique des partis communistes nationaux et le réveil des pays colonisés. Ce sont là, en tout cas, les éléments qui confèrent à son activité une particulière originalité.

Entre les deux guerres, la tactique des partis communistes a été soumise à des tournants brutaux. Le plus important, par ses répercussions immédiates, est celui arrêté au Congrès de 1928, qui proclama la nécessité d'une nouvelle ère de radicalisation des masses et d'actions révolutionnaires. La social-démocratie, baptisée « social-fascisme », y fut désignée comme le principal ennemi. Il est inutile d'insister sur l'importance de cette position dont A. Grosser a pu déclarer que «l'arrivée de Hitler au pouvoir le 30 janvier 1933 sortira tout droit » ${ }^{1}$. Instruit par l'exemple, le Congrès de 1935 lancera la tactique des fronts populaires qui entraînera, en particulier, un revirement des partis communistes à l'égard de la défense militaire : on sait le rôle que cette formule a joué en France. On connaît également l'emploi fait jusque vers les années 1947-48 de la méthode dite de front national.

Quant à l'éveil des peuples colonisés, il apparaît, à la lumière des événements actuels, qu'on en a généralement sous-estimé l'ampleur. À vrai dire, il serait contraire aux faits de considérer l'anti-colonialisme comme une attitude propre au Komintern. En plusieurs de ses congrès, la II $^{\mathrm{e}}$ Internationale prit position contre l'exploitation des peuples de couleur par le capitalisme colonisateur. Deux facteurs affaiblissaient pourtant ces déclarations. D'abord l'équivoque qui se manifestait dans les rangs de l'Internationale sur le sens de la lutte anti-coloniale. Au Congrès de Stuttgart, le délégué hollandais Van Kol s'opposa à ceux qui réclamaient [p. 15] la libération immédiate des colonies, en soutenant la nécessité d'une «politique coloniale socialiste » activiste et réformatrice ; or, la résolution finalement adoptée, tout en condamnant le colonialisme, à une faible majorité il est vrai, retenait divers éléments de la thèse modérée. Par ailleurs, les proclamations de la $\mathrm{III}^{\mathrm{e}}$ Internationale restaient, sur ce point comme sur les autres, des vœux pieux ${ }^{2}$.

Avec le Komintern, le style de l'anti-colonialisme va changer. Dès septembre 1916, Lénine déclare que les mouvements d'insurrection des peuples colonisés sont, en réalité, des guerres de libération nationale qui conduiront à la défaite et à l'expropriation de la bourgeoisie dans le monde entier ${ }^{3}$. En d'autres termes, l'écrasement du capitalisme viendra d'une conjonction, mieux, d'une fusion de deux fronts : celui des insurrections et guerres nationales révolutionnaires, celui des guerres

En une intéressante et utile étude publiée dans le tome XI de l'« Encyclopédie française », La Vie Internationale, Paris, 1957.

2 Voir les commentaires de Jacques FREYMOND in Lénine et l'impérialisme, Lausanne, 1951, pp. 52-57.

3 In « Le programme militaire de la révolution prolétarienne », Euvres, tome XXIII, Août 1916-mars 1917, Moscou, 1959, pp. 84-96. Il est à peine besoin de rappeler ici les thèmes de L'impérialisme, stade suprême du capitalisme (dont la dernière publication en français remonte à 1952). 
et soulèvements du prolétariat contre la bourgeoisie. Dans cette perspective, l'émir du Yémen est plus " progressiste » qu'un député travailliste, car le premier vise à détruire l'impérialisme britannique que le second, au besoin sous une forme nouvelle, s'efforce de protéger. L'émancipation coloniale devient donc partie intégrante de la stratégie révolutionnaire : la route de Paris passe par Pékin.

Il serait sans aucun doute absurde de faire de cette activité la source exclusive du puissant mouvement de libération des peuples dépendants qui caractérise ce second après-guerre. Mais la $\mathrm{III}^{\mathrm{e}}$ Internationale en a constitué un facteur non négligeable, son action en ce sens s'étant intensifiée, une fois disparu l'espoir d'une extension immédiate de la révolution à l'Europe (et spécialement à l'Allemagne). Cette vocation s'affirme au Congrès de 1920 qui proclame que « ... l'Internationale Communiste doit entrer en relations et conclure des alliances temporaires avec les mouvements national-révolutionnaires dans les colonies et les pays arriérés... »: elle est encore présente au Congrès de 1935 pour lequel « le prolétariat des pays impérialistes, dans l'intérêt de sa lutte de libération, doit soutenir par tous les moyens la lutte libératrice des peuples coloniaux contre les envahisseurs impérialistes ». Dès le début, l'espoir s'affirme que les masses des pays arriérés, grâce à l'aide du prolétariat des pays développés, parviendront au communisme sans obligatoirement passer par les différents stades du capitalisme.

Il ne saurait être question ici d'examiner en détail cette action, dont le point de départ peut être fixé au Congrès des peuples de l'Orient, tenu à Bakou vers la fin de $1920{ }^{1}$. L'un des principaux aspects en a [p. 16] été la fondation d'une Université, dont on sait le rôle qu'elle a tenu dans la préparation des cadres communistes destinés aux pays afro-asiatiques. Dès les années 1920, quelque six cents Asiatiques suivaient des cours à Moscou ${ }^{2}$. Indiquons également, car ce fut un geste très expressif, que le $\mathrm{IV}^{\mathrm{e}}$ Congrès du Komintern décida d'étendre aux Noirs des États-Unis, les thèses sur la question coloniale et établit une série de directives à l'usage de sa section américaine ${ }^{3}$.

Le Komintern avait été dissous en 1943, mais dès octobre 1947, était rendue publique la création d'un Bureau d'Information des Partis Communistes (Kominform). Fondé lors d'une conférence tenue en Pologne au mois de septembre, il groupait les représentants de neuf partis (U.R.S.S., pays d'Europe orientale passés sous direction communiste, France et Italie). Était-ce une résurrection pure et simple de l'ancien Komintern?

Il ne le semble pas. Indiscutablement, l'opération correspondait à une volonté de durcissement. La déclaration mettait en cause notamment «la politique de trahison des socialistes de droite », lesquels "s'efforcent de dissimuler le caractère de

1 Voir sur l'ensemble de ces questions BOERSNER (Demetrio), The Bolsheviks and the National and Colonial Question (1917-1928), Genève, 1957.

2 Visitant l'Indochine en 1931, P. REYNAUD fut informé qu'une trentaine d'élèves annamites suivaient les cours des écoles révolutionnaires de Moscou. Mémoires, tome I, p. 327.

3 Consulter RECORD (W.), The Negro and the Communist Party (étude approfondie des tentatives effectuées aux États-Unis par le communisme pour canaliser à son profit les revendications noires). 
brigandage de la politique impérialiste sous le masque de la démocratie et d'une phraséologie socialiste... ». Il était prévu que le Bureau aurait pour tâche d'organiser l'échange d'expériences entre les partis et, si nécessaire, la coordination de leur activité « sur la base d'un libre consentement ».

Le Kominform, presque immédiatement touché par la défection yougoslave, ne paraît pas avoir, comme tel, joué un rôle appréciable dans les affaires internationales. On a de bonnes raisons d'estimer que, réserve faite de diverses menées contre la Yougoslavie " titiste ", son action s'est limitée à publier un magazine hebdomadaire, Pour une paix durable, pour une démocratie populaire, et à constituer une sorte de bureau de presse et de propagande au service des organisations communistes. Un organisme comme le Conseil mondial de la Paix (que certains désignent comme le coordinateur suprême de la tactique des divers mouvements para-communistes) a probablement joué un plus grand rôle que lui dans le déroulement des événements. En tout cas, sa dissolution à des fins de politique internationale, annoncée le 18 avril 1956, suscitera peu de commentaires ${ }^{1}$.

Pendant ce temps, on s'efforçait à l'Occident de reconstituer non sans peine une Internationale socialiste. Motifs de ces réticences : les mauvais souvenirs laissés par la stérilité de l'Internationale Socialiste Ouvrière et aussi la diversité des positions occupées et des tactiques suivies par [p. 17] les formations socialistes (en particulier, volonté d'indépendance du Labour Party et des Scandinaves). On commença très modestement en 1946 par la fondation, sous le nom de Conférence Socialiste Internationale, d'un Bureau d'information et de liaison où il fut décidé de n'admettre qu'un seul parti pour chaque pays.

Un peu plus tard la Conférence d'Anvers (novembre-décembre 1947) faisait un pas supplémentaire en créant un comité exécutif de la Conférence Socialiste Internationale (Comisco, selon les initiales de son appellation anglaise). Le départ des délégations des pays de l'Est devait permettre de clarifier les attitudes (adoption à Vienne en juin 1948 d'une ligne nettement anti-communiste et vote d'une résolution affirmant que «le socialisme est inséparable de la démocratie »). Mais il fallut attendre l'année 1951 (Francfort, juin-juillet) pour la formation d'une internationale proprement dite.

Celle-ci, qui prit le nom d'Internationale Socialiste, repose sur une déclaration précisant les buts et devoirs du socialisme démocratique dont le rapporteur au congrès fut M. Guy Mollet ${ }^{2}$. Dans ses dispositions essentielles, ce manifeste qui taxe le communisme de "nouvel impérialisme », rend un son réformiste. L'Internationale Socialiste possède un certain nombre d'organismes auxiliaires: en particulier, un Conseil International des Femmes sociales-démocrates fondé à Londres en 1955 (pour succéder à une Internationale Féminine Socialiste qui remontait à 1907) et une

1 Voir MORRIS (B.S.), « The Cominform. A Five Years Perspective », World Politics, avril 1953, pp. 368-376.

2 Pour un historique de ces efforts, voir PICKLES (W.), «The Revived International », Political Quarterly, octobre-décembre 1951, pp. 335-345. Et aussi HEALEY (D.), « The International Socialist Conference, 1946-1950 », International Affairs, juillet 1950, pp. 363-373. 
Union Internationale de la Jeunesse Socialiste créée à Paris en 1946 (pour faire suite à une Internationale de la Jeunesse Socialiste remontant également à 1907).

En dehors des internationales socialiste et communiste dont on vient d'évoquer l'histoire, il n'existe que de rares éléments. On peut certes, relever d'autres mouvements et en particulier les Nouvelles Équipes Internationales d'inspiration démo-chrétienne, que l'on présente souvent comme l'internationale des partis sociochrétiens et démo-chrétiens. Qu'en est-il ?

Sous leur forme actuelle, les N.E.I. ont été créées au lendemain de la seconde guerre mondiale. Elles avaient été précédées, durant l'entre-deux-guerres, par un secrétariat international de coordination des partis démocratiques d'inspiration chrétienne. Dès 1946, des démocrates-chrétiens commencent de se rencontrer, d'abord en Suisse et décident bientôt de fonder un mouvement qui vit officiellement le jour en 1947. Il [p. 18] semble que, dès le départ, la volonté d’instituer l'Europe constitue le ciment de l'organisation.

Les N.E.I. déclarent avoir des équipes dans dix pays européens : Allemagne, Autriche, Belgique, France, Italie, Luxembourg, Pays-Bas, Royaume-Uni, SaintMarin, Suisse. L'équipe britannique se limite d'ailleurs à un groupe numériquement faible, mais assez actif dont plusieurs membres sont catholiques. De plus, les N.E.I. ont formé des équipes « en exil », composées de démocrates-chrétiens chassés de leur pays: Bulgarie, Hongrie, Lithuanie, Pologne, Roumanie, Tchécoslovaquie, Yougoslavie (section qui sont d'ailleurs pour la plupart regroupées au sein de l'Union Chrétienne-Démocrate d'Europe Centrale, membre associé du Mouvement Européen). Enfin, plus récemment (1956), les N.E.I. se sont implantées dans plusieurs pays d'Amérique latine: d'où la fondation d'une Organisation Démocrate-Chrétienne d'Amérique qui a depuis 1958 un comité continental. Au total, la base du mouvement est essentiellement européenne, l'extension à d'autres continents venant à peine de commencer.

Sauf en France et en Belgique, où les adhésions sont individuelles, c'est le parti démocrate-chrétien local qui s'associe en bloc au mouvement et en constitue l'équipe nationale (encore en Belgique, le Parti Social Chrétien est-il l'élément dominant de la combinaison). L'organisation internationale du mouvement (quatre présidents d'honneur : C. Adenauer, R. Schuman, P. Van Zeeland, feu Gasperi) regroupe les N.E.I. et les deux organisations pour l'Europe centrale et l'Amérique latine. Enfin, les N.E.I. ont un mouvement auxiliaire : l'Union Internationale des jeunes Démocrates Chrétiens (qui est, exactement, la section « jeunes » du mouvement).

Les N.E.I. ont tenu plusieurs congrès au cours des dernières années. Les équipes nationales n'ont pas un comportement pleinement uniforme : certaines (Hollande, par exemple), sont empreintes d'une grande religiosité ; la France, au contraire, témoigne d'une optique plus souple et plus large. Quelques équipes voudraient que le mouvement prît l'allure d'une véritable internationale du type de l'Internationale Socialiste, un tel but apparaît difficile à réaliser si l'on considère leurs divergences (par exemple, sur le libéralisme économique) que ne suffisent pas à combler quelques principes communs. Il semble, en particulier, que les sections française et italienne 
aient plus de sympathie pour certaines expressions du socialisme que pour le libéralisme de M. Ehrardt.

[p. 19] Au total, en considérant la place occupée par les partis socio-chrétiens dans divers pays européens, on est tenté d'attribuer quelque poids à cette force. Mais pour l'instant l'Europe constitue sa base de recrutement, son lieu de réunion et son principe d'action : les N.E.I. ont essentiellement pour objectif de faire l'Europe et, à ce titre, on les retrouvera plus loin.

Mentionnons enfin la fondation à Oxford, en avril 1947, d'une Union Libérale Mondiale qui, un peu plus tard, devait prendre le titre d'Internationale Libérale. À vrai dire, ces appellations ne manquent pas d'ambition si l'on considère le nombre et la localisation géographique des membres. D'après les dernières informations disponibles, l'organisation posséderait des partis affiliés dans quinze pays et des adhérents individuels dans six. Israël figurant dans les deux catégories, l'Internationale est donc en contact avec vingt pays seulement, dont quatorze en Europe. Au surplus, son activité reste dans des limites relativement modestes.

\section{b) SITUATION ACTUELLE}

Retour à la table des matières

Si l'on fait abstraction des organisations d'inspiration démo-chrétienne et libérale, on ne trouve plus aujourd'hui dans le monde, du moins en apparence, qu'une seule Internationale de partis : l'Internationale Socialiste ${ }^{1}$. Cette unicité lui vaut-elle de jouer un rôle actif dans les affaires internationales? On a de solides raisons d'en douter.

À première vue, l'Internationale Socialiste semble disposer de forces puissantes : en 1959, plus de 10 millions de membres répartis dans 38 partis nationaux (dont une douzaine «en exil »). Les 26 partis qui agissent dans la légalité ont groupé 65 millions de voix aux dernières élections dans leurs pays respectifs. La presse contrôlée par les partis adhérents comprend 175 quotidiens et 301 périodiques ${ }^{2}$. Cependant, il serait erroné d'admettre que les chefs de l'Internationale ont la possibilité de mobiliser, à leur gré, ces ressources humaines et matérielles pour peser

1 On doit cependant mentionner l'existence d'une Quatrième Internationale d'inspiration trotzkiste. Voir les informations fournies sur ce groupement par Paul MARABUTO, Les partis politiques et les mouvements sociaux sous la IV République, Paris, 1948, pp. 171-178. Voir aussi in Quatrième Internationale, décembre 1957, le compte rendu du $\mathrm{V}^{\mathrm{e}}$ Congrès mondial. Dans la même revue, juillet 1960, pp. 51-71, le projet de thèses pour le $\mathrm{VI}^{\mathrm{e}}$ Congrès mondial : "Bilan, problèmes et perspectives de la Révolution coloniale ». Il ne semble pas que ce mouvement ait joué un rôle politique considérable. Y. CHAIPEAU évoquant l'influence des communistes internationalistes, parle d'organisations « amenuisées, divisées et sclérosées politiquement » (La révolution qui vient. Paris, 1957, p. 282).

2 Indications extraites de la brochure de Jules MOCH, Socialiste vivant. Dix lettres à un jeune, Paris, 1960, pp. 167-168. 
sur le cours des relations entre États. Les dirigeants eux-mêmes ont eu parfois à cœur de rejeter de telles conceptions. D'après l'un d'entre eux, "l'Internationale n'est pas et ne saurait être ... un organisme autonome disposant d'une vie indépendante ... Le mythe selon lequel l'Internationale dispose d'une puissance qui lui appartient [p. 20] en propre et qui serait plus grande que la puissance totale des partis affiliés ... a suscité beaucoup d'illusions parmi les travailleurs ${ }^{1}$.

Les faits justifient une telle modération. Évoquons par exemple la position prise par le Conseil général, le 3 décembre 1956, à Copenhague, au lendemain de l'opération de Suez. La violente condamnation prononcée contre la France et la Grande-Bretagne n'a pas empêché le retour des conservateurs au pouvoir ${ }^{2}$ : l'Internationale n'a même pas réussi à écarter $M$. Guy Mollet de la direction de la S.F.I.O. Simplement, ce parti tient désormais dans l'Internationale le rôle d'accusé qui fut longtemps, après 1945, celui de la social-démocratie allemande. Sur un plan plus modeste, l'Internationale a, du moins jusqu'à présent, connu l'échec en tentant de ressouder les diverses fractions du socialisme italien (alors qu'en cette matière, le Comisco avait remporté certains succès). Les marges de manœuvre de l'Internationale, même à l'égard de ses membres, sont en définitive très étroites.

Il y a un autre facteur de faiblesse. Sur de nombreux problèmes fondamentaux, l'intégration européenne, ou le contenu de la "décolonisation » — l'Internationale Socialiste n'est pas parvenue à définir une position homogène et commune. Dans les pays sous-développés et spécialement en Asie, des voix lui ont reproché d'être plus anti-communiste qu'anti-impérialiste ${ }^{3}$. Ces idées ont conduit à la fondation à Rangoon, en 1953, d'une Conférence Socialiste d'Asie. Cette organisation, qui a pour principal objet de resserrer les liens entre les partis socialistes d'Asie, comporte aujourd'hui des membres dans 11 pays (Birmanie, Ceylan, Inde, Indonésie, Israël, japon, Liban, Malaisie, Népal, Pakistan, Vietnam). Son activité, est-il besoin de l'écrire, est dominée par l'anticolonialisme. Encore que la Conférence conserve des liens étroits avec l'Internationale Socialiste, sa fondation ne peut passer pour un renforcement de cette dernière.

Si l'on rapproche ce dédoublement de l'absence d'implantation solide de l'Internationale en Afrique, il devient évident que celle-ci ne se trouve pas très bien placée dans un monde où le bloc de Bandoeng a pris l'importance que l'on sait. Certains ont sur ce point des vues pessimistes. Selon une thèse, trop dogmatique pour

Déclaration de Julius BRAUNTHAL rapportée par A. GROSSER, op. cit.

Il semble qu'à l'époque, pour des raisons de polémique, on ait présenté de façon trop brutale l'opposition des Britanniques à la politique d'Eden et surtout qu'on ait passé sous silence le revirement en faveur de ce dernier intervenu après le cessez-le-feu en Égypte. Pour une tentative d'évaluation chiffrée, voir le numéro de Sondages sur "l'Affaire de Suez », 1956, n 4, pp. 3-37 (spécialement p. 31). Il arrive souvent qu'en raisonnant au jour le jour on grossisse la force réelle des éléments les plus dynamiques ou, si l'on préfère, les plus bruyants. Les récentes élections japonaises (20 novembre 1960), ne confirment pas les manifestations tumultueuses et les émeutes de l'été dernier.

3 Voir par exemple TRIPATHI (K.D.), «International Socialist Cooperation, 1848-1954 », India Quarterly, janvier-mars 1955, pp. 63-77. 
emporter la conviction, il n'y aurait dans les pays afro-asiatiques d'autre substitut au nationalisme que le communisme: pour se faire une place en opposition au nationalisme, le socialisme devrait adopter une ligne si voisine du communisme qu'il serait alors presque impossible de l'en distinguer.

[p. 21] Comme on le montrera en d'autres occasions, ce souci de simplification relève davantage de l'argumentation polémique que de l'analyse objective. Appliquée à l'évolution sociale la tendance au raisonnement manichéen est toujours suspecte. Au surplus, la transposition aux pays sous-développés des " ismes » forgés dans un cadre industriel ne saurait s'effectuer sans nuances. Ces réserves exprimées, il reste que le socialisme réformiste ne constitue pas une formule idéale pour réaliser l'accumulation initiale du capital. La possession d'une certaine richesse n'est-elle pas indispensable à sa mise en œuvre?

Telle est, en ce milieu du $\mathrm{XX}^{\mathrm{e}}$ siècle, la situation qui ne paraît pas très brillante de l'Internationale Socialiste. On vient de dire que c'est actuellement la seule Internationale des partis digne de ce nom. N'est-ce pas jouer sur les mots en ignorant l'existence et l'activité du mouvement communiste international ? La question est de celles que l'on ne saurait éviter : elle est difficile à traiter sans partialité.

On peut concevoir l'expression " communisme international » en deux sens. Le premier traduit les efforts d'organisation commune et de coordination des politiques qu'entreprennent les États à direction communiste : en relèvent, par exemple, le Pacte de Varsovie et le Conseil d'Assistance Économique Mutuelle (Comecon). Ce Conseil, institué en janvier 1949, groupe tous les pays communistes d'Europe (la Yougoslavie qui n'en fait pas partie y étant toutefois représentée depuis 1956) : il a comme objectifs l'organisation du commerce, la coordination des plans à long terme, l'échange d'informations techniques, scientifiques et économiques. Mais l'expression est généralement entendue autrement: elle vise l'ensemble des activités mises en œuvre pour assurer la diffusion mondiale des thèses communistes et accélérer la survenance de la révolution marxiste dans tous les pays.

Il est parfois possible d'établir une distinction entre ces deux plans d'action : ce fut le cas pour les deux conférences organisées à Moscou à l'occasion du quarantième anniversaire de la Révolution d'Octobre ${ }^{1}$. La première (14-16 novembre 1957) réunissait les partis communistes occupant le pouvoir en Europe et en Asie (à l'exclusion de la Yougoslavie). La seconde (16-19 novembre), qui rassemblait les délégués d'une soixantaine de partis (y compris les précédents), s'est achevée par la signature d'un « Manifeste pour la paix » (seule la Yougoslavie, qui participait à cette deuxième manifestation, ayant refusé de l'avaliser). Cependant, si la différenciation est conceptuellement souhaitable, on [p. 22] admettra que les deux plans restent liés et que la force de pénétration et d'attraction du communisme tient actuellement, pour une large part, à la puissance globale des pays qui se réclament de ce système. Dans

On en trouvera un bref compte rendu in Temps Nouveaux (Moscou), 1957, n 48, pp. 1-8. 
cette perspective, l'unité du mouvement communiste à travers le monde reste un objectif d'importance vitale ${ }^{1}$.

Il existe désormais une immense littérature qui traite des activités du communisme international en tant que force expansive ${ }^{2}$. Ces documents insistent en particulier, sur l'œuvre de propagande, d'éducation et d'infiltration : ils soulignent, notamment, l'existence d'universités et d'écoles chargées de former et d'entraîner les révolutionnaires professionnels qui seront ensuite dirigés vers les pays susceptibles d'agitation et d'endoctrinement. Les auteurs décrivent les liaisons instituées entre le centre mondial du communisme et les partis communistes nationaux ${ }^{3}$. Ils rattachent systématiquement à cette stratégie de conquête l'aide économique accordée par le bloc communiste aux pays sous-développés ${ }^{4}$. En bref, cette école de pensée voit dans

Voir BRZEZKINSKI, The Soviet Bloc. Unity and Conflict, Cambridge (Mass.), 1960.

À titre d'échantillons, on mentionnera les ouvrages d'Evron M. KIRKPATRICK qui présentent un abondant matériel statistique dont une large partie fournie par les services officiels des États-Unis : Target : the World. Communist propaganda activities in 1955, New York, 1956, et Year of Crisis, Communist propaganda activities in 1956, New York, 1957. Voir aussi GURIAN (Waldemar) (ed.), Soviet Imperialism. Its origins and tactics, Notre-Dame (Indiana), 1953, et HAINES (C. Grove) (ed.), The Threat of Soviet Imperialism, Baltimore, 1954 (qui comporte certaines contributions, celle de G. KENNAN, par exemple, d'esprit modéré). Voir également COLLINET (Michel), Du bolchevisme. Évolution et variation du marxisme-léninisme, Paris, 1957. L'ouvrage d'Anthony T. BOUSCAREN, Imperial Communism, Washington, 1953, est le type d'une analyse dépourvue de nuances... D'une inspiration fort différente est le récent ouvrage de W. LIPPMANN, The Communist World and ours, Londres, 1959, qui, sur la base d'une entrevue avec M. Khrouchtchev s'efforce d'éclaircir la conception soviétique du statu quo. Mentionnons enfin le dernier ouvrage de Suzanne LABIN, Il est moins cinq. Propagande et infiltration soviétiques, Paris, 1960. Pour un point de vue plus ancien, voir BORKENAU (F.), The Communist International, Londres, 1938.

3 Voir par exemple, SWEARINGEN (B.), LANGER (P.), Red Flag in Japan. International communism in action, 1919-1951, Cambridge (Mass.), 1952 ; MASANI (M.R.), The Communist Party of India. A short-history, Londres, 1954 ; KAUTSKY (John H.), Moscow and the communist party of India. A study in the postwar evolution of international communist strategy, New York, 1956 ; DRUHE (David N.), Soviet Russia and Indian Communism, 1919-1947, New York, 1959 ; WINT (Guy), Dragon and sickle. How communist revolution happened in China, Londres, 1958 ; BRIMMEL (J.H.), Communist in South-East Asia : a political analysis, Londres, 1959 ; TRAGER (Franck N.), Marxism, in South-East Asia : A study of four countries, Stanford, 1959 ; BARNETT (A. Doak), Communist China and Asia. Challenge to American policy, New York, 1960 ; BALL (W. Macmahon), Nationalism and Communism in East Asia, Melbourne, 1952 ; ALEXANDER (Robert J.), Communism in Latin America, New Brunswick, 1957. L'affaire du Guatemala a suscité de nombreux travaux. Voir notamment JENSEN (Amy E.), Guatemala. A historical survey, New York, 1955 (d'allure assez partiale) et SCHNEIDER (R.M.), Communism in Guatemala 1944-1954, New York, 1958, qui présente une description minutieuse de l'infiltration communiste aux divers échelons du système gouvernemental.

4 Voir WELTON (Harry), The Third World War. Trade and Industry. The New Battle-ground, Londres, 1959. À son avis, la Russie cherche à se créer surtout parmi les pays sous-développés une clientèle d'États dont la dépendance économique aboutira à une dépendance idéologique. Également ALLEN (Robert L.), Soviet Economic Warfare, Washington, 1960. Voir aussi les cinq volumes publiés par la National Planning Association sous le titre The Economics of Competitive Coexistence, Washington, 1959. Ajouter LUBRANO-LAVADEFIA (Michel), L'ours dans la bergerie. La pénétration soviétique dans les pays sous-développés, Paris, 1960. 
tout acte ou déclaration de portée externe des dirigeants communistes la manifestation d'un programme concerté de subversion mondiale : ainsi, Suzanne Labin considère-telle les invitations à visiter les pays communistes dont bénéficient tant de personnalités comme une «énorme machine de mystification et de perversion ... devenue l'objet d'une véritable industrie ${ }^{1}$.

Selon ces analyses, qui, sur plusieurs points, procèdent davantage par affirmations que par démonstrations, l'une des tactiques favorites du mouvement réside dans l'utilisation d'organisations internationales para-communistes, c'est-à-dire d'« organisations annexes » fonctionnant à l'échelle mondiale ${ }^{2}$. Les organismes le plus souvent cités sont: Conseil Mondial de la Paix; Fédération Syndicale Mondiale ; Fédération Mondiale de la jeunesse Démocratique ; Union Internationale des Étudiants Fédération Démocratique Internationale des Femmes ; Fédération Internationale des Résistants; Organisation Internationale des journalistes ; Organisation Internationale de Radiodiffusion ; Fédération Internationale Syndicale de l'Enseignement, etc. ${ }^{3}$.

Op. cit., p. 39.

Pour une discussion générale de la valeur de cette tactique, voir MORRIS (B.S.), «Communist International Front Organizations : their Nature and Function », World Politics, octobre 1956, pp. 76-87. Pour une analyse monographique, se reporter à CLEWS (John), "La "quatrième force" du communisme : les "fronts" de la jeunesse et des étudiants », Problèmes du communisme, novembredécembre 1956, pp. 61-68 ; POURICHKEVITCH (de), « Moscou à la conquête des jeunes », Revue de Défense nationale, décembre 1960, pp. 19892005 (rôle de l'Union Internationale des Étudiants et de la Fédération mondiale de la jeunesse démocratique, spécialement à l'égard des Africains) ; TOMA (P.A.), «The World Peace Council : a case study of a communist international front organization », World Affairs Quarterly, 1959, pp. 379-391 ; KABES (V.), SERGOT (A.), Blueprint of Deception, Character and record of the International Association of Democratic Lawyers, La Haye, 1957 ; BASS (Robert H.), "Communist Fronts : their History and Function », Problems of Communism, septembre-octobre 1960, pp. 8-16. Pour le point de vue de l'Internationale socialiste, voir « The Communist Network », Socialist International Information, 4 décembre 1954, pp. 864-871

3 On trouvera des notices sur ces organisations dans la dernière édition du Yearbook of International Organizations, 1958-59, publié à Bruxelles par l'Union des associations internationales. Signalons, une fois pour toutes, l'importance de cet élément de travail qui, dans son ultime version, fournit des indications sur 1060 organisations internationales non gouvernementales : on prie le lecteur de s'y reporter à propos des O.N.G. qui seront mentionnées dans ce volume. De plus l'ouvrage, dont un index analytique détaillé (en français et en anglais) facilite la consultation, fournit des informations précises sur le secteur intergouvernemental de l'organisation internationale (149 institutions analysées à ce titre). Consulter également MASTERS (Ruth D.) et al., Hand book of International Organizations in the Americas, Washington, 1945.

Pour la situation dans l'entre-deux-guerres, le document de base est le Répertoire des organisations internationales, publié à Genève par la S.D.N. (pour la première fois en 1923 et la dernière en 1938). Le lecteur qui voudra obtenir des informations sur la période antérieure à 1914 pourra se reporter à l'Annuaire de la vie internationale dont le premier numéro est paru en 1905. Fondé par Alfred H. FRIED, cet annuaire fut édité pour les années 1905, 1906, 1907 par l'Institut International de la Paix et à partir de 1908 par l'Office Central des Associations Internationales. La consultation de ces volumes montre l'ampleur que revêtait déjà à cette époque la coopération internationale privée. 
Ces groupements sont de style très divers et leur dépendance vis-à-vis du communisme international s'avère plus ou moins étroite : le plus important d'entre eux, par l'ampleur et la force de l'audience, a probablement été le Conseil Mondial de la Paix ${ }^{1}$. Ces organismes s'efforcent de recruter un nombre élevé d'adhérents noncommunistes, veillant toutefois à ce que les leviers de commande soient tenus en mains par [p. 23] des agents ou des sympathisants du mouvement. Dans cette optique, un fait suffirait à établir les relations : ces associations n'émettent jamais une critique à l'égard de l'U.R.S.S. et adoptent, immanquablement, des positions conformes aux thèses soutenues par la diplomatie soviétique. Ce seraient donc, en bref, les postes avancés de propagande du communisme mondial.

Tel est, sommairement résumé, le tableau que l'on fait volontiers dans les pays occidentaux des activités du communisme international. Ainsi que le montre le thème d'une conférence internationale récemment tenue à Paris (novembre 1960), sur la guerre politique des Soviets, on déclare qu'il s'agit là d'une lutte implacable, menée avec de très puissants moyens, contre les démocraties libérales. Il est probable qu'aux éléments relativement ostensibles du mouvement s'ajoute un appareil de type clandestin dont la composition et les missions, très mal connues, ont donné lieu d'ailleurs à la fabrication de véritables romans. Un tel élément est en particulier indispensable pour l'établissement de liaisons avec les pays où l'activité ouverte est interdite ou risque de l'être.

Quelle puissance attribuer à cette Internationale ? Les auteurs qui acceptent, au moins dans ses grandes lignes, cet exposé des choses, diffèrent quant à l'évaluation de la force actuelle de cet ensemble. Pour les uns, il s'agirait d'un facteur de pression irrésistible, capable d'influencer, de façon décisive, le cours des affaires mondiales. D'autres se plaisent à énoncer les difficultés, notamment d'ordre interne, que le communisme mondial rencontrerait aujourd'hui ${ }^{2}$. Il y a quelques années, Milovan Djilas soulignait la faiblesse foncière des partis communistes occidentaux « errant entre un faux patriotisme et l'obédience à Moscou ${ }^{3}$. Cependant la présentation du phénomène lui-même correspond-elle à la réalité ?

On pourrait justifier a contrario l'existence du communisme international par la vigueur avec laquelle les théoriciens soviétiques luttent contre le communisme dit national. Ils y voient une forme du nationalisme, un produit du révisionnisme et de l'impérialisme. Il n'y a pas, d'après eux, de théorie qui en établisse scientifiquement les fondements : ce serait seulement une arme idéologique. Toujours selon le même point de vue, la formule est une grande tentation pour les États nouvellement promus au socialisme et dans lesquels se manifestent des tendances favorables à un retour au

1 Pour un exposé des résultats qu'en attend le monde communiste, voir DIENNE (Jean), «Le mouvement de la paix et la lutte pour le désarmement Nouvelle Revue Internationale, septembre 1960, pp. 33-50.

2 Par exemple entre autres, LOWENTHAL (R.), «The Ideological Crisis of International communism », Yearbook of World Affairs, 1958, pp. 29-54. Voir aussi STRAUSZ-HUPÉ (R.), " The crisis of international communism », Confluence, automne 1957, pp. 228-244.

3 In « Les partis communistes des pays capitalistes », Questions actuelles du socialisme, mars-avril 1953, pp. 110-129. 
capitalisme. Les Soviétiques déclarent par ailleurs que l'adoption de tels schémas conduirait inévitable-[p. 24] ment à choisir une voie contraire aux lois marxistes, car si chaque pays possède ses caractéristiques propres, les lois communes sont plus fortes que les différences. La condamnation est donc radicale et se relie à la lutte constante menée contre le révisionnisme ${ }^{1}$.

À vrai dire, sur le plan pratique, le courant du communisme national n'a jamais revêtu une grande ampleur. À tort ou à raison, le « titisme » passe pour en avoir été la principale manifestation. Cependant, ceux qui voyaient dans le système yougoslave le modèle le plus probable pour les régimes communistes de l'avenir, se sont trompés ${ }^{2}$. Le réalignement progressif du gouvernement polonais sur la politique soviétique, aujourd'hui pleinement assuré, offre ample matière à réflexion.

L'unité d'inspiration idéologique est essentielle au mouvement et l'on s'explique aisément les gigantesques efforts des dirigeants communistes pour la sauvegarder quand elle paraît menacée. Elle implique, en particulier, la certitude du triomphe final du communisme «la seule bonne voie de développement l'humanité, la seule raisonnable et conduisant, au bonheur ${ }^{3}$. Sur cette base, ce qui paraît aux uns complot permanent et œuvre de pure subversion, est pour les autres un moyen légitime de faciliter et d'accélérer le cours d'une évolution inévitable. Une telle opposition est susceptible de frapper le dialogue de stérilité. Selon que nous admettons ou non la philosophie marxiste de l'histoire, nous qualifierons de façon radicalement opposée les mêmes phénomènes.

Cependant, qu'on la considère comme un bien ou un mal, on ne saurait contester l'existence d'une activité communiste internationale visant à la transformation radicale de l'ordre établi. Le compte rendu qui en est donné par ses adversaires comporte sans doute des excès et des erreurs. Il arrive souvent qu'on crédite d'une trop grande puissance les responsables de ce combat, ou qu'on leur attribue trop de machiavélisme. Mais la masse des faits enregistrés ces dernières décennies, comme

1 Dont on trouvera l'une des dernières manifestations dans la réunion, tenue à Bucarest (aoûtseptembre 1959) de la $\mathrm{V}^{\mathrm{e}}$ Conférence internationale des Instituts du marxisme-léninisme, des Instituts et des Commissions d'histoire du Parti. L'un des thèmes de travail était : « Les tâches de la science historique dans la lutte contre le révisionnisme moderne ». Voir « À propos de la lutte contre le révisionnisme », Nouvelle Revue Internationale, janvier 1960, pp. 108-141, qui reproduit les déclarations faites par les membres. Peut-être la meilleure définition du communisme international se trouve-t-elle dans un propos rapporté par un communiste italien, G. BOFFA (in Le grand tournant, Paris, 1960, pp. 132-133), qui oppose le comportement de Gomulka et Kadar d'un côté, Nagy de l'autre ; le second "petit bourgeois ambitieux » n'ayant jamais été un communiste alors que les autres, malgré les injustices commises à leur égard, n'ont jamais renoncé à la solidarité les unissant « aux prolétaires du monde entier et, partant, à l'Union soviétique ».

2 Ainsi MCVICKER (Charles P.), Titoism. Pattern for international communism, New York, 1957. Consulter également ZINNER (Paul E.) (ed.), National Communism and Popular Revolt in Eastern Europe, New York, 1957, ainsi que l'intéressant recueil The Anti-Stalin Campaign and International Communism. A selection of documents edited by the Russian Institute Columbia University, New York, 1956.

3 Expressions de M. Krouchtchev dans son discours au XII ${ }^{\mathrm{e}}$ Congrès du Parti Ouvrier Roumain dont on trouvera le texte intégral dans Temps Nouveaux, 1960, n² 28, pp. 33-46. 
aussi le contenu des déclarations prononcées par les dirigeants eux-mêmes, laissent peu de doute sur la force et la constance de la pression exercée.

Jusqu'à une époque récente, l'U.R.S.S. était considérée comme l'indiscutable leader de la coalition. Beaucoup tiennent désormais la Chine pour un second pôle d'attraction destiné à exercer une influence grandissante au sein des pays afroasiatiques et même latino-américains. Certains n'hésitent pas à voir dans ce dualisme les germes d'une rivalité et donc d'un affaiblissement : ils spéculent volontiers sur les oppositions [p. 25] d'idéologie et peut-être d'intérêt qui, dès maintenant, semblent affecter le monde communiste.

Cette attitude est, au moins pour le présent, contestable. Certes, l'alliance sinosoviétique a ses éléments de force et ses facteurs de faiblesse. Il paraît y avoir aujourd'hui, entre les deux "Grands », divers motifs de friction et notamment une querelle sérieuse sur l'interprétation de la « coexistence » : il s'agit, en somme, de savoir si le passage universel du capitalisme au communisme s'effectuera pacifiquement ou exigera une troisième guerre mondiale. D'apparence doctrinale, le débat qui a lourdement pesé sur la dernière réunion de la Fédération Syndicale Mondiale (Pékin, juin 1960) se ramène donc comme d'habitude à une controverse sur la tactique. D'autres causes de conflit existent (notamment différences dans les structures sociales, décalages dans le rapport entre la population et les ressources naturelles). Mais le communisme possède une puissance cohésive dont sont dépourvues la plupart des autres philosophies des relations sociales ${ }^{1}$.

Telle est en tout cas l'opinion que l'on peut se faire à la suite de la réunion des 81 partis qui vient de se tenir à Moscou (novembre 1960) et dans laquelle on a pu voir la première réunion de l'Internationale communiste depuis 1935. La longueur même des débats a en quelque sorte confirmé l'ampleur et la vivacité des discussions qui s'instituent aujourd'hui dans le monde communiste. Mais, contrairement à certains espoirs assez naïfs, aucune rupture n'a été enregistrée. Quant à la déclaration émise à la suite de cette réunion, elle demande une interprétation nuancée, (le texte intégral ayant été publié en supplément à Temps Nouveaux, 1960, n 50). Manifestement, ce texte a été rédigé en des termes suffisamment larges pour dissimuler les motifs de

1 Sur quelques aspects récents de cette lutte, voir ZAGORIA (Donald S.), «Strains in the SinoSoviet Alliance ", Problems of Communism, mai-juin 1960, pp 1-11 : l'auteur souligne à l'excès les facteurs de division sans tenir compte des éléments de solidarité. Voir aussi BRZEZINSKI (Zbigniev), "Pattern and Limits of the Sino-Soviet Dispute », même revue, septembre-octobre 1960, pp. 1-7. Sur les positions du communisme chinois, voir SCHRAM (Stuart R.), «La "révolution permanente" en Chine. Idéologie et réalité », Revue Française de Science Politique, septembre 1960, pp. 635-657. Au niveau journalistique, on souligne volontiers que la Chine considèrerait: la Russie comme la "première puissance colonialiste du monde ». Comme témoignage d'un tel courant, l'article de Virgilio LILLI, "L'Asia posseduta dai russi fa rabbia e gola alla Cina », Corriere della Sera, 26 octobre 1960. On ne signalerait pas ces points de vue si d'éminents hommes d'État ne se livraient à d'aventureuses spéculations sur une nouvelle version du «péril jaune » qui menacerait tous les Blancs (Russes compris). Pour une étude historique, se reporter à MCLANE (Charles B.), Soviet Policy and the Chinese Communists, 1931-1946, New York, 1958. L'auteur souligne que depuis janvier 1931, les Russes n'ont plus jamais ouvertement exprimé leur désapprobation à l'égard de la politique définie par le P.C. Chinois. 
conflit : cependant, il est clair que les partis représentés, y compris le parti chinois, sont tombés d'accord pour établir un programme de combat qui, comme d'habitude, compense la rigidité des buts par la souplesse des moyens.

La montée de la Chine ne compromet donc pas pour l'instant l'unité du monde communiste, mais elle place sous un jour nouveau la controverse relative à la nature du communisme international. Beaucoup persistent à y voir un simple instrument de la diplomatie soviétique ou encore une version nouvelle de l'impérialisme russe traditionnel ${ }^{1}$. Il est difficilement contestable qu'il en a été ainsi en de nombreuses circonstances. Mais l'attribution au communisme international d'un contenu spécifiquement russe constitue probablement une très sérieuse erreur. [p. 26] Pendant longtemps, la confusion a été facilitée par l'absence de partenaires à la taille de l'U.R.S.S. dans le camp communiste : qui prendrait sur soi d'affirmer qu'un passage dans le bloc de l'Allemagne tout entière n'aurait pas modifié la situation ?

Dans cette perspective, le comportement des Chinois est significatif de disciples extrêmement humbles, ils sont très vite devenus des alliés « à part entière » et sur certains points de la doctrine, donc de la tactique, des opposants résolus. On peut en déduire qu'au moins dans certaines limites le communisme international constitue un facteur propre de la politique mondiale, susceptible de recevoir des impulsions de plusieurs sources. L'autonomie de l'Internationale s'accentuerait sans doute si la zone aux mains des communistes continuait de s'étendre.

L'acceptation globale du schéma «communisme international » doit toutefois s'accompagner de quelques réserves. En premier lieu, on doit se garder d'y voir le moteur exclusif de la vie internationale et de lui attribuer la responsabilité de tous les événements observés. En Afrique, par exemple, les tentatives de pénétration et de noyautage effectuées par les forces communistes ne sont pas niables. L'infiltration est peut-être plus avancée que les autochtones ne sont prêts à l'admettre. Pourtant, ce serait une piètre interprétation que d'attribuer à cette activité seule la naissance et, éventuellement, l'exaspération des nationalismes africains. Au surplus, ce souci passionné d'indépendance est de nature à contrarier, en plusieurs cas, les efforts de pénétration communiste, dont quelques uns des leaders noirs actuels connaissent beaucoup mieux l'inspiration et les modalités que plusieurs de leurs collègues d'autres continents ${ }^{2}$.

\footnotetext{
Pour une affirmation récente avec des nuances de ce point de vue, voir CRANKSHAW (Edward), Krushchev's Russia, Baltimore, 1959.

2 On trouvera une intéressante évaluation des possibilités d'action du communisme en Afrique in PADMORE (George), Pan-Africanism or Communism ? The coming struggle for Africa, Londres, 1956. L'auteur souligne que les mouvements nationalistes africains sont bien plus anciens que le communisme qui tente aujourd'hui de les capter (lire en particulier le chapitre sur les rapports entre le communisme et le nationalisme noir). Voir aussi CATTELL (David T.), « Communism and the African Negro », Problems of Communism, septembre-octobre 1959, pp. 35-41. Voir aussi VALLET (René), «Énigmes guinéennes », Revue de Défense nationale, juillet 1960, pp. 12411247. Consulter également STACKELBERG (G.A. von), «The Political Line in Soviet African Studies ", Bulletin, Institute for the Study of the U.S.S.R. (Munich), août 1958, pp. 14-21 et " Soviet African Studies as a Weapon of Soviet Policy », même revue, septembre 1960, pp. 3-14.
} 
Il est en second lieu indispensable de considérer que le monde communiste n'a pas le monopole de certaines formes d'action et d'intervention. À partir de matériaux indiscutables, il ne serait probablement pas difficile de reconstituer le schéma d'une internationale "occidentale », ou même "américaine», de contenu fluide et hétérogène. La création et le financement d'organisations, d'apparence indépendante, pour peser sur l'opinion publique; la distribution de subventions à des partis ou syndicats et à des organes de presse ; l'octroi d'invitations à visiter les États-Unis ; la concession de facilités financières pour établir ou sauvegarder des parentés idéologiques; l'utilisation permanente, au-delà des frontières, d'un réseau de correspondants et d'amis : tous ces procédés, [p. 27] et beaucoup d'autres, ont été employés par les Américains, à une échelle massive, depuis la fin de la seconde guerre mondiale.

Reste, il est vrai, que cette action, essentiellement conçue comme une riposte, a été souvent d'une médiocre efficacité par insuffisance de coordination et, surtout, par manque d'un principe positif d'unification idéologique. Mais ceci est une autre histoire, qui n'infirme pas la validité du rapprochement esquissé : analogie qu'il ne convient pas de pousser trop loin, les États-Unis n'ayant jamais pu, ou voulu, donner à leurs activités, la rigueur et l'inflexibilité de l'action communiste.

\section{c) LES SOCIÉTÉS SECRÈTES}

\section{$\underline{\text { Retour à la table des matières }}$}

La place ainsi attribuée aux sociétés secrètes, à côté des internationales de partis, peut prêter à la controverse. On la justifiera cependant, de façon provisoire, en soulignant les rapports qui, souvent, s'établissent entre partis et sociétés, et en observant qu'à de multiples reprises la formule de la société secrète a servi de substitut à celle du parti (lutte contre l'oppression ou la domination étrangère).

Serge Hutin a évoqué dans un récent ouvrage «le mythe d'un pouvoir occulte préparant en secret tous les grands bouleversements historiques ${ }^{1}{ }^{1}$. En fait, le sujet a donné lieu à de multiples exagérations et même à de véritables divagations. Il serait pourtant dangereux de l'écarter a priori. Si on est fondé à repousser les allégations excessives, il demeure que diverses sociétés secrètes ont exercé une réelle influence, politique à l'échelon international. Citons seulement, pour l'Europe, le rôle des Carbonari, et, plus tard, celui de la Main Noire (dont l'ambition était la formation d'un grand État des Slaves du Sud sous direction serbe) ${ }^{2}$. Mais la difficulté essentielle est, bien entendu, d'apprécier correctement les conséquences de cette activité.

1 Dans un ouvrage, Histoire mondiale des sociétés secrètes, Paris, (s.d.), auquel nous avons emprunté plusieurs des exemples cités.

2 Sur ces sociétés, Voir LEANHOFF (Eugène), Histoire des sociétés politiques secrètes aux XIX ${ }^{e}$ et $X X^{e}$ siècles, Paris, 1934. Et aussi HERON LEPPER (J.), Les sociétés secrètes de l'Antiquité à nos jours, Paris, 1936, ainsi que FALCIONELLI (Albert), Les sociétés secrètes italiennes, Paris, 1936. 
Prenons l'exemple de la Franc-maçonnerie, dont on oublie fréquemment qu'elle est composée de diverses obédiences qui ne sont pas toujours en bons termes les unes avec les autres ${ }^{1}$. Il n'est généralement pas contesté qu'elle a bénéficié d'une autorité politique appréciable sous divers régimes, on a même pu dire que la III $^{\mathrm{e}}$ République avait été fondée par des maçons. D'autre part, la solidarité maçonnique a souvent joué, d'un pays à l'autre : il semble qu'elle ait ainsi permis aux insurgés américains en révolte contre la métropole anglaise, d'obtenir l'appui du vieux continent. Cependant, l'acceptation de cette vue n'entraîne nul [p. 28] acquiescement aux positions extrêmes qui lui attribuent une sorte de faculté universelle de conspiration.

Voici un aspect bien connu de ces considérations : un complot maçonnique serait à l'origine de la Révolution de $1789^{2}$. Encore que cette thèse ait, pour des raisons compréhensibles, reçu la caution de plusieurs historiens maçons, il paraît difficile d'y voir un principe d'explication se suffisant à lui-même (cette réserve ne devant pas faire oublier que des frères maçons, et les idéaux de la maçonnerie, ont joué un rôle notable dans la première phase de la Révolution) ${ }^{3}$.

Autre allégation : la responsabilité de la franc-maçonnerie internationale dans le déclenchement de la seconde guerre mondiale. Cette allégation se rattache au mythe du «complot judaïco-maçonnico-bolcheviste » qui constitua l'un des thèmes fondamentaux de la propagande national-socialiste ${ }^{4}$. Les tenants de cette conception affirment, imperturbablement, que le Convent maçonnique international (organisé à Prague en août 1936 par la Grande Loge Nationale de Tchécoslovaquie) eut « valeur d'un conseil de guerre décidant d'engager une lutte acharnée contre l'Allemagne » ${ }^{5}$. Ils vont jusqu'à faire de Franklin Roosevelt, idéologue et apôtre de la franc-

Ajouter le numéro du Crapouillot sur ce sujet ( $\left.{ }^{\circ} 20\right)$, qui contient plusieurs contributions intéressantes, et un ouvrage d'initiation de S. HUTIN, Les sociétés secrètes, Paris, 1954, (Que saisje ?, $\left.\mathrm{n}^{\circ} 515\right)$.

1 La bibliographie sur la Franc-maçonnerie est immense. On pourra partir de la monographie brève, mais substantielle de S. HUTIN, Les francs-maçons, Paris, 1960, qui donne de nombreuses références pour une étude détaillée. Voir aussi LEPAGE (Marius), L'ordre et les obédiences. Histoire et doctrine de la franc-maçonnerie, deuxième édition, Lyon, 1956. On trouvera un point de vue catholique dans LEDRÉ (Charles), La franc-maçonnerie, Paris, 1958. Enfin, comme type d'analyse anti-maçonnique, consulter deux numéros spéciaux de Lectures Françaises, « La francmaçonnerie gouverne » et « Les mystères de la franc-maçonnerie ».

2 Voir sous cet angle le récent ouvrage de Bernard FAY, La grande révolution, 1715-1815, Paris, 1959. Mais le thème de la « Révolution maçonnique » remonte indubitablement au livre de l'abbé BARRUEL, témoin de l'événement, Mémoires pour servir à l'histoire du jacobinisme.

3 La thèse du complot a été solidement attaquée par Roger PRIOURET, La franc-maçonnerie sous les lys, Paris, 1953. Pour une autre réfutation, brève mais perspicace, voir COLINON (Maurice), L'Église en face de la franc-maçonnerie, Paris, 1954, chap. IX. L'auteur rapporte en particulier l'opinion de Pierre Gaxotte : « Il n'y a pas eu de complot maçonnique ourdi de longue date pour renverser la monarchie. Ce serait, si l'on ose dire, trop simple et trop beau ».

4 On pourra consulter sur ce point ROLLIN (Henri), L'apocalypse de notre temps. Les dessous de la propagande allemande d'après des documents inédits, Paris, 1939.

Jacques BEARN in «Le rôle de la franc-maçonnerie dans la préparation de la deuxième guerre mondiale », Lectures Françaises, juin 1957, pp. 156-216 (numéro consacré aux origines secrètes de la guerre 1939-1945). 
maçonnerie, le grand responsable de la « vague belliciste » ayant submergé le monde en $1939{ }^{1}$. Sans entrer dans une discussion de ces thèses (dont l'adoption aboutirait à un retournement complet des responsabilités), il est juste de reconnaître que les arguments présentés sont vraiment inconsistants et incohérents.

Un dernier exemple enfin: le mythe de la synarchie. Sous sa forme la plus extrême, il postulait l'existence d'une société secrète internationale ayant pour objectif de préparer le renversement universel des régimes parlementaires. La branche française (dénommée Mouvement Synarchique d'Empire) aurait joué un rôle important dans les hautes sphères du gouvernement de Vichy. En réalité, aucun élément précis n'a pu être fourni sur la synarchie, son organisation et ses méthodes de travail. Le schéma technocratique (sans oublier le pullulement des petites intrigues et la multiplication des cliques) suffit pour expliquer la situation d'alors, sans qu'il soit nécessaire d'introduire dans le jeu une société secrète d'allure mystérieuse.

Il arrive que ces sociétés agissent et se développent en des lieux éloignés de leur secteur géographique d'origine. L'un des cas les mieux connus de cette extension est l'activité, à implications politiques et criminelles, exercée aux États-Unis par la Maffia sicilienne. De même, [p. 29] plusieurs sociétés secrètes de la Chine du Sud, se sont implantées en divers pays possédant un fort contingent de Chinois émigrés (Malaisie, Indonésie, États-Unis...); ce transfert a d'ailleurs suscité de multiples frictions avec les autorités de la zone d'émigration. Au total, ces mouvements créent des ramifications internationales dont il n'est pas possible de tenir pour acquise la neutralité à l'égard des affaires politiques.

Convenons que le sujet reste mal connu et qu'il est vain d'en attendre beaucoup d'éléments sérieux pour l'interprétation des relations internationales. Dans certains cas, l'historien en vient à pressentir des connexions troublantes (ainsi l'appui actif apporté par le Grand Orient de la France aux jeunes Turcs en 1908 et l'aide consentie par la Franc-Maçonnerie américaine à la Révolution chinoise de 1911). Cependant, il lui est difficile de faire la démonstration de tels phénomènes. De même, on sait qu'au Japon plusieurs sociétés secrètes, d'esprit ultra-nationaliste, ont joué un grand rôle dans la préparation et la mise en exécution des plans qui devaient assurer à ce pays le contrôle de l'Asie ; pourtant, on ne paraît guère en mesure d'évaluer leur influence globale, et, encore moins, le poids spécifique de chacune d'entre elles.

$\mathrm{Au}$ total, la science politique commettrait une erreur sérieuse en écartant les sociétés secrètes de ses préoccupations, mais, en pareille matière, il n'est pas aisé de dépasser le stade des approximations.

1 L'ouvrage de G. OLLIVIER, Franklin Roosevelt. L'homme de Yalta, Paris, 1.955, se situe dans la même perspective. 


\section{d) AUTRES FORMES DE CONTACT}

$\underline{\text { Retour à la table des matières }}$

On traitera ici des liaisons internationales, de type collectif, instituées entre les parlementaires de divers pays. Ces formules, qui permettent d'instaurer une coopération des hommes politiques, en dehors des internationales de modèle classique, peuvent être ramenées à deux grandes catégories.

La première, à la fois la plus ancienne et la moins originale, met en œuvre des groupements, semi-officiels ou purement privés, qui rassemblent, à des fins générales ou particulières, un nombre variable de parlementaires. Citons d'abord l'Union Interparlementaire dont la création remonte à 1889. Elle se compose de groupes nationaux qui comprennent, soit le Parlement tout entier d'un pays donné (cas des États-Unis ou de la Suède), soit des membres du Parlement actuellement en fonctions et recrutés à titre individuel (cas de la France ou du Royaume-Uni). Le total de ces groupes atteint actuellement la cinquantaine, mais [p. 30] une notable fraction d'entre eux correspond à des parlements dont l'activité se limite à un rôle de figuration. Cette particularité entrave évidemment la capacité d'action et la marge de manœuvre de l'Union. Toutefois, ses conférences plénières, de périodicité annuelle offrent aux membres une tribune qui n'est pas sans audience auprès de l'opinion mondiale ${ }^{1}$.

En dehors de l'Union, on signalera trois groupes à vocation spécialisée : l'Association Parlementaire du Commonwealth dont l'objet propre est de faciliter l'échange d'informations, l'entretien de relations plus étroites et une meilleure compréhension entre les représentants parlementaires des pays du Commonwealth ; le Conseil Parlementaire du Mouvement Européen dont le but est d'aider les membres des parlements d'Europe dans leurs efforts pour promouvoir une politique d'unité et d'intégration de l'Europe ; l'Association pour un Parlement Mondial (ou Association Universelle des Parlementaires pour un Gouvernement Mondial) dont le programme est l'attribution à une autorité supra-nationale du pouvoir législatif, judiciaire et exécutif pour un groupe de matières déterminées (les questions qui ne figurent pas sur cette liste étant laissées aux États nationaux). Cette dernière est la seule des organisations de parlementaires qui tende à un but politique précis : elle possède des membres dans une trentaine de pays.

La seconde formule de coopération repose sur la formation d'assemblées parlementaires internationales, spécialement dans le cadre de l'intégration de l'Europe. La plus intéressante pour notre propos, est l'Assemblée Parlementaire Européenne

Voir en particulier le Compte rendu de la $48^{e}$ Conférence tenue à Varsovie du 27 août au 4 septembre 1959, Genève, 1960, xx-1288 p. À cette conférence - la première organisée depuis 1936 dans l'Europe de l'Est - furent discutés les thèmes suivants : élimination des obstacles au commerce international ; problème de la sécurité internationale et du désarmement ; rôle du Parlement pour la protection des droits de l'individu. 
dont la mission de contrôle s'exerce aujourd'hui sur les trois communautés : CharbonAcier, Marché commun et Euratom. Sans disposer de prérogatives comparables à celles des parlements nationaux de type occidental, elle possède déjà quelques facultés de contrôle dont les partisans d'une Europe unie souhaitent l'extension ${ }^{1}$.

Cette assemblée se compose de 142 membres (à raison de 36 pour l'Allemagne, la France et l'Italie, 14 pour la Belgique et les Pays-Bas, 6 pour le Luxembourg). Les représentations nationales reflètent les principales tendances politiques de chacun des six pays (à l'exception toutefois des extrémistes de gauche et de droite qui en sont écartés par un accord tacite entre les partis pro-européens). Le point important est que ces parlementaires siègent à l'Assemblée en fonction de leurs affinités partisanes et non comme délégations nationales. Ce recours à la [p. 31] formule des groupes politiques particularise l'Assemblée Européenne et rapproche ses structures de celles d'un parlement ordinaire ${ }^{2}$.

Alors qu'en de nombreux cas, et spécialement en France, il fallut très longtemps aux groupes parlementaires pour être officiellement admis dans les parlements nationaux, l'opération n'a pas soulevé de difficultés dans le cadre des communautés européennes. L'existence de ces formations n'ayant pas été prévue dans le traité instituant la C.E.C.A., c'est un vote de l'Assemblée, en date du 16 juin 1953, qui a autorisé leur création et les a dotées de moyens financiers. Trois groupes se sont aussitôt constitués : démocrates-chrétiens, libéraux et apparentés, socialistes. Ils sont demeurés tels lorsque la compétence de l'Assemblée a été élargie au Marché commun et à l'Euratom.

Ces groupes parlementaires sont évidemment privés du droit de participer à la formation de l'Exécutif européen, mais ils interviennent dans la constitution du bureau et des commissions de l'Assemblée. Leur tâche primordiale devrait être de formuler les principes fondamentaux au nom desquels se feront les choix déterminants de la politique européenne, mais l'accomplissement de cette mission est à peine ébauché. Un autre aspect de leur activité, dont la réalisation se trouve déjà plus avancée, est de faciliter l'harmonisation des points de vue nationaux.

En dehors de sa signification générale, ce phénomène a des implications particulières pour notre sujet : sous réserve que le mouvement d'intégration politique ne soit pas démantelé dans les années à venir, il n'apparaît pas chimérique de supposer que ces groupes finiront par jouer le rôle d'une force de pression capable d'accélérer la construction européenne ${ }^{3}$.

1 Sur ces problèmes, Voir GINESTET (Pierre), L'Assemblée parlementaire européenne, Paris, 1959, (Que sais-je ?, $\mathrm{n}^{\circ}$ 858).

2 Sur ce phénomène consulter le chapitre $\mathrm{V}$, « The role of political party groups », de l'ouvrage de Kenneth LINDSAY, European Assemblies. The experimental period 1949-1959, Londres, 1960.

3 Afin de ne pas alourdir l'exposé, on a laissé de côté le cas du Conseil de l'Europe qui a pourtant suscité un intéressant, ouvrage de HAAS (Ernst B.), Consensus Formation in the Council of Europe, Londres, 1960. 
On n'a pas encore évoqué les comportements et manifestations que l'on réunit parfois sous le titre «Internationale Nazie» ou «Néo-Nazie». Que recouvre l'expression?

Le point de départ du mouvement est souvent fixé à un congrès tenu à Malmöe en mai 1951 (Congrès fasciste international) organisé avec la participation d'une centaine de délégués, de divers pays européens. Instigateur du congrès : un mouvement d'opposition suédois tirant lui-même ses origines de l'ex-Mouvement Suédois Nazi. Selon certaines informations, la France y aurait été représentée par une dizaine de personnes. À l'issue du congrès - dont l'atmosphère fut celle des réunions [p. 32] national-socialistes - un plan de campagne d'ampleur mondiale aurait été adopté, un Exécutif de quatre membres nommé et un secrétariat permanent organisé.

Sous cette perspective, les manifestations antisémites (spécialement celles de décembre 1959) apparaissent comme le résultat d'un plan concerté et coordonné dans son exécution. Mais beaucoup de ceux qui ont examiné le problème se refusent à admettre l'existence d'une telle organisation, au moins sous la forme rigide et structurée que lui prêtent les tenants de la thèse «Internationale Nazie ». Tout au plus s'agirait-il de réseaux, aux liens assez lâches, institués entre divers mouvements ou centres nationaux. Que sont ces derniers ?

Le point essentiel est qu'il y a dans tous les pays d'Europe des vestiges, parfois assez importants, d'anciennes organisations nazies ou fascistes : tous les partisans de ces idéologies n'ont pas disparu du seul fait de la défaite hitlérienne et, en beaucoup de cas, les souffrances et difficultés, d'intensité variable, qu'elle leur a values ont engendré de profonds ressentiments. On trouve facilement de tels éléments, travaillant à visage plus ou moins découvert (partis déclarés ou sociétés secrètes) non seulement en Allemagne, mais en France, en Grande-Bretagne, en Italie, aux PaysBas, en Suède, etc.

Il faut également tenir compte des groupements formés en divers pays par les nazis qui sont parvenus à fuir l'Europe occupée par les Alliés. L'Espagne en a recueilli un bon nombre, et beaucoup, semble-t-il, ont réussi à s'introduire en Amérique latine, notamment au Chili et en Argentine (où l'ampleur du phénomène sous le régime péroniste appela l'attention du Département d’État). Ces pays comportent aussi, il est vrai, un fort contingent d'éléments anti-nazis. L'existence de filières d'évasion permettant l'immigration illégale d'anciens nazis allemands, mais aussi norvégiens ou hollandais, peut être tenue pour une certitude. Les sommes placées en dépôt dans des banques étrangères par des dignitaires de l'ancien parti hitlérien n'ont pas été sans faciliter de tels passages.

Les camps de personnes déplacées ont pu également tenir lieu de refuge à des gens qui avaient servi dans les troupes allemandes et commis avec elles des atrocités : on a relevé dans certains de ces camps des manifestations d'antisémitisme notoire. 
L'existence de pays tendant à établir les relations sociales sur une base raciale (Afrique du Sud), est un autre aspect du problème. Enfin, selon plusieurs sources, la haine du [p. 33] sionisme aurait conduit divers États arabes à accueillir des rescapés de l'aventure hitlérienne (dont quelques-uns sont évidemment des techniciens de valeur).

Au total, il y aurait ainsi dans le monde des groupes très nombreux, mais pas toujours puissants, rattachés à une idéologie antisémite ou raciste, souvent dotés de ressources financières et cherchant à garder le contact entre eux au-delà des frontières. D'où la possibilité d'un ou plusieurs réseaux fonctionnant probablement de façon sporadique.

Dans cette perspective, les récentes manifestations d'antisémitisme appelleraient une autre interprétation: ne relevant pas d'une tête organisatrice, elles seraient (et c'est peut-être plus grave) le fait d'une contagion. En ce sens, on note que la plupart des manifestants arrêtés en Allemagne étaient jeunes (vingt-cinq ans au plus) et sans affiliation politique (au moins 75\% dans ce cas). Plusieurs se sont révélés totalement incapables d'expliquer le motif de leur comportement.

Dans l'état actuel de la documentation, cette interprétation semble plus réaliste que la précédente : mais sa supériorité ne peut être scientifiquement démontrée.

\section{INTERNATIONALES SYNDICALES}

Retour à la table des matières

Le destin du mouvement ouvrier international est singulier. Au cours d'une histoire qui s'étend sur plus d'un demi-siècle, il n'est jamais parvenu à combiner l'unité et l'universalité. Aujourd'hui, la tendance à un emploi universel de la formule syndicale s'affirme, y compris dans les pays à peine touchés par l'industrialisation : pourtant, le mouvement reste plus divisé que jamais et il est possible que de nouveaux éléments (volonté chez certains d'un regroupement panafricain) apportent un élément supplémentaire de fragmentation.

Les causes de ce phénomène sont multiples: inégalité du développement économique des différents pays et des continents ; divergences sur le sens et la portée de l'action syndicale ; poids du facteur religieux ; répercussion des luttes idéologiques qui ôtent aux plus optimistes l'espoir d'un «monde uni ». Le facteur principal est, bien entendu, l'engagement dans la politique qu'en l'état actuel des forces, le syndicalisme, international comme national, ne saurait éviter qu'au prix de sa dispa[p. 34] rition. À moins de se résigner à devenir un objet, voire un simple enjeu dans la lutte planétaire, les travailleurs, qu'ils le veuillent ou non, sont obligés de « faire de la politique » en tant que tels : et il est normal que leur mouvement en subisse le contrecoup. Il faudrait désormais beaucoup de mauvaise foi ou de naïveté pour s'étonner d'une pareille servitude. 


\section{a) RAPPEL HISTORIQUE}

$\underline{\text { Retour à la table des matières }}$

L'évolution du syndicalisme ouvrier est complexe : on ne peut en retracer, et encore avec un grand recul, que les lignes essentielles ${ }^{1}$.

Notons tout d'abord la lenteur du démarrage : en fait, les premières réalisations n'interviendront guère qu'au début du $\mathrm{XX}^{\mathrm{e}}$ siècle. Le mouvement prendra d'abord la forme de secrétariats professionnels internationaux dont l'esprit corporatif initial se teintera peu à peu de socialisme. Par contre, les divergences sur les conceptions de l'action syndicale retarderont jusqu'à la veille de la première guerre mondiale la constitution définitive de la Fédération Syndicale Internationale. En 1913, le mouvement, malgré des progrès récents, ne compte encore que 7,4 millions de syndiqués dont 5,4 fournis par trois pays (Allemagne, États-Unis, GrandeBretagne...), la France où les querelles sur la doctrine et la tactique ont été très vives, n'intervenant dans ce total que pour 387000 membres.

Le bilan de cette période est facile à dresser : des efforts de solidarité corporative à porter essentiellement au crédit des secrétariats professionnels et, au surplus, un développement des échanges d'information (en somme c'est toujours la «boîte aux lettres » dont Lénine parlait à propos de la II $^{\mathrm{e}}$ Internationale). Les facultés d'action de la Fédération furent sévèrement restreintes, les participants ayant précisé, dès le début des longues négociations qui devaient conduire à la formation de cet organisme, que les problèmes d'orientation et de tactique des centrales nationales échapperaient à sa compétence. Cependant des idées avaient été émises dont la première guerre mondiale allait précipiter la maturation.

Assez vite, sous l'impulsion de syndicalistes anglais et français, va s'affirmer la revendication d'un Parlement ouvrier international ayant pouvoir direct de décision sur tous les problèmes du travail. L'Organisation Internationale du travail, créée par le traité de Versailles, ne correspond [p. 35] que très imparfaitement à ce modèle, mais

\footnotetext{
Pour une bonne vue d'ensemble du sujet, voir LORWIN (L.L.), The international Labor Movement : history, policies, outlook, New York, 1953 ; LEFRANC (Georges), Les expériences syndicales internationales des origines à nos jours, Paris, 1952. Et aussi BOZZOLA (Gian Battista), Problemi del movimento operaio nel mondo, Florence, 1954. Consulter également Le syndicalisme mondial, Paris, 1960 (La Documentation française. Notes et études documentaires, $n^{\circ}$ 2670); LORWIN (L.L.), "The Structure of International Labor Activities », Annals of the American Academy of Political and Social Science, mars 1957, pp. 1-11, ainsi que les études de Georges VIDALENC et Gaston TESSIER sur « Les organisations syndicales mondiales » dans le volume déjà cité de l'« Encyclopédie française », La vie internationale. Pour une vue historique, voir LORWIN (L.L.), Labor and Internationalism, New York, 1929 ; DOLLÉANS (E.), Histoire du mouvement ouvrier, 3 vol., Paris, 1936-1953; et aussi SCHEVENELS (W.), A Historical Precis. Forty Five Years International Federation of Trade Union. 1901-1945, Bruxelles, 1956.
} 
elle ouvre aux syndicats des perspectives nouvelles d'action. Signalons dès maintenant une particularité de la charte de l'O.I.T. essentielle pour notre propos : la structure tripartite des organes dirigeants qui, à côté des délégués gouvernementaux comprennent des représentants des employeurs et des travailleurs. Les professionnels bénéficient ainsi d'un accès direct aux centres décisionnels de l'institution ${ }^{1}$.

Au surplus, des efforts sont rapidement entrepris pour reconstituer la Fédération Syndicale Internationale et ils aboutissent lors du congrès tenu à Amsterdam en juillet 1919. En dépit de ses prétentions à l'universalité, l'organisme est encore d'assiette purement européenne : le président est anglais, les deux vice-présidents français et belge, les deux secrétaires généraux hollandais. Les objectifs retenus se révèlent d'une grande platitude.

Dans l'immédiat après-guerre, la Fédération, portée par la vague d'expansion des mouvements syndicaux nationaux, va entreprendre de multiples actions dont plusieurs à incidences immédiatement politiques (boycott du gouvernement hongrois de l'amiral Horthy, grâce à la discipline de la Fédération Postale Autrichienne ; refus de transporter des armes à destination de la Pologne en guerre avec l'U.R.S.S.; intervention dans les affaires de Haute-Silésie...). Cependant la crise économique mondiale et la montée des fascismes réduiront la Fédération à la défensive : l'effondrement des syndicats allemands devant Hitler est pour elle un rude coup.

En définitive, l'originalité de la Fédération aura été sa participation massive à l'œuvre de l'O.I.T. (facilitée par la présence d'Albert Thomas à la tête du Bureau International du Travail). De tous les services que les syndicalistes obtiendront de l'Organisation — dans laquelle la Fédération tient un rôle dominant — l'un nous intéresse surtout. Il s'agit de la disposition d'une tribune de vaste résonnance pour, en quelque sorte, interpeller les gouvernements dont les travailleurs ont à se plaindre. C'est en somme une véritable pression de type indirect, exercée par les syndicats sur les responsables de l'activité étatique ${ }^{2}$. Par ailleurs, la Fédération tentera aussi d'intervenir sur la S.D.N. (notamment à propos des affaires économiques et des problèmes du désarmement).

Un autre phénomène devait dominer cette époque : la rupture de l'unité syndicale internationale par la fondation à Moscou d'une Internationale syndicale rouge. Ce fut la manifestation d'une coupure que, [p. 36] sous réserve d'un bref intermède de réunification, le monde ouvrier n'est pas parvenu à résorber depuis. Lors du congrès constitutif tenu à Moscou en juillet 1921, cette nouvelle Internationale syndicale comprend encore, en dehors des communistes, la tendance anarcho-syndicaliste qui s'en séparera un peu plus tard. Finalement, l'Internationale Rouge deviendra un relai

1 Pour une information récente sur l'O.I.T., voir deux petits ouvrages, l'un de Guy de LUSIGNAN et l'autre de Marc MONTCEAU, qui portent le même titre, L'Organisation Internationale du Travail 1919-1959, tous deux Paris, 1959. Voir aussi deux publications du B.I.T. lui-même, Principes d'action, programme et statut de l'O.I.T., Montréal, 1944 et L'Organisation Internationale du Travail. Trente ans de combat pour la justice sociale, 1919-1949, 2e édition, Genève, 1950.

2 Voir LEFRANC, op. cit., p. 30. 
de la III $^{\mathrm{e}}$ Internationale avec laquelle, dès le début, elle a entretenu les rapports les plus étroits.

Sa tactique ne fut pas de pousser à la création de nouvelles centrales nationales, mais de s'assurer le contrôle des syndicats existants. Son objectif a toujours été de conserver des relations suivies avec les masses non communistes : attitude conforme, en effet, aux directives de Lénine qui n'a jamais eu assez de sarcasmes pour critiquer la position des révolutionnaires refusant de militer dans les syndicats « réactionnaires ». "Il faut consentir tous les sacrifices, écrivait-il, user même, en cas de nécessité, de tous les stratagèmes, recourir à la ruse, aux procédés d'action clandestine, taire, celer la vérité, à seule fin de pénétrer dans les syndicats, d'y rester et d'y mener coûte que coûte l'action communiste ${ }^{1}$. Dans une telle perspective, la conclusion d'un accord avec la Fédération Syndicale Internationale était impossible : tous les contacts établis dans ce but - y compris ceux de 1937 provoqués par l'aggravation de la situation internationale - restèrent vains.

Un trait spécifique de l'Internationale Rouge est l'attention portée aux travailleurs des pays colonisés ou économiquement dépendants, spécialement en Asie. Ce souci, qui se situe dans la ligne adoptée, dès le départ, au sein du mouvement communiste, est devenu depuis une préoccupation commune à toutes les centrales : nouveauté pour l'époque, cette action de soutien fut aussi, peut-on dire, un placement d'avenir.

On aura achevé de caractériser cette période de l'entre deux guerres en signalant la fondation à La Haye en juin 1919, de la Confédération Internationale des Syndicats Chrétiens qui, à son apogée, vers 1930, comptera un peu plus de 2 millions de membres. C'est essentiellement un syndicalisme de minorité : en aucun pays, la Confédération ne possède la centrale la plus représentative et, le plus souvent, l'influence de ses adhérents est cantonnée géographiquement ou professionnellement. Les rapports seront rarement bons avec la F.S.I. à laquelle la Confédération reproche, en particulier, de s'assurer un monopole dans l'Organisation Internationale du Travail.

[p. 37] Au total, de 1919 à 1939, le mouvement ouvrier international reste divisé. Forte et respectée au sein des instances internationales, la F.S.I. ne semble pas avoir acquis un pouvoir appréciable sur le déroulement de la politique internationale. Son impuissance devant l'ascension des régimes fascistes est éclatante : quant à l'action dans les colonies, elle a davantage été le fait du communisme que du syndicalisme proprement dit. Ce second après-guerre allait-il transformer la situation ?

Le point capital fut d'abord la création à Paris, lors de la Conférence-Congrès de septembre-octobre 1945, d'une Fédération Syndicale Mondiale destinée à rassembler les travailleurs de tous les pays. Le vieux rêve de l'unité prolétarienne - une unité faisant abstraction des divergences dans les régimes sociaux et des différences dans le degré de développement - semblait prendre corps. Moins de quatre ans après, la rupture était à nouveau consommée. À vrai dire, lors de la fondation de l'organisme, les espoirs nés de la lutte commune contre l'hitlérisme avaient déjà subi des atteintes.

In La maladie infantile du communisme, p. 43 de l'édition française de 1953. 
Plusieurs mouvements syndicaux de l’Occident — spécialement les Trade-Unions britanniques conduits par Sir Walter Citrine — n'étaient pas sans inquiétude à l'égard des projets en cours. Il est intéressant de rappeler qu'à l'époque, l'un des plus fermes partisans de l'union fut le C.I.O. des États-Unis, dont le représentant, S. Hillman, témoignait d'un enthousiasme exceptionnel.

La rupture de l'unité syndicale vint simplement traduire et consacrer la division du monde en blocs idéologiques opposés. Dès le début, des forces avaient pris position contre l'unification ainsi réalisée (en particulier la Fédération Américaine du Travail (A.F.L.), qui dépêcha en Europe à cet effet M. Irving Brown). Mais ces tentatives n'auraient pas eu de suite si, dans la querelle entre les anciens alliés, la F.S.M. n'avait pris, et avec une force de plus en plus grande, le parti du camp soviétique. Le plan Marshall allait fournir l'occasion d'une épreuve de force : on peut d'ailleurs penser que même sans elle, la rupture se fut également produite. L'opposition entre les blocs était trop aiguë et massive pour qu'en tout état de cause, le syndicalisme ouvrier put faire l'économie d'une scission. En cette matière, comme en tant d'autres, l'apolitisme serait une pure illusion.

Les syndicats qui démissionnèrent de la F.S.M., dans le courant de 1949, représentaient, dans l'ensemble, les pays économiquement développés du monde occidental. Le C.I.O. fut de ceux-là et l'on observa [p. 38] sans surprise qu'il en vint très vite à reprendre les critiques exposées dès le début par l'A.F.L. Firent exception à ce mouvement, les Confédérations du Travail française et italienne, solidement contrôlées par les communistes. Après une période de tâtonnements et une phase de négociations plutôt laborieuses, une nouvelle internationale syndicale était fondée à Londres (novembre-décembre 1949) : la Confédération Internationale des Syndicats Libres dont l'objet est « d'unir les travailleurs des organisations syndicales libres et démocratiques du monde ».

Quant à la Conférence Internationale des Syndicats Chrétiens, elle s'est maintenue sans interruption par rapport à l'avant-guerre. Elle a pris comme premier objectif la reconstitution du syndicalisme chrétien dans tous les pays où il avait été détruit par les régimes totalitaires. Elle n'y est qu'imparfaitement : parvenue, principalement en Allemagne qui fut pourtant le pilier de son activité, de la création jusqu'à l'avènement de l'hitlérisme et qui s'en est tenue, durant cet après-guerre, à une formule de syndicat unitaire ${ }^{1}$. Ajoutons que les pourparlers d'unification, lors de la création de la C.I.S.L., n'eurent aucune suite, la Confédération chrétienne réclamant la reconnaissance du pluralisme syndical auquel ne voulait pas souscrire le nouvel organisme.

Signalons toutefois la reconstitution en date du 27 juin 1959 d'une authentique Confédération des syndicats chrétiens d'Allemagne, la première depuis 1933. Elle ne compte d'ailleurs pour l'instant que 200000 membres. Ses partisans exposent que le mouvement syndical chrétien ne bénéficie en fait d'aucune garantie au sein du D.G.B. (ce dernier ayant, en de nombreuses occasions, témoigné d'intolérance). Bien entendu, la C.I.S.C. n'a pas ménagé les efforts pour pousser à cette reconstitution d'une centrale chrétienne dont le développement à une large échelle entraînerait une scission de portée considérable dans le syndicalisme allemand. 


\section{b) SITUATION ACTUELLE}

$\underline{\text { Retour à la table des matières }}$

Lors du IV ${ }^{\mathrm{e}}$ Congrès syndical mondial, tenu à Leipzig (4-15 octobre 1957), la F.S.M. revendiquait 106280115 membres (ses adversaires lui en attribuant tout au plus 90-92). Il est intéressant de décomposer ce chiffre. Par continent d'abord. On trouve Afrique, 379800 ; Amérique, 3873690 ; Asie et Australie, 24952075 Europe, 75498735 ; Proche et Moyen-Orient, $1592815^{1}$. Sur les 106 millions de membres, le camp communiste compte pour environ 80 (dont 47 pour la seule U.R.S.S.). En dehors des pays du bloc, les seules organisations ayant des relations avec la F.S.M. et dont les effectifs dépassent le million sont: les syndicats indonésiens (ensemble 6 millions, ce qui semble beaucoup, vu le faible développement industriel du pays), la C.G.I.L. (Italie) avec 3,9 ; la centrale japonaise SOHYO avec 3,5; la C.G.T. avec 3. Encore s'agit-il des organisations «représentées » au $\mathrm{IV}^{\mathrm{e}}$ Congrès : situation qui n'implique pas nécessairement l'existence ou le maintien de liens organiques avec la F.S.M. (cas, assez complexe, du Japon). La puissance de la F.S.M. dans le monde non communiste [p. 39] est donc relativement réduite : mais elle y possède des points d'appui solides.

L'inspiration fondamentale de la F.S.M. se découvre aisément dans une déclaration de son Comité exécutif (19 ${ }^{\mathrm{e}}$ session, Varsovie, avril 1959) : «Le Comité exécutif de la F.S.M. estime que la mobilisation et l'action coordonnée des masses travailleuses en défense de la paix demeurent la tâche la plus importante du mouvement syndical international ». Parmi les premières mesures à prendre en ce sens, on indique : solution pacifique du problème allemand, conclusion d'un traité de paix avec l'Allemagne; proclamation de Berlin-Ouest comme ville libre et démilitarisée; unification de l'Allemagne par le rapprochement des deux États allemands souverains. La résolution générale présentée par le Comité exécutif dans sa $20^{\mathrm{e}}$ session (Bucarest, décembre 1959) revient, inlassablement, sur le problème : elle énonce en particulier les mesures spécifiques que devraient prendre les centrales nationales pour participer « au grand mouvement populaire pour le désarmement » ${ }^{2}$.

Il serait très facile de trouver de semblables déclarations dans des résolutions plus anciennes. En fait, l'action de la F.S.M. s'est complètement identifiée avec celle des Partisans de la Paix et, plus profondément, avec les objectifs de la diplomatie soviétique. Parmi les manifestations récentes les plus significatives, mentionnons la

1 Chiffre extrait du compte rendu des travaux du IV Congrès mondial (Leipzig, octobre 1957) (pp. 864-871). Le lecteur attentif aura noté que l'addition des chiffres par continents donne un total de 106297115 (et non de 106280 115, comme il est déclaré par la F.S.M. ...). Sur la F.S.M., voir LICHTBLAU (G.E.), "The World Federation of Trade Unions », Social Research, printemps 1958, pp. 1-36 (étude de la F.S.M. comme instrument de la politique étrangère de la Russie soviétique).

2 On trouvera le texte de cette résolution in Le Peuple, $1^{\mathrm{er}}$ janvier 1960. 
«Conférence des syndicats et travailleurs d'Europe pour le traité de paix avec l'Allemagne, le désarmement et l'interdiction des armes atomiques », tenue les 8-10 mai 1959 à Goerlitz-Zgorzeled sur " la frontière de la paix Oder-Neisse " ${ }^{1}$. Mais ce souci est toujours présent. Lors de la première Conférence syndicale mondiale des jeunes travailleurs (Prague, juillet 1958), le second point de l'ordre du jour était « l'avenir des jeunes travailleurs du monde et leurs actions unies pour la défense de la paix, contre les dangers d'une guerre atomique et thermo-nucléaire » ${ }^{2}$.

Cette attitude conduit la F.S.M. à prendre position, au fur et à mesure, sur tous les problèmes de politique internationale. Ainsi, lors des événements de l'été 1958 au Moyen-Orient (Irak, Liban...), son Comité exécutif a-t-il jugé opportun de tenir une session extraordinaire. Dans un "Appel aux travailleurs et aux organisations syndicales de tous les pays », il a condamné « l'intervention armée des gouvernements des États-Unis et de Grande-Bretagne » et les « agissements des gouvernements de la République fédérale allemande et d'autres pays capitalistes qui mettent leurs territoires à la disposition des agresseurs [p. 40] américains et anglais ». Un télégramme fut envoyé au secrétaire général de l'O.N.U. et une lettre adressée aux organisations syndicales internationales pour une réunion destinée à promouvoir des « actions communes ou parallèles ».

La lutte contre l'unification européenne, et spécialement contre l'intégration des Six, a toujours constitué l'une des préoccupations de la F.S.M. ainsi que du monde communiste tout entier : jusqu'à présent, cette action n'a pas été infructueuse (le rejet de la C.E.D. ayant probablement compromis, pour une longue période, tout essai d'intégration politique). Mais la F.S.M. a trouvé une audience encore plus large dans son combat contre l'exploitation coloniale qui reprend, en les élargissant, les traditions de l'Internationale Rouge : on verra pourtant que sur ce point la C.I.S.L. entend ne pas lui céder de terrain.

En définitive, la F.S.M. est totalement plongée dans la lutte politique. Certes, dans ses proclamations et résolutions, elle n'abandonne pas le plan des conquêtes professionnelles (encore que pour l'essentiel de ses adhérents de telles manifestations revendicatives n'aient pratiquement aucun sens, le niveau du salaire et les conditions du travail dans les pays communistes échappant, en principe, à la pression collective des syndiqués). Mais l'action sur les affaires internationales reste l'essentiel ou, si l'on préfère, est tenue pour la condition nécessaire de l'amélioration sociale. En va-t-il différemment des autres internationales ? Ouvrons, afin d'en débattre, le rapport des activités 1957-1959 présenté au VI ${ }^{\mathrm{e}}$ Congrès mondial de la C.I.S.L. (décembre 1959).

Trois chapitres sont significatifs : le 11, "La liberté et la paix » (Berlin ; contrôle des armes atomiques et désarmement universel ; Tibet, la lutte contre la dictature se poursuit en Espagne); le 12, «Émancipation des pays non autonomes » (Communauté française ; Guinée ; Malaisie et Singapour ; Chypre ; Algérie ; autres

1 Le compte rendu de cette conférence a été publié en supplément au nº 5 de 1959 de Mouvement Syndical Mondial.

2 Compte rendu publié en supplément au n 10 de 1959 de Mouvement Syndicat Mondial. 
pays d'Afrique) le 13, «La lutte pour les droits syndicaux » (Algérie; Haïti ; Thaïlande Espagne ; Union Sud-Africaine ; Japon ; Turquie ; Îles Bahamas ; Chypre ; Pakistan; Venezuela). Cette concordance suffit à établir qu'une large partie, de l'activité de la C.I.S.L. tombe aussi, sans équivoque, dans le domaine politique.

Au $1^{\mathrm{er}}$ janvier 1959, la C.I.S.L. possédait des effectifs de 55955881 d'individus (disons, en gros, une cinquantaine de millions) répartis entre 137 organisations appartenant à 97 pays ${ }^{1}$. L'universalité paraît donc acquise, mais trois pays (Allemagne, Grande-Bretagne et États-Unis) [p. 41] représentent à eux seuls 28,2 millions, soit environ la moitié. On comprend facilement que, dès le début, son action se soit placée dans le cadre du bloc occidental (dont chacun sait d'ailleurs qu'il comporte de graves fissures). Auprès de beaucoup de gens, la C.I.S.L. passe pour être dominée par les forces américaines : on notera en revanche que les syndicats des États-Unis lui ont fait souvent grief d'être contrôlée par les organisations socialistes d'Europe.

Un point très important est la « régionalisation » de l'activité de la C.I.S.L. ${ }^{2}$. Elle répond à l'idée que les problèmes concrets sont trop différents selon les continents pour faire l'objet d'un examen centralisé qui soit efficace. Admettons aussi que ce découpage a pour fondement le souci de valoriser les pays sous-développés (rappel des difficultés de l'Internationale Socialiste). Successivement, trois secrétariats régionaux ont été établis: l'Organisation Régionale Européenne avec siège à Bruxelles (créée en novembre 1950) ; l'Organisation Régionale Interaméricaine des Travailleurs, Mexico (janvier 1951); la Confédération Régionale Asienne, NewDelhi (mai 1951). Le cas de l'Afrique a soulevé des difficultés singulières dont on parlera plus loin ${ }^{3}$.

Cette structure permet, sans doute, d'adapter l'action aux particularités et nécessités régionales. Soit, par exemple, le cas de l'Organisation Interaméricaine. L'élévation du pouvoir d'achat et la consolidation des syndicats sont liées à un renforcement et à une rationalisation des économies nationales. Aussi, lors de son $\mathrm{IV}^{\mathrm{e}}$ Congrès (Bogota, décembre 1958), l'O.R.I.T. a-t-elle décidé d'agir dans les instances internationales afin d'activer et de faciliter l'industrialisation des pays latino-

1 Selon les chiffres fournis (pp. 203-207) du rapport d'activité. Ce rapport présente aussi des informations détaillées sur la situation financière (pp. 191-201) alors que celui de la F.S.M. ne dit rien de cette question (suivant, en cela, la pratique habituelle des organisations para-communistes).

2 Sur cette structure, voir STEINBACH (A.L.), « Regional Organisations of International Labor », Annals of the American Academy of Political and Social Science, mars 1957, pp. 12-20.

3 Notons que cette « régionalisation » correspond en gros au plan exposé dès le début de 1949 par Irving BROWN, qui proposait de fonder la Nouvelle Internationale sur cinq grands secteurs continentaux, à savoir : Europe Occidentale Continent américain ; Extrême-Orient ; Afrique, Proche-Orient, Moyen-Orient pays placés derrière le rideau de fer (pour lesquels on fonderait « un centre syndical libre en exil, qui agissant en tant que force idéologique associée à la puissance économique des travailleurs libres, servirait d'aimant en Europe Orientale, afin d'élargir les fissures qui ont déjà commencé à se produire dans les régimes totalitaires»: programme rapporté par LEFRANC, op. cit., p. 115). Il existe aujourd'hui un Contre International des Syndicalistes Libres en Exil (regroupant les anciens membres des syndicats des pays passés sous régime communiste). Son siège est à Paris. 
américains, de stabiliser les prix de leurs produits sur les marchés internationaux et de promouvoir des accords commerciaux permettant aux gouvernements d'entreprendre des programmes de développement avec des garanties suffisantes de continuité. De plus, elle a choisi de s'intéresser aux projets d'intégration fondés sur la complémentarité de plusieurs des économies nationales.

L'O.R.I.T. apporte son appui aux revendications des travailleurs latino-américains qui sont au service de trusts étrangers comme l'United Fruit Company et ses filiales : à bien des reprises, les dirigeants de l'Organisation sont entrés en lutte contre cette firme à laquelle ils reprochent de vouloir affaiblir par tous les moyens les groupements syndicaux «bona fide » (y compris en favorisant ceux des communistes). Ils ont souvent dénoncé dans la presse des États-Unis les brimades, persécutions et [p. 42] représailles par lesquelles cette compagnie (qui représente le principal élément économique d'Amérique centrale) s'efforce d'anéantir les syndicats libres.

La C.I.S.L. attache une grande importance au soutien des mouvements nationaux dans les pays colonisés. Elle a eu, de ce fait, de nombreux et sérieux démêlés avec le gouvernement français (les positions de l'Internationale ayant souvent été contestées par son membre français la C.G.T.-F.O.). L'une de ses tactiques favorites a été d'agir sous couvert de la violation des droits syndicaux ce qui, comme on le verra plus tard, lui permet de mettre en branle l'Organisation Internationale du Travail (illustration supplémentaire de l'intime liaison entre le social et le politique). La C.I.S.L. s'est expliquée avec franchise sur ce point lors de la première réunion de son Conseil général (Berlin, juillet 1952).

Évoquant la fréquente identité de revendications entre les syndicats libres d'un pays non autonome et un mouvement populaire national, la résolution du Conseil proclame: "Cette situation ne doit pas gêner l'action du mouvement syndical international libre si le mouvement national s'attache à l'instauration d'un régime démocratique, s'il s'engage à défendre les principes du syndicalisme libre et s'il s'oppose sans équivoque à toute forme de totalitarisme. Le mouvement national sera soutenu en l'occurrence et cela ne fera que renforcer son aile ouvrière, constituée par les syndicats libres ${ }^{1}{ }^{1}$ (texte qui suscita l'abstention des représentants de la C.G.T.F.O.).

Parmi les dernières initiatives de la C.I.S.L., mentionnons la réunion à Genève, en mars 1959, d'une conférence économique mondiale groupant des délégués syndicaux venant du monde entier à l'exclusion des pays communistes (encore y notait-on la présence de membres du Centre International des Syndicalistes Libres en Exil). S'adressant aux gouvernements et aux Nations Unies la conférence a esquissé un programme des mesures que les syndicats estiment nécessaires au maintien du plein emploi et de l'expansion économique d'une part, à la promotion du progrès économique et social dans les pays insuffisamment développés de l'autre ${ }^{2}$.

Voir le texte complet de cette résolution in Bulletin d'Information de la C.I.S.L du 18 juillet 1952.

On en trouvera le texte dans le Bulletin d'Information du $1^{\mathrm{er}}$ avril 1959. 
D'inspiration plutôt libérale et de contenu assez souple, ce plan, qui attribue une large place à la stabilisation du cours des matières premières, à la démobilisation douanière et à l'aide financière, n'est pas sans intérêt : on peut cependant douter qu'il soit à la mesure des besoins du siècle.

[p. 43] Plusieurs facteurs ont gêné l'action de la C.T.S.L. : singulièrement la diversité des conceptions politico-sociales de ses membres (qui vont d'un réformisme très modéré à des attitudes franchement anti-capitalistes, en passant par les tenants de la lutte sur deux fronts : contre Moscou et Wall Street...) ; l'extrême disparité entre la puissance et les ressources des syndicats des États-Unis et ceux de la plupart des autres pays ${ }^{1}$; l'énormité des décalages existant sur le plan du développement économique ${ }^{2}$; l'hostilité de nombreux gouvernements à l'égard des revendications syndicales, etc. La guerre froide, si elle a simplifié certains problèmes, en a aggravé d'autres, obligeant l'organisation à s'aventurer sur des sujets délicats ${ }^{3}$. En revanche, la C.I.S.L. a toujours joui d'un accès privilégié à l'O.N.U., à l'Unesco et à l'O.I.T. (encore que le retour de l'U.R.S.S. dans cette dernière organisation en 1954 y ait quelque peu réduit la puissance des syndicats libres).

Si l'on se place sur le terrain syndical, le risque le plus grave qu'affronte aujourd'hui la C.I.S.L. est celui d'une confusion totale entre le social et le politique, comme c'est déjà le cas pour la F.S.M. Cependant, le monde étant ce qu'il est, l'établissement de liaisons privilégiées et presque exclusives, avec l'un des camps en présence, était et reste pratiquement inévitable. Mais cette situation comporte, à l'évidence, le danger d'une trop grande sensibilité aux fluctuations de la conjoncture internationale.

On a déjà souligné le désaccord entre la C.I.S.L. et la Confédération Internationale des Syndicats Chrétiens. La C.I.S.C. a proposé diverses formes d'entente qui n'ont pas reçu l'assentiment de la C.I.S.L. : ainsi l'établissement de comités de contact et de liaisons ne devant infirmer en rien la compétence des organes directeurs des deux centrales. La dispute s'est parfois envenimée, la C.I.S.L. reprochant à la C.I.S.C. d'être un instrument de division du syndicalisme libre (création d'un « syndicalisme sectaire ») et de faire en quelques pays (notamment en France), le jeu des communistes. Selon certains observateurs, depuis la constitution de la C.I.S.L., la Confédération chrétienne aurait adouci son hostilité initiale envers le mouvement syndical communiste (étant parfois allée jusqu’à accepter la réalisation d'actions communes) : l'évolution récente de la C.F.T.C. vers des positions " gauchistes » est l'un des arguments avancés dans cette campagne. Sans entrer dans le détail d'une

1 Ce point a été bien mis en lumière par STURMTHAL (A.), «International Labor Problems », World Politics, avril 1956, pp. 441-453.

2 Le poids de cette disparité (et des rivalités internes dans le syndicalisme américain) a été souligné par BRAUNTHAL (A.), "Economic and Social Aspects of International Trade Union Work », Annals of the American Academy of Political and Social Science, mars 1957, pp. 21-30. Pour une vue plus générale, Voir WINDMULLER (J.P.), American Labor and International Labor Movement, New York, 1954.

3 Voir JACOBSON (H.R.), « Labor, the U.N. and the Cold War », International Organization, hiver 1957, pp. 55-67. 
controverse, dont l'impartialité n'est pas le trait dominant, observons que le [p. 44] rejet du communisme a toujours constitué l'un des principes de base du syndicalisme chrétien ${ }^{1}$.

Aux termes de ses statuts, la C.I.S.C. se donne pour but de faire régner dans le monde un ordre social conforme aux principes chrétiens (le texte cite expressément le christianisme, sans faire aucune référence au catholicisme). Sur cette base, elle comprend des organisations strictement confessionnelles, d'autres qui, sans être confessionnelles, se recommandent de la doctrine sociale de l'Église ou des principes chrétiens, d'autres enfin dont les bases sont identiques ou analogues à celles de la doctrine sociale chrétienne (cas fréquent en Afrique et en Asie où les chrétiens sont une minorité peu nombreuse). Cette souplesse est, pratiquement, la condition d'une expansion hors d'Europe.

Par rapport à l'avant-guerre, la C.I.S.C. a subi des pertes sévères en Allemagne, en Italie (où la rupture de l'unité syndicale s'est effectuée au profit de la centrale affiliée à la C.I.S.L.) et en Europe centrale. Mais elle s'est efforcée d'universaliser sa position par une implantation au Canada (Confédération des Travailleurs Catholiques du Canada) qui pourrait être remise en question, en Amérique latine, en Afrique... Ses effectifs s'élèvent actuellement à 5 millions. Cette centrale a manifesté, elle aussi une tendance à la «régionalisation »: fondation en 1954 à Santiago du Chili de la Confédération latino-américaine des syndicalistes chrétiens et, en 1959, à Brazzaville, de l'Union Panafricaine des Travailleurs Croyants. Enfin, et en attendant la formation envisagée d'une Organisation régionale en Asie, on a procédé, le 16 avril 1959, à la constitution définitive de l'Organisation Européenne de la C.I.S.C. (dont l'un des objectifs est de coordonner et de promouvoir l'action du mouvement syndical chrétien au sein des institutions européennes).

Cette «régionalisation » traduit un intérêt certain à l'égard des pays sousdéveloppés. Diverses manifestations vont dans le même sens : telle l'organisation à Saïgon, du 19 au 31 janvier 1959, d'un stage euro-asien pour syndicalistes où se sont rencontrés 50 dirigeants syndicaux provenant de 12 pays d'Asie et de 5 occidentaux. Le programme comportait une confrontation des vues dans trois domaines : doctrine et conceptions sociales; situation actuelle sur le plan économique et social ; évolution, structure et organisation du mouvement syndical ${ }^{2}$.

L'une des ambitions de la C.I.S.C. est de demeurer à l'écart de la politique. Le rapport d'activité présenté au XIII ${ }^{\mathrm{e}}$ Congrès (juin 1958) souligne la tentation et le risque de faire du syndicalisme une organisa-[p. 45] tion annexe des partis. "Faute d'un syndicalisme libre, peut-on lire, tout serait politisé, ce qui conduirait à un

Le meilleur document disponible sur la Confédération est le volume publié à l'occasion du XIII Congrès (Vevey, juin 1958), Le mouvement syndical chrétien dans le monde. Malheureusement, les données statistiques (en particulier les effectifs) et les indications d'ordre financier sont presque inexistantes. Voir aussi le numéro spécial de la revue Labor, 1960, n 3, "Quarante ans de C.I.S.C. ». Sous l'angle historique, voir ZIRNHELD (Jules), Cinquante années de syndicalisme chrétien, Paris, 1937.

2 On trouvera un compte rendu de la réunion in Labor, mars-juin 1959, pp. 50-128. 
étatisme plus ou moins providentiel ou à une forme de gouvernement totalitaire ${ }^{1}$. Et il est vrai que les travaux et publications de la C.I.S.C. font beaucoup moins de place aux problèmes et controverses politiques que les documents correspondants de la F.S.M. et de la C.I.S.L. Mais ce détachement a des limites, comme le montre le chapitre $1^{\mathrm{er}}$ du rapport consacré à... « la situation politique mondiale », qui exprime plusieurs jugements particulièrement tranchés. Soit, par exemple, le problème hongrois. Il y est affirmé (p. 78) que le travail publié sur ce thème par la F.S.M. est un « document scandaleux » et il est indiqué (p. 147 » que le représentant de la C.I.S.C. à New York a maintenu le contact avec le Comité spécial des Nations Unies et lui a transmis « les différentes déclarations et prises de position émises par la C.I.S.C. en cette matière ». Est-il besoin d'insister sur la relativité de cet apolitisme...

Ce tableau comporterait une très sérieuse lacune si l'on n'y mentionnait d'une part, l'existence de mouvements autonomes qui échappent aux internationales (Confédération des Syndicats Arabes), d'autre part, le cas des fédérations spécialisées qui ont toujours posé aux centrales internationales de difficiles problèmes. Les secrétariats professionnels internationaux ont été la première forme de l'internationalisme syndical. À la veille de la première guerre mondiale, il en existait 28 (dont 24 ayant leur siège en Allemagne). Entre les deux guerres, le problème de leur coordination avec la Fédération Syndicale Internationale fut résolu par un compromis qui, en fait, laissait leur autonomie à ces organisations (dont certaines, telle l'Internationale des Transports, étaient fort importantes).

La question allait rebondir avec la création de la F.S.M. au sein de laquelle se manifesta très vite une tendance profonde à la centralisation. Les partisans de cette conception voulaient en faire une fédération de centrales nationales, les fédérations spécialisées devenant de simples départements de l'organisation. Mais cette position qui allait se durcissant, suscita des protestations d'abord, des départs ensuite : dès octobre 1947, la Fédération Internationale des Ouvriers des Transports décidait de rompre avec la F.S.M.

Observons au passage que cette fédération pas plus que les autres, n’hésite à prendre position sur les problèmes politiques: ainsi, lors de [p. 46] son dernier congrès (juillet 1960), elle a vigoureusement condamné la République arabe unie pour les restrictions qu'elle impose au trafic avec Israël à travers le canal de Suez. La Fédération a aussi engagé la lutte contre les pavillons de complaisance dits Pan. Lib. Hon. Co. (Panama, Libéria, Honduras, Costa-Rica) : il est difficile de lui refuser un rôle dans le déclanchement du courant intense de rapatriement dont bénéficie aujourd'hui le pavillon grec.

Actuellement, la division syndicale se prolonge au niveau des organisations spécialisées. C'est ainsi que l'on trouve trois syndicats de mineurs : la Fédération Internationale des Mineurs (C.I.S.L.), la Fédération Internationale des Syndicats de Mineurs Chrétiens ; l'Union Internationale des Syndicats des Mineurs (F.S.M.). Les

Op. cit., p. 100. 
rapports avec la centrale internationale varient selon les cas. La C.I.S.C. entend laisser à ces organismes une entière liberté d'action tout en les associant étroitement à ses travaux pour éviter dispersion ou divergences. Les internationales professionnelles sont statutairement représentées aux divers organes dirigeants. La C.I.S.L. a créé un Comité de liaison pour assurer ses relations avec les secrétariats professionnels internationaux, mais le rapport fait au dernier congrès mondial montre que cette question continue de soulever des difficultés et que la coordination n'est pas toujours très bien assurée. L'avenir du Comité de liaison est soumis à discussion. Quant à la F.S.M., il semble que les contacts y soient nettement plus hiérarchisés que dans les autres internationales.

Reste à mentionner l'existence d'une Confédération Internationale des Cadres qui, fondée en 1950, possède des sections nationales dans 5 pays (Allemagne, France, Italie, Luxembourg, Pays-Bas). De plus, par l'intermédiaire de fédérations affiliées (en particulier la Fédération Internationale des Cadres de la Chimie et des Industries annexes), elle couvre également 4 autres pays (Autriche, Belgique, Royaume-Uni, Suisse). L'organisation est donc purement européenne (la fonction « cadre » étant comprise de façon différente aux États-Unis). Parmi les sujets qui retiennent aujourd'hui l'attention de la Confédération, on signalera : répercussions de l'« accélération » du Marché Commun sur la situation des cadres, représentation de ces derniers sur le plan international (B.I.T., communautés européennes...), coordination du régime des retraites entre les divers pays intéressés, etc. Cette activité est naturellement mal vue des internationales syndicales qui s'estiment compétentes pour représenter tous les travailleurs (cadres compris).

[p. 47]

\section{c) SYNDICALISME AFRICAIN}

$\underline{\text { Retour à la table des matières }}$

Compte tenu de la formidable partie qui se livre aujourd'hui à propos de ce continent, il est nécessaire de lui consacrer un développement particulier. Le problème est des plus complexes et l'on ne pourra en retracer que certains aspects. Au surplus, la situation y est toujours fluide. En beaucoup de pays africains, la séparation entre l'économique et le politique est pratiquement dépourvue de sens : dans des régions à peine industrialisées, le syndicalisme a constitué moins un instrument de promotion sociale, qu'une arme du combat politique (éducation et encadrement pour la libération d'abord, le développement ensuite).

On peut ramener à trois les sources d'implantation du syndicalisme dans ces territoires: il s'agit naturellement non pas de décrire un processus d'application universel, mais d'analyser des procédés-type dont la combinaison a varié selon les régions. 
Une première direction est celle de la projection des structures syndicales métropolitaines sur la réalité d'outre-mer : à considérer les choses avec quelque recul, on peut y voir comme la transition entre le stade exclusivement colonial et l'accession au self-government.

Ainsi pour l'Afrique noire française, l'extension du syndicalisme aux autochtones remonte en fait à un décret du 7 août 1944 dont l'objet était l'institution de syndicats en A.O.F. et A.E.F., au Cameroun, an Togo et sur la Côte des Somalies : la loi du 15 décembre 1952 dite "Code du travail d'outre-mer", achevant la légalisation du phénomène. Cette réglementation s'est accompagnée de l'installation en Afrique des diverses centrales métropolitaines, chacune bénéficiait d'atouts particuliers (la C.G.T. de son ancienneté et du prestige des victoires sociales de la Libération ; la C.F.T.C. de sa vocation spirituelle et de l'influence des Missions ; la C.G.T.-F.O. de ses rapports avec l'Administration). Les relations entre centrales métropolitaines et unions territoriales sont alors étroites et fréquentes, mais ce sont encore les directives venues de Paris qui prévalent. Durant cette phase de promotion, le syndicalisme progresse relativement peu parmi les autochtones.

Une seconde source d'impulsion a été donnée par les internationales syndicales elles-mêmes : de ce point de vue, la C.I.S.L. semble avoir joué très rapidement un rôle notable et, sur certains points, considérable, son action empruntant exactement la direction tracée lors de la réunion de Berlin (supra). La Confédération s'est efforcée d'obtenir la [p. 48] promulgation de la liberté syndicale là où elle n'existait pas encore et elle a encouragé, par tous les moyens en son pouvoir, la formation et le développement de nouveaux syndicats. Elle a systématiquement pris parti pour les mouvements nationaux en lutte contre la métropole. Cette attitude s'est nettement manifestée en Afrique du Nord où la C.I.S.L. possède quatre organisations affiliées (pour l'Algérie, la Lybie, le Maroc et la Tunisie). Elle a accordé notamment un puissant soutien à l'Union Générale des Travailleurs Tunisiens, son premier membre africain. D'une façon plus générale, elle n'a cessé de prendre des positions propres à lui valoir la sympathie des autochtones ${ }^{1}$.

Lors de la I ${ }^{\text {re }}$ Conférence régionale africaine de la C.I.S.L. (Accra, janvier 1957), il avait été décidé de fonder l'organisation africaine envisagée sur trois "sousrégionales » ayant chacune leur propre secrétariat (Afrique orientale, centrale et méridionale ; Afrique du Nord ; Afrique occidentale). Le premier de ces comités de zone fut créé à Nairobi au début de 1959 cependant que, du fait de l'opposition du Ghana (attitude liée à la création de l'U.G.T.A.N.) il se révélait impossible de faire aboutir le projet de comité pour l'Afrique occidentale (un Centre de, consultation et

Un témoignage entre tant d'autres : la réunion à Genève, les 8 et 9 mars 1958, sous l'égide de la C.I.S.L., d'une conférence groupant les représentants des quatre organisations affiliées d'Afrique du Nord. La conférence a publié un appel à la France lui demandant de mettre fin aux hostilités en Algérie et effectué des propositions devant permettre à la C.I.S.L. d'appeler l'attention de l'opinion mondiale sur la cause algérienne : Bulletin d'Information de la C.I.S.L. du 15 mars 1958. On notera qu'aujourd'hui les syndicats tunisiens sont le meilleur appui de la C.I.S.L. dans son effort contre la création d'une internationale syndicale purement africaine qui serait nécessairement d'inspiration neutraliste. 
d'information pour l'Afrique occidentale fonctionnant toutefois à Accra). Lors de la II $^{\mathrm{e}}$ Conférence régionale africaine (Lagos, novembre 1959), on a entrepris la discussion de plans destinés à promouvoir une organisation régionale pan-africaine de la C.I.S.L.

Enfin, la troisième impulsion est venue des autochtones eux-mêmes. Elle se décompose eu deux moments : d'abord effort pour se débarrasser de la tutelle des centrales métropolitaines et, ensuite, essai de création d'un syndicalisme africain exclusif de toute affiliation internationale.

Le premier stade s'observe en Afrique noire française, avec la fondation d'une Fédération des Cheminots Autonomes de l'A.O.F. non rattachée à l'une des confédérations syndicales françaises. Le mouvement s'affirme spécialement lorsque se crée en Côte d’Ivoire (1951) une « Union Syndicale Autonome ». En 1955, l'Union Territoriale des Syndicats C.G.T. du Sénégal et de Mauritanie décide de se séparer de la C.G.T. Dès lors, le mouvement s'accélère, les centrales françaises réagissant de façon différente à la menace de sécession. Puis, une phase de négociations très complexes s'ouvre, dont sortira finalement, à la Conférence de Cotonou (janvier 1957), l'Union Générale des Travailleurs de l'Afrique Noire (U.G.T.A.N.). Au point de départ, celle-ci résultait principalement de la fusion de deux organismes : la C.G.T. dirigée par [p. 49] M. Abdoulaye Diallo, très liée à la C.G.T. française et à la F.S.M. (dont M. Diallo fut vice-président jusqu'en 1957), et la Confédération Générale des Travailleurs Africains, fondée par M. Sékou Touré en dissidence de la précédente ${ }^{1}$.

La philosophie de base de l'U.G.T.A.N. a été énoncée par M. Sékou Touré dans le rapport d'orientation et de doctrine présenté au $1^{\text {er }}$ Congrès de l'organisation (Conakry, janvier 1959) ${ }^{2}$. Il a marqué le caractère du combat entrepris, en soulignant que, dans les pays colonisés, la lutte des classes se confond avec celle livrée contre le système colonial. En conséquence, il revenait à l'U.G.T.A.N. de se placer au premier rang du combat contre le colonialisme et l'on sait, en particulier, que l'organisation a préconisé de répondre «non » au référendum sur la Communauté (septembre 1958). Bien que rejetant formellement toute espèce d'affiliation ou d'intégration, M. Sékou Touré a déclaré en cette occasion voir dans l'internationalisme prolétaire un élément efficace pour le développement et la réalisation du programme du syndicalisme africain.

\footnotetext{
On trouvera des documents sur ces problèmes dans une brochure imprimée par l'Union Marocaine du Travail et publiée, sans nom de lieu et date, sous le titre "Mouvement syndical africain. Unité », Revue U.G.T.A.N. Sur la question, voir aussi MATIP (Benjamin), « Les mouvements de travailleurs en Afrique noire aujourd'hui », Tribune Marxiste $\mathrm{n}^{\circ}$ 6, pp. 43-54. Bonne introduction d'ensemble sur le mouvement panafricain in P. DECRAENE, Le panafricanisme Paris, 1959 (Que sais-je ? n ${ }^{\circ}$ 847). Voir aussi le numéro spécial de Monde Uni, « L'Afrique et l'O.N.U. », octobre 1960.

2 Le compte rendu du Congrès de Konakry a été publié à Paris par Présence Africaine sous le titre Congrès général de l'U.G.T.A.N. La précision terminologique n'est pas le propre de cette brochure (ainsi, l'U.G.T.A.N. est-elle présentée, p. 48, comme une " centrale nationale » cependant que p. 73, les statuts la définissent comme une " organisation de caractère international » qui, de ce fait, réclame le « statut consultatif » auprès des Nations Unies et de ses agences spécialisées).
} 
Notons qu'à l'issue des débats, le Congrès, « considérant l'impérieuse nécessité d'unifier toutes les organisations syndicales du continent africain », a décidé de mandater le bureau " pour prendre toutes initiatives et entreprendre toutes démarches en vue de la tenue d'une conférence pan-africaine de toutes les organisations syndicales d'Afrique ». Déjà annoncée à diverses reprises (la dernière fois pour mai 1960 à Casablanca), puis renvoyée, la conférence syndicale n'a pas encore eu lieu (mars 1961).

Il apparaît pour l'instant difficile de se prononcer avec certitude sur le chemin que suivra, dans un proche avenir, le syndicalisme africain. On a déjà noté la création par la C.I.S.C. de l'Union Pan-Africaine des travailleurs Croyants, qui entend grouper les syndicats d'une vaste zone allant de la Mauritanie à la Rhodésie ${ }^{1}$. De son côté, la C.I.S.L. redouble d'activité : elle bénéficie d'une bonne implantation dans le continent, spécialement en Afrique du Nord et dans l'Afrique orientale encore sous contrôle britannique. Mais la défection du Ghana, ancien pilier de la Confédération et désormais attaché à la réalisation du projet pan-africain de M. Sékou Touré, est un signe avertisseur: il est significatif que l'audience de l'U.G.T.A.N., d'abord strictement limitée aux anciens territoires de souveraineté française, se soit étendue à des territoires d'expression anglaise.

[p. 50] Lors du dernier congrès de la C.I.S.L. (Bruxelles, décembre 1959), la question a longuement retenu l'attention des participants: les délégués africains, spécialement par la voix de Tom M'Boya (leader nationaliste du Kenya), ont réclamé l'octroi, dans le cadre de l'organisation africaine de la C.I.S.L., d'une large autonomie pour leurs syndicats. Ils ont aussi demandé que faculté leur soit laissée de participer aux rencontres du «Congrès des peuples africains », réunions mixtes syndicalopolitiques et de prendre part à la future conférence panafricaine (non encore tenue). Incontestablement, ces revendications vont dans le sens d'un regroupement africain ${ }^{2}$.

Cependant, lors d'une réunion tenue à Genève en septembre 1960, la C.I.S.L. a décidé d'aller de l'avant en fondant officiellement, avant la fin de 1960, l'Organisation Régionale Africaine. Il semble que le souci d'exercer une puissante action dans l'exCongo belge n'ait pas été étrangère à cette décision dont le principe a été approuvé par les représentants des syndicats de Tunisie, d'Algérie (Union Générale des Travailleurs Algériens), du Kenya, de Rhodésie, etc.

Ce projet a été effectivement réalisé avec la création, en novembre 1960, d'une organisation africaine autonome au sein de la C.I.S.L. Installé à Lagos, le nouvel organisme a pour président un Nigérien et pour vice-président un Tunisien. Nul ne

1 On trouvera le texte de la Résolution générale votée par le Congrès constitutif dans le rapport d'activité présenté au 30 Congrès confédéral de la C.F.T.C (Issy-les-Moulineaux, juin 1959), p. 130.

2 Voir «L'Afrique au premier plan du congrès de la C.I.S.L. », Force ouvrière, 17 décembre 1959, et ROLLAND (Max), « À Bruxelles les syndicats africains revendiquent leur indépendance à l'égard des internationales ouvrières ", Revue de la Communauté France-Afrique, décembre 1959, pp. 3132. 
sait encore s'il sera en mesure de contenir la poussée d'un syndicalisme purement africain dont le centre se situe aujourd'hui sur l'axe Ghana-Guinée.

La F.S.M. encourage cette poussée pan-africaniste dont elle comprend l'attrait sentimental et se borne à offrir voyages et littérature aux syndicalistes africains (une tentative analogue se déroulant aujourd'hui en Amérique Latine à partir des syndicats de Cuba et du Venezuela). L'aboutissement du mouvement, qui s'accompagne d'un puissant effort de la Fédération Mondiale de la jeunesse Démocratique, poserait de sérieux problèmes à la C.I.S.L. et contribuerait à renforcer les facultés d'influence dont dispose déjà la centrale de Prague. La C.I.S.L. sera-telle finalement victime des éléments qu'elle a contribué à libérer et dont plusieurs se dirigent déjà, sans équivoque, vers le neutralisme ?

Le courant, auquel les pays communistes (en particulier depuis quelques temps, l'Allemagne de l'Est) apportent divers concours matériels, est certes très fort. Il suscite pourtant des réticences en plusieurs milieux africains, qui estiment que l'U.G.T.A.N. (interdit en plusieurs pays), loin de réaliser et consolider l'unité syndicale aurait, au contraire, par ses [p. 51] confusions et contradictions, accentué la division de la classe ouvrière africaine.

Le problème est essentiellement politique: il ne saurait échapper, ni aux fluctuations de la situation internationale, ni à l'évolution des nationalismes africains et au mode de règlement des questions encore pendantes. Mais on sait que toute question politique a un côté moral — pour les Africains, la revendication d'une totale indépendance est d'abord affaire de dignité. Or ce sentiment est, par essence, générateur de solidarité entre tous ceux qui ont été et demeurent humiliés : sous cet angle, il importe peu que le contenu économique de ces solidarités soit très faible, sinon même, à la limite, inexistant.

\section{d) SYNDICALISME ÉTUDIANT}

\section{$\underline{\text { Retour à la table des matières }}$}

L'insistance de nombreux mouvements d'étudiants à se réclamer du syndicalisme, suggère d'en traiter à cette place. Au surplus, pour ce second après-guerre, les ressemblances avec le syndicalisme ouvrier international ne font pas défaut ${ }^{1}$. On observera toutefois que les positions du syndicalisme estudiantin par rapport aux

Pour une bonne esquisse de l'évolution voir FOURNIÈRE (M. de la), BORELLA (François), Le syndicalisme étudiant, Paris, 1957, chap. VI (surtout pp. 150-166). Sur la formation du Cosec, voir INGRAM (Avrea Jr), «Students Cooperate on a World Scale », Associations, juin 1955, pp. 368374. La Revue Associations est la publication, de rythme mensuel, de l'Union des Associations Internationales. Nous la citons désormais invariablement sous ce titre, sauf pour la période 19491953 où elle portait le nom de Bulletin O.N.G. Pour la période antérieure à 1939, consulter « Les organisations internationales d'étudiants », La Coopération Intellectuelle, 15 juillet 1929, pp. 409442, et aussi POCHON (Roger), Les associations internationales d'étudiants, Fribourg, 1928. 
blocs en présence ne sont pas totalement identiques à celles du mouvement ouvrier (au Ghana, par exemple, les étudiants restent liés aux Britanniques, cependant que les travailleurs penchent pour le neutralisme de l'U.G.T.A.N.).

En 1919, est créée la Confédération Interalliée des Étudiants qui, en 1921, prend le nom de Confédération Internationale des Étudiants. Cet organisme, essentiellement basé sur les pays européens, témoignera d'une activité appréciable dans le domaine des échanges universitaires, des voyages, du sport et de la presse, c'est-à-dire, en somme, des questions proprement corporatives. Or, au lendemain de la seconde guerre mondiale, un fort courant estime que les étudiants ne doivent pas écarter de leurs préoccupations les problèmes politiques et en particulier les efforts d'aménagement des relations internationales. Ce courant amènera la création de l'Union Internationale des Étudiants.

Cette fondation intervient à Prague en août 1946 au cours d'un congrès auquel participent les représentants de 43 nations. Une charte est adoptée dont le préambule marque la nécessite de réaliser « une paix juste et durable et l'égalité de tous les peuples». Elle énonce le devoir des étudiants d'apporter " une aide active aux gouvernements et aux [p. 52] organisations sociales qui luttent pour la paix et la sécurité ». Elle souligne la volonté de «diffuser et faire progresser l'idéologie démocratique, c'est-à-dire aider les étudiants coloniaux dans leur combat pour la liberté et l'indépendance ». Le nouveau groupement naît dans l'enthousiasme et l'équivoque (chacun pensant que le voisin interprète comme lui les mots de démocratie et de liberté).

Très vite, l'U.I.E. va connaître les mêmes difficultés que la F.S.M. Grâce à une conception particulièrement extensive de l'état d'étudiant, les pays communistes y disposent d'une majorité écrasante. Ils en profiteront pour orienter l'essentiel de l'activité de l'Union vers la défense de la paix, dans l'esprit et avec le vocabulaire des Partisans de la paix. L'organisation prend alors une position sectaire : elle dénonce avec vigueur les brimades dont sont victimes les étudiants de Malaisie et d'Amérique centrale, mais passe sous silence les épurations réalisées dans les universités tchèques au lendemain du coup d'État. Elle en vient à exclure, sans même les entendre, les représentants de la jeunesse étudiante yougoslave.

Dès lors, de nombreux groupements nationaux, estimant que leur présence au sein de l'U.I.E. est impossible, démissionnent ou retirent leur demande d'affiliation. L'Union sortira très diminuée de cette épreuve. Aux dernières informations, elle rassemblerait une trentaine de nations, essentiellement en pays communistes et en anciens pays colonisés d'Afrique et d'Asie pour lesquels elle demeure un pôle d'attraction.

Après beaucoup de vicissitudes, les étudiants du reste du monde vont s'organiser en un groupement séparé. Au point de départ, on se borne à créer une armature très souple, une sorte de secrétariat de coordination conçu de manière à ne pas accentuer la rupture et à ne pas retomber dans les velléités centralisatrices de l'U.I.E. Cet organisme, dont le siège est fixé à Leiden, prend le nom de Secrétariat de Coordination des Unions Nationales d'Étudiants (C.O.S.E.C., selon les initiales de 
son appellation anglaise). On prévoit qu'une Conférence Internationale des Étudiants (C.I.E.) se réunira chaque année pour élaborer des recommandations. L'ensemble C.I.E.-C.O.S.E.C. est ainsi respectueux de la liberté d'action des associations nationales qui s'y retrouvent en grand nombre (le chiffre d'une soixantaine étant rapidement atteint). La contre-partie de ce libéralisme sera, surtout au début, une assez grande stérilité. Sur un point pourtant la C.I.E.-C.O.S.E.C. prend des posi[p.53] tions vigoureuses: la défense des mouvements pour l'indépendance des peuples colonisés.

Depuis lors, spécialement dans les phases de relative détente internationale, des efforts ont été accomplis pour permettre la réunification ou, au minimum, l'établissement de liaisons et de consultations permanentes entre les organismes de Leiden et de Prague (formule des « actions conjointes » : lutte contre le colonialisme, démocratisation de l'enseignement...). Après son tournant de 1955-56 l'U.N.E.F., en particulier, prendra de nombreuses initiatives pratiques en ce sens. Cependant le problème n'a pu être réglé : le $\mathrm{IV}^{\mathrm{e}}$ Congrès Mondial réuni à Prague en 1956 (avec des observateurs belges, britanniques, français et néerlandais) fut de ce point de vue un insuccès total ${ }^{1}$.

Après cet échec, des tentatives ont été faites, sinon pour ressouder complètement les deux fractions du mouvement étudiant, du moins pour établir des contacts entre elles. La dernière des expériences engagées dans ce but (table ronde de l'unité) vient

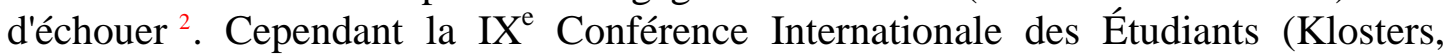
Suisse, septembre 1960) a reconsidéré le problème, spécialement sous l'impulsion des groupes venus du Tiers Monde et en particulier de l'Union Générale des Étudiants Musulmans d'Algérie (U.G.E.M.A.), soucieuse d'obtenir une approbation universelle des revendications nationalistes algériennes. Il est possible que l'on parvienne à convoquer en 1961 une table ronde groupant directement les associations nationales (y compris celle de la Chine et de l'U.R.S.S.) sans passer par les centrales existantes. À partir de là, on pourrait envisager de reprendre l'idée des «projets-joints ». L'accomplissement d'une action commune serait une réelle victoire pour les tendances neutralistes qui se manifestent avec force au sein du syndicalisme étudiant: sa réalisation qui paraît encore très incertaine dépend en partie de l'évolution politique générale.

\footnotetext{
Voir le commentaire assez sévère de cette conférence donné par The Economist dans son numéro du 8 septembre 1956.

2 Il s'agit d'une initiative de l'Union Nationale des Étudiants de Suisse agissant, semble-t-il, à la demande de la C.I.E. Un comité chargé d'examiner le problème avait conclu qu'une « table-ronde de l'unité » n'aurait de chances de succès que si on l'organisait indépendamment des deux centrales et que, même sous cette forme, le projet était prématuré. Voir à ce propos le Livre blanc des travaux de l'U.N.E.S. pour l'organisation d'une table-ronde de l'unité mondiale des Étudiants (publié à Lausanne, sous forme ronéotypée, le 20 mai 1960). Cependant, une telle table-ronde a été organisée à Bâle (août 1960) sur d'autres bases que celles posées dans le Livre blanc : elle a connu un insuccès quasi-total (les étudiants communistes et plusieurs associations du C.I.E. ayant refusé d'y participer).
} 
Le trait essentiel de la situation est la volonté de plus en plus arrêtée des organisations d'étudiants de s'intéresser à la vie politique. On en trouve un témoignage sans ambiguïté dans le $\mathrm{X}^{\mathrm{e}}$ Séminaire International organisé à Wassenaar (Pays-Bas), en août 1959, par le Conseil des Étudiants Néerlandais conjointement avec le C.O.S.E.C. Deux questions étaient à l'ordre du jour : le rôle de l'étudiant dans la politique en tant qu'individu et l'organisation professionnelle comme moyen d'expression de ses points de vue politiques. Le séminaire se prononça en [p. 54] faveur de l'engagement politique et accepta en particulier une résolution tendant à encourager dans leur lutte les étudiants d'Algérie et de Nicaragua ${ }^{1}$.

Au cours des derniers mois, les étudiants ont pris, en de nombreux pays (Corée du Sud, Japon, Panama, Turquie, Venezuela, etc.) une part active à des mouvements révolutionnaires ou à des démonstrations anti-gouvernementales (et généralement disproportionnée à leur audience réelle dans la population). Encore qu'à une échelle beaucoup plus modeste, le phénomène s'observe aussi aux États-Unis : manifestations d'étudiants noirs, auxquels se joignent parfois des blancs, contre la ségrégation ${ }^{2}$. N'oublions pas non plus la place tenue par la jeunesse universitaire dans les troubles et essais de révolution au sein du monde communiste (Hongrie, Pologne, etc.).

À vrai dire, cette situation n'est pas nouvelle : l'étudiant révolutionnaire est une figure familière du $\mathrm{XIX}^{\mathrm{e}}$ siècle (dont le type pourrait être le groupe de polytechniciens déployant le drapeau tricolore sur les tours de Notre-Dame en 1830). Mais l'originalité actuelle réside dans le rassemblement de vastes forces se barricadant dans les Universités (grèves) ou les quittant pour se lancer à l'assaut des bâtiments publics (sans que, contrairement au $\mathrm{XIX}^{\mathrm{e}}$ siècle, l'armée fasse toujours barrage contre eux). Ce phénomène, qui ne semble pas près de disparaître, commanderait une analyse attentive.

L'action des étudiants est spécialement grande dans les mouvements de libération des peuples colonisés. On l'observait déjà avant la seconde guerre mondiale dans des pays comme l'Égypte et l'Inde : en l'absence d'une organisation ouvrière solide et compte-tenu de la neutralité de l'armée vis-à-vis de la politique, l'Université représentait alors un puissant foyer de maturation pour les revendications nationales et un centre de démonstration contre les autorités publiques. Depuis 1945, la tendance s'est considérablement intensifiée. L'exemple de l'Union Générale des Étudiants Musulmans Algériens suffira à illustrer ce propos : les relations internationales que l'Union est parvenue à établir constitue, sans aucun doute, l'un des atouts dont dispose le Front de Libération Nationale sur le plan de l'opinion mondiale ${ }^{3}$.

1 On trouvera un bref compte rendu des débats in Enseignement supérieur et recherches scientifiques aux Pays-Bas, décembre 1959, pp. 30-31. Voir aussi The Student, novembre 1959, pp. 14-17.

2 Le point est signalé par U.S. News and World Report, 6 juin 1960, dans une étude d'ensemble «Why Students riot around the world». Voir aussi WASHINGTON (S.W.), «Student politics in Latin America. The Venezuelan Example », Foreign Affairs, avril 1959, pp. 463-473.

3 Voir la brochure Les étudiants algériens en lutte... publiée par l'U.G.E.M.A. à l'occasion de son IV Congrès national (Tunis, juillet 1960). Durant l'année universitaire 1958-59, on recensait hors des Universités françaises (Alger compris) environ 700 étudiants musulmans algériens dont un peu plus 
[p. 55]

\section{INTERNATIONALES D'AFFAIRES}

\section{$\underline{\text { Retour à la table des matières }}$}

On entend étudier ici les efforts entrepris pour promouvoir et défendre des intérêts économiques (au sens large de l'expression) à l'échelle internationale. Des doctrinaires sont portés à y voir le ressort principal, sinon exclusif, des rapports entre les nations : en tout état de cause, c'est un facteur important qui exige une étude particulière.

L'une des difficultés de cet examen vient de la grande diversité des formes qu'adopte ce secteur. On verra plus loin qu'elle constitue un sérieux obstacle à l'élaboration d'un concept homogène de pression internationale. Pour l'instant, on se bornera à une énumération dont point n'est besoin de souligner le caractère purement indicatif.

\section{a) GROUPES ET AFFAIRES CAPITALISTES}

Partons d'un cas précis : celui de la firme Unilever qui, dans son état présent est le résultat de la fusion sur une base d'égalité de la société anglaise Lever Bros (devenue Unilever Ltd) et de la société hollandaise Margarine Unie (devenue Unilever N.V.). En 1951, son chiffre d'affaires s'élevait à 9\% du revenu national britannique de la même année. Cette firme contrôle près de 500 sociétés dont l'activité s'étend à plus de 50 pays. Employant 300000 personnes, elle fabrique (en pourcentages arrondis), les $2 / 3$ du savon utilisé dans l'Empire britannique et $12 \%$ du savon mondial, les 3/4 de la margarine européenne et $40 \%$ de celle consommée dans le monde entier, un tiers des huiles comestibles du marché mondial. Elle possède au surplus d'immenses intérêts dans d'autres secteurs industriels (glycérine et produits chimiques, par exemple) et dans de puissantes chaînes de magasins de détail. Or le potentiel et l'activité de cette firme qui, en 1959 a réalisé un profit, de 113 millions de livres sterling n'ont fait que s'accroître durant les années récentes. Voici une autre donnée intéressante : le nombre des actionnaires d'Unilever Ltd est de l'ordre de 200000 (celui des détenteurs d'actions d'Unilever N.V. ne pouvant, pour des raisons techniques, faire l'objet d'une

de 250 dans les pays arabes (Moyen-Orient, Maroc, Tunisie). Les deux plus gros blocs - chacun d'une centaine - se situaient en Suisse et dans la République Démocratique Allemande, le surplus de ces étudiants étant répartis dans une quinzaine de pays (par exemple, une vingtaine aux ÉtatsUnis, moins de dix en U.R.S.S.). 
détermination rigoureuse). Dans les deux cas, l'influence des actionnaires sur la politique de la firme est nulle ${ }^{1}$.

On imagine facilement les implications internationales d'une telle activité et l'ampleur des problèmes posés aux responsables par les [p. 56] changements actuels (sur 151 fabriques de la firme en Europe 69 sont chez les Six et 76 chez les Sept). Selon un commentateur, il existerait en Afrique occidentale trois institutions ne connaissant pas de frontières: l'Islam, le Catholicisme et... Unilever ${ }^{2}$. Encore observera-t-on que, si l'on raisonne sur le chiffre d'affaires, Unilever ne vient qu'au quatrième rang dans le monde (derrière General Motors, Standard Oil N.J. et Royal Dutch Shell) ${ }^{3}$. Malheureusement, l'état de notre documentation sur ces combinaisons d'affaires reste, dans l'ensemble, médiocre ${ }^{4}$.

Dans un curieux ouvrage, déjà relativement ancien, un auteur proposait la notion d'« État économique » caractérisé par trois traits : parité à l'égard de l’État politique, concentration du capital mobilier et immobilier, affranchissement des limites douanières. L'expression lui semblait convenir pour marquer la fusion de la puissance économique et de certaines prérogatives paraissant n'appartenir jusque là qu'à l'État politique ${ }^{5}$. La thèse reste excessive, mais elle éclaire correctement quelques aspects du comportement de ce que l'on appelle aussi des « empires économiques ».

Ce caractère international de l'activité économique se maintient même si l'on passe à des firmes de dimensions plus réduites (encore que dominant leur branche). L'Aluminium Company du Canada (A.L.C.A.N.), par exemple, est implantée dans de

1 Voir l'étude d'Annie Voss-LYTTON, «Étude concrète de l'effet de domination : le cas Unilever », Économie Appliquée, juillet-décembre 1955, pp. 485-524. Pour une vue rapide voir EVELY (Il.), " L'histoire d'Univeler », Cartel, octobre 1954, pp. 131-141. Pour une étude approfondie, WILSON (Charles), The History of Univeler. A study in economic growth and social change, 2 vol., Londres, 1954. Cette firme, que The Economist (5 mai 1956) appelle " the universal provider », a de telles assises financières que selon ses dirigeants un profit ou une perte d'un million de livres sterling sur les stocks «ne fait pas matière » (au sens où le phénomène ne conduit pas à mettre en cause les réserves dans un sens ou l'autre). De 1950 à 1959, le total annuel des investissements nouveaux a été en moyenne de 30 millions de livres. Durant cette période, la répartition géographique des dépenses en capital s'est effectuée comme suit : Royaume-Uni, 29\% ; Pays-Bas, 5\% ; autres pays européens, 24\% ; Moyen-Orient, Australie, Afrique, 25\% ; Amérique du Nord et du Sud, 13\% ; Orient, 4\% (The Times, 27 avril 1960).

2 C.E. CARRINCTON, Où va l'Afrique noire (série de causeries diffusées en novembre 1959 par les services français de la B.B.C.), p. 7.

3 Voir la liste des cent premières entreprises mondiales en 1956 in J. HOUSSIAUX, Le pouvoir du monopole, Paris, 1958, pp. 250-252. Chiffre d'affaires de General Motors (en millions de dollars) : 10976 (Unilever, 4 680).

4 Soit par exemple l'Union minière du Haut-Katanga. La documentation disponible est soit de style marxiste - JOYE (Pierre), Les trusts en Belgique, $2^{\mathrm{e}}$ édition, Bruxelles, 1960 - soit de tendance apologétique : YDEWALLE (Charles d'), L'Union minière du Haut-Katanga de l'âge colonial à l'indépendance, Paris, 1960. Aucun de ces deux travaux n'éclaire le lecteur sur les mécanismes de gestion de cet ensemble et les dimensions réelles de l'influence exercée sur le pouvoir politique.

5 MARCUS (Alfred), "Un essai d'État économique », dans un volume consacré à KREUGER, Neuchatel, 1932. La firme ayant servi de modèle à cette étude s'est écroulée, mais d'autres subsistent auxquelles il serait possible, mutatis mutandis, d'appliquer le même schéma. 
multiples pays, tant pour l'extraction des matières premières (Guinée, Guyane britannique, Jamaïque...), que pour la fabrication de produits finis (États-Unis, Royaume-Uni, France, Allemagne, Norvège, Espagne, Suisse, Brésil, Japon, Inde, Australie, Nouvelle-Zélande...). Une autre manière de saisir cette internationalisation est de partir des combinaisons établies pour l'exploitation d'une source déterminée. Soit la Compagnie Internationale pour la Fabrication de l'Aluminium (F.R.I.A.) créée pour l'utilisation de la bauxite guinéenne (capacité de production 480000 tonnes par an). Son capital est réparti entre des entreprises appartenant à cinq pays : Olin Mathieson Chemical Corporation (États-Unis), 48,5\% ; Péchiney-Ugine (France), 26,5\% ; The British Aluminium Company Ltd (Grande-Bretagne), 10\% ; Aluminium Industrie Aktiengesellschaft (Suisse), 10\%.Vereinigte Aluminitun-Werke A.G. (Allemagne), 5\% Il est bien entendu inutile de multiplier les exemples.

Péchiney est le pivot de plusieurs combinaisons. Avec Kaiser des États-Unis, l'entreprise vient de fonder la Compagnie Internationale [p. 57] pour la Fabrication de l'Aluminium Kaiser Seichimé dont l'objet est de créer de nouvelles usines d'aluminium en Espagne. De même, Péchiney est le chef de file d'un consortium (ayant pour autres membres Reynolds Metal et l'armateur S. Niarchos) dont le but est de créer une industrie de ce métal en Grèce.

L'établissement de liaisons entre l'économique et le politique, à propos de l'exploitation des ressources, ne constitue certes pas une nouveauté. Pour ne pas remonter plus haut, mentionnons simplement le cas de la Compagnie Hollandaise des Indes qui, avec son homologue anglais, a joué aux $\mathrm{XVII}^{\mathrm{e}}$ et $\mathrm{XVIII}^{\mathrm{e}}$ siècles, un rôle capital dans l'instauration de l'hégémonie mondiale des pays d'Europe occidentale. Au sommet de sa puissance, la Compagnie Hollandaise pouvait écrire aux États Généraux : «Les colonies des Indes orientales ne sont pas des acquisitions faites par l'État, mais par des commerçants particuliers qui peuvent les vendre à qui ils veulent, fût-ce même au roi d'Espagne ou à un autre ennemi des Provinces Unies » ${ }^{1}$. Et, de fait, les États généraux s'abstinrent de toute intervention dans les affaires de la Compagnie jusqu'au moment de son déclin. Cependant, à notre époque, l'élargissement des marchés et la concentration de la puissance financière ont considérablement accru, et surtout multiplié, les phénomènes de contrôle ou de domination (au sens technique du terme) par les intérêts associés.

Au cours des dernières décennies, on a publié dans divers pays économiquement avancés, une vaste littérature sur l'influence des affaires dans la politique nationale et internationale. On tentera d'évaluer plus tard ce qu'il reste aujourd'hui de cette force (notamment face à l'assaut des jeunes nationalismes). Précisons pourtant un point. En parlant du pouvoir des grandes affaires capitalistes, on évoque de préférence l'action exercée sur le gouvernement de petits pays arriérés : c'est le schéma classique de l'United Fruit qui a longtemps régné, sans partage, sur l'Amérique centrale. Mais n'observe-t-on pas aussi de tels évènements au niveau des pays les plus puissants ?

Cité par Emile COORNAERT in Économie Appliquée, juillet-décembre 1955, p. 473. 
En dix ans (1950-1960), le montant cumulatif des investissements américains à l'étranger est passé de 11,7 milliards de dollars à une trentaine de milliards se répartissant en trois zones géographiques principales : le Canada (qui, à lui seul, compte pour le tiers) l'Amérique latine et l'Europe (la part la plus importante allant à la Grande-Bretagne). Les autres continents, Afrique et Asie, attirent moins les capi[p. 58] taux privés américains (à la seule exception du Moyen-Orient pétrolier). Or, ce mouvement provoque des préoccupations et, souvent, des réticences dans les États bénéficiaires.

En Grande-Bretagne, l'emprise croissante des capitaux américains sur l'industrie britannique a suscité de nombreuses inquiétudes (rappel de la lutte menée par deux groupes américains de l'Aluminium, Alcoa et Reynolds Metal, pour s'assurer le contrôle du British Aluminium, seul producteur de ce métal en Grande-Bretagne ; on sait que, finalement, Reynolds, en association avec le groupe britannique Tube Investment, a racheté la totalité du capital de la société British Aluminium). Il semble que, dans ce pays, les Américains contrôlent déjà les 2/5 de la construction automobile, un tiers de l'industrie pétrolière, la moitié de la production des détergents. Aux Pays-Bas, une grande partie des actions d'affaires comme Royal-Dutch, Unilever, Philips, est entrée dans les portefeuilles américains. Au Canada, la dépendance à l'égard de l'économie américaine s'est accrue depuis la guerre, les investissements internes des sociétés contrôlées par les États-Unis ayant été de 4 à 10 fois supérieurs à ceux des sociétés à capitaux nationaux (plus de la moitié des profits y échoit à des « non-résidents ») ${ }^{1}$.

Pour l'Allemagne, M. Pritzkoleit, entre bien d'autres, a posé le problème en écrivant : «L'économie allemande est-elle dominée par l'étranger ? ». Et pour justifier cette question outrancière, il cite de nombreux cas où cette pénétration lui semble importante (pétrole, produits alimentaires, chimie, électrotechnique, charbonnages). Or, cette participation étrangère lui paraît comporter une « forte impulsion politique et économique " ${ }^{2}$. Est-ce là comme nous le croyons une vue de polémiste, ou une affirmation sagement méditée.

Quand on parle de l'influence des affaires sur la politique internationale, on en vient nécessairement à rappeler l'activité des "marchands de canons ", ou plus généralement, celui des "profiteurs de guerre " ${ }^{3}$. L'affirmation liant l'échec du désarmement aux manœuvres des fabricants d'armes, est toujours d'actualité et ne

1 BLYTH (C.D.), CARTY (E.B.), « Non Resident Ownership in Canadian Industry », Canadian Journal of Economics and Political Science, novembre 1956, pp. 449-460. Voir également PARIZEAU (J.), "Les investissements américains sont-ils devenus une menace ? », Actualité Économique, avril-juin 1956, pp. 140-156. Consulter enfin AITKEN (Hugh G.J.) et al. The American Economic Impact on Canada, Durham (N.C.), 1959.

2 In Le Saint-Empire industriel germanique, traduit de l'allemand, Paris, 1954, pp 279-304. En sens inverse, n'oublions pas l'action offensive des cartels allemands, spécialement entre les deux guerres. Voir LADOR-LEDERER Capitalismo mondiale e cartelli tedeschi tra le due guerre, Turin, 1959.

3 Dans son livre Les profits de guerre à travers les siècles, Paris, 1935, Richard LEWINSOHN dresse une galerie des "profiteurs »: généraux, financiers, fabricants d'armes, fournisseurs, spéculateurs. 
cesse de connaître une grande popularité ${ }^{1}$. Elle a conduit la France, à la loi du 11 août 1936, nationalisant un certain nombre d'usines d'armement. Elle poussera à réclamer le jugement du vieux von Krupp par le Tribunal de Nuremberg (son état de profonde et constante hébétude constaté par le verdict d'un aréopage international de médecins, le sauvant toutefois du procès) ${ }^{2}$. En réalité, il apparaît difficile et d'exonérer les fabricants [p. 59] d'armes de toutes les responsabilités dans la genèse des guerres d'agression et d'y voir le facteur dominant du déclenchement des hostilités : l'histoire se rit toujours des explications monistes.

\section{b) BANQUIERS ET FINANCIERS}

\section{$\underline{\text { Retour à la table des matières }}$}

Selon certaines thèses que nous discuterons plus tard, le capitalisme aurait subi une transformation fondamentale en passant sous le contrôle du capital financier. Point n'est d'ailleurs besoin de les admettre pour reconnaître que les détenteurs de monnaie ont volontiers pesé sur les décisions politiques. Nier l'existence d'une action internationale de la finance reviendrait, après tant d'études irrécusables ${ }^{3}$, à exprimer une puérilité ou une apologie. Mais il paraît discutable de ne faire remonter le phénomène qu'au $\mathrm{XIX}^{\mathrm{e}}$ siècle. On a d'autre part de bonnes raisons de penser qu'aujourd'hui, dans beaucoup de pays occidentaux, le pouvoir des financiers privés s'affaiblit.

1 À compter du numéro du 23 mai 1960, Temps Nouveaux publie une série de notices sur les « consortiums de guerre », dont, selon cette revue, quelques-uns cesseraient d'exister s'il était mis fin à la course aux armements. La revue souligne qu'à l'aide de leurs filiales et succursales à l'étranger ces consortiums (américains, anglais et allemands) contrôlent l'industrie de guerre de nombreux pays capitalistes (japon, Canada...). Les neuf firmes américaines citées sont: General Dynamics, Boeing Airplane, North American Aviation, Lockheed Aircraft Corporation, General Electric, Douglas Aircraft, Martin Company, United Aircraft, Dupont de Nemours. Temps Nouveaux estime qu'elles constituent aujourd'hui les principaux fournisseurs d'armes du monde occidental (la part des productions de guerre dans leurs chiffres d'affaires variant de 25 à $90 \%$ ). L'ouvrage classique sur le sujet reste NOEL-BAKER (Ph.), The private manufacture of Armaments, Londres, 1936.

2 Argument principal des accusateurs : les profits tirés par Krupp de l'avènement de l'hitlérisme. Déficitaire au début du réarmement, la firme réalisa par la suite des profits croissants (57 millions de marks en 1935, 97 en 1938, 111 en 1941). En même temps, la valeur comptabilisée du trust passe de 76 millions de marks en 1933 à 237 en 1943 chiffres cités par HEYDECKER (Joe J.), LEEB (J.), Le procès de Nuremberg, traduit de l'allemand, Paris, 1959, pp. 90-91. Sur la maison Krupp on pourra lire MUHLER (Norbert), The Incredible Krupp's. The rise, fall and comeback of Germany's industrial family, New York, 1959.

3 Voir par exemple l'excellent livre de LANDES (David S.), Bankers and Pashas. International finance and economic imperialism in Egypt, Londres, 1958, qui décrit, à partir de la correspondance de deux banquiers (dont l'un, banquier personnel du vice-roi d'Égypte) la lutte engagée entre 1860 et 1870 pour la domination financière de l'Égypte. 
Passant sur des phénomènes très anciens, difficilement comparables à ceux de notre temps ${ }^{1}$, nous pouvons trouver un jalon solide dans l'étude d'une dynastie comme celle des Fugger, et spécialement de la carrière de Jacob Fugger (14591525) ${ }^{2}$. À lui seul, l'examen de l'élection de Charles Quint (en bref, une extraordinaire foire aux consciences), jette une vive lumière sur les rapports entre la finance et la politique, ainsi que sur les implications internationales des facultés dont disposent, en certaines circonstances, les possesseurs de capitaux liquides. De plus, il y a dans la carrière de ce manieur d'argent, des épisodes qui s'insèrent admirablement dans un schéma moderne de pression internationale.

En 1525, le Parti National Magyar mène une lutte violente contre l'activité du groupe Fugger-Tharzo, en Hongrie. Les accusations lancées sont très voisines du reproche d'exploitation que les pays colonisés ont adressé à leur métropole. Des émeutes éclatent et tous les biens de Fugger dans ce pays sont saisis. Celui-ci entreprend alors d'agir de l'extérieur sur les autorités hongroises, par l'intermédiaire de souverains qui lui sont dévoués. Craignant de s'exposer aux représailles des princes d'Occident, à un moment où se précisait la menace des Turcs, les dirigeants de la Hongrie capitulèrent en acceptant les contre-propositions, d'abord écartées, de Jacob Fugger, dont ce devait être la dernière victoire.

[p. 60] La monarchie française, quant à elle, n'est pas demeurée insensible à l'influence des financiers, comme le montre la carrière de Jacques Cœur, Nicolas Fouquet ou Samuel Bernard. Celui-ci, petit marchand commissionnaire, lorsqu'il abjure le protestantisme sous le coup de la révocation de l'Édit de Nantes, va devenir, en quelques années, l'un des plus grands banquiers d'Europe, sinon le plus grand. Après une âpre lutte, il en arriva à obtenir le monopole du financement des armées et notamment de la guerre de Succession d'Espagne. L'ampleur des services rendus lui vaudra la reconnaissance et des marques de gratitude particulières de Louis XIV. À propos d'une entrevue entre le souverain et le financier, Saint-Simon dira cruellement : «J'admirais ... cette espèce de prostitution du roi ... à un homme de l'espèce de Bernard ». Et en ayant appris la cause, il ajoute : « J'admirai alors où les plus grands rois se trouvent quelquefois réduits ${ }^{3}$. Naturellement, la contrepartie des services ne se limitait pas à de simples politesses. S. Bernard put, grâce à la bienveillance du pouvoir, entreprendre plusieurs trafics très fructueux.

À notre époque, l'un des noms qui, pour l'homme moyen, symbolise le mieux le pouvoir de la haute finance internationale, est celui de Rothschild. Et il est vrai,

1 Voir toutefois les pages savoureuses consacrées par Léon Homo aux financiers romains (dont les opérations s'étendaient à une portion toujours plus grande du monde méditerranéen) in Scènes de la vie romaine sous la République, Abbaye de Saint-Wandrille, 1952, pp. 85-96.

2 Sur les Fugger, le livre classique est EHRENBERG (R.), Le siècle des Fugger, Paris, 1955 (dont la version originale allemande date de 1896). Sur le cas de Jacob Le Riche voir SHICK (Léon), Un grand homme d'affaires au début du XVI siècle. Jacob Fugger, Paris, 1957.

3 Cité par Jacques SAINT-GERMAIN dans un ouvrage de vulgarisation, Samuel Bernard, le banquier des rois, Paris, 1960. Pour une étude savante de ce financier, consulter LUTHY (Herbert), La banque protestante en France de la révocation de l'édit de Nantes à la Révolution. I, Dispersion et regroupement (1685-1730), Paris, 1959. 
comme l'écrit Jean Bouvier, que «le destin de cette famille, dont la grande fortune compte aujourd'hui un siècle et demi d'âge a de quoi faire rêver tous ceux que l'histoire enivre $"{ }^{1}$. Mais si cette maison fut et demeure très représentative du grand capital, elle a trouvé des émules, et aussi des rivaux, parfois acharnés. Encore qu'elle ait des aspects contestables, la division (usuelle en France) de la haute finance en trois branches : catholique, israélite, protestante, explique divers comportements. De toutes façons, ces puissances financières, en accord avec les forces installées dans d'autres pays, ou contre leur gré, ont joué un rôle dans la politique internationale spécialement dans le partage de la Terre en colonies ou zones d'influence économique (du type de la convention franco-allemande sur le chemin de fer de Bagdad) au profit des grands États de l'Occident ${ }^{2}$.

Malheureusement, les modalités et les péripéties de cette activité demeurent mal connues. La plus grosse difficulté reste d'apprécier le poids propre des intérêts considérés sur la décision ${ }^{3}$. Soit par exemple, l'établissement du Protectorat français en Tunisie. On sait que ce pays souffrait alors d'une crise financière que les dépenses excessives des beys n'avaient fait qu'aggraver. Les consuls, installés à Tunis, favo[p. 61] risaient les désordres de l'administration locale afin d'en tirer un surcroît d'influence politique. Est-il possible d'imputer aux seuls intérêts financiers la responsabilité des mesures qui aboutirent au traité du Bardo et à la dégradation rapide du protectorat en administration directe par la convention de La Marsa ? Les avis sont partagés. L'analyse la plus récente conclut que les financiers ne semblent pas avoir eu un rôle déterminant. Cependant, souligne l'auteur, «les intérêts en jeu étaient trop évidents pour que les spéculateurs du "groupe" tunisien, qui avaient tant d'amis au Parlement, ne soient pas intervenus au moment opportun pour peser sur une décision encore en suspens ${ }^{4}$.

Voici un autre cas situé hors du contexte colonial : la pénétration de l'Union générale sur le marché autrichien vers les années 1880. Il s'agissait, pour l'animateur de l'Union, Eugène Bontoux, de créer à Vienne « un établissement de premier ordre,

1 Dans une intéressante analyse, Les Rothschild, Paris (Club français du livre) 1960. À l'exception des recherches de B. GILLE qui couvrent la première moitié du XIX ${ }^{\mathrm{e}}$ siècle (voir en particulier $L a$ Banque et le crédit en France de 1815 à 1848, Paris, 1959), il existe peu de travaux en langue française sur la question. L'ouvrage d'Egon Cesar Comte CORTI, La Maison Rothschild, 2 vol., Paris, 1929-1930, apporte une riche documentation, mais reste difficile à lire. On trouvera quelques éléments d'information sur cette période in BIGO (Robert), Les banques françaises au cours du XIX siècle, Paris, 1947, passim.

2 On mentionnera ici, en raison de l'intérêt du sujet dont ils traitent, les livres polémiques de Henry COSTON, Les financiers qui mènent le monde, Paris, 1955, et La haute banque et les trusts, Paris, 1958. Du même auteur Le retour des " 200 familles », Paris, 1960, et « Partis, journaux et hommes politiques", Lectures Françaises, décembre 1960 (numéro spécial). Discutables dans leur inspiration et contestables sur de nombreux points, ces travaux signalent des problèmes et, parfois, ouvrent des pistes.

3 Pour un bon exposé de l'état de la question dans le cadre français, voir GRUNEWALD (Jacques), "L'influence des facteurs économiques sur les décisions dans la politique étrangère de la France », dans l'ouvrage collectif La politique étrangère et ses fondements, Paris, 1954.

4 GANNAGE (Jean), Les origines du protectorat français en Tunisie, 1861-1881, Paris, 1959. 
un allié fidèle " - projet contre lequel se dressaient les deux groupes viennois dominants (dont l'un aux mains des Rothschild). Bontoux obtint la concession nécessaire lors d'un changement de ministère, le nouveau chef de gouvernement et son ministre des finances cherchant le moyen de ne plus demeurer sous la dépendance trop absolue de la banque juive et allemande. Ainsi, ce furent des considérations à la fois politiques et financières qui dictèrent sa décision à l'autorité autrichienne ${ }^{1}$.

Il arrive que les intéressés, par exemple les participants à une négociation, racontent eux-mêmes le déroulement de l'opération. Ainsi Emile Moreau a-t-il exposé dans ses Souvenirs, non d'ailleurs sans quelque complaisance, la pression faite en 1928 sur la Banque d'Angleterre, pour l'amener à reconnaître la sphère d'influence financière de la France dans l'Europe danubienne et balkanique ${ }^{2}$. L'argument de la négociation était celui de la puissance financière de la Banque de France (alors institution privée) : en liquidant ses avoirs sterling, celle-ci aurait pu porter un coup sérieux à la livre (qui devait succomber un peu plus tard). Mais de telles « confessions » sont rares, les financiers internationaux n'étant pas encore atteints par l'intempérance littéraire qui sévit aujourd'hui chez les hommes politiques et les généraux ${ }^{3}$.

Les formes extérieures que revêtent les intérêts financiers, en intervenant sur le plan international, sont nombreuses et il est difficile d'en dresser en quelques mots un tableau ordonné (difficulté accrue par la diversité des structures nationales de distribution de l'argent). La pénétration à l'étranger peut se faire par l'ouverture de succursales ou [p. 62] comptoirs, la création de filiales, la prise de participations dans des sociétés locales. Les combinaisons entre les intérêts financiers de plusieurs pays adoptent, en certains cas, le cadre d'un syndicat d'affaires (en particulier, placement d'un emprunt sur divers marchés par les banques de plusieurs pays) ; souvent aussi, les liaisons résultent d'accords généraux, an besoin assez souples et non écrits. Les grandes dynasties internationales (du type Rothschild et Lazard) ont bénéficié de facilités considérables par la seule installation des différentes branches de la famille sur les grands marchés du monde.

On emploie volontiers, et généralement de façon vague, l'expression «milieux financiers ». Elle traduit parfois la réalisation d'une conduite commune délibérée, parfois aussi de simples convergences de comportement (provoquées par le souci d'imiter une firme leader, ou par une appréciation identique des circonstances). Elle exprime également dans quelques cas, une sorte de partage tacite: ainsi, sous le Second Empire, les Pereire considèrent l'Italie comme un fief, tandis que les

1 D'après BOUVIER (Jean), Le krack de l'Union Générale, 1878-1885, Paris, 1960, pp 58-62. Cet ouvrage apporte beaucoup de matériaux à l'étude de notre sujet. Voir en particulier tout le chapitre III, « Les premières luttes pour le rail dans les Balkans » (1878-1882).

2 In Souvenirs d'un gouverneur de la Banque de France, Paris, 1954. Voir les commentaires de EINZIG (P.), «Behind the Scenes of International Finance », Fortnightly, septembre 1954, pp. 160-165.

3 Par exemple, le livre de Bernard M. BARUCH, Ma vie, traduit de l'américain, Paris, 1959, vaut au lecteur une complète déception. L'auteur, qui aurait certes beaucoup à dire, s'en tient à un plan lénitif et édifiant. Il est vrai qu'un second volume est prévu. 
Rothschild se consacrent à l'Autriche et commencent à s'intéresser à l'Espagne. Il est d'ailleurs possible que l'on soit tenté d'attribuer à ces milieux plus de cohérence dans l'action qu'ils n'en témoignent habituellement. Et de la sorte, on finit par présenter une notion quelque peu mythique des phénomènes.

Ainsi en a-t-il été à une époque, en Grande-Bretagne, quant à un prétendu assaut des «banquiers de Zurich » contre la livre. Que les 87 banques installées à Zurich aient volontiers poussé à fond les facultés d'arbitrage ouvertes sur le marché est peu contestable ; mais, de ce souci de profit pur à une tentative systématique d'affaiblir la livre, il y a une longue distance que les esprits sérieux en Angleterre et ailleurs, n'ont jamais accusé les maisons zurichoises d'avoir franchie ${ }^{1}$. La notion de « complot » est l'un des accessoires obligés — et aujourd'hui totalement déconsidérés — de la présentation journalistique: en matière financière, le secret des opérations et l'ignorance où se trouve le public des mécanismes techniques (pourtant fort simples) facilitent les tendances à l'affabulation. Quand on regarde attentivement les faits, on voit s'évanouir ou se fondre en opérations normales, beaucoup des prétendues machinations ou autres conjurations de financiers.

Il reste à signaler que la séparation entre les intérêts économiques (production et distribution des produits) et les intérêts financiers (circulation des capitaux), sans être dépourvue de fondement, ne traduit [p. 63] qu'imparfaitement le fonctionnement concret de la vie des affaires. Les relations entre la banque et l'industrie ont obéi à des schémas qui diffèrent selon les pays (un trait quasi-universel toutefois étant l'accroissement de l'indépendance ou la diminution de la dépendance de la seconde à l'égard de la première, par suite des politiques d'auto-financement).

On pourrait évoquer en tout cas une multitude d'exemples d'association ou de combinaison d'intérêts proprement économiques avec des intérêts purement financiers : réunion dans un groupe, plus ou moins cohérent et homogène, de grandes banques et de sociétés industrielles, agissant directement ou par le canal d'une organisation professionnelle. Reconnaissons toutefois que la situation peut varier : par exemple, la liaison entre l'exportation des capitaux et l'ouverture aux produits nationaux des marchés étrangers a toujours été beaucoup plus ferme en GrandeBretagne qu'en France.

Voir par exemple l'excellente mise au point de The Economist, 7 mars 1959, « Bankers of Zurich ». 


\section{c) CARTELS INTERNATIONAUX}

$\underline{\text { Retour à la table des matières }}$

Sous certains aspects, il n'existe pas de différence fondamentale entre les objectifs et le mode d'organisation des cartels nationaux et internationaux. Les seconds peuvent, en un sens, s'interpréter comme l'extension horizontale des premiers. Cependant des schémas, très utilisés au niveau national, sont difficiles à mettre en œuvre au plan international : ainsi, la fixation d'un barème rigide de prix (malaisé à établir et à imposer du fait de la diversité des facteurs d'un pays à l'autre : douanes, salaires, ressources technologiques, produits de substitution, réglementations publiques...). Par suite, même si, ce qui est rare, les conditions sont favorables à la manipulation des prix (contrôle quasi-monopolistique d'un produit standardisé), les arrangements conclus aboutissent presque obligatoirement à des variations nationales dans les tarifs pratiqués.

La formule de prédilection de cartels internationaux est celle du partage des marchés : généralement, les parties au contrat se réservant chacune le contrôle du marché national et se partageant les autres. Souvent ces ententes ont pour corollaire la mise en commun de brevets, la cession de licences, etc. ${ }^{1}$.

Les formules juridiques adoptées par les cartels internationaux sont variables. Il s'agit souvent de simples accords s'analysant selon le cas [p. 64] en un dispositif très souple du type gentleman's agreement ou en un ensemble complexe de réglementations (avec organes disciplinaires, mécanismes d'arbitrage, pénalités...). Autrement dit, l'absence d'une structure juridique formelle est compatible avec l'exercice d'une action puissante et le respect d'une stricte discipline. Cependant les cartels ont de plus en plus tendance à dépasser ce stade en créant une personne morale qui rassemble toutes les parties à l'accord: le cartel international est, dès lors, en mesure d'agir comme un sujet légal et le fonctionnement de l'entente se rationalise (établissement d'une hiérarchie d'organes, possibilités de définir et de restreindre les droits des membres par les statuts, etc.). Enfin, on a eu parfois recours (surtout sur le continent européen) à une formule dualiste : signature d'un accord qui fixe les droits et obligations mutuels et création d'une personne morale qui a pour tâche de le mettre en œuvre.

Les dispositions juridiques adoptées par les États vis-à-vis des cartels varient considérablement d'un cas à l'autre. Des pays témoignant à leur égard d'attitudes particulièrement amicales, les cartels internationaux qui aboutissent à la création d'une personne morale, ont pris l'habitude de s'y installer. Mais, en fait, cette

La bibliographie sur les ententes internationales est considérable. On pourra partir de l'étude suivante qui comporte de multiples références : FRIEDMANN (W.), VERLOREN van THEMAAT (P.), «International Cartels and Combines », in FRIEDMANN (W.) (ed.), Antitrust Laws. A comparative symposium, Londres, 1956, pp. 469-515. 
domiciliation a souvent peu de portée, car les cartels les plus puissants se fient bien davantage pour assurer leur fonctionnement à la puissance économique qu'à la règle légale. Pour des raisons compréhensibles, ils cherchent à éviter les procès, les manquements aux règles fixées faisant l'objet de sanctions économiques (boycott, dumping...).

Dès lors, des auteurs n'hésitent pas à les interpréter en termes de droit international public, y voyant une institution parvenue à arracher un élément de souveraineté aux États dits souverains. Le cartel international (et l'on retrouve ainsi une idée déjà connue) serait une sorte d'État (ou de fédération) partiel, exerçant le pouvoir sur ses membres, sans se soucier des ordres juridiques nationaux (spécialement dans le règlement des conflits qui s'élèvent en son sein et aussi à l'égard des dissidents ou des outsiders).

L'un des organismes qui ont le plus retenu l'attention et suscité le plus de controverses est l'Entente Internationale de l'Acier (1926-39), Son action se décompose en deux phases. Durant la première, 1926-1930, l'Entente s'efforce de réaliser, par la voie du contingentement, l'adaptation de la production au tonnage total représentant les besoins probables du marché, mais la grande dépression provoque la dislocation [p. 65] du mécanisme. La seconde phase (1933-39), qui fait suite à un avilissement des prix sans précédent, est d'ambition modeste : l'Entente abandonne aux cartels nationaux le soin d'organiser les marchés intérieurs, se réservant le droit de régulariser le mouvement des exportations et des prix internationaux.

On a émis de nombreuses accusations à l'encontre de l'Entente de l'Acier dont l'un des torts fut de se couvrir d'un voile impénétrable de secret : en particulier, on lui a reproché, non sans quelque excès, d'avoir consacré et favorisé la disparité dans le rythme de développement des sidérurgies allemande et française. Observons toutefois que ce cartel a fini par obtenir, en un temps difficile, la stabilisation du prix de vente de l'acier et la régularisation des échanges sidérurgiques internationaux : mais il n'y parvint qu'en accordant aux organisations nationales le droit exclusif de réglementer leur propre marché ${ }^{1}$.

Un autre accord fort connu, et de portée encore plus vaste, est celui qui fut signé en 1928 pour régir le marché international du pétrole (Achnacarry Agreement ou encore As is agreement). Nous aurons à analyser plus loin le sens de ce cartel, actuellement soumis à des menaces considérables. Adolf Berle l'a défini comme « un traité de paix commercial, mettant fin à une guerre entre grandes sociétés ${ }^{2}$. C'est en tout cas un essai de planification partielle à l'échelon mondial.

Entre les deux guerres de nombreux cartels internationaux ont été fondés et ont fonctionné avec des fortunes diverses dans le domaine des produits alimentaires (thé),

1 Sur ce sujet, le meilleur livre est RIEBEN (Henri), Des ententes de maîtres de forges au plan Schuman, Lausanne, 1954. Voir aussi dans le recueil des cours 1956 l'enseignement donné par Rieben à l'Académie de Droit International sous le titre « De la cartellisation des industries lourdes européennes à la Communauté européenne du Charbon et de l'Acier ».

2 In Le capital américain et la conscience du roi, traduit de l'anglais, Paris, 1957, p. 112. 
matières premières (étain), objets fabriqués (lampes électriques à incandescence) ${ }^{1}$. Depuis 1945, une certaine évolution s'observe vers des accords proprement intergouvernementaux, conformes aux stipulations de la Charte de La Havane (accord sur le blé ou le café, par exemple). Sans entrer ici dans une discussion de la valeur comparée des deux techniques, privée et publique, d'aménagement des rapports, disons que l'une comme l'autre soulèvent des problèmes complexes. Disons aussi que l'organisation du marché sous une forme quelconque est indispensable. On a souvent critiqué les cartels internationaux et il est vrai que quelques-uns d'entre-eux (pétrole en particulier) ont profité de leur position pour obtenir, en faveur de leurs membres, des bénéfices substantiels : la plupart toutefois, n'ont pas eu un destin financier aussi brillant. Ces reproches ne doivent pas faire oublier que plusieurs ententes se sont efforcées, sans y parvenir toujours, de réaliser une ébauche, parfois grossière, de planification industrielle.

[p. 66] On peut certes se féliciter que l'Entente Internationale de l'Acier ait été remplacée par la C.E.C.A. Mais reconnaissons que le passage d'une formule à l'autre découle de considérations exceptionnelles. Admettons aussi, à la lumière des faits, que les grandes sociétés ont souvent témoigné d'une aptitude à la négociation supérieure à celle des États. La dissolution pure et simple des diverses conventions mondiales de nature privée serait génératrice de désordres, voire de chaos. On en arrive alors à la nécessité d'un contrôle de ces accords: dans l'état actuel de l'organisation internationale, on ne voit pas bien qui pourrait l'exercer.

\section{d) ASSOCIATIONS PROFESSIONNELLES}

$\underline{\text { Retour à la table des matières }}$

C'est une autre forme de défense et de promotion des intérêts économiques et financiers. Il s'agit généralement d'organisations sans but lucratif qui rassemblent des éléments nationaux. L'une des mieux connues est la Chambre de Commerce Internationale dont la fondation remonte à $1920^{2}$.

1 Sur le problème voir International Cartels. A League of Nations memorandum. New York, 1947 ; HEXNER (Ervin), International Cartels, Chapel Hill, 1946 ; STOCKING (George W.), WATKINS (Myron W), Cartels in Action. Cases studies in international business diplomacy, New York, 1946. Voir aussi NEWMAN (Philip C.), Public Control of Business. An international approach, New York, 1955 (spécialement pp. 118-163). Pour l'avant-guerre voir : BALLANDE (Laurence), Les ententes économiques internationales. Étude monographique et statistique, Paris, 1937 ; ELLIOT (W.Y.), International Control in the Non-Ferrous Metal, New York, 1937 ; PRIBRAM (Karl), Cartel Problems. An Analysis of collective monopolies in Europe with American application, Washington, 1935.

2 Sur la Chambre, voir l'ouvrage de RIDGEWAY (George L.), Merchants of Peace, Twenty years of business diplomacy, New York, 1938 (dont une seconde édition vient de paraître à Boston). Voir aussi ALEXANDROWICZ (Charles H.), International Economic Organisation, Londres, 1952, pp. 91-97. 
Aux termes de ses statuts (art. 1, alinéa 3), la Chambre est « une fédération des principales forces économiques des pays qui en font partie, unies à l'intérieur de chaque pays en un comité national ». Ces comités nationaux, appelés à grouper toutes les organisations de branches ou de fonctions (ainsi que toutes les entreprises intéressées par le commerce international) constituent la base de l'organisation. En 1959, la Chambre en possédait dans 39 pays : elle avait, de plus, des membres (collectifs ou individuels) dans 25 pays sans comité national. Au total, elle pouvait dès lors prétendre représenter les intérêts économiques de 64 nations. On ne s'étonnera pas que cet organisme passe pour disposer de grosses ressources financières.

Entre les deux guerres, la C.C.I. a entretenu des rapports étroits avec la S.D.N. et exercé une pression, souvent puissante, sur les diverses instances de l'organisation. Par exemple, lors de la Conférence économique de 1927 (une des plus importantes réunions officielles qui aient eu lieu sur les problèmes du commerce mondial), la Chambre prit part à son aménagement en rassemblant la documentation et en participant au Comité préparatoire. Ce dernier accepta son rapport sur les barrières douanières, de préférence aux travaux du secrétariat de la S.D.N., comme document de travail pour la discussion. À la Conférence proprement dite, la Chambre fut représentée par 5 délégués et 6 experts, mais de [p. 67] plus, au sein des délégations nationales désignées par les gouvernements elle comptait 64 délégués membres de l'un ou l'autre de ses conseils ou comités. Il est donc compréhensible que plusieurs des recommandations exprimées par cet organisme aient été incorporées dans le rapport final ${ }^{1}$.

L'objectif essentiel de la Chambre est de favoriser dans toute la mesure du possible l'initiative privée et la libre circulation des hommes, des marchandises, des services et des capitaux entre les nations. Dans de nombreux cas, les intéressés sont en mesure d'améliorer les mécanismes du commerce international sans avoir besoin de faire appel aux autorités publiques. Mais on sait qu'aujourd'hui la solution de multiples problèmes dépend des seuls gouvernements. La Chambre fait donc entrer expressément dans ses moyens d'action l'intervention auprès des pouvoirs publics. Elle se proclame volontiers "conseiller des gouvernements ". "Auprès des gouvernements, peut-on lire dans une publication récente, la C.C.I. est le porte-parole mondial de tous les secteurs de la vie économique ${ }^{2}{ }^{2}$.

L'intervention prend alors la forme de déclarations de principe ou, éventuellement, de recommandations détaillées. Par exemple, la Chambre fera des propositions pour la suppression des doubles impositions ou encore suggérera les mesures que les pays sous-développés devraient à son sens adopter s'ils voulaient vraiment attirer chez eux les capitaux privés. Ces deux thèmes ont fait l'objet de vœux sans ambiguïté lors

1 D'après WHITE (Lyman C.), International Non-Governmental Organizations, New Brunswick, 1951, pp. 19-32, qui donne de nombreux exemples de cette influence.

2 In Rapport biennal, 1957-1959. La Chambre précise que l'énumération de toutes les questions sur lesquelles elle a soumis des vues aux gouvernements ou a été consultée par eux, dépasserait largement le cadre matériel de cet examen général de ses activités. 
d'une conférence organisée par la Chambre à Karachi (décembre 1960) et qui fut la première de ce type à se tenir en Asie.

Une large partie de ces démarches s'effectue actuellement auprès des organisations intergouvernementales dont, si l'on en croit la C.C.I., une bonne centaine prennent chaque jour des positions et décisions susceptibles d'affecter l'activité des hommes d'affaires. La Chambre entretient avec la plupart d'entre elles des rapports très étroits (et, bien entendu, en premier lieu, avec le Conseil Économique et Social des Nations Unies).

On ne saurait envisager d'examiner ici, ni même simplement d'énumérer, toutes les associations professionnelles créées sur le plan international dans les différents secteurs de la vie économique. Reflétant les préoccupations des multiples branches de la production et de la distribution, ces organismes sont nécessairement fort nombreux. En matière d'agriculture par exemple, nous trouvons des associations à [p. 68] vocation générale comme la Fédération Internationale des Producteurs Agricoles (groupant 26 pays) dont les tâches centrales sont d'améliorer la situation économique et sociale de ceux qui vivent sur la terre et par la terre : elle a, en particulier, pour rôle de transmettre à toutes les organisations internationales compétentes, les points de vue coordonnés de ses membres ${ }^{1}$.

Mais il existe aussi des groupements à vocation spécialisée : Fédération Internationale de Laiterie, Fédération Internationale d'Oléiculture, Association Internationale des Producteurs de l'Horticulture, etc. On note également plusieurs organes centrés sur la poursuite d'améliorations techniques : Union Internationale des Instituts de Recherches Forestières, Congrès International des Herbages, Association Internationale de Recherches sur la Qualité des Plantes Alimentaires... N'oublions pas les «services »: Confédération Internationale du Crédit Agricole, Association Internationale des Assureurs contre la Grêle... ${ }^{2}$. On trouverait, bien entendu, la même variété dans tous les domaines de la vie économique.

1 On trouvera dans le rapport de la XII ${ }^{\mathrm{e}}$ Conférence de la F.I.P.A. l'exposé de son programme (« Vers une politique internationale de l'exploitation agricole et de l'alimentation ») et quelques indications sur les rapports de l'organisme avec la F.A.O. L'Agriculture dans le Monde, vol. XI, $\mathrm{n}^{\circ} 1$, janvier 1960, pp. 1-23. Pour un très bref exposé sur la F.I.P.A., voir l'article de K. NASH dans le Bulletin O.N.G., décembre 1952, pp. 471-474. Il existe également une Confédération Européenne de l'Agriculture sur laquelle on trouvera une brève note de Charles FELDMANN, Bulletin O.N.G., mars 1953, pp. 109-111. Elle a conclu un accord avec la F.I.P.A. reconnaissant à celle-ci la qualité de porte-parole des agriculteurs pour les problèmes mondiaux. Voir C.E.A. Historique. Organisation. Activité, Brougg (Suisse), 1958 (ouvrage publié par la Confédération à l'occasion de son dixième anniversaire).

2 Voir l'intéressant numéro spécial de Associations, novembre 1958 sur «La coopération internationale dans le domaine de l'agriculture ». Au cours des dernières années, l'U.A.I. a consacré plusieurs numéros de sa revue à des études de ce type. Citons « La coopération internationale en matière de chemins de fer » (mai 1955), « La navigation maritime et fluviale, instrument et objet de la coopération internationale » (octobre 1955), « La coopération internationale dans le domaine de l'aviation civile » (novembre 1956), une série d'articles sur les organisations se préoccupant des problèmes de l'énergie nucléaire (septembre 1957), « Les organisations techniques internationales à l'âge nucléaire » (décembre 1958). Ces livraisons apportent de précieuses indications sur des 
Sans être aussi complet que celui des grandes, l' « accès » à la vie internationale des petites entreprises s'effectue par l'intermédiaire de divers organes. Citons en particulier l'Institut International des Classes Moyennes. Jusqu'à présent, ce groupe était de recrutement essentiellement européen : il vient d'établir des liaisons avec quelques-uns des États africains nouvellement promus à l'indépendance.

Toutes ces organisations n'ont ni la même importance, ni la même influence. Certaines se cantonnent volontairement dans l'exécution de programmes ou recherches techniques, n'utilisant qu'exceptionnellement la "voie politique » pour réaliser leurs buts. D'autres se tiennent en liaison constante avec les gouvernants ou les bureaucrates des organisations intergouvernementales. Il est probable que la vie des affaires dépend encore principalement des pressions exercées par les organisations nationales sur leur propre gouvernement: cependant, l'activité des organes internationaux, qui s'est intensifiée depuis 1945, ne saurait être ignorée.

[p. 69]

\section{e) ENTREPRISES INTERNATIONALES}

Retour à la table des matières

On vise ici des affaires qui semblent relever de la vie internationale non seulement par les dimensions de leur activité, mais par les conditions de leur constitution et les règles de leur fonctionnement. Mentionnons, à titre d'exemples, l'Aéroport International de Bâle-Mulhouse, la Banque des Règlements internationaux, la Scandinavian Airlines-System, etc. Ces unités correspondent à des formules nouvelles dont la nature, juridique fait encore l'objet de contestations.

Parmi les conceptualisations proposées pour en rendre compte, figure la notion d'établissement public international. Il s'agit d'une catégorie juridique spécifique, forgée pour rassembler des activités économiques d'intérêt international qui, par la nouveauté de leur mode d'agencement, ne trouvent pas place dans les catégories habituelles. Selon H. Adam, qui en fait la systématisation, l'établissement public international se distingue, aussi bien de l'organisation internationale courante, que de l'établissement national. On peut le définir comme " une entreprise ou un service public créé par deux ou plusieurs États, indépendamment de toute organisation intergouvernementale, ayant pour objet, soit de faire des prestations à des particuliers, soit de réglementer l'usage, par ces derniers, du domaine public des dits États » ${ }^{1}$.

H. Adam fait entrer par exemple dans cette catégorie, la Société Européenne pour le Financement du Matériel Ferroviaire (Eurofima) dont l'objet est de procurer dans

secteurs de la vie internationale presque entièrement négligés par les chercheurs. Voir toutefois ROGIU (G.S.), Le Organizzazioni Internazionale nel Settore dei Trasporti, Rome, 1956.

1 ADAM (H.T.), Les établissements publics internationaux, Paris, 1957. Voir aussi HUET (Pierre), « L'Agence Européenne pour l'Énergie Nucléaire et la Société Eurochimie. Contribution à l'étude des sociétés internationales ", Annuaire Français de Droit International, vol. IV, 1958, pp. 
les meilleures conditions possibles, aux administrations de chemins de fer qui sont ses actionnaires, ainsi qu'à d'autres administrations ou organismes ferroviaires, les matériels de type ou à performance unifiés, nécessaires à leur exploitation. Cette société constituée dans le cadre d'une convention entre 14 pays européens, a son siège à Bâle où elle bénéficie d'exonérations fiscales. Autres organismes rangés dans la même catégorie : la Commission et la Société Internationale de la Moselle ; la Société Financière Internationale; l'Agence Internationale de l'Énergie Atomique; les entreprises communes à créer en vertu des art. 45 et suivants du traité instituant l'Euratom...

Un cas particulier : les entreprises nationales, mais à intérêt international et également à statut international, comme, par exemple, les entreprises concessionnaires de la construction du tunnel sous le Mont Blanc entre l'Italie et la France ${ }^{1}$. Selon l'art. II de la convention entre [p. 70] les deux États, les sociétés en cause bénéficient de concessions ayant pour objet la construction et l'exploitation du tunnel, qui leur sont octroyées par leur gouvernement respectif, mais sur les bases déterminées par la Convention. H. Adam en déduit que le percement du tunnel sous le Mont Blanc s'effectue sous régime international. Quant à l'exploitation, l'art VII prévoit que ces sociétés la confieront à une société anonyme dont les grandes lignes sont également déterminées par la Convention (partage par moitié du capital entre les deux parties). À l'expiration des concessions pour une cause quelconque (art. XV), le tunnel deviendra «la propriété commune et indivisible des États français et italien » et, comme tel, fera l'objet d'une exploitation en commun à égalité de droits et de charges.

Adoptera-t-on des formules du même ordre, si l'on se décide finalement à réaliser le tunnel sous la Manche ? On sait que le projet de percement continue de soulever en lui-même de nombreuses objections, spécialement en divers milieux britanniques ${ }^{2}$. Actuellement, un groupe d'études franco-britannique (dans lequel les chemins de fer sont fortement représentés) exerce une pression considérable pour l'établissement d'une liaison purement ferroviaire - ce qui, pour l'Union Routière, revient à préconiser en 1960, une solution de type 1875. La partie n'est pas jouée, mais si l'affaire aboutit, il est évident que construction et exploitation devront emprunter des traits à la notion de l'établissement public international.

On notera un dernier exemple : le cas de la Société Eurochimie qui constitue une «entreprise commune» de l'Agence Européenne pour l'Énergie Nucléaire de l'O.E.C.E. ${ }^{3}$. La société a été créée par une convention internationale, en date du 20 décembre 1957, conclue entre 12 pays européens. La convention lui confère sa personnalité et définit son régime, les statuts annexés précisant les règles

1 Sur ce problème, voir l'étude de ROUILLER (Jean-Frédéric), Le tunnel du Mont-Blanc, trait d'union européen, Lausanne, 1960.

Voir SLATER (II.), BARNETT (C.), The Channel Tunnel, Londres, 1957.

Sur les «entreprises communes» de l'Agence (et en particulier Eurochimie), voir le Deuxième rapport d'Activité, présenté à l'Assemblée consultative du Conseil de l'Europe, Paris, 1960, pp. 1119. 
d'organisation et de fonctionnement. Le capital est actuellement détenu par des gouvernements, des organismes publics ou semi-publics et, à concurrence de $20 \%$ environ, par des entreprises privées. Il s'agit donc, indubitablement, d'une entreprise internationale à caractère industriel.

Il ne nous appartient pas de juger ici la solidité et la validité de la catégorie offerte par H. Adam, dont l'effort se relie directement aux controverses sur la notion de "société internationale ». Sans entrer dans le différend, disons que la construction proposée nous paraît justifier d'assez sérieuses réserves. Nous l'avons rappelée ici, car plusieurs des [p. 71] organismes mentionnés sont susceptibles d'agir comme des forces de pression internationales, mais l'ambiguïté de ces établissements pose des problèmes d'interprétation et de classification que nous retrouverons dans les chapitres suivants.

Tels sont les principaux aspects de la poussée internationale des affaires. Elle s'est exercée dans les territoires politiquement dépendants, mais elle n'a certainement pas épargné les États formellement indépendants (particulièrement ceux économiquement en retard : capital français en Yougoslavie entre les deux guerres).

De ce point de vue, l'Amérique dite latine apporte d'innombrables exemples de pénétration et d'immixtion qui n'appartiennent pas tous au passé. En de multiples occasions les grandes affaires des États-Unis, notamment, ont pesé sur les gouvernements locaux ainsi réduits à la condition de partenaires mineurs. On ne saurait dire que l'Eglise catholique, qui trouve dans cette région le tiers de ses fidèles, ait pris position contre ces errements.

\section{INTERNATIONALES RELIGIEUSES}

$\underline{\text { Retour à la table des matières }}$

«Les sociétés religieuses, a écrit Gabriel Le Bras, constituent le plus vaste et le plus durable réseau de groupements humains dans le monde ». Et il poursuit : « Bien que les sociétés religieuses aient pour principe et pour fin le sacré, elles ne peuvent échapper au besoin de structure temporelle. Elles vivent dans le monde et leur double nature accroît plutôt qu'elle n'atténue la volonté de puissance » ${ }^{1}$.

1 Dans une remarquable étude « Sociétés religieuses et sociétés politiques » que publie le tome déjà cité de l'« Encyclopédie française », La vie internationale, Voir également " Politique et religion », numéro spécial d'Esprit, mars 1958, pp. 337-430 (en particulier l'étude de Léo HAMON, « Laïcité et politique étrangère »). On pourra aussi se reporter à MENSCHING (Gustave), Sociologie religieuse. Le rôle de la religion dans les relations communautaires des humains, Paris, 1951; WACH (J.), Sociologie de la religion, traduit de l'anglais, Paris, 1955 ; YINCER (J. Milton), Religion, Society and the Individual. An introduction to the sociology of religion, New York, 1957. Sur un plan pratique, on trouvera beaucoup de chiffres et d'informations utiles dans Bilan du monde, 1958-1959, tome I, Paris, 1958 (Encyclopédie catholique du monde chrétien). On obtiendra 
Vieux problème sur lequel on a déjà écrit des bibliothèques entières : si l'analyse paraît s'en renouveler d'une génération à l'autre, le changement est surtout dans les termes. C'est, sans doute, l'un des thèmes à propos desquels il est plus difficile de ne pas verser dans une présentation unilatérale. Mais un autre obstacle se dresse: comment saisir le sens des démarches d'une confession à laquelle on n'appartient pas ? La religion tient à la fois aux relations sociales et à l'expérience intime : à se limiter aux premières on risque d'en donner une vue inachevée et peut-être fallacieuse. Pourtant, on ne saurait s'aventurer ici sur le terrain particulièrement mouvant de la psychologie religieuse.

[p. 72] Dès lors, le lecteur comprendra aisément que la seule ambition de ces pages soit de situer la question et de poser quelques jalons d'analyse ${ }^{1}$.

\section{a) ÉLÉMENTS DU PROBLÈME}

$\underline{\text { Retour à la table des matières }}$

Deux traits en augmentent la complexité : on peut hésiter à introduire dans le même cadre de raisonnement les bonzes du Cambodge, le clergé catholique de France et les docteurs de l'Islam. On doit aussi compter avec l'évolution des religions dont la transformation s'affirme dans l'ordre interne comme sur le plan des rapports avec les autorités séculières: selon les époques envisagées, le tableau des liaisons entre religion et politique présente donc de vastes différences. Les notions dégagées pour le $\mathrm{XX}^{\mathrm{e}}$ siècle n'ont peut-être qu'une valeur passagère ${ }^{2}$.

Un aspect du problème consiste dans les rapports officiellement noués entre la (ou les) société religieuse et la société politique. Quant à la première, ils impliquent à la fois des principes (position à l'égard du temporel) et des intérêts (propriété, paiement des ministres du culte). La position de la seconde dépend d'idéologies, mais aussi de calculs : à de nombreuses reprises, la religion a été placée aux ordres de la cité et employée, par exemple, comme moyen de «camouflage » ou de renforcement d'un projet impérialiste. On peut trouver dans le monde moderne beaucoup d'exemples de cette confiscation du sacré par le temporel.

une bonne présentation d'ensemble en consultant BRADEN (Charles- Samuel), Panorama des religions, traduit de l'américain, Paris, 1960.

1 Pour une analyse des principales religions, voir GLASENAPP (H. de), Les cinq grandes religions du monde, traduit de l'allemand, Paris, 1954 ; ANNVANDER (A.), Les religions de l'humanité, traduit de l'allemand, Paris, 1955 ; RINGGREN (H.) et STZÖM (A.V.), Les religions du monde, traduit de l'allemand, Paris, 1960.

2 Soit par exemple le cas de l'Église catholique en France. Depuis les origines jusqu'à nos jours, ses rapports avec l'État ont emprunté presque tous les types de relations concevables. Voir le bon résumé de BEAU DE LOMÉNIE (E.), L'Église et l'État. Un problème permanent, Paris, 1957. Également, LEPOINTE (Gabriel), L'Église et l'État en France, Paris, 1960 (Que sais-je ?, n 886). Pour un autre exemple, voir GAVALDA (Berthe), Les Églises en Grande-Bretagne, Paris, 1959 (Que sais-je ? $n^{\circ}$ 837), et TOLEDANO (André D.), L'anglicanisme, Paris, 1960. Consulter également DAULTE (Philippe), Le problème de l'État chrétien, Lausanne, 1958. 
La typologie de ces rapports a été souvent exposée : confusion de la religion et de l'État (califat); séparation complète des deux pouvoirs, coordination entre leurs activités (méthode du concordat). On a beaucoup discuté de leur valeur respective, et surtout de leur opportunité dans une communauté déterminée ${ }^{1}$. Cependant, si cette classification est utile, elle ne nous livre qu'une partie, et souvent mineure, de la réalité. Le sens de chaque formule varie d'après les époques et les pays : la séparation signifie tantôt souci de neutralité, tantôt laïcisme, sinon anticléricalisme militant. Au surplus, ce modèle ne dit rien quant à la pression effective des milieux religieux, en tant que tels, sur les autorités civiles. On peut estimer a priori une situation concordataire plus favorable à l'influence de l'Église catholique qu'un régime de séparation : l'histoire la plus récente, pourtant, ne ratifie pas pleinement cette vue.

[p. 73] On a soutenu que, pour demeurer libre, la religion devrait s'écarter de la politique ${ }^{2}$. Un tel détachement est peut-être concevable dans des confessions comme l'Hindouisme pour laquelle Dieu est l'esprit qui réside dans le cœur de l'homme et dont la contemplation donne accès à la pure béatitude ${ }^{3}$. Cependant, si l'Inde a été fort tolérante à l'égard des courants religieux (absorbant ainsi toutes sortes de croyances), elle a témoigné d'une extrême rigueur quant au respect du système social qui en découle - régime des castes. L'hindouisme est donc un facteur de la politique, comme l'établit l'ampleur des obstacles culturels rencontrés par le gouvernement indien lors de son action de développement économique, mais, réserve faite de mouvements qui réclament un retour à la tradition (Jan Sangh, Hindu Mahasabha), il s'agit d'une influence plutôt passive.

Pour d'autres religions, et en particulier le catholicisme, le conseil d'abstention représente une pure utopie. Tant du point de vue matériel que moral (régime de la famille, mode d'éducation des enfants, divorce, liberté de la conception), l'Eglise ne saurait ignorer les décisions des autorités qui, pour se placer sur le plan temporel, n'en suscitent pas moins, en de nombreux cas, de profondes conséquences spirituelles. Répétons une fois encore que lorsqu'il n'est pas une tactique ou un camouflage, l'apolitisme constitue une utopie ou une illusion. Vivant dans le siècle, l'Église ne peut échapper à cette dure loi.

Un second aspect de notre problème est celui de la part que prennent les facteurs religieux dans les comportements politiques ou, le cas échéant, les actes que les membres de la communauté sont susceptibles d'accomplir en se fondant sur leur foi. La question peut se poser au niveau des gouvernants suprêmes : voir par exemple le procès livré au trio Adenauer - Gasperi - R. Schuman que l'on accuse d'avoir voulu la constitution d'une « Europe vaticane » (partie intégrante de l'« Internationale noire » à

Voir par exemple les intéressantes réflexions formulées par BETH (L.P.), in « Towards a Modem American Theory of Church State Relationships », Political Science Quarterly, décembre 1955, pp. 573-597. Voir aussi MURRAY (A.V.), The State and the Church in a Free Society, Cambridge, 1958 (principalement d'après l'Église anglicane).

Par exemple ARENDT (H.), « Religion and Politics », Confluence, septembre 1953, pp. 105-126.

Voir QUEGUINER (Maurice), Introduction à l'hindouisme. Exposé critique, Paris, 1958. Voir aussi RENOU (L.), L'hindouisme, Paris, 1951 (Que sais-je ? n 475) 
ramifications synarchiques). Bien entendu, elle vaut aussi au niveau des simples membres de la collectivité.

Ces conduites résultent souvent d'ordres ou de suggestions. Gabriel Le Bras a heureusement choisi le terme de «meneurs » pour qualifier les responsables de la direction adoptée ou de l'excitation manifestée (le clergé dans les Églises hiérarchiques; les docteurs et liturges dans les communautés sans ordination; le fondateur ou ses disciples dans les sectes). Il arrive aussi que l'explosion ou la résistance se passent de consignes, une sensibilité religieuse exacerbée suffisant à déclencher [p. 74] l'événement: contrairement à ce que proclament les autorités polonaises, il est peu probable que plusieurs manifestations récentes (notamment les démonstrations ouvrières de Nowa Huta au nom de «Liberté pour la religion») relèvent d'un complot organisé.

Les deux aspects sont étroitement liés. La capacité de mobiliser leurs fidèles constitue certes l'une des dimensions de l'influence temporelle des Églises. Cette mobilisation à son tour dépend de l'idée que celles-ci se font de leur mission et de la part qu'elles entendent attribuer aux « laïcs » (au sens d'un état de l'individu et non d'une mentalité) dans la réalisation de leurs objectifs. Certes, les différences sont grandes entre les confessions. Il arrive pourtant qu'elles rencontrent des problèmes communs : ainsi, à notre époque, la diffusion du communisme.

On pose volontiers dans nos pays le problème des incompatibilités (et éventuellement des affinités) entre communisme d'une part, Islam ou Christianisme de l'autre. Le débat a atteint aussi d'autres religions par exemple le Bouddhisme. Les estimations du nombre des bouddhistes sont très imparfaites. Une large partie en tout cas vit désormais sous régime communiste, mais un nombre encore assez considérable (de l'ordre de 100 millions, dit-on) reste hors des limites de ce régime. Selon certains courants (assez forts, semble-t-il, chez les jeunes bouddhistes cinghalais), il n'y aurait pas incompatibilité absolue entre la doctrine communiste et le Bouddhisme : en ce sens, on va jusqu'à se fonder sur les similitudes existant entre l'organisation des monastères bouddhistes et celle du Parti communiste. Ces thèses sont contestées : on relève ainsi que l'idéal de renonciation aux biens matériels repose sur la libre volonté, l'individu auquel on l'impose n'en ayant nul mérite. On souligne aussi que, loin d'être tolérant à l'égard des doctrines religieuses, le régime communiste leur fait une guerre incessante (attitude que, par contre, n'a pas adoptée le gouvernement socialiste de Birmanie) ${ }^{1}$. Les événements du Tibet sont venus à point pour renforcer la thèse de l'incompatibilité ${ }^{1}$.

SUCATANANDA (A.), «Il Buddhismo e la Politica », Politico, septembre 1955, pp. 262-264. À la suite, une note d'E. FROLA (pp. 265-270) proposant une interprétation des enseignements bouddhistes dans l'ordre politique et social. Voir aussi CONZE (E.), Le bouddhisme dans son essence et son développement, Paris, 1952. Au niveau de la vulgarisation, ARVON (H.), Le bouddhisme, Paris, 1951 (Que sais-je ? n 468). Pour un spécimen de l'opinion affirmant la parfaite compatibilité du communisme et du bouddhisme, on se reportera à une lettre : « Succès neutraliste à Ceylan ", adressée au Monde, 9 août 1960. Voici un fait nouveau : la campagne lancée contre le communisme, en Birmanie, au nom du bouddhisme durant les deux dernières années. C'est la 
Ceux qui ont analysé de tels problèmes soulignent que l'une des faiblesses essentielles du Bouddhisme est l'absence d'une direction centrale et d'une organisation unifiée. De tels phénomènes s'observent aussi en Europe. L'Église orthodoxe autocéphale de Serbie, bien que animée d'une volonté de résistance, inquiète moins les dirigeants yougoslaves que les évêques catholiques du pays (désormais enclins semble-t-il, à plus de souplesse vis-à-vis des autorités civiles). C'est immé-[p. 75] diatement évoquer le rôle particulier que joue le Saint-Siège sur la scène internationale : encore qu'on en exagère parfois les implications, la hiérarchie catholique (les clergés nationaux, mais aussi les missions et les grands ordres religieux) constitue un facteur de la politique mondiale.

Dans cette perspective, il conviendrait probablement de distinguer les Églises internationales, dont le catholicisme est un cas privilégié, des Églises nationales dont on trouve de bons exemples dans le protestantisme : l'Église anglicane, entre autres, est une Eglise anglaise dont le monarque est nominalement le chef. Sa politique et sa diplomatie ont toujours tenu compte des positions de l'État auquel elle était adossée. On peut aussi citer le cas de l'Église orthodoxe russe qui a toujours eu pour règle de servir les intérêts du Tsar. C'est là un type de césaropapisme dans lequel, pour reprendre l'expression de Leo Hamon « c'est César qui est pape ${ }^{2}$.

En dehors des églises et des grandes confessions religieuses, on doit mentionner le phénomène des sectes. Il en existe des centaines, d'importance très variable. La plupart ne comptent que quelques milliers (voire quelques centaines) de membres, d'autres comportant un assez grand nombre de fidèles (ainsi l'Armée du Salut posséderait-elle deux millions de membres dans le monde entier dont environ 30000 officiers) ${ }^{3}$. On n'en citera ici qu'une seule dont l'influence internationale semble certaine: la Société des Amis, plus connue sous le nom de Quakers (180 000 adhérents dont 120000 aux États-Unis).

Extrêmement remuants, les Quakers, qui d'ailleurs se considèrent comme un mouvement et non comme une secte, estiment que les détenteurs du pouvoir doivent faire le moins possible usage de la force. Dans le domaine des relations internationales, ils déplorent la course aux armements et l'emploi des armes de

première fois que cette confession est systématiquement utilisée dans un tel conflit. Voir MEHDEN (Fred von der), a Burma's Religious Campaign Against Communism », Pacific Affairs, septembre 1960, pp. 290-299.

1 Pour les pièces du dossier, voir $1^{\circ}$ la publication chinoise La Question du Tibet (Documents), Pékin, Éditions en langues étrangères, 1959 ; $2^{\circ}$ l'ouvrage de la Commission Internationale de juristes, La question du Tibet et la primauté du droit, Genève, 1959, et aussi, de la même source, Le Tibet et la République Populaire de Chine, Genève, 1960 (rapport établi par un comité juridique d'enquête). Il est difficile d'apprécier les conséquences de cette affaire sur les communautés bouddhistes vivant hors du monde communiste : elles ne semblent pas avoir été négligeables.

Op. cit., p. 415.

Voir la bonne mise au point de COLINON (Maurice), Le phénomène des sectes au $X X^{e}$ siècle, Paris, 1959. Du même auteur, Faux prophètes et sectes d'aujourd'hui, Paris, 1953 et aussi WELTER (C.), Histoire des sectes chrétiennes des origines à nos jours, Paris, 1950. 
« dissuasion » : ils plaident volontiers pour la coopération pacifique ${ }^{1}$. L'un de leurs thèmes de prédilection est le développement des procédures de médiation dans lesquelles ils voient un puissant élément de pacification à tous les niveaux ${ }^{2}$.

$\mathrm{Au}$ bénéfice de ces remarques, on va examiner quelques-unes des grandes confessions dont l'action sur les relations internationales est le plus volontiers mise en cause.

[p. 76]

\section{b) ÉGLISE CATHOLIQUE}

$\underline{\text { Retour à la table des matières }}$

Quelle est l'importance numérique du catholicisme ? Soulignant les difficultés d'établissement d'une démographie exacte, G. Le Bras nous conseille de procéder par ordre de grandeur : 700 à 800 millions de baptisés (mais non, bien sûr, de pratiquants) dont la moitié au moins dans la religion catholique. Probablement peu de spécialistes accepteraient-ils de refuser à la catholicité un rôle dans les affaires mondiales, mais comment définir les facteurs permettant de l'évaluer ? ${ }^{3}$.

Le trait propre de cette confession est l'existence de la Papauté. On confond souvent le Saint-Siège, qui de tout temps a été une personne morale de droit international, avec les États pontificaux lesquels ont incontestablement disparu en 1870 et la Cité du Vatican qui depuis 1929, constitue un État vassal du Saint-Siège. Cet État, membre de l'Union Postale Universelle, ne pourrait être admis aux Nations Unies en raison de ses faibles dimensions. Quant au Saint-Siège, gouvernement central de l’Église, il ne peut devenir membre de l'O.N.U. dont l'accès est réservé aux

1 BYRD (R.O.), « Quakerism and Foreign Policy », International Spectator, 8 janvier 1958, pp. 3856. Pour une étude plus approfondie, voir du même auteur, Quaker Ways in Foreign Policy, Toronto, 1960. Consulter également HALL (Willis H.), Quaker International Work in Europe since 1914, Chambéry, 1938 (Thèse de l'Institut Universitaire de Hautes Études Internationales de Genève).

2 Voir en particulier la brochure publiée par la Société The United States and the Soviet Union : some Quakers proposals for peace, Londres, 1949, qui met l'accent sur la nécessité de développer le principe et la pratique de l'intervention médiatrice dans les conflits. Un ouvrage comme celui de JACKSON (E.), Meeting of Minds. A way to peace through mediation, New York, 1952, se situe directement dans cette perspective.

3 Pour une bonne introduction, se reporter à l'étude d'André LATREILLE in Les forces religieuses et la vie politique, Paris, 1951. On trouvera une énorme masse d'informations in MOODY (Joseph N.) (ed.), Church and Society. Catholic social and political thought and movements 1789-1950, New York, 1953 (L'étude sur la France depuis 1945 est due à Paul VIGNAUX). Voir aussi EHLER (Sidney Z.), MORRAL (John B.), Church and State Through the Centuries. A collection of historic documents with commentaries, Londres, 1954. Sur la situation actuelle consulter FOLLIET (Joseph), Le catholicisme mondial aujourd'hui, Paris, 1958, et HALES (Edward E.Y.), The Catholic Church in the Modern World, Londres, 1950. 
« États » : toutefois, la coutume internationale lui confère le droit de légation active et passive, et le droit de signer des traités et des concordats ${ }^{1}$.

L'Eglise possède aujourd'hui une solide administration (entièrement refondue sous le pontificat de Pie $\mathrm{X}$, bien qu'on ait conservé les noms antiques pour désigner ses différents rouages). Elle est assurée par plusieurs séries d'organes (consistoires, offices, tribunaux et commissions) dont le but est de servir d'instrument au pape régnant. Leur rôle effectif dépend du caractère du pontife au pouvoir mais, en tout état de cause, on observe une forte tendance à la centralisation. Le Saint-Siège possède sa propre diplomatie dont les membres sont formés avec soin par l'Académie pontificale ecclésiastique ${ }^{2}$.

L'énumération des structures de l'Église serait très incomplète si l'on ne soulignait le poids de deux éléments. Les Missions, d'abord ${ }^{3}$. L'œuvre missionnaire est accomplie par le canal de nombreux organes sous la surveillance suprême de la Congrégation de la Propagande. Non sans une grande habileté, l'Église qui s'appuyait au départ sur les puissances coloniales et les aidait en retour, s'est attachée à développer le caractère autochtone du clergé de ces pays et à perdre peu à peu le caractère d’Église des «Blancs ». Dès 1926, elle compte en Asie 11 évêques de nationalité asiatique : le premier africain est nommé en [p. 77] 1935 (Érythrée). Aujourd'hui, ces chiffres sont d'environ 110 en Asie et une dizaine en Afrique. Un cardinal chinois a été promu en 1946, un indien en 1952. Mais l’Église est allée plus loin, n'hésitant pas à adopter des méthodes qui relèvent plus de la politique que de la

Bonne mise au point sur le problème in KUNZ (J.L.), « The Status of the Holy See in International Law », American Journal of International Law, avril 1952. pp. 308-314. Voir aussi WAGNON (H.), « La personnalité juridique du Saint-Siège en droit international », Annales de Droit et de Sciences Politiques, 1954 (2), pp. 3-19. Voici quelques ouvrages auxquels on pourra se référer pour une étude rapide du Vatican : PICHON (Charles), Histoire du Vatican, $2^{\mathrm{e}}$ éd., Paris, 1948, et surtout Le Vatican, Paris, 1960 ; McKNIGHT (John P.), The Papacy. A new appraisal, Londres, 1953 ; CRISTIANI (Mgr L.), Le Vatican politique, Paris, 1957 ; ORMESSON (Wladimir d'), La Papauté, Paris, 1957. Témoignages journalistiques non dépourvus d'intérêt: NEUVECELLE (Jean), Église, capitale Vatican, Paris, 1954 et FROSSARD (André), Les greniers du Vatican, Paris, 1960.

2 Voir HESTON (Edward L.), Comment le pape gouverne l'Église, traduit de l'anglais, Montréal, 1950, et VAN LIERDE (Mgr P.C.), Derrière les portes vaticanes. Le gouvernement central de l'Église, traduit du néerlandais, Tours, 1957. Voir aussi TESSON (E.), « L'administration centrale de l'Église », Études, novembre 1954, pp. 210-221; BACHELET (V.), "L'organisation administrative du Saint-Siège et de la Cité du Vatican », Revue Internationale des Sciences Administratives, 1955, pp. 231-274 ; MONTANI (G.B.), « Formazione e funzione della diplomazia pontifica ", Rivista di Studi Politici Internazionali, janvier-juin 1952, pp. 149-156 ; ITURRIAGA ROMERO (J.), « Organizacion interna del Vaticano », Revista Peruana de Derecho internacional, janvier-juin 1954, pp. 58-87.

3 Pour une présentation globale, voir Bilan du Monde, op. cit., pp. 203-211. Une analyse des données contemporaines de la politique missionnaire face au grand mouvement de décolonisation se trouve dans : Aspirations nationales et missions. Rapports et compte rendu de la XXVII ${ }^{e}$, Semaine de Missiologie, Louvain, 1958, Paris, 1958. Voir aussi BOUCHAUD (R.P. Joseph), L'Église en Afrique noire, Paris, 1958, où l'on peut lire un exposé des questions que posent aux missions africaines les forces traditionnelles et les nouveaux courants idéologiques. Consulter enfin DELAVIGNETTE (R.), Christianisme et colonialisme, Paris, 1960. 
théologie (formation de syndicats capables de s'opposer à leurs homologues socialistes ou communistes) ${ }^{1}$. On a vigoureusement protesté en divers milieux contre cette action (spécialement sous Pie XII), y voyant un ferment de décomposition des anciens Empires coloniaux ${ }^{2}$.

Le second élément est constitué par les ordres religieux. Selon une statistique établie à Rome en décembre 1957, le total des membres des congrégations religieuses

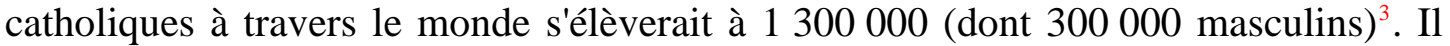
s'agit là, sans doute, d'une armée puissante et extrêmement disciplinée entre les mains du Saint-Siège qui, le plus souvent, tient les «réguliers » en étroite tutelle. Les membres de ces ordres, qui aliènent une grande partie des droits et libertés fondamentales de l'homme, relèvent donc directement, en bien des cas, d'une hiérarchie étrangère : il est dès lors compréhensible qu'ils soient dans la plupart des pays soumis à un régime juridique spécial ${ }^{4}$. Parmi eux, la Compagnie de Jésus reste l'un des plus agissants ${ }^{5}$.

Certains organes de l'Église sont particulièrement difficiles à analyser : ainsi, notamment les instituts séculiers. Ces organismes, qui ne sont ni des ordres monastiques, ni des congrégations religieuses, se présentent comme des "familles » de laïcs ou de prêtres séculiers, vivant isolément dans le monde, mais en respectant une règle et en obéissant à des supérieurs ${ }^{6}$.

Un exemple intéressant en est l'Opus Dei. C'est un Institut dont le statut a été définitivement approuvé par Rome en 1950. Officiellement, ses fins sont purement

Voir DESSAZZIE (Eve), L'Afrique noire chrétienne, Paris, 1960, spécialement pp. 75-150.

Comme exemple de telles attaques, Voir MEJAN (François), Le Vatican contre la France d'OutreMer, Paris, 1957. L'ouvrage entend prouver que la politique du Vatican à l'égard de l'Union française, telle que définie par les Encycliques, notamment "Evangelii Proecones » de 1953, constitue une trahison de la France et de la civilisation gréco-latine. Comme document propre à éclairer le débat, lire GHEDDO (R.P. Piero), Le réveil des peuples de couleur, Paris 1957 (réflexions d'un missionnaire en face des problèmes que pose ce réveil) ; LORY (Marie-Joseph), Face à l'avenir. L'Église au Congo belge et au Ruanda-Urundi, Tournai, 1958 ; Le Monde Noir, Pax Christi, campagne 1958-1960, fasc. 2.

3 Pour un tableau de ces ordres, voir Bilan du Monde, op. cit., pp. 182-194. Et aussi CANU (Jean), Les ordres religieux masculins, Paris, 1959.

4 Voir l'étude de MEJAN (F.), «Les régimes des congrégations », Revue Administrative, septembreoctobre 1956, pp. 461-480, et novembre-décembre 1956, pp. 604-617 (traite surtout du régime français).

5 Sur la Compagnie de Jésus, la documentation sérieuse est rare. La livraison du Crapouillot sur le sujet ( $\left.\mathrm{n}^{\circ} 24\right)$ n'est certainement pas dépourvue d'intérêt, mais elle ne saurait tenir lieu d'un exposé d'ambition scientifique! Parmi les travaux disponibles, voir SIMONNET (René), Les congrégations religieuses non autorisées dans l'État, Paris, 1891 ; BOEHMER (H.), Les Jésuites, traduit de l'allemand, Paris, 1910 ; BRODEYCK (James), Origine et expansion des Jésuites. 2 vol., Paris, 1950 ; BOURDON (A.), Les Jésuites à Madagascar au XIX siècle, Paris, 1940 ; MONESTIER (Marianne), Les jésuites et l'Extrême-Orient, Paris, 1956 ; DESCOLE (Jean), Quand les Jésuites sont au pouvoir, Paris, 1956 ; CHARMOT (F.), La pédagogie des Jésuites, Paris, 1951.

6 Sur ces organismes voir CANALS (Salvatore), L'Église et les instituts séculiers. Paris, 1960. (Point de vue théologique : l'auteur, prêtre de l'Opus Dei, est président de la Commission des Instituts Séculiers au sein de la Sacrée Congrégation des Religieux.) 
religieuses. Ses membres se proposent, par leur action personnelle et leur exemple, de répandre les principes chrétiens, surtout auprès de ceux qui ont des responsabilités dans la société ; mais le pas est vite franchi qui conduit à vouloir influencer l'organisation de cette société. La composition de cet organisme (dont le président nommé à vie par le pape réside à Rome) est mal connue, ses participants se voyant imposer une consigne de " discrétion ». Rares sont les occasions où il est fait état, ouvertement, d'une appartenance à l'Opus Dei. On a surtout parlé de cet Institut à propos de l'Espagne où il possède plus de 5000 membres et de nombreuses fondations. [p. 78] Il y dispose de larges moyens financiers qui lui permettraient, diton, de contrôler de grands journaux, une banque, une maison d'édition, un groupe de production de films, etc. On l'accuse aussi de noyauter systématiquement plusieurs secteurs de la société espagnole (Université, Ministère de l’Économie Nationale, etc.). Mais l'institut s'est installé et travaille aujourd'hui dans un nombre important de pays (déjà une trentaine) ${ }^{1}$ : ainsi en Italie s'efforce-t-il d'obtenir du gouvernement le relèvement des conditions de vie et des garanties de sécurité sociale, les unes et les autres très médiocres, dont jouit le clergé.

Les relations des États avec le Saint-Siège prennent souvent la forme de concordats. Ce type d'instrument diplomatique correspond à un essai de recherche du point d'équilibre entre les activités et les intérêts du temporel et du spirituel ${ }^{2}$. Depuis la fin de la seconde guerre mondiale, la politique concordataire a connu des vicissitudes ${ }^{3}$ : rupture d'un certain nombre de concordats avec les pays passés sous régime communiste; maintien des accords conclus avec les gouvernements de Mussolini et d'Hitler (la validité des pactes de Latran ayant été affirmée par l'art. 7 de la nouvelle Constitution italienne et celle du concordat avec l'Allemagne, confirmée par un arrêt de la Cour Constitutionnelle en date du 26 mars 1957) ; signature d'un nouveau concordat avec l'Espagne franquiste.

Ce dernier offre un intérêt spécial : on l'a présenté comme une victoire politique pour Franco qui reçut, entre autres, le droit de modifier le découpage des circonscriptions ecclésiastiques pour les harmoniser avec les circonscriptions civiles (faculté importante dans le cadre de la lutte contre les particularismes locaux). En fait, sans introduire de modifications substantielles dans l'ordre existant, il constitue un exemple frappant de la soumission d'un État aux exigences de l’Église. Le Concordat a pour but d'assurer une collaboration entre les deux parties, sur la base d'une reconnaissance de la loi divine comme loi fondamentale obligatoire pour l'une et

1 Pour quelques informations sur l'Opus Dei, voir PICHON (Charles), Le Vatican, op. cit., pp. 361366. Voir aussi CRÉAC’H (Jean-Marie), Le cœur et l'épée, Paris, 1958, pp. 295-299.

2 Voir IUNG (Nicolas), Le droit public de l'Église dans ses relations avec les États, Paris, 1948 (point de vue essentiellement théologique). Voir OUSSI CASORIA (G.M.), Concordati $e$ Ordinamento Giuridico Internazionale, Rome, 1953 ; NUCCITELLI (N.), Le fondement juridique des rapports diplomatiques entre le Saint-Siège et les Nations Unies, Paris, 1956.

3 Voir l'étude de SALOMON (J.), « La politique concordataire des États depuis la fin de la seconde guerre mondiale », Revue Générale de Droit International Public, octobre-décembre 1955, pp. 570623. Selon lui, les Concordats continuent d'être recherchés et la position internationale du SaintSiège reste très forte. 
l'autre. L’Église reçoit un statut privilégié de religion d'État (dont le seul autre exemple pour la confession catholique est, semble-t-il, l'Italie). Elle y est reconnue, en somme, comme la "société parfaite " de la doctrine canonique et se voit ainsi garantir non seulement l'exercice libre et public du culte, mais aussi le libre et plein exercice de son pouvoir spirituel et de sa juridiction. L'État espagnol renonce même à tout droit de surveillance et de contrôle des communications entre le Saint-Siège, les évêques et les fidèles [p. 79] espagnols. Toutes cérémonies et manifestations, hormis celles de la religion catholique sont interdites ; notons cependant que l'exercice privé d'une religion autre que catholique ne l'est pas ${ }^{1}$.

Cette clause vise surtout les Protestants qui sont environ 30000 . Plusieurs témoignages sérieux permettent de penser qu'en dépit des progrès réalisés durant ces dernières années, ils éprouvent toujours de grandes difficultés à pratiquer leur religion et, ce faisant, s'exposent à divers dangers. Quant aux juifs, ils sont si peu nombreux, deux mille peut-être, que le régime paraît leur laisser une liberté complète et leur accorder toutes facilités en matière religieuse ${ }^{2}$.

Le cas espagnol conduit naturellement à étudier les ingérences du Saint-Siège, force internationale de pression, dans la vie des États. Sur ce point on a beaucoup « affirmé », souvent non sans vraisemblance; les archives vaticanes sur ces problèmes étant difficilement accessibles aux tiers, il a toujours été peu aisé de « prouver ».

Il est rare en pareille matière de rencontrer une présentation impartiale. Les études disponibles évoluent de la pure apologétique ou de visions iréniques ${ }^{3}$ au réquisitoire passionné ${ }^{4}$. Celles qui s'essaient à une évaluation nuancée sont dans l'ensemble assez

1 Sur l'ensemble du problème, voir le cours de Jean MEYRIAT, «L'Église et la nation espagnole », in La péninsule ibérique, Cours de l'Institut d'Études Politiques de Paris, année 1956-57 (ronéoté, hors commerce), fasc. III, pp. 482-514. Voir aussi la présentation de l'affaire donnée par Jean CRÉAC'H (dans un sens favorable au régime) in Le cœur et l'épée, op. cit., sous le titre «L'Église d'Espagne bâtit sa forteresse », pp. 284-307 ; selon lui, l'objectif de l'opération, du point de vue de Rome, aurait été de permettre à l'Église «de ne pas se laisser confondre avec la dictature personnelle ». Sur le Concordat, voir les conférences prononcées à l'Université de Madrid en 195354 et publiées sous le titre El Concordato de 1953, Madrid, 1956, et EBENSTEIN (William), Church and State in Franco Spain, Princeton, 1960.

In La Vie Juive, décembre 1959.

3 Voir par exemple BUTTERFIELD (H.), Christianity. Diplomacy and War, New York, 1953 ; CLONMORE (Lord), Pope Pins XI and World Peace. An authentic biography, Londres, 1938. Ajouter PADELLARO (Nazareno), Pie XII, traduit de l'italien, Paris, 1950.

4 Par exemple, les deux livres d'Edmond PARIS, Le Vatican contre la France, Paris, 1957 (ouvrage dédié à "toutes les victimes de la géopolitique papale »: il y est question en particulier de " collusion vaticano-arabe »), et Le Vatican contre l'Europe, Paris, 1959. Selon l'auteur, qui utilise volontiers la technique de l'amalgame, le Vatican serait le principal responsable de tous les maux qui ont accablé l'Europe: du déclenchement de la guerre de 1914-18 jusqu'aux méfaits de l'hitlérisme. L'ouvrage de Paul SCHMID-AMMAN, Le catholicisme politique, traduit de l'allemand, Genève (1947), est certes plus modéré de ton, mais ses conclusions restent très sévères. 
rares ${ }^{1}$. Avouons que le fil directeur de l'appréciation objective reste difficile à trouver et n'est peut-être pas près de se laisser saisir.

Un seul point est sûr: il existe une politique pontificale ${ }^{2}$. Des observateurs sérieux pensent même que l'influence diplomatique du Saint-Siège s'étend de plus en plus, non seulement en matière de rapports étatiques, mais surtout et essentiellement, dès que des problèmes humains sont en jeu. L'Église, forcée de vivre au milieu des gouvernements, et donc de compter avec eux, ne saurait esquiver une ligne de conduite. Il semble que l'un de ses aspects dominants ait été la recherche de points d'appui. Or, l'Église demeure tandis que les gouvernements et, sur une longue période, les États aussi, passent : d'où l'obligation de réviser constamment le dispositif pour l’adapter aux impératifs du siècle.

Dans cette optique, la première guerre mondiale a provoqué pour l'Église une lourde perte en lui ôtant un puissant protecteur: l'Autriche-Hongrie. La situation empirera lorsque les États catholiques de l'Europe centrale d'entre les deux guerres, États bien faibles d'ailleurs (Autriche, Pologne, Hongrie), seront pris dans un étau entre l'Allemagne hitlérienne et la Russie soviétique. Perpétuellement re-[p. 80] commencée, cette recherche de bases de défense explique, pour le second aprèsguerre, l'intérêt que porte le Saint-Siège à la consolidation de l'Allemagne fédérale et à la progression du catholicisme aux États-Unis.

Cependant, Rome a d'autres principes: ne jamais céder sans combattre et maintenir la flamme catholique jusqu'au bout (l' «Église du silence » dans les pays communistes, qui lutte sans répit contre les groupements de division du type de l'association polonaise Pax, destinée à rassembler les catholiques progressistes), mais aussi ne pas soutenir les causes manifestement perdues ou, si l'on préfère, prendre des « réassurances » en fonction de l'évolution prévisible (voir le " doigté » avec lequel, en France, l’Église s'est dégagée de diverses situations pénibles depuis la Libération) ${ }^{3}$. Dans l'état présent du monde, les points d'appui vraiment solides ne

1 Voir par exemple DUCLOS (Paul), Le Vatican et la seconde guerre mondiale. Action doctrinale et diplomatique en faveur de la paix, Paris, 1955. Également TUNSTALL (B.), « The Papacy and World Peace. A critical summary ", Yearbook of World Affairs, 1951, pp. 309-340. Comparer avec VALERI (Cal Valerio), Le Relazioni Internazionali della Santo Sede dopo il Secondo Conflitto Mondiale, Rome, 1956.

2 On en trouvera une intéressante vue cavalière in HOURS (J.), «La politique pontificale », Année Politique et Économique, avril-juin 1958, pp. 81-204. De cet auteur, voir aussi « Les catholiques français et la patrie », même revue, janvier-mars 1955, pp. 1-24. Marquant qu'à l'époque actuelle, le vide de la pensée politique en France a favorisé l'action directe de Rome sur les milieux politiques, il souligne que cette influence s'est exercée en faveur de la création d'une fédération européenne (dont la C.E.D. devait constituer la pièce maîtresse).

3 Voir par exemple HOUART (Pierre), L'attitude de l'Église dans la guerre d'Algérie, 1954-1960, Bruxelles, 1960. L'auteur estime que la Hiérarchie a su naviguer assez adroitement en cette conjoncture. Encore qu'une documentation authentique fasse défaut, on peut admettre que l'Église n'a pas été absolument prise de court au Congo belge. Dans une étude sur «les véritables responsabilités », Cahiers Internationaux, septembre-octobre 1960, pp. 59-78, J. LEFEBVRE a pu parler de la " prévoyance de l'Église catholique » (augmentation rapide du nombre de prêtres noirs ; consécration de quatre évêques congolais ; ouverture, dès 1955, de l'Université Lovanium, première 
sont pas nombreux et il est possible qu'aujourd'hui la dominante de la politique de l'Église soit de compter sur ses seules forces.

Si ces considérations ne sont pas trop inexactes, on peut admettre qu'elles conduisent le Saint-Siège à jouer un jeu politique propre. Ainsi, par exemple, a-t-on beaucoup épilogué sur le rôle tenu par celui qui devait devenir Pie XII alors qu'il était nonce en Allemagne : on lui a imputé, notamment, une attitude particulièrement nuancée à l'égard du Zentrum ${ }^{1}$. On a également affirmé que, pendant sa mission en Pologne, Mgr Achille Ratti, le futur pape Pie XI, aurait joué un rôle décisif dans l'envahissement de l'Ukraine, par les encouragements donnés en ce sens à Pilsudski ; il serait par ailleurs intervenu dans le plébiscite sur la Haute-Silésie au profit des intérêts allemands (refusant de déplacer les autorités ecclésiastiques allemandes, malgré leur attitude anti-polonaise).

Le même reproche a été adressé au Saint-Siège à propos de la Sarre. On l'a accusé d'avoir été par deux fois, spécialement à l'occasion des plébiscites, favorable à la thèse du rattachement à l'Allemagne ${ }^{2}$. Cependant une étude approfondie de la question après 1945 amène à des conclusions plus modérées, sans la contester, elle signale pourtant que l'action du clergé en faveur de l'Allemagne a été peut-être moins décisive que ne l'affirmaient à l'époque les partisans d'une restriction de cette activité. Elle souligne aussi la réserve du Saint-Siège et l'action apaisante exercée dans la phase finale par le Visiteur apostolique ${ }^{3}$.

[p. 81] L'intervention du Saint-Siège dans la politique internationale n'est certainement pas un mythe, encore qu'on puisse en discuter le sens et la portée. En Europe, après avoir défendu les partis conservateurs, il inspira les partis démochrétiens même si ceux-ci se défendent d'être confessionnels (Gabriel Le Bras attribue à l'Église, dans ce vaste enrôlement, la fonction d'un « recruteur assidu »). Sur un point, au surplus, le doute ne semble pas permis: la lutte livrée par les autorités pontificales au communisme. Cette intervention s'est manifestée sous de multiples formes et, naturellement, par le moyen de condamnations doctrinales dont l'encyclique Divini Redemptoris du 19 mars 1937 reste le texte de base ${ }^{4}$.

université pour Noirs et Blancs au Congo ; organisation d'un laïcat noir encouragé à présenter des revendications politiques modérées du type du manifeste de « Conscience Africaine » ...).

1 Voir sur ce point MITTERRAND (Jacques), La politique extérieure du Vatican, Paris, 1959. Encore que très "engagé ", l'ouvrage vaut d'être lu. Autre réquisitoire d'un ton très violent, HOFFET (Frédéric), L'équivoque catholique, Paris, 1956.

2 Ainsi MOURIN (Maxime), «Le Saint-Siège et la Sarre », Politique Étrangère, juillet-août 1956, pp. 411-426.

Jacques FREYMOND, Le conflit sarrois, 1945-1955, Bruxelles, 1959, spécialement pp. 291-295.

4 On en trouvera une bonne présentation in CHAMBRE (R.P. Henri), Christianisme et communisme, Paris, 1959. Voir aussi ALESSANDRINI (F.), Chiesa e Comunismo, Rome, 1956 et GUERRY (Mgr), Église catholique et communisme athée, Paris, 1960. Pour un exposé des griefs de l'Église en dehors des questions de dogme, voir GALTER (Albert), Le communisme et l'Église catholique. Le "livre rouge de la persécution", Paris, 1956 (ouvrage publié sous les auspices de la Commission pour l'Église persécutée des Organisations internationales catholiques). 
Encore que le journal n'ait pas à proprement parler un caractère officiel, on doit mentionner la récente prise de position de l'Osservatore Romano (17 mai 1960) : ce texte affirme sans ambiguïté le droit et le devoir pour l'Église d'intervenir dans les choix politiques des catholiques selon les principes de la morale chrétienne. Il réaffirme l'antithèse irréductible entre le système marxiste et la doctrine chrétienne : d'où l'impossibilité pour les autorités ecclésiastiques d'autoriser les fidèles à donner leur adhésion aux mouvements qui adoptent (ou suivent) l'idéologie marxiste et à collaborer avec eux. Il apparaît que des considérations de politique italienne n'ont pas été étrangères à l'élaboration de cette philippique : on n'a pourtant pas le sentiment que seuls les catholiques italiens soient visés ${ }^{1}$.

Le poids du Saint-Siège s'affirme avec force en Italie où d'aucuns comparent la Papauté à une sorte de "Pentagone politique ${ }^{2}$. En France, la situation est plus nuancée, ne serait-ce qu'en raison de la diversité caractérisant les attitudes des catholiques ${ }^{3}$. Cependant, en plusieurs domaines, l'action romaine s'est manifestée avec force, sinon même avec brutalité (surtout à l'égard de diverses tendances socialement progressistes dont l'expérience des prêtres ouvriers était un aspect important).

Autre exemple d'intervention du Saint-Siège, qui s'exerce cette fois, par la condamnation portée contre les mesures de prévention des naissances. Cette attitude reste très rigide, en dépit dune certaine tolérance à l'endroit de divers procédés généralement peu efficaces. Dans un monde menacé de pullulement, c'est certes

1 Lors du récent voyage en France de M. Khrouchtchev, la position de l'Église n'a pas été sans nuances. Il semble que le ton général en ait été, selon Le Monde (22 mars 1960), de conseiller aux fidèles « une grande réserve, digne et lucide ». Dans un autre secteur géographique, on notera que la hiérarchie cubaine a pris position dès le mois de mai 1960 contre certaines orientations de la révolution fidéliste, les catholiques eux-mêmes n'hésitant pas a s'engager plus loin que leurs évêques (démonstration à la sortie des Églises en juillet). En tout cas, il n'est pas sans intérêt de comparer l'article déjà cité de L'Osservatore Romano au texte de l'interview sur les relations entre l'Église et l'État donné par Mgr J. LALLY à U.S. News and World Report, 30 mai 1960, sous le « chapeau » : "If a Catholic is President », pp. 64-69. Ne pas négliger la réponse de John A. MACKAY (président du séminaire théologique de Princeton, 1936-1959), « The Other Side of the Catholic Issue », même revue, juillet 1960, pp. 48-51.

2 Voir dans l'ouvrage satirique d'Alfredo PIERONI, Chi Commanda in Italia, Milan, 1959, les chapitres XI à XIV. Sur les rapports entre l'Église et la démocratie chrétienne : SCOPPOLA (P.), «Le parti catholique », Esprit, septembre-octobre 1955, pp. 1569-1584. Ajouter CANDELORO (T.), Il Movimento Cattolico in Italia, Rome, 1955.

3 Qui vont de points de vue proches des philosophes autoritaires (voir en particulier l'étude de Madeleine GARRIGOU-LAGRANGE «Intégrisme et national catholicisme », Esprit, novembre 1959, pp. 515-543) à des positions qui s'intègrent dans la gauche. Sur ces dernières, voir SUFFERT (Georges), Les catholiques et la gauche, Paris, 1960. Ces tendances "gauchistes » font l'objet de vives critiques en divers milieux où l'on va jusqu'à accuser les cadres de l'Église catholique d'être « infestés de progressisme), selon l'expression de Jean CALBRETTE in La crise actuelle du catholicisme français, Paris, 1959. On consultera avec profit la publication du Centre Catholique des Intellectuels Français, Politique et religion, Paris, 1959 : pour une opinion communiste sur cet effort, voir VERRET (Michel), "Les intellectuels catholiques et la politique », Nouvelle Critique, juin-juillet 1960, pp. 11-21. 
prendre une grave responsabilité (comme en témoigne, par exemple, le cas de l'Italie méridionale).

[p. 82] Est-il possible de définir la « ligne » dont s'inspirerait aujourd'hui l'autorité vaticane pour prodiguer ses conseils ou prononcer ses verdicts? Ou, si l'on préfère, quelles missions Rome confie-t-elle aux points d'appui qu'elle tente de se ménager dans le siècle ${ }^{1}$ ? Essayons de résumer les notions déjà examinées ou évoquées. Ferme condamnation du communisme tel qu'il se manifeste dans les pays du monde soviétique et hors de ce dernier. Exaltation de la paix comme l'une des valeurs prédominantes de l'humanité bien que certaines guerres puissent être justifiées. Approbation de la volonté d'indépendance des peuples colonisés (Encyclique Fidei, Domum de Pie XII sur les missions africaines) encore qu'il puisse être de l'intérêt de ceux-ci de ne pas brusquer les étapes. Encouragement à l'idée européenne, l'échec de la C.E.D. ayant provoqué au Vatican une déception profonde : appui, accordé sous condition que le mouvement pour l'Europe s'accompagne de la défense des valeurs spirituelles et n'aboutisse pas à la création d'un super-nationalisme, qui serait un obstacle à la coopération universelle. Affirmation de la primauté de la personne humaine en matière économique. Exclusion du matérialisme et du capitalisme pour lesquels l'homme n'est qu'un objet, mais conservation de la propriété individuelle.

Ce sont là évidemment des positions de principe sur lesquelles les exigences de la vie quotidienne imposent parfois des concessions. Au surplus, beaucoup d'esprits spécialement, mais non exclusivement communistes - n’hésiteront pas à dire qu'il s'agit là d'un pur camouflage masquant plusieurs aspects significatifs du catholicisme contemporain : les liens de l'Église avec les milieux bourgeois, le fait que l'Église est elle-même une puissance capitaliste, la justification et le soutien qu'elle accorde à un régime social sur son déclin.

Un dernier point reste à considérer : l'action du laïcat et plus particulièrement l'appui que les catholiques apportent à la défense de l'Église et à la réalisation de ses buts. Nous ne saurions entrer ici dans l'exposé des enseignements pontificaux qui sont abondants et explicites ${ }^{2}$. Il nous suffira de constater qu'il existe aujourd'hui un important mouvement catholique diversifié et coordonné. Les organisations qui le composent constituent à la fois un moyen d'encadrement et un instrument de

1 Voici quelques références à cet égard : LECLER (R.P. J.), L'Église et la souveraineté de l'État, Paris, 1946 ; MONTCHEUIL (R.P. Yves de), L'Église et le monde actuel, $2^{\mathrm{e}}$ éd., Paris, 1945 ; FESSARD (R.P. Gaston), Libre méditation sur un message de Pie XII, Paris, 1957 ; GUERRY (Mgr), L'Église et la communauté des peuples. La doctrine de l'Église sur les relations internationales : l'enseignement de Pie XII, Paris, 1958. Voir aussi MURRAY (J.C.), « L'Église et la démocratie totalitaire », Vie Intellectuelle, mars 1953, pp. 6-34, et avril 1953, pp. 5-23. Sur la charte rédigée en septembre 1948 par des catholiques, en majorité du monde hispano-américain, dans le but de compléter la Charte des Nations Unies, voir X, "La Charte de Saint-Sébastien », Rythmes du Monde, $2^{\mathrm{e}}$ trimestre 1949, pp. 48-54.

2 Cf. sur tous ces problèmes Le laïcat. Orientations et structures. Présentation et tables par les Moines de Solesmes, Tournai (1956). 
pénétration, spécialement au niveau des organisations intergouvernementales. Voici les articulations essentielles de l'Action Catholique Internationale ${ }^{1}$.

[p. 83] Ce mouvement est d'abord diversifié au sens où il est formé d'associations répondant aux nombreuses caractéristiques des fidèles et, par là, aux exigences de l'apostolat ou de l'action sociale. Les grands facteurs de groupement des intéressés ou des œuvres s'occupant d'eux sont ainsi :

l'âge: Bureau International Catholique de l'Enfance; Association Catholique Internationale des Euvres de Protection de la Jeune Fille; Fédération Mondiale des jeunesses Féminines Catholiques ; Fédération Internationale de la jeunesse Catholique Masculine.

le sexe: Fédération Internationale des Hommes Catholiques; Union Mondiale des Organisations Féminines Catholiques.

l'état social et la profession : Fédération Internationale des Universités Catholiques ; Pax Romana (avec ses deux subdivisions: Mouvement International des Intellectuels Catholiques; Mouvement International des Étudiants Catholiques); Union Mondiale des Enseignants Catholiques; Office International de l'Enseignement Catholique; Union Internationale des Associations Patronales Catholiques; Jeunesse Ouvrière Chrétienne Internationale; Comité International de l'Apostolat de la Mer; Comité International Catholique des Infirmières et assistantes médico-sociales.

l'action sociale : Association Internationale des Dames de Charité de St-Vincent-dePaul ; Société de St-Vincent-de-Paul ; Société Féminine de St-Vincent-dePaul; Conférence Internationale des Charités Catholiques; Commission Internationale Catholique pour les Migrations; Association Sociale Chrétienne Internationale; Union Internationale d’Études Sociales ; Union Catholique Internationale de Service Social; Fédération Internationale Catholique d’Éducation Physique ; Ligue Catholique Internationale contre l'alcoolisme.

apostolat et formation: Union Internationale de la Presse Catholique qui comprend deux groupes: Fédération Internationale des Journalistes Catholiques, Commission internationale des Éditeurs de Journaux Catholiques ; Association Catholique Internationale pour la Radiodiffusion et la Télévision ; Office Catholique International du Cinéma ; Union Mondiale des Sociétés Catholiques de Philosophie; Fédération Mondiale des Congrégations Mariales ; Centre International d’Études pour une Formation Religieuse.

Voir Les catholiques dans la vie internationale, Paris, 1957. Voir aussi in VAN LIERDE, op. cit., un tableau général du mouvement, pp. 223-238. 
[p. 84] Point n'est besoin d'insister sur la densité et la précision du réseau auquel on peut ajouter le mouvement Pax Christi dont l'objet est de coopérer à la construction de la paix internationale en prenant appui sur l'unité fondamentale de l'Église ${ }^{1}$. Enfin, une collaboration s'établit entre ces multiples organisations par l'intermédiaire de la Conférence des Organisations Internationales Catholiques.

Fondé en 1927, sous le titre de Conférence des Présidents, cet organisme, dont le siège est à Fribourg (Suisse), s'efforce d'unifier les tendances de ses membres, sans empiéter sur leur autonomie. Il se réunit en session ordinaire chaque année, notamment en vue de procéder à l'étude des grands problèmes de la vie catholique internationale et à l'examen des divers aspects de la vie internationale publique et privée. De plus, la Conférence a créé des centres de coordination et de liaison chargés d'assurer la représentation des catholiques auprès de plusieurs organisations intergouvernementales (B.I.T., Unesco.).

Bien entendu, ces mouvements d'action catholique restent sous le contrôle suprême du Saint-Siège, seul compétent pour donner instructions et directives au rassemblement international des organisations catholiques. Le gouvernement central de l'Église suit donc de très près la vie intérieure et les démarches externes de ces groupements avec le concours des nonciatures et des délégations apostoliques. Le contrôle de la hiérarchie distingue les mouvements d'action catholique (dont la fondation répond à des normes fixées par Rome) des organisations qui, tout en adoptant la foi ou la morale chrétienne comme principe de recrutement, n'engagent pas, en principe, l'Église par leurs activités (la Confédération Internationale des Syndicats Chrétiens).

Arrêtons-nous un instant sur Pax Romana, qui place au premier plan sa mission d'« apostolat intellectuel ». Selon une note établie par le Mouvement lui-même, celuici a pour premier objet le rayonnement de la vérité divine sur le plan de la pensée. Il a également pour fin la collaboration des universitaires laïcs à l'élaboration de la pensée chrétienne. Cet apostolat conduit aussi à un effort pour implanter l'Église dans les différents pays et dans les domaines culturels les plus divers. Mais, pour que l'Église puisse accomplir sans trop d'entraves sa mission spirituelle, le monde a besoin d'être rendu toujours plus perméable à l'Évangile : la conséquence en étant, et ici nous retombons sur notre sujet, qu'à chaque instant, le chrétien est appelé à porter sur la vie et les événements de la Cité un jugement moral et a le devoir de colla-[p. 85] borer, à sa place, avec les autres membres de la Cité, au bien commun de tous.

Nous avons tenu à insister sur cet aspect du catholicisme contemporain en raison des perspectives et possibilités d'action internationale qui en découlent pour le SaintSiège. Cette construction laisse une impression de puissance à laquelle peu d'autres sont comparables dans le monde actuel. L'organisation des travaux préparatoires au second Concile du Vatican, dit par les Catholiques Concile « æcuménique », montre

1 Sur ce mouvement, qui n'entre pas dans l'Action Catholique proprement dite, voir l'étude publiée dans le numéro spécial de Chroniques sociales de France, "Vie internationale 1953 », 1953 (2-3), pp. 258-263. 
l'importance que la papauté attache à cette source d'influence. Des dix commissions constituées par le pape en date du 5 juin 1960, la dixième a pour objet l'apostolat des laïcs pour toutes les questions concernant l'action catholique, religieuse et sociale. Selon certains, Jean XXIII, renouant d'ailleurs avec une ancienne tradition, envisagerait d'inviter aux séances du Concile les représentants de grands mouvements catholiques internationaux et même nationaux.

\section{c) ÉGLISE ORTHODOXE}

Retour à la table des matières

Un trait caractérise aujourd'hui l'orthodoxie : la plupart de ses fidèles vivent dans des pays à régime communiste. La Révolution d'Octobre s'étendit d'abord sur le territoire du Patriarcat de Moscou, qui contrôlait le bloc, de très loin le plus nombreux, de cette confession. À l'issue de la seconde guerre mondiale, ce fut le tour de plusieurs Églises autonomes ou autocéphales (pour l'essentiel celles de Bulgarie, Roumanie et Serbie). Actuellement, si l'on met à part l'Église synodale de Grèce (dont relève la presque totalité des habitants de ce pays), la religion orthodoxe, hors du monde communiste, ne compte plus que des communautés d'ampleur réduite (quelques centaines, parfois quelques dizaines de milliers de membres); c'est seulement aux États-Unis que la communauté orthodoxe dépasse encore le million (rôle de l'immigration).

Les patriarcats d'Alexandrie, d'Antioche (Damas) et de Jérusalem, souffrent d'une disproportion écrasante entre un passé illustre et un présent d'importance affaiblie. Le siège du Patriarcat œcuménique de Constantinople a toutefois une résonnance internationale en raison des traditions historiques qui pèsent sur lui et aussi du fait qu'il exerce son autorité sur un certain nombre de diocèses de la Dispersion ortho[p. 86] doxe (Europe occidentale, Amérique du Nord et du Sud, Australie...) ${ }^{1}$.

Ainsi que le signale S. Boulgakoff, l'Église orthodoxe a toujours exercé son influence sur l'État d'une manière spécifique : «Si l'État peut être pénétré par l'esprit de l'Église, écrit-il, ce n'est pas extérieurement, mais intérieurement, non d'en haut, mais d'en bas " ${ }^{2}$. En d'autres termes, l'Église pèse finalement sur les autorités par son action sur les âmes des fidèles. Il est de fait, en tout cas, que cette Église n'a que fort rarement tenté d'intervenir directement comme telle, dans les affaires politiques. C'est

1 Pour une bonne mise au point de la situation présente, voir MEYENDORFF (Jean), L'Église orthodoxe. Hier et aujourd'hui, Paris, 1960.

2 In L'Orthodoxie, Paris, 1932 (réimprimé en 1958), p. 225. Sur cette confession, voir aussi SERAPHIM (Metropolite), L'Église orthodoxe. Les dogmes, la liturgie, la vie spirituelle, Paris, 1952, ainsi que DUMONT (P.), MERCENIER (F.), LIALINE (C.), Qu'est-ce que l'orthodoxie? Bruxelles, 1945. 
dans cette perspective que se situe aujourd'hui le problème des rapports entre l'Église et l'État en Union soviétique ${ }^{1}$.

L'idéologie marxiste s'oppose certes à toute idée religieuse : et de fait, durant les premières décennies de son implantation, le pouvoir soviétique se livra à la persécution des fidèles et mit en œuvre un athéisme militant ${ }^{2}$. Mais la guerre nationale contre l'envahisseur allemand allait provoquer un renversement spectaculaire de ces principes et conduire, dès 1943, à la signature d'une espèce de concordat entre les autorités politiques et ecclésiastiques. L'Église ayant, durant les hostilités, convaincu le gouvernement de sa loyauté, put ensuite continuer sa tâche et adopta, en 1945, une nouvelle Constitution qui renforçait le pouvoir centralisateur du Patriarcat. De nombreux témoignages, qu'il convient d'accueillir avec modération, confirment qu'elle serait aujourd'hui très vivante : le renouveau de la propagande antireligieuse en porterait témoignage.

Il est certain que l'Église russe n'a obtenu un tel régime qu'en se soumettant à une tutelle étroite des autorités communistes et en acceptant sur plusieurs points (activités des Partisans de la paix) de se mettre au service de la propagande du gouvernement. Les uns y voient le signe d'une complète abdication, d'un total asservissement aux autorités marxistes. D'autres pensent au contraire, que tout en faisant beaucoup de concessions dans l'ordre politique, elle a maintenu de façon inflexible son caractère d'Église chrétienne et n'a abandonné aucune de ses positions essentielles dans l'ordre de la foi. Certains enfin, prétendent que les deux partenaires ont gagné à cet accord, mais peut-on le considérer comme permanent ? Même si sa virulence a disparu, ou s'est atténuée, un conflit fondamental ne demeure-t-il pas entre l'athéisme communiste et l'adhésion à une religion?

[p. 87] À plusieurs reprises, on a émis l'idée que la relative bienveillance du gouvernement soviétique s'expliquait par le souci d'utiliser au dehors le capital d'influence de l'Église russe. Ainsi celle-ci serait-elle devenue, de plus ou moins bon gré, une force de pression au service de la politique extérieure de l'U.R.S.S. (conformément à une tradition que l'on peut faire remonter, au moins, à Catherine II). On cite à ce propos les tentatives faites pour établir des relations cordiales avec les patriarches d'Alexandrie, d'Antioche et de Jérusalem, en vue d'affaiblir le patriarcat œcuménique de Constantinople (dont le titulaire actuel d'origine hellénique, mais de nationalité américaine, exerçait auparavant les fonctions d'archevêque orthodoxe de

1 Sur ce problème voir dans la collection des Notes et Études documentaires de la Documentation française les $\mathrm{n}^{\text {os }} 1624$ et 1931 ; MAKLAKOFF (G.), «L'Église et le pouvoir civil en U.R.S.S. de 1917 à nos jours ", Russie et chrétienté, 1946 (1), pp. 22-72. Voir aussi SPINKA (Matthew), The Church in Soviet Russia, New York, 1956 ; WADDAMS (H.), "The Church in Soviet Russia ", Soviet Studies, juillet 1953, pp. 8-17 ; TTIMASHEFF (N.S.), " The Anti-Religious Campaign in the Soviet Union », Review of Politics, juillet 1955, pp. 329-344. Sur les pays d'Europe orientale consulter : SHUSTER (George N.), Religion Behind the Iron Curtain, New York, 1954 ; IVANYI (N.G.), « Church and State in Eastern Europe », Yearbook of World Affairs, 1952, pp. 98-123.

2 Voir SZCZESNIAK (B.), The Russian Revolution and Religion. A collection of documents concerning the suppression of religion by the communists, 1917-1925, Notre-Dame (Indiana), 1959. 
New York); il semble que l'opération ait particulièrement bien réussi à l'égard de l'ancien patriarche d’Antioche, d'ethnie arabe, décédé en 1958.

Autres témoignages de cette action extérieure : toutes les Églises orthodoxes des pays d'Europe orientale se sont vu conférer l'autocéphalie. Cette décision a vivement irrité le patriarche de Constantinople pour lequel les Églises orthodoxes autocéphales ne participent à l'Église grecque universelle que par les liens les unissant à son siège. Par ailleurs, l'Église orthodoxe russe tente de conserver le contrôle spirituel des fidèles émigrés à l'Occident (et désormais de leurs enfants et petits-enfants qui, ayant généralement renoncé à toute idée de retour, désirent la fondation d’Églises indépendantes). Dernière manifestation de ce souci d'action à l'étranger : dans le cadre de la politique de détente, la hiérarchie orthodoxe russe a noué des rapports suivis avec les dignitaires d'Églises protestantes et en a reçu plusieurs à Moscou même. Des contacts ont été pris avec le mouvement œcuménique protestant.

Il est aisé de voir que, sur tous ces points, les intérêts de l'Église et de l’État coïncident réellement. Voici un exemple récent de cette concordance : la tournée au Moyen-Orient (novembre 1960), du patriarche Alexis en vue de freiner le rapprochement des orthodoxes avec les religions "gagnées à la cause impérialiste occidentale » (Anglicanisme et surtout Catholicisme). Ces faits, sur lesquels on a peut-être tort de bâtir l'hypothèse d'une conjonction systématique entre les deux pouvoirs, établissent en tout cas, la persistance des implications internationales de l'orthodoxie.

La situation des autres Églises nationales change selon les pays. Leur degré de résistance aux autorités communistes a été très variable. [p. 88] L'Église de Serbie dont le Patriarche avait été déporté à Dachau, s'est efforcée de relever le défi lancé par la nouvelle société et a engagé des luttes parfois sévères avec les gouvernants. Par contre, l'orthodoxie roumaine a accepté d'emblée une situation de subordination aux pouvoirs établis, qui lui vaut d'ailleurs d'appréciables avantages matériels.

Mais cette Église reste au total divisée, comme l'a prouvé l'impossibilité jusqu'à maintenant de réunir, sous l'égide du patriarche de Constantinople, un Congrès panorthodoxe en vue de définir une attitude commune à l'égard du Second Concile du Vatican décidé par Jean XXIII.

\section{d) PROTESTANTISME}

\section{$\underline{\text { Retour à la table des matières }}$}

À la fin du siècle dernier, le protestantisme présentait une grande diversité de mouvements et de tendances conforme aux attitudes individualistes que l'on attribue volontiers aux membres de cette confession. Cependant d'importants éléments de concentration prenaient naissance qui devaient faciliter, dès 1910, les premières 
manifestations du courant œcuménique ${ }^{1}$. Aujourd'hui, le Conseil œcuménique des Églises est une force active que l'on ne saurait oublier dans un exposé de la vie internationale. En quel sens sont susceptibles de s'établir les rapports entre protestantisme et politique?

S'attachant à définir la mentalité protestante, F. Dürrleman trouva jadis l'une de ses caractéristiques dans « un esprit tout à la fois de discipline et de liberté » ${ }^{2}$. Discipline politique ? De nombreux témoignages, directs et précis, attestent dès les débuts, chez le protestant, le souci de l'ordre et le respect pour l'autorité légale. Mais aussi, et là encore le point est net dès le départ, goût profond pour la liberté politique (rappel de l'apostrophe fameuse de Théodore de Bèze : le peuple n'a pas été créé pour les magistrats, mais les magistrats pour le peuple).

De telles attitudes sont nettement favorables à la démocratie représentative, et il ne serait pas absurde de trouver une confirmation aux remarques de Dürrleman dans le fait, qu'en moyenne, ce régime n'a jamais très bien fonctionné dans les pays de civilisation catholique, exclusive ou prépondérante. En tout cas, il semble ne rien exister dans la religion protestante qui commande à ses fidèles de se désintéresser des affaires de la Cité. Ou plutôt seule pourrait motiver un tel refus la [p 89] volonté bien arrêtée de n'accomplir aucune mission hors la proclamation du salut éternel.

Au cours des années récentes, de nombreuses voix se sont fait entendre pour rendre les protestants conscients de la nature et de l'étendue de la mission de l'Église dans la cité ${ }^{3}$. L’Église n’est pas « du monde », mais elle est réellement « dans le monde ", a-t-on pu dire. La religion n'est pas un domaine à part, étranger à la politique. Il n'est aucune question dans l'ordre de la Cité, à l'égard de laquelle l'Église puisse rester indifférente car il n'est aucun problème social qui n'implique en même temps un problème moral et spirituel en face duquel la foi doit se prononcer. D'où, entre autres, l'idée que la préoccupation du renouveau des âmes restera inopérante si l’Église demeure insensible aux conditions extérieures de la vie des masses.

De telles conceptions sont volontiers soutenues par les représentants des « jeunes Églises » de l'Asie, spécialement de l'Inde (telle l’Église unie de l'Inde du Sud, fondée en 1943, qui ne connaît plus de divisions). Leurs membres soulignent qu'il y

1 Pour une introduction générale au problème, voir COURVOISIER (Jacques), Brève histoire du protestantisme, Neuchâtel, 1952. Voir aussi BERTRAND (A.N.), Protestantisme, Paris, 1938 ; LÉONARD (E.-G.), Histoire du protestantisme, Paris, 1950 (Que sais-je ? n 427). De ce dernier auteur, on pourrait également consulter l'excellent travail, Le protestantisme français, Paris, 1953.

2 Voir son Initiation protestante. Église nationale vaudoise, 1945 (texte conforme à la $3^{\mathrm{e}}$ édition, la première remontant à 1917).

3 Sans prétendre fournir un échantillon représentatif : mentionnons, Reconstruire, mais sur quelles bases ? Documents réunis et collationnés par le Rév. D.G.M. PATRICK, Genève, s.d. (Les Églises anglo-saxonnes et l'après-guerre); LEENHARDT (Franz J.), Christianisme et vie publique, Genève, 1945, qui établit une distinction entre les combinaisons partisanes (dans lesquelles l'Église n'a pas à entrer) et la politique comme fixation des normes régissant l'action gouvernementale (dans laquelle on ne saurait lui refuser le droit de s'ingérer) ; ELIOT (Thomas S.), Sommes-nous encore en chrétienté ? traduit de l'anglais, Bruxelles, 1946 ; Positions protestantes, Paris, 1946 (collection Rencontres). 
aurait un danger pour l'Église à tenter de résoudre les problèmes spirituels en niant les exigences de la vie matérielle. L'Asie a besoin d'institutions économiques et sociales fondées sur l'unité, la liberté, la justice et l'ordre et il est désirable que la communauté religieuse s'associe à l'effort accompli pour les promouvoir. En Asie, les Églises ne seront pas jugées d'après des déclarations, mais selon la conduite quotidienne de leurs dirigeants ${ }^{1}$.

Ce souci de réflexion sur la politique a naturellement atteint le domaine des rapports internationaux: étude des lacunes de l'organisation internationale et des possibilités qu'ouvrirait l'existence d'une force de police internationale ; examen des solutions propres à permettre une décolonisation sans heurts; enfin, et peut-être surtout, prise de position sur l'emploi des engins nucléaires ${ }^{2}$. Ces thèmes, et plusieurs autres, ont alimenté la recherche d'un ordre international conforme aux principes chrétiens, l'idée étant parfois expressément affirmée que l'Église ne tient pas, comme telle, à sauvegarder une forme particulière de civilisation.

Cependant, pour que les positions spirituelles trouvent le chemin des gouvernants et spécialement des conférences ou organisations internationales, une concentration des moyens était indispensable. Pour étudier les étapes de sa réalisation, il semble que l'on puisse partir d'une double série de phénomènes.

[p. 90] D'abord, la formation de mouvements ou groupements spécialisés qui déploient souvent une grande activité, principalement dans leurs rapports avec les organisations non gouvernementales. L'Alliance Évangélique Universelle, fondée à Londres en 1846, est le plus ancien témoignage de cette tendance. Son objet est de réunir les membres des Églises protestantes, par-dessus les barrières confessionnelles, dans un but d'entraide ou de défense spirituelle. Notons ensuite la création, dès 1855, de l'Alliance Universelle des Unions Chrétiennes de jeunes gens (Y.M.C.A., selon les initiales anglaises), que suivra en 1894, l'Alliance Universelle des Unions Chrétiennes Féminines (Y.W.C.A.) ${ }^{3}$ Ces deux organismes sont certes bien distincts des Églises et il est même arrivé qu'ils se défendent d'être spécifiquement protestants (encore que la plupart de leurs membres soient de cette confession). Travaillant dans un esprit résolument œcuménique, ils ont joué un rôle important sur la voie de l'unité. On citera enfin la Fédération Universelle des Associations Chrétiennes d'Étudiants : fondée en 1895, elle possède aujourd'hui des membres dans près de 70 pays (groupant en particulier les sections estudiantines des deux organismes que l'on vient de mentionner).

Voir FERNANDO (C.), The Role of the Christian Church in the New Asia ", New Lanka (Colombo), avril-juillet 1956, pp. 68-82.

Voir entre autres, WERNER (Alfred), L'Église et la bombe atomique, Genève, s.d.

Sur l'Y.M.C.A., voir SHEDD (Clarence P.), and al., History of the World's Alliance of Young men's Christian Associations, Londres, 1955. Pour un bref exposé, LIMBERT (Paul A.), « The Origin and Development of the World Alliance of Y.M.C.A. », Associations, juin 1956, pp. 370-384. Voir aussi Période d'essai, De Mysore 1937 à Paris, 1955. Rapport à la XX $\mathrm{X}^{\mathrm{e}}$ Conférence universelle. Sur l'Y.M.C.A. voir RICE (Anna V.), A History of the World's Women's Christian Association, New York, 1947. 
Ces institutions, et spécialement les deux Alliances, n'hésitent pas à prendre des positions fermes sur les grands problèmes de politique internationale de notre temps et à participer aux travaux des organisations intergouvernementales chargées de les étudier ou de les régler. Dès 1947, il fut décidé de créer un comité pour les affaires internationales, cette expression entendue en un sens large - problèmes significatifs pour la jeunesse - couvrant notamment le renforcement de l'organisation internationale ; la mobilisation de l'opinion publique sur des bases chrétiennes; le développement du sens civique ; les droits fondamentaux de l'homme ; l'amélioration des relations raciales et des conditions économiques des peuples ; l'aide aux peuples non émancipés dans leur lutte pour la liberté, etc. Il serait difficile d'établir une liste plus compréhensive et comportant un plus sérieux engagement dans les controverses et difficultés politiques de notre temps. Soulignons enfin que l'Alliance des Unions Féminines (reprenant un thème déjà abordé en 1898) a décidé de proposer à ses membres un programme d'éducation civique ${ }^{1}$.

La seconde orientation qui a conduit à l'œcuménisme a été la réunion des Églises elles-mêmes, sous forme de conférences périodiques [p. 91] (du type de la Conférence de Lambeth qui rassemble une fois par an, à Canterbury, tous les évêques anglicans du monde) ou d'organisations permanentes. Parmi celles-ci, il faut rappeler l'Alliance Réformée Mondiale (ou Alliance Presbytérienne), qui, fondée en 1875, rassemble aujourd'hui 70 Églises appartenant à 45 pays ; également la Fédération Luthérienne Mondiale qui remonte à 1923 et groupe 62 Églises autonomes relevant de 29 pays. Enfin, n'oublions pas l'une des organisations les plus notables du protestantisme : le Conseil International des Missions. Fondé en 1921, il se compose de Conseils nationaux missionnaires (ou Conseils nationaux chrétiens) établis dans 38 pays. Parmi ses objectifs déclarés, figurent le souci de coordonner les activités des organisations nationales missionnaires, mais aussi la volonté de rassembler les forces chrétiennes en vue de défendre la liberté de conscience et la justice dans les relations internationales et inter-raciales.

On fait généralement remonter l'œcuménisme à la Conférence missionnaire mondiale d’Édimbourg (1910) qui jeta les premiers fondements du Conseil International des Missions. Il n'entre pas dans notre programme de retracer l'histoire du mouvement qui a déjà été présenté à de nombreuses reprises ${ }^{2}$. Retenons seulement que la date-clé fut l'année 1948, où se réunit pour la première fois à Amsterdam le

\footnotetext{
Voir « Citizenship Education Selected Programme Material », Youth Leaders Bulletin, printemps 1959.

2 Sur le mouvement œcuménique, l'ouvrage fondamental est ROUSE (R.), NEILL (S.), A History of the Ecumenical Movement, 1517-1948, Londres, 1954. Mais il ne couvre pas la période récente, en fait la plus importante pour notre propos. Au plan de la vulgarisation BELL (G.K.A.), The Kingship of Christ, the Story of the World Council of Churches, Londres, 1954 (Pingouin Books), et GAVALDA (Berthe), Le mouvement œcuménique, Paris, 1959 (Que sais-je ? n 841). Pour un point de vue catholique autorisé, se reporter à VILLAIN (Maurice), Introduction à l'œcuménisme, Tournai, 1958 (avec une bonne bibliographie). Voir aussi DUFF (Edward S.J.), The Social Thought of the World Council of Churches, Londres, 1956 (thèse de l'Institut Universitaire de Hautes Études Internationales de Genève).
} 
Conseil Ecuménique des Églises. Cependant, l'on attache en général une importance considérable à la seconde réunion qui se tint six ans plus tard à Evanston (E.U.), la troisième devant prendre place vers la fin de 1961 à la Nouvelle-Delhi ${ }^{1}$.

Le Conseil Ecuménique ne constitue pas une super-Église qui aurait juridiction sur ses membres. Il ne s'agit en aucune mesure d'une nouvelle Rome. C'est un guide qui avertit les Églises et les aide éventuellement à se réformer, un carrefour où elles se rencontrent pour converser, un instrument de travail appliqué à tous les problèmes ecclésiastiques chrétiens. Les plus ardents de ses inspirateurs vont jusqu'à déclarer que les Églises membres sont encore spirituellement mal préparées à l'unité et ne témoignent pas d'une passion suffisante à cet effet : ils insistent sur la nécessité de la coopération comme moyen de promouvoir l'unité. Les décisions du Conseil en tout cas ne lient les membres que s'ils acceptent en pleine souveraineté d'y adhérer. Il semble que le principe d'une fusion avec le Conseil International des Missions soit admis.

[p. 92] Le nombre des Églises inscrites au Conseil dépasse actuellement le chiffre de 170 se répartissant en une cinquantaine de pays et réunissant environ 350 millions de fidèles. L’Église catholique n'y participe pas (les «Vieux Catholiques » qui en sont membres ayant quitté celle-ci en 1871 à la suite de la promulgation du dogme de l'infaillibilité, pontificale). Si l'Église grecque universelle (patriarcat de Constantinople) a donné son adhésion au Conseil Ecuménique, l'Église orthodoxe russe, avec laquelle des rencontres ont eu lieu en 1956 et 1958, en demeure toujours extérieure (un premier rapprochement ayant d'abord été entravé par des divergences de position sur le conflit de Corée). Au cours des derniers mois, l'intérêt porté par l'orthodoxie russe à l'œcuménisme s'est accentué, comme en témoignent les initiatives suivantes : envoi d'observateurs en juillet 1960 à l'Assemblée Ecuménique de la jeunesse Européenne réunie à Lausanne et en août à la session du Conseil Mondial des Églises en Écosse ; formation d'un « exarquat pour l’Europe moyenne » ; création auprès du Saint-Synode d'une commission pour les « liens entre Chrétiens », etc. ${ }^{2}$.

Toutefois, l'Église orthodoxe russe ne fait pas partie de l'œcuménisme qui est donc encore pour l'essentiel d'allure pan-protestante. Il rassemble aussi divers groupes considérés par certains comme des «sectes »: ainsi Quakers et Armée du Salut. Cependant quelques milieux protestants lui demeurent fermement opposés.

Dans la perspective de notre étude, l'organe le plus intéressant est la Commission des Églises pour les Affaires Internationales ; elle a été établie officiellement en 1948 par la I ${ }^{\text {re }}$ Assemblée du Conseil et le Comité du Conseil International des Missions en tant que département permanent commun de ces deux organisations. Son rôle est d'informer les Églises des problèmes internationaux contemporains; d'offrir à ses fondateurs un moyen de se consulter et de leur permettre de formuler une opinion

Les documents de la réunion ont été publiés sous le titre L'Espérance chrétienne dans le monde d'aujourd'hui, Evanston, 1954, Neuchâtel, 1955.

2 Les relations se poursuivent. Le Service Ecuménique de Presse et d'Information ( $\mathrm{n}^{\circ}$ du 17 juin 1960) signale que dans le cadre d'un échange de livres décidé en 1959 le patriarche de Moscou vient d'offrir de nombreux ouvrages au Conseil. 
unifiée sur les problèmes mondiaux; de représenter le mouvement œcuménique auprès des Nations Unies et de leurs agences spécialisées et d'y exercer une action conforme aux exigences des principes chrétiens.

Le mouvement œcuménique a ainsi tenté de lutter contre les violations de la justice et des droits humains, d'agir sur la réglementation mondiale des armements, de promouvoir des institutions humanitaires, etc. Cependant les positions individuelles de ses membres sur de graves problèmes continuant de diverger, il doit souvent adopter une attitude [p. 93] prudente. On lui a d'ailleurs reproché de s'en départir sur quelques points ${ }^{1}$.

Sans entrer dans la discussion, citons parmi les interventions les plus récentes du Conseil : une ferme protestation en date du 9 janvier 1960 contre la dernière vague d'anti-sémitisme ; la condamnation de l'explosion atomique française au Sahara et l'organisation d'une conférence avec les huit Églises d'Afrique du Sud membres du Conseil, afin d'étudier la situation actuelle et de rechercher les moyens propres à l'améliorer (sept de ces Églises, ainsi d'ailleurs que le clergé catholique, condamnant l'apartheid sous sa forme actuelle). Lors de sa réunion d'août 1960, le Comité central du Conseil a invité la Commission des Églises pour les Affaires Internationales à poursuivre son effort en vue d'un règlement du problème chinois (règlement devant, selon les auteurs de ce vœu, permettre aux 650 millions de Chinois de partager les bénéfices et d'accepter les responsabilités de tous les membres de la communauté internationale).

Le contraste entre le Saint-Siège et le Conseil Ecuménique des Églises suffit à expliquer la différence dans le comportement des deux confessions sur le plan international. Sans doute beaucoup d’Églises protestantes constituent-elles de puissants groupes de pression nationaux, dont les auteurs américains et anglais ont, depuis longtemps, analysé le jeu. Mais, en l'absence d'une organisation centralisée et hiérarchisée, il reste difficile d'utiliser cette puissance hors de ses points d'application nationaux (réserve faite de protestations d'ordre moral qui ont parfois un certain effet, au moins sur l'opinion publique : ainsi, en avril dernier, la vigoureuse condamnation de la politique sud-africaine d'apartheid par le Conseil Britannique des Églises). Pourtant, malgré la souplesse de sa constitution, le Conseil Ecuménique forme un premier essai de rassemblement des forces : son rôle dans les affaires internationales devra être suivi avec soin.

Faut-il aller plus loin et évoquer dès maintenant une possibilité d'unité du monde chrétien (catholiques compris). Divers indices autorisent à penser que la position de Rome serait devenue moins rigide. En particulier, on a noté avec intérêt l'envoi d'un observateur du Saint-Siège à la dernière réunion du Comité central du Conseil Ecuménique. Ce prélat a été nommé secrétaire d'un organe nouveau, créé au Vatican

GAVALDA, op. cit., pp. 113-119. Comme exemple de positions prises par le Conseil, voir Intergroup relations. The Church and Racial and Ethnic Tensions. An ecumenical survey prepared under the auspices of the World Council of Churches, Londres, 1954. Voir aussi VISSER'T HOOFT (W.A.), Le mouvement œecuménique et la question raciale, Paris, Unesco, 1954. 
pour l'étude de l'union des chrétiens. Certains commentateurs ont vu dans la fondation de ce secrétariat un " grand événe-[p. 94] ment » : elle marque en tout cas le désir de la papauté de ne plus abandonner les contacts à des initiatives individuelles.

Le dialogue se poursuit et l'on doit observer que l'archevêque de Canterbury a fait une visite de courtoisie au pape au début de décembre 1960 (ce qui ne s'était plus produit depuis 1397). Peut-être ces rapports, qui résultent d'un sincère désir de rapprochement, s'intensifieront-ils à l'occasion du second Concile du Vatican. Mais jusqu'à présent, la seule transformation acquise est celle du climat, les divergences fondamentales subsistant ${ }^{1}$.

Ces difficultés sont, bien entendu, d'ordre théologique ; cependant, les positions politiques du Saint-Siège et du Conseil, en particulier à l'égard de la politique internationale, ne sont pas identiques. On voit dès lors le problème que soulèverait la création d'une fédération entre les Églises chrétiennes, même si l'on en limitait les tâches à des œuvres de charité et d'assistance, ou encore à une activité en faveur de la paix et de la détente internationales.

\section{e) JUDAÏSME}

\section{Retour à la table des matières}

Un souci élémentaire de précision commande de séparer le judaïsme, confession religieuse que l'on peut abandonner pour une autre ou simplement ne plus pratiquer — du sionisme, mouvement spécifiquement politique ayant en vue l'installation du peuple juif en Palestine. Après tout, il existe de nombreux juifs qui ont peu de sympathie pour le sionisme ou lui sont même franchement opposés : et l'on a pu observer dans ce dernier des conflits entre membres religieux et athées. Nous renvoyons donc l'étude du sionisme à la rubrique suivante sans dissimuler que cette séparation risque d'être critiquée et comporte de sérieux problèmes ${ }^{2}$.

Pour des raisons relevant de la morale et de l'acquis scientifique, on ne tiendra aucun compte des conceptions liant les deux phénomènes sur la base d'une prétendue race juive cherchant à dominer le monde. Notons toutefois que le comportement même des Israélites, dans les pays occidentaux surtout, ne permet pas de réduire la

1 Voir WEIGEL (Gustave), A Catholic Primer on the Ecumenical Movement, Westminster (Mar.), 1959 : étudie, en particulier, les diverses manifestations de l'œcuménisme catholique.

2 Sur le judaïsme, HESCHEL (Abraham J.), Les bâtisseurs du temps, Paris, 1957 (1'un des principaux penseurs du judaïsme contemporain); BERKOVITS (E.), Judaism. fossil or Ferment, New York, 1956, qui part en guerre contre les thèses de TOYNBEE présentant les juifs comme des « fossiles »; ROTH (Cecil), Histoire du peuple juif (des origines à la résurrection de l'État d'Israël), Paris, 1957 ; SIEGFRIED (André), Les voies d'Israël, essai d'interprétation de la religion juive, Paris, 1958. Au niveau de la vulgarisation, CROURAQUI (A.), Histoire du judaïsme, Paris, 1957 (Que sais-je ? $\mathrm{n}^{\circ}$ 750). Sur le rôle de l'Alliance Israélite Universelle, voir ISRAEL (Gérard), L'Alliance israélite universelle 1860-1960, Paris, 1960, et l'article de J. POIRIER sur cette association in Bulletin O.N.G., décembre 1952, pp. 475-478. 
qualité de juif au seul exercice d'une pratique religieuse. Nombreux sont en effet ceux qui, sans fréquenter la synagogue, ont conscience d'une appartenance juive. Pour eux, le judaïsme constitue une tradition, une culture, une civilisation, une entité ethnique auxquelles ils restent vivement atta-[p. 95] chés. Observons par ailleurs, sans tomber dans le piège de l'amalgame, que, sur le plan des comportements concrets, les échanges et passages de la religion au mouvement sioniste ont été et restent nombreux et constants.

Selon l'American Jewish Yearbook, il y avait en 1957 dans le monde environ 12 millions de juifs, dont un peu plus de 1,6 million en Israël. Par suite de l'extermination hitlérienne, l'Amérique vient désormais en tête avec 6 millions dont 5,2 aux États-Unis. Les pays communistes d'Europe en comptent encore environ 2,5 millions dont les 4/5 en Russie soviétique (certaines estimations donnant le chiffre de 3 millions pour la seule U.R.S.S.). Signalons sans insister qu'on distingue actuellement à l'intérieur du judaïsme trois grandes divisions religieuses: les « orthodoxes» partisans de l'application fidèle et intégrale de la Tradition; les « libéraux » qui préconisent une réforme du judaïsme pour l'adapter aux conditions de la vie moderne ; les « conservateurs » qui, avec de multiples nuances, se situent entre les deux courants précédents et s'efforcent de concilier empiriquement pratique juive et temps modernes.

L'un des atouts essentiels du judaïsme sur le plan mondial réside dans la cohésion de ses membres, cimentée par tant de persécutions : aujourd'hui, spécialement aux États-Unis, elle joue souvent en faveur de l'État d'Israël (liaison des phénomènes) ${ }^{1}$. De plus, le judaïsme dispose de quelques grandes associations qui défendent ses thèses et ses intérêts, tant auprès des gouvernements nationaux que des organisations intergouvernementales. Voici les principales.

D'abord l'Alliance Israëlite Universelle, fondée en 1860 à Paris, en vue de travailler au progrès moral et à l'émancipation des juifs, ainsi que pour prêter secours à ceux qui souffrent en cette qualité. L'une de ses préoccupations essentielles a été la diffusion des connaissances (entretien d'un vaste réseau d'écoles, spécialement dans le bassin méditerranéen).

Ensuite, le Congrès juif Mondial, fondé en 1936, mais succédant au Comité des Délégations juives, créé en 1918, pour représenter leurs intérêts à la Conférence de la paix. C'est actuellement une puissante organisation qui compte des membres dans plus de 60 pays. Son but est d'assurer la survivance du peuple juif et de renforcer son unité. Notons, qu'il existe une coopération entre le Congrès et le Mouvement Sioniste Mondial ${ }^{2}$.

Soutien qui ne signifie pas nécessairement adhésion au mouvement sioniste. Voir les observations de The Economist, 11 mai 1957, « Divided Jewry ».

2 Sur le Congrès, voir les publications suivantes (assurées par ses soins) : Le Congrès juif mondial. Principes et réalisations, 1948-1953 ; SCHWARZBART (Isaac I.), 25 années au service du peuple juif, août 1932-février 1957, juin 1957 ; Notre lutte pour la défense des droits et de la dignité des Juifs. Quinze années d'activité du Congrès Juif Mondial. 
[p. 96] Le Congrès joue un rôle important dans la vie de la communauté juive : depuis la fin de la guerre, il s'est efforcé de faire triompher les revendications matérielles de ses membres à l'égard de l'Allemagne, de mettre fin à toutes les persécutions ou discriminations dont souffrent encore les juifs dans tant de pays et d'améliorer la culture juive. Un optimisme allant jusqu'à l'exaltation avait fait suite à l'écroulement du nazisme : mais il ne fallut pas beaucoup de temps pour découvrir que la question juive était loin d'un règlement définitif. Des problèmes nombreux et graves n'ont cessé de se poser dont beaucoup ne trouvaient pas leur solution dans la création d'un État juif, tandis que d'autres en étaient la conséquence directe. Le Congrès a tenté de lutter sur tous les fronts et en particulier sur celui de l'opinion publique mondiale : de plus, il entretient des rapports aussi étroits que possible avec les organisations intergouvernementales. Parmi ses dernières décisions figure la convocation d'une conférence pour la création d'une Union mondiale des journalistes juifs ${ }^{1}$.

Mentionnons enfin le Conseil Consultatif d'Organisations juives qui rassemble l'Alliance Universelle, l'American Jewish Committee et l'Anglo-Jewish Association. Ce Conseil a été fondé en 1946 en vue d'une action commune, notamment auprès du Conseil Économique et Social des Nations Unies. L'American Jewish Committee est l'organisation juive la plus ancienne des États-Unis : elle a été formée pour combattre l'intolérance et défendre les droits civils et religieux des juifs à travers le monde ${ }^{2}$.

Pour donner un tableau complet de la question, il faudrait énumérer d'autres organisations. Nous en citerons seulement deux. L'Union Mondiale O.R.T. (Organisation-Reconstruction-Travail) : elle rassemble les sociétés (dont la première créée en Russie durant l'année 1880) qui se proposent de développer le travail agricole, artisanal et industriel parmi les juifs. Autre groupement (avec statut consultatif à l'O.N.U.) : l'Organisation Mondiale Agudas Israël qui a pour mission de trouver une solution aux problèmes du peuple juif dans l'esprit traditionnel et selon la perspective orthodoxe du judaïsme. Avant la seconde guerre mondiale les comités nationaux de Lithuanie, Pologne et Roumanie bénéficiaient d'une représentation officielle auprès des gouvernements de ces pays. Parmi les organes suprêmes de l'Association figure le Conseil Mondial des Rabbins, responsable de l'interprétation religieuse.

[p. 97] Il semble que, actuellement, devant la renaissance de l'antisémitisme, l'on s'oriente vers la constitution d'une « Conférence des Organisations juives », une sorte de super-organisme (dont ferait partie, avec les autres, le Congrès Mondial). Mais il ne paraît pas que des décisions aient déjà été prises quant à la nature juridique et au

Voir l'ouvrage (sur lequel nous reviendrons) ROBINSON (Nehemiah), The United Nations and the World Jewish Congress, New York, s.d. (publication du Congrès). Voir aussi LEWIN (Isaac), Religious Jewry and the United Nations. Addresses before the United Nations, New York, 1953 (point de vue de l'Organisation Mondiale Agudas).

2 La revue en langue française Évidences est publiée sous son égide. Voir la brochure publiée par le Comité lui-même sur ses buts et réalisations, Quarante ans de lutte contre un mal millénaire. On y trouvera l'exposé de plusieurs cas de pression anciens ou actuels ainsi qu'un aperçu sur les techniques de lutte du Comité contre l'Antisémitisme. 
mode de fonctionnement de cet organe. L'une des résolutions votées à la Conférence de Rome, où fut lancé le mouvement, déplore la situation faite aux juifs en Union soviétique et réclame pour eux le droit d'une émigration libre en Israël. On doit, en tout cas, noter la création récente (novembre 1960) d'une Conférence permanente des leaders des communautés juives d'Europe, (organisme groupant au départ les représentants de 14 pays).

Il faut pourtant reconnaître que ces efforts n'ont pas réussi à supprimer les discriminations ${ }^{1}$. Les organisations juives sont certes aidées en ce sens par les mouvements qui luttent contre toutes les formes de préjugés raciaux (personnes de couleur) : nous les retrouverons plus loin. Mais cette combinaison d'activités se heurte à des facteurs qui sont dans l'esprit des hommes et ne veulent pas céder.

\section{f) ISLAM}

$\underline{\text { Retour à la table des matières }}$

C'est aujourd'hui une religion conquérante. Elle compte, au bas mot, 350 millions de fidèles et en plusieurs régions du monde sa pénétration ne cesse de s'accentuer ${ }^{2}$. Moteur ou simplement support de vastes aspirations politiques (panislamisme, panarabisme...), l'Islam mérite d'occuper un rang privilégié dans notre tableau ${ }^{3}$.

1 Sur les discriminations qui frappent encore les juifs aux États-Unis, voir SIMPSON (C.E.), YINGER (J. Milton), Racial and Cultural Minorities : an analysis of prejudice and discrimination, New York, 1953. Voir aussi les remarques d'A. SIEGFRIED in Tableau des États-Unis, $3^{\mathrm{e}}$ éd., Paris, 1958 (chap. XII). L'ouvrage de S. KENNEDY, Introduction à l'Amérique raciste, Paris, 1955, relève davantage de la polémique que de l'analyse scientifique. Ne pas négliger les observations de Vance PACKARD, Les obsédés du standing, traduit de l'américain, Paris, 1960, pp. 234-248. On a beaucoup reproché aux sociétés communistes de témoigner d'antisémitisme et il est établi qu'à certaines époques au moins les accusations étaient fondées. Voir entre autres MEYER (P.), WEINRYB (B.D.), DUSCHINSKY (Eugène), SYLVAIN (Nicolas), The Jews in the Soviet Satellites, Syracuse, 1953 ; FEJTO (François), Les Juifs et l'antisémitisme dans les Pays communistes, Paris, 1960 ; DONATH (D.), « La situation des juifs en U.R.S.S. », Études février 1958, pp. 221-230. Consulter enfin SLOVES (Haïm), « La culture juive en U.R.S.S. », supplément de La Vie Juive, Paris, 1959 (publication du Congrès juif mondial) ainsi que les articles publiés dans L'Arche, octobre 1960. Sur les manifestations antisémitiques en Russie, voir l'écho présenté dans Le Monde, 17-18 janvier 1960.

2 Voir trois ouvrages de Roux (Jean-Paul), L'Islam en Asie, Paris, 1958; L'Islam en OccidentEurope-Afrique, Paris, 1959 ; L'Islam au Proche-Orient, Paris, 1960 ; GOUILLY (Alphonse), L'Islam, dans l'Afrique occidentale, Paris, 1952 ; LEWIS (W.H.), « Islam, a Rising Tide in Tropical Africa ", Review of Politics, octobre 1957, pp. 446-461 ; MONTEIL (Vincent), "L'Islam noir en marche », Le Monde, 14 et 15 juin 1960 (exemples d'expansion: la Nigéria, un Islam « aristocratique »; Sénégal, un Islam « confrérique »; Guinée, un Islam « anti-maraboutique »). Voir enfin VAN DER KROFF (J.M.), "The Role of Islam in Indonesian Nationalism and politics », Western Political Quarterly, mars 1958, pp. 33-54.

3 Pour une analyse d'ensemble, on pourra partir de Pierre RONDOT, L'Islam et les Musulmans d'aujourd'hui. Tome I, La Communauté musulmane; tome II, De Dakar à Djakarta. L'Islam en devenir, Paris, 1958-1960. Voici quelques livres à consulter : MASSE (H.), L'Islam, $4^{\mathrm{e}}$ éd., Paris, 
Pendant plus de dix siècles, la théorie et la pratique du Califat ont joué un rôle considérable dans la conception et le fonctionnement des institutions politiques de l'Islam. Abolie le 3 mars 1924 par la Grande Assemblée Nationale de Turquie, le Califat, qui avait été d'ailleurs progressivement dépouillé de sa substance, n'a pas été rétabli. Est-ce à dire que le concept de l'État dans les pays islamiques se trouve désormais vidé de tout contenu théocratique et qu'il est possible d'y installer des gouvernements de type moderne ?

Il semble qu'en dépit du culte de la tradition, la confusion entre l'Église et l'État soit là aussi en voie d'affaiblissement. Sans doute peut-on observer (en dehors de l'Arabie saoudite et du Yémen à structures presque médiévales) le cas très significatif du Pakistan dont la première Constitution affirmait encore la souveraineté de Dieu et, à un degré de moin-[p. 98] dre engagement, le texte de la Constitution égyptienne du 16 janvier 1956 faisant de l'Islam la religion d'État. Des courants du même ordre, quoique moins puissants, existent aussi en Malaisie et en Indonésie. Mais ailleurs, l'évolution s'est accomplie dans le sens d'une séparation des deux pouvoirs (Syrie et plus encore Tunisie) : il semble permis d'avancer, à la lumière des faits les plus récents (République Arabe Unie), qu'une conception millénaire des rapports entre le spirituel et le temporel est en train de subir une grande transformation ${ }^{1}$.

La modification jouera-t-elle en faveur de la démocratie ? Certains auteurs le pensent pour lesquels il n'existe aucune opposition entre les principes politiques de l'Islam et les idées maîtresses de la démocratie ${ }^{2}$. Mais ici encore le problème majeur

1945 ; GARDET (Louis), La Cité musulmane. Vie sociale et politique, Paris, 1954 ; CHELHOD (Joseph) Introduction à la sociologie de l'Islam, Paris, 1958 (tableau d'ensemble des causes qui ont préparé son avènement); FYZEE (Asaf A.A.), Conférences sur l'Islam, Paris, 1956. Ajouter CHARLES (Raymond), L'âme musulmane, Paris, 1958, BENNABI (Malek), Vocation de l'Islam, Paris, 1954 ; FERNAU (F.W.), Le réveil du monde musulman, traduit de l'allemand, Paris, 1954 ; LEWIS (Bernard), Les Arabes dans l'histoire, Neuchâtel, 1958. Au niveau de la vulgarisation, CHARLES (Raymond), L'évolution de l'Islam, Paris, 1960. Consulter enfin BAHADUR (Lal), The Muslin League. Its history, activities and achievements, Agra, 1954.

1 Pour une analyse de la théorie islamique de l'État, en dehors des ouvrages cités, se reporter à MILLIOT (L.), Introduction à l'étude du droit musulman, Paris, 1953. Voir aussi WATT (W.M.), Mahomet à Médine, Paris, 1959, pp. 267-316 ; FAKHRY (M.), « The Theocratic Idea of Islamic State in Recent Controversies », International Affairs, octobre 1954, pp. 450-462 ; HOBALLAH (M.F.), « Political Organization in Islam », Pakistan Horizon, mars 1951, pp. 3-11; AHMAD (I.), "Sovereignty in Islam », Pakistan Horizon, septembre 1958, pp. 141-146, et décembre 1958, pp. 244-257. Sur le cas du Pakistan, BINDER (L.), «Problems of Islamic Political Thought in the Light of Recent Developments in Pakistan » Journal of Politics, novembre 1958, pp. 655-675 ; KARUMAKARAN (K.P.), "Interrelation between Religion and Politics in Pakistan ", India Quarterly, janvier-mars 1958, pp. 43-62 ; GLEDHILL (A.), « The Pakistan Constitution », Public Law (London), hiver 1956, pp. 350-367. Voir enfin RONDOT (Pierre), «Islam et État dans la nation turque », Preuves, juillet 1960, pp. 58-66.

2 NIAZ AHMED ZIKRIA, Les principes de l'Islam et la démocratie, Paris, 1958, et NAJJAR (F.M.), "Islam and Modern Democracy », Review of Politics, avril 1958, pp. 164-180. Consulter également FRYE (Richard N.) (ed.), Islam and the West, La Haye, 1957. 
est celui des incompatibilités et des affinités éventuelles de la religion islamique avec le système communiste ${ }^{1}$.

Pendant longtemps, les auteurs occidentaux ont professé une vue irénique du problème : l'Islam leur semblant constituer une barrière infranchissable à l'expansion du régime communiste. Or, au contraire, plusieurs facteurs sont susceptibles de favoriser une telle poussée : sentiment anti-occidental très prononcé ; mécontentement économique et social (auquel il ne paraît pas possible d'apporter des remèdes immédiats) ; tendance autoritaire dans la tradition politique islamique et aussi diverses habitudes de gestion collective; prestige accru de la Chine dont l'expérience de planification extensive et intensive retient particulièrement l'attention des peuples pauvres (valeur exemplaire du « bond en avant ».

Sans doute les dirigeants actuels sont-ils dans l'ensemble peu favorables au communisme, mais qu'en sera-t-il de la génération qui va prendre la relève, spécialement si le lancement de l'industrialisation provoque le développement d'un prolétariat urbain insatisfait ? Il est possible que le facteur principal de résistance de l'Islam lui vienne, en définitive, d'être une religion (ce que le communisme n'est pas, malgré diverses assimilations de portée simplement littéraire).

Religion, en effet, l'Islam est pour ses fidèles une religion révélée. Pour le musulman, l'essentiel du devoir religieux réside dans la protection et la défense du dépôt de la Révélation et de ses commentaires autorisés, Ce sentiment donne à la communauté islamique, et c'est un point important pour notre sujet, une cohésion solide - face à un [p. 99] monde chrétien longtemps déchiré par d'inexpiables discordes et aujourd'hui encore désuni. On objectera que, dès le début de son existence, la communauté musulmane s'est, elle aussi, divisée en sectes. Cependant, ces groupes sont d'inégale importance. Les Sunnites, que, l'on peut qualifier d'orthodoxes, y entrent pour 90\%. Les Chiites (eux-mêmes répartis en plusieurs branches: Duodécimains, Zaidites, Druzes, Ismaïliens...) forment de 8 à $9 \%$ : leur implantation touche surtout l'Asie moyenne. Quant aux Kharidjites (dont on trouve des éléments notamment en Afrique du Nord), leur poids global est très faible. En somme, la masse des musulmans se range sous la même bannière. Pour elle, le rôle du Calife est de faire observer la loi. La fidélité à la volonté de Dieu est assurée par le consentement unanime de la communauté, tel qu'il s'exprime par la bouche des docteurs de la foi.

RONDOT, op. cit., chap. XX. Voir aussi LEWIS (B.), « Communism and Islam », International Affairs, janvier 1954, pp. 1-12, et CRAGG (K.), «The Intellectual Impact of Communism upon Contemporary Islam », Middle East journal, printemps 1954, pp. 127-138. On trouvera plusieurs éléments utiles in FISHER (Sydney Nettleton) (ed.), Social Forces in the Middle East, Ithaca (N.Y.), 1955, en particulier pp. 252-262. Voir aussi VAN DER KROEF (J.M.), « Communism and Islam in Indonesia. A Western View », India Quarterly, octobre-décembre 1954, pp. 314-352. Consulter SPECTOR (Ivar), The Soviet Union and the Muslin World. 1917-1958, Seattle, 1959 (dont l'élément le plus intéressant est le texte des programmes des partis communistes du MoyenOrient pour 1934). Voir enfin l'étude de Mme Hélène CARRÈRE d'ENCAUSSE, « Nationalisme et Islam dans la société communiste », Preuves, octobre 1958. 
Cette volonté implacable de sauvegarder la Révélation conduit les forces musulmanes à être constamment présentes dans le domaine de la vie publique. L'Islam est, au plein sens de l'expression, un facteur politique. L'affirmation qui eût été un truisme à l'époque d'identification complète de la religion avec l'État, demeure pleinement valable en cette phase de laïcisation progressive (qui suscite d'ailleurs diverses protestations). Elle traduit correctement le glissement perpétuel qui s'opère de la religion vers la politique ou, en d'autres termes, l'élan que la seconde reçoit de la première. L'Association des Frères Musulmans fournit, pour la période récente, un excellent témoignage de cette symbiose.

Le mouvement, qui débute vers les années 1925, a pour base religieuse les leçons de la Salafiya. Les adeptes de ce mouvement, dont le centre est au Caire, veulent une purification de l'Islam par un retour aux sources, la réunification du monde musulman et son intégration au monde moderne grâce au dynamisme ainsi retrouvé. Les Frères Musulmans sont une association militante fondée en Égypte, mais avec de nombreuses ramifications externes: elle emprunte beaucoup au programme salafi dans l'espoir de rendre la communauté musulmane strictement conforme aux principes islamiques. L'Association, qui fera beaucoup parler d'elle après 1945, a une structure organisée (cellules, formations para-militaire...); le passage à l'action politique (dont l'action directe et l'attentat sont un aspect) est inclus dans l'essence même du mouvement qui ne saurait accomplir sa mission sans une réforme de l'État et de la Constitution. Au moment, où l'Association sera dissoute pour la [p. 100] première fois (décembre 1948), plusieurs de ses membres songeaient à un coup d'État permettant de réaliser un aménagement des pouvoirs « théocratique et républicain ».

La liaison entre l'activité des Frères Musulmans et la révolution du 26 juillet 1952 reste obscure: ainsi, leur participation aux émeutes incendiaires du 26 janvier précédent demeure controversée ${ }^{1}$. Sans aucun doute, une liaison a existé entre les officiers libéraux et les Frères Musulmans ${ }^{2}$, des commentateurs assurant même que la révolution aurait été effectuée par les seconds et confisquée ensuite par les premiers. Se parant de l'étiquette de " groupement religieux », l'Association échappe d'abord aux mesures de dissolution des partis politiques. Cependant, le pouvoir qui redoute le noyautage de l'armée et de la police, va y procéder en janvier 1954 : le groupe n'arrête pas pour autant son activité et sa propagande. L'attentat dirigé contre Nasser en octobre, a été probablement perpétré par une branche secrète du mouvement : c'est le signal d'une impitoyable répression.

Cependant, l'Association des Frères Musulmans a essaimé en plusieurs pays arabes, particulièrement en Syrie. À ce titre, elle entre, selon notre terminologie, dans la catégorie des forces de pression internationale. Mais de quelle nature ? En un sens,

\footnotetext{
Voir LACOUTURE (Jean et Simone), L'Égypte en mouvement, Paris, 1953 ( $1^{\text {ère }}$ partie), chap. XII. Pour le récit des premiers contacts, Voir VAUCHER (Georges), Gamal Abdel Nasser et son équipe, tome I, Paris, 1959, pp. 119-125. On trouvera dans le tome II de cet ouvrage, L'édification de la République arabe unie, d'intéressants commentaires sur le nationalisme arabe et son attitude à l'égard du communisme. L'histoire des "Officiers libres" (pour la période 1938-1952) a été racontée par ANWAR EL SADAT (Colonel), Révolte sur le Nil, préface de G. Nasser, Paris, 1957.
} 
le but final de l'organisation était le perfectionnement moral de l'individu par une affirmation des principes coraniques : sous cet angle, on a pu l'interpréter en termes de pure théologie musulmane. Par d'autres côtés, ce fut une société terroriste qui se survit peut-être clandestinement (société secrète internationale ?). En réalité, l'Association a constitué, à la fois et de façon indissoluble, un mouvement religieux réformiste lié à la branche orthodoxe (sunnite), une société culturelle et scientifique, un parti politique ayant des conceptions économiques et sociales, une organisation de résistance à implications terroristes: puissance d'unification de la confession islamique.

Mais, justement, cette puissance n'est-elle pas suffisante pour conduire à la constitution d'un État islamique mondial ? Écoutons l'ancien président de la Ligue Musulmane du Pakistan déclarer — «... Il convient que tous les musulmans s'efforcent, non plus de trouver par le nationalisme une solution à leurs problèmes, mais de promouvoir l'État islamique unique et de construire une autorité centrale pour le monde musulman ... Un État islamique ... peut servir de tampon entre Orient et [p. 101] Occident et constituer un terrain de rencontre pour l'un et l'autre ... Le Pakistan est venu, l'Islamistan doit venir ${ }^{1}$.

On a déjà dit que la Constitution pakistanaise se proposait de bâtir un régime conforme à la norme islamique (les constituants se heurtant souvent au désaccord du Comité des Oulémas). Le nouveau régime de nature militaire qui gouverne aujourd'hui ce pays a pris l'engagement de ne promulguer aucune loi qui soit contraire « aux saints principes de l'Islam ». Dans l'esprit de nombreux Pakistanais, le système édifié devait être une sorte de modèle permettant d'accélérer la survenance des conditions nécessaires à l'établissement d'un État islamique mondial. Que penser de ce vœu de rééditer au $\mathrm{XX}^{\mathrm{e}}$ siècle, la formule du Califat?

Le terme Pan-islamisme, que l'on utilise volontiers à ce propos, est superflu car exactement synonyme d'Islam ou de communauté musulmane. Il est vrai que pour un musulman rigoureux, le seul État satisfaisant est celui qui s'étendrait aux dimensions de la communauté tout entière. La possession d'une langue liturgique unique accroît la cohésion spirituelle sous réserve qu'en de nombreux points (monde malais, turc, iranien, indo-pakistanais), l'arabe n'a pas supplanté les langues nationales. Divers milieux déploient une activité, quelque peu désordonnée, pour assurer le passage de cette unité spirituelle à une unification étatique. Le Pakistan a été le lieu d'élection de ces comités, ce qui les rend suspects à d'autres États du monde musulman, tentés d'y voir un instrument de la politique pakistanaise. Rappelons toutefois la fondation déjà ancienne (1953) d'un Congrès Islamique par les gouvernements égyptien, pakistanais et saoudite ${ }^{2}$.

D'après RONDOT, op. cit., pp. 258-259.

Ce Congrès institué lors du pèlerinage de 1953, déclare se préoccuper uniquement d'apostolat en évitant toute participation à la vie politique. Selon ses dirigeants, il s'agirait d'une institution religieuse dirigée par des laïcs dans le seul but d'enseigner aux musulmans les vrais principes de l'islamisme. De plus, le Congrès se propose d'apporter une aide culturelle, sanitaire et matérielle à tous les musulmans des diverses parties du monde (fondation d'écoles, d'hôpitaux, de dispensaires). 
Dans le monde contemporain, l'Islam, comme l'a souligné Jacques Pirenne ne représente encore qu'une «tendance idéologique " ${ }^{1}$. Certes, un grand courant nationaliste le parcourt qui a beaucoup contribué à ébranler le colonialisme et à valoir l'indépendance à tous les pays, musulmans qui, avant 1945, se trouvaient pour la plus large part dans un état de dépendance politique. Ce réveil fait donc suite à une longue phase d'engourdissement et de chaos qui avait fait des musulmans, selon l'expression de l'algérien Malek Bennabi, des éléments parfaitement colonisables, en proie à une paralysie morale et intellectuelle, ayant tendance à parler beaucoup plus qu'à agir. Aujourd'hui, de puissants efforts sont accomplis pour surmonter ce désarroi et bien que ses moyens matériels soient encore très réduits, la communauté islamique redevient un facteur autonome de la politique mondiale.

[p. 102] Mais cette unité spirituelle n'a pas permis à l'Islam de supprimer tous les particularismes nationaux au sein de sa zone propre. Sur le plan politique, on observe dans le monde musulman, où coexistent des niveaux de civilisation fort différents, des systèmes et des tendances opposés ${ }^{2}$. Bien plus, il arrive que, dans certaines circonstances, l'Islam confère à quelques-uns de ces particularismes un surcroît de force : ainsi, par exemple pour l'arabisme. En définitive, quel est donc aujourd'hui le poids de l'appartenance religieuse par rapport aux aspirations nationalistes ?

Dans une déclaration récente l'actuel président du Pakistan affirmait en le déplorant que la religion a perdu de sa puissance par rapport au nationalisme territorial comme motivation de la politique. En d'autres termes, même dans les pays de l'Islam le nationalisme aurait une force d'attraction supérieure à celle du sentiment religieux. On peut certes discuter le bien-fondé de cette thèse, mais nous observons dans ce secteur du monde de nombreux faits que l'on ne saurait ramener à une pure application de la religion ou dont la foi est impuissante à enrayer la manifestation.

Ouvrons toutefois une parenthèse pour noter que le «panislamisme » n'est pas le seul phénomène de son espèce. La catégorie des mouvements "pan " est très fournie : ils vont de l'affirmation de tendances messianiques à prolongements d'ordre politique (premières expressions du panafricanisme), à la justification éventuellement brutale d'une volonté de conquête (pan-germanisme au temps de Guillaume II). L'un des plus intéressants fut le pan-slavisme que divers traits rattachent au sujet de cette rubrique. Devant beaucoup au romantisme, avec des éléments d'utopisme et de messianisme, il visait à associer les divers peuples slaves sur les plans politique et culturel. Ainsi, ces derniers auraient-ils disposé d'une communauté cohérente et stable leur permettant de remplir la mission du slavisme dans le monde : l’Église orthodoxe

On n'est pas en mesure d'indiquer si ce congrès est en fait aussi dépourvu de préoccupations et d'influences politiques que ses dirigeants se plaisent à l'affirmer.

In Les grands courants de l'histoire universelle, tome VII, Neuchâtel, 1956, p. 902.

Par exemple à l'égard d'Israël. Ainsi l'Iran n'a-t-il jamais suivi sur ce point la ligne du Caire. Il n'y a pas en Iran de boycottage des marchandises israéliennes et Israël est un bon client de ce pays pour le pétrole. Les deux États ont des relations assez cordiales pour que leurs équipes de football puissent se rencontrer... Les projets prêtés au Shah, à tort peut-être, de reconnaître Israël (juillet 1960) ont suscité néanmoins en plusieurs capitales arabes de très violentes réactions : les grands Oulémas de la R.A.U. ont solennellement « excommunié » le souverain iranien. 
en aurait constitué le support et il n'aurait pas été difficile de trouver une langue commune pour cimenter l'union ${ }^{1}$.

En une large mesure, le panslavisme fut un instrument utilisé par la Russie tsariste pour donner une allure respectable à des visées clairement impérialistes: mais le mouvement était trop lié aux intérêts russes pour remplir son rôle avec efficacité. De plus, et l'obstacle se révéla décisif, le panslavisme fit son apparition au moment où les divers nationalismes slaves aspiraient à l'indépendance. La religion musulmane [p. 103] est certes un instrument d'unité beaucoup plus fort que le christianisme orthodoxe : cependant, on a vu à de multiples reprises que la communauté islamique ne pouvait échapper aux mêmes contradictions.

Actuellement, la tendance la plus active est celle du panafricanisme. La multiplicité des conférences interafricaines en témoigne (depuis le début de 1960 : Conférence des peuples africains à Tunis en janvier; deuxième session de la Commission Économique des Nations Unies pour l'Afrique à Tanger en février ; quinzième session de la Commission de Coopération Technique dans l'Afrique au Sud du Sahara à Tananarive, en mars ; conférence des pays indépendants d'Afrique, à Addis-Abeba en juin, etc. Plusieurs projets de regroupement des États noirs sont en discussion. Cependant, jusqu'à présent, les dirigeants ne s'entendent pas sur la forme et l'opportunité de ces rassemblements. Aux aspirations à l'unité qui sont le thème des réunions, s'oppose — en pratique — une tendance puissante à la « balkanisation ».

\section{MOUVEMENTS DE REVENDICATION NATIONALE}

Retour à la table des matières

L'inclusion de ces mouvements dans un tableau des forces de pression internationales pourrait être taxée de paradoxe. Pourtant leur comportement et leur destin sont inséparables des vicissitudes de la communauté internationale. Les combats qu'ils livrent, les amitiés qu'ils suscitent et les appuis qu'ils reçoivent, les échecs qu'ils subissent comptent parmi les éléments qui façonnent l'état des relations mondiales. Pour s'en apercevoir, il suffit d'envisager les conséquences du conflit algérien sur la position diplomatique de la France.

Ces mouvements correspondent soit à des peuples qui tentent de se libérer comme tels et de se créer un État propre, soit à des minorités qui, mécontentes de leur statut, s'efforcent d'obtenir leur rattachement à une autre structure politique. Le problème de ces dernières est souvent complexe : il naît du conflit entre l'idéal d'un État national homogène et la réalité d'une hétérogénéité ethnique. On a imaginé bien des solutions

1 Voir le bon ouvrage de KOHN (Hans), Panslavism : its history and ideology, Notre Dame (Indiana), 1953. Du même auteur, "Dostoïevsky and Danilevsky: nationalist messianism », Occidente, juillet-août 1954, pp. 349-360. 
pour le résoudre : organisation internationale garantissant les droits spécifiques des minorités; transformation des mœurs dans le cadre d'une assimilation et d'un pluralisme culturel ; élimination physique par la révision des frontières ou le transfert des populations. En [p. 104] tout cas, depuis 1919, et compte tenu des injustices commises par le traité de Versailles en Europe centrale, cette question n'a cessé d'être au cœur de l'actualité internationale ${ }^{1}$.

Un exemple fort intéressant pour l'analyse, est celui des minorités religieuses. Ainsi celle des chrétiens d'Orient, vivant encore à plus de trois millions, dans des régions conquises par l'Islam depuis des siècles. Ces chrétiens, dont la protection a si souvent fourni matière ou prétexte à intervention de la part des grandes puissances, sont d'une extrême diversité (six communautés reconnaissant l'autorité du pontife latin, cinq autres en étant complètement séparées, etc.). Leur destin a été bien différent d'un cas à l'autre (les Assyriens, par exemple, se trouvant en une large mesure décimés par des éléments irakiens, alors que les orthodoxes, souvent avec une grande habileté, parvenaient à s'intégrer dans les nouveaux États créés depuis la fin de la première guerre mondiale). Aujourd'hui, face à la poussée du nationalisme arabe, leur situation est ambiguë ${ }^{2}$.

Car, bien entendu, l'évolution du problème est commandée par l'élan du nationalisme, l'une des idées qui, actuellement, mènent le monde ${ }^{3}$. L'accroissement spectaculaire du nombre des membres des Nations Unies, porte témoignage de la force de ce courant : d'ici la fin de l'année, leur chiffre aura pratiquement doublé par rapport à la situation d'origine et l'on peut déjà prévoir, pour l'avenir, d'autres demandes d'adhésion ${ }^{4}$. Cette tendance conduit aussi bien à l'aggravation des disputes (voir, par exemple, le « durcissement » récent de l’Autriche sur la question du Tyrol du Sud) qu'à l'apparition de réactions de défense. Ainsi, chez divers États de l'Asie du

1 Voir l'ouvrage d'ensemble de CLAUDE (Inis L. Jr.), National Minorities. An international problem, Cambridge (Mass.), 1955. L'U.R.S.S. prétend avoir réussi à régler cette question à l'intérieur de ses frontières. La discussion de cette thèse sortirait du cadre de ce livre. On trouvera une sélection, de grande valeur, de matériaux soviétiques in SCHLESINGER (Rudolf) (ed.), The Nationalities Problem and Soviet Administration. Selected readings on the development of Soviet nationalities policies, Londres, 1956.

2 Sur tous ces problèmes, le meilleur ouvrage est RONDOT (Pierre), Les Chrétiens d'Orient, Paris, 1955. Sur les Assyriens, WALTERS (F.P.), A History of the League of Nations, Oxford, 1952, vol. II, pp. 573-578.

3 WARD (Barbara), Five Ideas that Change the World, Paris, 1959. L'ouvrage du général ANDRÉ (Pierre-J.), Le réveil des nationalismes, Paris, 1958, donne une présentation valable de l'extension de ce courant. Voir aussi entre tant d'autres livres disponibles : La Conscience chrétienne et les nationalismes, Semaine des intellectuels catholiques (5-11 novembre 1958), Paris, 1959 ; HODGKIN (Thomas), Nationalism in Colonial Africa, Londres, 1956 ; THAYER (Philip W.), PHIILLIPS (William T.) (ed.), Nationalism and Progress in free Asia, Baltimore, 1956. Sur le plan des doctrines : VERGNAUD (Pierre), L'idée de la nationalité et de la libre disposition des peuples dans ses rapports avec l'idée de l'État, Paris, 1955. Sur le plan de la formation des nationalités, l'ouvrage de ZNANIECKI (Florian), Modern Nationalities : a sociological study, Urbana (Illinois), 1952, reste toujours intéressant à consulter.

4 État actuel du problème (novembre 1960) : 99 membres contre 51 au départ. 
Sud-Est, à l'égard des importantes et puissantes minorités chinoises vivant sur leur territoire : très vive entre l'Indonésie et la Chine, la querelle vient de se terminer par la signature d'un accord dans lequel le gouvernement chinois accepte, pour la première fois, les mesures d'assimilation voulues par Djakarta.

En réalité, la question n'est pas nouvelle, mais le contexte dans lequel elle se pose a subi des modifications qui, généralement, accroissent l'intensité des conflits. Les moyens modernes d'information, par leur ampleur et aussi leur rapidité, facilitent la présentation au monde entier des pièces de chaque dossier. Les organisations intergouvernementales constituent une tribune idéale, utilisée au besoin par personnes interposées. L'acuité du conflit Est-Ouest ouvre aux intéressés de larges facultés de manœuvre.

[p. 105] Les mouvements que l'on analysera ici revêtent des formes variées, dépendant aussi bien de la nature de la revendication, que du cadre dans lequel s'insère la lutte : partis politiques agissant à visage découvert, sociétés secrètes avec ou sans organisation terroriste dans leur prolongement, éléments militairement encadrés et armée de libération. Ils sont souvent difficiles à classer : par exemple, nature exacte de l'Union des Populations du Cameroun dont l'analyse serait particulièrement précieuse pour l'étude des tactiques (pénétration et subversion du communisme international en territoire africain). Il arrive et que l'on passe d'une forme à l'autre à mesure de la poursuite du conflit et que le même mouvement se présente sous plusieurs aspects, ou comporte divers compartiments, plus ou moins bien unifiés. Au cours des dernières années, on a observé des organisations mettant en œuvre des procédés de lutte rationalisés, selon les schémas de la guerre révolutionnaire, mais il s'en est trouvé d'autres qui se fondent sur un terrorisme assez élémentaire et font appel à la tradition (ainsi les Mau Mau) ${ }^{1}$.

Notons un point important: plusieurs de ces mouvements ont un pouvoir d'attraction et même de marchandage (bargaining power) assez grand pour susciter l'intérêt et obtenir l'appui, matériel ou moral, de nombreuses forces qui, habituellement, ne font pas preuve d'un comportement unifié. À l'égard de plusieurs nationalismes africains, par exemple, on observe des convergences dans la conduite des internationales syndicales, des Églises chrétiennes (protestante et catholique) et même de certains groupements d'affaires : les uns et les autres souhaitent, en effet, pour des raisons diverses, gagner les sympathies et au minimum, ne pas s'aliéner des éléments actuellement « rebelles » mais dans lesquels ils voient les gouvernants de demain.

\footnotetext{
Voir le rapport parlementaire (publié seulement en mai 1960) Historical Survey of the Origins and Growth of the Mau-Mau, Cmd, 1030. Voir aussi LEAKEY (L.S.B.), Defeating Mau-Mau, Londres, 1954. Sur certains aspects de la révolte des peuples dépendants, voir le curieux ouvrage de LANTERNARI (Vittorio), Movimenti religiosi di Libertà e di Salvezza dei popoli oppressi, Milan, 1960 .
} 


\section{a) LA RÉSURRECTION D'UNE NATION : LE SIONISME}

\section{$\underline{\text { Retour à la table des matières }}$}

Sans entreprendre ici l'historique complet de l'Organisation Sioniste Mondiale, on tient à marquer les principales étapes de son activité : car c'est, sans aucun doute, l'une des plus puissantes forces de pression qui aient jamais opéré sur le plan mondial ${ }^{1}$.

Le mouvement juif du retour en Palestine s'amorça dans la seconde moitié du $\mathrm{XIX}^{\mathrm{e}}$ siècle : à partir des années 1880, la recrudescence de l'antisémitisme et des pogroms - spécialement dans l'Empire des tsars [p. 106] — allait l'intensifier. Ces aspirations trouveront un cadre dans le groupement des Amants de Sion qui fonda, plusieurs colonies agricoles. D'autres furent créées par l'Alliance Israëlite Universelle qui reçut un large appui financier du baron Edmond de Rothschild ${ }^{2}$. Mais un facteur devait précipiter l'évolution : la publication, en 1895, par un journaliste viennois, Théodore Herzl, d'un ouvrage L'État juif. Finalement se tint à Bâle, en août 1897, le premier Congrès sioniste qui adopta un programme sans équivoque : « Le sionisme a pour but de créer pour le peuple juif en Palestine, un asile garanti par le droit public ». C'est de ce moment que date la fondation de l'Organisation sioniste comme mouvement populaire et international. Son activité peut être divisée en trois phases.

En premier lieu, l'ensemble des efforts qui devaient aboutir à la Déclaration Balfour (2 novembre 1917). Ce fut d'abord un échec, la Turquie refusant de laisser s'organiser une colonisation juive de la Palestine. À partir d'une proposition de l'Angleterre, un programme portant sur l'Ouganda fut présenté au $\mathrm{VI}^{\mathrm{e}}$ Congrès sioniste : soulevant une violente opposition (spécialement de la part des délégués venus de Russie), il fut mis à l'écart. Cependant, le travail pratique se poursuivait en Palestine (fondation, en 1906, d'un premier lycée juif à Jaffa). Compromise par les persécutions turques, l'activité fut stoppée par les hostilités qui, au surplus, séparèrent les groupes juifs appartenant aux pays belligérants. C'est pourtant le moment où l'Exécutif sioniste put obtenir de l'Angleterre, avec l'appui notamment de la France, une déclaration favorable à l'établissement en Palestine d'un Foyer National juif.

1 Sur l'histoire du sionisme, voir l'ouvrage (témoignage vécu) de WEIZMANN (Chaïm), Naissance d'Israël, traduit de l'anglais, Paris, 1957. Pour une bonne vulgarisation : CHOURAQUI (André), L'État d'Israël, Paris, 1959 (Que sais-je ? n 673). Du même auteur, Théodore Herzl, Paris, 1960. L'ouvrage de Josué JEHOUDA, Sionisme et messianisme, Genève, 1954, donne une juste idée de la complexité du phénomène et de l'acuité des oppositions qui ont surgi au sein du mouvement. Voir aussi POLK (W.R.), STAMLER (David M.), ASFOUR (E.), Backdrop to Tragedy. The struggle for Palestine, Boston, 1957 (effort pour décrire objectivement les divers points de vue en présence).

2 Voir MARGALITH (Israël), Le Baron Edmond de Rothschild et la colonisation juive en Palestine, 1882-1899, préface de David Ben-Gourion, Paris, 1957. 
On a beaucoup discuté des mobiles de cette déclaration. Bien que fondée sur un élément d'idéalisme désintéressé, elle comportait aussi des motifs stratégiques (couvrir les abords de Suez par un territoire bien disposé à l'égard des Britanniques). Toutefois, la raison principale fut de susciter les sympathies du monde juif pour les Alliés, car la russophobie des juifs les conduisait à graviter vers le camp des puissances centrales. L'objectif immédiat était de mettre un frein aux activités proallemandes des juifs russes dont on estimait à Londres, qu'elles contribuaient à la désagrégation du régime tsariste. Selon Gathorne-Hardy, qui s'en tient à ces explications, la déclaration Balfour se révéla un mauvais calcul ${ }^{1}$.

La seconde phase correspond, en gros, au mandat britannique sur la Palestine. Sur le plan de l'organisation, une Agence juive pour la Palestine est créée dès 1922, dont le but est de représenter le peuple juif [p. 107] auprès de la puissance mandataire : dans ce rôle l'Agence bénéficiera d'un statut semi-officiel. Elle est aussi l'instrument grâce auquel les Juifs non sionistes peuvent aider la colonisation juive. Finalement, après d'assez nombreuses dissensions internes, l'exécutif de l'Agence en viendra à s'identifier pratiquement à celui de l'Organisation Sioniste Mondiale.

Mais, très vite, la résistance arabe va s'affirmer et ne cessera de croître. À plusieurs reprises, des troubles sanglants éclatent et, sous l'impulsion du Haut Comité Arabe, une véritable révolte se précise. Pris entre des intérêts contradictoires, les Anglais louvoient et, après l'échec d'une ultime tentative de conciliation, en arrivent à renverser leur politique (Livre blanc du 17 mai 1939). L'immigration juive est stabilisée à un taux réduit cependant qu'un règlement foncier limite sévèrement la possibilité laissée aux juifs d'acquérir des terres. Ces mesures indignent les juifs et risquent de stopper l'expansion du Foyer qui, avec le, appuis de tous ordres de l'Organisation Sioniste, s'effectuait à une cadence rapide. Cependant, durant la guerre, les juifs se battront aux côtés des Anglais (d'abord incorporation dans l'armée anglaise, puis constitution en 1944 de la brigade juive combattante).

Le XXII ${ }^{\mathrm{e}}$ Congrès de l'Organisation Sioniste (Bâle, décembre 1946) venant, après l'échec de la commission d'enquête anglo-américaine, se tient sous le signe d'une reprise de la bataille pour l'indépendance politique. L'Exécutif sioniste et Chaïn Weizmann vont dès lors jouer un rôle de premier plan dans la lutte devant les instances internationales qui sanctionneront la décision de partage et, finalement, la création de l'État d'Israël.

Le sionisme eut donc finalement gain de cause. Il avait bénéficié à cet effet d'immenses ressources : réseau de relations, appui moral, aides financières... Une longue pression — étalée sur près d'un demi-siècle — obtenait le résultat souhaité. Mais, en définitive, rien n'aurait pu être conservé sans la puissance de feu de la Haganah.

Après la fondation de l'État israélien, l'Agence juive fut déchargée de la plus grande part de ses fonctions. En la dotant d'un statut particulier (1954) on décida

In Histoire des événements internationaux de 1919 à 1939, traduit de l'anglais, Paris, 1946, p. 124. 
qu'elle continuerait de fonctionner comme branche exécutive de l'Organisation Sioniste Mondiale dans certains domaines : immigration, absorption des immigrants, colonisation, travail sioniste dans la diaspora. Soulignons à cet égard l'importance des concours financiers reçus par Israël de l'extérieur (y compris de milieux juifs [p. 108] non sionistes). Selon des chiffres officiels, les transferts de fonds effectués par les institutions juives pour la période 1950-57 s'élèvent à 736 millions de dollars, auxquels s'ajoutent 330 millions de dollars versés par le gouvernement américain (dont 85 à titre de prêt, le reste sous forme de don) et de sérieuses contributions de la République fédérale allemande (412 millions de \$ à titre de réparations collectives et 114 pour dédommagements personnels) ${ }^{1}$.

La fondation de l'État d'Israël n'a donc pas arrêté l'activité du sionisme qui s'est fixé un triple rôle : consolidation de cet État, rassemblement des exilés, maintien de l'unité du peuple juif. L'organisation, qui se réunit en congrès mondial tous les deux ans, possède aujourd'hui des fédérations dans une soixantaine de pays. Cependant, au cours des dernières années, des difficultés se sont produites dans l'application du statut concédé à l'Agence en raison, semble-t-il, de l'opposition de M. David Ben Gourion. Motifs de cette réticence : le fait qu'un petit nombre seulement de leaders sionistes soit venu s'établir en Israël ; la difficulté d'établir une réelle différence entre «sionistes » continuant de vivre dans leur pays d'origine et «non sionistes » soutenant l'État juif ; peut-être aussi les critiques émises par divers milieux sionistes contre la politique du chef du gouvernement israëlien.

Ce point de vue n'a pas prévalu, la majorité des hommes politiques d'Israël continuant d'estimer que le renforcement du Mouvement Sioniste est nécessaire, pour unifier et valoriser l'aide juive mondiale à cet État. D'où un effort de réorganisation du Mouvement devant permettre d'y affilier les organisations juives qui, sans porter l'étiquette "sioniste », soutiennent matériellement et moralement, l'État d'Israël. Finalement la décision a été prise de poursuivre dans ce nouveau cadre l'application de l'accord de 1954.

Au cours de la période récente l'État d'Israël et le Sionisme ont été soumis aux attaques incessantes des États arabes. De plus, la Russie qui, pourtant, fut avec les États-Unis la première à reconnaître le nouvel État, s'est rangée dans le camp antisioniste ; et, à sa suite, les autres États communistes ${ }^{2}$. Il n'y a pas à cette attitude que

1 Israël, faits et chiffres (publication gouvernementale), p. 76. Sur l'État d'Israël il existe une vaste littérature dont voici une petite sélection : GOTTMANN (Jean), Études sur l'État d'Israël et le Moyen-Orient (1935-1958), Paris, 1959 ; BERNSTEIN (Marver H.), The Politics of Israel. The first decade of statehood, Princeton, 1957 ; PARAF (Pierre), L'État d'Israël dans le monde, Paris, 1958 ; WILLIAMS (L.F. Rushbrook), The State of Israël, Londres, 1957 (un peu journalistique, mais intéressant). Sur les relations avec les Arabes au cours du temps, voir GOITEN (S.D.), Jews and Arabs. Their contacts through the ages, New York, 1955.

2 Voir le récit des persécutions infligées en Tchécoslovaquie à un militant sioniste de nationalité israélienne in OREN (Mordekhaï), Prisonnier politique à Prague (1951-1956), traduit de l'hébreu, Paris, 1960. Ce livre est si dur qu'en dépit de la caution de Jean-Paul Sartre, on hésite à admettre toutes les allégations de l'auteur; y est-on conduit par souci d'esprit critique ou par une réaction de « petit bourgeois » humanitariste... 
des raisons de politique arabe. En un sens, le sionisme qui exprime le souhait d'une nouvelle patrie traduit l'absence d'intégration des juifs à la communauté dont ils sont membres. En l'interprétant avec malveillance, il est facile d'y voir un refus conscient de l'unité nationale. C'est là un facteur propre à renforcer l'antisémitisme auquel l'antisionisme apporte [p. 109] un prétexte commode. La Russie, spécialement sous Staline, n'a pas échappé à ce cercle vicieux. Ajoutons-y la persistance, déjà notée, d'un antisémitisme traditionnel qui atteint même un pays comme la Pologne où il reste à peine 50000 juifs.

Si l'on en croit divers commentateurs, la virulence de ces oppositions et discriminations se serait atténuée sous le gouvernement de $\mathrm{M}$. Khrouchtchev, mais l'antisionisme persiste (refus d'autoriser l'émigration) ${ }^{1}$.

\section{b) UN MOUVEMENT DE RÉNOVATION NATIONALE : L'ARABISME}

$\underline{\text { Retour à la table des matières }}$

C'est aux environs des années 1900 que se fondèrent la Ligue de la Patrie Arabe et le journal Le Réveil de la Nation Arabe. Mais c'est seulement le 22 mars 1945 que sera souscrit au Caire le pacte de la Ligue Arabe. Entre ces deux évènements se situent les facteurs déterminants : la liquidation de l'Empire ottoman et l'activité du sionisme. Aujourd'hui, l'arabisme (on dit parfois " panarabisme », le préfixe d'ailleurs n'ajoutant rien) constitue une tendance politique qui s'extériorise volontiers avec éclat. Une communauté se manifeste, une solidarité s'affirme: ce que René Grousset appelait un empire des consciences. Quels sont le sens et la portée de cette force ? ${ }^{2}$

1 Le 15 septembre 1960, s'est tenue à Paris, sous la présidence de M. Daniel MAYER, une conférence internationale sur la situation des juifs en U.R.S.S, Le président du Congrès juif Mondial - accusé par les Russes d'être au service de l'impérialisme occidental - y a déclaré que la communauté juive souffrait en U.R.S.S. d'une discrimination, soit à titre de minorité nationale, soit à titre de minorité religieuse : politique susceptible de mener à longue échéance à la désintégration de cette communauté. La conférence s'est achevée par le vote d'une résolution réclamant, en particulier, la faculté pour les juifs de l'U.R.S.S. d'entretenir des relations avec les autres communautés juives dans le monde.

2 Sur le problème, BERQUE (Jacques), Les Arabes d'hier à demain, Paris, 1960 ; RONDOT (Pierre), Destin du Proche-Orient, Paris, 1959 ; au niveau de la vulgarisation, MONTEIL (Vincent), Les Arabes, Paris, 1957 (Que sais-je ? n 722). Voir naturellement NASSER (C.A.), Egypts Liberation. The philosophy of the revolution, Washington, 1955. Voir aussi NUSEIBEN (Hazen Zaki), The Ideas of Arab Nationalism, Ithaca (N.Y.), 1956. Pour l'évolution historique, se reporter également à BONNE (Alfred), State and Economics in the Middle East. A society in transition, Londres, 1948 ; LENCZOWSKI (Georges), The Middle East in World Affairs, 2 e éd., Ithaca (N.Y), 1957 ; LAQUEUR (Walter Z.), (ed.),The Middle East in Transition, Londres, 1958 ; FINER (H.), " Reflections on the Nature of Arab Nationalism », Middle Eastern Affairs, octobre 1958, pp. 302313 ; DIB (G. Moussa), The Arab Bloc in the United Nations, Amsterdam, 1956. Bonne introduction in PARTNER (P.), A Short Political Guide to the Arab World, Londres, 1960. L'ouvrage de FODA (Ezzeldin), The Projected Arab Court of Justice, La Haye, 1957, aborde 
Au point de départ, le phénomène sera mal perçu et beaucoup lui dénieront toute valeur. Comme l'a parfaitement montré Robert Montagne, la notion même de nationalisme arabe est difficile à saisir et, encore plus, à enfermer dans une formule précise. Le même concept peut s'étendre aussi bien à des groupes réduits qu'à des ensembles très vastes : ce sera tantôt l'expression d'un particularisme local, tantôt l'appel à l'unité des peuples de langage arabe allant du golfe Persique à l'Atlantique. À la limite, le nationalisme couvre toute la partie du monde peuplée par les disciples du Prophète ${ }^{1}$.

La religion islamique étant, en somme, le principal (et éventuellement le seul) facteur commun à toutes ces situations, il est tentant d'identifier complètement Islam et nationalisme arabe. Encore que les deux attitudes soient en liaison étroite (conjugaison naturelle, on l'a montré. du réformisme religieux et de l'élan nationaliste), il ne parait pas possible, actuellement, de ramener la totalité de la conscience arabe à un phénomène de pure affiliation religieuse. L'Islam soutient l'arabisme et a constitué, surtout à l'origine, son ferment essentiel. Mais le monde [p. 110] arabe s'est ouvert à d'autres forces qui pourraient bien jouer un rôle ultérieur.

On n'a pas compris tout de suite dans les pays occidentaux l'importance du combat contre le sionisme, "le drame central, ou, pour mieux dire, le drame unique » de l'Orient arabe, selon les expressions de Pierre Rondot. C'est le critère par lequel on apprécie tout le reste et en fonction duquel notamment, on classe les autres peuples en «amis» ou «adversaires ». Les États-Unis en particulier ont mis longtemps à comprendre que la conciliation des forces rivales au Moyen-Orient était une entreprise au-dessus de leur force.

Parmi tant d'autres erreurs les grands États de l'Occident ont commis celle de vouloir imposer aux pays arabes leurs problèmes particuliers et leur échelle d'appréciation des périls. Or, le propre de tous les nationalismes, est de se déterminer exclusivement en fonction des intérêts et des objectifs qu'à tort ou à raison l'on attribue à l'ensemble national. Pouvait-on demander aux Arabes de se départir de cette ligne universelle ? On s'y risquait pourtant en les conviant (déclaration tripartite de 1950 et pacte de Bagdad) à recevoir des armes à propos d'un conflit Est-Ouest qui ne les intéressait pas, mais en leur interdisant de les utiliser dans le combat araboisraëlien. L'impasse était totale et elle l'est restée. Dès le moment où elle mettait le Sionisme en accusation, la tâche de l'U.R.S.S. ne présentait plus de difficulté.

plusieurs des problèmes importants qui concernent la Ligue arabe. À l'occasion de son quinzième anniversaire, la Ligue a publié une brochure énonçant ses origines, objectifs, structure et activités (Le Caire, 1960).

D'après RONDOT, Destin du Proche-Orient, op. cit., pp. 117-119. 
Sans qu'il en ait toujours été ainsi ${ }^{1}$, l'Égypte apparaît aujourd'hui comme le pilier du nationalisme arabe. C'est autour d'elle, en tout cas, que s'est matérialisé le premier effort de construction de la nation arabe (République arabe unie). On sait, au surplus, que l'organisation politique est restée très en-deçà du sentiment de solidarité spirituelle. Depuis sa création, la Ligue Arabe a rarement constitué un faisceau de forces cohérentes obéissant à un commandement unifié. Comme l'exprime avec franchise son secrétaire général " elle a eu ses hauts et ses bas, des périodes de lumineuses espérances et des moments de prostration ${ }^{2}{ }^{2}$. Cependant l'effort d'unification se poursuit. Citons par exemple, les travaux de l'Union Économique Arabe en vue de la création d'un Marché commun arabe dont l'un des objectifs serait, au dire de ses promoteurs, de lutter contre les effets de la Communauté Économique Européenne: il semble d'ailleurs que pour l'instant l'on se borne à envisager une réduction des droits de douane et un échange [p. 111] d'informations sur les programmes d'industrialisation en vue d'éviter les doubles emplois.

Encore qu'elles aient changé d'orientation au cours du temps, les rivalités à l'intérieur du monde arabe ont été considérables et parfois prépondérantes. La transformation du régime en Irak n'a pas modifié le problème que complique la volonté des derniers venus à l'indépendance de jouer leur jeu propre sur la scène mondiale. Soit, par exemple, l'Afrique du Nord: on peut se demander si, pour les pays qui la composent, le panmaghrébisme n'est pas un idéal plus accessible, ou du moins, plus proche que le panarabisme. Mais la situation en Algérie constitue la pierre d'achoppement de la Fédération maghrébine, tout en apportant un nouvel aliment au nationalisme arabe lato sensu.

\section{c) MOUVEMENTS POUR L'INDÉPENDANCE}

\section{$\underline{\text { Retour à la table des matières }}$}

À l'époque contemporaine, ils ont été nombreux, revêtant des formes diverses, avec des tactiques multiples. Les uns ont connu le succès, d'autres un échec total, le sort de certains restant encore en suspens. Dans cette évolution, une place spécifique doit être réservée à la lutte pour la libération des territoires colonisés.

Le cas du nationalisme irlandais, aboutissant à la création d'un État libre d'Irlande, est trop bien connu pour justifier un long commentaire : il donna naissance, chez les Irlandais émigrés aux États-Unis, à une sorte de nationalisme irlando-américain (sentiment à la fois ambigu et puissant). On notera seulement que l'indépendance

Voir CHEJNE (A.G.), « Egyptian Attitudes toward Pan-Arabism », Middle East Journal, été 1957, pp. 253-268. Voir aussi COLOMBE (M.), «L'Égypte et le nationalisme arabe de la Ligue des États arabes à la République Arabe Unie (1945-1958) », Orient, $1^{\mathrm{er}}$ trimestre 1958, pp. 113-134. Pour une étude plus approfondie, se reporter à AHMED (J.M.), The Intellectual Origins of Egyptian Nationalism, Londres, 1960.

2 M. Abdel Khalek HASSOUND, dans une brochure publiée par la Ligue, où l'on trouvera en particulier un effort pour dégager les éléments constitutifs du nationalisme arabe 
s'accompagna de la sécession des Comtés de l'Ulster. De même, se bornera-t-on à signaler qu'à l'issue de la première guerre mondiale, la défaite des Empires centraux permit d'apaiser plusieurs revendications nationales, le découpage effectué créant d'ailleurs par ses erreurs et ses excès, de nouveaux foyers d'insatisfaction et de révolte.

Parmi les plus puissantes des forces qui intervinrent à cette époque, mentionnons le Comité National Tchèque qui sous l'impulsion de Masaryck effectua un vaste travail de propagande au sein des pays alliés : agissant sur des secteurs sensibles de l'opinion (partis de gauche, loges maçonniques, milieux universitaires), les leaders de la résistance "extérieure » — beaucoup plus radicaux que ceux demeurés sur le sol national — persuadèrent plusieurs secteurs et hommes politiques [p. 112] de l'Entente de la nécessité d'attribuer l'indépendance au peuple tchécoslovaque ${ }^{1}$.

Cependant, à cette époque même, toutes les revendications nationales ne reçurent pas satisfaction. L'exemple de la Géorgie illustre l'écrasement des velléités d'indépendance d'un petit pays par un puissant voisin : mettant en cause les instances internationales, il éclaire directement le propos de cet ouvrage.

Dans une première phase, ce fut le succès : proclamation, dès la fin de 1917, par le Conseil National Géorgien de l'indépendance de la Géorgie comme État jouissant de tous les droits d'un État indépendant: signature le 7 mai 1920 d'un traité entre la Russie et la Géorgie, par lequel la première admet sans réserve l'indépendance de l'État géorgien et renonce à toute intervention dans ses affaires intérieures (la région de Batoum, notamment, entrant expressément dans la délimitation territoriale reconnue par les Soviétiques) ; enfin reconnaissance de jure de l'indépendance de la République géorgienne par la Conférence interalliée à Paris (27 janvier 1921).

Notons toutefois qu'en décembre 1920, la S.D.N. adoptait une attitude ambiguë à l'égard d'une demande d'admission. Celle-ci fut rejetée, l'Assemblée invitant toutefois ce pays à prendre part, au même titre que les États-membres, aux travaux des organisations techniques: la France et l'Angleterre votèrent contre l'admission en expliquant leur position par l'impossibilité où serait la S.D.N. d'aider la Géorgie si celle-ci venait à être attaquée ${ }^{2}$.

La suite des événements devait justifier cette réserve! Quand se produisit l'intervention militaire communiste - qui, sur le moment, ne semble pas avoir fait l'unanimité des chefs soviétiques - la Géorgie fut laissée à son destin et il fallut plusieurs années de luttes (une insurrection générale noyée dans le sang éclatant encore en 1924) pour rétablir l'ordre et stabiliser la conquête.

Voir DROZ (Jacques), L'Europe centrale. Évolution historique de l'idée de « Mitteleuropa », Paris, 1960, pp. 236-238.

2 Voir WOYTINSKY (Vladimir), La démocratie géorgienne, préface de E. VANDERVELDE, Paris, 1921. Rappelons toutefois qu'au départ, la Géorgie se mit sous la protection de l'Allemagne (en vue de s'abriter de la Turquie, dirent ses dirigeants d'alors). La question géorgienne s'insère dans le cadre plus vaste de la Transcaucasie (Azerbaïdjan, Arménie, Géorgie) pour laquelle une République éphémère fut proclamée le 22 avril 1918. 
Autre mouvement qui subit à la même époque un échec complet celui tendant à la création d'un État arménien. Après diverses vicissitudes, les puissances laissèrent se constituer l'embryon d'un tel État qui devait succomber sans recevoir la moindre protection internationale sous la double poussée des Russes et des Turcs ${ }^{1}$.

Parmi les mouvements susceptibles de jouer un rôle dans les années à venir figure le Mouvement National Kurde. On a pu parler des Kurdes comme d'un «peuple oublié ». La légitimité de leurs aspirations [p. 113] nationales avait été admise par les puissances lors de la signature du traité de Sèvres dont le chapitre III prévoyait la création d'un Kurdistan indépendant : mais la clause devait être annulée lors du traité de Lausanne. Depuis, l'audience internationale du mouvement est restée faible. Les récents événements d'Irak ont à nouveau appelé l'attention sur le problème. La Constitution provisoire de la nouvelle République précise en effet : "La société irakienne est fondée sur la coopération totale entre tous les citoyens, sur le respect de leurs droits et de leurs libertés. Les Arabes et les Kurdes sont associés dans cette nation. La Constitution garantit leurs droits nationaux au sein de l'entité irakienne » ${ }^{2}$.

Les Kurdes sont actuellement répartis entre cinq pays : Turquie, Irak, Iran, Syrie, Arménie soviétique. Leur nombre est difficile à évaluer, certains États, la Turquie en particulier, allant jusqu'à nier l'existence du fait kurde et à présenter les Kurdes comme des « Turcs montagnards ». Les estimations vont d'un minimum de 5 millions à un maximum de 12. Leur sort a été différent selon les pays, la Turquie ayant été la plus dure à leur égard. Ils ont, par contre, bénéficié en Syrie d'une grande tolérance n'entraînant d'ailleurs aucun privilège politique. Enfin, ils ont joui d'un traitement très favorable en Arménie soviétique (où au nombre de 60000 ils ne représentent qu'un pourcentage infime de la population).

Les Kurdes occupent une position stratégique importante au cœur des montagnes de l'Asie antérieure. Les provinces qu'ils revendiquent sont particulièrement riches en pétrole (Mossoul). Au cours des années récentes, l'U.R.S.S. s'est beaucoup intéressée

1 Voir sur ce problème MANDELSTAM (André N.), La Société des Nations et les puissances devant le problème arménien, Paris, 1926 (édition spéciale de la Revue Générale de Droit International Public). Sur l'évolution historique, voir THOROSSIAN, Histoire de l'Arménie et du peuple arménien depuis les temps les plus reculés jusqu'à nos jours, Paris, 1957, et ATANIAN (Sarkis), The Armenian Community, New York, 1955. Bonne présentation générale in ALEM (Jean-Pierre), L'Arménie, Paris, 1959 (Que sais-je ? n 851). Évoquons également le cas différent et, lui aussi, très controversé du nationalisme ukrainien : LAWRYMENKO (J.), Ukrainian Communism and Soviet Russian Policy Toward the Ukraine An annotated bibliography, 1917-1953, New York, 1953, et surtout ARMSTRONG (John A.), Ukrainian nationalism, 1939-1945, New York, 1955, qui donne un tableau lucide et impartial des mouvements en cause (qui, selon lui, se fondaient sur des revendications, en partie justifiées, mais restaient souvent enclins à verser dans un extrémisme très voisin du fascisme).

2 Voir NIKITINE (Basile), Les Kurdes. Étude sociologique et historique, Paris, 1956 ; EDMONDS (C.J.), Kurds, Turks and Arabs, Londres, 1957 ; GAVAN (S.S.), Kurdistan : divided nation of the Middle East, Londres, 1958 ; RONDOT (Pierre), «La nation kurde en face des mouvements arabes », Orient, $3^{\mathrm{e}}$ trimestre, 1958, pp 55-69 ; ZEIDNER (R.F.), « Kurdish Nationalism and the New Iraq Government», Middle Eastern Affairs, janvier 1959, pp. 24-31 ; EDMONDS (C.J.), « The Kurds and the Revolution in Iraq », Middle East Journal, hiver 1959, pp. 2-10. 
à eux, ce qui a conduit certains à voir dans le mouvement un atout ou un levier de la politique des Soviétiques au Moyen-Orient ${ }^{1}$. C'est très probablement une vue simpliste. Il y a certes chez ce peuple des communistes et des partisans de l'U.R.S.S. Cependant, de bons connaisseurs estiment que les Kurdes ne sont pas, pour autant, prêts à prendre les armes au premier appel de Moscou. S'ils constituent une force potentielle, on en discerne encore mal, dans l'état actuel du Moyen-Orient, les points d'application éventuels.

Cependant, à notre époque, le mouvement des nationalités a surtout pris la forme d'une lutte anti-coloniale. Celle-ci s'est exercée sur tous les plans, allant du combat militaire à l'action diplomatique. Il en est résulté un vaste mécanisme de pression trouvant son origine dans les [p. 114] mouvements d'indépendance ou leurs défenseurs et atteignant l'État responsable soit directement soit par des canaux variés (suggestion de gouvernements amis, menaces proférées par les adversaires...). Le F.L.N. en est aujourd'hui l'exemple le plus significatif : rares sont désormais les organisations internationales et les gouvernements qui lui restent inaccessibles. Sa capacité de pression, tenant en partie à la lutte des deux blocs pour s'assurer la sympathie de pays afro-asiatiques, lui permet de placer dans une situation délicate aussi bien les États-Unis que l'U.R.S.S. ${ }^{2}$.

Les organisations inter-gouvernementales ont joué un rôle considérable dans ce processus de lutte pour l'indépendance. On en a déjà mentionné divers aspects (Internationales syndicales et Organisation Internationale du Travail) et on pourrait en évoquer beaucoup d'autres (ainsi à l'O.N.U., rôle du Comité des renseignements relatifs aux territoires non autonomes). Mais un point particulier sera cité ici: l'utilisation du droit de pétition à l'O.N.U. dans le cadre du système de la tutelle ${ }^{3}$.

1 L’U.R.S.S., il est vrai, a toujours tenu en réserve une carte kurde (ainsi, après l'échec en 1945 de la tentative visant à créer un État kurde, accueil de l'armée battue et de son chef Mustafa al Bazzani et mise à la disposition de celui-ci d'un émetteur à Tiflis). Mais elle a commis des erreurs qui semblent lui avoir aliéné une notable partie des militants. En voici un exemple : lors d'un Congrès national kurde tenu en décembre 1958 avec des fonds soviétiques, elle a obtenu la désignation par les congressistes, comme président du "Kurdistan libre », de Khalib BAGDACHE, secrétaire général en exil du Parti Communiste Syrien. Opération traduisant clairement la volonté russe de contrôler le mouvement.

2 Sur le F.L.N., l'essentiel de la documentation accessible reste principalement journalistique et doit donc être abordée avec une extrême prudence. Par ailleurs, les ouvrages disponibles ne sont pratiquement plus à jour. Sous ces réserves, voir: ARON (Raymond), La tragédie algérienne, Paris, 1957 ; TILLON (Germaine), L'Algérie en 1957, Paris, 1957 ; BROMBERGER (Serge), Les rebelles algériens, Paris, 1958 ; FAVROD (Charles-Henri), La révolution algérienne, Paris, 1959 ; SAVARY (Alain), Nationalisme algérien et grandeur française, Paris, 1960. On trouvera des portraits de quelques-uns des leaders algériens in CROZIER (Brian), The Rebels : a study of postwar insurrections, Londres, 1960.

3 Ce système a donné lieu à une vaste littérature dont voici quelques titres : TOUSSAINT (C.E.), The Trusteeship System of the United Nations, Londres, 1956; MURRAY (James N.), The United Nations Trusteeship Systems, Urbana (Illinois), 1957; MULENZI (Janvier), La tutelle internationale et le problème des unions administratives, Louvain, 1955. Pour une comparaison avec le système des mandats, voir HALL (H. Duncan), Mandates, Dependencies and Trusteeship, 
Le Conseil de tutelle a mis au point un mécanisme de contrôle qui repose sur trois éléments : examen de rapports annuels fournis par les autorités administrantes ; étude des pétitions ; visites périodiques dans les territoires. Les deux derniers ouvrent aux mouvements locaux des possibilités d'intervention ou, si l'on préfère, des facultés d'accès. Une procédure a été montée pour tirer le maximum d'efficacité de la technique des pétitions. Le nombre de ces démarches a été assez élevé — à sa session de 1953, le Conseil avait à son ordre du jour l'examen de 395 pétitions (chiffre portée en 1956 à 432 dont 159 de caractère général et 273 concernant des points particuliers).

L'examen d'une telle masse de documents, si l'on y ajoute les observations de l'État considéré, constitue un énorme travail : en une occasion au moins le système a atteint un point de rupture ${ }^{1}$.

Ces pétitions couvrent les thèmes les plus variés et sont envoyées par des groupes aux dénominations multiples (conférences, congrès, associations, conseils, commissions, unions, ligues, comités, tribus, etc.) ainsi que par des personnes physiques. Quelques-unes de ces plaintes sont dépourvues de sérieux ou traitent de matières extérieures à la compétence du Conseil (par exemple, difficultés matrimoniales ou financières). D'autres sont rédigées en termes si généraux et vagues qu'il est difficile de leur donner une suite pertinente. Hors ces cas, le Conseil [p. 115] s'est toujours efforcé d'apporter une réponse positive (par exemple, appelant l'attention des auteurs de la pétition sur certaines dispositions prises par l'autorité de tutelle ou en leur suggérant une action déterminée). Au total, le Conseil dont les membres sont des représentants des gouvernements, a constitué pour les mouvements considérés un instrument indirect de pression sur les gouvernements responsables. L'une des questions les plus délicates qu'il ait eu à aborder fut le statut du Togo sous administration britannique (en liaison avec la création du Ghana) ${ }^{2}$.

Les anciens États coloniaux reprochent parfois aux grandes puissances (États-Unis et U.R.S.S.) de soutenir les élans d'indépendance nationale afin de se préparer une place privilégiée dans les nouveaux États. Ainsi la décolonisation s'analyserait-elle en une substitution d'influence ; tout en paraissant accéder avec spontanéité et générosité aux revendications de souveraineté, les nouveaux maîtres de la politique mondiale suivraient en somme un programme égoïste et resteraient les «meneurs du jeu ». Bien qu'assez sommaire, cette vue explique une partie des comportements : pourtant, elle serait fallacieuse si l'on en déduisait une absence d'autonomie dans le déclenchement de ces mouvements. Au surplus, les très grands États ne sont pas les seuls à s'intéresser aux territoires promus à l'indépendance. Voir par exemple, les efforts

Washington, 1948, et surtout CHOWDHURI (R.N.), International Mandates and Trusteeship. A Comparative Study, La Haye, 1955.

1 Voir dans The Economist, 28 juillet 1956, le récit de l'embouteillage provoqué par l'arrivée de 33000 pétitions en provenance du Cameroun sous tutelle française. Un dépouillement intégral aurait coûté 1 million de dollars et exigé plus de stencils qu'il ne s'en consomme annuellement dans tous les bureaux de l'O.N.U. réunis.

2 Pour un exposé de ce problème, voir le volume collectif de la Brookings Institution, The United Nations and Promotion of General Welfare, Washington, 1957, pp. 967-979. 
actuellement accomplis par la Yougoslavie, en utilisant le levier idéologique et la technique commerciale, pour s'implanter en Afrique ${ }^{1}$.

\section{d) LES RÉFUGIÉS}

\section{$\underline{\text { Retour à la table des matières }}$}

Les techniciens estiment qu'il y a eu depuis la fin de la seconde guerre mondiale environ 40 millions de réfugiés. Il en reste encore un grand nombre, 15 millions peutêtre, dont plus de 2 millions ont toujours besoin de l'aide des Nations Unies. De nouvelles catégories viennent sans cesse en renouveler le flot (Chinois réfugiés à Hong-Kong et Macao, Algériens en Tunisie et au Maroc, Tibétains dans l'Inde et au Népal...).

On a proposé de répartir les réfugiés depuis 1914 en cinq grandes catégories : réfugiés d'avant la seconde guerre mondiale (Russes blancs, Arméniens, Espagnols...) ; rapatriés (personnes déportées pendant la guerre par les Allemands et les Russes et qui, en principe, ont été rendues à leur patrie à la fin des hostilités) ; personnes déplacées (déportés du [p. 116] temps de guerre ayant refusé de rentrer dans leur pays d'origine à la fin des hostilités) ; réfugiés des pays communistes (qui ont fui ceux-ci, principalement après 1948) ; populations transférées, c'est-à-dire groupes issus de règlements politiques d'après guerre engendrant de véritables déportations (Allemands, Arabes de Palestine, Finlandais, Indiens... ).

Ce dernier poste est de loin le plus significatif pour notre propos, car il s'agit d'éléments auxquels le départ a été dans une large mesure imposé et qui en ont gardé des attitudes politiques caractéristiques. Les Allemands fournissent un très gros contingent de cette catégorie (une dizaine de millions d'«expulsés » selon le recensement effectué en date du 29 octobre 1946). Les Arabes de Palestine entrent également dans ce groupe (total un peu supérieur au million). Mais l'élément numériquement le plus considérable est fourni par les personnes transférées de l'Inde au Pakistan, ou vice-versa, à la suite du partage du sous-continent indien : au total 18 millions se répartissent à peu près par moitié dans chaque sens ${ }^{2}$.

1 Tenue à Belgrade, en décembre 1959, sous l'égide de la Ligue Yougoslave pour la Paix, l'Indépendance et l'Égalité des Peuples, de la III $^{\mathrm{e}}$ Conférence pour la lutte anti-coloniale dans la Méditerranée et le Moyen-Orient, mais aussi effort pour développer le commerce avec l'Afrique (passé dans les sept dernières années de quelques centaines de millions de dinars à 12 milliards) ; ouverture de crédits pour l'achat de divers types de biens; conclusion de nombreux accords de commerce et de collaboration (économique, scientifique, technique, culturelle), signature de conventions sur les communications maritimes et aériennes. N'oublions pas l'accueil d'étudiants africains (ils sont environ deux cents qui fréquentent facultés et écoles yougoslaves).

2 Pour l'étude de cet immense sujet, on pourra se reporter à : VERNANT (Jacques), Les réfugiés dans l'après-guerre, Monaco, 1953 ; PROUDFOOT (Malcolm J.), European Refugees : 19391952. A study in forced population movement, Londres, 1957 ; STOESSINGER. (John G.), The Refugee and the World Community, Minneapolis, 1956. On trouvera également d'importants 
L'exemple de la Palestine atteste que les réfugiés sont, dans certaines circonstances, un facteur essentiel de la politique internationale ${ }^{1}$. Mais ce n'est pas un cas unique. Qu'ils constituent un enjeu, un levier ou un moteur, les blocs de réfugiés correspondant à des personnes transférées, occupent souvent de façon directe ou indirecte une place importante dans les relations internationales ${ }^{2}$.

Les rapports germano-polonais, durant ce second après-guerre, en apportent une illustration typique (problème de l'Oder-Neisse) ${ }^{3}$. L'expulsion des Allemands constitue probablement, au moins à vue d'homme un phénomène irréversible. Il est également possible - c'est un autre problème - que l'état de la situation mondiale rende désirable, ou impose, de donner une sanction juridique au fait accompli (position du général de Gaulle). Mais, à moins de considérer l'Allemagne et les Allemands comme de simples objets de la politique internationale, on ne saurait, en plus, exiger des victimes qu'elles approuvent une décision dont les responsables se sont toujours efforcés de masquer la signification réelle aux alliés occidentaux. En tout cas, ce n'est pas en attribuant un fondement punitif à l'opération qu'on conduira les expulsés à l'acquiescement (ceux-ci sachant bien que la volonté de l'U.R.S.S. de revenir à la ligne Curzon fut, en réalité, le mobile unique de l'affaire). [p. 117] Seul l'enchaînement de l'histoire reste susceptible d'amener dans la longue période, une authentique résignation.

Dans cette perspective, le retour des Sarrois à leur patrie d'élection fut une opération pleinement heureuse, éliminant de la vie internationale une source de pression et un facteur de conflit.

Tout un agencement a été réalisé pour aider les réfugiés et faciliter leur reclassement. Sur le plan intergouvernemental: création de l'Organisation Internationale pour les Réfugiés et, à sa suite, du Haut Commissariat pour les Réfugiés (qui travaille notamment, grâce au Fonds des Nations Unies pour les

éléments d'information (sous la rubrique des «migrations politiques ») in Bureau International du Travail, Les migrations internationales, 1945-1957, Genève, 1959 et LADAME (Paul A.), Le rôle des migrations dans le monde libre, Genève, 1958.

1 Voir sur ce problème, PERETZ (Don), Israel and the Palestine Arabs, Washington, 1958 ; GABBAY (Rony), A Political Study of the Arab-Jewish Conflict. The Arab refugee problem, Genève, 1959 ; SCHWARZ (Walter), The Arabs in Israel, Londres, 1959.

2 Pour une analyse des récentes manifestations de réfugiés allemands en matière de politique étrangère, voir LEMBERG (Hans), "Le rôle politique des réfugiés », Documents, septembreoctobre 1960, pp. 506-520. L'étude donne une bonne présentation des groupements actuels et de leur force respective. Voir aussi les observations présentées sur la notion de "droit à la patrie » (revendiqué, voici déjà dix ans, par les représentants des fédérations de réfugiés).

3 Même si la thèse polonaise comporte des aspects contestables, sa formulation et sa défense commandent le respect. Il arrive pourtant que ses exposants dépassent la mesure. Voir, par exemple, le livre haineux de SAWICKI (Jerzy), De Nuremberg à la nouvelle Wehrmacht Varsovie, 1958 (qui contient de nombreuses déformations et de multiples absurdités). Pour l'affirmation de la thèse polonaise en termes plus modérés, voir RAPACKI (Z.), « Le problème polono-allemand », Politique Étrangère, décembre 1959, pp. 446-482. Sur l'utilisation par les Polonais des territoires pris à l'Allemagne, voir SCZANIECKI Michel), «Données et travaux polonais sur les terres occidentales », Politique Étrangère, 1959 (n 4), pp. 434-445. 
Réfugiés) ${ }^{1}$. Ceux de Palestine relèvent d'un organisme spécial : l'Office de Secours et de Travaux des Nations Unies pour les Réfugiés de Palestine dans le Proche-Orient (U.N.R.W.A.). L'effort s'effectue aussi sur le plan de l'organisation internationale privée. Une seule indication témoignera de son ampleur : la Conférence permanente des agences bénévoles s'occupant des réfugiés rassemble 25 organisations internationales. On sait aussi que l'Assemblée générale des Nations Unies a décidé de faire de 1960 l'année mondiale des Réfugiés.

Un dernier point : le rôle joué à l'étranger par des hommes politiques en exil : ainsi, celui des républicains espagnols chassés par Franco ou encore celui des socialistes allemands s'étant expatriés devant Hitler ${ }^{2}$. Bien que leurs facultés d'influence sur les gouvernements ou l'opinion publique aient été réduites, elles n'ont probablement pas été nulles. Dans la même perspective, on manque des données qui permettraient d'apprécier les résultats de l'action entreprise par les réfugiés des pays communistes (sous l'impulsion et avec une aide matérielle souvent importante du gouvernement américain).

[p. 118]

\section{ORGANISMES D'INSPIRATION HUMANITAIRE}

\section{$\underline{\text { Retour à la table des matières }}$}

Les organisations d'aide aux réfugiés que l'on vient d'énumérer entrent dans cette catégorie dont les aspects sont multiples et les frontières incertaines. Les notions de secours aux victimes, de protection des faibles, d'adaptation et de réadaptation sociales, de bien-être, expriment sans en garantir une présentation exhaustive, les objectifs de ces groupements dont les possibilités de travail sont, souvent, médiocres. Néanmoins on observe aujourd'hui une tendance au développement de la coopération internationale en vue d'améliorer le sort des hommes ${ }^{3}$.

La plupart de ces organismes se disent «non politiques » et, à ce titre, ne sembleraient pas relever de notre exposé. Cependant l'affirmation, même sincère, demeure équivoque et doit être précisée.

1 Sur ce problème, voir HOLBORN (Louise W.), L'organisation internationale pour les réfugiés 1946-1952, Paris, 1955. Voir aussi RISTELHUEBER (René), Au secours des réfugiés. L'œuvre de l'organisation internationale pour les réfugiés, Paris, 1951. Enfin, sur l'un des plus importants aspects de la question, WEIS (P.), « Le statut international des réfugiés et apatrides », Journal du Droit International, janvier-mars 1956, pp. 5-69. Comparer avec SCHWARZ (Leo W.), Refugees in Germany today, New York, 1957 (qui rapproche la législation allemande de la réglementation internationale).

2 EDINGER (Lewis J.), German Exile Politics. The Social Democratic Executive Committee in the Nazi Era, Berkeley, 1956.

3 Voir le numéro des Annals of the American Academy of Political and Social Science, mai 1960, pp. 1-153, « International cooperation for Social Welfare. A New Reality ». 
En premier lieu, beaucoup des objectifs visés, la plupart sans doute, ne sauraient être atteints que par des mesures gouvernementales. Si un trait domine notre époque, c'est bien la volonté de substituer à la charité et au paternalisme, qui diminuent moralement leurs bénéficiaires, l'affirmation des droits sociaux de la famille et de l'individu : il s'agit, dans tous les domaines, de substituer la sécurité à l'assistance. Les groupements qui s'attachent à cette mission doivent, au sens neutre du mot, faire pression sur les gouvernements (ou les organisations qui les rassemblent) afin d'en obtenir que soient prises les dispositions nécessaires. Il arrive aussi que les autorités fournissent à ces groupes, directement ou indirectement, les ressources indispensables à la poursuite des activités engagées. D'où, en définitive, l'établissement de contacts qui concernent exactement notre propos.

Il y a plus. Même si les conceptions de ces associations sont exclusives de tout esprit partisan, il n'en résulte pas que leurs démarches soient sans implications politiques. La dénonciation de l'esclavage et du trafic des esclaves répond certes à un idéal humanitaire, mais, par la force des choses, elle vise des États déterminés qui n'hésiteront pas à y voir une ingérence intéressée dans leurs affaires. Enfin, il est possible que sous couvert d'humanitarisme, l'organisme considéré prenne en fait des positions partisanes et s'engage au service de l'un des blocs en présence. Sans doute faut-il n'accueillir qu'avec réserve les reproches de partialité faits à certains d'entre eux, car ils dissimulent souvent la volonté de disqualifier une activité dont on a de bonnes raisons de re-[p. 119] douter les résultats. Pourtant, il n'est pas exceptionnel que l'accusation soit fondée (« la politisation » de l'organe en cause étant acquise dès le départ, ou survenant en cours de route).

Le rattachement de ces groupes à une étude de science politique étant ainsi expliqué, voici quelques organes typiques de cette catégorie. Comme pour les autres rubriques de ce chapitre, l'exposé se réduira à une énumération très partielle.

\section{a) DÉFENSE DES VICTIMES}

\section{$\underline{\text { Retour à la table des matières }}$}

On citera en premier lieu le mieux connu, la Croix-Rouge Internationale, vaste collectivité sans caractère officiel, comportant les éléments suivants : d'abord les Sociétés Nationales de la Croix-Rouge qui en sont le pilier. Actuellement au nombre de 84, elles réunissent plus de 130 millions de membres, y compris les Sociétés du Croissant Rouge et la Société du Lion et du Soleil Rouge (Iran). Durant les hostilités, elles se vouent surtout à l'assistance aux militaires blessés et aux prisonniers ; en temps de paix, elles se consacrent aux malades civils et aux enfants, etc. Le second élément est le Comité International de la Croix-Rouge (C.I.C.R.) qui, composé uniquement de citoyens suisses est, en temps de guerre, l'intermédiaire neutre par excellence. Enfin, la Ligue des Sociétés de la Croix-Rouge, fondée en 1919, est une fédération des Sociétés nationales : elle a pour objet d'encourager et de faciliter à tout 
moment et sous toutes ses formes, l'œuvre humanitaire de la Croix-Rouge. C'est un organe permanent de liaison, de coordination et d'études ${ }^{1}$.

La Croix-Rouge possède un Parlement avec sa Conférence internationale qui réunit tous les quatre ans les représentants de toutes les sociétés, du C.I.C.R. et de la Ligue ainsi que des délégués des États parties aux conventions de Genève (dotés eux aussi d'une voix délibérative). Chaque Conférence nomme une commission permanente qui lui assure continuité entre deux sessions.

De ces divers organismes, le C.I.C.R. est celui qui relève le plus directement de notre propos. Il offre la particularité d'être national par sa composition (citoyens suisses, au maximum 25, se recrutant par cooptation) et international par son action. S'il n'a sur les sociétés nationales qu'une autorité morale, il possède d'importantes bases d'action au sein de la communauté mondiale du fait des conventions de Genève, (surtout dans les textes révisés de $1949^{2}$. À cette date, les trois pre-[p. 120] mières (amélioration du sort des blessés et des malades dans les forces armées en campagne ; amélioration du sort des blessés, des malades et des naufragés des forces armées sur mer ; traitement des prisonniers de guerre) ont simplement été revues et complétées, compte tenu des enseignements de la seconde guerre mondiale. Mais on a ajouté à ce dispositif une $4^{\text {ème }}$ convention relative à la protection des personnes civiles en temps de guerre (qui prohibe les prises d'otages, les déportations, les atteintes à la dignité des personnes, les exécutions sans jugement...).

Le C.I.C.R. agit, sans nul doute, comme une force de pression internationale. D'abord il est certain qu'il a joué un rôle considérable dans la codification et la révision de la législation internationale: les groupements dont il est l'œuvre ne pouvant manquer d'avoir recours à son expérience ${ }^{3}$. De plus et surtout, dans la mesure où il a qualité pour surveiller l'exécution des obligations assumées, son activité a précisément pour but de peser sur le comportement des responsables en les amenant, ou les ramenant, au respect des normes établies. Le phénomène est d'autant plus notoire qu'au cours des années récentes, le C.I. C.R. a étendu son action aux conflits internes.

C'est là une matière délicate et la position actuelle du C.I.C.R. représente à cet égard une innovation. Sur la base d'une doctrine juridique établie avec le concours d'experts, il est parvenu à agir sur le terrain des troubles intérieurs (ainsi, en Grèce

1 Voir JOYCE (J.A.), Red Cross and the Strategy of Peace, Londres, 1959. Bonne introduction in COURSIER (Henri), La Croix-Rouge internationale, Paris, 1959 (Que sais-je ? n ${ }^{\circ}$ 831). Voir aussi HUBER (Max), La pensée et l'action de la Croix-Rouge, Genève, 1954 et JUNOD (Dr Marcel), Le troisième combattant. De l'hypérite en Abyssinie à la bombe atomique d'Hiroshima, Lausanne, 1947. Pour les principes, Voir PICTET (Jean S.), Les principes de la Croix-Rouge, Genève, 1955.

2 Voir la publication du C.I.C.R., Les conventions de Genève du 12 août 1949, $3^{\mathrm{e}}$ édition, Genève, 1951. Voir aussi DRAPER (G.I.A.D.), The Red Cross Conventions, Londres, 1957. Consulter SIOTIS (Jean), Le droit de la guerre et les conflits armés d'un caractère non international, Paris, 1958 ; GIRAUD (E.), « Le respect des droits de l'homme dans la guerre internationale et dans la guerre civile », Revue du Droit Public et de la Science Politique, juillet-août 1958, pp. 613-675.

3 Sur son action de guerre, voir Inter Arma Caritas. L'œuvre du C.I.C.R. pendant la seconde guerre mondiale, Genève, 1947. 
lors de la guerre civile, en Amérique lors des révolutions du Guatemala et de CostaRica et plus récemment en Algérie). Tout en indiquant que le C.I.C.R. s'attache depuis longtemps à ce problème, le rapport d'activité pour 1958 souligne que cette préoccupation est devenue impérieuse, tous les conflits où l'organisme a eu à intervenir au cours de la période récente étant précisément d'ordre interne ${ }^{1}$.

L'action du C.I.C.R. se caractérise par un sens exceptionnellement élevé de dignité et de responsabilité. S'il fait pression sur les gouvernements, c'est en les plaçant devant leurs propres obligations, en montrant clairement l'écart qui sépare les pratiques suivies des devoirs assumés. Euvre singulièrement utile si l'on considère que les autorités centrales, ne sont pas toujours bien informées des agissements de leurs subordonnés. De plus, en prenant connaissance des faits, le C.I.C.R. montre que d'autres, n'ayant ni sa réserve, ni son impartialité, pourraient aussi les découvrir et les exploiter: c'est une incitation pressante à y mettre fin, du moins pour les gouvernements qui se soucient de leur réputation internationale.

Constatons, sans originalité, que la tâche du C.I.C.R. est extrêmement complexe, compte tenu notamment du retard du droit international public à s'adapter aux nouvelles formes de conflit (sabotage et terrorisme, guérilla...). S'il est appelé à faire pression sur les gouvernements responsables, le Comité est lui-même sujet à l'intervention d'autres États (États arabes à propos de l'Algérie) qui lui reprochent de n'aller ni assez vite, ni assez loin. Ajoutons-y le risque d'une exploitation publique de son travail qui complique sa tâche.

On l'a vu en France, au début de 1960, lorsque, grâce à une « fuite », le journal Le Monde en date du 5 janvier a publié une longue analyse des rapports sur les camps et lieux d'internement en Algérie que le C.I.C.R. venait de soumettre au gouvernement français (à la suite d'une visite — la septième de ce genre - intervenue du 15 octobre au 27 novembre). Le Comité, tout en notant une amélioration sensible des conditions de vie dans les camps depuis la dernière mission (décembre 1958), émettait de nombreuses critiques et se faisait l'écho de multiples plaintes. Nous ne discuterons ici, ni des mobiles qui ont provoqué la « fuite » et la publication, ni de l'exploitation qui a été faite de ce texte sur le plan intérieur et auprès des instances internationales (communication aux membres de l'O.N.U. d'une analyse du rapport sur la demande du groupe afro-asiatique et malgré l'opposition du Président du C.I.C.R.). L'affaire nous a montré, en tout cas, qu'à la suite du dépôt du rapport le ministre des armées avait adressé au commandement une nouvelle circulaire pour interdire certaines pratiques : il faut voir là une preuve de l'efficacité de la pression morale du C.I.C.R. Mais la publicité est-elle susceptible de la renforcer ou de la restreindre ?

Genève, 1959, p. 53. Voir le rapport (imprimé) sur l'action de secours en Hongrie, octobre 1956juin 1957, Genève 1957 et le rapport (ronéotypé), Le C.I.C.R. et le conflit algérien, décembre 1959. Les têtes de chapitres de ce rapport sont: Action du C.I.C.R. en faveur des Algériens détenus en Algérie et en France ; action du C.I.C.R. en faveur des prisonniers français aux mains de l'A.L.N. et assistance à des prisonniers non-français aux mains de l'A.L.N. ; action du C.I.C.R. en faveur des populations victimes des événements (réfugiés algériens au Maroc et en Tunisie; invalides algériens au Maroc ; assistance aux populations déplacées et regroupées en Algérie). 
La doctrine du C.I.C.R. est claire : «ne jamais être associé à des manifestations publiques ayant pour objet de protester contre les mesures prises par tel ou tel gouvernement pour assurer l'ordre public sur son territoire ${ }^{1}{ }^{1}$. Une telle attitude lui vaut d'ailleurs des critiques. On lui reproche entre autres de ne pas utiliser le levier de l'opinion pour arrêter certains abus. Elle est pourtant la seule qui puisse permettre au Comité de sauvegarder le capital moral et le crédit dont il jouit auprès de tant de gouvernements.

[p. 122] Le second organisme que nous mentionnerons est la Fédération Mondiale des Anciens Combattants dont le financement de départ a été assuré par des sources américaines. Constituée à Paris en 1950 pour succéder à la Fédération Internationale des Anciens Combattants (1920) et au Rassemblement International des Anciens Combattants (1948), la Fédération groupe actuellement plus de 80 associations se répartissant entre une quarantaine de pays. Certaines d'entre elles sont elles-mêmes des fédérations: ainsi, l'Union Française des Associations de Combattants et des Victimes de Guerre qui adhère au nom de 56 associations. La Fédération compte aussi un membre international: la Confédération Internationale des Anciens Prisonniers de Guerre. Cet organisme affilié comprend des fédérations dans 5 pays européens. À l'exception de la Yougoslavie, aucun pays communiste ne prend part aux travaux de la Fédération Mondiale ${ }^{2}$.

L'un de ses objectifs est de défendre les intérêts matériels et moraux des anciens combattants et victimes de guerre. Dans cette perspective, il faut citer l'organisation à La Haye, en novembre 1958, d'une Conférence internationale sur la législation concernant les anciens combattants et victimes de guerre. Y ont participé des experts gouvernementaux de rang élevé (dont plusieurs directeurs de ministères), ainsi que des représentants d'organisations intergouvernementales. La Conférence a émis de nombreuses recommandations sur les pensions, la réadaptation, etc. Une autre de ses préoccupations est de lutter contre la guerre et, pour cela, de faciliter l'entente et la compréhension internationales. À ce souci se rattache, par exemple, la tenue en août 1958 à Royaumont, d'un cycle d'études sur les tendances culturelles et sociales en Occident et en Orient ${ }^{3}$.

Aux termes de ses statuts la Fédération «n'intervient que dans les affaires intéressant les relations entre les peuples et les nations » (art. II, alinéa final). Mais quand elle agit sur ce plan, c'est d'une manière qui ne laisse aucun doute sur son appartenance au monde occidental. On pourrait citer à ce propos plusieurs résolutions sans équivoque, adoptées à la huitième assemblée générale (Rome, avril 1959), sur la

1 Selon les termes d'un communiqué publié à la suite de démarches faites auprès du C.I.C.R. par des avocats parisiens venus lui demander d'assurer la protection des détenus algériens (Le Monde, 29 fév. 60). Sur la position des avocats, voir les documents présentés par Temps Modernes, févriermars 1960, pp. 1192-1229.

2 Sur la Fédération, voir l'étude de CAMPAIGNE (Curtiss), in Associations, septembre 1956, pp. 560-565.

3 Voir l'intéressant et copieux rapport (multigraphié) préparé par Jacques PEYREGA. 
réunification de l'Allemagne et le problème de Berlin, la Hongrie, le désarmement, etc. ${ }^{1}$.

La Fédération Mondiale (dont M. Vincent Auriol est président d'honneur) a reçu à l'occasion de sa huitième Assemblée, des messages de plusieurs hommes d'État et chefs de gouvernement, dont un assez [p. 123] chaleureux du maréchal Tito ${ }^{2}$. Elle estime avoir réussi à établir entre ses membres un "esprit commun » qui aurait exercé une influence notable en des périodes de grandes tensions : ainsi, en 1953, entre membres italiens et yougoslaves au sujet de Trieste ; en 1957, entre grecs et britanniques sur Chypre ; en 1959, entre autrichiens et italiens sur le Tyrol du Sud ${ }^{3}$. Il est difficile d'apprécier le poids effectif de telles solidarités : la Fédération semble portée à l'exagérer.

\section{b) PROTECTION DE LA FAMILLE}

$\underline{\text { Retour à la table des matières }}$

Voici maintenant un autre domaine : la protection de la famille. On citera d'abord l'Union Internationale des Organismes Familiaux. Constituée à Paris en 1947, pour établir en dehors de considérations de race et d'opinions, un lien entre tous les groupements qui travaillent au mieux-être des familles, l'Union rassemble actuellement près de 200 organismes (appartenant à une trentaine de pays) de nature diverse : associations familiales et groupes d'action sociale à but familial de nature privée, mais aussi, institutions semi-publiques et publiques (ministères et sections de ministères). Cette combinaison privé-public, sans être très fréquente, n'est pas exceptionnelle dans les associations étudiées par cet ouvrage ${ }^{4}$.

C'est là, en réalité, un point important. En obtenant l'affiliation de services gouvernementaux, l'Union s'assure un contact direct avec des éléments qui, dans leur pays respectif, exercent une influence considérable sur les conditions de vie des familles par l'orientation qu'ils donnent à la législation ainsi qu'à l'équipement social et éducatif. Or, elle possède déjà de tels membres dans une douzaine de pays (dont Allemagne, Belgique, France, Israël, Pays-Bas, République Arabe Unie, Suisse...).

1 Sur cette Assemblée, voir Le Monde Combattant, juin 1959. Voir aussi dans le numéro de février 1960 les pages réservées aux réfugiés tibétains, pp. 11-13 (« événements qui indigneront le monde entier »).

Le Monde Combattant, janvier 1960, p. 4.

Même revue, décembre 1959.

Sur l'U.I.O.F., voir l'étude de Robert BOUDET in Associations, janvier 1958, pp. 18-22. L'Union qui publie une revue trimestrielle Familles dans le Monde, a également édité de nombreuses et intéressantes publications parmi lesquelles nous citerons : Redécouverte de la famille à travers le monde; Études sur le logement familial ; Surfaces minima d'habitation; Modalités sociales et familiales des règles d'attribution des logements locatifs construits par la collectivité ou avec son aide, L'adaptation de programmes de construction de logements aux structures familiales; Les vacances familiales; Conditions de vie des familles de travailleurs ; Niveaux de vie et dimensions de la famille. 
L'Union a établi une Déclaration des droits de la Famille dont elle s'efforce de promouvoir les principes, spécialement par son activité, auprès des organisations intergouvernementales. Dotée de moyens matériels qui semblent appréciables, elle a pu préparer de nombreux congrès, conférences ou journées d'études sur les principaux problèmes d'ordre économique, social et psychologique, où l'avenir des familles se trouve engagé. L'une de ses réalisations originales est la création d'une « Commission des Conseils Matrimoniaux » (consultations matrimoniales, conciliation entre époux, préparation au mariage) ${ }^{1}$.

[p. 124] Dans un domaine voisin, on citera le Mouvement Mondial des Mères dont l'ambition la plus large est de promouvoir dans les diverses sociétés qui se partagent le monde, un ordre juridique, économique et social, capable de faciliter leur tâche. Le mouvement qui possède des membres dans une quinzaine de pays se préoccupe aussi d'exprimer la pensée des mères dans la vie internationale. Ainsi a-t-il pris position à plusieurs reprises sur des problèmes de politique internationale : respect des droits de l'homme ; lutte contre les préjugés et les discriminations ; action en faveur de la paix... (tenue d'un congrès sur " les mères au service de la paix »). Bien entendu, le mouvement intervient aussi souvent dans des questions d'ordre économique et social (par exemple, auprès de l'O.I.T. : déclaration, en mai 1952 à propos de la Convention internationale sur la protection de la maternité des travailleuses, etc.) ${ }^{2}$.

Beaucoup d'associations internationales s'occupent de l'enfance, en dehors du Bureau International Catholique de l'Enfance déjà cité. Il y a, en particulier, l'Union Internationale de Protection de l'Enfance, qui comprend environ 65 organisations membres appartenant à une quarantaine de pays. Son but est de venir en aide aux enfants dans la détresse, de contribuer à leur développement et de faire connaître dans le monde entier les principes de la « Déclaration des droits de l'Enfant ».

On se rappelle que, dès 1923, l'Union Internationale de Secours aux Enfants, dont la présente Union est issue, proclamait une Déclaration des droits de L’Enfant dite Déclaration de Genève. Le 10 novembre 1959, l’Assemblée générale des Nations Unies a adopté, en séance plénière, une nouvelle Déclaration qui vient, en cette matière, compléter la " Déclaration universelle des droits de l'Homme » : démarche particulièrement opportune si l'on considère que l'on attend d'ici 1975 deux milliards de naissances (dont $80 \%$ dans les pays sous-développés) ${ }^{3}$.

Le nombre des organisations qui s'intéressent à l'enfance est considérable. En 1956, le Comité d'Organisations Non-Gouvernementales auprès de l'U.N.I.C.E.F. (Fonds des Nations Unies pour l'Enfance), qui centralise tous les efforts intergouvernementaux accomplis sur ce plan, comportait 53 organisations ${ }^{4}$.

\footnotetext{
L'Union a publié une brochure relatant les premiers travaux de la Commission.

Pour un bref aperçu de l'action du mouvement, voir sa revue Nouvelles et Documents, $\mathrm{n}^{\circ} 12$, pp.

16-21.

On en trouvera le texte et un bref commentaire in Unicef, $\mathrm{n}^{\circ} 47$ (avril-juin 1960).

La liste en est donnée in Unicef. Résumé de son œuvre, Nations Unies, 1956, p 27.
} 
Actuellement, ce comité, qui possède une structure propre, réunit une soixante de membres.

Parmi les organismes de création récente, mentionnons l'Union Mondiale des Organismes pour la Sauvegarde de l'Enfance et de l'Adoles-[p. 125] cence, qui se spécialise dans le secteur de l'enfance inadaptée (coordination des efforts entrepris sur le double plan administratif et technique ${ }^{1}$. Signalons aussi l'existence d'une Association internationale des juges des Enfants ${ }^{2}$.

\section{c) AMÉLIORATION DE L’EXISTENCE}

\section{$\underline{\text { Retour à la table des matières }}$}

Nous voudrions citer maintenant quelques-unes des multiples associations qui, avec des fortunes diverses, luttent contre les "fléaux " sociaux ou s'efforcent de promouvoir des «causes » sociales. Le propre de ces activités est de s'attaquer à des intérêts puissants ou à des préjugés tenaces: on ne s'étonnera donc pas que leurs moyens matériels soient généralement réduits.

D'abord, la suppression de la prostitution et la répression de la traite des personnes. Il existe une Fédération Abolitionniste Internationale (fondée en 1875) et un Bureau International pour la Répression de la Traite des Personnes (créé en 1889) ${ }^{3}$. Il y a aussi une Société Anti-Esclavagiste, qui entend condamner l'esclavage sous toutes ses formes: elle possède environ 400 membres dans une vingtaine de pays. La S.D.N. avait consacré de grands efforts à la lutte contre ces fléaux. L'O.N.U. a repris la question, sans d'ailleurs arriver à des résultats positifs dans l'ordre de la prostitution. De même, malgré la création d'un comité ad hoc, elle n'a guère fait progresser la suppression de l'esclavage ${ }^{4}$.

Plusieurs associations se vouent à la lutte contre l'alcoolisme. On citera : Commission Internationale pour la Prévention de l'Alcoolisme (composée de personnes individuelles dans une trentaine de pays) Fédération Prohibitionniste Internationale (organisations et particuliers) Union Internationale contre l'Alcoolisme, qui groupe des membres de nature diverse (sociétés internationales, fédérations

1 La branche française en est l'Union Nationale des Associations Régionales pour la Sauvegarde de l'Enfance et de l'Adolescence. Voir, en particulier, dans sa revue, janvier-mars 1959, pp. 1-320, les actes du $\mathrm{X}^{\mathrm{e}}$ Congrès sur l'inadaptation juvénile en milieu rural qui ouvre de vastes perspectives sur un problème très mal connu.

Voir une étude de F. Lox sur cette association in Associations, août 1956, pp. 506-509.

Sur le Bureau, voir l'étude de L.D. POTTER in Associations, février 1954, pp. 77-79.

On trouvera un exposé des survivances de l'esclavage in GREENIDGE (C.W.W), Slavery, Londres, 1958. Sur l'action de l'O.N.U., voir l'ouvrage déjà cité The United Nations and the Promotion of the General Welfare, pp. 543-545 (trafic des personnes) et 766-770 (esclavage). Voir aussi FISCHER (G.), «Esclavage et droit international public », Revue Générale de Droit International Public, janvier-mars 1957, pp. 71-101 (critique de la Convention supplémentaire relative à l'abolition de l'esclavage, de la traite et des institutions et pratiques analogues). 
nationales, services gouvernementaux et particuliers) dans une trentaine de pays également. L'Union organise des congrès internationaux (le vingt-sixième s'étant tenu à Stockholm en août 1960). Il y a aussi l'Union Internationale pour l'Éducation AntiAlcoolique de la jeunesse, la Fédération Internationale des Cheminots AntiAlcooliques et l'Ordre International des Bons Templiers (dont la suppression du trafic de l'alcool n'est que l'une des préoccupations).

[p. 126] Sur le plan de la défense des « causes », on retiendra d'abord, étant donné sa signification sociale considérable, l'œuvre de la Fédération Internationale pour le Contrôle des Naissances. Fondée en 1948, elle se propose de répandre dans le monde entier les principes du birth-control dans la conviction que l'équilibre entre la population et les ressources du monde est la condition indispensable à une paix mondiale durable (attitude dans laquelle l'U.R.S.S. voit un néo-malthusianisme inhumain au service de l'impérialisme). La Fédération possède des organisations nationales dans 20 pays (mais non encore sous une forme officielle en France dont la législation interdit toute propagande, et même toute information en la matière) ${ }^{1}$. La Fédération dispose de plusieurs secrétariats régionaux (hémisphère occidental ; Europe, Proche-Orient et Afrique ; océan Indien ; Extrême-Orient et Australie). Cependant, ses ressources financières sont modestes (cinquante mille livres en 1957).

Autre orientation : le renforcement de la sécurité sociale. C'est la tâche propre de l'Association Internationale de la Sécurité Sociale qui remonte à 1927 (Conférence internationale de la mutualité et des assurances sociales). Constituée sous l'égide du B.I.T. (et d'Albert Thomas, le directeur général d'alors), l'Association travaille en étroite liaison avec cette organisation qui la fait bénéficier de ses services généraux. Elle rassemble (au nombre de plus de 140 dans une soixantaine de pays) instituts nationaux de sécurité sociale, caisses centrales d'assurance sociale, départements ministériels et mutualités. Elle a procédé, en particulier, avec le concours du B.I.T., à une vaste enquête internationale sur le coût de la sécurité sociale ${ }^{2}$.

Il ne servirait à rien d'allonger cette liste. On se limitera donc à citer encore trois organismes répondant à une telle inspiration. L'Institut International de l'Épargne qui, au service des caisses, se propose avec leur collaboration de multiplier le nombre des épargnants. S'appuyant sur environ 6000 organismes affiliés (dans une trentaine de pays), il utilise les méthodes classiques d'information et de propagande ${ }^{3}$. En second lieu, la Société Internationale de Défense Sociale dont le but est de protéger la société contre les criminels, mais aussi de sauvegarder les hommes du risque de tomber dans la criminalité. Groupant des juristes, médecins et sociologues, elle a entrepris des tâches variées (dont la création, au Vénézuéla, de l'Institut Interaméricain de Défense

1 Sur ce problème, dont de puissantes forces bloquent en France la solution, voir les deux ouvrages du Docteur LACROUA WEILL-HALLE, Le "planning» familial, Paris, 1959, et la Libre conception à l'étranger, $2^{\mathrm{e}}$ édition, Paris, 1960. Voir aussi SAUVY (Alfred), «La démographie devant la prévention des naissances », Maternité Heureuse, septembre 1960, pp. 1-9.

2 Sur cet organisme, voir une étude de Leo WILDNUN in Associations, octobre 1954, pp. 473-477. Parmi ses travaux les plus importants, voir le $4^{\mathrm{e}}$ rapport présenté à la $\mathrm{XI}^{\mathrm{e}}$ Assemblée générale (Paris, 1953), «Relations entre les institutions de sécurité sociale et le corps médical ».

3 Sur l'Institut, voir l'étude publiée dans Associations, juin 1946, pp. 385-390 par G. HAMM. 
sociale). Enfin, l'Union Internationale pour la Protec-[p. 127] tion de la Moralité Publique qui a pour objet de coordonner les efforts entrepris dans les différents pays en vue d'assurer le respect de la moralité publique et de lutter contre les atteintes aux bonnes mœurs.

Comme le note le Cartel Français d'Action Morale et Sociale, «la moralité publique est un sujet difficile ... Il lui faut se garder à la fois du zèle intransigeant de l'apôtre et de la passivité sceptique ${ }^{1}$. Cependant, dès qu'une tentative est faite en ce sens, elle conduit nécessairement à exercer une action sur les pouvoirs publics pour en obtenir les réglementations appropriées (publications destinées à la jeunesse, écrits et images pornographiques, publicité faite au crime, etc.). La lecture des travaux de l'Union atteste qu'elle tente de coordonner et de renforcer cette activité : on en trouve témoignage dans ses congrès, généralement triennaux (Cologne, mai 1955, «L'enfance et la jeunesse face à l'immoralité publique »; Fribourg, Suisse, juillet 1958, «L'opinion publique et la moralité publique ») ${ }^{2}$. Il reste ensuite aux membres de ces congrès à en faire circuler les conclusions dans l'opinion publique et surtout dans les milieux les plus utiles à toucher : législateurs et autorités publiques.

Rappelons maintenant les groupements qui s'occupent de la santé. L'un des plus importants d'entre eux est la Fédération Mondiale pour la Santé Mentale, créée à Londres en 1948, dans le but de reprendre l'œuvre du Comité International pour l'Hygiène Mentale (1931). Elle se propose d'encourager les peuples à atteindre un niveau de santé mentale aussi élevé que possible et coopère à cet effet avec les gouvernements et organisations internationales. Elle compte comme membres cinq associations internationales et une centaine d'organisations nationales ou régionales (privées et publiques) ${ }^{3}$.

Les organismes qui s'occupent de la santé sont nombreux ${ }^{4}$. Au début de 1958, un peu moins d'une cinquantaine entretenaient des relations consultatives avec l'Organisation Mondiale de la Santé (O.M. S.). Citons parmi eux : l’Association Médicale Mondiale qui rassemble des associations nationales dans plus de cinquante pays; la Fédération Dentaire Internationale; la Fédération Internationale Pharmaceutique ; la Société Internationale de la Lèpre ; la Société Internationale pour la Protection des Invalides...

Notons d'ailleurs que leur classement sous une rubrique unique est très contestable. Les uns sont de simples organisations de spécialistes qui se préoccupent

In Civisme et moralité publique (publication du Cartel).

Pour le compte rendu de ces Congrès, se reporter à la publication Bulletin de l'U.I.M.P. respectivement $n^{\circ} 6$ et 7 (pp. 5-139) et $n^{\circ} 10$ et 11 (pp. 3-135).

3 Voir l'étude du Dr T.A. RATCLIFFE sur la Fédération in Bulletin O.N.G., avril 1953, pp. 173-178. Voir également ROSE (A.M.) (ed.), Mental Health and Mental Disorder : a sociological approach, Londres, 1956, et BARUK (H.), La psychiatrie sociale, Paris, 1955.

4 L'ouvrage de GOODMAN (Neville M.), International Health Organizations and their Work, Londres, 1952, contient un chapitre sur l'activité des organisations « volontaires » en cette matière. Voir aussi in Les dix premières années de l'organisation mondiale de la Santé, Genève, 1958, les informations données pp. 141-145 et 515. 
volontiers de la défense des intérêts de leurs mem-[p. 128] bres (encore que le plus souvent cette défense intervienne au plan national). À ce titre, on pourrait les rapprocher des Internationales Professionnelles. D'autres répondent davantage à la notion sociale choisie comme critère de cette rubrique (ainsi, l'Union Internationale contre le Cancer et celle contre la Tuberculose qui, l'une et l'autre, s'efforcent d'établir des liaisons entre les efforts scientifiques accomplis sur le plan national, de poursuivre des campagnes d'éducation populaires).

Si l'on ajoute à ce tableau les organisations s'occupant des réfugiés, on aboutit à un ensemble imposant. Pourtant l'exploration faite ici ne donne qu'une idée médiocre de la richesse du sujet. Ainsi, n'a-t-on pas mentionné l'œuvre des Fondations américaines qui interviennent souvent, et parfois de façon massive, dans ce secteur des relations humaines ${ }^{1}$; mais il n'est pas rare que leur activité déborde sur le terrain de la lutte idéologique et de la résistance au communisme. De même n'avons-nous pas mis suffisamment en lumière le rôle joué par les femmes et leurs organisations en ce domaine ${ }^{2}$. C'est ainsi que, parmi les objectifs du Conseil International des Femmes (dont les ressources financières sont d'ailleurs très limitées), figure la consultation des membres sur l'action à entreprendre " pour promouvoir le bien de l'humanité, de la famille et de l'individu ». Citons également l'Internationale de la Porte Ouverte pour l'Émancipation Économique de la Travailleuse (fondée en 1929), en vue d'obtenir que toute femme ait la liberté de travailler et qu'elle soit protégée en tant que telle aux mêmes titres que l'homme, ainsi que l'Union Mondiale des Femmes Rurales qui s'efforce d'améliorer les conditions de travail et de vie de ses membres ${ }^{3}$.

\section{MOUVEMENTS DE DÉVELOPPEMENT MORAL}

Retour à la table des matières

Les termes choisis pour délimiter cette rubrique sont intentionnellement larges : souplesse indispensable si l'on considère l'extrême variété dans les conceptions et les ambitions des organismes qu'il s'agit de présenter. Un trait les unit pourtant : même si plusieurs ne sont pas techniquement «partisans » tous sont proches de la vie publique et de l'engagement politique (défendant par exemple une forme de civilisation et

1 Voir notamment ANDREWS (F. Emerson), Philanthropic Foundations, New York, 1936 (étude d'ensemble des fondations américaines qui, en 1953, disposaient d'actifs d'un montant de 4,5 milliards de dollars et ont distribué 371 millions : on sait qu'une partie de ces ressources est dépensée à l'étranger).

2 Ce problème est spécialement important dans les pays sous-développés. Voir la publication de l'Institut international des civilisations différentes, Le rôle de la femme dans le développement des pays tropicaux et subtropicaux, Bruxelles, 1959 et Femmes africaines. Témoignages de femmes du Cameroun, du Congo belge... réunies à Lomé par l'Union Mondiale des Organisations Féminines Catholiques, Paris, 1959.

3 Sur cette association, voir l'étude de Mrs John BELL, Bulletin O.N.G., mars 1953, pp. 103-108. 
d'organisation sociale vis-à-vis d'une autre). Or chacun sait que les choix politiques comportent nécessairement référence explicite [p. 129] ou implicite à une morale, à une conception de l'homme et des relations humaines : constatation banale, mais qui nous semble, en tout cas, légitimer le titre retenu.

\section{a) COMBAT CONTRE LES PRÉJUGÉS RACIAUX}

\section{Retour à la table des matières}

Nous partirons de la lutte contre le racisme sous ses formes multiples (en particulier le combat contre les discriminations et appels à la haine à l'encontre des juifs et hommes de couleur). Cette ligne d'action se rattache directement à plusieurs des activités déjà étudiées, surtout à celles des grandes organisations juives et des mouvements de libération coloniale. Mais elle s'exprime également en des formules d'orientation différente.

Signalons d'abord l'existence d'organismes spécialisés tels que l'Union Internationale Antiraciste fondée en 1944 en vue de combattre, sur une «base apolitique », le racisme et toutes les formes d'oppression ${ }^{1}$. Ou encore la Ligue Internationale contre le Racisme et l'Antisémitisme fondée en mars 1927 (avec l'appui initial d'Édouard Herriot, Léon Blum, Léon Jouhaux, Albert Einstein, Romain Rolland, Séverine, Thomas Mazaryck, Édouard Benès, etc.) pour « lutter contre la haine des races et l'intolérance, pour la paix entre les hommes et les peuples ». La Ligue comptait avant 1940 de nombreuses sections nationales qui furent en plusieurs cas décimées par la guerre. Aujourd'hui, sa section française est en rapport avec plusieurs autres organisations (comme la Ligue pour la Tolérance au Danemark, l'Association des Hommes de Couleur au Brésil, le Congrès des Peuples d'Orient au Japon, la Ligne pour les peuples en Grande-Bretagne, etc.). Ce rassemblement, dont les éléments ne paraissent unis que par des liens très souples, toucherait environ 400000 personnes (dont près de 20000 pour la France).

Ces associations groupent, sans les distinguer d'ailleurs, deux séries de membres : les uns menacés par les excitations et les mythes qu'il s'agit de détruire, les autres qui n'en seraient pas directement affectés (au moins pour l'immédiat) et adhèrent sur le fondement de convictions morales. Dualité qui, au plan conceptuel, complique les problèmes de classification. Si l'on en juge par les structures existantes, il ne semble pas facile d'établir et de faire vivre à l'échelle internationale des mouvements spécialisés contre le racisme (situation qu'explique, au moins partiellement, la variété des formes revêtues par cette attitude, [p. 130] dans les diverses cultures nationales). Par contre, il est aisé de constater que des organismes, nationaux par la composition, étendent leurs préoccupations à des phénomènes situés hors des frontières : en France, l'activité de la L.I.C.A. et du Mouvement contre le Racisme et

1 Qui paraît être en sommeil ne figurant plus sur l'édition 1958-59 du Yearbook of International Organizations. 
l'Antisémitisme pour la Paix (M.R.A.P.) illustre cette universalisation de la lutte ${ }^{1}$. Au total, la liaison internationale entre les efforts antiracistes paraît résulter davantage d'une commune aversion, que d'une structure d'encadrement bien établie.

Une seconde forme de lutte ouverte résulte justement des positions prises à ce sujet par des groupements dont le combat contre les préjugés raciaux n'est pas l'objectif principal. Beaucoup considèrent pourtant comme de leur devoir d'apporter une contribution à cette lutte, spécialement dans l'ordre de l'élimination des pratiques discriminatoires. Une manifestation de ce courant fut la réunion à Genève (mars-avril 1955), sous les auspices des Nations Unies, d'une centaine d'associations désireuses de procéder à un échange de vues sur les méthodes les plus propres à s'opposer aux mesures de discrimination, les moyens de coordonner les efforts déployés et la possibilité d'arrêter des programmes et objectifs communs ${ }^{2}$.

En dépit de cette volonté, les tendances à la discrimination raciale subsistent et en premier lieu, l'antisémitisme: aucune des thèses émises pour expliquer cette persistance n'est pleinement satisfaisante ${ }^{3}$.

1 Comme le montre la lecture de leurs journaux Le Droit de Vivre pour la L.I.C.A. et Droit et Liberté pour le M.A.A.P. Voir en particulier dans le numéro de juin-juillet 1960 de ce dernier le compte rendu de la journée nationale contre le Racisme tenue le 29 mai. Voir aussi la brochure (publiée en annexe au $\mathrm{n}^{\circ} 184$ de ce journal), contenant les rapports et exposés présentés à la Journée de 1959. Pour le M.R.A.P., l'antiracisme s'inscrit dans le cadre d'une préférence politique nettement affirmée, l'anti-sémitisme néo-nazi étant, selon lui, «l'auxiliaire d'une politique revancharde et belliciste ».

2 Sur cette réunion, voir l'étude de G.P. SPEECKAERT in Associations, avril 1955, pp. 212-220.

3 Sur les aspects les plus récents de l'antisémitisme, voir "Antisémitisme 1960 " in Évidences, janvier-février .1960, pp. 1-25. Voir aussi les numéros de Le Droit de Vivre (1 $1^{\mathrm{er}}$ février 1960) et Droit et Liberté (janvier 1960) qui leur consacrent d'amples développements. Au cours des dernières années, plusieurs travaux de grande valeur ont été publiés sur l'antisémitisme et la question juive. Mentionnons à titre indicatif : ACKERMAN (Nathan W.), JAHODA (Marie), Antisemitism and National Disorder. A Psychoanalytic Interpretation, New York, 1950 ; SARTRE (Jean-Paul), Réflexions sur la question juive, Paris, 1954 ; LOVSKY (F.), Antisémitisme et mystère d'Israël, Paris, 1955 ; LOEWENSTEIN (R.), Psychanalyse de l'antisémitisme, Paris, 1952 ; POLIAKOV (L.), Du Christ aux Juifs de Cour : Histoire de l'antisémitisme, Paris, 1955 ; BYRNES (R.F.), Anti-Semitism in Modern France. The Prologue at the Dreyfus Affairs, N. Brunswick, 1950 ; ISAAC (Jules), Genèse de l'antisémitisme. Essai historique, Paris, 1956 et Jésus et Israël, nouvelle édition, Paris, 1959 ; NANTET (Jacques), Les Juifs et les nations, Paris, 1956 ; GYGES, Les Israélites dans la société française, Paris, 1956 ; AUBERY (Pierre), Milieux juifs de la France contemporaine à travers leurs écrivains, Paris, 1957 ; JEHOUDA (Josué), L'antisémitisme. Miroir du monde, Genève, 1958. Pour une étude du racisme et spécialement des « mythes raciaux », on se reportera à l'ouvrage collectif d'exceptionnelle valeur, publié par l'Unesco, Le racisme devant la science, Paris, 1960. 


\title{
b) PROMOTION DES DROITS DE L'HOMME
}

\author{
$\underline{\text { Retour à la table des matières }}$
}

On signalera ensuite le cas des organisations dont l'objectif est la protection et la promotion des « Droits de l'Homme ». Les Nations Unies elles-mêmes ont déployé une grande activité dans cette direction, le point de départ en étant l'adoption par l'Assemblée générale, en date du 10 décembre 1948, d'une « Déclaration universelle des droits de l'Homme ${ }^{1}$. D'une façon générale, beaucoup d'organisations internationales privées ont apporté un concours à la réalisation de ce programme qui, sur le plan des conséquences pratiques, est resté très en deçà des espoirs de ses initiateurs. Participant avec assiduité aux travaux des divers organes intéressés de l'O.N.U., elles ont tenté d'agir aussi sur l'opinion publique mondiale. Le chairman de la Ligue Internationale des Droits de l'Homme ${ }^{2}$ a clairement défini la situation en qualifiant la période 1948-1957 de décourageante si l'on considère les [p. 131] résultats effectifs obtenus, mais d'encourageante quant à la dénonciation des périls et la formulation des principes ${ }^{3}$.

L'un des meilleurs moyens de la protection des droits de l'homme est la sauvegarde de la règle de droit ou, si l'on préfère, l'affirmation et la défense de la primauté du droit. Parmi les organismes qui s'attachent à cette mission, on retiendra la Commission Internationale de Juristes (fondée en juillet 1952 à Berlin-Ouest lors d'un congrès international). La Commission se compose d'un petit nombre de personnalités (limité à 25 par les statuts et choisies pour leurs qualifications individuelles) : elle s'appuie sur des sections nationales ou groupes de travail qui, selon ses déclarations, lui permettaient de bénéficier de l'appui de 36000 juristes à travers le monde.

L'ambition de cet organisme a été confirmée et précisée au cours d'un Congrès international de juristes tenu à New Delhi en janvier 1959, qui adopta une déclaration sur la primauté du droit, "principe dynamique », et une série de conclusions sur le principe de la légalité (dans ses rapports avec le législatif, l'exécutif et la procédure

1 Pour une appréciation critique de cette tentative, MOSKOWITZ (M.), Human Rights and World Order. The struggle for human rights in the United Nations, New York, 1958. Sur les efforts en Europe qui ont abouti en septembre 1958 à l'institution d'une Cour pour la Protection des Droits de l'Homme, Essai sur les droits de l'homme en Europe (première série)... sous la direction et avec un avant-propos de Robert PELLOUX, Turin, 1959. Également ROBERTSON (A.H.), «The European Court of Human Rights », International and Comparative Law Quarterly, avril 1955, pp. 396-403. Consulter également European Commission of Human Rights. Commission Européenne des Droits de l'homme, Documents and / et décisions 1955-1956-1957, La Haye, 1959.

2 La Ligue Internationale des Droits de l'Homme a été fondée en 1941 à New York où son siège reste fixé. Elle comprend des membres individuels (un millier environ) et 31 organisations affiliées appartenant à 22 pays. Son budget annuel est de l'ordre de 6000 dollars. Il existe aussi une Fédération Internationale des Droits de l'Homme créée à Paris en 1921 et dont le siège est dans cette ville. Elle a des sections affiliées dans 6 pays Européens et possède aussi des groupes d'exilés (Espagne, Sud-Vietnam).

3 R. BALDWIN in « Some Techniques for Human Rights », Associations, août 1957, pp. 466-469. 
pénale.). L'une des idées de base de la Commission est que cette primauté ne saurait être instituée et sauvegardée sans l'existence d'une Magistrature et d'un Barreau indépendant ${ }^{1}$. Dans cette perspective, elle a décidé d'organiser à Lagos, en janvier 1961, un congrès de juristes africains sur le thème général suivant: "L'activité gouvernementale, la sécurité de l'État et les droits de l'homme » ${ }^{2}$.

La Commission s'attache à mettre son programme en pratique par la recherche des cas où de tels principes sont systématiquement violés, voire même éliminés, et la dénonciation publique des procédés d'injustice. Son effort rejoint ainsi, mais par d'autres moyens, certaines actions du C.I.C.R. (troubles internes). Au sommaire des derniers numéros de son Bulletin, figurent des études qui expriment l'orientation de cette activité. Elles concernent généralement les pays coloniaux (Algérie, Kenya, Nyassaland), les pays communistes (Allemagne de l'Est, Tchécoslovaquie, Tibet), les régimes de dictature (Espagne), les discriminations et persécutions raciales (Afrique du Sud). Si la Commission est attentive à dénoncer les abus, elle prend acte des mesures qui ont pour effet d'améliorer le respect de la légalité (par exemple, la réforme du droit pénal en Union soviétique, les décisions de la Cour suprême des États-Unis à propos des droits individuels). Elle dénonce avec vigueur les procès où sont méprisés ou sacrifiés les droits de la défense [p. 132] (procès de trahison en Afrique du Sud, procès et exécution des partisans de Battista à Cuba, procès de Bagdad devant le Tribunal du Peuple, procès des étudiants de Dresde ....) ${ }^{3}$.

Il est difficile d'évaluer le retentissement d'organismes de ce type tant sur l'opinion publique que sur les décisions des gouvernants. La Commission exerce presque certainement une influence sur ceux qui sont directement associés à ses travaux ou en suivent les résultats. Or il s’agit souvent de personnalités importantes ou détenant des postes de responsabilité dans leur pays respectif. C'est là un moyen d'intervention non négligeable. Mais, en un pareil domaine, l'action pour la légalité se heurte très vite aux exigences de la politique et de la raison d'État. On a le sentiment que, dans l'état actuel du monde, la dénonciation d'abus auprès de l'opinion et la réalisation de démarches auprès des gouvernants, ne sont jamais totalement inutiles (les secondes ayant parfois plus d'efficacité auprès des gouvernements tenant à leur réputation, du moins si elles sont accomplies de façon discrète).

Encore qu'elle diffère de l'organisation des juristes par l'esprit et les méthodes de travail, on mentionnera la Commission Internationale contre le Régime Concentrationnaire dont l'objectif est de dénoncer l'existence des camps de concentration et des camps de travail forcé, pour en obtenir l'abolition. Fondée par

1 On en trouvera le compte rendu in Revue de la Commission internationale de juristes, printempsété 1959, pp. 3-57. Voir dans le même numéro un important article de K.W. GREENAWALT sur «Les aspects juridiques des libertés civiles et politiques aux États-Unis et leur évolution récente » (pp. 95-162). Voir aussi dans le numéro printemps-été 1958 une intéressante note de G. DOBRY, « Interception de communications téléphoniques. Étude comparée », pp. 339-358.

Nouvelles de la C.I.J., septembre-octobre 1960.

Voir en particulier les derniers exemplaires de ce Bulletin ( ${ }^{\circ} 7$ à 10$)$ qui portent tous sur « divers aspects de la légalité ». Le $\mathrm{n}^{\circ} 5$ donne (pp. 20-37) des indications sur l'organisation de la Commission et les groupes nationaux. 
des associations nationales d'ex-déportés politiques des camps nazis, elle s'est rendue célèbre par ses études sur le phénomène concentrationnaire dans le monde communiste ${ }^{1}$. La Commission s'est également attaquée à toutes les manifestations de cette tendance dans les pays occidentaux (et sur ce point, elle accomplit elle aussi avec des préoccupations différentes, un travail qui rappelle celui du C.I.C.R.). Ainsi a-t-elle effectué en janvier 1953, à la demande des syndicats tunisiens et avec l'autorisation du gouvernement français, une étude minutieuse sur les conditions de la détention politique en Tunisie (dont les résultats ont été publiés dans un Livre blanc) ${ }^{2}$. Elle a fait de même des missions d'enquête en Algérie ${ }^{3}$.

Quelques mots enfin de la liberté de la presse. Nous citerons à cet égard l'Institut International de la Presse, fondé à Zurich en 1951. Son but déclaré est de promouvoir et sauvegarder cette liberté qui inclut le libre accès aux informations et leur libre distribution, la libre publication des journaux, la libre expression des opinions. L'institut se compose de membres individuels, assumant des fonctions de responsa[p. 133] bilité dans la politique rédactionnelle de journaux, ou associés à cette activité (chiffre des adhérents voisin d'un millier).

L'une de ses enquêtes les plus caractéristiques est une analyse des pressions des autorités sur la presse: pressions découlant de la loi, mais aussi, pressions économiques et politiques ${ }^{4}$. L'étude qui portait sur les pays non communistes a souligné l'intensité des pressions subies (découlant plus souvent d'un abus d'autorité de la part des pouvoirs publics que d'un principe foncièrement hostile à la liberté des journaux). L'Institut s'est également préoccupé de la situation de la presse dans les États autoritaires ${ }^{5}$.

La sauvegarde de la liberté de la presse constitue aussi l'un des objectifs de la Fédération Internationale des journalistes qui, par exemple, lors de son dernier congrès (mai 1960), a protesté contre les atteintes portées à ce droit en Turquie et dans l'Union sud-africaine. À cette occasion, la F.I.J. a maintenu son refus de toute coopération avec les organisations de journalistes communistes.

1 Voir en particulier Livre blanc sur le travail forcé et les institutions concentrationnaires dans la République populaire de Chine, 2 vol., Paris, 1957-58 Voir aussi BARTON (Paul), ROUSSET (David), L'institution concentrationnaire en Russie (1930-1957), Paris, 1959.

2 Les livres blancs concernant les enquêtes sur l'U.R.S.S., l'Espagne, la Grèce et la Tunisie ont été publiés en un seul volume sous le titre The Regime of the Concentration Camp in the Post-War World, 1945-1953.

3 La Commission a rendu publiques ses conclusions sur l'Algérie dès juillet 1957. Voir dans sa revue Saturne, août-septembre 1957, pp. 110-117, une déclaration sur les conditions de la détention politique. Voir également le récit d'une autre mission d'enquête sous la signature de Louis MARTIN-CHAUFFIER, "Journal de voyage en marge d'une enquête », Saturne, octobrenovembre 1957, pp. 5-10 et décembre 1957, pp. 7-16.

$4 \quad$ Les pressions du pouvoir sur la Presse, Zurich, 1955.

5 La presse dans les États autoritaires, Zurich, 1959. L'Institut a fait entrer dans son enquête les pays communistes, mais aussi d'«autres régimes autoritaires» (Espagne, Portugal, divers pays d'Amérique latine, Égypte, Chine nationaliste et Sud-Vietnam). 


\section{c) DIFFUSION D'IDÉOLOGIES}

\section{$\underline{\text { Retour à la table des matières }}$}

Venons-en maintenant aux organisations qui professent et défendent ouvertement une idéologie. Elles sont nombreuses et il est permis de s'interroger sur le quantum d'efficacité de certaines d'entre elles (par exemple, l'Union Internationale de l'Humanisme et de l'Éthique, qui a été fondée en 1952 pour propager l'humanisme éthique et scientifique, et manifeste le souci d'améliorer la condition humaine...). Le Mouvement International pour l'Union Atlantique semble plus efficace, ne serait-ce que pour les appuis que son président (M. Clarence Streit) est parvenu à acquérir au Congrès des États-Unis : récemment, une résolution y a été présentée invitant cette assemblée à se prononcer sur la convocation d'une conférence extraordinaire qui examinerait les moyens de transformer l'Alliance Atlantique en une véritable Union. Deux exemples viennent immédiatement à l'esprit que l'on se bornera à citer ayant l'intention d'en faire plus loin l'étude détaillée: la Fédération Mondiale des Associations pour les Nations Unies qui entend être un «mouvement des peuples pour les Nations Unies », et les divers mouvements qui tentent de diffuser l'idéologie européenne.

L'un des mieux connus de cette catégorie, est celui qui porte le titre de Réarmement Moral. Récemment, Temps nouveaux (Moscou) stigma-[p. 134] tisait les « charlatans » qui l'animent et présentait sa dernière brochure Idéologie et coexistence comme le «rejeton littéraire né de l'union incestueuse d'une secte religieuse, de la police et des services d'espionnage de l'impérialisme américain ${ }^{1}{ }^{1}$. Voici quelques années, un évêque belge a écrit un livre pour justifier l'interdiction faite aux fidèles de toute participation au Mouvement, en raison des dangers qu'il recèle pour l'intégrité de la foi catholique ${ }^{2}$. Dès lors, comment situer sur l'échiquier de la politique internationale un groupement qui suscite de telles controverses?

Un point est hors de doute : le R.A.M. dispose de moyens matériel sérieux. La brochure qui a provoqué les injures de Moscou a été publiée en 18 langues et à plus de 15 millions d'exemplaires. En Suisse, par exemple, elle a été distribuée gratuitement dans chaque foyer du pays. Le Mouvement est en mesure de s'assurer dans la presse mondiale un accès qui a peu d'équivalents ${ }^{3}$. Il organise d'innombrables manifestations et semble disposer d'un ample crédit pour les frais de voyage (poste qui constitue un handicap pour l'activité de la plupart des organisations

No 27 de 1960, pp. 28-30.

SULNES (Mgr Léon-Joseph), Que faut-il penser du réarmement moral ? Paris-Bruxelles, 1953.

À titre de spécimen, mentionnons un supplément spécial de huit pages à la Gazette de Lausanne (6 novembre 1959); une page complète du Times (9 juin 1960) sous le titre "A Hurricane of Common Sense »; dans The Economist (deux pages dans le numéro du 29 août 1959), sous le titre " The Wrong Way and the Right Way »; dans la Tribune de Genève (19 décembre 1959), une page sous le titre " Il existe une solution », etc., etc. 
« volontaires »). D'où vient cet argent ? Si l'on en croit les publications officielles, le R.A.M. aurait progressé "grâce aux sacrifices de ceux qui croyaient en sa mission $"{ }^{1}$. La notice publiée dans le Yearbook of International Organizations mentionne laconiquement : sous la rubrique des ressources financières : " dons ». Sont-ce les innombrables apports de gens modestes, ou les donations plus substantielles de grands organismes privés ou de services gouvernementaux ?

Le Réarmement Moral n'est pas un groupement possédant des associations membres. Il est comme tel, juridiquement organisé (les Anglo-Saxons disent « incorporé ») dans 7 pays (Allemagne, Canada, États-Unis, Pays-Bas, Royaume-Uni, Suède, Suisse), et possède deux centres d'enseignement : Caux (Suisse) et Mackinac Island (E.-U.).

Nous n'évoquerons pas ici, après tant d'autres, son développement historique dont la présentation varie selon les sources. Dans les exposés de type apologétique, on le fait volontiers remonter à 1921-22, époque à laquelle M. F. Buchman commença à constituer à Oxford des équipes de discussion. Mais c'est seulement en 1938 que se concrétisa le projet de créer un vaste mouvement de rénovation spirituelle à l'échelle mondiale (sur le fondement des quatre critères moraux absolus : honnêteté absolue, pureté absolue, désintéressement absolu, amour absolu) ${ }^{2}$. Il présente aujourd'hui son idéologie comme la seule alternative au [p. 135] Communisme. Réarmement ou communisme : «Il nous faut choisir » ${ }^{3}$. Accepter de s'enfermer dans ce dilemme, ou même d'en discuter, serait tomber dans un piège qu'un minimum de culture et d'esprit critique permet généralement d'éviter. Sans être obligé pour autant d'accepter les dogmes de la philosophie marxiste de l'histoire, on peut se borner à dire que les choses ne sont pas si simples.

Le seul point dont nous ayons à traiter ici est celui de l'action effective du Mouvement sur les affaires mondiales. Or, de ce point de vue, une surprise attend le commentateur : l'ampleur des succès que le R.A.M. revendique, les dimensions de l'influence qu'il se déclare en mesure d'exercer. Donnons-en un exemple qui concerne l'Europe : il aurait contribué à sauver le continent, en jouant un rôle majeur dans la réconciliation entre l'Allemagne et la France, en ouvrant la voie du miraculeux redressement de l'Allemagne, en facilitant l'aboutissement des négociations économiques européennes ${ }^{4}$. De même aussi, c'est en suivant la voie du R.A.M. que le

1 Voir la brochure La Fondation pour le Réarmement Moral qui donne quelques indications sur le mode de création et la structure juridique du Centre européen de Caux-sur-Montreux.

2 Sur lidéologie du Mouvement, on pourra consulter: MARCEL (Gabriel), Un changement d'espérance. A la rencontre du Réarmement Moral, Paris, 1958 ; HOWARD (Peter), Le monde reconstruit. L'histoire extraordinaire de F. Buchnam et du Réarmement Moral, Paris, 1951 ; CAMPBELL (Paul), HOWARD (Peter), L'Amérique a besoin d'une idéologie, Caux, 1957 ; BUCHMAN (Franck), Refaire le monde, Caux, 1958.

3 À l'heure actuelle, deux idéologies se disputent le monde ", lit-on dans la brochure Idéologie et Coexistence... « Le Réarmement moral ... le communisme. L'une ou l'autre doit l'emporter », le type de raisonnement n'est pas propre au Mouvement. Voir par exemple KRUTH (R.P. André), S.J., Le monde doit choisir : communisme-libéralisme-doctrine sociale chrétienne, Paris, 1954.

4 Exemple puisé dans le numéro 9 de M.R.A., Revue illustrée du Réarmement Moral. 
Kérala aurait renversé le régime communiste et Chypre trouvé une solution. Or ces prétentions sont appuyées par des déclarations d'hommes d’État à l'échelon le plus élevé : ce sont, par exemple, MM. Adenauer et Schuman qui se portent garants de son rôle en Europe.

S'il est une démarche indispensable en science politique, c'est de ne repousser $a$ priori aucun facteur dans le déclenchement d'un phénomène. Bien des activités, que l'on pourrait être tenté de négliger, finissent par exercer une influence selon des processus qui, pour la plupart, nous échappent encore. L'analyse montre par ailleurs qu'en dehors du jeu quasi-mécanique des forces, il faut aussi compter, à l'intérieur de limites que nous ne savons pas calculer, avec l'action des hommes. Dans cette perspective, il n'y aurait rien d'étonnant à ce que le R.A.M. - qui a parfaitement raison de souligner le poids de l'idéologie — ait eu sa part dans les événements de cet après-guerre, spécialement comme centre organisateur de contacts et de relations. Cela étant dit, il n'existe probablement pas de commune mesure entre les succès proclamés, selon des techniques publicitaires très au point, et les résultats effectivement acquis : tout bien pesé, il semble que la politique pontificale serait mieux fondée à revendiquer des victoires. Mais l'un des critères de la puissance réelle s'évalue au silence dont ses détenteurs savent entourer leurs gains.

[p 136] Depuis 1945, les pays européens non soviétisés ont évolué de façon différente à l'égard du communisme. En trois d'entre eux seulement (Finlande, France, Italie), il reste une force appréciable : ce phénomène différentiel, encore mal expliqué, ne saurait être ramené à l'activité d'un mouvement quel qu'il soit (et de ce point de vue il n'est que de rappeler le lamentable échec de Paix et Liberté). Il faudrait une grande naïveté pour s'imaginer que des conférences de stratégie idéologique soient susceptibles d'abaisser le pourcentage de voix communistes aux élections françaises (le général de Gaulle l'ayant, pour sa part, ramené aux élections de novembre 1958, de façon d'ailleurs provisoire, de 25\% des votants à 19\%).

Beaucoup d'Européens partagent sur de nombreux points (communisme, intégration européenne...), les vues défendues, sans originalité particulière, par le R.A.M. Allons plus loin : les communistes ne pourraient réfuter ses thèses sur le conflit Est-Ouest qu'à condition d'admettre que la coexistence doit s'accompagner d'un désarmement idéologique : ce qu'ils affirment précisément ne pas vouloir (la coexistence étant, d'après les déclarations des chefs soviétiques, un moyen de renforcer le camp communiste et d'accélérer la "décomposition » des sociétés « capitalistes »). Mais rien n'autorise à attribuer au R.A.M. la responsabilité, ou, si l'on préfère, le bénéfice de la résistance aux thèses marxistes de la plupart des pays industrialisés de l'Occident. Rien ne permet, non plus, d'affirmer que l'évolution de notre monde n'empruntera pas des voies différentes à la fois et du communisme et des thèses du Réarmement ${ }^{1}$.

Voir les commentaires présentés sur «l'Engagement politique du Réarmement moral », dans la Gazette de Lausanne, 5 janvier 1960. En particulier l'article du pasteur S. Dunuis, « Surmonter nos répugnances ». 
Parmi les groupements orientés vers le combat idéologique sur le plan international, nous citerons enfin le Congrès pour la Liberté de la Culture, dont l'activité se réclame d'un " Manifeste aux hommes libres » adopté à Berlin (juin 1950) par une assemblée d'écrivains et de scientifiques. Considérant que la liberté d'opinion est un des droits inaliénables de l'homme, ce texte la définit comme « la liberté pour chacun de se donner une opinion et de l'exprimer même et surtout quand cette opinion n'est pas conforme à celle des gouvernants ». Il exprime que les idées de "paix et liberté sont inséparables », que « le danger de guerre grandit dès qu'un gouvernement supprime les institutions représentatives et dépossède la majorité des moyens qu'elle a d'imposer sa volonté de paix ». Ce Manifeste est dirigé, sans équivoque contre les États totalitaires, « la plus grande menace que l'humanité ait dû affron-[p. 137] ter au cours de son histoire ». L'objet eu Congrès est de défendre et d'illustrer les principes ainsi formulés ${ }^{1}$.

On peut tenir pour significatives de la philosophie du Congrès, les trois motions votées lors de l'assemblée générale de 1955 à Milan: protestation contre la suspension du quotidien libéral El Tiempo de Bogota ; dénonciation de la campagne de persécutions frappant les penseurs chinois; expression de la solidarité des congressistes pour les intellectuels des régions sous-développées et désir d'apporter à ceux-ci une aide pratique qui facilite leur pleine participation à la vie culturelle mondiale. Notons un peu au hasard parmi les dernières prises de position publiques de cet organisme : protestation contre la politique d'apartheid dans les universités sudafricaines; publication d'un Livre blanc sur la révolution hongroise ${ }^{2}$; édition, à Calcutta, d'une brochure sur l'affaire Pasternak; déclaration contre l'arrestation d'intellectuels en Espagne; protestation contre l'expulsion d'Italie de plusieurs collaborateurs, français et suisses, de Danilo Dolci, etc.

Au cours des années récentes, le Congrès a organisé de nombreux séminaires. Citons en particulier une série centrée sur le thème général «Tradition et évolution. Les problèmes du progrès ». S'y sont intégrés un séminaire organisé à Karachi sur «L'Islam dans la société moderne » un autre à Ibadan (Nigeria) sur les possibilités d'introduire le gouvernement représentatif dans les sociétés non industrialisées ; un troisième à Tunis, sur «Éducation et société »; etc. Une dernière indication : le Congrès a organisé, en juin 1960, une conférence sur le progrès dans la liberté qui était en somme un débat sur les idéaux humains dans le monde moderne.

Le Congrès pour la Liberté de la Culture, qui a reçu d'importantes subventions de la Fondation Ford, n'a jamais fait mystère de ses positions au sujet du communisme. Mais spécialement au cours des dernières années, il s'est efforcé de donner à son action un caractère positif (notamment par les liaisons établies avec les pays sous-

1 Sur les premières années de l'activité du Congrès, voir sa brochure Cinq ans de présence, juin 1950-septembre 1955.

2 Sous le titre La révolution hongroise. Histoire du soulèvement d'octobre précédé de "Une révolution antitotalitaire ", par Raymond ARON, Paris, 1957. Le Congrès a également donné son concours à la préparation de La vérité sur l'affaire Nagy. Les faits, les documents, les témoignages internationaux, préface d'Albert Camus, Paris, 1958. 
développés). Il est probable que cette activité n'a pas été sans influence : il en reste en tout cas plusieurs témoignages intéressants ${ }^{1}$.

Or, pourrait sans aucun doute étendre l'inventaire à des organismes qui, de prime abord, semblent étrangers aux problèmes de la vie gouvernementale. Soit, par exemple, la Fédération Internationale des Pen Clubs. Se proposant de maintenir des relations amicales entre les écrivains de tous les pays, elle affirme ne poursuivre aucun but politique. [p. 138] Cependant elle ne peut éviter de prendre position sur des problèmes qui relèvent de ce domaine (ainsi, la collaboration avec les centres d'écrivains formés dans les pays autoritaires). Elle est aussi presque nécessairement amenée à se prononcer sur des questions qui soulèvent et passionnent l'opinion publique. Voir en particulier la récente démarche (lundi 4 juillet 1960), du Comité du Centre Français auprès du Garde des Sceaux, au sujet de M. Henri Alleg, le Comité déclarant qu'au cours du prochain Congrès international des Pen Clubs (août 1960, Rio de Janeiro), la France risque d'être mise en accusation à propos des toitures (Le Monde, 6 juillet 1960).

En définitive, il est de plus en plus difficile de se tenir à l'écart des affaires publiques dans un monde où culture et littérature deviennent souvent les armes du combat idéologique. Après tout, le $\mathrm{XXV}^{\mathrm{e}}$ Congrès d'orientalistes, tenu à Moscou en août 1960, s'est ouvert sans la présence... des Chinois qui, après avoir annoncé une importante délégation, auraient « changé d'avis » (Le Monde, 10 août 1960).

On achèvera ce tour d'horizon en rappelant le cas des organismes qui agissent pour l'établissement d'un gouvernement mondial ${ }^{2}$. Certains considèrent - on reviendra sur ce point - que les organisations internationales privées contribuent, dans leur ensemble, à l'édification d'institutions supra-nationales ${ }^{3}$. Mais il existe des groupements spécialisés. On a déjà cité le cas de l'Association pour un Parlement Mondial : en voici quelques autres.

D'abord le Mouvement Universel pour une Fédération Mondiale qui, fondé en 1927, combat en vue d'une autorité mondiale, ayant une sphère de juridiction constitutionnellement définie, votant des lois et disposant de moyens qui permettent

1 Voir en particulier Science et liberté. Rapports et débats du Congrès de Hambourg, juillet 1953, supplément de la revue Preuves, $\mathrm{n}^{\circ}$ 37, mars 1954 : Freedom and Responsibility : the scholar and society. A bulletin of the Committee on Science and Freedom, $n^{\circ} 13$, novembre 1959 ; Colloques de Rheinfelden, Paris, 1960 (sur les problèmes de la société industrielle). La démocratie à l'épreuve du XX ${ }^{\mathrm{e}}$ siècle, Paris, 1960 (Actes d'une réunion tenue à Berlin à l'occasion du dixième anniversaire de la fondation du Congrès). Ce dernier publie plusieurs revues : Preuves, Encounter, Forum (en langue allemande), etc.

2 La bibliographie est considérable : voir CLARK (G.), et SOHN (Louis B.), World Peace through World Law, Cambridge (Mass.), $2^{\mathrm{e}}$ édition, 1960 ; WRIGHT (W.) (ed.), The World Community, Chicago, 1948; BRINTON (C.), From many One, Cambridge (Mass.), 1948; FELLER (A.H.), United Nations and World Community, Boston, 1953; From Disorder to World Order, Marquette, University Press, 1956.

3 On trouvera plusieurs études sur leur rôle in BRYSON (L.), et al. (ed.), Foundation of World Organization : a political and cultural appraisal, New York, 1952. 
de les appliquer aux États comme aux individus ${ }^{1}$. Il est en rapport avec plusieurs autres organisations: les jeunesses Fédéralistes Mondiales, la République des Citoyens du Monde et le Conseil Mondial pour l'Assemblée Constituante des Peuples (sous la garantie morale duquel s'est placé en 1952 le Registre International des Citoyens du Monde). Si l'on en juge par la puissance de la vague nationaliste qui déferle aujourd'hui sur notre planète, on sera tenté de penser que le travail de ces hommes de bonne volonté n'a pas encore eu beaucoup d'influence.

On peut rapprocher de cet effort, l'activité de divers groupements qui, sur des bases diverses, tentent d'unir les hommes à travers les frontières ${ }^{2}$. Ainsi, le Mouvement International pour l'Union Fraternelle [p. 139] entre les Races et les Peuples, fondé en 1952 pour travailler à la compréhension universelle dans l'esprit de la Déclaration des droits de l'Homme. Ou encore la Fraternité Mondiale (créée en 1950), qui veut promouvoir la collaboration entre les peuples quelles que soient leur religion, leur race, leur nationalité et leur culture.

Sur un plan différent, on mentionnera l'Association Internationale des Lions Clubs créée à Dallas en 1917 et qui possède aujourd'hui des clubs dans 80 nations ; elle vise à susciter un esprit de compréhension et de respect mutuel entre les peuples par l'étude des problèmes de relations internationales. On ne saurait oublier dans cette énumération le Rotary International (fondé en 1905, total des membres 450000 dans une centaine de territoires) et son homologue féminin, l'Association Soroptimiste Internationale, créée en 1928. L'objet propre du Rotary est d'encourager « l'idéal de service » considéré comme base de toute entreprise honorable.

Il est hors de doute que ces organisations aboutissent à un renforcement et à une multiplication des contacts entre individus appartenant à des nations et, jusqu'à un certain point, à des civilisations différentes. Elles constituent un instrument pour la circulation et l'échange d'informations et d'idées (voir, par exemple, les organisations du Rotary qui, dans une même ville, sont représentatives de toutes les activités). À ce titre, elles sont l'un des éléments du cadre dans lequel s'extériorise et s'applique la politique mondiale. Nul n'a encore analysé le rôle ou simplement l'influence qu'elles sont susceptibles d'exercer dans l'aménagement des rapports avec les États (en tout cas, de façon très discrète). Il serait au surplus intéressant de rechercher l'appui

1 Sur le mouvement, voir l'étude de Ralph LOMBARDI in Associations, juin 1957; pp. 337-343. Voir aussi : FUCHS (L.H.), « The World Federation Resolution : a case study in congressional decision making », Midwest Journal of Political Science, août 1957, pp. 151-162 (qui analyse les effets de la pression des fédéralistes sur les membres du Congrès des États-Unis : conclusions réservées quant à l'efficacité de cette pression). Il a tenu son dernier congrès à Cologne (19-21 septembre 1960) sur les thèmes de l'«Ordre mondial » et du «Progrès mondial ». L'organisme français affilié au Mouvement est l'Union Fédéraliste Mondiale qui vient de créer une sorte de front commun avec la Fédération Nationale des Combattants Républicains : voir dans Monde Uni, juin 1960, le compte rendu de son $\mathrm{V}^{\mathrm{e}}$ Congrès principalement consacré au « renforcement des pouvoirs des Nations Unies».

2 De telles idées d'ailleurs ne sont pas nouvelles. Voir LEDERMANN (Laszlo), Fédération internationale. Idées d'hier. Possibilités de demain, Neuchâtel, 1950. 
qu'elles ont pu apporter à la diffusion, à travers le monde, des idéaux politiques et moraux de la civilisation anglo-saxonne (spécialement le Rotary).

Plusieurs groupements féminins peuvent enfin être rangés dans cette rubrique. Beaucoup ont été très actifs à l'O.N.U. et dans d'autres organisations intergouvernementales, notamment pour assurer la protection et la promotion des droits de la femme. En dehors du Conseil International des Femmes, déjà cité (ainsi que des associations catholiques, protestantes et paracommunistes déjà nommées), on mentionnera ici: le Comité de Liaison des Grandes Organisations Féminines Internationales (dont les moyens matériels paraissent très limités : secrétariat tenu de façon bénévole); l'Alliance Internationale des Femmes : droits égaux responsabilités égales (fondée en 1904 sous le titre d'Alliance Interna-[p. 140] tionale pour le Suffrage des Femmes.) ; l'Union Mondiale de la Femme pour la Concorde Internationale (mouvement entièrement consacré à la paix) ; la Fédération Générale des Clubs de Femmes (qui déclare grouper 11 millions de membres dans une soixantaine de pays), etc.

\section{OBSERVATIONS FINALES}

$\underline{\text { Retour à la table des matières }}$

Voici quelques remarques qui aideront à mieux comprendre l'esprit dans lequel ce tableau a été établi et à en mieux saisir la portée.

$1^{\circ}$ L'inclusion dans la liste des forces de pression est, cela va de soi, exclusive de tout jugement de valeur sur la qualité morale de l'effort entrepris. La science politique est neutre ou, du moins s'efforce-t-elle de l'être. Il est douteux que ses adeptes parviennent à réaliser cet idéal quand il s'agit d'apprécier la portée des phénomènes : et sans doute beaucoup de lecteurs feront-ils des réserves sans qu'elles soient nécessairement convergentes, sur les pages précédentes. Par contre, ce souci de neutralité est plus facile à observer au niveau de la simple signalisation.

On peut être choqué de voir mettre sur le même plan les mouvements d'émancipation coloniale et les grands trusts pétroliers; mais les uns et les autres pèsent sur la politique mondiale et le cours des affaires humaines. Dans certaines situations, leurs intérêts et attitudes s'opposent ; il arrive aussi que leurs lignes de conduite se rejoignent (par exemple, à l'égard de l’État légalement responsable du territoire contesté), les trusts pétroliers, tout comme les missions catholiques, étant fort attentifs, on l'a dit, à ne plus jouer la carte de la colonisation (du moins celle qui s'exprime par le drapeau).

Le comportement actuel des trusts miniers en Rhodésie du Nord (Rhodesian Selection Trust, Rhodesian Anglo-American...) offre matière à réflexion. Considérant que l'avenir appartient au nationalisme africain, ils n'hésitent, pas à lui donner des gages (non seulement participation aux dépenses pour le développement de 
l'instruction des autochtones mais encore appui à celles des formations politiques susceptibles de s'imposer lors de l'accession à l'indépendance). Le chairman de la Rhodesian Anglo-American n'a pas craint de déclarer publiquement $\left(31^{\mathrm{e}}\right.$ assemblée générale des actionnaires) que dans les États multi-raciaux le mérite individuel et non plus la couleur doivent constituer le fondement de l'accès [p. 141] aux droits politiques. Le calcul, dont on trouve l'analogue en d'autres régions du monde, s'inspire du désir de réaliser une division du travail : aux élites noires, la direction du gouvernement, aux trusts la responsabilité de l'exploitation minière. C'est un pari. Dans le cas évoqué, c'est aussi, probablement, la seule voie disponible.

Sur le plan des valeurs, il est permis de considérer avec sympathie les mouvements qui luttent contre les préjugés et discriminations ethniques ${ }^{1}$, ainsi que ceux qui veulent propager l'idée et les techniques du birth-control : les unes et les autres sont des mouvements de libération de l'homme. Pourtant, on n'a pas hésité, et on ne pouvait, le faire à les inclure dans ce tableau.

$2^{\circ}$ Autre motif d'insatisfaction pour le lecteur: l'inclusion dans notre liste de groupements dont le poids sur les affaires mondiales risque d'être faible, sinon insignifiant. Spécialement sous les rubriques 6 et 7 (mouvements d'inspiration humanitaire et de développement moral), une place a été faite à des organismes dont il n'est pas évident que l'action sur les décisions gouvernementales et intergouvernementales soit appréciable.

Gardons-nous, cependant, d'en décider a priori. L'opinion publique est un facteur qui, sous tous les régimes, exerce une influence sur les responsables. Or, à l'égard de certains problèmes, on voit s'affirmer les éléments d'une opinion mondiale dont les manifestations ne peuvent être ignorées dès qu'on analyse la conduite des acteurs de la vie internationale et, en particulier, le comportement des fonctionnaires internationaux. Dans cette perspective, il serait absurde d'exclure les « citoyens du monde " simplement parce qu'ils suscitent chez la majorité de leurs contemporains indifférence ou ironie. Nos outils d'appréciation sont trop grossiers pour justifier les éliminations systématiques.

L'analyse de la vie politique établit que tout groupe, même si ses missions apparaissent très éloignées du domaine public, est susceptible, à un moment quelconque, d'intervenir sur les mécanismes étatiques. Or nous vivons dans un monde cloisonné où la délivrance des visas d'entrée à une équipe de foot-ball étrangère a constitué, en plusieurs cas, une opération de nature politique ${ }^{2}$. Cette "politisation » de sphères d'activités que l'on tient habituellement pour privées, est le résultat de causes multiples parmi lesquelles l'action de plusieurs des groupes étudiés ici : elle

\footnotetext{
Combat dans lequel G.P. SPEECKAERT voit, ce qui est discutable, le « rôle commun » des O.N.G., Associations, mars 1955, pp. 140-141.

2 Il n'est pas inexact de dire que pour les États, et spécialement les pays communistes, une victoire aux Jeux Olympiques constitue un succès majeur dans la guerre froide. WASHBURN (J.N.), « Sport as a Soviet Tool », Foreign Affairs, avril 1956, pp. 490-499.
} 
accroît naturellement le nombre de ceux qui interviennent sur le plan gouvernemental ou intergouvernemental.

[p. 142] Dans ces conditions, on a peut-être eu tort de ne pas réserver une place aux associations internationales sportives, qui sont elles-mêmes d'une grande variété (Comité International Olympique, Union Cycliste Internationale...). Les relations du sport et de la politique mériteraient une étude attentive. En un sens, le premier, on vient de l'écrire, subit l'influence de la seconde (querelle des drapeaux entre les deux Allemagnes...). Mais à l'inverse, la compétition sportive n'est-elle pas, à quelque égard, facteur d'apaisement des rivalités idéologiques (l'« apolitisme » du sportif) ? Toutefois il reste possible que cette seconde tendance soit plus profonde sur le plan national qu'au niveau international.

$3^{\circ}$ Mais alors, notre tableau n'est-il pas très incomplet ? C'est incontestable et nul n'en saurait avoir mieux conscience que l'auteur lui-même. Trois facteurs au moins expliquent les lacunes que l'on y pourra relever.

D'abord, le caractère complexe de plusieurs mouvements qui ne permet pas de les ranger dans une rubrique bien précise. Prenons, par exemple, les associations d'enseignants, de professions libérales, etc. Elles sont, certes, à buts désintéressés, mais la plupart du temps leur activité comporte la défense des intérêts économiques de leurs membres, et la propagation de certaines valeurs. La Confédération Mondiale des Organisations de la Profession Enseignante relève de cette conception dualiste ${ }^{1}$. On ne traduirait pas la totalité de son inspiration en la classant simplement sous la rubrique du développement moral.

En second lieu, le degré inégal d'activité dont témoignent les associations internationales (souvent pour des raisons pécuniaires). Les difficultés subies entraînent d'ailleurs un taux de mortalité appréciable dans la catégorie. Selon une étude de l'Union des Associations Internationale ${ }^{2}$, on comptait qu'il s'était formé dans le monde jusqu'à la fin de 1954, 1709 organisations internationales non gouvernementales, l'ampleur du mouvement variant avec les époques, mais suivant une ligne ascendante (1850-1854, une association nouvelle ; 1900-1904, 61 ; 19501954, 319). C'est seulement à partir de 1875-1879 que s'affirme l'expansion de ce mode de relations. Encore qu'une analyse historique fasse défaut, il semble que le facteur initial de constitution ait été la défense de " causes » humanitaires et morales (y compris la défense de la paix). C'est seulement après 1900 que le motif syndical et professionnel prend de l'importance en ce domaine.

[p. 143] Or, au moment de l'étude, 1170 de ces organisations demeuraient en activité - ce qui traduit un taux de disparition de l'ordre de 30\%. Encore doit-on noter que diverses associations, sans s'éteindre juridiquement, n'ont en fait qu'une activité réduite (organisme « en veilleuse» ou « en sommeil »). Dès lors,

1 Pour une analyse de la Confédération, voir l'étude de G. CARR in Associations, août 1958, pp. 500506.

2 Les 1978 organisations internationales fondées depuis le Congrès de Vienne. Liste chronologique, avec une introduction par G.P. SPEECKAERT, Bruxelles, 1957. 
l'interprétation des données fournies par les annuaires doit s'effectuer avec prudence et on doit éviter de tenir pour des forces actives des organismes tout juste capables de fournir une fiche d'état civil : sans aucun doute, il s'agit là d'une proportion non négligeable de la catégorie.

Le renouvellement de cette classe est assuré, en permanence, par la création d'organismes dont l'ampleur accuse l'aptitude des «intérêts » à s'associer pour affronter les situations nouvelles. Durant les dernières années, le processus d'intégration européenne a entraîné la fondation d'un nombre important de groupes à activité centrée sur les six pays.

Ces traits de contenu inverse impriment à la catégorie des forces internationales une grande fluidité qui rend difficile d'en présenter un recensement qui soit d'actualité.

Enfin, dans certains cas, les lacunes de ce tableau traduisent une carence dans l'organisation du secteur considéré. Ainsi en va-t-il, par exemple, pour les consommateurs. La faiblesse de leurs groupements dans le cadre national est notoire (encore que la situation se modifie lentement) : elle retentit directement sur le plan international où, jusqu'à une époque récente, il n'existait pas d'organisme pouvant légitimement prétendre à assurer la représentation de leurs intérêts propres.

On peut certes mentionner le cas de l'Alliance Coopérative Internationale qui déclare rassembler 148 millions de membres. Lors de son $\mathrm{XX}^{\mathrm{e}}$ Congrès (Stockholm, 1957), elle décida d'entreprendre une action spécifique pour la défense du consommateur, en particulier, du point de vue de la santé. Une triple préoccupation s'est manifestée dans ce but : développer le champ et accroître l'efficacité de la législation visant à protéger les consommateurs; étendre les programmes d'information et d'éducation; élargir et rationaliser les recherches (création de laboratoires chargés d'analyser les additifs chimiques, les matières déterminées et l'emballage des denrées, les procédés physiques de traitement, etc.). Mais les coopératives jouent un rôle important dans la distribution commerciale et sont dès lors sujettes à des préoccupations de producteurs: ce qui leur ôte, au moins partiellement, l'indépendance requise pour assurer la défense des utilisateurs.

[p. 144] L'Organisation Internationale de Normalisation participe à la promotion de la consommation (certificats de conformité aux normes), mais si cette contribution est appréciable, l'organisme reste inspiré par des préoccupations industrielles et commerciales. Ce n'est pas le cas du Bureau International des Unions de Consommateurs. Fondé à La Haye en avril 1960, il s'applique à la réalisation d'essais comparatifs : c'est là un aspect important, mais spécial de la défense des acheteurs qui, dès lors, reste globalement embryonnaire sur le plan international.

N'oublions pas pourtant les organismes qui s'attachent aux aspects scientifiques de l'alimentation. Il arrive que leurs membres soient en mesure d'influencer certaines décisions gouvernementales. Nous signalerons en premier lieu l'Union Internationale des Sciences de la Nutrition fondée en 1946, notamment pour promouvoir des échanges d'information entre savants. Citons aussi la Société Internationale pour la Recherche sur l'Alimentation et les Substances vitales créée en 1954, en vue de lutter 
contre les maladies dites de civilisation (cancer, troubles cardiaques et circulatoires, caries dentaires, etc.) : l'idée des dirigeants du mouvement - contestée par d'autres médecins - étant que les conditions présentes de l'alimentation jouent un rôle majeur dans le déclanchement de ces affections.

L'Alliance Coopérative présente un trait original : parmi les grandes organisations non-gouvernementales, c'est l'une des rares qui comportent des membres de l'Est et de l'Ouest. Il en est résulté un état perpétuel de tension interne qui se révèle, actuellement, d'une grande acuité. La bataille s'est livrée sur plusieurs plans. D'abord, un effort des vieilles coopératives de l'Occident pour limiter l'ampleur de la participation des organismes communistes qui relèvent d'une inspiration et d'un mode de fonctionnement entièrement différents des schémas traditionnels. Les coopératives russes, bulgares, roumaines, tchécoslovaques et yougoslaves, qui appartenaient à l'Alliance avant la guerre, en sont restées membres : les partisans de leur exclusion demeurent minoritaires. Par contre, celle de plusieurs autres pays (Albanie, Allemagne de l'Est, Chine, Corée du Nord, Hongrie, Nord-Vietnam, Pologne) n'ont pas été acceptées (position confirmée par 810 voix contre 410 lors du Congrès tenu à Lausanne en octobre 1960). Un tel compromis, de nature boiteuse, permet tout au plus de sauvegarder les apparences de l'unité, disparue depuis longtemps dans les esprits.

[p. 145] Aujourd'hui, le combat s'intensifie à propos de la coopération dans les pays «non engagés » (sur 48 membres de l'Alliance, on n'en compte plus que 21 d’Européens). Il s'agit de savoir si dans ces sociétés le mouvement coopératif prendra la forme d'un réseau étatique de modèle soviétique ou conservera la tradition de selfgovernment en vigueur à l'Occident. Sous cet angle, les partisans de la coopération de type occidental viennent de subir une défaite au Ghana : la vieille organisation fondée par les Britanniques y ayant été liquidée et remplacée par un Conseil national qui semble se rapprocher du type russe ${ }^{1}$.

Au total, on observe sans surprise que cette lutte s'apparente à celle qui se livre au sein des diverses organisations intergouvernementales auxquelles participent des États communistes.

$4^{\circ}$ Un trait complique l'établissement du tableau : l'existence d'organismes qui, tout en étant juridiquement indépendants, se rattachent à un centre dont le but est d'inspirer leur activité et parfois de leur assurer des moyens d'existence. Tel est le cas notamment des «organisations annexes» du parti communiste (communisme international), des associations d'action catholique et, dans certaines limites, des

Il existe aussi une Guilde Internationale des Coopératrices : fondée en 1921, elle possède des sections dans une vingtaine de pays dont quelques États communistes (l'U.R.S.S. en particulier fournissant une large partie des membres) Sur l'idéologie coopérative, la référence de base est LAMBERT (P.), La doctrine coopérative, Bruxelles, 1959. L'auteur pour lequel « sans démocratie politique la doctrine coopérative n'est qu'un leurre », prend nettement ses distances à l'égard des pays communistes dans lesquels une "doctrine de libération» a abouti à "une pratique d'asservissement ». 
groupements protestants. Malgré des analogies, ces situations sont, à plusieurs égards, dissemblables. Le propre d'une " organisation annexe » qui fonctionne bien, est de déborder dans son recrutement, de la sphère des communistes proprement dits ; sinon elle n'aurait guère de raison d'être, le parti et ses services auxiliaires suffisant à mobiliser et à encadrer les énergies. En principe, les organisations de l'Église ne visent que les catholiques bona fide dont elles sont souvent (en l'absence éventuelle d'un parti catholique) le moyen primaire de rassemblement,

Or, on a cité ces groupements, spécialement ceux d'inspiration catholique et communiste, à propos du centre animateur ou coordonnateur. Démarche nécessaire si l'on veut apprécier la puissance respective des forces en présence. Afin d'éviter les redites, on n'a généralement pas rappelé ces mouvements dans les rubriques spécialisées où leur activité propre, réserve faite de l'élément moteur, conduirait à les situer : ainsi, n'a-t-on nommé dans la rubrique « développement moral » ni le Conseil Mondial de la Paix ni l'Union Internationale de la Presse Catholique. On n'a pas non plus signalé le Mouvement des Étudiants de Pax Romana dans le paragraphe correspondant. Le lecteur attentif ayant la possibilité de redistribuer les cartes, il n'en résultera, pensons-nous, aucun dommage sérieux pour la compréhension des choses.

[p. 146] Il y a cependant un risque plus subtil et plus sérieux : nous avons souligné les liens qui sont avoués ou éclatants. Mais il y a d'autres connivences plus discrètes, quoique finalement effectives. Tenant à des attaches partisanes ou confessionnelles, elles impliquent souvent des rapprochements, sinon même des alignements dont seules des analyses monographiques parviendraient à établir la substance et la portée généralement, de tels travaux ne sont pas encore disponibles.

Enfin, n'oublions pas les servitudes et les complaisances (au minimum les silences) qu'entraîne la dépendance financière. Plusieurs des organisations mentionnées dans la rubrique 7 (« développement moral ») ont été fondées et vivent encore avec de l'argent américain. Ne mettons pas nécessairement en doute la sincérité de leurs animateurs qui trouvent ainsi le moyen de défendre des positions auxquelles ils sont foncièrement attachés; mais, après tout, catholiques et communistes croient aussi en leurs idéaux.

Nous retrouvons ainsi la notion, déjà esquissée, d'une sorte d'internationale « occidentale » dont les grandes Fondations philanthropiques américaines seraient l'une des bases. Certes, les États-Unis sont une société pluraliste et de multiples incidents ont établi que les Fondations ne conforment pas toujours leur politique aux vœux du Département d'État (et encore moins à ceux de tous les secteurs du Congrès). Une telle "internationale » s'apparente dès lors bien davantage à une nébuleuse qu'à une organisation centralisée: les rapports y sont souples et changeants. Les distributeurs de fonds n'y sont même pas à l'abri des critiques des bénéficiaires de l'aide.

Ces réserves émises, le phénomène ne doit pas être ignoré. À toujours raisonner sur le «communisme international » ou l' «internationale vaticane », on risque d'oublier les efforts entrepris ailleurs pour promouvoir une situation globalement analogue: la différence n'est pas dans l'intention, mais dans l'ampleur des résultats 
obtenus. Malheureusement, nous ne disposons pas des pièces et éléments qui permettraient d'établir dès maintenant, avec certitude, un bilan comparatif.

$5^{\circ}$ Les organisations féminines fournissent un autre type d'entrecroisement des intérêts. Il n'existe pas dans ce secteur de centre unificateur comparable à ceux que l'on vient d'examiner. Cependant, un critère de l'ordre physique, que l'on pourrait traiter de pôle de rassemblement, intervient pour particulariser le recrutement. Comment classer ces phénomènes ?

[p. 147] Ces organisations sont diverses. Les unes ont été fondées pour soutenir des revendications propres à la femme (essentiellement l'égalité des droits sous ses diverses formes): il s'agit en somme d'aboutir à une complète égalisation de la condition des deux sexes. D'autres rassemblent des femmes qui ont obtenu l'assimilation et s'unissent, assez paradoxalement, sur la base de leur qualité féminine: Fédération Internationale des Femmes de Carrières Libérales et Commerciales ; Fédération Internationale des Femmes diplômées des Universités; Organisation Internationale des Femmes Chefs d'Entreprises. D'autres encore représentent des pièces tactiques dans un dispositif destiné à rassembler tous les adeptes d'une confession, les partisans d'une idéologie, etc.

Dès lors, de deux choses l'une. Ou l'on classe les organisations féminines en une rubrique déterminée : et l'on restreint arbitrairement les catégories spécialisées auxquelles chacune devrait être rattachée. Ou l'on affecte ce rattachement : mais on omet de faire apparaître la force du bloc féminin. L'hétérogénéité des associations constituées sur cette base a conduit à préférer ici la seconde solution. Admettons pourtant que la première conserve une justification : même quand elles accordent l'égalité des droits, nos sociétés demeurent, dans la plupart des cas, " masculines ».

Aux associations féminines, il faudrait ajouter, pour avoir une notion du rôle total des femmes, leur activité au sein des organisations mixtes. Il n'existe aucun document qui permette de l'évaluer avec certitude : cependant, plusieurs indices concordent pour suggérer que cette part est plutôt réduite.

$6^{\circ}$ On n'insistera pas sur l'extraordinaire variété des intérêts ou des attitudes qu'embrassent les forces internationales. La constellation de ces forces reflète pratiquement toute la gamme des relations humaines. On peut en dire autant pour les groupes nationaux et ajouter qu'à bien des égards, le dispositif international constitue simplement l'élargissement du modèle national. Cependant le passage de l'un à l'autre permet d'observer des dissemblances.

Il en est ainsi notamment quant à l'aptitude des divers secteurs économiques à s'organiser et à réaliser des pressions efficaces : plusieurs différences existent du plan national au niveau international. L'une, particulièrement visible, concerne l'agriculture. Elle est dans beaucoup [p. 148] de pays une force de premier plan : or l'action des groupes qui la représentent sur le plan International paraît, au total, peu efficace. Cette faiblesse était très nette au temps de la S.D.N. : il ne semble pas que la création d'une Agence spécialisée de l'O.N.U. (F.A.O.) ait vraiment transformé la situation. 
L'explication réside probablement dans le caractère généralement national des solutions données aux difficultés agricoles, dans la permanence des diversités structurelles de la vie rurale à travers le monde, dans la volonté des différents pays de réaliser une autarcie alimentaire ou de s'en approcher le plus possible. On pourrait présenter des remarques analogues à propos de divers secteurs professionnels (carrières libérales telle la médecine...).

Au contraire, l'interpénétration des intérêts à travers les frontières et la faculté de trouver aux problèmes nationaux des solutions d'esprit uniforme facilitent le développement de l'organisation internationale et en renforcent l'efficacité : ce fut souvent le cas pour la grande industrie (en particulier, cartels internationaux).

$7^{\circ}$ Autre similitude avec l'expérience interne: le rôle diviseur joué par les idéologies partisanes et religieuses dans l'organisation et la gestion de plusieurs intérêts. Si l'impossibilité de faire prévaloir le sens de l'intérêt commun sur la force de tels clivages s'observe sur le plan national, il semble que la rivalité s'accuse au niveau international. La Confédération Internationale des Syndicats Chrétiens témoigne de plus d'intransigeance à l'égard du communisme que la C.F.T.C. Situation facile à expliquer : il existe dans un pays donné, malgré les disputes idéologiques, diverses solidarités pacifiantes qui font défaut dans le contexte international.

Le secteur d'élection de tels combats est le syndicalisme où s'affirment à la fois les divisions religieuses et politiques (F.S.M. et C.I.S.L. à l'égard de la C.I.S.C., C.I.S.L. et C.I.S.C. à l'égard de la F.S.M.). La division politique est d'ailleurs fondamentale, la C.I.S.C. n'ayant sur tous les plans qu'une importance réduite. Un nouveau facteur de division pourrait bien apparaître si le souhait d'un syndicalisme panafricain, d'inspiration neutraliste, prenait corps. Mais le monde syndical n'occupe pas sous cet angle une position isolée. En plusieurs secteurs, on trouve face à face une O.N.G. communiste ou paracommuniste, une autre rattachée au mouvement catholique (et dans quelques [p. 149] cas une reposant sur le protestantisme), une enfin se voulant neutre à l'égard de ces forces.

Soit par exemple, les journalistes. Parmi les nombreux organismes qui les rassemblent, nous citerons les suivants : l'Organisation Internationale des journalistes (siège: Prague), qui relève du communisme international; la Fédération Internationale des journalistes Catholiques (siège: Paris); la Fédération Internationale des journalistes (siège: Bruxelles) qui, on l'a vu, se propose de défendre la liberté de la presse et la condition professionnelle journalistique sans s'attacher à des considérations partisanes. Et l'on a noté que le Congrès juif Mondial entend créer sur ce point sa propre organisation.

D'une façon générale, les associations intergouvernementales s'efforcent d'atténuer ces divergences et de promouvoir des groupes à recrutement universel. Un tel objectif a été réalisé dans un petit nombre de secteurs, notamment celui des milieux scientifiques et de diverses branches professionnelles (Organisation Internationale de Normalisation. Union Internationale des Architectes qui comprend 85000 membres répartis en 40 pays dont l'U.R.S.S....). Cependant, réserve faite de quelques cas (Alliance Coopérative, Union Interparlementaire...), la plupart des O.N.G. qui 
disposent d'une réelle influence dans leur parti acceptent comme base de recrutement et de fonctionnement les clivages habituels d'ordre politique ou religieux.

Sur le plan des principes, l'universalité apparaît certes souhaitable. Mais le vieux rêve du monde uni n'a pas beaucoup de consistance dans l'état présent de division des esprits. Sauf circonstances exceptionnelles, les associations qui ont tenté de réaliser de tels rassemblements en ont surtout récolté une exaspération des tensions internes et une stérilisation de leurs facultés d'action. Il est facile de comprendre que l'acceptation d'un désarmement idéologique constituerait le seul remède à la situation.

En formulant cette proposition, on ne se fait aucune illusion sur ses chances d'adoption. L'idéologue marxiste ne manquera pas de la taxer d'«idéaliste » en se référant à de prétendues « lois objectives » du développement social : mais ce faisant n'apporte-t-il pas une justification solide à ceux qui, à l'Occident, critiquent le principe de tels contacts en les déclarant inutiles ou dangereux ?

[p. 150] $8^{\circ}$ Enfin, le tableau présente ces forces comme des facteurs séparés et détachés de tout ensemble. C'est, bien entendu, une vue purement statique du problème. La réalité quotidienne est génératrice de confrontations dans lesquelles s'affirment des rivalités et se nouent des accords. Les formes de ces contacts sont multiples, difficiles à recenser et à classer : il y a, par exemple, des convergences spontanées, d'autres résultant de tactiques minutieusement établies. Certaines sont éphémères, d'autres durables et mêmes permanentes.

Aucune interprétation dynamique de la politique n'est concevable sans un examen de la position des forces de pression les unes à l'égard des autres. C'est faire un contre-sens majeur (étroitement lié aux conceptions traditionnelles de l'État) que de limiter l'analyse de ces éléments à leurs relations avec les autorités publiques. Les rapports qu'elles entretiennent entre elles ont au moins autant d'importance. Ne commettons pas cette erreur, encore courante en matière interne, dans le domaine de la politique internationale.

Soit, par exemple, l'industrie privée d'armement à laquelle divers, auteurs n'hésitent pas à imputer la responsabilité du déclenchement des guerres et de l'échec du désarmement. Plusieurs affaires de ce secteur sont d'authentiques internationales.

Ainsi à la veille de la guerre de 1914 la Vickers britannique avait-elle des intérêts ou des usines dans la plupart des pays appelés à se combattre (Allemagne comme France, Russie comme Turquie).

Reste à savoir s'il est possible de passer de ces faits indiscutables à la notion d'une véritable Internationale des marchands d'armes s'étendant aux activités «alliées » (acier, cuivre, etc.).

La documentation disponible fournit certes de troublantes connivences et de curieuses liaisons : elle révèle aussi de graves rivalités qui ne permettent guère de soutenir la thèse d'un comportement centralement unifié. Reste, il est vrai, l'éventualité d’une convergence spontanée des intérêts. 
[p. 151]

\section{CHAPITRE II}

\section{L’ÉLABORATION DU SCHÉMA}

$\underline{\text { Retour à la table des matières }}$

ON VOUDRAIT, dans ce chapitre, proposer une construction théorique qui aide à systématiser, répartir et interpréter les phénomènes précédemment analysés. Il ne s'agit pas seulement d'appliquer la notion de " pression » à la politique internationale : l'objectif est de présenter un cadre spécifique permettant de tirer le meilleur parti de cette transposition.

La démarche repose, initialement, sur l'emploi du concept « groupe de pression ». On ne surprendra personne en soulignant ses imperfections actuelles. Par son utilisation sur une large échelle, les spécialistes ont considérablement accru, surtout aux États-Unis, la somme des connaissances disponibles. Mais cet emploi a pris, chez la plupart, une allure empirique. Il a fallu attendre jusqu'à ces dernières années pour que sa portée et sa valeur fassent l'objet d'un examen méthodique. Il ne sera pas possible de présenter ici le résultat de ces discussions qui ont rarement abouti à des positions uniformes. Cependant, il reste indispensable d'énoncer, en fonction de notre objet, les incertitudes les plus graves et les défauts les plus évidents.

L'orientation principale de ce chapitre est de sélectionner un critère qui particularise la catégorie «groupe de pression international». On peut tenter l'opération à partir de la «nationalité » du groupe ou de la qualité de son influence, mais on ne parviendra à un résultat qu'en combinant divers facteurs. Tout en recommandant un cadre d'analyse déterminé, on admettra qu'il n'est pas à l'abri de la controverse. Cepen-[p. 152] dant, n'oublions pas que le débat porte, non sur les phénomènes, mais sur leur conceptualisation. Le cadre proposé n'est pour lors qu'une hypothèse de travail. Ce serait déjà un succès si, en montrant son intérêt, on incitait d'autres auteurs à des critiques et vérifications ultérieures. 


\section{INCERTITUDES MÉTHODOLOGIQUES}

$\underline{\text { Retour à la table des matières }}$

Dans les milieux les plus exigeants, c'est-à-dire les mieux informés des imperfections présentes de la discipline politique, on en vient à dire que, pour l'étude de n'importe quel problème, un bon modèle est plus nécessaire que le rassemblement de milliers de faits. Ce point de vue gagne du terrain en Europe et ce n'est certes pas l'état de la théorie des groupes qui permettrait d'en contester l'opportunité. Voici quelques-unes des principales sources d'hésitation.

Les problèmes en cause seront exprimés par des formules qui opposent des situations extrêmes. Disons tout de suite que, pour le moment et peut-être de façon durable, il ne saurait être question de fixer sur chacun des points en litige une ligne rigide de séparation qui rejetterait d'un seul côté, ou vers un seul pôle, les organismes à introduire dans la catégorie des groupes de pression, En réalité, chacune de ces formules représente une sorte de continuum imposant de raisonner et c'est, précisément, la difficulté de la conceptualisation, envisagée par un système de transitions ou si l'on préfère, de progression insensible.

\section{a) ACTION PUBLIQUE ET PRESSION PRIVÉE}

Explicitement ou implicitement, la plupart des études se réfèrent à un critère d'extériorité pour spécifier l'autonomie des groupes de pression comme catégorie d'intervention dans les affaires publiques. Leur mission propre serait en somme l'action exercée du dehors sur les centres compétents, pour préparer, prendre et exécuter les décisions. Globalement, l'analyse reviendrait à étudier la confrontation secteur public — secteur privé en insistant sur l'impulsion donnée par le second au premier. Cette attitude s'étend au domaine des relations extérieures dès qu'on $\mathrm{y}$ oppose le secteur privé de la coopération internationale (les organisations non gouvernementales) au secteur public ou étatique ${ }^{1}$.

[p. 153] Nous avons initialement adopté et, en gros, conservé cette conception malgré diverses critiques. Mais, si l'acceptation de ce clivage (d'esprit juridique et non sociologique, reconnaissons-le) a semblé préférable dans la phase d'exploration préliminaire, il n'en résulte pas d'aveuglement sur ses immenses défauts. En creusant

L'expression «secteur privé » est volontiers utilisée par George LANCROD. Par exemple ses remarques sur " Le rôle du secteur privé de la coopération internationale » Associations, octobre 1954, pp. 466-467. G. Langrod a d'ailleurs montré en d'autres écrits une pleine conscience des limites actuelles de cette opposition. 
davantage, on constate que cette séparation prend appui sur une philosophie libérale de l'État, un État se limitant aux tâches traditionnelles de souveraineté (maintien de l'ordre public et défense extérieure). Inutile de souligner que ce cantonnement, correspondant d'ailleurs à une vue dogmatique et non aux résultats de l'observation historique, n'est plus réalisé nulle part. Dans tous les pays, on observe un transfert massif des responsabilités au profit des administrations publiques. L'interpénétration des secteurs gouvernementaux et privés ne cesse de s'accentuer: elle se traduit, surtout par la réalisation en commun de multiples tâches, voire par la délégation de facultés réglementaires à des organes extra-étatiques.

Phénomène encore plus frappant: les mêmes fonctions, dans le processus économique par exemple, sont, selon les cas, assurées par des unités de nature différente (nationalisation, totale ou partielle, de certaines productions ; gestion d'une branche professionnelle par un office public ou une entente privée, etc.). On doit admettre que la ligne habituelle de division est de plus en plus artificielle.

Cette expansion des responsabilités gouvernementales a eu un corollaire sur le plan international : la création de nombreuses organisations intergouvernementales dont la compétence s'étend aux questions économiques, sociales, scientifiques, culturelles (Organisation Mondiale de la Santé ; Organisation pour l'Alimentation et l'Agriculture ; Fonds Monétaire International ; Unesco...). Ce fait a conduit (le terme « obligé » serait peut-être plus exact) les groupements internationaux privés concernés à s'intéresser au travail des assemblées intergouvernementales et à tenter d'y participer ${ }^{1}$. C'est un processus classique: l'extension des préoccupations et responsabilités étatiques provoque, inévitablement, une multiplication et une intensification des pressions subies par les pouvoirs publics. Mais est-on fondé à transposer sur la scène internationale le dilemme public-privé et à limiter en conséquence cette étude aux interventions des seuls organismes de nature privée ?

Sans être à même de présenter une vue exhaustive du problème, nous allons énumérer quelques situations illustrant le caractère rudimentaire, et même fallacieux, de cette division. Cette brève évocation, qui nous [p. 154] conduira finalement à des questions de théorie politique particulièrement ardues, sera centrée sur deux notions : pénétration par des éléments publics d'organismes que l'on classe habituellement sous une rubrique " privée »; attribution à des organes publics de structures et de facultés qui ont pour conséquences de rapprocher leur comportement usuel de celui de groupements privés.

$1^{\circ}$ La conjugaison des éléments « public » et " privé » est de pratique courante. Elle s'affirme avec une force particulière au niveau des relations internationales. Allant au point extrême du raisonnement, on peut se demander s'il subsiste quoi que ce soit de la distinction des deux termes, dès que l'on introduit dans les associations internationales non gouvernementales des représentants des pays communistes.

1 Évolution bien retracée par Vladimir HERCIK, «Évolution des rapports entre les pouvoirs publics et les organisations non gouvernementales ", Associations, février 1960, pp. 78-88. 
La conception d'un secteur privé de l'organisation internationale s'explique par référence aux pays pluralistes dans lesquels le citoyen se trouve en mesure de prendre position, de son propre chef et sans avoir à tenir compte de consignes gouvernementales. Si les O.N.G. constituent seulement une tribune supplémentaire pour l'affirmation des thèses officielles, leur raison d'être s'affaiblit considérablement. Or il faudrait être aveugle ou partisan pour contester que, dans la plupart des cas, les délégués des États de l'Est dans les O.N.G. ont pour mission d'y exposer le marxisme, d'y faire l'apologie de la diplomatie soviétique en y diffusant ses mots d'ordre, d'y attaquer le mode de vie occidental, etc. Il est possible que diverses associations scientifiques fassent exception à cette norme, mais celle-ci traduit avec fidélité le cas des organisations professionnelles, culturelles, humanitaires.

Le cas communiste est certes le plus clair. Mais la même situation prévaut pour tous les pays autoritaires et dictatoriaux qui envoient généralement dans les O.N.G. des membres de la faction au pouvoir ou, des éléments fortement sympathisants. On doit aller plus loin : la distinction public-privé a-t-elle un sens au niveau de nombreux pays sous-développés, et spécialement de plusieurs des nouveaux États africains (qui d'ailleurs participent encore relativement peu à l'organisation non gouvernementale) ?

Enfin, il faut admettre que, même dans les pays attachés à l'ordre, pluraliste, les représentants nationaux dans les O.N.G. reçoivent parfois, et éventuellement sollicitent, consignes et suggestions d'origine gouverne-[p. 155] mentale (attitude souvent en relation avec l'octroi de subventions de fonctionnement ou le remboursement de frais de voyage).

Cette puissance du point de vue officiel s'explique aisément par l'extrême «politisation» des relations internationales. Les cyniques diront que l'absence d'interférence publique dans le fonctionnement des O.N.G. traduit, quand on la constate, non un respect de la liberté du citoyen, mais la futilité du domaine abordé vis-à-vis des préoccupations gouvernementales. Malgré son aspect outrancier, le propos n'est pas absurde ; il n'existe aujourd'hui que fort peu de pays autorisant leurs ressortissants à prendre ouvertement position à l'extérieur contre des thèses soutenues ou des intérêts endossés par les dirigeants politiques.

Actuellement, l'opposition privé-public, ou simplement la distinction entre les deux secteurs, a perdu une large part de son fondement. Les forces internationales reproduisent, et parfois amplifient, les clivages qui s'observent dans l'ordre interne. Mais le principe de la différence est trop bien ancré dans les esprits et constitue un paravent trop commode pour qu'on ne continue pas de l'invoquer longtemps encore.

Cette évolution se répercute sur le fonctionnement des organisations intergouvernementales. En bien des occasions, les procédures consultatives que l'on décrira plus loin, aboutissent à donner à des thèses gouvernementales un moyen supplémentaire d'expression. La plus atteinte des instances officielles, par cette interpénétration du public et du privé, est l'Organisation Internationale du Travail. Aucune argutie juridique ne saurait dissimuler l'incompatibilité radicale entre le «tripartisme» qui est le fondement de l'O.I.T. et la structure des économies collectivistes. Cette contradiction, jointe à l'arrivée massive de pays non 
industrialisés, est de nature à modifier radicalement l'esprit et les facultés de cette institution.

La tendance que l'on vient d'exposer contribue donc à affaiblir in globo la portée de la distinction traditionnelle. D'autres phénomènes de caractère plus technique, que l'on rencontre spécialement dans les pays de civilisation pluraliste, exercent une influence analogue: en particulier, l'association du secteur public et des groupes privés pour l'accomplissement de diverses tâches. En voici quelques exemples.

Soit l'Union Internationale des Organismes Familiaux : elle comprend à la fois des groupements privés et des organismes publics (départements ministériels ou sections de ministère). L'Association Internationale de la Sécurité Sociale admet en son sein des institutions d'assu-[p. 156] rances sociales autonomes et des départements gouvernementaux administrant une ou plusieurs branches de la sécurité sociale. Autre organisme de recrutement mixte : l'Union Internationale des Villes et des Pouvoirs Locaux qui rassemble des unions de villes, des pouvoirs locaux individuels, des associations libres en rapport avec l'administration locale et des particuliers intéressés à cette administration ${ }^{1}$. On pourrait citer plusieurs autres cas d'une telle interpénétration qui traduit, au niveau international, une coopération déjà réalisée au plan national.

Or, aujourd'hui, personne, on le verra, ne propose d'exclure de tels groupements de la catégorie des O.N.G. à cause de leur recrutement dualiste ou de l'octroi de subventions de fonctionnement d'origine gouvernementale. Le secteur dit privé est donc pénétré, en droit et en fait, par des éléments publics. Mais la question présente un autre aspect : l'existence d'organismes dont le comportement s'apparente à celui des groupements privés. Quel sort leur réserver dans notre schéma?

$2^{\circ}$ Le point de départ de cette situation est simple. En étendant leurs activités à de nouveaux domaines, les pouvoirs publics adoptent volontiers des structures et des modes de gestion différents des méthodes utilisées pour les services traditionnels. L'un d'entre eux est la formation de sociétés d'économie mixte dont le capital est réparti, selon des proportions variables, entre les secteurs public et privé. Une autre est la constitution d'organismes autonomes qui échappent au pouvoir hiérarchique et possèdent une liberté de manœuvre souvent considérable. Mentionnons, entre plusieurs, l'E.N.I. (Ente Nazionale Idrocarburi) qui est la plateforme des activités de M. Enrico Mattei.

Observons sous cet angle les acteurs du marché pétrolier dont les liaisons avec la politique internationale sont bien connues. Les uns sont des représentants typiques du secteur privé (Standard Oil N.J., Royal Dutch-Schell...). D'autres relèvent de l'économie mixte (Compagnie Française des Pétroles, British Petroleum...). Certains enfin (E.N.I.) forment de pures entreprises d'État. Faut-il considérer que leur comportement à l'égard des États du Moyen-Orient est profondément différent, selon

Bonne présentation de cet organisme dans l'étude de N. ARKEMA, Bulletin O.N.G, août-septembre 1952, pp. 199-204. 
le type d'organisation auquel ils se rattachent ? Dans l'état présent des rivalités pétrolières, il serait hasardeux de l'affirmer. Dès lors, n'est-il pas souhaitable de négliger les différences dans les structures juridiques pour se concentrer sur les ressemblances de fond?

[p. 157] La coexistence, au sens technique du terme, d’États à régimes sociaux différents accroît nécessairement l'hétérogénéité des formules. Quand elle s'institue, la coopération entre États communistes et pluralistes met souvent en contact des hommes ou des organismes auxquels les présentations classiques concèdent des étiquettes diverses. Et la remarque reste valable pour les situations de rivalité.

Soit, par exemple, le domaine des relations culturelles dont on connaît les compétitions de plus en plus sévères qu'il suscite ${ }^{1}$. En U.R.S.S., c'est le Ministère de la Culture et l'Organisation Voks qui assument les rapports de cette nature. La Voks (Société panunioniste pour les relations culturelles avec l'étranger) est ouverte en principe à tous les citoyens soviétiques, mais fonctionne en fait comme un organe d’État dans le cadre des plans du Ministère de la Culture. Aux États-Unis, il existe en cette matière de nombreuses administrations publiques (dont l'International Éducation Exchange Service ou encore l'United States Information Agency) et aussi des fondations officielles (National Science Foundation ou Smithsonian Institution): pourtant, n'oublions pas le rôle des fondations privées qui, au total, disposent de ressources considérables.

La France possède une Direction Générale des Relations Culturelles (née après la seconde guerre mondiale du Service des Euvres Françaises à l'Étranger). Cependant, sans même parler de l'effort propre des Missions religieuses, on voit aussi intervenir, d'ailleurs en collaboration avec le Quai d'Orsay, deux grandes associations privées : l'Alliance Française qui date de 1883 et la Mission Laïque Française créée en 1902. En Suisse, la défense spirituelle et le rayonnement culturel sont largement l'œuvre d'une fondation de droit public Pro Helvetia: les membres de son Conseil sont nommés par le Conseil fédéral, mais celui-ci les choisit ad personam. Et si le programme de travail est soumis au gouvernement fédéral, ce dernier ne semble pas avoir empiété sur l'autonomie de la fondation.

Ces quelques exemples donnent une idée, certainement partielle, de la variété des organismes qui interviennent dans ce secteur de l'activité internationale. Or, encore que dans un esprit différent, ils se préoccupent tous des mêmes questions. Au total, il paraît simplement impossible, eu égard à l'objet de cet ouvrage, de séparer brutalement " public » et « privé » dans le jeu des rapports internationaux. Sur quelle base réaliser l'indispensable rapprochement?

[p. 158] $3^{\circ}$ Une attitude radicale serait de considérer les États eux-mêmes, spécialement dans leurs rapports respectifs, comme des groupes de pression. À supposer qu'il existât un gouvernement mondial, la démarche ne serait pas différente de celle voulant attribuer une telle qualité à deux villes d'un même pays (luttant, par

Voir DOKA (Carl), Les relations culturelles sur le plan international, Neuchâtel, 1959. 
exemple, pour l'attribution d'une subvention). Cependant, la médiocrité du pouvoir de décision des Nations Unies (choix d'une solution et possibilité d'en exiger l'application), rend l'assimilation peu plausible. De plus, nous avons la certitude qu'au stade actuel des études politiques il en résulterait une confusion irrémédiable (exactement comme si, sur le plan interne on ramenait à la catégorie "groupes de pression », Parlement, Armée, Ministères...). Jusqu'à nouvel ordre, il paraît préférable de traiter les États (et, bien entendu, les diverses pièces de l'appareil d'autorité) comme une catégorie spécifique, irréductible à la formule du groupe de pression.

On est, par contre, en droit d'hésiter à l'égard d'organismes qui, tout en ayant été fondés par les autorités gouvernementales ou en se trouvant rattachés au secteur public, possèdent une autonomie de gestion et dont les dirigeants se comportent, dans leur secteur d'intervention, avec une sorte de volonté propre : faculté qui met ces derniers en mesure de mener directement le jeu et de tenir le rôle impliqué par le type de relations en cause. On pourrait attribuer cette qualité, dans l'ordre culturel, au British Council et, sur le plan commercial, à l'E.N.T. Ce raisonnement s'accommode parfaitement de l'idée, qu'en définitive, le premier sert, ou tend à le faire, les intérêts britanniques et la seconde les positions italiennes. Mais dans leur activité quotidienne, ils disposent d'une liberté de conception et d'une marge de manœuvre assez grandes pour exercer, de leur propre mouvement et sous leur responsabilité, des pressions sur l'interlocuteur.

On verra probablement dans ce critère, une sorte de mesure de « rattrapage » destinée à atténuer les effets d'une attitude initialement trop restrictive. C'est vrai et, comme toutes les dispositions de compromis, notre suggestion pèche dans la mesure où elle ouvre la voie à l'interprétation. Faut-il en particulier concentrer l'exégèse sur la qualité de cette autonomie qui peut n'être qu'apparente ? La suggestion, fondée sur les exemples qui viennent d'être cités, est séduisante, mais nous sommes tenté de douter de sa valeur. Si la théorie des groupes conduit à distinguer ceux qui sont des moteurs indépendants de ceux qui ne constituent, en fait, que des instruments au service d'une volonté supé-[p. 159] rieure, elle n'oblige pas à rejeter les seconds hors du schéma. En tout état de cause, le souci chez un gouvernement de doter telle activité, d'une structure autonome, même s'il s'agit d'une simple contrefaçon, n'est pas sans implications politiques.

Le facteur permettant une telle interprétation serait donc un acte de volonté tendant à détacher de l'appareil gouvernemental ordinaire l'organisme considéré : opération dont le commentateur devrait scruter les mobiles réels. Cette séparation constatée, il deviendrait légitime d'utiliser le schéma "forces de pression " sans oublier que certains des organes rendus autonomes ont pour seule fonction, malgré une façade d'indépendance, de diffuser et d'amplifier directives et consignes d'origine gouvernementale.

En adoptant, au moins à titre provisoire, ce point de vue, on établit entre les secteurs public et privé, des ponts conformes à la nature des choses. Dans cette perspective, rien n'oblige à écarter de notre analyse les organismes mixtes, spécialement si les intérêts et représentants gouvernementaux n'y sont pas 
prédominants. Le compromis suggéré pourra peut-être déplaire en introduisant, dans le cadre des forces de pression internationales, un élément de service public que les partisans d'une séparation rigoureuse jugeront trop important. Mais de toutes façons, une position qui réduirait ces forces aux seuls organes de caractère privé, devrait tenir compte de l'interaction qui se manifeste entre les deux sphères.

En effet, le secteur privé agit sur le secteur public, mais au niveau international comme dans le domaine interne, le second a souvent besoin du premier. Il arrive même que le sens de l'opération soit renversé et, qu'en fait, le groupe de pression serve, avec plus ou moins de bonne grâce et d'efficacité, la politique gouvernementale: on a pu constater un tel détournement dans le cas de groupes purement privés (y compris celui de groupements bancaires et financiers, volontiers décrits comme étant les plus "égoïstes »). Convergence bien faite d'ailleurs pour inciter à ne pas séparer le secteur public de structure autonome et le secteur privé.

$4^{\circ}$ Un dernier point : la situation des internationales de partis. Sur le plan interne, on a généralement coutume d'opposer, toujours d'après le critère d'extériorité, les partis qui ont pour mission d'occuper le pouvoir et les groupes qui tentent d'influencer les autorités du dehors (en [p. 160] particulier au moyen d'une pesée sur les partis). En un sens, l'ambition des internationales est de renforcer et, dans le cas communiste, d'orienter selon une norme unique, les formations nationales à la conquête du pouvoir. Cependant les internationales tentent aussi, par des proclamations ou d'autres moyens, d'infléchir l'action des gouvernants même s'ils appartiennent à d'autres formations (Internationale Socialiste et Sir Anthony Eden à propos de Suez). À ce titre, elles relèvent du schéma des forces de pression. Cependant, un souci de clarté qui ne semble pas d'une importance décisive, pourrait conduire à les en exclure, et à les rattacher entièrement au jeu des partis.

Mais ceux-ci posent d'autres questions. On a souligné l'audience et l'activité internationale de divers mouvements de libération. Or ils revêtent, selon les époques et les pays, des formes variables, parmi lesquelles celle d'un parti d'opposition. Il n'est pas rare que, dans l'immédiat, ce dernier ait plus d'influence sur l'opinion internationale et les gouvernements étrangers qu'auprès de l'État directement responsable. On ne saurait semble-t-il exclure de tels phénomènes de notre champ d'étude ${ }^{1}$.

\footnotetext{
Nous avons volontairement omis le cas des « gouvernements en exil » qui correspondent d'ailleurs à des situations très variées. Leur qualification sociologique est complexe. Soit, par exemple, le gouvernement républicain espagnol qui a continué de se manifester une fois le régime franquiste reconnu comme le gouvernement légal. Le premier tentait d'agir à l'encontre du second, notamment par des proclamations publiques et des interventions auprès des gouvernements où il avait conservé des sympathies. Un tel organisme, dépourvu de tout titre légal, ne représenterait-il pas, en fait, une simple force de pression internationale ? Il serait également intéressant de soumettre à ce schéma les diverses catégories de "gouvernements provisoires ». Rappel de l'ouvrage bien connu FLORY (M.), Le statut international des gouvernements réfugiés et le cas de la France Libre, 1939-1945, Paris, 1952.
} 


\section{b) INTERVENTIONS INDIVIDUELLES ET COLLECTIVES}

\section{$\underline{\text { Retour à la table des matières }}$}

La notion de groupe évoque l'idée d'une force collective. Mais en concentrant la recherche sur cet aspect de la question, ne risque-t-on pas d' " omettre un facteur : l'action de personnalités capables d'intervenir du niveau retenu, de leur propre fait et sans le secours d'une organisation ? La question vaut d'être envisagée.

On pourrait citer de multiples circonstances où l'intervention individuelle paraît avoir constitué le facteur décisif. Revenons au pétrole, pour citer l'exemple de $\mathrm{M}$. Enrico Mattei, "l'homme le plus discuté d'Italie » comme titrait Entreprise non sans quelque concession au sensationnel ${ }^{1}$, le «chevalier des temps modernes » selon l'expression d'un thuriféraire maladroit... ${ }^{2}$. Des commentateurs sérieux n'ont pas hésité à dire qu'il avait renoué avec la tradition des grands aventuriers comme Rockefeller ou Deterding. Écartons l'hyperbole, pour conserver la substance. L'action de l'Italie au Moyen-Orient pétrolier et en Afrique du Nord, c'est d'abord Mattei. Mais attention ! S'il s'est acquis une telle réputation, d'ailleurs controversée, c'est tout de même en utilisant le levier fourni par l'E.N.I. À partir de là, son cas rentre dans la norme [p. 161] de l'explication. Un groupe vaut par l'habileté et l'énergie de son leader. L'E.N.I. a eu la chance d'être servie par un homme de premier plan. Ainsi estelle devenue un groupe puissant.

Avouons une nette préférence pour ce second mode de présentation. Rares sont les individus extérieurs à l'appareil gouvernemental proprement dit, qui se révèlent néanmoins capables d'exercer des pressions efficaces sans s'appuyer sur des forces déterminées ou éventuellement, sur des milieux enclins, globalement, à les soutenir. Dès lors, l'unité d'analyse est, non plus l'homme seul, mais le complexe indissociable formé par lui-même, son entourage et la force, organisée ou diffuse, qui lui sert de base ou de levier. Mais, si telle doit être la méthode dans la quasi-totalité des cas, vaut-elle encore pour ceux que l'on doit se résigner à qualifier d'« exceptionnels » ? Convient-elle, par exemple, au destin de Ferdinand de Lesseps ${ }^{3}$ ? Ou encore à celui d'un Sir Basil Zaharoff, ce magnat de l'industrie des armements, dont les historiens soulignent l'influence qu'il exerça notamment sur Lloyd George à propos du statut du

$\mathrm{N}^{\circ}$ du 26 mars 1960. L'article qui porte ce titre constitue d'ailleurs un bon essai pour recenser les facteurs objectifs du succès de l'homme (pp. 23-27).

ROH (Henri), Enrico Mattei, chevalier des temps modernes, Sion, 1960.

Voir les deux volumes de Georges Edgar-BONNET, Ferdinand de Lesseps, I, Le diplomate. Le créateur de Suez. II, Après Suez. Le pionnier de Panama, Paris, 1951-1959. Pour une présentation plus brève, BEATTY (Charles), Ferdinand de Lesseps, traduit de l'anglais, Paris, 1957. Sur Zaharoff, voir LEWINSOHN (R.), Zaharoff, l'Européen mystérieux, Paris, 1929, et NEUMANN (R.), Sir Basil Zaharoff, le roi des armes, traduit de l'allemand, Paris, 1935. 
Moyen-Orient après la première guerre mondiale (autorisation donnée aux Grecs en mai 1919 de débarquer à Smyrne).

Cependant, à notre époque, celui qui symbolisa le mieux cette capacité d'influence humaine fut Gandhi. On pourrait dire que sa puissance lui vint d'être présent dans le cœur et l'esprit de millions d'hommes, autrement dit de sa faculté de mobiliser un immense public attentif à suivre ses consignes : mais il parvenait à un tel résultat par son seul rayonnement et malgré la faiblesse insigne des ressources matérielles à sa disposition.

Toute théorie prétendant nier le rôle de l'individu en politique au profit du groupe semble, en définitive, pécher par excès de généralisation. Et la remarque vaut aussi bien pour l'homme d'État que pour ses interlocuteurs. En dépit de l'expansion des groupements, la personnalité reste, pour le bien ou le mal, un facteur de la décision et un aspect de l'histoire. Le plus souvent, cet élément pourra être dégagé et évalué en fonction et à partir d'une force collective ; mais ceci admis, il semble difficile de ne pas attribuer une «case » ou un symbole dans le modèle d'explication, au facteur individuel à l'état pur.

Une seconde cause d'hésitation réside dans la place à donner aux firmes qui interviennent à titre isolé, ou selon des combinaisons d'affaires du type « cartel » sans passer par le canal d'une association professionnelle. Sur le plan international aussi bien que national, on observe [p. 162] l'un et l'autre genre de démarche : il y a l'action de la Chambre de Commerce Internationale ou de la Fédération Internationale des Armateurs, mais il existe également de nombreuses firmes assez puissantes pour agir directement sur des gouvernements étrangers, ou même des organisations internationales.

Le point n'est pas de savoir si ces combinaisons d'affaires constituent ou non une force de pression, une réponse positive ne pouvant faire de doute. Il s'agit d'examiner s'il y a intérêt à les traiter comme un élément entièrement spécifique ou, au contraire, à les introduire dans la catégorie globale des groupes de pression.

La discussion est compliquée par des questions terminologiques, les économistes n'ayant pas abouti à un vocabulaire uniforme pour désigner les phénomènes nés de la concentration. D'abord pour reconnaître que l'économie moderne est une économie de groupes, ils divergent sur le sens du terme. Certains le prennent dans une acception technique : le groupe serait la combinaison financière de plusieurs entreprises qui, tout en conservant leur individualité juridique, demeurent sous la dépendance d'une même autorité dominante ${ }^{1}$. Unilever, déjà nommé, en constituerait un, de même que, par exemple, Dupont de Nemours, Krupp, Thyssen, Péchiney, Saint-Gobain. Ces unions financières, de formes diverses, seraient à distinguer, d'une part, des unions commerciales (cartels, ententes), d'autre part, des syndicats professionnels (auxquels il arrive parfois de gérer des ententes et institutions corporatives). Les spécialistes en science politique ayant pris l'habitude d'employer en priorité les termes «groupe de

Définition de J. LAJUGIE in Traité d'économie politique, publié sous la direction de Louis Baudin, deuxième édition, tome I, Paris, 1955, p. 633. 
pression » pour saisir les syndicats professionnels et autres fédérations (en principe à but non lucratif), le hiatus entre terminologie politique et économique est complet.

Cependant d'autres économistes semblent avoir une vue plus large de la notion de groupe, y introduisant non seulement ententes et cartels, mais aussi les organisations d'artisans et de petites entreprises, bref, toutes les manifestations de regroupement des efforts. Soulignant que, la plupart du temps, les groupes en viennent à agir comme des «blocs de puissance politico-économique », ces spécialistes rencontrent naturellement la notion de groupe de pression comme facteur d'« investissement » de l'État: l'écart terminologique entre les deux disciplines se trouve alors fortement réduit ${ }^{1}$.

[p. 163] Après des hésitations, nous penchons vers une extension de la catégorie des groupes de pression aux diverses structures créées par l'agrandissement des entreprises et la tendance de celles-ci à unifier leur comportement. Le principal objectif de l'assimilation est de présenter une vue globale de phénomènes que les analyses courantes dispersent à l'excès. Certes, le processus de formation de la volonté est différent d'un cas à l'autre : la décision d'intervenir n'est pas prise de la même façon au sein de la grande firme et dans une fédération professionnelle. Mais le point d'aboutissement du processus est identique.

Un fait, au surplus, paraît suffire à justifier cette assimilation : la variété des formes choisies provient assez souvent du seul souci d'adapter l'action envisagée aux exigences de la situation et aux possibilités du secteur. En d'autres termes, il est fréquent que pour réaliser le même objectif, les diverses branches doivent utiliser des techniques différentes, le niveau de concentration réalisé constituant l'une des causes essentielles de ces divergences. Si l'on s'en tient à la substance, il n'y a pas dès lors de raisons sérieuses pour séparer l'action politique de la grande firme (le "groupe » au sens technique), du cartel et de l'entente de celle du syndicat de professionnels. Dès l'instant qu'ils décident de passer par la voie gouvernementale et sont en mesure de le faire, les premiers peuvent être insérés, sans aucune difficulté, dans la catégorie des « groupes de pression ».

Ajoutons pourtant que dans la sélection du mode de groupement, plus exactement de la « couverture » qui sera donnée à la démarche effectuée, des considérations de tactique joueront à côté des facteurs découlant de la concentration économique. En certaines occasions, la grande firme, qui pourrait intervenir seule, préférera s'abriter derrière un rideau de petites affaires. Encore que de telles habiletés soient plus faciles à pratiquer sur le plan national qu'au niveau international (il serait difficile à l'Aramco de trouver un paravent ou un substitut en Arabie saoudite), elles ne sont, nulle part, totalement inconnues.

Nous n'établirons donc pas ici de différence conceptuelle entre les diverses modalités que revêt la promotion des intérêts économiques. L'absence de but lucratif dont se recommandent les associations patronales (comme d'ailleurs toutes les autres)

En ce sens, Raymond BARRE, Économie politique, tome I, Paris, 1956, pp. 126-128. 
ne doit pas dissimuler que l'enjeu reste toujours d'améliorer la capacité de profit des membres ou de faciliter leur travail. Mais cette démarche effectuée, il conviendra de distinguer nettement les principales variétés du système d'inter-[p. 164] vention et, pour autant qu'un choix existe au profit des intéressés, de rechercher les motifs ayant présidé à la sélection de l'une d'entre elles.

Au total, dans le schéma adopté, on se limitera à une seule ligne pour la désignation globale du phénomène sans oublier toutefois la nécessité d'une décomposition ultérieure, seule capable d'indiquer l'orientation du jeu et de montrer les possibilités de chacun des acteurs.

\section{c) ACTIVITÉS ORGANISÉES ET TENDANCES DIFFUSES}

$\underline{\text { Retour à la table des matières }}$

La notion de groupe, dès qu'on l'emploie à d'autres fins que la classification ou la distribution statistique, suppose un mécanisme d'unification des conduites et donc un minimum d'organisation administrative. Nous étudions alors l'activité déployée à partir du groupe qui en revendique la responsabilité. Cette démarche est pratique pour l'analyse. Si elle est, très souvent du moins, conforme à la nature des choses, on observe cependant en certaines occasions, une activité dont il est difficile de rapporter le principe à un centre concret d'impulsion. Il arrive que l'on évoque, à ce propos, l'action du milieu. Est-ce un concept explicatif?

Cette notion peut d'abord s'entendre dans une acception relativement restrictive. On a déjà rencontré les «milieux » bancaires ou financiers en conjonction avec des opérations de portée internationale. L'expression peut correspondre aussi à des situations diverses: limitation des personnes intéressées ou capables d'agir, à un nombre si réduit que la formation d'une structure administrative est inutile ; existence, au sein d'une branche quelconque, d'une sorte de principe ou facteur commun d'appréciation qui, en une certaine mesure, tient lieu de mécanisme d'unification ; présence, dans le secteur considéré, d'un ou plusieurs éléments (généralement assez rares), dont le comportement sert de modèle ou d'inspiration aux autres. Dans tous ces cas, nous demeurons aux frontières du groupe de pression et, sous réserve d'identifier les acteurs et leur position respective, le schéma reste applicable.

Mais le terme de «milieu » est souvent utilisé dans un sens beaucoup plus vaste : on mentionne, par exemple, les milieux internationaux de Genève, les milieux économiques de Londres, ou encore les milieux intellectuels de Paris. On déclare par exemple qu'en juillet 1914 la Cité était peu favorable au déclenchement d'une guerre. L'opération revient en somme à symboliser un secteur de l'opinion publique ou, [p. 165] si l'on préfère, un public délimité par divers critères. Comment interpréter de telles notions? 
Les réactions de l'opinion ont une portée considérable aussi bien pour le gouvernement que pour les groupes: l'opinion constitue à la fois un facteur d'impulsion, ou de contrôle, et un complexe que l'on s'efforce de modeler. Les groupes de pression, qui en dépendent à de multiples égards (facilités de recrutement, réputation sociale, appui donné aux revendications), en font dès lors l'un des objectifs, ou des points d'application de leurs activités. Les deux plans d'analyse - l'action du groupe et le rôle du milieu qui l'entoure — doivent donc être soigneusement distingués.

Sur le terrain pourtant la différenciation peut se révéler difficile. Considérons la naissance d'une volonté de libération dans une collectivité dépendante, ou d'un désir de rattachement à une autre unité politique au sein d'une minorité nationale. Admettons que, durant une période, ce sentiment reste diffus, sans engendrer un cadre organisateur. Est-il possible de se référer à ce propos à un concept de " groupe de pression virtuel », au sens où, à tout moment, un groupe organisé pourrait surgir d'un tel contexte?

Cette démarche purement verbale semble peu utile et comporte des aspects critiquables. En l'accomplissant, on ne fait rien d'autre qu'évoquer un état de disponibilité de l'opinion (d'un public ou d'un milieu, si l'on préfère) et, au surplus, l'expression, malgré la restriction instituée par l'adjectif final, suggère un cadre, dont l'absence est justement la caractéristique de la situation. Toutefois, ce manque de structure que l'on a postulé pour les besoins du raisonnement est peu fréquent, surtout à notre époque. Il est rare qu'une disposition puissante ou intense de l'opinion n'engendre pas une volonté d'organisation (éventuellement sous une forme d'abord clandestine); on peut, à l'inverse, concevoir une attitude qui s'étend dans la population grâce à l'activité d'un groupe initialement minoritaire.

Dans de telles circonstances, l'élucidation des rapports entre l'opinion et le groupe, soulève des problèmes considérables. Il n'est pas toujours aisé de localiser la force d'impulsion. Bornons-nous à un cas particulier de cette interaction entre les deux plans dont, en une certaine mesure, les modèles cybernéticiens facilitent la compréhension : celui où le groupe, pour des raisons diverses, ne parvient à mobiliser et à encadrer qu'une fraction de l'énergie disponible. Dès lors, on [p. 166] aboutirait à une vue trompeuse des choses en se limitant à considérer les seuls moyens du groupe organisé. Cependant, la mesure du potentiel d'action non saisi par l'association reste délicate (nombre des «supporters », nuances des positions, intensité des convictions...).

Tant qu'il demeure à l'état diffus, ou encore potentiel, un tel courant n'est pas un facteur actif de la vie politique. Mais, il exerce parfois une influence considérable en suscitant des mesures destinées à le neutraliser ou à lui enlever sa raison d'être. Quand il engendre une activité, ce peut être sous des formes (terrorisme individuel, par exemple) difficilement réductibles à un schéma de pression organisée. Il s'agit typiquement de l'action d'un milieu (qui, dans le cas d'un territoire colonisé, se délimite par la dépendance subie et désormais mise en cause). Néanmoins, le terme 
« milieu » pris avec une telle extension est équivoque : mieux vaut employer la notion d'opinion publique et les concepts dérivés.

On peut hésiter à propos des «milieux scientifiques ». En de nombreux cas, les savants constituent désormais des O.N.G. du type classique. Cependant, il est douteux que cette structure traduise la totalité et, peut-être, l'essentiel de leur influence à l'échelle internationale. Le cas des physiciens atomistes méritaient dans cette perspective une analyse attentive.

Observons par exemple le mouvement Pugwash (fondé en 1957) à l'initiative de Cyrus Eaton: à en croire ses promoteurs, il aurait joué un rôle capital dans les décisions qui ont abouti à la suspension des essais nucléaires et, de façon plus générale, exercé une influence réelle, sur les dirigeants des pays occidentaux. Il serait probablement plus exact de dire que les déclarations et activités de nombreux savants (dont les six conférences tenues, en trois ans, par le mouvement Pugwash ne sont qu'un aspect) ont contribué à la formation des attitudes populaires à l'égard des armes de destruction massive. Mais si le phénomène est vraisemblable, il reste difficile de lui donner sa juste place dans la constellation des forces politiques.

On a parfois proposé de faire une distinction entre « mouvement » et « groupe de pression »; le groupe se caractérisant par une organisation tendue vers la réalisation d'un but particulier, généralement limité. Au contraire, encore qu'il puisse contenir divers centres dotés d'un cadre administratif, le mouvement ne constituerait pas un ensemble formellement structuré : ce serait une sorte de collectivité, susceptible [p.167] de continuer à vivre, même en cas de changement important dans la composition de ses membres. Le mouvement libéral, par exemple, se composerait éventuellement du parti portant ce titre, mais aussi de tous les groupes ou services fondés autour de lui, de la presse qui le soutient, des électeurs qui votent pour lui sans adhérer au parti, etc. Ce serait, en bref, une sorte de communauté trouvant son unité dans l'acceptation d'une certaine philosophie ${ }^{1}$.

Le langage courant, on l'aura vu au chapitre précédent, fait volontiers usage du terme « mouvement » sans le charger d'une signification précise. Il est possible que dans la terminologie courante, «mouvement» ait un sens un peu plus large que « groupe », mettant en valeur un certain dynamisme dans les rapports observés. Peutêtre, pour certains auteurs, le « mouvement » (par exemple, le mouvement patronal ou syndical) est-il le groupe en action (tendance à son apogée dans une expression fréquemment utilisée : celle de mouvements révolutionnaires). Ces nuances, qui ne correspondent pas à une longue tradition de la langue française, restent incertaines ${ }^{2}$. Et, finalement, il n'apparaît pas indiqué de se rallier à l'opinion qui tend à attribuer un contenu scientifique différent aux deux notions. La définition proposée pour le

Voir R. HEBERLE, Social Movements, New York, 1951, pp. 8-10.

Sur le plan qui nous intéresse, LITTRÉ définit le mouvement comme une « agitation suscitée dans des personnes ou dans un pays ou dans un peuple » (XVIII ${ }^{\mathrm{e}}$ siècle), ou encore comme une "sorte d'agitation des corps et des esprits " (XIX ${ }^{\mathrm{e}}$ siècle). La notion de mouvement correspond donc à une manifestation, organisée ou spontanée. L'usage actuel emploie le mot pour désigner l'instigateur ou l'animateur de ces manifestations. 
mouvement reste équivoque. De deux choses l'une : ou l'on insiste, malgré tout, sur l'organisation qui sous-tend l'activité exercée et l'on retombe sur le groupement (parti ou groupe de pression); ou l'on se réfère aux principes qui dictent l'inspiration commune et l'on aboutit à la diffusion des idéologies.

Disons quelques mots de ce dernier thème qui a des relations nombreuses avec le sujet de notre étude. L'idéologie cimente l'unité des groupes et inspire des conduites qui s'en réclament ou en assurent la mise en œuvre. Pourtant, cette insertion dans la pratique facilite, en retour, l'expansion de l'idéologie, non d'ailleurs sans la simplifier et la dénaturer. Ainsi, en particulier, les groupes de pression participent-ils de diverses manières au processus de diffusion des idéologies. Pourtant, même s'ils se spécialisent dans cette tâche, ils ne sont que l'un des instruments, et pas nécessairement le plus efficace, de cette propagation.

Examinons par exemple le neutralisme ${ }^{1}$. Il s'agit, en vérité, d'un courant qui a pris des significations multiples. Au début, en Europe occidentale et spécialement en France, l'objectif des neutralistes était d'obtenir une réorientation de la politique américaine, laissant une plus grande indépendance aux États de ce continent. Assez vite, cette [p. 168] attitude allait se charger d'un contenu hostile à l'Amérique (n'impliquant pas nécessairement une volonté de rupture avec le camp occidental). En Asie, spécialement dans l'Inde, le neutralisme a été élevé à la hauteur d'une politique mondiale dont les partisans estiment qu'en refusant la division du monde en deux blocs, ils contribuent de manière positive au maintien de la paix. Cependant le neutralisme asiatique contient aussi un élément d'hostilité à l'égard de l'Occident tout entier dont les manœuvres constitueraient selon ce point de vue la menace la plus immédiate pour les nouveaux États. Ailleurs, le neutralisme traduit un sursaut de prudence : éviter autant que possible les difficultés et incidents que provoque inévitablement l'affiliation à l'un des camps. Mais il se présente aussi comme une tactique au service d'intérêts nationalistes (pays arabes en particulier), s'exprimant notamment, sous cet angle, par une technique d'appel simultané à l'aide économique

1 HEALEY (D.), Neutralism, Londres, 1955. Sur les différentes acceptions du neutralisme, voir : MARCUS (J.T.), (« Neutralism in France », Review of Politics, juillet 1955, pp. 295-328; ARON (Raymond), « French Public Opinion and the Atlantic Treaty », International Affairs, janvier 1952, pp. 1-8 ; BABOULÈNE (J.), «L'Europe contre les attentismes », Esprit, mars 1951, pp. 393-403 ; LAPIERRE (J.W.), « La neutralité française : utopie ou solution », Esprit, mars 1951, pp. 375-392 ; SALVIN (M.), " Neutralism in France », International Conciliation, juin 1951, pp. 285-303 (à la suite du même auteur, pp. 304-318, «Neutralism in Germany. Materials collected and annotated ») ; BARRIA TRELLES (C.), «Polémica en Torno al Neoaislacionismo Europeo », Cuadernos de Politica Internacional, avril-juin 1950, pp. 71-81 (du même auteur, et dans la même revue, «El Problema de la Unitad Occidental y la Polémica de los Neutralismos », juilletseptembre 1951, pp. 45-71; MOSCA (R.), « Revisionismo, Neutralismo e Ragion di Stato nella Jugoslavia d'Oggi », Comunità internazionale décembre 1958, pp. 623-631 et janvier 1959, pp. 3644 ; AGOSTINI (R.), «Égypte et Inde : deux conceptions du neutralisme », Orient, $2^{\mathrm{e}}$ trimestre 1958, pp. 73-87 ; SCALAPINO (R.A.), " Neutralism in Asia », American Political Science Review, mars 1954, pp. 49-62 ; HENDERSON (W.), "The Roots of Neutralism in Southern Asia », International journal, hiver 1957-58, pp. 30-40 ; RONDOT (P.), « Conflits en Orient et neutralisme arabe », Afrique et Asie, $2^{\mathrm{e}}$ trimestre, 1957, pp. 15-25 ; STEVENS (G.S.), « Arab Neutralism and Bandung », Middle East journal, printemps 1957, pp. 139-152. 
et financière des deux blocs. N'oublions pas enfin les cas où l'adhésion aux positions neutralistes s'accompagne, en fait d'une sympathie, plus ou moins ouverte, en faveur de l'un des deux camps (en fait assez souvent l'U.R.S.S.).

En dépit, ou peut-être à cause, de cette plasticité, le neutralisme connaît aujourd'hui un développement considérable. Devenu en somme l'une des composantes de l'esprit de Bandoeng, il gagne chaque année de nouveaux adeptes et, pratiquement, la plupart des États récemment entrés aux Nations Unies ont tendance à s'en réclamer. On peut certes interpréter ce mouvement de façons diverses; des commentateurs ont souligné les ressemblances du neutralisme actuel avec la politique des États Unis au XIX ${ }^{\mathrm{e}}$ siècle ${ }^{1}$. On ne saurait, en tout cas, l'assimiler à la neutralité même en qualifiant celle-ci d'« active ${ }^{2}{ }^{2}$ : d'une part, beaucoup d'États neutralistes ne disposent pas des moyens militaires qui leur permettraient, le cas échéant, de soutenir et de défendre une position classique de neutralité; d'autre part et surtout, contrairement à un usage linguistique qui tend à se répandre, les «neutralistes » ne sont nullement «neutres » dans les affaires mondiales, prenant constamment position et, volontiers de façon unilatérale, sur les problèmes de l'heure ${ }^{3}$. Jusqu'à présent, l'U.R.S.S. a tendu à favoriser, non sans quelque habileté, la tendance au neutralisme qui s'est souvent soldée, spécialement chez les États sous-développés, par un relâchement des liens avec l'Occident.

[p. 169] Il ne s'agit donc pas d'un mouvement international concerté, mais d'un ensemble d'attitudes nationales divergentes dans leur inspiration et, en plusieurs cas, convergentes dans leurs conséquences pratiques (attitudes déjà très agissantes dans les pays arabes et asiatiques, et de portée plus limitée en Europe où les divers plans de « désengagement » n'ont trouvé qu'une audience restreinte). L'idéologie va ainsi d'un «non engagement» tourné vers l'Occident au neutralisme épaulé par le camp socialiste. Cette fluidité permet la réalisation d'actions et de manœuvres communes entre États dont l'inspiration et le mode d'organisation comportent, en réalité, des divergences notables (Égypte, Ghana, Inde, Indonésie, Yougoslavie).

La diffusion de cette idéologie a, sans doute, été facilitée par d'innombrables groupes dans les différents pays ainsi que par plusieurs organisations internationales privées (certaines internationales syndicales en particulier). Elle a cependant trouvé ses meilleurs atouts dans des éléments beaucoup plus profonds (par exemple, la méfiance des peuples ex-colonisés à l'égard de l'Occident).

1 NORTHROP (F.S.C.), « Neutralism and United States Foreign Policy », Annals of the American Academy of Political and Social Science, juillet 1957, pp. 42-68.

2 Selon l'expression utilisée par KRIPALANI (A.J.B.) pour définir la position de l'Inde in « For principled neutrality. A new Appraisal of Indian Foreign Policy », Foreign Affairs, octobre 1959, pp. 46-60.

3 Sur ce problème, MORGENTHAU (H.J.), « Neutrality and Neutralism », Yearbook of World Affairs, 1957, pp. 47-75 ; ZARTMAN (I.W.), « Neutralism and Neutrality in Scandinavia », Western Political Quarterly, juin 1954, pp. 125-160; FROHMAN (H.), "An Analysis of Neutrality and Modem Neutralism », Journal of International Affairs, 1958, n 2, pp. 187-192 ; ARMSTRONG (H.F.), « Neutrality : Varging Tunes », Foreign Affairs, octobre 1956, pp. 57-71. 
L'enseignement qui se dégage de cette section est clair: un critère précis et indiscutable (au sens d'une solution excluant l'interprétation) manque pour distinguer sur la scène politique ce qui est groupe de pression de ce qui ne l'est pas. Admettons que la complexité (et dans une large mesure l'«impureté ») des formules de la pratique rende difficile la sélection d'un facteur unique, convenant à toutes les situations. Admettons aussi que, dans la majorité des cas, une sorte d'accord empirique s'institue entre les spécialistes quant au contenu de la catégorie : l'essentiel des organismes susceptibles d'être étudiés entre, sans trop de difficulté, dans le cadre courant. Pourtant, faute d'un effort théorique suffisant, les frontières de celui-ci restent vagues et, sur certains points, encore totalement indéterminées: ces imperfections sont très fâcheuses pour qui voudrait tenter d'établir un modèle général de la vie politique ${ }^{1}$.

En vue de résoudre le problème, on est allé jusqu'à proposer d'en renverser les termes : au lieu de raisonner sur le groupement, il s'agirait de partir du résultat de son fonctionnement, c'est-à-dire de l'activité déployée par des hommes agissant en groupes dans le dessein d'influencer l'action gouvernementale (ce que les AngloSaxons appellent d'une [p. 170] expression intraduisible Public policy) ${ }^{2}$. Mettant l'accent sur la notion d'activité, et une activité de nature collective, ce critère apporte une réponse catégorique à certaines des questions soulevées. Il prend un relief particulier si l'on inclut dans les actes de pression toutes les interventions et démarches, d'où qu'elles viennent (syndicats professionnels, et aussi assemblées parlementaires, fonction publique, etc.) dès lors que leur but est d'influencer le cours de la politique en général ou de peser sur une décision particulière. L'adoption du critère revient alors à accepter la thèse, d'audience spécialement américaine, qui fait du groupe la base de la vie politique : si on la repousse, on retrouve, bien entendu, en se servant de l'approche «activité » des incertitudes identiques à celles rencontrées avec l'approche « groupement».

Peut-être jugera-t-on raisonnable de différer toute utilisation nouvelle de la catégorie " groupes de pression » jusqu'au moment, lointain encore, où ces difficultés seront résolues selon des principes uniformes Mais d'un autre côté, la recherche gagne à être poursuivie simultanément sur plusieurs fronts et c'est ce qui paraît justifier notre propos de définir une catégorie spécifique de groupes. N'oublions pas toutefois, ce faisant, les imperfections de la notion-mère.

Beaucoup d'historiens et de sociologues éprouveront une méfiance instinctive à l'égard d'un projet tendant à introduire dans un cadre nécessairement affecté de quelque rigidité une matière d'une extraordinaire richesse et d'une grande fluidité. Appréhension légitime si l'on considère les déformations et mystifications que

1 Ces insuffisances ont été correctement soulignées par Samuel ELDERSVELD dans l'ouvrage collectif EHRMANN (H.), (ed.), Interest Groups on Four Continents, Pittsburgh, 1958, pp. 173195. Voir aussi ALMOND (G.), " The Comparative Study of Interest Groups », American Political Science Review, mars 1958, pp. 270-282.

2 D. BLAISDELL semble très proche de cette conception, American Democracy under Pressure, New York, 1957, pp. 54-65. 
provoque ou permet le maniement des concepts traditionnels (pouvoir, autorité, régime présidentiel, parlementarisme, prolétariat...). Il semble possible de diminuer ces réserves en n'attribuant aucune valeur ontologique aux catégories retenues : ce sont de simples instruments de travail que l'on abandonnerait sur-le-champ si une technique plus efficace se trouvait disponible.

La construction de cette classe se ramène, en somme, à donner un sens assez précis pour être opérationnel au terme "international ». Or, il est souvent utilisé en une acception approximative et sans référence à la présence de caractéristiques déterminées. En matière commerciale, par exemple, les journaux financiers parlent volontiers de sociétés internationales, caractérisant simplement par là des affaires dont le déroulement s'étend à l'échelle mondiale. La désignation ainsi faite n'a qu'un [p. 171] caractère littéraire : on peut dire qu'elle n'engage en rien son auteur. L'objectif premier de cet effort est donc de donner au terme « international », dans son application aux groupes, une signification contraignante et sans équivoque.

Une conception simple serait de partir de la sphère d'action: serait dit « international » tout groupe exerçant simultanément son activité en deux ou plusieurs pays (une exigence plus rigoureuse pouvant éventuellement être formulée: par exemple, une dizaine de pays). Ce facteur d'extension territoriale n'est certes pas à dédaigner dans l'étude du sujet et on l'utilisera à diverses reprises. Mais il est trop flou et élémentaire pour constituer un principe solide de répartition des groupes. La différenciation envisagée n'aura de valeur heuristique que si on la fonde sur de nettes divergences dans les propriétés habituelles des groupes. D'après quels éléments tracer la ligne de séparation?

\section{2. À LA RECHERCHE D'UN CRITÈRE LE STATUT DE L'ORGANISME}

$\underline{\text { Retour à la table des matières }}$

Est-il possible de distinguer les groupements qui se rattachent à l'ordre international de ceux liés à un système national particulier ? Ce serait évidemment un procédé commode de répartition s'il était utilisable, plus exactement s'il était possible de l'appliquer, sans introduire une discordance sérieuse entre la réalité des rapports observés et l'esprit du schéma qui tend à les traduire. Il convient parfaitement au Saint-Siège auquel la coutume confère une personnalité internationale (ou au moins plusieurs attributs de celle-ci). Pourtant, avant d'émettre un jugement général sur la valeur de la «nationalité » comme critère, on doit examiner deux cas particuliers : les sociétés commerciales et les associations sans but lucratif (organisations non gouvernementales).

Observons au préalable que plusieurs juristes contestent qu'il soit souhaitable d'appliquer le concept «nationalité » aux personnes morales (le rapport ainsi qualifié n'ayant à peu près rien à voir avec la nationalité des personnes physiques). Il leur 
parait absurde de traiter la société ou l'association comme une sorte de «fétiche » indépendant de la qualité de ceux qui en sont membres. D'où l'emploi d'autres notions comme celle de l' « allégeance » pour caractériser la situation.

[p. 172] N'ayant aucune compétence pour entrer dans ces controverses juridiques, nous utiliserons ici les notions traditionnelles, mais sans oublier les courants qui les mettent en cause.

\section{a) CAS DES SOCIÉTÉS COMMERCIALES}

$\underline{\text { Retour à la table des matières }}$

Les juristes posent en général qu'une société doit nécessairement être soumise à la loi d'un pays déterminé. Dans la mesure où l'on admet que la notion de " nationalité » convient aussi aux personnes morales, ils déclarent qu'il ne saurait y avoir de sociétés sans nationalité ou en possédant plusieurs (position qui n'est pas absolument confirmée par la jurisprudence). On qualifie parfois dans le langage non-juridique certaines sociétés d'internationales : c'est là, on vient de le dire, une appréciation de fait fondée, par exemple, sur l'ampleur des liaisons à travers le monde, et non la formulation d'un diagnostic légal.

Certes, comme l'a noté G. Ripert, il ne serait pas impossible de concevoir de véritables sociétés internationales. Jusqu'à présent, aucun statut n'a encore été établi à cet effet ${ }^{1}$. On peut relever dans la pratique récente la constitution de divers organismes auxquels certains attribuent la qualité de " sociétés internationales » : ces organismes, peu nombreux d'ailleurs, résultent chacun d'une convention particulière intergouvernementale. En principe, réserve faite de quelques orientations très nouvelles, il n'existe aujourd'hui que des sociétés nationales, quel que soit le critère mis en œuvre pour établir cette nationalité. Dès lors dans un pays quelconque, on trouve seulement des sociétés nationales et étrangères.

Au niveau des très grandes firmes capitalistes, ce trait contraste avec la diffusion internationale des actions par l'intermédiaire des divers marchés de valeurs. Cette dispersion du capital entre des actionnaires de nationalité différente, est plus ou moins accentuée selon les sociétés ; dans le cas très fréquent où le capital est représenté par des titres au porteur, on ne peut en avoir qu'une notion approchée. Cette internationalisation du capital reste parfaitement compatible avec la gestion de

1 In Traité élémentaire de droit commercial, $4^{\mathrm{e}}$ édition, Paris, 1959, $1^{\mathrm{er}}$ volume, pp. 716-717. Pour une étude de plusieurs des problèmes évoqués dans cette rubrique, voir ABRAHAM (R.), Les sociétés en droit international privé, Paris-Liège, 1957. Voir enfin, un récent ouvrage de l'Institut de Droit Comparé de l'Université de Paris, La personnalité morale et ses limites. Études de Droit comparé et de Droit international Public, par S. BASTID, R. DAVID... Paris, 1960. Pour une étude du problème dans le cadre européen consulter les Actes du colloque des Facultés de droit, Lille, juin 1959, parus sous le titre : Les problèmes juridiques et économiques du Marché commun, Paris, 1960 - en particulier SAVATIER (René), «Le Marché commun au regard du droit international privé », pp. 55-71. 
l'affaire par un groupe purement national, la fraction du capital qui ouvre en fait la voie à cette gestion et en garantit l'exercice étant d'autant plus réduite que le capital est plus dispersé. Il arrive aussi que des dispositions soient arrêtées pour éviter qu'une trop grande proportion du capital ne tombe en des mains étrangères.

[p. 173] Ces mesures peuvent résulter de décisions prises par l'affaire elle-même : contrôle financier de la répartition du capital en employant éventuellement des procédés institués par la loi à cet effet (moyens très variables selon les pays : actions de fondateurs ayant seules le droit de vote, actions à vote plural...). Nestlé a récemment entrepris une politique de ce type dans la crainte que, d'ici quelques années, les actionnaires étrangers n'aient acquis la majorité ${ }^{1}$. Il arrive aussi que l'initiative vienne du législateur lui-même: ainsi le texte relatif à l'Organisation Commune des Régions Sahariennes prévoit-il qu'en vue de sauvegarder le caractère national de la gestion des ensembles industriels, le capital des sociétés créées dans ce but pourra comporter des actions privilégiées (mesure qui ne semble pas pleinement compatible avec le souci, affiché par ailleurs, d'obtenir le concours de nombreuses forces étrangères pour la mise en valeur de ce territoire) ${ }^{2}$.

Au niveau de la grande firme capitaliste, la possession d'une nationalité unique contraste avec une politique commerciale d'ambition internationale, sinon pleinement mondiale. Cette pénétration à l'étranger s'effectue par des procédés divers entre lesquels la sélection s'opère d'après la stratégie de la firme et aussi selon les impératifs des législations locales. La firme peut se présenter sous son propre nom en ouvrant des succursales ou des comptoirs ; dans d'autres cas, elle sera conduite à créer des filiales répondant aux exigences légales du pays d'installation (cette solution pouvant lui être imposée par des dispositions réglementaires). Le groupe (au sens technique du terme), sera le plus souvent constitué par des sociétés ayant des nationalités différentes. Nestlé, par exemple, se compose de 120 sociétés réparties dans 64 pays: à travers elles, le groupe dispose de 150 usines, occupe 65000 personnes, gère 450 marques. Mais, sur le plan juridique, cela n'aboutit nullement à créer une unité internationale. Il existe une société de tête (en plusieurs cas une société holding), ayant une nationalité déterminée et contrôlant toutes les autres par le fil habituel des participations.

La jurisprudence française fait volontiers choix du siège social comme critère de la nationalité. Elle exige, bien entendu, qu'il s'agisse du centre réel de l'activité (sans demander absolument la concentration de tous les éléments de direction dans le pays) : si le tribunal a des raisons de suspecter le caractère fictif de ce siège, il lui revient, par une enquête de fait, d'établir la nature des attaches et, éventuellement, de [p. 174] dénoncer la simulation. À ce système s'oppose la théorie anglo-saxonne du contrôle qui retient habituellement comme critère la nationalité effective du personnel de direction et des détenteurs du capital social. Parmi d'autres critères concevables, citons le lieu d'incorporation ou le centre d'exploitation.

Voir un schéma de l'organisation financière de Nestlé, in Entreprise, 25 juin 1960, pp. 17-19.

Pour l'étude de l'O.C.R.S. voir THOMAS (Marc-Robert), Sahara et Communauté, Paris, 1960. 
Cependant le critère du siège a parfois été abandonné en France, spécialement durant la première guerre mondiale, les tribunaux s'efforçant de démasquer les biens ennemis (spécialement allemands), dissimulés sous une apparence juridique française. Ce critère cèdera alors le pas à la notion de contrôle, qui implique la recherche des propriétaires effectifs. Ainsi, une circulaire ministérielle du 29 février 1916 recommandait aux tribunaux de considérer comme ennemie toute société dont la direction ou les capitaux étaient en majeure partie aux mains de sujets ennemis. Les traités de paix ont d'ailleurs consacré cette pratique à propos de la liquidation des actifs situés dans les pays alliés et appartenant à des sociétés «contrôlées » par l'ennemi.

Mais les tribunaux français n'ont vu là qu'une position de circonstance dictée par les hostilités et l'état de péril national. Ainsi, après la première guerre mondiale, reviendront-ils rapidement à leur critère traditionnel. Un indice typique de cette attitude est l'application des lois sur la "propriété commerciale » à des sociétés à actionnaires étrangers, mais régulièrement domiciliées en France. En définitive, la jurisprudence n'emploiera plus guère la notion de contrôle que sur les instructions expresses du législateur (dommages de guerre ; concessions de ressources minières et d'énergie hydraulique; primes à la marine marchande ; groupage et distribution des journaux...). Sur cette base, on en arrive à des phénomènes de double nationalité, les tribunaux attribuant aux sociétés des affiliations différentes selon le problème considéré.

Une telle attitude s'explique si l'on envisage les difficultés considérables que comporte l'élucidation du contrôle. Dans des cas délicats, on peut soupçonner ou présumer que les actionnaires déclarés agissent en fait pour le compte d'autres personnes («l'homme de paille»), mais la technique des opérations financières permet des manœuvres nombreuses et subtiles, difficiles à déceler. En se fondant sur la notion de contrôle, on peut soutenir des positions s'inspirant davantage de considérations politico-économiques que de mobiles d'ordre strictement juri-[p. 175] dique. L'attitude américaine dans l'affaire de l'Interhandel ne semble pas exclusive de motivations extérieures au droit pur ${ }^{1}$.

Étant donné la complexité et l'enchevêtrement des liaisons, la notion de contrôle sera souvent utilisée dans les procès internationaux: elle n'aboutit pas à nier le principe de l'unité de la nationalité de la société, mais à définir ce lien par un autre critère que le siège social. Malgré les contestations pratiques et mêmes les abus de puissance, auxquelles cette notion peut donner lieu, elle est la seule qui convienne à l'analyse politique.

Le cas de la Compagnie de Suez illustre clairement le sens de ce débat. Encore qu'il n'ait pas constitué l'élément dominant de l'affaire, ce problème de la nationalité en a été un aspect important. La société concessionnaire s'intitulait Compagnie Universelle du Canal Maritime de Suez, mais son siège social fut fixé dès le début à

1 Voir le remarquable exposé de C. PERRIN in Annuaire suisse de droit international, 1958, pp. 3992. 
Alexandrie. Cependant l'administration même avait été placée à Paris et, à diverses reprises, le gouvernement égyptien avait dispensé la Compagnie de certaines obligations de droit local (en particulier de la loi du 29 juillet 1947, sur la composition des sociétés égyptiennes). Quelle était donc la nationalité de la compagnie à la veille de la nationalisation ?

Lors de la Conférence de Londres sur le Canal (août 1956), le ministre français des Affaires étrangères, $M$. Christian Pineau, a soutenu que la Compagnie relevait à la fois de la loi égyptienne, de la loi française et du droit international. Il l'a définie comme égyptienne par le siège de ses activités et universelle par son objet. Un juriste éminent, Georges Scelle, est allé plus loin. « Selon nous, écrit-il, la Compagnie n'était en réalité, ni égyptienne, ni française : elle n'avait qu'une nationalité d'emprunt, à moins qu'on ne veuille qualifier de façon purement formelle la nationalité de rattachement à un ordre juridique quelconque. En réalité la Compagnie est internationale ${ }^{1}$.

Cette position correspond peut-être à une vue d'avenir dans le domaine des relations internationales: pour l'instant, la notion de société internationale n'existe pas. Aucun des arguments avancés par G. Scelle n'est convaincant (capital entièrement entre les mains d'étrangers - en fait, le gouvernement britannique et des porteurs français; - minorité d'Égyptiens au Conseil d'administration, recettes ne provenant en rien de l’Égypte...). Certains de ces traits étaient en voie d'atténuation. Ainsi, la Compagnie s'était-elle engagée à procéder à une large « égyptia-[p. 176] nisation » de son personnel : élévation progressive de deux à sept du nombre des administrateurs égyptiens; augmentation du personnel local dans les services d’Égypte (à compter de 1949, quatre Égyptiens sur cinq vacances pour les emplois techniques, neuf sur dix pour les emplois administratifs) ; engagement par priorité aux prochains postes vacants de vingt capitaines-pilotes égyptiens, etc. (informations puisées dans le Bulletin de la Compagnie, 15 mars 1949).

L'application du critère d « effectivité » (notion de contrôle) aurait pu éventuellement pousser les intéressés à revendiquer une autre nationalité (française ?) que l'égyptienne, mais cette thèse se serait probablement heurtée à de fortes objections. Ne la soutenant pas, c'est-à-dire n'ayant pas le désir ou les moyens de poser le problème de la nationalité sur le plan des réalités économiques, on était nécessairement conduit, par la règle de l'unité, à attribuer à la Compagnie de Suez le caractère d'une société égyptienne ; ce qu'à la lumière du système français du siège social, il semble raisonnable d'admettre qu'elle était ${ }^{2}$.

1 In Bulletin de la Compagnie.... octobre 1957. Voir également son étude in Annuaire français de droit international, 1956, Paris, 1957 (condamnation de la nationalisation à partir de la notion « progressive » de domaine public international mais critique de l'intervention anglo-française).

2 En ce sens, GEOUFFRE de LA PRADELLE (R. de), "L'Égypte a-t-elle violé le droit international ", Internationales Recht und Diplomatie, 1958 (1), pp. 20-27. Dans le même sens, CALVERT (H.), « The Nationalization of the Suez Canal Company in International Law », Annual Law Review, décembre 1957, pp. 30-57. 
Ne peut-on en trouver une preuve supplémentaire dans la loi du $1^{\mathrm{er}}$ juin 1957 (J.O., 3-4) (« déclarant sans effet, sur une société régie par la loi française, les dispositions d'une loi étrangère ») si l'on considère que ce texte avait pour but d'abroger « les dispositions des statuts de la Compagnie soumettant à l'approbation du gouvernement égyptien l'exécution des résolutions de l'assemblée générale tendant à apporter des modifications ou des additions aux dits statuts »? On imagine mal une « société internationale » dépendant de l'approbation d'un gouvernement déterminé, à l'exclusion de tout autre, pour modifier ses statuts.

Le cas pourtant privilégié de Suez confirme donc, entre autres enseignements, l'absence d'une catégorie "sociétés internationales". Compte tenu de tendances récentes, il n'est pas possible, du moins pour l'avenir, d'attribuer à cette observation une portée définitive. Voici une brève présentation de ces essais qui se rattachent aux efforts d'unification européenne.

Le premier se manifeste dans la recommandation de l'Assemblée générale du Conseil de l'Europe pour la création de compagnies européennes (adoptée en 1952, après modification profonde d'une proposition soumise en 1949 et à la rédaction de laquelle collabora l'Institut International pour l'Unification du Droit Privé). L'art. 1 de ce texte ouvre la possibilité de l'octroi d'un «statut européen » à des compa-[p. 177] gnies privées bénéficiaires d'une concession de service ou de travail public. Notons toutefois que cette recommandation n'avait pas pour objectif de constituer une catégorie ouverte ad libitum (comme l'est aujourd'hui en France la formule de la société anonyme). Il était formellement prévu que l'octroi du statut européen, loin d'être acquis de plein droit par la seule application de la convention générale, résulterait d'un accord particulier conclu entre les États intéressés ${ }^{1}$.

Selon certains, le principal mérite de cette proposition, qui semble avoir inspiré au moins partiellement la création d'Eurofima (supra), aurait été de susciter le chapitre $\mathrm{V}$, «Entreprises communes », du traité instituant la Communauté Européenne de l'Énergie Atomique. Selon l'art. 45, peuvent être constituées en entreprises communes avec les avantages attachés à cette qualité, celles «qui revêtent une importance primordiale pour le développement de l'industrie nucléaire dans la Communauté ». Le projet peut émaner de la Commission, d'un État membre ou de toute autre initiative (et donc d'un particulier ou d'un groupe de particuliers). Mais la formule « entreprises

Pour un commentaire de ce système voir ADAM (H.T.), Les établissements publics internationaux, op. cit., pp. 27-39 (avec le texte de la recommandation). À une époque récente, le souci d'associer les capitaux étrangers au développement de l'Union française conduisit divers auteurs à préconiser des formules dont la mise en œuvre aurait provoqué une internationalisation de fait et sur certains points, de droit des sociétés. Voir LATTRE (J.M. de), La mise en valeur de l'ensemble euroafricain français et la participation de capitaux étrangers. Sociétés à participation étrangère. Compagnies à chartes, Paris, 1954. Plus récemment, on a proposé (Barreau de Paris) de créer dans le cadre du Marché commun, une formule de sociétés par actions «de type européen " (Jean CHEVALIER, Banque, août 1960, pp. 495-497) : notons qu'il s'agit seulement de créer un type universel de société commun à toutes les législations du Marché commun, de manière à unifier les conditions de création et de fonctionnement des affaires. Ce serait un pas vers la création d'un statut international (au moins sur le plan européen). 
communes » n'est pas non plus une catégorie ouverte: l'octroi de cette qualité s'effectue au terme d'un long processus qui s'achève par une décision du Conseil ${ }^{1}$.

On ne saurait encore prévoir l'usage qui sera fait de ces dispositions. Sur le plan de la typologie on rappelle la proposition émise par H.T. Adam de classer les entreprises communes, en compagnie d'autres unités, dans la rubrique des « établissements publics internationaux ». D'autres préfèrent peut-être employer pour les définir l'expression "sociétés internationales ». On peut penser que la question n'est pas encore assez mûre pour justifier l'établissement d'une formulation définitive. Le seul point qui compte ici, est le nombre extrêmement réduit d'activités relevant d'un tel mode d'organisation. C'est donc à la formule de l'entreprise nationale (au sens où elle possède une nationalité déterminée) que l'on doit toujours se référer dans la construction du schéma.

Revenons cependant, pour achever cette brève esquisse, à la position de ceux qui refusent d'utiliser le concept «nationalité » dans l'ordre des sociétés commerciales : en particulier Suzanne Bastid et François Luchaire (dans l'ouvrage cité à la note 1, p. 172). Ces auteurs proposent de lui substituer une double « allégeance », juridique et politique, dont voici l'idée de base.

[p. 178] L'allégeance juridique serait déterminée par le lieu du siège social. Sous réserve de plusieurs limitations, les intéressés disposent à cet égard d'une faculté d'option, mais ils sont ensuite liés par le choix réalisé. Une société fondée en France par des hommes d'affaires américains devient, sous cet angle, une société de droit français. L'allégeance politique se fixe au contraire d'après la nationalité de ceux qui forment ou contrôlent l'entreprise : autrement dit, abstraction faite des techniques de «camouflage», les membres ne peuvent échapper, de ce point de vue, aux conséquences de leur qualité propre. Notre société américaine reste en état de rapport politique avec le gouvernement des États-Unis. Conséquence fondamentale : tout en étant de droit français, la société demeure politiquement étrangère à la France.

Sans discuter la valeur juridique de ce système, nous observerons qu'il présente un réel intérêt pour l'analyse politique des situations qui se caractérisent par une divergence entre les deux ordres d'allégeance. Se plaçant sous la dépendance de l'ordre juridique français, la société américaine qui a installé son siège en France reste sous la protection que le gouvernement américain accorde à ses nationaux (et particulièrement la « protection diplomatique »). Sur cette base, la Compagnie du Canal de Suez, société de droit égyptien, relevait du gouvernement de l’Égypte (allégeance juridique), les porteurs français d'actions ayant droit à la protection diplomatique de leur gouvernement (allégeance politique).

Mais qu'arrive-t-il si le capital de la société est réparti entre associés de nationalité différente ? Les tribunaux admettent aujourd'hui que l'État est fondé à protéger ses nationaux même s'ils ne sont pas majoritaires (position dite de l'« intérêt substantiel ». Il semble à S. Bastid et F. Luchaire que la protection serait complète si l'on faisait

1 Pour un commentaire, voir ERRERA (J.) et al., Euratom. Analyse et commentaire du Traité, Bruxelles, 1958, pp. 108-115. Voir aussi ADAM, op. cit., pp. 174-189. 
disparaître la fiction de la personnalité morale : c'est là un point qui sort de notre débat.

\section{b) CAS DES ASSOCIATIONS}

$\underline{\text { Retour à la table des matières }}$

La catégorie des organisations non gouvernementales, dont de nombreux membres ont été mentionnés dans le précédent chapitre, offre un paradoxe : se développant sur une large échelle et mobilisant d'importantes ressources, elle demeure pourtant très négligée par les commentateurs. Les travaux donnant une présentation d'ensemble du phé-[p. 179] nomène sont rarissimes ${ }^{1}$. Ce silence tient partiellement au culte universitaire pour les sujets rebattus (la révision de la Charte...) et aussi à une évaluation pessimiste de l'activité de ces organismes. Ce jugement serait admissible s'il était formulé en conclusion d'une longue enquête et avec un matériel probatoire à l'appui : énoncé a priori, il traduit un parti pris ou une ignorance. Avant d'aborder l'examen du statut juridique des O.N.G. il est donc nécessaire de préciser rapidement leur place dans la société internationale : on y parviendra en utilisant les recherches de l'Union des Associations Internationales (U.A.I.) généralement publiées dans la revue Associations.

Éléments d'information - En 1958, l'U.AI. a recensé 1060 organisations internationales non gouvernementales (auxquelles s'ajoutent 12 organisations nationales consultatives) ${ }^{2}$. Encore que les totalisations effectuées en cette matière

1 Le principal, et quasi-unique effort, est à porter au crédit de WHITE (Lyman Cromwell), The Structure of Private International Organizations, Philadelphie, 1933, et International NonGovernmental Organizations. Their purposes, rnethods and accomplishments, New Brunswick, 1951 : nous avons largement utilisé ces deux ouvrages, surtout le second. Pour une présentation très rapide PICKARD (Bertram), The Greater United Nations. An essay concerning the place and significance of international non-governmental organizations, New York (Carnegie Endowment), s.d. Pour un exposé déjà ancien, mais toujours utile, voir NORMANDIN (André), Du statut juridique des associations internationales, Paris, 1926. Consulter également CAHIER (Philippe), Étude des accords de siège conclus entre les organisations internationales et les États où elles résident, Genève, 1959 (thèse de l'Institut Universitaire de Hautes Études internationales). Voir aussi EAGLETON (C.), International Government, revised edition, New York, 1948 (spécialement pp. 157-188), et POTTER (P.B.), An Introduction to the Study of International Organization, $5^{\mathrm{e}}$ édition, New York, 1948 (spécialement pp. 35-45). Nous avons trouvé mention dans une bibliographie, sans être en mesure de le consulter, d'un travail en langue espagnole, BARCENA Y GUZMAN (José de), Manual de las Organizaciones Internacionales. Madrid, 909 p. (dactylographié). Voir les observations de B. AKZIN sur ce problème, in New States and International Organizations, Paris, 1955, pp. 40-45.

2 Voir «Un réseau inextricable », Associations, octobre 1958, pp. 680-686. On observera que le chiffre de 1060 est sensiblement inférieur à celui (indiqué au chapitre précédent) des organisations fondées depuis le Congrès de Vienne et encore en vie (1 170). La différence s'explique probablement par un effort de sélection de l'U.A.I. qui écarte de son annuaire les organismes ne répondant pas à certains critères. 
soient rarement précises, il n’est pas sans intérêt d'en souligner quelques caractéristiques globales.

$1^{\circ}$ Nombre de membres : il est sans doute considérable. On peut, au premier abord, le fixer à plusieurs centaines de millions. Quelques-unes de ces organisations dépassent chacune le chiffre de 100 millions (Alliance Coopérative Internationale ; Fédération Syndicale Mondiale; Ligue des Sociétés de la Croix-Rouge...). La Fédération Démocratique Internationale des Femmes (organisation para-communiste) déclare un chiffre de 200 millions. Ces indications doivent être interprétées avec prudence : on ne possède aucun moyen d'en vérifier l'exactitude et, surtout, aucune information n'est donnée sur le sens et la qualité de l'adhésion. De plus, il est clair qu'une fraction appréciable de ces membres est commune à plusieurs organisations (affiliations multiples). Ces réserves faites, on doit admettre que les O.N.G. touchent, avec une efficacité diverse, un public important.

Il n'existe, bien entendu, aucune relation rigide entre le nombre des membres et la puissance de l'organisme. Rappelons à cet égard que le maximum statutaire des membres du C.I.C.R. s'élève à 25. D'un autre côté, on classe dans la catégorie « membres » des éléments parfaitement hétérogènes. En un sens, l'Association du Transport Aérien International n'a que 80 adhérents, mais il s’agit des compagnies de navigation aérienne de plus de 50 pays qui assurent la plus large part du trafic mondial. Cependant, spécialement dans les instances internationales, [p. 180] la référence à un recrutement massif constitue toujours un argument solide.

$2^{\circ}$ Domaines d'activité : Ils sont très nombreux et couvrent pratiquement, on l'a vu, les divers secteurs des relations humaines. On observe à ce niveau la même tendance à la spécialisation que sur le plan interne : ce phénomène, qui n'est pas exclusif d'un émiettement des forces, s'affirme à propos de l'objet choisi (engendrant des associations à préoccupations étroitement définies) et aussi dans l'ordre du cadre géographique (provoquant parfois la naissance d'organismes voués à un continent ou une région). Si l'on tente de regrouper ces efforts en quelques secteurs, on observe que plusieurs grandes séries de motivations sont à la base des O.N.G. : intérêts économiques et financiers ; alignements sociaux; préoccupations idéologiques, religieuses et humanitaires ; affinités techniques ; communauté de travail scientifique. Il existe aujourd'hui, en particulier, beaucoup d'O.N.G. réunissant professeurs et chercheurs dans les diverses branches de la connaissance.

L'« intérêt commun » qui sert de base à ces groupements est donc très diversifié. Ceux qui déclarent un engagement direct dans la politique sont assez rares (une vingtaine au maximum). D'un autre côté, beaucoup de ces organisations sont mal outillées pour faire pression sur l'appareil gouvernemental ou n'en ressentent nul besoin pour la réalisation de leur but. Cependant plusieurs de ces groupements défendent en réalité des positions politiques, au besoin malgré la lettre des statuts, ou passent par la voie gouvernementale pour accomplir leur programme.

$3^{\circ}$ Puissance financière : elle est dans l'ensemble très mal connue. Les 327 organisations ayant répondu à l'enquête de l'U.A.I. en 1958 ont déclaré, ensemble, des 
ressources budgétaires de 290 millions de dollars. Ce chiffre est sans doute fort inférieur au total des sommes manipulées par les O.N.G. (il ne comprend certainement pas les ressources des organisations para-communistes qui sont toujours silencieuses sur ce point, ni les dépenses d’organes comme le Réarmement Moral). Mais il paraît déjà important si on le compare au budget de 1958 des Nations Unies qui (y compris le programme élargi d'assistance technique et le Fonds pour l'Enfance) était de l'ordre de la centaine de millions de dollars (celui de l'Unesco d'une douzaine seulement). Le total ainsi présenté doit pourtant être interprété sur les 290 millions, 231 relevaient [p. 181] de la rubrique « religion, développement moral » (ce qui serait inexplicable sans l'inclusion dans ce poste des sommes considérables transitant annuellement par l'Agence juive pour la Palestine : 150 millions de dollars selon l'édition 1956-57 de l'Annuaire des Organisations Internationales, mais peut-être davantage pour l'année en question).

Nous avons, au total, le sentiment que les O.N.G. disposent, en bloc, de ressources assez considérables : mais, bien entendu, la répartition de ces sommes est très inégale, et la plupart de ces organes sont très mal pourvus financièrement. C'est là un facteur crucial quant à l'exercice d'une influence continue. Plusieurs de ces organisations reçoivent des subventions d'organismes intergouvernementaux (ou passent avec eux des contrats de services). Il y a de bonnes raisons de penser que la prospérité financière apparente de certaines d'entre elles tient au versement de subsides gouvernementaux. Pourtant, si l'on se réfère aux déclarations officielles, ce sont les cotisations des membres - dont le mode de fixation varie d'un organisme à l'autre, qui assureraient l'essentiel du fonctionnement ${ }^{1}$.

$4^{\circ}$ Structure administrative : nous n'insisterons pas ici sur le mode d'aménagement et de fonctionnement de ces associations. Tout en accusant des différences de l'une à l'autre, le système d'organisation s'inspire, dans l'ensemble, de certaines règles d'expérience commune. Encore que leurs attributions ne soient pas nécessairement identiques, on trouve, presque toujours, les mêmes organes ${ }^{2}$.

Un point intéressant est la réglementation du droit de vote dont on sait l'importance pour la prise des décisions internationales: d'une façon générale, les O.N.G. ont tendu à adopter le principe majoritaire (l'ampleur de la majorité requise variant selon les problèmes en cause). En de nombreux cas, la question la plus délicate est celle de l'attribution du nombre des voix : les discriminations établies à cet égard entre les membres relèvent de critères multiples ${ }^{3}$.

1 Voir BOCKSTAEL (C.), «Le système de cotisation dans les organisations internationales non gouvernementales », Associations, novembre 1957, pp. 769-772.

2 Du même auteur, "La structure des organisations internationales non gouvernementales ", Associations, avril 1958, pp. 251-254 et mai 1958, pp. 308-312. Dans la même revue, TIENNE (Pierre de), "Les problèmes d'organisation administrative qui se posent aux organisations internationales non gouvernementales », août 1959, pp. 569-576.

3 Encore de G. BOCKSTAEL, «Le vote dans les organisations internationales non gouvernementales », Associations, décembre 1957, pp. 839-844. 
Il n'est pas aisé d'évaluer la masse des personnes qui se consacrent à de tels organismes. Selon l'enquête de l'U.A.I. le chiffre des "personnalités dirigeantes » s'élèverait à 7642 . Il est difficile à interpréter : si, dans certains cas, les " personnalités dirigeantes » se bornent à prêter leur nom, il arrive aussi (niveau des petites organisations) qu'elles accomplissent les plus humbles besognes de secrétariat. Quant au «personnel », proprement dit, 478 réponses font état d'un total de [p. 182] 4837 employés (dont 1839 bénévoles). Ces données n'ont qu'un mérite : souligner l'existence d'une certaine bureaucratie permanente au sein des O.N.G. Mais, dans la plupart des cas, les secrétariats de ces organismes sont mal assurés.

$5^{\circ}$ Universalité des liaisons : beaucoup d’O.N.G., encouragées en cela par les organisations intergouvernementales, s'efforcent d'avoir le plus grand nombre possible de pays adhérents. La fragmentation idéologique du monde compromet souvent, on l'a déjà établi, ce souci de l'universalité (qui, d'ailleurs, lorsqu'on la recherche à tout prix, a des inconvénients notables). On peut prendre la question d'un autre côté en examinant l'ampleur respective de la participation des continents et des pays dans le mouvement O.N.G. Pour nous en tenir aux pays, mentionnons que, selon les données de 1956, les dix pays les plus représentés dans les O.N.G. étaient (par ordre décroissant) : France, Belgique, Pays-Bas, Allemagne, Italie, Royaume-Uni, Suisse, États-Unis, Suède, Autriche. On voit l'écrasante prépondérance de l'Europe occidentale en ce domaine ${ }^{1}$.

Traits caractéristiques — Venons-en maintenant au problème des caractéristiques juridiques de l'organisation internationale non gouvernementale, ou si l'on préfère, des qualités que l'on exige d'elle notamment pour l'admission auprès des instances internationales. La définition officielle due au Conseil Économique et Social de l'O.N.U. s'énonce ainsi : « Toute organisation internationale qui n'est pas constituée par un accord intergouvernemental sera considérée comme une organisation internationale non-gouvernementale » (résolution du 27 février 1950). Cette formule est si vague qu'on peut lui contester toute utilité. Il en résulte au surplus des situations curieuses, en particulier l'attribution de la qualité d'O.N.G. à des organismes entièrement constitués de services officiels sous prétexte que leur fondation ne résulte pas d'un accord intergouvernemental. Ainsi, la Commission Internationale de Police Criminelle (Interpol) créée à Vienne lors du II $^{\mathrm{e}}$ Congrès de police judiciaire. Groupant aujourd'hui les organismes de police criminelle d'une soixantaine de pays et fonctionnant uniquement avec des subventions étatiques, elle n'en jouit pas moins du statut consultatif auprès des Nations Unies et de deux Agences spécialisées (Aviation civile et Télécommunications).

\footnotetext{
Voir les indications fournies dans Associations, octobre 1957, pp. 707-711. Selon un tableau déjà ancien (données de 1954-55), sur 6209 dirigeants d'O.N.G, on aurait compté 879 Français, 807 Britanniques, 744 Nord-Américains, 481 Belges, 423 Suisses, 361 Néerlandais, 309 LatinoAméricains, 320 Italiens, etc. (d'après E.S. TEW, "Who's who in International Organizations », Associations, février 1955, pp. 87-90).
} 
[p. 183] En fait, on a l'habitude de définir les O.N.G. par la juxtaposition de certains critères. Voici la liste de ces éléments (étant toutefois observé que les divers auteurs ne leur attribuent pas la même valeur et même en rejettent formellement certains).

$1^{\circ}$ Nature privée de l'organisation. Beaucoup estiment nécessaire que la presque totalité des adhérents (groupes ou particuliers) appartiennent au secteur privé. Cependant même les plus exigeants reconnaissent que l'O.N.G. ne perdrait pas son caractère en admettant quelques membres gouvernementaux et en recevant des subsides des pouvoirs publics. La résolution de l'Ecosoc du 27 février 1950 a tranché ce débat en admettant au bénéfice de ces dispositions les organismes mixtes composés de représentants officiels et de collectivités privées. Cependant le développement des formes intermédiaires résultant de l'interpénétration croissante des deux secteurs crée, selon l'expression de G. Langrod, des " phénomènes innommés » à cheval entre les O.N.G. et les institutions intergouvernementales.

Un point très délicat, généralement passé sous silence (conformisme ou hypocrisie) est celui des instructions éventuellement données par les gouvernements à ceux de leurs ressortissants qui participent aux travaux de ces organismes et comptent parmi leurs dirigeants. Cette pratique déjà évoquée est probablement plus répandue qu'on ne veut bien l'admettre dès que les organismes touchent à des questions idéologiques ou à des événements brûlants. Les instructions revêtent des nuances multiples de contrainte, allant de la suggestion à l'ordre. Elles évitent l'improvisation, ce qui, selon certains fonctionnaires internationaux, aurait de bons côtés. Mais cet usage, même sous une forme atténuée, est en complète contradiction avec l'esprit du système.

$2^{\circ}$ Composition internationale. Pour la plupart des auteurs, c'est un point fondamental. Aucune organisation ne pourrait se déclarer internationale sans inclure des nationaux (particuliers ou groupes) d'au moins deux pays (certains avançant le chiffre de dix). Cette position est contestée à partir du cas du C.I.C.R. dont, on l'a vu, tous les membres sont statutairement de nationalité suisse (mais n'est-ce pas la seule exception connue à la règle).

Il nous paraît nécessaire d'insister sur le caractère international et de témoigner à cet égard d'une certaine intransigeance. En l'état actuel [p. 184] des choses, il semble que rien ne s'oppose à l'octroi de l'étiquette "internationale » à des associations constituées sur une base régionale (européenne ou asiatique, par exemple). Ce n'est peut-être pas là le dernier mot d'un problème complexe sur lequel on reviendra ${ }^{1}$. De toute façon, il faut prendre garde aux cas marginaux. Convient-il, comme on le fit parfois à l'O.N.U. de juger comme « internationales » les Fédérations syndicales des États Unis sous prétexte qu'elles ont un certain nombre de membres canadiens et,

$1 \quad$ Il n'existe pour l'instant aucune notion ou définition de l'organisation régionale. Certains proposent toutefois de les distinguer des organisations internationales sur la base de la limitation géographique du recrutement. Seules auraient droit à la qualité d'« internationales » les associations à vocation œcuménique. 
dans une moindre mesure, mexicains ? Pratiquement, beaucoup des syndicats des États-Unis sont, en cette acception limitée, internationaux. Les deux tiers des ouvriers canadiens syndiqués y sont affiliés, mais, à l'exception de l'industrie papetière, les éléments canadiens représentent à peine 10\% des membres.

$3^{\circ}$ Absence de but lucratif (ce que les Anglo-Saxons appellent activité non profitable). Ce critère est généralement tenu pour essentiel. Mais on a fait valoir la nécessité d'adopter une position souple à l'égard d'organismes qui réalisent effectivement des profits sans toutefois les considérer comme le but essentiel ou même premier de leur activité. L'exemple le plus connu est celui des coopératives, mais il en existe beaucoup d'analogues (mutualités, instituts bénévoles d'assistance ou de prévoyance). Dans des cas de ce type, le bénéfice obtenu est plutôt le résultat indirect du fonctionnement que sa raison d'être : il est soit distribué aux membres, soit employé à des tâches d'intérêt collectif. L'exception ainsi faite paraît admissible bien qu'elle risque d'engager sur une pente dangereuse.

$4^{\circ}$ Possession d'une structure corporative. La fonction de cette structure est d'assurer la permanence de l'association dans le sens de l'« institutionnalisation » de son but. C'est le problème fort débattu de la «personnalité morale» ou de l'« incorporation » qui garantit la stabilité de l'entreprise par delà les changements dans la composition physique de ses membres. Rien ne s'oppose à ce que l'association soit constituée pour une durée déterminée dès l'instant qu'elle peut fixer un terme à la réalisation de son objectif : l'essentiel est que la structure corporative de soutien soit assurée durant toute la phase d'activité (exigence soulevant un problème pour les « congrès périodiques » qui ne sont pas rattachés à une institution permanente).

[p. 185] $5^{\circ}$ Existence de moyens administratifs. Il s'agit de l'aménagement matériel ou du cadre d'organisation indispensable à un travail sérieux. Ce critère, formulé seulement par certains auteurs, se situe entièrement sur le plan d'une appréciation d'opportunité. Il n'est pas applicable à la définition de l'association internationale qui existe comme telle dès que certaines exigences sont remplies. Par contre, quand il s'agit d'attribuer divers avantages ou facultés (ou simplement l'inscription sur un annuaire) on peut se demander s'il n'est pas souhaitable d'exiger un minimum d'instruments matériels et d'activité effective.

Tels sont les principaux critères énoncés ou utilisés. Cependant un point complique la discussion : la variété des types d'O.N.G. qui a conduit certains à douter qu'il soit possible de les ramener à une commune mesure ${ }^{1}$. Cette variété s'exprime, on l'a déjà noté, au niveau des buts et on pourrait établir d'innombrables juxtapositions qui en sont significatives: Alliance Universelle des Unions Chrétiennes de jeunes Gens et Alliance Internationale du Tourisme, Association Mondiale des Femmes Rurales et Association Internationale du Calendrier, Bureau International contre l'Alcoolisme et Bureau International des Étalons Physicochimiques, Union Mondiale des Organisations Féminines Catholiques et Union

Voir Bulletin O.N.G., février 1951, pp. 36-39. 
Radio-Scientifique Internationale, etc. Mais la diversité est également considérable si l'on s'en tient à la composition.

Il est usuel de distinguer plusieurs types :

Les associations dont les membres sont des collectivités d'assiette nationale (réunissant soit des particuliers, soit des personnes morales, soit les deux). On considère parfois que la forme la plus parfaite de l'association est à deux degrés : des sections nationales (une par pays, de préférence) groupant à la base l'ensemble des intéressés, ces sections se rassemblant ensuite en une Confédération ou Fédération omninationale. Mais il n'est pas toujours possible ou opportun de réaliser un mécanisme d'une telle simplicité.

Les associations dont les membres sont des particuliers. Certains les qualifient du terme de «cosmopolites". Quelques-unes de ces associations (Instituts, Académies, Commissions...) ont un recrutement restreint, sinon fermé (cas de l'Institut de Droit International dont le recrutement est statutairement limité à 60 membres et 60 associés). D'autres, admettant une affiliation ouverte, possèdent un nombre d'adhérents plus élevé (Commission Internationale pour la Préven-[p. 186] tion de l'Alcoolisme, Société pour la Liberté de la Science, République des Citoyens du Monde...). Certains voient dans ces associations cosmopolites le meilleur instrument de la coopération internationale, les associations composées de groupes nationaux traduisant jusque dans leur structure les rivalités entre États et subissant en permanence les contre-coups des disputes politiques. Cependant, il ne semble pas aujourd'hui que la tendance soit en faveur du recrutement direct de particuliers.

Les associations dont les membres sont des collectivités internationales par exemple le Conseil International de la Philosophie et des Sciences Humaines.

En de nombreux cas, les diverses catégories de membres ne sont pas mises sur le même pied. Soit le Conseil des Organisations Internationales des Sciences Médicales. Formé d'O.N.G., il admet, mais seulement comme membres associés et à raison d'une par État, des institutions nationales (du type académie nationale de médecine ou comité représentatif des sciences médicales dans le pays considéré).

Naturellement, il existe beaucoup d'associations «composites », c'est-à-dire groupant plusieurs sortes d'éléments. Une combinaison simple est celle qui rassemble des adhérents individuels et des membres collectifs nationaux (cas, entre autres, de l'Association Internationale pour la Protection de la Propriété Industrielle qui admet des organisations nationales, des entreprises industrielles et des particuliers). Il existe aussi des combinaisons plus complexes, comme celle de l'Association Universelle pour l'Espéranto qui réunit des organisations nationales et locales, des groupements internationaux de spécialistes, des particuliers. Il est inutile de mentionner ici la gamme, assez étendue, des combinaisons possibles ${ }^{1}$.

Voir Bulletin O.N.G., février 1951, pp. 36-39. 
Statut des organismes - Quelques mots suffisent à le caractériser. En dépit d'efforts répétés, il n'existe aucun statut international dont ils pourraient se réclamer. La situation qui leur est faite varie selon les pays.

Soit, par exemple, la France. Un décret-loi du 12 avril 1939 a prévu un régime spécial pour les associations étrangères. Est réputée telle l'association ayant son siège à l'étranger et aussi une association siégeant en France, dès l'instant qu'elle est dirigée en fait par des étran-[p. 187] gers, ou encore si elle possède des administrateurs étrangers, ou un quart au moins de membres étrangers. Ces associations sont soumises à un contrôle administratif tant pour leur formation que pour l'exercice d'une activité en France. Il n'existe aucune disposition visant spécialement les associations internationales: vis-à-vis du droit français, celles-ci sont réputées associations étrangères et traitées comme telles. Si l'on s'en remet à l'expérience, il ne semble pas dans la moyenne des cas en résulter de gêne particulière pour les O.N.G., étant donné le grand libéralisme du contrôle exercé sur elles par les autorités de police.

En beaucoup de pays, la plupart peut-être, on ne trouve pas de réglementation propre aux associations internationales qui bénéficient dès lors du même régime que les associations nationales : il en va ainsi par exemple dans le droit anglais, allemand, américain et néerlandais. Le cas de la loi belge du 25 octobre 1919 «tendant à accorder la personnification civile aux associations internationales à but scientifique » est resté exceptionnel : l'un des motifs de la loi était d'ailleurs d'accorder une faveur à ce type d'association, les associations belges elles-mêmes ne jouissant pas à cette époque de la personnalité civile.

Les organisations internationales non gouvernementales ont donc le choix entre deux solutions : ou se placer sous le régime de la loi du pays dans lequel elles ont établi leur siège, ou se dispenser d'adopter un statut juridique (ce que plusieurs ont fait). Certains auteurs jugent cette situation fâcheuse : ils estiment que le manque d'uniformité du statut risque d'entraver ces organismes et de les placer en condition d'infériorité. D'autres sont moins affirmatifs : la carence actuelle correspondrait à un simple défaut d'architecture sans grandes conséquences pratiques. En tout cas, plusieurs efforts ont été entrepris pour doter d'un statut international les organisations internationales non gouvernementales, aucun pourtant n'a encore abouti.

La première de ces tentatives remonte à 1910 : ce fut une proposition de Nicolas Politis à l'Institut du Droit International, d'étudier «la condition juridique des associations internationales ». En 1923, l'Institut adoptait sur son rapport un projet de convention comportant reconnaissance d'une personnalité juridique internationale à ces associations ${ }^{1}$. Depuis lors, plusieurs projets ont été préparés, le dernier en date

\footnotetext{
Voir ce rapport dans le 30 volume de l'Annuaire de l'Institut de Droit International, pp. 110-127.
} 
étant la résolution votée par l'Institut de Droit International au cours de sa $44^{\mathrm{e}}$ session (Bath, septembre 1950) sur proposition et rapport de S. Bastid ${ }^{1}$.

[p. 188] Ce projet définit les associations internationales comme « des groupements de personnes ou de collectivités, librement créés par l'initiative privée, qui exercent, sans esprit de lucre, une activité internationale d'intérêt général, en dehors de toute préoccupation d'ordre exclusivement national ». Le but de la convention n'est pas d'instituer un régime juridique défini dans tous ses éléments, mais d'obtenir pour les associations considérées, le bénéfice du traitement de droit commun le plus favorable accordé aux associations nationales à but non lucratif. Ce que l'art. 3 du projet appelle « le statut international » consiste donc, d'abord et surtout, en l'absence de discriminations à rencontre des associations internationales (dans l'exercice de leur activité, la perception des cotisations...). De plus, l'art. 7 prévoit que les autorités réserveront à ces associations «le meilleur régime compatible avec la législation en vigueur », en divers domaines très importants pour elles et où les réglementations nationales pourraient les handicaper (circulation des personnes, emploi de la main-d'œuvre étrangère, transmission postale de documents, transfert des capitaux). Cet article vise donc à introduire des éléments de faveur dans le «statut international »: mais, sur ce point, les autorités restent maîtresses d'apprécier souverainement la situation.

D'après ce projet, le statut est applicable aussi bien à une association constituée sous l'empire d'une loi nationale qu'aux groupements " en l'air » (c'est-à-dire ne se rattachant à aucune législation particulière) : il n'est nullement réservé à celles qui ont obtenu le bénéfice d'arrangements consultatifs auprès des Nations Unies ou de leurs agences. En principe, les États sont tenus d'accorder le bénéfice des droits mentionnés aux associations remplissant les conditions posées par le texte ; mais faculté leur est laissée d'une vérification de ces conditions.

Au total, le dispositif ainsi proposé reste d'ambition modeste. Il ne va pas jusqu'à reconnaître aux associations internationales des prérogatives de droit public. Il se borne à envisager le maximum d'uniformité possible dans le mode de traitement de ces organismes par les autorités nationales sans instituer un régime juridique uniforme s'imposant à tous les États. Il semble que cette réserve n'ait pas été sans relation avec les craintes suscitées par les activités partisanes de diverses O.N.G.

Depuis 1950, la situation n'a pas évolué de façon sensible. Il n'apparaît pas que la préparation et l'adoption d'un "statut international » [p. 189] aient marqué des progrès appréciables, en dépit de plusieurs initiatives de l'Union des Associations Internationales ${ }^{2}$.

1 On trouvera dans le $43^{\mathrm{e}}$ volume de l'Annuaire de l'Institut de Droit International (tome I, pp. 547630, et tome II, pp. 342-362 et pp. 383-387), le rapport et projet de résolution présenté par S. BASTID, les délibérations de la session et le projet de convention.

2 Dont le dernier en date est la préparation d'un « projet de convention visant à faciliter l'activité des organisations internationales non gouvernementales » (dont on trouvera le texte in Associations, juillet 1959, pp. 496-498). Ce projet avait été transmis à l'Unesco (mai 1959), en vue d'inciter celle- 
Formules de regroupement - On voudrait évoquer un dernier problème : les essais et efforts de coopération systématique entre organisations internationales non gouvernementales : Le sujet est complexe et nous nous bornerons à en indiquer les grandes lignes ${ }^{1}$. Deux forces ont joué (de façon inégale selon les cas) : la prise en considération par les intéressés eux-mêmes des avantages d'une telle collaboration (en particulier, renforcement de la faculté d'influence) et la pression des organisations intergouvernementales en vue de rationaliser et de coordonner les activités entreprises.

Le type même de l'entreprise volontaire est donné par l'Union des Associations Internationales. Créée en 1910 pour servir de représentant sur le plan mondial à l'ensemble de l'organisation internationale privée, elle fournit à celle-ci des services de documentation et d'études. Dès 1913, l'Union fédérait 230 associations. Cependant, l'élan brisé par la guerre ne devait reprendre que bien plus tard, en 1949. Aujourd'hui l'U.A.I. a organiquement la forme d'un Institut, composé de 100 membres individuels élus à titre personnel (les organisations internationales pouvant devenir « correspondantes », ce qui n'implique pas la qualité de membre). Avec des moyens réduits, l'Union accomplit un travail de représentation et de documentation fort utile : il en a été et il en sera encore question souvent dans cet ouvrage ${ }^{2}$.

D'une assiette plus réduite et d'une moindre ambition, sont les fédérations régionales d'associations internationales. On en compte deux : la Fédération des Institutions Internationales Semi-Officielles et Privées établies à Genève (fondée en 1929) et la Fédération des Associations Internationales établies en Belgique (1949). L'objectif essentiel de ces organismes est d'aider à résoudre les problèmes nés d'une communauté de localisation. Ainsi la Fédération de Genève a-t-elle obtenu des avantages fiscaux pour ses membres de la part des autorités fédérales et cantonales et des facilités diverses dans le Palais des Nations Unies.

Mentionnons enfin comme organes volontaires, divers comités ou groupes de liaison s'efforçant de coordonner l'activité d'organismes qui s'inspirent de la même idéologie ou partageant des préoccupations communes. En relèvent par exemple, le Comité de Liaison des Secréta-[p. 190] riats Professionnels Internationaux créé en 1952 dans le cadre de la C.I.S.L. ; la Conférence des Organisations Internationales Catholiques déjà mentionnée, le Comité de Liaison des Grandes Associations Féminines Internationales, etc. Sans entrer dans le détail, soulignons la diversité et la multiplicité de ces formules de regroupement.

ci à préparer une Convention et à la soumettre à une prochaine session de la Conférence générale. Selon les dernières informations communiquées par l’U.A.I., il ne semble pas que l'affaire doive connaître un proche aboutissement.

1 Pour un inventaire, voir l'étude de G.P. SPEECKAERT, in Associations, janvier 1957, pp. 29-36 (avec d'intéressantes références bibliographiques), et PICKARD (B.), op. cit., pp. 59-67.

2 Sur l'U.A.I. (ancien style), voir le volume publié en 1912 à Bruxelles par l'Office Central des Associations Internationales. Sur la phase de reconstitution, voir en particulier Bulletin O.N.G., janvier 1949, pp. 3-6 ; juin-juillet 1950, pp. 142-161. Voir aussi le rapport d'ensemble présenté à l'Assemblée générale de 1955, Associations, août 1955, pp. 495-500. 
En d'autres occasions; la volonté de coopération trouve son impulsion directe dans une démarche de l'organisation intergouvernementale ; ainsi, la fondation, en 1952, sous l'égide de l'Unesco, du Conseil International des Sciences Sociales qui rassemble les diverses associations internationales spécialisées dans l'étude des faits sociaux (économie, science politique, sociologie, etc.). Plusieurs rassemblements importants ont été réalisés directement sous la pression de l'Ecosoc qui soulignait l'urgence d'une unification des travaux et l'utilité d'une confrontation des vues pour la présentation de conseils ou suggestions. Les principaux exemples de ce mouvement sont : Réunion des institutions spécialisées et des organisations non gouvernementales intéressées à la prévention du crime et au traitement des délinquants (1948); Conférence des organisations non gouvernementales intéressées aux problèmes de la migration (1950) ; Conférence des organisations mondiales intéressées à l'adaptation des handicapés (1953) ${ }^{1}$. Rappelons aussi l'existence du Comité d'Organisations non Gouvernementales auprès de l'Unicef.

On mentionnera enfin la Conférence des Organisations Consultatives non Gouvernementales auprès de l'O.N.U. dans la formation de laquelle ont joué les deux motivations énoncées ci-dessus. Constituée en 1950 pour étudier la procédure et les moyens d'améliorer les méthodes de consultation avec l'O.N.U., elle dispose de deux secrétariats (l'un à New York, l'autre à Genève) ${ }^{2}$. Signalons également la Conférence des Représentants des Organisations Internationales non Gouvernementales bénéficiant des arrangements consultatifs auprès de l'Unesco ${ }^{3}$. Nous retrouverons ces questions au chapitre suivant.

On sortirait du cadre limité de ce paragraphe en émettant un jugement sur la portée ou la valeur de ces regroupements. Disons simplement qu'elle est inégale. Les difficultés, voire parfois l'inefficacité, tiennent aux réticences qu'éprouvent les O.N.G. à l'égard de toute tentative d'unification ou de coordination qui ne tournerait pas à leur avantage propre: attitude que renforcera, le cas échéant, la présence d'une bureaucratie professionnelle. Mais ces formules d'action com-[p. 191] mune souffrent aussi de l'extrême diversité des organes que l'on cherche à rassembler. L'appellation « organisations internationales non-gouvernementales» couvre des éléments hétérogènes par l'objet, la structure administrative, l'ampleur des moyens disponibles. Il en résulte une grande variété dans le «style d'action » qui pèse fatalement sur les conférences et réunions où la qualité d'O.N.G. est le seul critère d'admission.

Quoi qu'on en dise, il est difficile de trouver un langage qui exprime à la foi les soucis de Pax Romana et de la Société internationale de Mécanique des Sols et des Travaux de Fondation, du Congrès juif Mondial et du Comité International Spécial des Perturbations Radioélectriques. Dès que l'on dépasse le seuil des proclamations

1 On trouvera des études sur les organismes relatifs au crime et aux délinquants, aux migrations ainsi que sur la Conférence Unicef in Associations, janvier 1957, pp. 9-24.

2 Sur la $8^{\mathrm{e}}$ session de cet organisme (Genève, 30 juin-4 juillet 1960), voir Associations, septembre 1960, pp. 551-552.

3 Pour un compte rendu de la $7^{\mathrm{e}}$ session de la Conférence (Paris, 30 mai-2 juin 1960), voir Associations, août 1960, pp. 491-494. 
générales, ou que l'on sort du cadre de la recherche d'avantages matériels, les divergences se précisent. Les uns et les autres, par exemple, attribuent un sens différent aux facultés consultatives ouvertes par les agences intergouvernementales : certaines organisations y voient un instrument technique permettant d'exercer une influence discrète sur divers points du programme tandis que d'autres entendent les utiliser pour alerter l'opinion publique et mettre les gouvernements en accusation.

Ainsi s'explique l'impression de grande inutilité et de parfaite incohérence que laissent certaines assemblées, à vocation œcuménique, d'organisations internationales non gouvernementales. Si les O.N.G. constituent une force de pression effective, c'est au niveau des organismes particuliers ou des regroupements spécialisés qu'on est susceptible de la trouver.

\section{c) NATURE DU GROUPEMENT ET DIMENSIONS DE L'ACTIVITÉ}

\section{$\underline{\text { Retour à la table des matières }}$}

En rapprochant les précédentes analyses du tableau dressé au chapitre premier, on observe que ces deux notions sont, l'une par rapport à l'autre, tantôt dans un rapport d'harmonie, tantôt en position de discordance. Cette situation est l'un des éléments qui rendent complexe l'établissement d'un schéma cohérent.

Nous trouvons d'une part des organismes indubitablement rattachés à un ordre national et dont l'activité s'étend au-delà des frontières de cet ordre. Dans ce cas, la nature nationale du groupement envisagé contraste, en quelque sorte, avec sa vocation ou ses prétentions internationales. [p. 192] Le cas échéant d'ailleurs, pour agir avec efficacité à l'extérieur, le groupe devra accepter une incorporation formelle à tel ordre juridique étranger (fondation d'une filiale) : l'opération résultant soit d'une obligation légale, soit d'une option volontaire effectuée dans un souci de commodité ou d'efficacité. Sur ce point, la substitution au concept «nationalité » d'un système de double allégeance ne modifie pas réellement l'état du problème.

Il apparaît difficile d'écrire que les O.N.G. dépendent d'un ordre international. Plus exactement, ce rattachement n'est que partiel et même secondaire (en particulier reconnaissance par les organisations intergouvernementales de leur position spéciale lors de l'octroi de facilités consultatives). Au surplus, en l'absence d'un statut international, ces organismes relèvent d'un ordre national qui les assimile aux organisations nationales ou les traite en éléments " étrangers » ou sont dépourvus de tout support de ce type. La situation est donc ambiguë. Cependant un accord global existe pour les considérer comme des « internationales » bien qu'elles n'aient pas la personnalité juridique internationale et dès lors, il y a cette fois correspondance entre la nature du groupement et sa vocation.

Avec des nuances, il semble possible d'appliquer le même raisonnement aux cartels internationaux: s'ils appartiennent à un ordre national (très souvent de 
complaisance) c'est pour en recevoir des facilités de fonctionnement dont l'objet est justement de permettre l'accomplissement aux meilleures conditions d'une mission de caractère international.

Mais il faut faire dès maintenant une observation propre à marquer le sens et la portée de la distinction ainsi présentée. La divergence entre le rattachement à un ordre et l'accomplissement d'une activité de portée internationale, éventuellement mondiale, n'exprime qu'une partie de la question, peut-être pas la plus significative. La véritable opposition se situe entre le caractère national des intérêts en cause et l'internationalisation de leur sphère. Autrement dit, le point capital du débat est la signification socio-politique de l'appartenance à un ordre national. Il est donc indispensable d'examiner la nature des intérêts qui utilisent un tel support.

La société commerciale qui travaille en divers pays étrangers ou, plus exactement l'élément de tête dans un groupe de dimensions internationales, possède, si l'on raisonne en termes traditionnels, une nationa-[p. 193] lité déterminée : un tel lien ne traduit-il pas simplement le fait que ce complexe d'organismes relève de l'économie d'un pays donné ? En raisonnant ainsi, on postule une identité entre la nationalité attribuée au groupement et l'inspiration qui anime son fonctionnement. General Motors est un organisme dont le champ d'action s'étend à l'ensemble du monde noncommuniste : mais c'est d'abord une société américaine dirigée par des Américains dans le sens des intérêts américains.

Cette conception qui peut être utilisée, on le verra, pour restreindre la catégorie " groupes de pression internationaux » est solide en apparence et ne saurait être ignorée. Pourtant on montrera qu'ignorant plusieurs aspects de la gestion des grandes affaires, elle ne peut emporter la conviction sur tous les plans. Mais de toute façon elle n'a de valeur que si l'on emploie le critère du contrôle effectif pour déterminer la nationalité. Selon l'interprétation dite du siège social, la Compagnie de Suez était une société égyptienne : il serait pourtant absurde, à partir de cette allégeance juridique, de décrire ses démarches vis-à-vis du gouvernement de l'Égypte comme celle d'un groupe de pression égyptien.

L'analyse politique en cette matière se caractérise donc par une exigence préliminaire : la reconstitution ou la restitution de la réalité des forces qui inspirent ou commandent l'affaire à travers le cadre juridique apparent ou, autrement, l'élucidation de l'allégeance politique réelle. Or, cette tâche est compliquée par le pullulement des formules de complaisance (sociétés «holding " installées hier au Luxembourg et à Monte-Carlo par exemple, aujourd'hui au Lichtenstein...). Elle est pourtant indispensable : une société américaine qui travaille en plusieurs pays d'Europe par le truchement d'un bureau domicilié, avec des dizaines d'autres, chez un avocat de Vaduz ne saurait être traitée de groupe de pression liechtensteinois : or seuls ceux qui ont une certaine pratique des affaires connaissent l'ampleur et la variété des « camouflages » auxquels se livrent de nos jours les grandes firmes capitalistes.

Le problème est tout différent pour les organisations non gouvernementales, auxquelles on peut, sous cet angle, assimiler jusqu'à un certain point les cartels internationaux. Le choix éventuel d'un ordre national de rattachement (formalité que 
négligent beaucoup de ces organes) a pour fin d'assurer la satisfaction d'intérêts qui relèvent de plusieurs pays. Le support n'a donc qu'un rôle accessoire : il est matière d'opportunité.

[p. 194] Il n'est pas impossible pourtant de concevoir qu'une association internationale puisse, en fait, être «capturée » par un intérêt national. C'est un point qui a déjà été évoqué et dont on traite généralement sur le plan de la polémique. Si, en quelques cas, le jeu est sans équivoque, dans beaucoup d'autres, il est plus subtil : relève notamment de ce souci de confiscation, l'effort accompli par chaque organisation ou délégation nationale pour accroître sa part dans la gestion de l'organisme. Et il en sera nécessairement ainsi tant que l'on n'aura pas créé l'espèce « citoyen du monde ».

On a donc, au total, trois catégories de situation : rattachement à un ordre juridique national traduisant l'appartenance de l'organe considéré au système de relations économico-sociales couvert par cet ordre (élément de tête des grandes firmes d'activité internationale) ; rattachement à un ordre juridique national de pure façade destiné à permettre une action d'inspiration internationale (O.N.G., cartels internationaux) ; rattachement à un ordre juridique national tendant simplement à faciliter la pénétration d'éléments étrangers dans un système social donné (filiales, à formes nationales, d'un trust étranger) ou à permettre des camouflages, généralement mais non exclusivement, à buts fiscaux. Le point délicat sera justement de redistribuer ces positions de contenu juridique dans des catégories valables pour l'analyse politique.

L'étude des situations de complaisance peut se révéler très délicate. En plusieurs cas, une bonne documentation (du type de celle que procure un dépouillement méticuleux des grands journaux financiers comme le Financial Times) permet de déterminer avec une raisonnable sécurité le contenu réel des liaisons. Dans d'autres situations, le « camouflage » est si poussé que le rétablissement des rapports tient de la spéculation (holding d'intérêts français constitué par les soins d'une banque suisse en société domiciliée au Panama et gérée par un trustee canadien). Mais, sous l'angle théorique, la situation la plus complexe est celle où le comportement effectif des intéressés rend fallacieux tout essai de passage d'un ordre de complaisance à un système national. Autrement dit, on se trouve en présence d'allégeances juridiques notoirement fictives qu'il ne semble pas possible ou légitime de convertir en allégeances réelles.

Soit par exemple le cas des grands armateurs d'origine hellénique (MM. Livanos, Niarchos, Onassis...). Leur rattachement à l'ordre juri-[p. 195] dique panaméen ou monégasque et éventuellement à quelques autres est, certes, de pure complaisance. Ainsi, à un moment donné, M. Aristote Onassis a-t-il pris la nationalité argentine : ses sociétés étant domiciliées en Uruguay, et ses bateaux navigant sous divers pavillons, il vivra pourtant dans la principauté de Monaco. Tous ces rapports, et d'autres liens encore, sont certes de " complaisance », mais est-il pour autant raisonnable de relier au système hellénique l'incontestable force internationale qu'il a représentée en diverses occasions (démêlés avec le gouvernement américain ; signature avec l'Arabie 
Saoudite le 20 janvier 1954 d'un contrat qui, sous une couverture transparente, lui assurait le monopole du transport du pétrole brut extrait de l'Arabie, mais qui sera finalement annulé sur l'intervention de trusts internationaux ; activité exercée lors de la fermeture du Canal de Suez, etc.).

Certes, au cours des toutes dernières années ces hommes ont transféré en Grèce une partie de leurs actifs (prise de participation dans un programme de fabrication d'aluminium par M. Niarchos ; fondation d'un réseau national de lignes aériennes par M. Onassis ; rapatriement de navires...). Cependant il ne s'agit là encore que d'une fraction des activités et avoirs de ces armateurs, ceux-ci restant pour le surplus en mesure de n'avoir aucun compte à rendre au gouvernement grec. Indépendance qu'atteste parfaitement le caractère ostensible du rattachement à des pays de complaisance.

Faut-il, dès lors, assimiler de tels intérêts à une force internationale pure du même ordre que celle d'un cartel se fondant par simple commodité sur un ordre juridique quelconque ? Convient-il dans un tel cas d'interpréter le système de complaisance non plus comme un "paravent » à écarter si l'on veut connaître la réalité, mais comme l'instrument de remplacement, effectif et se suffisant à lui-même, d'un ordre national dont les intéressés ont eu la faculté de se couper complètement?

On pourrait hasarder d'autres hypothèses (un élément d'« apatridie » économique, par exemple). La documentation disponible, sans même parler de l'insuffisance de recul, est trop limitée pour permettre de qualifier exactement de semblables situations, peut-être en voie d'évolution. En tout état de cause, une bonne partie de l'affaire s'explique par la disproportion des forces entre ces constellations d'intérêts et les services gouvernementaux de la Grèce ${ }^{1}$.

[p. 196] Une vue sommaire des choses pourrait conduire à contester l'importance des contradictions relevées dans ce paragraphe. En de très nombreux cas, les firmes capitalistes travaillent à l'étranger par l'intermédiaire de filiales possédant la nationalité du pays d'exploitation. Dès lors, pourquoi ne pas se borner à les considérer comme les unités réelles de pression? Une telle dissociation supprimerait notre problème, mais au prix d'une omission fondamentale: l'existence d'un centre extérieur d'impulsion et de coordination qui le cas échéant par des détours très subtils, inspire l'action de l'organisme à forme juridique nationale. Spécialement si l'on s'en tient au critère du siège social, pour fixer la nationalité, on pourrait aboutir à des contre-sens flagrants (attribution de la qualité de groupes de pression français aux filiales des trusts pétroliers en France). Il reste donc essentiel de se reporter à l'organisme de tête et l'on retombe sur la difficulté étudiée.

1 On trouvera quelques indications sur la technique de ces armateurs dans un reportage journalistique dû à Victor FRANCO, Un conquérant des mers, Niarchos Paris, 1960. Voir aussi (sur Onassis), BENOIST-MÉCHIN, Le roi Saud ou l'Orient à l'heure des relèves, Paris, 1960, pp. 47-62. 


\section{3. À LA RECHERCHE D'UN CRITÈRE LA QUALITÉ DE L'INFLUENCE}

$\underline{\text { Retour à la table des matières }}$

C'est une autre orientation de recherche. Il peut paraître indiqué de définir le groupe de pression international comme celui qui est capable ou, simplement, désireux de peser sur le cours des rapports entre les pays. Pourtant, si l'on décompose cette notion, il apparaît rapidement que les choses ne sont pas si élémentaires. Des groupes que nul ne songe à inclure sur une liste internationale exercent pourtant une influence sur les relations entre États tandis que d'authentiques forces internationales tentent de déterminer le comportement des gouvernements dans des domaines relevant de la politique intérieure (mode d'exploitation des ressources naturelles; octroi de permis de recherches ou de concessions d'exploitations ; statut religieux ; réglementation du divorce, position des écoles confessionnelles...). Il faut donc énoncer un critère plus complexe.

[p. 197]

\section{a) POLITIQUE INTERNATIONALE ET PRESSION SUR LES GOUVERNEMENTS}

L'expression « relations internationales » manque de clarté : elle a été obscurcie, pour les besoins de la cause, par les partisans de l'octroi à cette branche d'études d'un statut d'indépendance universitaire. Stanley Hoffmann nous offre un point de départ solide en définissant leur analyse comme celle "des facteurs et des activités qui affectent les politiques extérieures et la puissance des unités de base entre lesquelles le monde est divisé ${ }^{1}{ }^{1}$. Notons, c'est d'ailleurs sans importance, que beaucoup d'auteurs britanniques préfèrent, pour qualifier le même domaine, l'expression « affaires internationales ».

Il existe une autre terminologie : politique internationale (international politics). Les auteurs qui l'utilisent l'entendent généralement comme couvrant l'ensemble des phénomènes qui résultent des politiques étrangères suivies par les différents États.

\footnotetext{
Dans son dernier ouvrage, Contemporary Theory in International Relations, Englewood Cliffs (N.J.), 1960, p. 6. Sur le problème de l'influence des organisations politiques (Concert européen, S.D.N., O.N.U.) et sur les pouvoirs des États on aura le plus grand intérêt à étudier son important ouvrage Organisations internationales et pouvoirs politiques des États, Paris, 1954. Pour l'époque actuelle, on pourra consulter CLAUDE (Inis L.) Jr, Swords into Plowshares. The problem and progress of international organization, New York, 1956.
} 
Ainsi comprise, la politique internationale coïncide avec l'acception donnée par Hoffmann aux relations internationales.

L'expression « relations internationales » pouvant, le cas échéant, être étendue à des rapports qui n'ont rien de politique (au sens où la puissance publique ne prend aucun engagement dans leur déroulement concret), nous préférons employer la formule « politique internationale » qui ne présente pas la même ambiguïté.

Les acteurs - La notion ainsi acceptée de la politique internationale tend à suggérer que les États sont actuellement les seuls acteurs de la politique internationale ou, si l'on préfère, qu'ils sont seuls à intervenir, par la négociation ou par la force, dans la détermination de leur position les uns à l'égard des autres. En l'absence d'un gouvernement mondial, cette conception paraît raisonnable. Une réserve toutefois : l'existence d'un processus de "politification » qui, au sens de la fondation des éléments d'un tel gouvernement, se traduit par la création d'un grand nombre d'agences intergouvernementales, dont une bonne centaine ayant une réelle activité ${ }^{1}$. S'agissant des relations extérieures entre États, ces organisations et spécialement l'O.N.U. sont-elles de simples lieux de rencontre, ou jouent-elles un rôle autonome ? Ont-elles, en particulier, leurs propres motivations par rapport aux positions des membres?

Question à laquelle nul n'est probablement en mesure de répondre avec une totale exactitude. Elle ne se ramène pas à celle de savoir si [p. 198] l'O.N.U. joue un rôle politique qui appelle une réponse incontestablement positive ${ }^{2}$ : il suffira, à cet égard, d'évoquer l'immense prestige dont elle bénéficie, peut-être à titre provisoire, dans les nouveaux États africains, et tout particulièrement au sein des masses encore colonisées. On ne saurait en particulier négliger l'influence accélératrice des Nations Unies dans le processus de "décolonisation ». Pour éviter de poser le problème en termes métaphysiques ou difficilement saisissables (influence du climat de l'organisme sur les déterminations des participants), demandons-nous seulement si ce rôle de l'O.N.U. est le fait des États qui la composent et des blocs qu'ils y forment, ou si une partie en revient au propre personnel de l'Organisation.

Sur les organisations intergouvernementales, l’ouvrage de référence (qui n'a pas que des mérites) est PEASLEE (Amos J.), International Governmental Organization Constitutional documents, 2 vol., La Haye, 1956. Les études d'ensemble sur les agences de l'O.N.U. sont rares. Voir LABEYRIE-MENAHEN (C.), Des institutions spécialisées. Problèmes juridiques et diplomatiques de l'administration internationale, Paris, 1953. Pour une très bonne initiation, se reporter à COLLIARD (Claude-Albert), Institutions Internationales, Paris, 1956.

2 Voir le récent ouvrage de H.G. NICOLAS, The United Nations as a Political Institution, Londres, 1959. Voir aussi les développements consacrés à l'O.N.U. in KERTESZ (S.D.), FITZSIMONS (M.A.) (ed.), Diplomacy in a Changing World, vol. I, Notre-Dame (Indiana), 1959. Également VELLAS (Pierre), "Sociologie des organisations internationales", Revue de l'Institut de Sociologie, 1959, n 2, pp. 157-176. 
Le Secrétaire Général d'abord. On lui a consacré plusieurs études qui dans l'ensemble, n'ont pas beaucoup éclairci le problème ${ }^{1}$. Certains ont expressément reproché à l'ancien une tendance à agir directement sur les gouvernements : ainsi, l'envoi à Ernest Bevin par M. Trygve Lie d'un émissaire suggérant un changement de la politique britannique sur la Palestine ${ }^{2}$. La manière de l'actuel titulaire du poste serait plus discrète, et surtout plus adroite : mais autant que son prédécesseur, $M$. Hammarskjoeld aurait pour principe d'intervenir sur le comportement des autorités nationales ${ }^{3}$. On lui prête volontiers l'idée que la conception classique faisant de l'O.N.U. un dispositif de négociation est dépassée: l'ampleur et la gravité des problèmes exigeraient que l'Organisation, s'appuyant sur les petites nations d'Asie et d'Afrique, intervienne directement sur les grandes puissances pour faciliter la solution de ces difficultés.

L'action des deux Secrétaires Généraux en tout cas ne semble guère contestable, mais comment l'interpréter? Elle apparaît avant tout diplomatique et peut-être médiatrice : ce serait une sorte de «diplomatie de la réconciliation » fondée sur l'autorité personnelle ou un crédit d'influence. Or la volonté d'obtenir ce crédit peut conduire à des prises de position (discrètes, bien qu'effectives). Le prestige dont a pu jouir M. Hammarskjoeld auprès du bloc afro-asiatique n'avait pas été acquis de façon tout à fait gratuite (affaire de Suez).

S'il veut exercer une mission propre, le secrétaire général de l'O.N.U. doit s'assurer des points d'appui (facteur beaucoup plus utile qu'une réputation d'impartialité dont le maintien impliquerait une totale inaction). Autrement dit, pour avoir une réelle influence politique, le secrétaire général ne doit pas hésiter, au préalable, à sortir d'une attitude [p. 199] purement administrative. Si l'on joint à cela des soucis de carrière et de tranquillité personnelle, dont n'est exempt aucun être humain, on comprend sans peine la complexité de la situation et le fait qu'aucune formule, juridique ou sociologique, ne soit encore disponible pour l'exprimer.

1 En particulier SCHWEBEL (S.M.), The Secretary General of the United Nations : his political powers and practice, Cambridge (Mass.), 1952. Voir aussi EGIDO (J.P.), «Funciones Administrativas y Diplomatico-Politicas de Secretario General de Las Naciones Unidad segun la Carta y la Pratica de la Organizacion », Zeitschrift fuer auslaendisches oeffentliches Recht und Völkerrecht, juillet 1959, pp. 36-72. Également JACKSON (E.), "The Developing Role of the Secretary General », International Organization 1957 (3), pp. 431-445 et JAMES (A.M.), « The Role of the Secretary General of the United Nations in International Relations », International Relations, octobre 1959, pp. 620-638. La meilleure étude disponible est VIRALLY (M.), « Le rôle politique du secrétaire général des Nations Unies », Annuaire Français de Droit International, 1958, pp. 360-399.

2 Ce reproche d'ingérence est fait en particulier par GOODWIN (G.L.), Britain and the United Nations, Londres, 1957 (l'auteur regrette manifestement l'«approche discrète » de Sir Eric Drummond). Pour une explication de cette démarche par son auteur, voir les mémoires de $\mathrm{M}$. TRYGVE LIE, Au service de la paix, traduit de l'anglais, Paris, 1957. Voir aussi HAMILTON (T.J.), « The United Nations and Trygve Lie », Foreign Affairs, octobre 1950, pp. 67-77.

3 Pour une comparaison entre les deux secrétaires généraux, SCHWEBEL (S.M.), "Secretary General and Secretariat », in Ninth Report of the Commission to Study in Organization of Peace, New York, 1955 (American Association for the United Nations). 
Le problème du personnel du Secrétariat reste, en dépit des nombreux travaux qui lui ont été consacrés, encore très mal connu : plus exactement, les multiples études effectuées ne nous disent pas grand chose du rôle propre de l'administration internationale ${ }^{1}$. Pendant les premières années de fonctionnement de l'O.N.U., la question a été surtout étudiée sous l'angle des rapports entre la loyauté internationale et l'appartenance nationale : la controverse prit, comme on le sait, un tour aigu avec les investigations du Comité Mac Carran. Sur le terrain des principes, les fonctionnaires internationaux sont avant tout soumis à une obligation de neutralité et d'indépendance vis-à-vis des États-membres. Admettons par une vue fort optimiste que l'on se rapproche peu à peu de cet idéal. N'en résultera-t-il pas un autre risque : la naissance d'une bureaucratie ayant ses propres conceptions et tentant de les imposer aux représentants gouvernementaux? Toutes choses égales, ne serait-ce pas la répétition de ce que l'on observe depuis longtemps sur le plan national ?

Nous n'en sommes certainement pas là, spécialement quant aux grandes options de politique internationale. Mais l'action publique, nationale et internationale, est faite aussi de multiples détails quotidiens. Sur de tels points, il n'est pas exclu que les fonctionnaires internationaux ne jouent dès maintenant un rôle appréciable : influence d'autant plus assurée que l'on s'écarte des grandes controverses idéologiques pour s'en tenir aux agencements techniques.

1 Pour l'étude de ce problème, on pourra partir de l'œuvre pionnière de S. BASTID Les fonctionnaires internationaux, Paris, 1931. Pour l'époque actuelle, se reporter à YOUNG (TienCheng), International Civil Service : principles and problems, Bruxelles, 1958. Le problème des liaisons avec le pays d'origine a été particulièrement étudié par BEDJAOUI (Mohamed), Fonction publique internationale et influences nationales, Londres, 1958. De la vaste littérature disponible, on retiendra: LANCROD (G.), «Les problèmes fondamentaux de la fonction publique internationale », Revue Internationale des Sciences Administratives, 1953 (1), pp. 9-109 ; BOOTH (D.A.), " The United Nations, the United States and the International Civil Service », même revue, 1955 (4), pp 703-740 ; FRIEDMANN (W.G.), "The United Nations and National Loyalty ", International Journal, hiver 1952-53, pp. 17-26; BOITEL (M.), « Situation et problèmes actuels de la fonction publique internationale », Politique Étrangère, mars-avril 1953, pp. 5-16 ; COHEN (M.), "The United Nations Secretariat. Some constitutional and administrative developments », American Journal of International Law, juillet 1955, pp. 295-319 ; « Some Functions and Problems of the International Civil Servant », Indian Yearbook of International Affairs, 1956, pp. 229-253 ; SHARP (W.R.), "The Study of International Administration : retrospect and prospect », World Politics, octobre 1958, pp. 103-117; GAUDEMET (P.M.), «Le statut des fonctionnaires internationaux en droit interne », Revue Administrative, janvier-février 1959, pp. 5-11; LEWIS (G.), « The Selection and Training of International Civil Servants », Cahiers de Bruges, 1957, pp. 67-76 ; SRIVASTANA (A.K.), "Geographical Distribution of Personnel in the United Nations », Indian Journal of Public Administration, octobre-décembre 1957, pp. 357-370 ; STROKE (P.), " Représentation et défense des intérêts professionnels des fonctionnaires internationaux », Journal de Droit International, avril-juin 1957, pp. 308-358 ; LOVEDAY (A.), « Staff Salaries in the U.N. Family », International Organization, automne 1957, pp 635-648. Sur l'Europe, consulter La Fonction publique européenne (statut futur, formation, perfectionnement), Bruxelles, 1956, et LASSALLE (C.), «Contribution à une théorie de la fonction publique supranationale. Le statut du personnel de la C.E.C.A. », Revue du Droit Public et de la Science Politique, mai-juin 1957, pp. 474-512. Consulter enfin "Le Fonctionnaire et l'Europe », Cahiers Chrétiens de la Fonction Publique, $\mathrm{n}^{\circ} 41$ (déborde le problème du statut proprement dit). 
Nous manquons des études monographiques qui permettraient de cerner les contours du phénomène et d'en déceler l'ampleur. Il conviendrait, au surplus, de distinguer selon les cas et de ne pas faire de généralisations indues: on ne saurait comparer le travail de l'Unesco avec celui de l'Union Postale Universelle qui, dans chaque pays, se trouve en liaison avec les administrations nationales des postes, services techniques par excellence. La question au total reste obscure, mais dès maintenant, de bons connaisseurs n'hésitent pas à souligner la «place exceptionnellement importante » des techniciens dans les organisations internationales ${ }^{1}$.

Faut-il, à cet égard, évoquer le schéma des groupes de pression et dire des administrations internationales, comme on le fait parfois à [p. 200] propos des services nationaux, qu'elles ressortissent à une telle catégorie ? Pour des raisons déjà exposées, l'assimilation ne paraît pas souhaitable ; si l'on veut un cadre de référence, celui de la technocratie ou de la techno-bureaucratie conviendait mieux.

Toutes ces situations exposées, il reste que dans l'état actuel du monde, l'essentiel de la politique internationale est le fait des gouvernements nationaux. Par conséquent, qui veut exercer une influence doit agir sur eux. Matériellement, si l'action peut s'exercer au siège même des assemblées et institutions nationales, elle peut aussi viser les représentations et délégations nationales dans les conférences et assemblées intergouvernementales.

Encore que la question n'ait pas fait, à notre connaissance, l'objet d'une étude systématique, il est possible d'admettre que les techniques d'intervention utilisées diffèrent selon le niveau où s'effectue la pression Pour agir au plan intergouvernemental, il arrive que l'on soit obligé de remonter à la source, c'est-à-dire à l'autorité qui donne les instructions (encore que la manière de les appliquer ait quelque valeur). Pourtant, si l'on en croit diverses expériences, il arrive que les délégués à une assemblée ne soient liés, même pour des questions importantes, que par des instructions souples, et il n'est pas exceptionnel que celles-ci fassent totalement défaut (spécialement pour les questions neuves). Une telle conjoncture ouvre, évidemment, des facultés d'action soit aux délégués des autres gouvernements (qui disposent d'arguments variés dont l'octroi de décorations n'est pas le plus répréhensible), soit aussi, naturellement aux représentants des forces de pression (présence universelle du lobby).

Les explications du chapitre précédent autorisent à admettre que les forces de pression déjà énumérées agissent sur les divers plans que nous venons de signaler, en vue d'influencer la politique internationale. Elles le font de façon plus ou moins systématique, plus ou moins continue et plus ou moins efficace : le prochain chapitre sera consacré à une étude détaillée de ces activités dont nous tiendrons ici le principe comme acquis. Mais ces forces sont-elles les seules à intervenir en pareil domaine ?

P. REUTER, "Techniciens et politiques dans l'organisation internationale », dans l'ouvrage collectif Politique et Technique, Paris, 1958, p. 189. 
Rôle des groupes nationaux — L'admettre serait faire abstraction de groupements jusqu'à présent écartés du tableau : les groupes que l'on peut qualifier de purement nationaux parce que chez eux la nature juridique s'accommode avec les dimensions de l'activité. Or de tels groupes peuvent avoir une influence internationale : songeons, par exemple, à ceux [p. 201] qui ont lutté pour et contre l'intégration européenne, pour et contre l'adhésion au Pacte Atlantique, etc.

Tout en se limitant à intervenir sur l'État de sa nationalité, un groupe de pression est susceptible d'agir sur la politique internationale de plusieurs façons. D'abord il peut viser à infléchir la ligne générale de la politique extérieure: maintien de l'alliance occidentale, renversement des alliances, neutralisme, fédération politique européenne... Il peut également intervenir dans les relations de l'État avec un autre État mais toujours au niveau des intérêts collectifs (octroi ou refus d'un prêt sur fonds publics, position à l'égard d'éventuelles réparations, reconnaissance d'un gouvernement provisoire ou révolutionnaire...). Enfin, le groupe peut également utiliser l'État national pour faire aboutir un projet particulier mettant en cause un État étranger. Ce dernier procédé doit être interprété avec soin, car il a souvent constitué le mode d'action de l'impérialisme du type léniniste.

Partons d'un cas simple. La Compagnie Générale d’Électricité (France) est placée par le Département d'État : américain sur la « liste noire » : interdiction est faite de traiter avec elle à toute administration et à toute société des États-Unis, de même qu'à tout pays disposant de crédits américains pour l'achat de matériel électrique. Motif : la C.G.E. a livré un câble coaxial à l'U.R.S.S. sans l'accord du Cocom. L'ambassadeur de France à Washington est chargé de régler l'affaire en obtenant l'annulation de la sanction ${ }^{1}$.

Un cas plus complexe est celui de la protection des créanciers nationaux à l'égard d'un État étranger qui en vient à négliger ou à renier les obligations souscrites (auquel on peut assimiler celui des victimes d'une nationalisation privées, d'une manière ou d'une autre, d'une compensation équitable). Il existe des groupes de défense générale des porteurs (Association Nationale des Porteurs Français de Valeurs Mobilières, Association Belge pour la Défense des Détenteurs de Fonds Publics, Council of Foreign Bondholders...) : il arrive aussi que l'on constitue une association particulière pour les victimes d'une opération déterminée ${ }^{2}$. Mais il est clair que seul le soutien de l’État est de nature à faire aboutir de telles revendications.

Les modalités de cet appui ont varié, depuis l'intervention par la force armée (droit affirmé dans une circulaire de Palmerston en 1848 et réglementé par la deuxième

Selon Le Monde, 21-29 février 1960.

Éventuellement sur une base internationale (auquel cas on a un groupe de pression international). Soit par exemple, le Conseil des Porteurs de la Dette Publique répartie de l'ancien Empire ottoman groupant des représentants de porteurs français, anglais, belges, suisses, hollandais, italiens, allemands et turcs ou encore la Caisse Commune des Porteurs des Dettes Publiques autrichiennes et hongroises émises avant la guerre rassemblant des délégués des associations nationales ou organismes correspondants de France, Grande-Bretagne, Hollande, Belgique, Suisse, Italie, Allemagne. 
Conférence de La Haye en 1907), jusqu'à [p. 202] la simple négociation diplomatique de mise aujourd'hui ${ }^{1}$. L'issue de l'affaire dépend alors des circonstances générales, de la force respective des parties en présence, des arguments, par exemple d'ordre commercial, dont dispose l'État lésé. Ainsi, l'Association Nationale des Porteurs Français demande-t-elle actuellement — octobre 1960 - au gouvernement de différer le renouvellement de l'accord commercial franco-tchécoslovaque, le gouvernement tchèque laissant en souffrance, sans raison valable selon l'Association, deux dettes financières.

Mentionnons sans insister qu'à diverses reprises l'État français s'est efforcé d'obtenir l'indemnisation des porteurs de fonds russes (la dernière fois, semble-t-il, à l'occasion du voyage à Moscou de MM. Mollet et Pineau en 1956). Ultime moyen d'action des États (dans l'ordre pacifique s'entend): défense des intérêts de leurs ressortissants devant la juridiction internationale (par exemple, affaire dite des zones franches entre la France et la Suisse).

Jusqu'ici, on s'est limité à des opérations de protection, d'esprit purement défensif (au moins au départ). Mais on sait qu'en plusieurs circonstances des États se sont fondés sur des griefs de leurs nationaux, pour entreprendre des opérations offensives, sinon agressives, à longue portée : la mainmise européenne sur divers pays d'Afrique du Nord et du Moyen-Orient en est, dans une large mesure, l'illustration. La thèse classique de l'impérialisme veut que l'impulsion soit venue des milieux économiques et surtout financiers, l'État se bornant à exécuter les consignes données. Cependant, on admet aujourd'hui que les rapports ont été plus complexes. Dans certains cas, il existait une coïncidence des mobiles économiques privés et des visées politiques. Dans d'autres situations, il apparaît même que l'économique a été placé au service du politique.

Mentionnons enfin le cas d'un groupe national, à sphère d'action internationale il est vrai, capable, par une action entreprise de son propre mouvement, d'apporter une perturbation plus ou moins grave dans les relations entre deux pays amis. En octobre 1959, la Régie Renault décide de ne pas renouveler le contrat signé avec une firme israélienne pour le montage des voitures Dauphine dans ce pays. Motif : mettre un terme au boycottage arabe dont souffrait la Régie (comme beaucoup d'autres firmes exécutant des contrats industriels avec des entreprises situées en Israël). Renault déclare avoir été mû par un mobile purement commercial (comparaison du montant des ventes dans les deux hypo-[p. 203] thèses). Mais l'affaire suscite forcément des

\footnotetext{
Voir les indications données par MOREAU-NERET (O.) in Les valeurs mobilières, tome I, Paris, 1939, pp. 278-287. Sur les aspects récents du problème, lire deux études publiées dans le volume de l'Institut de Droit Comparé de l'Université de Paris cité à la note 1, p. 172. Kiss (Alexandre-Ch.), " La protection diplomatique des actionnaires dans la jurisprudence et la pratique internationales », pp. 179-210, et VIGNES (Daniel), "La protection des actionnaires dans les conventions internationales bilatérales », pp. 211-241. Pour l'étude de la « protection diplomatique », se reporter à : GUGGENHEIM (P.), Traité de droit international public, tome I., pp. 310 et suivantes ; REUTER (Paul), Droit international public, Paris, 1958, pp. 162-174 (en particulier, pp. 164-166, les indications sur le concept d'« intérêt substantiel ») ; ROUSSEAU (Charles), Droit international public, Paris, 1953, pp. 361-370.
} 
remous politiques: des milieux de Tel-Aviv déclarent alors que la traditionnelle amitié franco-israélienne aurait pu inciter à ne pas brusquer les choses ; le Comité de l'« Alliance France-Israël » (président M. J. Soustelle) choisit de faire appel au général de Gaulle pour obtenir la reprise des activités Renault à Haïfa; le gouvernement d'Israël décide d'étudier l'application de représailles contre les firmes cédant aux menaces arabes (contre-boycottage appuyé sur le judaïsme mondial). En dépit des efforts accomplis de part et d'autre pour ne pas l'envenimer, il semble que l'affaire ait suscité en Israël une émotion considérable (beaucoup y voyant le premier signe d'un relâchement des liens avec la France).

Il n'entre pas dans le cadre de cet ouvrage d'examiner l'activité déployée par les groupes de pression nationaux dans l'ordre de la politique étrangère. On présentera seulement quelques brèves observations, dont la première pour souligner que le sujet demeure mal connu. Pendant longtemps, les études de politique étrangère ont simplement ignoré le problème ${ }^{1}$. Les plus récentes ne commettent pas cette erreur ${ }^{2}$. Cependant, comme le note l'auteur d'un inventaire de la littérature américaine spécialisée, le matériel déjà accumulé comporte de multiples défauts, et, finalement, n'a pas beaucoup de signification ${ }^{3}$.

Il n'est pas facile de dresser en quelques mots un tableau des groupes nationaux qui interviennent sur la politique étrangère. Parmi les plus actifs en la matière, on peut citer ceux dont les membres ont un intérêt direct dans les relations économiques internationales (commerce extérieur, marine marchande). D'une façon plus générale, la politique douanière a toujours suscité d'âpres interventions de la part des secteurs concernés, les projets d'intégration européenne ayant évidemment accru les préoccupations des milieux économiques (agriculteurs, industriels...) à l'égard de l'action extérieure de l’État.

Si l'on fait abstraction de ces problèmes, il semble que la plupart des groupes ne s'intéressent pas à la politique extérieure ou adoptent des positions de pure forme.

1 L'un des rares travaux français sur le sujet avant les toutes dernières années est BARTHELEMY (Joseph), Démocratie et politique étrangère, Paris, 1917. Or l'auteur consacre tout juste quelques pages à l'opinion publique (pp. 124-130) ; encore s'agit-il de banalités.

2 Voir en particulier ALMOND (G.), The American People and Foreign Policy, New York, 1950, PERKINS (Dexter), The American Approach to Foreign Policy, Cambridge (Mass.), 1953 ; MACRIDIS (Roy C.) (ed.), Foreign Policy in World Politics, Englewood Cliffs (N.J.), 1958. Voir aussi DEUTSCH (K.W.), EDINGER (Lewis J.), Germany Rejoins the Power, Stanford, 1959 (spécialement la deuxième partie).

3 COHEN (Bernard C.), The Influence of Non-Governmental Groups on Foreign Policy Making, World Peace Foundation, 1959 (cette brochure est la seconde d'une série de 7 publiée par la Fondation sous le titre "Studies in Citizen Participation in International Relations »). Dans la perspective de cette étude, voir aussi GARRIGUE (K.C.), U.S. Citizens in World Affairs. A directory of non-governmental organizations. Who they are. What they do, New York, 1953 (Foreign Policy Association), ainsi que SAVORI (R.), WASSON (D.) (ed.), American Agencies Interested in International Affairs, New York, 1955 (Council on Foreign Relations). De B. COHEN voir The Political Process and Foreign Policy: the making of the Japanese peace settlement, Princeton, 1957 (qui présente d'ailleurs le grave défaut de négliger les aspects internationaux du problème). 
Cependant quelques-uns d'entre eux ont toujours témoigné d'une considération soutenue à l'égard de ces questions: anciens combattants; syndicats ouvriers ; mouvements fédéralistes; groupes attachés à la défense de la paix et à la lutte contre l'armement nucléaire...

Aux États-Unis les minorités ethniques prêtent une vive attention à certains aspects de la politique étrangère et y jouent un rôle appréciable [p. 204] (dû en grande partie à leur force électorale): Irlandais, Italiens, Polonais... La minorité juive, inquiète du destin d'Israël et du sort des personnes déplacées, a été très active ces dernières années. Ces organismes sont naturellement à distinguer de ceux qui, dans un pays donné, se proposent exclusivement de défendre, plus ou moins ouvertement, les intérêts d'un État étranger ou d'un groupe d'États étrangers (minorité allemande d'inspiration national-socialiste dans les pays américains). Cependant la ligne de démarcation est parfois difficile à tracer (le cas le plus complexe étant celui de l'appui apporté à la diplomatie soviétique par les mouvements communistes nationaux).

Enfin, il faut citer les groupes qui ont comme objet le rapprochement et la compréhension des peuples, l'élargissement de l'audience des organisations intergouvernementales, la fondation d'une autorité mondiale (tâche que l'on peut aussi s'efforcer de réaliser sur le plan régional : mouvements « européens » dans chacun des États d'Europe et organisations «africaines » en plusieurs secteurs de ce continent). De telles associations sont plus ou moins actives selon les pays et les époques. En certaines occasions, spécialement dans les pays anglo-saxons, ces groupements ont joué un rôle notable. En plusieurs cas, ils se sont unis en fédérations internationales qui tentent dès lors d'agir directement au niveau des relations entre États (notamment dans le cadre des organisations intergouvernementales) : rappel des O.N.G., dites de « développe ment moral ».

Comme on l'a déjà noté, il arrive qu'une « cause » soit défendue sans être prise en charge par un groupe organisé. C'est ainsi qu'il existe à Paris, en dehors du parti communiste, tout un mouvement qui pousse au développement des relations avec l'U.R.S.S. et, plus récemment, avec la Chine. On y rencontre des hommes politiques, des journalistes et des intellectuels, des hommes d'affaires importants et des banquiers, etc. Dans beaucoup de cas, il serait faux d'imaginer que ces efforts font l'objet d'un ajustement préalable: cependant leur convergence est remarquable. Phénomène difficile à qualifier : ce n'est pas un groupe de pression et le terme de «milieu » ne saurait convenir à un ensemble de comportements aussi diffus et multiples. En prenant le mot dans son sens sociologique, disons qu'il s'agit d'un « public » (dont il n'est pas prouvé que les mobiles de ses membres soient identiques).

Toujours sous le même angle, il serait intéressant de centrer avec plus de précision qu'on ne le fait d'habitude les milieux français qui, aux di-[p. 205] verses époques, se sont prononcés contre le rapprochement franco-allemand : les changements constatés dans la composition de ces milieux pouvant servir de points de repère pour une analyse de l'interaction de la politique étrangère et intérieure. Sans doute, la droite nationaliste, après avoir témoigné d'un aveuglement complet à l'égard de la République de Weimar, a-t-elle fortement adouci, essentiellement par 
anticommunisme, sa germanophobie traditionnelle. La base de l'opposition à une entente avec l'Allemagne s'est déplacée. À côté des adversaires systématiques d'une alliance étroite avec l'Allemagne de Bonn (communistes et progressistes) on observe, en divers secteurs de la vie sociale (politique, religion, université, journalisme et correspondants à l'étranger, cinéma, etc.), d'assez nombreux efforts — d'inspiration différente et de formes variées - dont le seul facteur commun est le souci de maintenir la méfiance française à l'égard des Allemands et de l'Allemagne en général. Bien entendu, de tels éléments (dont on pourrait repérer une grande quantité avec des analyses de contenu portant notamment sur les journaux et les films) relèvent, plus encore que les précédents, du concept «public » et non du schéma "groupe de pression ». Un changement dans la vie politique allemande (par exemple, arrivée au pouvoir des sociaux démocrates) provoquerait vraisemblablement des modifications dans ces constellations.

Les spécialistes sont fort hésitants sur l'appréciation de la force de ces pressions. Certes, on a pu relever aux États-Unis des cas très nets d'arrêt ou de blocage à la demande de groupes (le China Lobby notamment) ${ }^{1}$. La plupart des auteurs pourtant déclarent que, si l'influence des groupes est apte à s'exercer en des occasions spéciales ou, sur des problèmes particuliers, les grandes lignes de la politique suivie relèveraient d'autres facteurs. En raison de la pauvreté de la documentation disponible, il est réellement impossible de prendre parti sur des évaluations de ce genre (qui sont peut-être des impressions).

En définitive, l'action intervient même si elle ne produit pas toujours les résultats escomptés. De même que les forces de pression qui agissent sur la scène internationale, les groupes, se limitant à peser sur le gouvernement dont ils relèvent, touchent à la politique internationale. Est-il possible de trouver un principe de distinction entre les deux situations?

[p. 206] Critère de distinction - La différence est apparente. Les groupes que nous venons de citer (groupes nationaux à la fois par la nationalité et la sphère d'action) ne peuvent agir sur la politique internationale que par l'intermédiaire de leur ordre étatique de rattachement : leur action est en quelque sorte de contenu interne. Il leur est certes possible d'atteindre tel gouvernement étranger et, finalement peut-être, de peser sur lui, mais dans ce cas, la pression est médiatisée. En d'autres termes, l'exercice d'une pression dépend de l'empressement d'un gouvernement particulier à faire siennes les suggestions ou revendications de ses ressortissants.

Observons maintenant les autres groupes - ceux dont un grand nombre ont été évoqués dans le premier chapitre (groupes internationaux par leur nature et les dimensions de leur activité; groupes nationaux par le premier facteur et internationaux par le second). Leurs facultés sont bien plus étendues. Ils ont en effet les moyens d'agir sur les instances inter-gouvernementales (pour autant que celles-ci

1 Voir les quelques exemples donnés par COHEN, The Influence..., op. cit., pp. 9-10. Et aussi FUCHS (L.H.), « Minority Groups and Foreign Policy », Political Science Quarterly, juin 1959, pp. 161-175. 
exercent un rôle autonome) ou sur des gouvernements singuliers tout en n'ayant avec eux aucun lien de dépendance initiale et, le cas échéant, aucun élément de rattachement juridique. Enfin, il arrive que les groupes cumulent ces deux possibilités.

Nous appellerons capacité d'intervention internationale (ou, brevitatis causa, « capacité internationale »), la possession par le groupe considéré de l'une ou l'autre, ou de l'une et l'autre de ces facultés. Le point caractéristique est que l'organisme dispose de cette capacité sans être obligé de passer par l'intermédiaire d'un gouvernement déterminé et sans dépendre de son bon vouloir.

Une remarque d'ordre terminologique. Nous disons capacité d'intervention et non capacité d'influence. C'est prendre position contre la tendance fâcheuse qui conclut de l'exercice d'une pression à la nécessité de son succès. On en arrive à se contenter d'étudier l'«accès » en supposant ou en laissant croire que son obtention par un groupe suffit à tout. En procédant ainsi, on donne une vue fondamentalement erronée du problème et on offre un aliment à des campagnes d'affolement ou à la formation de légendes. La capacité d'intervenir (ainsi, par exemple, la possession d'un statut consultatif auprès de l'O.N.U.) n'est nullement en soi, nous le verrons, un gage de succès.

Mais voici une nouvelle question: cette capacité internationale porte-t-elle seulement sur les éléments qui composent la politique internatio-[p. 207] nale (c'est-àdire pour l'essentiel encore, les politiques étrangères des États) ou vaut-elle aussi pour d'autres domaines?

\section{b) POLITIQUE INTÉRIEURE ET PRESSION SUR LES GOUVERNEMENTS}

\section{$\underline{\text { Retour à la table des matières }}$}

On peut se demander si la séparation de la politique intérieure et extérieure possède le moindre fondement dans la réalité. Les juristes de l'ancien régime avaient l'habitude de distinguer soigneusement les affaires internationales des problèmes domestiques. Les relations internationales n'étaient pas censées mettre en cause des sociétés, mais un certain nombre de souverains agissant à titre individuel : d'où l'idée que la conduite des affaires internes ne devait pas être affectée par les négociations diplomatiques et vice-versa. Mais le rappel des guerres religieuses suffirait à établir l'impossibilité finale de tenir la politique extérieure à l'écart des luttes idéologiques intérieures. Aujourd'hui, l'interaction de ces deux secteurs de l'action gouvernementale n'est plus mise en cause : son énoncé est une banalité. Il n'est toutefois pas certain que l'on apprécie correctement l'intensité de ces rapports.

En un sens, il n'est pas interdit d'énoncer que toute décision politique spécialement mais non exclusivement la politique militaire — retentit ou conditionne la politique étrangère : position particulièrement vraisemblable pour les États chargés de responsabilités mondiales et soumis en permanence aux curiosités de l'opinion 
internationale. Un publiciste américain n'a pas craint d'affirmer que «le comportement de l'Américain blanc envers son compatriote noir et vice-versa a plus d'importance pour notre politique étrangère que n'en pourrait avoir une conférence au Sommet ou la plupart des batailles que nous avons gagnées ou perdues ${ }^{1}$. Autrement dit, il n'y aurait plus pour l'Amérique de problème strictement privé, d'affaire qui ne soit chargée d'une résonance internationale ${ }^{2}$.

Cette séparation des actions interne et externe est couramment pratiquée à l'Université. On lui attribue parfois le mérite de permettre un examen plus systématique des problèmes ${ }^{3}$. En réalité, cet usage traduit à la fois une évidente paresse intellectuelle et l'incapacité provisoire de la science politique d'établir un modèle global. Gardons-nous d'élever une imperfection sérieuse à la dignité d'un principe d'explication.

La séparation est également revendiquée sur le plan de l'action par de nombreux gouvernements : il s'agit alors souvent d'une tactique dont voici deux exemples.

[p. 208] Parmi les objectifs d'une telle position figure en premier lieu la volonté de rassurer les voisins et le monde en cas de changement de régime. Les nouveaux maîtres du pays, spécialement les dirigeants de style autoritaire, déclarent souvent que rien ne sera modifié dans l'ordre des affaires extérieures : il est pourtant assez rare qu'un tel engagement se trouve respecté. Bien plus : les chefs des États totalitaires affirment volontiers l'existence d'une nette séparation entre les deux domaines (position revenant à signifier que l'idéologie interne n'est pas à usage d'exportation). Que Hitler ait réussi à en convaincre Neville Chamberlain ou le colonel Beck — qui tous deux, furent persuadés durant une brève période des « intentions pacifiques » du chancelier - illustre bien le sens de la manœuvre. Les chefs soviétiques sont plus francs en disant que leur désir de paix s'accompagne du refus de tout désarmement idéologique et se limite à écarter les conflits de type militaire.

Un second motif est d'éviter les ingérences extérieures dans la vie du pays ou même d'annuler certains problèmes (thèse polonaise affirmant que la frontière OderNeisse ne constituerait plus une question internationale par suite de la signature avec la R.D.A. à Zgorzelec, en 1950, d'un traité la ratifiant) ${ }^{4}$. Pour plusieurs pays, l'argument est utilisé à l'égard de l'O.N.U. Il trouve une base dans le paragraphe 7 de l'art. 21 de la Charte refusant aux Nations Unies l'autorisation d'intervenir dans des affaires qui relèvent essentiellement de la compétence nationale d'un État-membre. Mais cette notion de « compétence nationale » n'est pas définie par le texte et n'a pas été précisée depuis.

AGAR (Herbert), Les années de malaise, traduit de l'anglais, Paris, 1958, p. 19.

Un seul exemple : l'émotion mondiale soulevée par l'exécution des Rosenberg. On sait que la campagne avait atteint en France une ampleur et une violence considérables. Pour un témoignage, voir: Le chant interrompu. Histoire des Rosenberg, textes de ARAGON, Pierre COURTADE, Maurice DRUON..., Paris, 1955.

LONDON (Kurt), How Foreign Policy is Made, New York, 1949, p. 39.

4 OGRODZINSKI (P.), « Oder-Neisse aux yeux de l'Occident », Cahiers Internationaux, mai-juin 1960, pp. 41-48. 
C'est à propos des questions de caractère «colonial » que le conflit d'interprétation a été le plus aigu (France en Algérie, Union Sud-africaine à propos de l'apartheid, etc.). De vives disputes se sont également déroulées à propos d'actes reprochés aux pays communistes (situation en Tchécoslovaquie durant l'année 1948 ; atteinte portée aux droits et libertés fondamentales de l'homme en Bulgarie, Roumanie, etc. ; action soviétique en Hongrie ; affaire du Tibet, etc.).

On n'a pas l'intention d'esquisser ici un modèle de cette interaction dont seul le principe importe. L'action intérieure pèse sur les rapports extérieurs et contribue à en modeler le cours. La répercussion des événements internationaux sur les politiques nationales n'est pas moins nette. Cependant, on peut se demander si le raisonnement doit être poussé au point de disqualifier la notion de politique intérieure. Il ne le semble pas. D'une part, il arrive fréquemment que, même dans les États chargés [p. 209] de responsabilités mondiales, des préoccupations de politique interne, sinon locale, l'emportent sur les soucis extérieurs : situation qui est beaucoup plus marquée et fréquente dans les pays à vocation internationale limitée. D'autre part, s'il est possible de démontrer par la notion des enchaînements successifs, l'interaction finale de toutes les attitudes et de tous les problèmes, il en reste beaucoup qui ont une portée ou des conséquences essentiellement internes (la liaison avec la vie internationale étant seulement ou extrêmement lointaine ou absolument indirecte). Quelles forces interviennent dans un tel domaine ?

Ce sont d'abord, et pour l'essentiel semble-t-il, les groupes nationaux au double sens de l'expression (nature et sphère d'action). Mais il paraît difficile d'exclure de l'explication les autres forces. Citons, par exemple, l'intervention répétée des trusts internationaux du pétrole sur la politique pétrolière du gouvernement français (lors de la définition d'une politique de raffinage entre les deux guerres; au moment de la préparation du Code saharien; à propos de la constitution d'un réseau public de distribution, etc.). L'intervention du Saint-Siège dans l'affaire des prêtres ouvriers, par exemple, est patente et n'est pas dépourvue d'implications sur la politique interne du pays. La question du financement des écoles confessionnelles se présente aussi comme une affaire intérieure et elle l'est bien au départ : toutefois, en exaspérant le laïcisme qui est l'un des rares facteurs de rassemblement de la gauche et du parti communiste (peut-être le seul), la querelle pourrait contribuer à des regroupements politiques susceptibles de n'être pas sans conséquence sur la conduite des affaires étrangères. Mentionnons enfin celles des interventions de la C.I.S.L. qui s'attachent réellement à la vie syndicale et aux problèmes professionnels du pays considéré, etc.

Il existe dans l'action gouvernementale de nombreux secteurs où le facteur technique joue un rôle considérable : ce sont souvent d'ailleurs des matières relevant de réglementations administratives plus que de la législation proprement dite. Or, un nombre fort important d'associations internationales non étatiques est constitué sur la base d'un souci purement technique. Citons par exemple l'Association Générale des Hygiénistes et Techniciens Municipaux ; l'Association Internationale des Recherches Hydrauliques ; le Comité Technique International de Prévention et d'Extinction du Feu ; l'Institut International de la Soudure, etc. Ces associations internationales, dans lesquelles le rôle des facteurs idéologiques reste faible, sont elles-mêmes en contact 
officiel ou officieux avec des organi-[p. 210] sations inter-gouvernementales répondant aux mêmes inspirations. Mentionnons parmi elles un Bureau Hydrographique International, un Bureau international d'Éducation, un Comité Intergouvernemental du Droit d'Auteur, une Commission Internationale du Peuplier...

L'étude systématique de ces organismes n'a pratiquement jamais été faite, mais on peut admettre que les représentants gouvernementaux qui y siègent sont en contact avec les délégués des organisations privées intéressées par le problème en cause. Dès lors, le cheminement (généralement très discret) : organisation non gouvernementale technique $\rightarrow$ organisation intergouvernementale technique $\rightarrow$ administration nationale, s'avère plausible (le deuxième chaînon ne constituant pas un intermédiaire obligé).

En définitive l'intervention de forces internationales en des secteurs que l'on peut dire intérieurs ne saurait être négligée. Cette situation conduit à une vue compréhensive de la " capacité internationale » qui porte à notre sens, aussi bien sur la politique extérieure des États (leurs positions réciproques au sein et au dehors de l'organisation internationale), que sur le domaine interne (défini avec les précautions suggérées). En bref, elle s'attache au comportement gouvernemental tout entier. On peut concevoir dès lors que certaines forces, par vocation ou tactique, s'attachent à intervenir exclusivement, ou de préférence, sur telle ou telle branche, mais il en existe d'autres qui sont en mesure d'agir sur les deux plans et n’hésitent pas à le faire.

La « capacité internationale » ainsi caractérisée varie, en ampleur et en intensité, selon les groupes en cause. L'absence quasi complète d'analyses monographiques rend presque impossible de spécifier dès maintenant les facteurs qui en commandent le niveau. Cependant, il est clair qu'elle ne constitue nullement une faculté acquise une fois pour toutes. Les changements de toute nature qui modifient les rapports internationaux affectent, en termes absolus et relatifs, l'influence dont disposent ces forces. Un seul exemple : la montée des nationalismes a réduit la liberté de manœuvre et la capacité d'intervention des grandes affaires capitalistes, l'évolution ayant été particulièrement accusée dans la période la plus récente.

[p. 211]

\section{ESQUISSE D'UNE TYPOLOGIE}

$\underline{\text { Retour à la table des matières }}$

La principale difficulté est l'absence de concordance entre les divers critères concevables. L'un fait appel à la qualité de l'influence exercée : dans cette perspective serait réputée groupe international toute organisation qui se trouve en mesure d'agir selon certaines normes. On aboutit alors à retenir comme élément distinctif une capacité d'intervention internationale. Mais cette capacité appartient en fait à des groupes qui diffèrent quant à l'ordre juridique de rattachement (plus exactement peutêtre quant à la signification de leur rattachement à un tel ordre). Est-il possible, de combiner ces critères et selon quelles modalités ? 
Nous allons exposer et évaluer trois positions dont on établira qu'elles conviennent chacune à une optique particulière de l'analyse politique, la première se bornant à utiliser la catégorie " groupes de pression » pour expliquer la vie internationale, mais sans subdiviser la notion en fonction du domaine d'emploi ${ }^{1}$; la seconde distinguant et opposant deux séries de groupes: nationaux et internationaux; la troisième admettant la séparation de base entre les deux séries, mais introduisant dans le tableau des cas intermédiaires. Il ne semble pas, du moins à notre connaissance, que ces alternatives aient déjà fait l'objet d'une formulation et dune discussion.

\section{a) UTILISATION INDIFFÉRENCIÉE DE LA NOTION DE GROUPE}

\section{$\underline{\text { Retour à la table des matières }}$}

En tout état de cause l'extension de la notion de groupe aux forces internationales présente des aspects positifs : cependant l'absence d'une différenciation conceptuelle entre les divers organismes intégrés dans la catégorie réduit, selon nous, la portée de l'opération.

Bilan de l'extension - L'un des principaux avantages de la transposition est de faciliter l'unification des divers secteurs de la science politique et, au minimum, d'introduire plus de cohérence dans les démarches de cette discipline. Le transfert de cette catégorie d'une branche à l'autre de la science politique apporte un élément d'uniformisation méthodologique. Il devient possible d'éviter une solution de continuité en passant de l'A.F.L. ou de la C.G.T. à la C.I.S.L. ou F.S.M., de l'Action Catholique en France ou en Italie au Saint-Siège, etc. Et si la Standard Oil N.J. est un pressure-[p. 212] group vis-à-vis du gouvernement américain, on ne voit pas le miracle qui lui ferait perdre cette qualité quand, par l'intermédiaire de sa filiale, elle poursuit des négociations avec les autorités françaises. À moins de postuler une différence de nature dans le comportement des groupements selon qu'ils agissent à l'intérieur ou vers l'extérieur, il ne semble pas possible d'élever une objection préalable contre cette extension.

La théorie des groupes, on l'a dit, comporte de multiples imperfections dont la plus sérieuse est l'incertitude du critère distinctif. Des notions fondamentales comme la nature et les facteurs de l'échec, n'ont pas suscité d'analyses suffisamment systématiques. Mais cette théorie, qui se renforce progressivement, a déjà un acquis solide : sur de nombreux points (conditions et modalités de l'« accès »; inventaire des moyens ; position à l'égard de l'opinion publique ; rapports respectifs : alliances, rivalités...), elle propose un cadre d'analyse suggestif. Trop souvent encore, les études

Il semble que ce point de vue soit implicitement adopté par D. BLAISDELL. Voir « PressureGroup, Foreign Policies and International Polities », Annals of the American Academy of Political and Social Science, septembre 1958, pp. 149-157 et « Unofficial Groups in International Relations. Some Thoughts on Scope and Method of Study », Associations, juin 1959, pp. 436-438. 
dites des «relations internationales » sont conduites sans référence à un schéma uniforme : il en résulte une quasi-impossibilité de les rapprocher, de les comparer, de les superposer. Valable, peut-être, lorsqu'on se borne à la narration de cas particuliers, ce procédé devient impraticable si l'ambition finale est de généraliser.

On peut résumer ces observations en disant que l'emploi de la catégorie « groupe de pression " offre, deux avantages: assurer au chercheur un critère de rassemblement qui lui permette de réunir en une classe spécifique tous les actes, même d'apparence hétérogène, qui ont pour raison d'être l'exercice d'une pesée sur les autorités responsables; lui garantir la possession d'un facteur d'interprétation uniforme qui conduise à traiter ces phénomènes sans s'attacher à leur qualification idéologique ou morale.

Bien entendu, l'action dans le milieu international offre des particularités et implique des servitudes qui donnent au comportement des acteurs une allure propre. Ainsi souligne-t-on par exemple que l'élément «corruption » tient peu de place, si même il n'est pas inexistant dans le dispositif d'action de la plupart des O.N.G. De même, dans de très nombreux cas, ces dernières ne disposent que de ressources limitées et bien inférieures à celles des membres nationaux. Ce sont là des nuances que l'on ne saurait négliger. La présence d'organisations intergouvernementales, cette ébauche de "politification ", complique le problème dans la mesure où ces organismes, sans disposer de grands pouvoirs, ne sont pas entièrement dépourvus de moyens.

[p. 213] Est-il nécessaire de souligner que le schéma forgé pour l'étude des problèmes internes devra être adapté à ces réalités spécifiques ? Il est clair qu'il n'agit pas exactement de la même manière dans une assemblée générale d'organisation intergouvernementale et dans un Parlement national : pourtant, ceux qui ont quelque habitude de ces deux séries de « couloirs » y décèleront des ressemblances allant bien au-delà de simples analogies. Il existe peu de démarches qui ne soient communes aux deux situations (depuis la recherche de la "bonne âme » acceptant de déposer un amendement, jusqu'au « rameutage » des amis au moment du vote, en passant par la remise d'une documentation dont une invitation à déjeuner concomitante n'affaiblira pas nécessairement le poids).

Bien entendu, il ne faut attribuer à l'instrument aucun pouvoir magique. La littérature sociologique est déjà remplie de "slogans à tout faire » : les "deux cents familles » de la politique intérieure, par exemple, se transformant en « impérialistes » au niveau des relations extérieures, comme clé unique de l'explication. Même si l'on en accepte une vue compréhensive, les groupes de pression ne sauraient être considérés, ni sur le plan national, ni sur le plan international, comme les meneurs exclusifs du jeu. Les groupes, il faut le répéter sans cesse, ne sont que l'un des facteurs de la décision et, dans de nombreux cas, ce n'est pas le plus important.

Les avantages qui peuvent être retirés de la théorie des groupes dépendent en grande partie des travaux accomplis pour délimiter cette catégorie et éviter les assimilations abusives. Nous savons, certes, que les États font pression les uns sur les autres : pour nous éviter de l'oublier, un spécialiste américain a cru bon d'établir la 
liste des innombrables interventions américaines dans la politique des pays étrangers depuis $1789{ }^{1}$. Mais il n'en résulte pas l'obligation de considérer les États comme des groupes de pression. Les formules, suggérées à cet égard au début de ce chapitre, pêchent peut-être par excès de rigueur et, sur plusieurs points, sont teintées de juridisme. Dans un premier temps, la phase d'exploration si l'on veut, il est préférable de durcir les clivages. Peut-être le perfectionnement du savoir conduira-t-il à plus de souplesse.

[p. 214] Application aux forces - Le concept "groupe de pression " étant relativement nouveau dans l'étude des relations internationales, on doit insister sur la nécessité d'un effort attentif de distribution. Dans cette perspective, quel traitement réserver aux différentes catégories de forces évoquées dans le précédent chapitre ?

En premier lieu, tous les organismes mentionnés sous les rubriques « Internationales syndicales », « Organismes d'inspiration humanitaire » et « Mouvements de développement moral » peuvent entrer sans aucune difficulté dans la catégorie des groupes de pression. La plupart ont la forme d'associations internationales non-gouvernementales et, lorsqu'il n'en est pas ainsi (cas du Réarmement Moral), possèdent une structure qui les rend justiciables de notre analyse. Sans insister, disons qu'il n'est pas possible de considérer les journaux comme des groupes de pression (pourquoi pas alors les livres ?...), ni non plus les émetteurs de radio. Ce sont, comme tels, des instruments qui peuvent être utilisés, en particulier par les groupes de pression (mais aussi par le gouvernement, des intellectuels indépendants, etc.). Par contre, si les propriétaires ou le personnel des journaux se rassemblent pour agir sur les autorités, nous avons affaire à d'authentiques groupes.

La rubrique «Internationales d'affaires » soulève déjà un thème de discussion dans la mesure où les intérêts économiques (au sens large du terme) sont défendus auprès des pouvoirs par des organismes de formes diverses et d'inspiration différente en apparence. Ayant choisi de considérer la substance et non l'enveloppe, nous pourrons introduire dans notre cadre la plupart, peut-être même la quasi-totalité des organismes repérés : entreprises individuelles, combinaisons d'affaires ( groupes », cartels, ententes), associations professionnelles... Le cas des unités dites " établissements publics nationaux » pose le problème de la distinction à établir entre les domaines public et privé : pour les raisons énoncées dans ce chapitre, nous ne voyons pas d'obstacle à introduire ces établissements dans la catégorie. Il en est de même pour les entreprises publiques que la théorie et la pratique modernes incitent de plus en plus à constituer sous forme de corporations autonomes, ou de sociétés d'économie mixte.

On peut toutefois élever une objection contre cette extension. Si nous accueillons sans hésiter une activité relevant d'une corporation autonome, par exemple les chemins de fer, nous témoignerons au contraire de réticence si cette même branche

1 GRABER (D.A.), Crisis Diplomacy. A history of U.S. Intervention policies and practices, Washington, 1959. 
relève d'une régie pure et simple, [p. 215] assimilable à un service gouvernemental. Nous ne sommes pas en mesure de répondre nettement à l'argument qui pourrait justifier, ultérieurement, une légère révision de la distribution proposée : celui-ci ne serait toutefois décisif que si la neutralité des formes institutionnelles à l'égard des comportements humains était établie. Personne ne pouvant, sur la base des connaissances disponibles, soutenir un tel point de vue, la distinction présentée, bien que boiteuse, n'est pas entièrement dépourvue de fondement.

Dernier point relatif aux Internationales d'affaires: où classer la notion de « milieu » dont il est fait un emploi étendu dans ce secteur ? Nous avons déjà suggéré la solution : s'il s'agit d'éléments repérables et approximativement recensables (haute banque israélite ou protestante...), il semble possible d'accepter une assimilation aux groupes (assimilation incomplète, n'entraînant pas une totale transposition) ; mais s'il est question d'entités vagues («milieux boursiers »), nous pensons que la notion de « public » convient mieux que celle de « groupe » pour refléter la situation.

Le cas des Internationales de partis est plus délicat et implique des évaluations subjectives qu'il serait souhaitable d'uniformiser. Dans la mesure où il n'existe pas de gouvernement mondial et où l'activité des internationales ne consiste pas uniquement à renforcer et à coordonner les actions de leurs membres sur le terrain national, on peut, semble-t-il les considérer comme des groupes de pression. Beaucoup, toutefois, seront tentés de refuser cette qualité au Komintern et au Kominform, l'un et l'autre étant vus comme une démultiplication du gouvernement soviétique. Il ne paraît pas possible d'adopter ce point de vue déjà critiqué : dès qu'une organisation est créé (avec, en particulier, des moyens de secrétariat) nous devons nous en saisir quitte ensuite à interpréter le sens de son activité et son degré d'autonomie. On peut cependant se demander si le Kominform n'était pas une organisation intergouvernementale (comme aujourd'hui le Comecon), deux de ses membres seulement représentant des partis hors du pouvoir.

Naturellement, le « communisme international » n'est pas comme tel un groupe de pression. C'est en définitive, une construction intellectuelle qui entend rendre compte d'un ensemble d'efforts coordonnés et inspirés par une idéologie unique. Par contre, tous les groupements qui s'inspirent de cette idéologie et de ces tactiques, forment des groupes de pression. On ne saurait toutefois ranger dans cette catégorie de simples [p. 216] manifestations comme celles tenues à l'occasion du $40^{\mathrm{e}}$ anniversaire de la Révolution d'Octobre : elles constituent une activité temporaire et non un cadre permanent d'intervention.

On peut hésiter sur le cas des sociétés secrètes (incertitude s'étendant à l'ensemble du sujet fort négligé par la science politique classique). Sur le plan de la cohérence théorique le doute est permis. Il est dès lors tentant d'y voir une classe intermédiaire entre le parti et le groupe, mais on peut également tenir cette complication pour inutile et trouver légitime l'assimilation de ces sociétés aux groupes. Cette thèse qui néglige, ou minimise, le rôle de l'«initiation » a des aspects plausibles mais non vraiment convaincants: elle sera probablement révisable dans un état moins rudimentaire de la théorie. 
Par ailleurs, le lecteur ne sera pas étonné que nous écartions de ce tableau les assemblées extra ou supranationales, même si l'essentiel ou une large part de leurs facultés se ramène à une "magistrature d'influence ": Conseil de l'Europe, Assemblée Parlementaire Européenne... Par contre, les groupements de parlementaires, se réunissant à titre individuel pour promouvoir une «cause » (gouvernement mondial), sont assimilables à nos groupes.

En apparence, le cas des Internationales religieuses n'est pas facile à élucider. Plusieurs distinctions peuvent être proposées pour le résoudre. En principe, la science politique ignore la formulation des dogmes et l'action pastorale pour s'intéresser seulement aux conditions et modalités d'insertion de l'Église dans le siècle, mais il est souvent difficile de tracer, entre ces deux aspects de l'action religieuse, une ligne de séparation indiscutable. On peut aussi se référer à une distinction entre le sentiment religieux (capable d'inspirer spontanément des phénomènes de comportement), et l'action organisée qui s'appuie sur ce sentiment pour réaliser d'autres objectifs. Valable d'ailleurs pour toutes les idéologies, la différenciation se heurte, en pratique, à des obstacles déjà signalés.

Deux traits facilitent l'étude de certaines religions : leur capacité à s'organiser sur le plan matériel et l'acceptation, au moins apparente, d'une séparation entre le spirituel et le temporel. L'Église catholique s’insère aisément dans notre schéma. Encore que le Saint-Siège bénéficie des facilités du droit des gens, on ne saurait, juridiquement, le considérer comme un État: par ses interventions dans les problèmes du siècle, qui sont innombrables, le Saint-Siège (mais non pas, naturellement, l'État du Vatican) est le prototype de la force qui pèse sur la vie [p. 217] internationale (même si la courtoisie conduit à ne pas lui appliquer crûment le terme de " groupe de pression »). Bien entendu, toutes les grandes associations catholiques relèvent aussi de ce type, l'ensemble dépendant d'un centre qui s'efforce d'unifier les idées et les attitudes. Nous avons donc ainsi une superposition hiérarchisée de groupes de pression dont les divers éléments ont chacun leur vocation propre.

Il est plus difficile de se prononcer sur la position dans la vie politique de quelques-uns des rouages de l'Église, par exemple, les Ordres religieux. Il apparaît impossible de ne pas classer certains d'entre eux (ainsi les Jésuites) dans notre schéma. En ce qui concerne les Missions, il est des régions du monde où elles ont joué un rôle politique considérable pouvant aller jusqu'à l'établissement de gouvernements quasi-théocratiques ${ }^{1}$. Faut-il attribuer l'influence au centre suprême de commandement, ou à l'élément décentralisé ?

Au cours des dernières décennies, on a observé chez les Protestants une nette tendance au regroupement et un effort vers l'unité : d'où la constitution de nombreux organismes, se présentant souvent comme des O.N.G. et dont une partie de l'activité

KOSKINER (Aarne A.), Missionary Influence as a Political Factor in the Pacific Islands, Helsinki, 1953 (attribue le même rôle aux missions protestantes). Voir aussi (analyse de l'apostolat jésuite), LUGON (C.), La République communiste chrétienne des Guaranis (1610-1768), Paris, 1949 (selon l'auteur, République « sans doute trop communiste pour les chrétiens bourgeois et trop chrétienne pour les communistes de l'époque bourgeoise »). 
relève directement de nos préoccupations. Une religion comme l'Islam soulève des difficultés d'interprétation beaucoup plus graves sur lesquelles nous ne sommes pas en mesure d'émettre un avis sérieux. Cette confession ne semble pas, même aujourd'hui, distinguer formellement le politique du spirituel. Quand une assemblée d'Oulémas ou les docteurs d'une grande université coranique prononcent une condamnation, c'est généralement sur la base de la sauvegarde de la foi ; mais très souvent, l'objet du verdict est un problème politique de brûlante actualité. Bornonsnous à signaler le phénomène, appelé peut-être à évoluer.

Reste enfin le cas de ce que nous avons désigné d'une expression assez large pour être compréhensive : les mouvements de revendication nationale. Là aussi, ce n'est pas le courant qui constitue le groupe de pression, ce sont les organismes qui en résultent. Or deux particularités compliquent le problème : l'absence d' « institutionnalisation » de certains de ces courants qui restent donc des tendances de l'opinion (capables d'engendrer parfois des sursauts spontanés, en particulier de révolte) ${ }^{1}$, et la variété des formes qu'est susceptible de revêtir cette institutionnalisation quand elle intervient: sociétés secrètes (avec ou sans prolongements terroristes), partis régulièrement représentés dans une assemblée parlementaire, groupes de pression de type classique, ligues armées, [p. 218] voire (aujourd'hui) gouvernement provisoire. Il est certes nécessaire de distinguer les mouvements selon le style choisi sans oublier que, selon les pays ou les époques, il a été possible de réaliser le même but par des moyens différents.

De plus, au niveau de la pression internationale, n'oublions pas trois éléments : toutes ces formes (y compris celle du parti) s'accommodent d'une activité sur la scène internationale ou en permettent la réalisation ; il est fréquent que la même cause nationale comporte l'emploi simultané de plusieurs instruments; finalement, la « capacité internationale » dépendra de la totalisation des efforts et éventuellement de l'habileté avec laquelle ils sont liés pour concourir au résultat visé.

On ne saurait passer sous silence que, dans certains cas, la pression pour l'émancipation ou l'indépendance engendre une contre-pression d'une puissance redoutable. Pensons par exemple aux Français d'Afrique du Nord qui, pour agir seulement sur l'appareil gouvernemental français (civil et militaire), n'en sont pas moins, involontairement d'ailleurs, un facteur-clé dans les rapports entre le monde occidental et les pays arabes (et peut-être demain tous les États d'Afrique noire) : facteur comparable à celui que constituent déjà Israël et le sionisme dans les relations entre l'Ouest et le Moyen-Orient (notons ici, entre autres, le rôle mondial que joue indirectement l'American Jewish Committee par son action sur la politique américaine).

Voir HOBSBAWN (E.J.), Primitive Rebels. Studies in archaic forms of social movement in the 19th and 20 centuries, Manchester, 1959. Ce livre étudie les mouvements sociaux, ruraux ou urbains des groupes primitifs (pour l'Europe centrale et méridionale Maffia et, plus encore, millénarisme) dont le seul moyen d'expression est la révolte. 
Dès l'instant que l'activité des divers organismes créés sous l'égide de ces mouvements de libération nationale s'exerce vers l'extérieur, il faut les considérer comme des groupes de pression (y compris même, exceptionnellement, les partis, si leur objectif n'est pas de conquérir le pouvoir dans l'État en cause, mais d'obtenir la formation d'une structure propre ou le rattachement à un autre système). Naturellement, selon notre convention, l'acquisition de la qualité d'État transforme la nature du phénomène. Encore qu'elle s'efforce d'agir sur divers gouvernements, la Ligue Arabe n'est pas un groupe de pression: c'est une organisation régionale intergouvernementale.

Dernière particularité : le cas d'un mouvement qui bénéficie, au même moment, de qualifications différentes dans la société internationale. Ainsi aujourd'hui, le F.L.N. : pour les uns, gouvernement légitime et reconnu comme tel; pour d'autres, groupement encore de nature privée, mais avec lequel on entretient déjà des relations suivies et cordiales ; pour les autorités françaises, enfin, organisation extérieure de la rébellion.

[p. 219] Portée de la formule - La systématisation de toutes ces forces dans la catégorie "groupes de pression " traduit, pensons-nous, un progrès sérieux pour l'analyse politique. Toutefois, en se limitant à une présentation globale, obtient-on tout le profit qu'il est permis d'escompter de l'opération ? Il ne le semble pas.

Certes, un avantage reste acquis : l'obligation qui incombe désormais au chercheur de fournir une analyse compréhensive de la catégorie "groupes de pression ». On peut en attendre un comblement progressif des lacunes qui affectent gravement notre documentation. S'il est admis que les forces internationales figurent parmi les groupes, il devient raisonnable d'espérer qu'elles susciteront un courant d'études monographiques à l'image de celui déjà réalisé pour les forces internes.

Cet élargissement des perspectives permettra un approfondissement et un perfectionnement de la théorie générale du groupe en politique. Les ressemblances observées d'un niveau à l'autre comme aussi les différences constatées rendront possible l'amélioration de la valeur du concept en précisant et en nuançant ses éléments et ses frontières.

Qui se limiterait à une analyse de cette notion pourrait donc se contenter du schéma indifférencié. Mais il n'en va pas de même si l'on souhaite contribuer à l'explication de la vie politique. En effet, en négligeant toute répartition, on ne tient nul compte des hiérarchies qui s'établissent entre les divers plans d'action et on ignore les divergences qui en résultent dans les orientations et les tactiques des intéressés. On aboutit ainsi à tracer un cadre d'analyse, lourd et relativement hétérogène, sans être en mesure de proposer une ventilation vraisemblable de ces forces selon les situations étudiées et les problèmes en cause. Certes, on peut interpréter comme une affirmation de l'unité de la science politique, le refus de diviser une catégorie d'intervention selon les niveaux où se situent habituellement les pressions. Mais l'établissement d'une classification cohérente n'entraîne aucun risque de fragmentation dès lors qu'elle ne met pas en cause l'homogénéité de l'inspiration des groupes. 
Sur le plan théorique une distinction entre les groupes semble nécessaire pour tenir compte de l'absence de politification de la société internationale. La réalisation d'un authentique gouvernement mondial aurait pour conséquence de rendre plausible et même logique l'unification des groupes: il n'y aurait plus entre eux d'autre dissemblance que les différences dans l'aptitude à se faire entendre aux divers niveaux de [p. 220] commandement (comparable à celle qui sépare aujourd'hui les groupes en mesure de jouer un rôle au niveau central et ceux seulement en état d'agir au plan local). Mais l'inexistence d'un tel gouvernement fait surgir une différence qualitative dans l'exercice de la pression.

Un partage est donc nécessaire pour mettre en vedette cette divergence. Mais où en situer la ligne?

\section{b) UNE TYPOLOGIE DUALISTE : GROUPES NATIONAUX ET GROUPES INTERNATIONAUX.}

\section{$\underline{\text { Retour à la table des matières }}$}

Son contenu dépend de l'ampleur donnée à la catégorie "groupes internationaux ». On partira d'une conception large qui semble la plus valable : mais une position restrictive sera également mentionnée.

Conception large - La notion compréhensive peut s'expliquer en termes simples: constituent des "groupes internationaux", les groupes dotés de la « capacité internationale", (précédemment définie), tous les autres formant des groupes nationaux.

La Fédération Internationale du Bâtiment et des Travaux Publics qui s'occupe de nombreux problèmes relevant de l'action gouvernementale (politique du logement, sécurité de la construction, salaire garanti, régime des adjudications...) s'intègre dans la première catégorie. Mais on y inclut aussi les grandes firmes capitalistes, par exemple, la Holding Schneider et Cie. En dehors des affaires propres au groupe (Société des Forges et Ateliers du Creusot, Compagnie Industrielle des Travaux et Société Générale Française des Mines) et de ses participations (notamment dans la Société Métallurgique Luxembourgeoise Arbed), Schneider possède d'importants intérêts à l'étranger qui sont mis en œuvre par le canal des sociétés spécialisées, domiciliées en diverses places (Londres, Montréal, Sydney, New York, Mexico, Caracas, Rio de Janeiro) : ainsi l'entreprise prend-elle part dans le monde entier aux adjudications de travaux publics et à l'établissement de nouveaux centres industriels.

Cette répartition offre deux avantages essentiels par rapport à la position précédente. D'abord elle établit une claire distinction entre les groupes selon leur domaine d'influence et, pour mieux dire, leur vocation : divergence qui se répercute dans le mode d'organisation, le choix des tactiques, les facteurs de succès ou d'échec, etc. Mais, de plus, cette présentation suggère que pour l'analyse de n'importe quel problème [p. 221] il est en particulier nécessaire de prendre en considération deux 
séries d'éléments : forces internationales et nationales. Or ce trait élémentaire est souvent perdu de vue.

Les études de politique internationale négligent trop souvent la pression des forces proprement nationales (au sens où leur action est " médiatisée » par le gouvernement auquel elles se rattachent) : plus exactement, peut-être, on tient seulement compte de ce facteur lorsqu'il s'agit de problèmes économiques - cas des relations horlogères américano-suisses, par exemple ${ }^{1}$, en le négligeant pour d'autres questions, de type ethnique ou religieux par exemple. D'autre part, les monographies de politique intérieure ignorent volontiers les influences internationales, ou n'en traitent que de façon polémique, ou encore n'en donnent qu'une vue fallacieuse en les assimilant, de façon expresse ou tacite, à des éléments proprement nationaux. Ces insuffisances provoquent inévitablement des lacunes dans la présentation des problèmes et des erreurs dans leur explication. Exploitées de manière systématique elles poussent à « mystification».

La part et le poids propre de chacune de ces deux séries, facteurs internationaux et nationaux, varient selon le centre décisionnel analysé et le problème en cause, mais l'éventualité de leur conjugaison (ou de leur opposition) à propos de n'importe quel sujet ne doit pas être oublié.

Mais, si cette typologie comporte des avantages, elle soulève plusieurs objections. Voici les principales, leur examen permettant de mieux préciser le contenu et la portée du schéma dualiste proposé.

$1^{\circ}$ En premier lieu, il est impossible d'établir avec une parfaite certitude la liste des groupes bénéficiant de la "capacité internationale». Soit une affaire dont l'activité se limite, généralement, au territoire national ; si l'on suppose qu'elle en vient à signer un marché important avec un gouvernement étranger, on peut tenir pour vraisemblable la réalisation d'un effort tendant à lui réserver une porte d'accès à ce gouvernement et les « amitiés » indispensables à cet effet.

Considérons par ailleurs les organisations intergouvernementales : la localisation de leurs activités en un point donné (siège social) ouvre à des groupes qui, normalement n'en bénéficient pas et ne la recherchent habituellement pas, la faculté d'intervenir directement au niveau de la gestion internationale (groupes américains auprès de l'O.N.U., diverses associations culturelles françaises auprès de l'Unesco, Union Syndicale [p. 222] Suisse auprès du B.I.T.). Il arrive que ces organisations agissent simplement comme le porte-parole d'un groupement international ; cependant cette conformité à un dessein extra-national, ne saurait toujours être présumée et on ne peut écarter l'hypothèse d'un groupe national profitant de relations de voisinage dans son intérêt, ou selon son inspiration propre. Enfin, plusieurs organisations intergouvernementales ont des rapports avec des organisations nongouvernementales nationales comme telles : le B.I.T. par exemple, entretient de facto

1 Voir l'étude de BOLLI (Jean-Jacques), L'aspect horloger des relations commerciales américanosuisses de 1929 à 1950, La Chaux-de-Fonds, 1956. 
des relations avec d'assez nombreuses associations de ce type et l'O.N.U. a même donné le statut consultatif à une dizaine d'associations de cette catégorie.

L'argument n'a d'autre résultat que de rappeler la relativité inévitable de toutes les classifications en sciences sociales. Dès qu'on quitte le plan des concepts de raison pour analyser la pratique, on découvre presque nécessairement des faits aberrants. Ceux que l'on vient de signaler (et on pourrait en ajouter d'autres) ne sont ni assez nombreux, ni assez sérieux pour motiver un rejet de la typologie proposée.

$2^{\circ}$ Une seconde objection tient à la présentation globale de la «capacité internationale ». On ne distingue pas selon qu'elle est mise en œuvre à l'égard d'organisations intergouvernementales ou de gouvernements singuliers. Or il est permis de penser que tous les groupes internationaux ne sont pas également aptes à lutter sur ces deux tableaux, ou désireux de le faire. Dès lors, ne serait-il pas intéressant de distinguer, dans les groupes internationaux, ceux qui sont spécialisés dans l'action sur les institutions intergouvernementales?

À supposer cette suggestion valable, un point empêcherait, au moins pour l'immédiat, de la prendre en considération : l'insuffisance de nos connaissances sur le secteur intergouvernemental. En dehors d'un tout petit nombre d'organisations de tête, l'analyse de ce secteur, du point de vue de la science politique, reste à faire, et en particulier celle de ses rapports avec le milieu privé. S'agissant des grands organismes, O.N.U., Unesco, B.I.T., etc., nous connaissons la liste des O.N.G. qui interviennent et occupent, non sans quelque complaisance, le devant de la scène. Mais, en fait, sont-elles seules à agir ainsi ?

Notre ignorance du comportement réel des fonctionnaires internationaux est trop grande pour que l'on puisse se prononcer avec certitude. Quand la Commission Économique pour l'Europe a décidé, en 1955, de [p. 223] publier un rapport sur le prix des produits pétroliers en Europe occidentale, il ne semble pas que les émissaires du cartel à Genève se soient désintéressés de la question : les milieux «bien informés ", selon l'expression courante, ont fait état de fortes pressions tendant à éviter la publication de ce document. On ne saurait présumer qu'il s'agit là de faits exceptionnels.

Il y a plus. Si l'on se place au niveau conceptuel, il n'est pas sûr que la séparation envisagée soit souhaitable. En effet, si elle s'exerce sur le secteur bureaucratique, la pression dirigée vers les organismes intergouvernementaux, touche aussi (et pour une très large part) les dirigeants nationaux. Or on peut les atteindre, soit à travers les rouages de l'organisation, soit par le truchement des services étatiques. Une classification des groupes, fondée sur les divergences dans le mode d'intervention serait difficile à mettre en pratique (le même organisme pouvant agir à la fois sur les deux plans, ou modifier sa tactique selon les circonstances).

Le point à retenir de cette objection est la nécessité d'étudier les diverses voies d'accès, d'en comparer l'efficacité, d'examiner les mobiles qui conduisent les groupes à utiliser telle ou telle de préférence : on fournira une ébauche de cette étude au chapitre suivant. 
$3^{\circ}$ La troisième objection tient à certaines modalités de la «capacité internationale ». Celle-ci repose souvent sur l'activité d'une branche nationale ou de quelques-unes d'entre elles (qu'il s'agisse d'une association pour les O.N.G. ou d'une filiale pour les groupements d'affaires). Mais ce mode de pénétration n'est pas toujours praticable: ainsi, la C.G.T.-F.O. s'est-elle opposée à plusieurs des interventions de la C.I.S.L. sur l'outre-mer français. Au surplus, l'emploi d'une telle modalité d'intervention n'apporte, en principe, aucun argument contre la typologie proposée : le maniement d'unités nationales constitue en effet l'une des particularités de la tactique internationale et l'un des éléments de la « capacité internationale ».

Une analyse plus attentive conduit toutefois à formuler des nuances qui trouvent leur origine dans la variété des rapports entre la capacité internationale dont dispose l'ensemble et les capacités nationales de ses diverses parties. Ces relations diffèrent, d'un cas à l'autre, entre des positions extrêmes : un centre actif et autoritaire qui utilise les organismes membres comme un instrument de pénétration ; un centre ré-[p. 224] duit à la condition de lieu de contact ou de boîte à lettres sans pouvoir réel sur des instances nationales jalouses de leur autonomie (le règlement précisant parfois que le centre n'exercera aucune activité en divers domaines exclusivement réservés aux membres).

Dans cette seconde hypothèse ce sont les unités nationales qui, en pratique, apportent la puissance et les ressources financières. Dès lors, la réalisation éventuelle des objectifs de l'organisation — spécialement par pression sur les gouvernements singuliers - n'est-elle pas exclusivement le fait des capacités nationales et n'y a-t-il pas quelque excès à invoquer, à ce propos, la notion de capacité internationale ? On pourrait d'ailleurs aller plus loin en mentionnant le cas où une organisation nationale se sert de son appartenance à un groupe international pour faire aboutir, auprès de l'ordre juridique auquel elle est rattachée, des revendications qui lui sont particulières. Quand il en va ainsi le facteur international perd toute autonomie et même tout contenu réel : il se ramène à fournir un argument d'opportunité ou de convenance grâce auquel les intéressés tentent d'assurer le triomphe d'une thèse ou d'une cause purement nationale.

En principe de telles déformations se produisent plus rarement dans le monde des affaires où la structure de la répartition du capital hiérarchise les rapports. Pourtant, dans la réalité, les situations respectives n'ont pas toujours une netteté d'épure (participations réciproques, relations individuelles, rôle des personnalités, etc.).

L'analyse des groupements internationaux, et spécialement des O.N.G., ayant été négligée jusqu'à présent, nous manquons des éléments d'information qui permettraient de donner une présentation cohérente du problème. Le peu que l'on en connaît autorise à penser que l'analyse de la question exigerait une typologie complexe. Voici un aspect de cette question : il arrive qu'a l'intérieur d'une même organisation les rapports entre le centre et les membres n'obéissent pas à un système uniforme (différences de comportement entre les associations nationales qui ont fondé le centre et celles dont il a lui-même provoqué ou aidé la création). 
$\mathrm{Au}$ total, les réserves auxquelles conduit cette objection sont importantes. N'oublions pas que dans le cas des O.N.G. les membres des groupes internationaux sont, déjà ou aussi, des groupes de pression nationaux. Il n'y a pas, d'une part, le membre français du Conseil des Fédérations Industrielles d'Europe, et, d'autre part, le Conseil Natio-[p. 225] nal du Patronat Français: le C.N.P.F. est précisément le représentant français au sein de l'organisation européenne. La situation est évidemment génératrice d'ambiguïté, le groupe national pouvant agir comme porteparole du centre ou pour son propre compte (en se parant ou non de la référence internationale).

Cependant il en va de même jusqu'à un certain point sur le plan d'un pays donné, pour tous les organismes de superposition (centrales patronale, syndicale, agricole...). Ces observations ne conduisent donc pas au rejet de la formule proposée : elles commandent simplement de tenir pour l'un des aspects essentiels du sujet qui est également l'un des plus mal connus, l'analyse des rapports qui s'établissent entre le centre et les unités composantes (compétences respectives, puissance relative, sens de l'influence, etc.).

Proposition restrictive - Voici maintenant une observation d'un autre type dont la validation conduirait à l'éclatement du système proposé et à une conception restrictive du groupe international. La typologie esquissée précédemment prend les termes « international » et «national » dans un sens qui ne tient aucun compte du rattachement de l'organisme en cause à l'ordre international ou à un ordre juridique national. Or, diront les critiques, il n'est pas légitime de considérer Nestlé, par exemple, comme un groupe international : c'est une affaire suisse et qui entend rester telle. En suivant cette position que nous avons déjà évoquée, on en viendrait à définir comme "groupes de pression internationaux » les seuls groupes pour lesquels il existe une correspondance, au moins approximative, entre la nature juridique et la qualité du mode d'intervention : c'est-à-dire ceux rattachés à l'ordre international (de façon éventuellement boiteuse et partielle, voir supra) ou, si l'on préfère, ceux indépendants d'un ordre gouvernemental particulier. On écarterait ainsi de la catégorie une large part des organismes d'affaires.

L'argument, on l'a dit, n'est purement juridique. Les grandes entreprises, à rayonnement international ou mondial, sont tout de même des instruments de puissance nationale. Dans une mesure difficile à préciser, mais qui est rarement négligeable, ces entreprises tiennent compte des désirs (et parfois des consignes) du gouvernement national. Aux environs des années 1940, par exemple, le Département d’État demanda aux firmes américaines installées en Amérique latine de cesser toutes [p. 226] relations commerciales avec les entreprises allemandes de cette région, beaucoup d'entre elles étant tombées sous la domination des nazis. En contrepartie, ces firmes peuvent compter, au moins dans certaines limites, sur ces mêmes autorités pour défendre leurs intérêts auprès des gouvernements étrangers. Selon A. Berle, plusieurs grandes sociétés, recevraient (mais de quelles sources ?) des rapports 
fréquents et détaillés sur l'aptitude des diplomates américains à défendre leurs intérêts à l'étranger et leur empressement à le faire ${ }^{1}$.

Cette thèse, on l'a déjà noté, n'est soutenable que si elle s'accompagne de la volonté d'élucider la nature et la position réelle des intérêts en cause, autrement dit du souci de faire prévaloir l'allégeance politique sur l'allégeance juridique. Il s'agit au premier chef de déterminer avec exactitude les éléments collectifs ou individuels, qui contrôlent la marche du groupe. S'il y a discordance entre les indications fournies par cette étude et la localisation du siège, ce dernier facteur doit être écarté. De plus, il est nécessaire de rétablir les liaisons masquées par les législations de complaisance qui, dans le domaine de l'armement maritime par exemple, ont pris à une certaine époque une extension considérable ${ }^{2}$. Est-ce à dire qu'en s'efforçant d'identifier les meneurs effectifs du jeu (que dissimulent des structures formelles d'une complexité parfois inouïe) on rend admissible la position restrictive suggérée ?

Nous répondrons par la négative, car le point décisif n'est pas là : la thèse que nous exposons aboutit à déformer les phénomènes en n'insistant pas assez sur le pouvoir et le comportement de ces grands centres d'affaires dans les relations internationales. Bien que la plupart d'entre eux entourent leur activité d'un secret hermétique, les interventions politiques qui en résultent ne peuvent être contestées et nous en fournirons des exemples au chapitre suivant. Cette vocation implique un certain mode d'organisation, tourné en particulier vers la recherche de renseignements concernant hommes et choses de l'étranger: Berle dira de certaines affaires américaines ayant des intérêts Outre-Mer qu’elles entretiennent un « Département

\footnotetext{
Op. cit., p. 101.
}

En matière de navigation maritime, la complaisance a atteint un tel degré que selon un avis consultatif de la Cour de La Haye, l'Allemagne fédérale et la France devraient céder au Libéria et à Panama les sièges qu'elles détiennent au sein du comité maritime de l'Organisation intergouvernementale consultative de la navigation maritime (le Libéria et le Panama, soutenus en l'occurrence par les États-Unis, se situant respectivement au troisième et au huitième rang sur la liste des pays classés par tonnage de jauge brute immatriculée) On observera que la Grèce ne figurait pas dans le dit Comité maritime. Il semble d'ailleurs que la situation soit en voie de transformation par suite du « courant de rapatriement » de la flotte grecque qui s'est accéléré au cours des dernières années (ce que l'on a appelé le « miracle maritime grec ». Ce rapatriement a été effectué en raison de la stabilité politique actuelle de la Grèce, du vote de lois garantissant un traitement équitable aux armateurs et du boycottage lancé contre les pavillons de complaisance par la Fédération Internationale des Ouvriers des Transports. Dès maintenant, ce pays occuperait le cinquième rang (la suppression complète des pavillons de complaisance le plaçant selon certains calculs au second). De façon générale, la fourniture de domiciles de pure complaisance assure de fructueux profits qui constituent une tentation permanente pour les États dits "exigus » qui possèdent une indépendance, plus ou moins complète, sans assumer les responsabilités de la communauté internationale. Il y a quelques années, l'État de Saint-Marin (alors à gouvernement socialo-communiste) tenta d'offrir un refuge fiscal aux grosses sociétés italiennes : il semble que le gouvernement de Rome soit parvenu, assez rapidement, à arrêter cet essai. Des informations de presse signalent qu'actuellement la principauté de Monaco étudierait des formules conduisant les grandes firmes, américaines et européennes, à y établir des sièges administratifs. 
d'État au petit pied » et disposent de «diplomates » qu'elles gardent à demeure ou envoient en mission à l'étranger ${ }^{1}$.

Le caractère international de ces firmes se manifeste, en particulier dans le choix du personnel. Le corps dirigeant d'une affaire comme Nestlé provient de divers pays ; l'entreprise tient à faciliter la formation [p. 227] méthodique et scientifique de cadres et de spécialistes venant de toutes les régions du globe. Une telle situation n'est pas exceptionnelle : on la trouve par exemple à un degré élevé dans les trusts du pétrole. « On parle beaucoup de l'Unesco et d'autres organisations mondiales analogues, disait le directeur de l'un d'entre eux. Mais, sur le plan pratique de l'internationalisme, rien ne peut être comparé à l'efficacité de l'industrie pétrolière ${ }^{2}$. Plusieurs de ces firmes ont une activité d'ampleur mondiale (au moins dans la partie du monde encore ouverte à ce genre d'entreprise). Il n'est pas impossible que leurs intérêts extérieurs entrent en concurrence avec les préoccupations internes du pays dont on affirme, peut-être trop vite, que ces combinaisons sont toujours prêtes à assurer la défense (voir les difficultés soulevées par le contingentement, sur le marché américain, du pétrole du Moyen-Orient qu'importent les sociétés du cartel et aussi les « indépendants »).

Quand ces firmes éprouvent des difficultés avec les autorités des pays étrangers dans lesquels elles disposent de centres d'exploitation il leur est possible de faire appel à leur gouvernement (qui d'ailleurs, surtout aujourd'hui, ne les soutiendra pas toujours), mais elles disposent de leur propre appareil de négociation et de pression. Il est probable que ces firmes évitent actuellement de s'insérer dans les différends de politique interne concernant leurs pays d'installation : ce ne fut pas toujours le cas et l'abstention n'est peut-être pas devenue aussi complète que diverses présentations, à tendance apologétique, veulent bien l'affirmer.

De plus, et nous aurons à revenir plus tard sur ce problème, dans des pays de faible capacité économique la présence de certaines grandes firmes étrangères a, par elle-même, une résonance politique au sens où des aspects majeurs de la vie du pays correspondant à des responsabilités gouvernementales (niveau de l'emploi, finances extérieures...) dépendent, en une large mesure, des décisions prises par leurs dirigeants. Que l'on songe par exemple aux cas suivants : manganèse pour le Gabon, aluminium pour la Guinée, fer pour la Mauritanie, pétrole pour plusieurs États arabes, etc. Or, ces ressources sont généralement exploitées par un petit nombre de firmes étrangères, parfois une seule. Il en résulte que, de plus en plus, ces firmes sont tenues de prendre en considération les intérêts des pays dans lesquels elles sont installées. L'observation s'applique à tous les sièges d'exploitation, qu'ils se situent dans les pays développés ou sous-développés.

[p. 228] Ces derniers témoignent désormais d'une hypersensibilité à l'égard de toute velléité d'exploitation coloniale: dès lors, la meilleure chance des firmes

Op. cit., p. 104.

Propos rapporté par Ed. WARD, Le pétrole dans le monde, Paris, 1960, p. 190. L'ouvrage ouvre d'intéressantes perspectives sur le fonctionnement pratique de l'industrie pétrolière. 
capitalistes est de montrer qu'il n'existe pas d'incompatibilité entre leurs intérêts propres et ceux du territoire d'accueil. Ce souci peut entraîner des attitudes et des décisions différentes de celles que dicterait la défense exclusive des soucis spécifiques de la firme ou des intérêts de son pays d'origine.

Dès lors, sans méconnaître la force de la thèse restrictive, nous pensons qu'elle présente une faiblesse fondamentale: masquer que les grandes constellations d'affaires, même si leur organe de tête se rattache à un intérêt national, sont en fait, des entités internationales dont il est nécessaire de rendre compte en tant que blocs de puissance. La conduite des firmes de distribution pétrolière en France n'est pas proprement française. Est-elle purement américaine ou anglo-néerlandaise ? La notion d'un comportement d'aspect et d'esprit internationaux n'exprime-t-elle pas mieux la réalité du phénomène?

En définitive, la position restrictive souffre d'un grave défaut : elle « nationalise » soit par scrupule juridique, soit par souci nationaliste, des forces dont la puissance réelle à travers le monde est notablement supérieure à celle de la plupart des groupes (spécialement les O.N.G.) que l'on accepte d'« internationaliser ». On a le sentiment que son adoption, qui rattacherait aux groupes nationaux d'authentiques internationales d'affaires aboutirait à fausser les dimensions et surtout les proportions des rivalités mondiales.

Comme on l'a souligné, la conception large du groupe international n'est pas à l'abri de réserves (dont une large part vaudrait aussi d'ailleurs à l'encontre de la notion restrictive). Cependant, ces critiques ne sont pas décisives si l'on considère l'avantage fondamental que procure un tel schéma : la possession d'un état systématique des forces disposant d'une capacité d'influence qualitativement internationale.

On détient ainsi, en particulier, un instrument cohérent pour l'étude du fonctionnement des instances internationales qui subissent, tout de même, d'autres pressions que celles émanant des organismes dotés du statut consultatif. Plus généralement l'adoption d'un concept unifié de "capacité internationale », portant aussi bien sur la politique étrangère que sur l'action interne des gouvernements, ouvre la voie à une interprétation plus réaliste de la société des États.

[p. 229] Au total, si l'on entend réaliser une présentation globale de la communauté internationale, la formulation dualiste dont on vient d'esquisser le contenu paraît constituer le meilleur outil d'interprétation et même le seul ayant une portée opérationnelle. À ce titre, nous l'adoptons, sans hésiter, comme fondement de cet ouvrage, qui a pour objet de donner une vue d'ensemble des phénomènes.

Mais l'instrument reste-t-il valable quand il s'agit d'analyser la politique d'un État particulier? 


\section{c) ADAPTATION DE LA TYPOLOGIE AUX ANALYSES NATIONALES}

\section{$\underline{\text { Retour à la table des matières }}$}

Quand on entreprend l'explication des politiques nationales, extérieure et intérieure, un facteur compromet la valeur opérationnelle de la typologie dualiste proposée : l'existence de groupes qui disposent, à la fois, d'une capacité nationale et internationale dans l'acception précédemment adoptée. La première par rattachement à un ordre juridique particulier qui exprime l'appartenance effective au système de relations couvert par cet ordre. La seconde comme résultat d'une extension à des pays étrangers des fonctions exercées qui se réalise avec assez d'ampleur et de continuité pour valoir une telle influence. On voit immédiatement que les combinaisons d'affaires sont un exemple typique de ces organismes.

Le propre de tels groupements est d'être de nature mixte par rapport aux deux pôles de la formulation dualiste. Dès lors, là où il existe de tels organismes, il devient nécessaire de réserver un traitement particulier à un nombre plus on moins grand de formations réputées internationales sous un certain angle, mais bénéficiant aussi d'une capacité nationale dans le pays considéré. Pour en bien marquer la double physionomie, disons simplement qu'il s'agit d'une catégorie nationale-internationale.

En une large mesure, le contenu de cette classe coïncide avec les éléments que les partisans de la conception restrictive des groupes internationaux souhaitent assimiler aux groupes nationaux (grandes affaires économiques). Mais on n'a nulle intention de reconnaître par ce détour la validité de la thèse limitative que ses partisans seront peut-être tentés d'appliquer aussi aux mouvements de libération nationale. On le montrera en préconisant un mode particulier d'insertion de ces organismes dans l'explication des politiques gouvernementales.

[p. 230] Voyons d'abord le cas du pays dans lequel le groupe nationalinternational dispose d'une capacité nationale propre. L'accent sera mis alors sur les aspects nationaux de l'organisme, mais sans oublier pour autant les caractéristiques que lui confère et les perspectives que lui procure le fait de bénéficier aussi d'une capacité internationale. Il n'est pas rare qu'une telle faculté renforce la capacité nationale.

Autre conséquence déjà signalée de cette nature mixte : à l'intérieur de certaines limites, les groupes de structure nationale-internationale sont en mesure d'effectuer une option entre deux modes d'intervention à l'étranger. Dans ses rapports avec tel État du Moyen-Orient la Standard Oil N.J. peut choisir de négocier directement avec les autorités responsables (capacité internationale). Elle peut aussi confier la défense de ses intérêts au gouvernement américain (capacité nationale). En pratique, de multiples facteurs interviennent dans l'option effectuée par l'organisme pétrolier et l'accueil réservé par l'autorité publique à une demande éventuelle de protection. La susceptibilité des jeunes nationalismes paraît d'ailleurs multiplier les cas dans lesquels 
une intervention venant d'un organisme d'affaires suscite moins de réticence qu'une démarche accomplie par une autorité publique.

Le cinéma américain offre un exemple très clair de cette ambivalence. En vue de centraliser et de défendre leurs intérêts à l'étranger, les principales compagnies de Hollywood ont créé la Motion Picture Export Association of America. Cet organisme, qui représente neuf sociétés produisant la presque totalité (95 à 98\%) des films réalisés aux États-Unis, constitue un organe d'intervention particulièrement efficace, qu'il s'agisse d'effectuer des enquêtes de marché, de traiter avec les groupes professionnels rivaux, ou de négocier avec les autorités publiques. À ce titre, les dirigeants de l'association ont plusieurs fois, en France, mené des négociations complexes avec le Directeur général du Centre National de la Cinématographie. Mais en d'autres occasions, le problème a été évoqué et traité à l'échelon gouvernemental franco-américain (accords Blum-Byrnes du 28 mai 1946). Sur ce point précis, l'expérience a montré que des conversations officieuses entre le Président de la Motion Picture et le Directeur Général du C.N.C. avaient une résonance politique moins grande que des débats directement engagés au niveau ministériel.

Passons maintenant an cas du pays où s'exerce l'activité extérieure de ces organismes. L'accent sera mis cette fois sur les aspects interna-[p. 231] tionaux du groupe national-international, Dans cette perspective le plus simple assurément est de les considérer et de les traiter comme des groupes étrangers. L'attribution de cette qualité ne soulève aucune difficulté quand l'organisme considéré agit dans le pays sous son aspect original ou ordinaire. Mais un sort identique doit être réservé aux éléments de forme nationale constitués et contrôlés par le groupe international en vue d'agir, au mieux de ses intérêts, sur le territoire. Cette position, qui néglige le critère du siège social, souligne les différences de préoccupation entre l'analyse politique et la recherche juridique traditionnelle : elle est cependant en accord avec le système nouveau de l'allégeance politique proposé par Suzanne Bastid et F. Luchaire.

Jusqu'ici on a considéré comme typiques de la catégorie nationale-internationale les groupes ou combinaisons d'affaires (à l'exclusion, bien entendu, des cartels internationaux). À quelque égard, on peut aussi y intégrer l'action des minorités nationales dès que celles-ci disposent d'une audience extérieure suffisante, La minorité agit directement sur le gouvernement auquel elle est juridiquement rattachée (capacité nationale), mais elle intervient également auprès des centres gouvernementaux ou intergouvernementaux externes (capacité internationale). Dans des situations de cet ordre, il arrive souvent aujourd'hui que la "capacité internationale », soit supérieure à la « capacité nationale », le mouvement trouvant à l'extérieur l'essentiel de ses appuis.

Abordons maintenant, toujours sous l'angle des politiques nationales, le cas des groupements qui, comme tels, disposent seulement d'une « capacité internationale » : ce qui est la situation normale des organisations non gouvernementales. En principe, ces groupes ne soulèvent pas de question, les organisations membres constituant des groupes nationaux dans leurs pays respectifs. Mais certains de ces groupes ne devraient-ils pas être traités de façon particulière : ainsi ceux qui, tout en étant de 
composition purement nationale, seraient en fait au service exclusif d'une force extérieure ? Ne conviendrait-il pas de les qualifier de « groupes étrangers »?

Une telle assimilation est volontiers effectuée au plan de la polémique. En voici un exemple tiré d'une analyse marxiste du catholicisme français ${ }^{1}$. Selon son auteur, la « terreur dans l'Église » signifierait en particulier « qu'il n'y a plus de place, dans la politique du Vatican, pour une Église de France, véritablement représentative du génie national ». Dès lors, le catholicisme au sens d'une organisation, d'une hié-[p. 232] rarchie, d'un corps constitué « menace de devenir à l'intérieur de la communauté française un véritable corps étranger ». On pourrait citer d'autres exemples d'une telle imputation : ainsi, l'accusation de « séparatisme » lancée par le Général de Gaulle au temps du R.P.F. contre un autre secteur de la communauté française. Ces critiques illustrent parfaitement le sens du problème posé : elles attestent aussi la difficulté de le traiter en termes non partisans.

Le lecteur observera aisément que l'inspiration principale du schéma proposé est de fournir un instrument qui, s'écartant au besoin des apparences formelles, permette de placer l'analyse au niveau des faits et assure la correspondance, autant que faire se peut, entre la théorie et la pratique. Sous l'angle d'une présentation globale de la vie internationale, l'adoption d'un critère compréhensif pour délimiter la catégorie «groupe de pression international» est une conséquence de ce souci. En relève également la volonté de traiter comme des éléments étrangers, dans l'analyse des politiques nationales, les groupes effectivement contrôlés ou manipulés par des forces extérieures (filiales françaises des trusts pétroliers internationaux).

La même conception pourrait conduire, le cas échéant, à traiter d'organisme national une institution internationale qui serait, en fait, dans les mains et au service exclusif d'un gouvernement particulier : mais il est indispensable en cette matière d’éviter les formules polémiques et émotionnelles (supra).

Plusieurs facteurs rendent cette ambition difficile à réaliser : le caractère vague de la formulation théorique et les importantes lacunes que contient la description des faits ; mais aussi l'effort des intéressés pour brouiller les pistes. Ces tentatives vont de simples affirmations de principe, de portée surtout morale, au montage de dispositifs complexes dont le but est de dissimuler ou de dénaturer la situation réelle. D'où le souhait, fréquemment émis dans ce chapitre, que les relations de complaisance soient décelées et interprétées afin qu'apparaissent les rapports effectifs de contrôle et de subordination.

Dans les précédents développements on a tenté de donner une notion, au moins approximative, de la complexité d'une telle tâche. Le souci de ne pas trop alourdir un texte déjà pesant a probablement conduit à une vue simplifiée de ces problèmes. Il n'est dès lors pas difficile d'imaginer [p. 233] l'ampleur des dépouillements monographiques nécessaires pour que l'on puisse légitimement essayer de formuler plus que de simples hypothèses de travail.

MURY (Gilbert), Essor ou déclin du catholicisme français, Paris, 1960, p. 281. 


\section{5. ÉLÉMENTS DE CLASSIFICATION}

\section{$\underline{\text { Retour à la table des matières }}$}

En matière de groupes de pression internationaux, au sens large de l'expression, il n'existe aucun système de classification qui suffise à tous les usages : on peut, par contre, énumérer plusieurs lignes de clivage dont l'avantage respectif est d'appeler l'attention sur un aspect particulier du fonctionnement de ces groupes. N'oublions pas, au surplus, que les positions de la vie concrète se situent souvent entre les types, plus ou moins rigides, marqués par les classifications théoriques.

Les éléments utilisés ici ayant déjà été analysés, pour la plupart, dans de précédents développements, on se bornera à un simple rappel énumératif.

Groupes de pression purs et occasionnels — On désigne ainsi les organismes dont la raison d'être et l'activité sont, exclusivement, d'exercer des interventions, directes ou indirectes, auprès des centres gouvernementaux. Le principal mérite de ce concept est d'appeler l'attention sur la place effectivement tenue par la pression sur les autorités publiques (au besoin par l'intermédiaire de l'opinion) dans le dispositif d'activité des différents groupes. Sur le plan international et national, cette place est généralement plus grande pour les organismes voués à des "causes » que pour les associations professionnelles (spécialement celles de l'industrie qui, par suite de la concentration, sont en mesure de réaliser, sans l'appui des autorités, une partie des tâches collectives d'aménagement et de gestion du secteur considéré).

Entrent dans la catégorie des groupes de pression purs ceux qui, par exemple, tendent à l'instauration d'un gouvernement mondial ou luttent contre la ségrégation raciale. Plusieurs autres groupements (organismes du type combinaisons d'affaires ou centrales syndicales), font seulement un usage occasionnel de la pression. Cependant l'extension des fonctions et responsabilités des États tendent à donner à ces interventions un caractère habituel.

[p. 234] Groupes de pression durables et temporaires - Les premiers correspondent à la satisfaction de besoins permanents mais susceptibles de prendre selon les époques, un contenu différent. Les seconds sont des instruments destinés à servir de cadre aux interventions à propos d'un problème ou d'une opération déterminée et appelés à disparaître, une fois la question en jeu réglée ou définitivement écartée. Les situations du deuxième type sont parfois difficiles à étudier : elles donnent lieu en plusieurs cas à de simples constellations de fait sans structure administrative. On en trouverait probablement d'assez nombreux exemples en dépouillant, sous cet angle, les travaux des organes chargés de négocier les traités de paix.

Ce type de classement appelle en tout cas l'attention sur une particularité des groupes : l'aptitude à survivre aux phénomènes qui ont provoqué leur constitution soit 
en modifiant les objectifs initiaux, soit en ralentissant l'activité au point de ne plus constituer qu'un cadre vide.

Organisations sans but lucratif et groupes à la recherche du profit L'opposition, fort courante, possède une signification juridique importante (sociétés et associations). Du point de vue politique, son adoption inconditionnelle provoquerait de graves erreurs d'interprétation. Beaucoup d'organisations non gouvernementales du type « associations » ont pour seul objectif de consolider et d'accroître la capacité de profit de leurs membres ou de contribuer à l'amélioration de leur niveau de vie. Les O.N.G. du secteur industriel, commercial, agricole... ne sont tout de môme pas des institutions philanthropiques encore qu'il leur arrive d'exciper de l'absence de gains pour améliorer leur situation ou leur réputation.

La classification proposée appelle toutefois l'attention sur un point important : l'aptitude de divers secteurs à se défendre et aussi à attaquer en utilisant des voies diverses, parfois de façon cumulative. Au niveau international plusieurs grandes firmes ont une capacité suffisante pour agir de leur propre chef et sans intermédiaire auprès des gouvernements nationaux ou de la bureaucratie des organisations intergouvernementales. Il est fréquent qu'elles préfèrent s'abriter derrière une association réputée sans but lucratif : ce choix n'est pas dépourvu de motifs.

[p. 235] Groupements "intéressés » ou "désintéressés » (au sens où les premiers recherchent des avantages matériels et les seconds se préoccupent de valeurs morales) - La classification n'est pas sans fondement, car, ignorant les divergences dans la forme juridique, elle rapproche et regroupe les divers organismes selon leur objet effectif. En pratique, elle présente souvent un inconvénient: la difficulté d'appréciation du but. Plusieurs O.N.G. (celles des enseignants, par exemple) se préoccupent à la fois de questions matérielles et culturelles. Les diverses associations rattachées aux internationales religieuses témoignent souvent de la même ambivalence. En définitive, ce type d'opposition accuse bien la relativité des classifications en matière sociale.

On utilise parfois, spécialement aux États-Unis, une terminologie différente en distinguant les groupes qui défendent des intérêts spéciaux ou spécialisés (matériels ou spirituels, peu importe), et ceux qui s'attachent à la promotion de l'intérêt public ou national. En l'appliquant, on séparerait les groupements luttant pour des intérêts d'expansion mondiale ou régionale (économiques, syndicaux, professionnels, religieux, humanitaires...) de ceux qui combattent pour des causes de portée générale (intégration mondiale ou européenne par exemple).

Cette séparation paraît logique: cependant, elle est dépourvue de valeur opérationnelle et peut-être de fondement moral en raison du caractère conventionnel de la notion d'intérêt public qui caractérise les sociétés pluralistes. Beaucoup placeront par exemple dans la catégorie de l'intérêt général la lutte contre la ségrégation raciale ou le combat pour améliorer la condition des consommateurs. Mais d'autres verront dans de telles positions qui sont le reflet de préférences idéologiques, l'expression de revendications spécialisées. 
Cette imprécision conduit à rejeter la notion d'intérêt public comme fondement d'une répartition des groupes, nationaux et internationaux. Ce refus se fonde en particulier sur le malaise que provoque chez de nombreux citoyens l'utilisation tactique de la notion d'intérêt général par des gouvernants qui réduisent volontiers ce concept au rôle d'une fiction commode. En l'adoptant on serait obligé de changer la distribution des groupes selon les fluctuations de la politique.

Avec ses défauts évidents, la vieille distinction de sens commun "intéressédésintéressé » représente le maximum de ce qui peut être admis, si du moins on n'est pas disposé à confondre science politique et prédication morale ou défense de la philosophie du gouvernement au pouvoir.

[p. 236] Groupements fondés sur des caractéristiques objectives ou sur des attitudes - Le fondement de beaucoup d'organisations est l'existence chez leurs membres d'une caractéristique commune, objectivement constatable et parfois ostensible (producteur, travailleur, ancien combattant, homme de couleur...). D'autres reposent sur des positions idéologiques ou morales adoptées de plein gré par leurs adeptes (lutte contre la peine de mort, défense des droits de l'enfant...). Les premiers seraient normalement, mais pas nécessairement "intéressés », les seconds seraient généralement « désintéressés ».

Cette classification a l'avantage et le mérite de montrer la diversité des racines de l'action collective: en de nombreuses occasions, les groupes fondés sur des « caractéristiques » ont des facilités supérieures de recrutement et de financement. Cependant elle comporte des imperfections. D'abord la difficulté de classer certaines situations dans l'une ou l'autre branche. Le fait de militer dans une organisation catholique doit-il être tenu pour une caractéristique objective ou la manifestation d'une attitude ? Si, à l'image du traitement souvent imposé aux juifs, on faisait de la naissance dans cette religion la base d'une discrimination ou d'une persécution, la notion de « caractéristique » devrait prévaloir. Sinon, il paraît souhaitable d'adopter le facteur « attitude ».

D'autre part, certains groupements possèdent des membres qui relèvent de l'une et l'autre inspiration. Dans les organismes luttant contre la ségrégation raciale, on trouve à la fois des personnes menacées par cette politique et d'autres qui se joignent à elles par souci de défense d'une conception de l'homme ou d'une doctrine morale.

Sur le plan conceptuel, il est possible de rapprocher les deux derniers modes de classification présentés en utilisant la notion d'apparence neutre d'« intérêt commun ». Dans le premier des cas cités, l'intérêt commun définit l'objet de l'activité collective, le sens que les membres donnent à leurs luttes tandis que dans le second la notion couvre le fondement du rassemblement, la structure du mobile qui les pousse à s'unir. En sa première acception, l'intérêt commun peut être qualifié immédiatement, sous les importantes réserves faites, d'«intéressé » ou de «désintéressé » s'agissant de la deuxième, on n'est pas en mesure d'effectuer d'emblée une telle répartition. Cependant, la pratique, on l'a dit, montre qu'il existe très souvent un rapport étroit entre la nature du mobile du groupement et l'inspiration de l'activité entreprise. 
[p. 237] Classification fondée sur l'agencement des structures - C'est un principe de division qui présente des aspects très variés. Si l'on examine par exemple les organisations non gouvernementales on découvre de multiples facteurs de différenciation. Par exemple, l'état des relations entre le centre et les unités composantes (formule de type fédéral et confédéral). Ou encore les caractéristiques du recrutement: membres collectifs, membres individuels, cumul de ces deux sources... Certaines O.N.G. ont également comme membres d'autres associations internationales, constituant ainsi de véritables organismes de superposition.

Ces clivages, de type institutionnel, sont importants pour l'analyse politique s'ils retentissent sur l'élaboration et l'exécution des décisions. Ce n'est pas toujours le cas, des organismes de structure différente fonctionnant en fait selon un modèle analogue. N'oublions pas au surplus qu'il existe souvent des décalages considérables entre la lettre des statuts el le mode effectif de gestion.

Sous cet angle, la différence essentielle tient à la nature des liens entre le centre ou élément de tête et les diverses cellules nationales. À un bout de la chaîne, on trouve les internationales d'affaires proprement dites dont les éléments relèvent d'un pouvoir ou d'une influence hiérarchiquement unifiée et distribuée: le commandement emprunte en général la ligne qui descend de l'organisme fondateur vers les unités composantes auxquelles est simplement dévolue une tâche de pénétration ou d'exploitation. À l'autre extrémité, se situe l'organisation non gouvernementale créée et dirigée par des organismes nationaux qui, tout en s'assemblant pour réaliser certaines missions, conservent leur autonomie et leurs caractéristiques singulières : en principe, le pouvoir y circule de la base vers le sommet.

Entre ces deux situations « idéales » s'affirme naturellement, à la manière d'un continuum, une gamme de structures et de pratiques composites. On en a déjà donné plusieurs exemples sans être en mesure, faute d'études monographiques, de traduire réellement la complexité des formules utilisées dans la pratique (qu'elles correspondent à un dessein sans équivoque ou représentent des déviations, plus ou moins accusées, par rapport au projet initial et à l'esprit des textes constitutifs).

Dernière observation : la multiplicité et la variété des usages qui sont faits d'un mode d'organisation déterminé. La formule syndicale n'est pas ou n'est plus le monopole des travailleurs et encore moins des seuls ouvriers industriels : en plusieurs pays toutes les forces sociales [p. 238] et corporatives ont appris à l'utiliser. Or, certaines traditions linguistiques, qui ne sont pas absentes de notre propre présentation, tendent à dissimuler cette extension.

On peut en dire autant, mutatis mutandis, de la technique des sociétés secrètes. Nous en avons traité principalement à propos des internationales de partis : rapprochement justifié par la nature partisane (au sens technique de l'adjectif) de plusieurs parmi les plus célèbres de ces organismes. Mais la formule a été aussi employée par des mouvements de libération nationale (et même en d'autres époques par des rassemblements de travailleurs dans le cadre d'un pays donné ainsi qu'à travers les frontières). 
On a même pu relever la présence de sociétés secrètes à l'intérieur de l'Église catholique: cas de la Société de Saint-Pie-V, mieux connue sous le nom de la Sapinière, qui aurait été fondée sous Léon XIII pour combattre les intentions prêtées au pontife d'adapter la religion aux transformations du monde moderne. Cette société à laquelle on rattache volontiers le courant intégriste aurait disposé d'un réseau international secret d'adhérents et de correspondants (avec signes de reconnaissance, code pour la correspondance...). En utilisant le raisonnement analogique, on pourrait y voir une sorte de groupe de pression destiné à influencer le gouvernement de l'Église. Cependant, les rapports que la Société aurait entretenus avec diverses forces séculières (l'Action Française, par exemple) autorisent à la mentionner ici : n'oublions pas pourtant que les observations faites à ce propos relèvent davantage de l'imputation que de la démonstration.

Capacité « autonome » et "dérivée » - De nombreux groupes tirent leur faculté d'intervention de leurs propres fonds, ne dépendent que d'eux-mêmes et n'ont de comptes à rendre qu'à leurs membres : ils disposent ainsi d'une capacité internationale autonome (cas, par exemple, de la Chambre de Commerce Internationale). D'autres sont liés de façon plus ou moins rigide à un centre unificateur : le bénéfice de leur activité profite en définitive à l'intérêt ou à la cause que défend ce centre mais, en contre-partie, les groupes de ce genre reçoivent de l'organisme commun appui moral et en plusieurs cas aide matérielle. Ils tirent généralement de l'appartenance à un tel ensemble un surcroît de prestige au sein de nombreux milieux, sinon parfois la raison d'être de leur audience. Il peut être utile d'employer à leur égard la notion de capacité dérivée.

[p. 239] Dans cette perspective, sur laquelle nous aurons à revenir, on retrouve la notion d'« organisation annexe », caractéristique du mouvement communiste international. C'est une notion particulièrement utile à condition de n'en pas abuser et de ne pas l'étendre indûment à d'autres situations. En particulier, elle ne convient pas pour décrire la position des mouvements d'Action catholique dont les liens avec le Saint-Siège sont spécifiques.

Certains vont plus loin en proposant la création d'une catégorie de groupes dont la caractéristique serait d'agir au profit d'un ou plusieurs États étrangers. Déjà perceptible au niveau national, le phénomène interviendrait aussi au niveau international par exemple quand une O.N.G. agit exclusivement au profit d'un gouvernement donné (soit dès le départ, soit après une opération de « capture »). Les phénomènes qui motivent cette remarque ne sont certes pas imaginaires. Faut-il pour autant user d'une formule rigide pour les interpréter ?

Il ne le semble pas. Les partisans de cette conceptualisation visent généralement de façon un peu unilatérale d'ailleurs, le cas du communisme international. Cependant, même dans cet exemple privilégié, les relations ne sont pas aussi simples que les présentations courantes le laissent volontiers admettre. Le dyptique proposé (capacité autonome et dérivée) semble assez compréhensif pour accueillir toutes les situations et assez souple pour éviter de forcer la réalité en raison d'une option initiale étroite. Mieux que l'utilisation d'une catégorie propre («groupes agissant au profit 
d'un État étranger »), il paraît apte à conceptualiser des phénomènes (parmi lesquels la « capture » plus ou moins effective d'une association internationale) dont l'ampleur et la densité sont un des traits des rapports interétatiques actuels.

Aucun des systèmes de classification ainsi présentés n'a certes la portée d'une division cardinale : tous cependant semblent apporter quelque élément d'interprétation utile au développement de la connaissance. Une extension des recherches en ce domaine permettrait d'y voir plus clair sur leur valeur respective.

[p. 240, sans texte.] 
[p. 241]

\section{CHAPITRE III}

\section{POINTS D’APPLICATION}

$\underline{\text { Retour à la table des matières }}$

L’AMBITION de ce chapitre est limitée: présenter, de façon encore très sommaire, les points du système politique sur lesquels les groupes de pression internationaux font porter leurs efforts. Il s'agit simplement de montrer comment ceux-ci recherchent et s'assurent ce qu'on est convenu d'appeler l'« accès ", sachant toutefois que l'obtenir ne signifie pas nécessairement remporter la victoire sur le fond du problème.

On analysera successivement l'intervention auprès des organisations intergouvernementales et des institutions gouvernementales propres à chaque pays. La distinction perd tout fondement si l'on considère qu'en plusieurs occasions, ce sont les mêmes autorités (du moins les mêmes catégories d'autorités) qui sont visées à travers les deux procédures. Cependant, il apparaît difficile de réduire les organisations intergouvernementales aux gouvernements qui les composent (rôle de l'administration internationale). Si l'on ajoute que l'accès à ces organisations présente des particularités (notamment arrangements consultatifs) la séparation redevient plausible.

Mais les groupes utilisent en de nombreux cas une autre voie : l'opinion publique. C'est un phénomène constaté et étudié depuis longtemps au niveau de la politique intérieure. Certains y ont vu parfois la manifestation d'une tactique nouvelle destinée à remplacer les activités de style ancien. Vue contestable, les groupes se préoccupant d'agir à la fois sur les autorités et sur l'opinion. L'objectif est notamment de ren[p. 242] dre cette dernière favorable ou, au moins, de diminuer son hostilité : en bref, on s'efforce de contrôler le sens selon lequel l'opinion publique pèsera sur les gouvernants. Il sera facile de montrer que les groupes de pression internationaux emploient aussi, et sur une large échelle, ce levier de portée indirecte : en diverses occasions, ce mode de pression s'avère le seul disponible.

Organisations intergouvernementales, institutions nationales, opinion publique : tels sont donc les trois points d'application qui seront évoqués dans ce chapitre. C'est 
un immense sujet et l'auteur ne parviendrait qu'à témoigner d'une ambition démesurée en prétendant dresser un tableau complet de la question. Si l'on souhaite simplement appeler l'attention sur ce problème et fournir quelques développements propres à l'illustrer, alors l'objectif ne semble plus inaccessible.

Une remarque limitant l'importance de l'exposé à venir doit être faite ici : ce livre a pour but de donner une vue générale du phénomène "groupes de pression internationaux », mais on ne saurait envisager d'y ajouter une analyse circonstanciée des comportements et tactiques de ces organismes.

Il est certes possible d'admettre que plusieurs des schémas préparés pour l'explication interne conviennent aussi au niveau international; par exemple, l'avantage que vaut à un groupe l'absence de rival, ou l'alliance avec une autre organisation; les difficultés que suscite pour lui la présence d'un groupement qui cherche systématiquement à « contrer »son action. À chaque niveau d'intervention, une large partie des efforts accomplis par les groupes, s'annule réciproquement.

Cette transposition, qui devra être sélective, de schémas déjà élaborés, est l'une des raisons qui poussent à recommander l'emploi du concept " groupe de pression » dans la politique internationale. Mais il n'est pas possible de se livrer à un essai quelconque de transfert sans disposer de monographies où puiser les éléments nécessaires. Or, la plupart des analyses courantes des forces de pression internationales ignorent les préoccupations de la science politique et sont donc peu utilisables pour un essai de systématisation théorique.

On doit ainsi se borner à souhaiter que cette présentation générale suscite les recherches monographiques sans lesquelles la connaissance du sujet ne pourrait progresser.

[p. 243]

\section{ORGANISATIONS INTERGOUVERNEMENTALES}

$\underline{\text { Retour à la table des matières }}$

Les groupes en attendent de multiples services. Ce peut être, par exemple, l'octroi de facilités matérielles ou l'attribution d'une aide financière. Mais ce type de concours (variable selon les organisations et, en définitive assez rare), n'est qu'un aspect secondaire du problème. Pour beaucoup d'associations parmi les plus puissantes, le principal avantage de l'organisation intergouvernementale est de constituer une «tribune» au sens large du terme (faut-il dire un forum ?) d'où il est possible d'influencer les gouvernants et l'opinion publique. Le souci des associations sera, au surplus, d'infléchir le comportement de ces institutions dans une direction conforme aux intérêts défendus ou aux idéologies proclamées. Dans quelques cas, l'effort essentiel du groupe portera sur la rédaction du programme de travail de l'organisation. 
Ces considérations, trop générales pour être utiles, devraient être précisées par rapport à chaque protagoniste. Les organisations intergouvernementales embrassent un ensemble d'activités et de préoccupations dans lesquelles les facteurs idéologiques et les considérations morales jouent un rôle variable; le style des liens qui les unissent aux O.N.G. en est nécessairement affecté : la question des droits de la femme et le problème de la lutte contre les viroses épidémiques, par exemple, ne peuvent être traités dans les mêmes termes. On évoquera quelques éléments de cette diversité, quoique de façon très superficielle.

Il faut aussi compter avec l'attitude des groupes que commandent de nombreux facteurs. Certains sont par nature discrets, évitent la presse et les controverses publiques, préfèrent la négociation à la menace. D'autres sont plus bavards et brutaux : la recherche de la publicité est parfois leur objectif principal. Les uns et les autres (et l'on pourrait, sur la base des enquêtes faites dans l'ordre interne, multiplier les clivages) ne feront pas le même usage des facilités ouvertes par les organisations intergouvernementales.

Les développements qui vont suivre seront limités aux aspects ostensibles de ces relations. C'est se résigner à une vue partielle du sujet, mais dans l'état présent des connaissances, il n'y a aucun moyen de l'éviter ${ }^{1}$. Il est possible que cette limitation fausse complètement le problème en éclairant les interventions (au moins une partie d'entre elles) des associations sans but lucratif et en dissimulant celles d'autres forces [p. 244] de pression, par exemple des groupes d'affaires. On ne dispose même pas des données qui permettraient d'évaluer l'importance de cette lacune. Aucun progrès dans la connaissance ne sera réalisé si l'étude des organisations intergouvernementales continue à se placer presque exclusivement sur le plan juridique et à conserver le ton conformiste qui, à quelques exceptions près, est le sien.

L'étude de la vie politique interne a donné des résultats dès le moment où les acteurs n'ont plus été considérés comme de simples catégories légales. Les fonctionnaires constituent certes la "fonction publique": mais ce sont aussi des hommes capables de repousser les sollicitations ou de se laisser séduire, de tenir tête aux menaces ou de prendre peur, de résister ou non à la corruption, etc. Malheureusement, ce souci de "réalisme » n'a guère prévalu dans l'examen de l'organisation internationale : on a peine à croire que la stérilité des analyses résulte simplement de la pauvreté de la matière ou qu'elle en soit l'expression.

En étudiant les rapports des groupes, spécialement des O.N.G., avec les organisations intergouvernementales, on doit se garder d'une erreur : considérer ces relations comme un mécanisme à sens unique et décréter dès lors, qu'elles bénéficient uniquement aux premiers. Ce grave défaut d'interprétation s'observe souvent dans les études d'ordre interne. On y dénonce volontiers (avec plus ou moins de bonne foi), les

Comme le lecteur pourra s'en assurer en lisant par exemple LOVEDAY (A.), Reflections on International Administration, Oxford, 1956. Cet ouvrage assez médiocre dans l'ensemble et d'un grand conformisme, repose sur une expérience acquise à la S.D.N. : il témoigne de très peu d'intérêt quant aux contacts des fonctionnaires internationaux avec les représentants d'associations ou d'entreprises privées. 
relations consultatives entre les gouvernants et les milieux privés, comme étant un processus d'assujettissement des premiers aux seconds. C'est oublier de préciser qu'il serait fâcheux et dangereux d'administrer en ignorant le point de vue des intéressés ou en refusant systématiquement d'écouter leurs suggestions. Il convient d'étendre ces remarques au secteur des relations internationales: les organisations intergouvernementales rendent des services aux O.N.C., et en reçoivent aussi. Même si la balance n'est pas égale (infra) les avantages sont réciproques.

On commencera l'étude du problème par le cas de l'Organisation Internationale du Travail qui, à plusieurs égards, est unique. Les arrangements consultatifs conclus entre les deux secteurs seront examinés ensuite dans leurs grandes lignes et, enfin, à partir de quelques éléments concrets, on évoquera les relations de fait ${ }^{1}$.

[p. 245]

\section{a) INTRODUCTION DES GROUPES DANS LES ORGANES DIRIGEANTS (O.I.T.)}

\section{$\underline{\text { Retour à la table des matières }}$}

C'est le cas de l'O.I.T. dont on doit rappeler, en quelques mots, la structure. L'organisation de base est la Conférence Internationale du Travail qui se compose de délégations nationales comprenant deux délégués gouvernementaux, un délégué employeur et un délégué des travailleurs. Les délégués non gouvernementaux sont désignés par les gouvernements en accord avec les organisations professionnelles les plus représentatives (formule qui a prêté à des contestations). Le point le plus important, qui tranche de manière absolue avec les formules classiques des négociations diplomatiques, reste l'attribution du droit de vote non aux délégations nationales comme telles ou aux seuls délégués gouvernementaux, mais à chacun des délégués selon son inspiration propre. Ce tripartisme prévaut aussi au Conseil d'Administration du B.I.T. (40 membres dont 10 employeurs et 10 travailleurs) : les membres non gouvernementaux du Conseil étant élus les uns par le groupe des employeurs et les autres par le groupe des travailleurs de la Conférence.

On voit aisément les relations qui, par l'intermédiaire des personnes, s'établissent entre les groupes de pression internationaux (ainsi d'ailleurs que nationaux) et l'O.I.T. Les délégués non-gouvernementaux sont, sur le plan national, membres de fédérations professionnelles, elles-mêmes affiliées à des organisations internationales. Celles-ci disposent donc, au niveau de la Conférence, d'une masse plus ou moins large d'alliés et de sympathisants susceptibles de défendre leurs positions. Cette

Pour une bibliographie sur l'ensemble du problème SPEECKAERT (G.P.), Les organismes internationaux et l'organisation internationale, Bruxelles, 1956 (783 références) : en particulier la section traitant des relations entre organisations intergouvernementales et organisations non gouvernementales (Une soixantaine de titres). 
osmose se prolonge au plan du Conseil d'Administration dans lequel, par le même procédé, les associations internationales peuvent compter sur un certain nombre de soutiens (sinon de représentants directs...). On aperçoit dès lors l'importance du choix des délégués non gouvernementaux à la Conférence (en particulier des délégués ouvriers, étant donné la fragmentation politique du syndicalisme international). Or, dans plusieurs cas, des gouvernements, mus par un souci de défense contre le communisme, ont pris certaines libertés avec la règle de la représentativité.

Dès 1919, avait été créée à Washington une Organisation Internationale des Employeurs Industriels en vue d'assurer une liaison permanente de ces employeurs avec le B.I.T. En 1948, l'association dont le siège est à Bruxelles a pris le nom d'Organisation Internationale des Employeurs et témoigne aujourd'hui d'un plus grand dynamisme que [p. 246] par le passé. Elle groupe une quarantaine de fédérations nationales centrales (représentant entre 80 et $90 \%$ des entreprises industrielles et commerciales de leurs pays respectifs).

Du côté des travailleurs, l'organisation dominante fut, entre les deux guerres mondiales, la Fédération Syndicale Internationale : ce quasi-monopole donna lieu à d'amers reproches de la part de la Confédération Internationale des Syndicats Chrétiens. En dépit d'une action tenace (allant jusqu'à une intervention devant la Cour Internationale de justice), la C.I.S.C. n'obtint guère de succès (Gaston Tessier luimême venant à la Conférence non comme délégué ouvrier, mais comme conseiller technique de la délégation gouvernementale française).

Après l'éclatement de la F.S.M., la C.I.S.L. a occupé une position de premier plan. Dès son Congrès de 1951, tout en reconnaissant, ou en affirmant, que les membres «travailleurs » du Conseil d'Administration n'étaient pas les mandataires de la C.I.S.L., elle donnait à son secrétaire général la consigne de rechercher avec eux une « collaboration libre » ${ }^{1}$. À une certaine époque, cette coopération avec les délégués travailleurs a pris ostensiblement une forme institutionnelle par la création d'un « Comité mixte C.I.S.L.-Groupe ouvrier ». Après avoir tenu plusieurs séances de mai 1954 à mai 1956, cet organisme a été dissous (pour des « raisons techniques » a-t-on dit) et on est revenu à la méthode des contacts directs ${ }^{2}$.

Le système ainsi décrit doit s'accommoder de l'existence des pays communistes. Le retour de l'U.R.S.S. dans l'Organisation en 1954 allait exacerber ce problème ${ }^{3}$. Renforçant la position de la F.S.M., la présence de la Russie et des autres États collectivistes posa une question de fond, bien plus grave que diverses manifestations épisodiques engendrées par certains événements, en particulier la révolte hongroise. La structure tripartite de l'Organisation a été fondée sur une conception déterminée des rapports économico-sociaux qui fait en somme du gouvernement l'arbitre naturel

Rapport du second congrès mondial (Milan, juillet 1951), Bruxelles, 1952, p. 88.

Voir l'analyse des dernières réunions de ce comité dans le Rapport du Cinquième Congrès Mondial (Tunis, juillet 1957), Bruxelles, 1958, pp. 155-159. L'une de ses préoccupations a été d'adopter une définition du «travail forcé que l'on ne saurait tenir pour exclusive d'arrière-pensées idéologiques.

3 En fait, se sont ajoutées comme d'habitude à l'adhésion de l'U.R.S.S. celles de la Biélorussie et de l'Ukraine. 
entre forces rivales : nul ne saurait sérieusement prétendre que la structure et le mode de fonctionnement des économies de l'Est est compatible avec cette philosophie.

Le problème s'élargit dans la mesure où plusieurs pays du monde occidental (France, Italie, Royaume-Uni) possèdent eux-mêmes un important secteur public économique. Et l'on peut se demander également si le tripartisme a le moindre sens dans les pays sous-développés qui adhèrent à l'O.I.T. dès leur accession à l'indépendance, et dont les délégués [p. 247] patronaux et ouvriers alignent souvent leur comportement sur celui des délégués gouvernementaux.

En définitive, le " tripartisme » ne cadre approximativement avec la pratique que pour les vieux pays industrialisés de l'Occident et leurs rares émules: (Japon, Commonwealth d'origine britannique...). Si l'opposition avec la doctrine communiste est absolue, on relève aussi bien des contradictions au niveau d'autres expériences, spécialement chez ceux des pays sous-développés qui adoptent des formes de socialisme autoritaire. D'où l'obligation d'accepter des compromis boiteux pour faire coïncider une structure liée à une certaine conception du monde et une vocation à l'universalité ${ }^{1}$.

Cette observation réduit sensiblement la portée des manifestations de la C.I.S.L. et de la C.I.S.C. contre les délégations de travailleurs venus de pays dont la philosophie et l'organisation des rapports sociaux ne s'accommodent pas de la liberté syndicale ou, si l'on préfère, la limitent au devoir de soutenir la politique gouvernementale. Ainsi en fut-il de la contestation par ces centrales, lors de la $39^{\text {ème }}$ Conférence internationale (juin 1956), de la validité des pouvoirs des deux délégations ouvrières d'Espagne et de Roumanie. Motif invoqué : appartenant à des pays privés de liberté syndicale, elles ne pouvaient engager " authentiquement » les travailleurs de ces pays. Autre opération du même ordre : l'invalidation des pouvoirs de la délégation des travailleurs hongrois après les événements de Budapest.

Cette attitude qui, selon la C.I.S.L., constitue un beau succès contre le totalitarisme, est en fait une banale manœuvre politique. Elle ne serait logique que si ses partisans allaient jusqu'au bout de leurs positions en réclamant l'exclusion, pure et simple, des pays en cause. Or la C.I.S.C., en particulier, rejette expressément ce point de vue : le rapport du secrétaire général au Congrès de Vevey (juin 1958), proclame (p. 188 de l'op. déjà cité) : " pas de compromis en matière de liberté syndicale » et

1 Voir BEGUIN (Bernard), Le tripartisme dans l'organisation internationale du Travail, Genève, 1959. Consulter également WALINE (Pierre), «La crise de l'organisation internationale du Travail ", Revue des Deux Mondes, août 1959. Du même auteur et dans la même revue un intéressant commentaire de la dernière session: "Au B.I.T. Coexistence pacifique ou combattive ? », août 1960, pp. 411-425. Pour une vue historique, voir SCHAPER (B.W.), Albert Thomas. 30 ans de réformisme social. Préface de Marius Moutet, Paris, 1960. Sur les deux grandes institutions évoquées dans le texte, voir LANCROD (G.), («La Conférence Internationale du Travail », Annales Universatis Saraviensis 1954 (1-2), pp. 73-88, et X, « La composition du Conseil d'administration du Bureau International du Travail », Revue Internationale du Travail, décembre 1954. pp. 538-569. 
affirme (p. 190) « l'inopportunité d'une action tendant à faire exclure certains États ». C'est une contradiction évidente qui relève soit de la naïveté soit de la démagogie.

On ne saurait évoquer ici les cas extrêmement nombreux dans lesquels les groupes — et spécialement les diverses internationales (F.S.M., C.I.S.L., C.I.S.C.) semblent avoir exercé une influence sur le comportement de l'O.I.T. En voici un exemple tiré de l'action de la C.I.S.L.

[p. 248] L'une des résolutions votées au Congrès de Milan demandait à l'O.I.T. d'offrir le statut de membre associé aux pays non autonomes (en accordant à ceux-ci la possibilité de ratifier les conventions de l'O.I.T. en leur propre nom). Présentée par le groupe ouvrier du Conseil d'administration au directeur général du B.I.T. cette requête a d'abord provoqué des objections. On a finalement donné satisfaction partielle à la C.I.S.L., en permettant au secrétariat d'inviter ces territoires (mais par l'intermédiaire de l'État-membre responsable) à envoyer aux sessions de la Conférence une délégation tripartite d'observateurs. Dès la $39^{\text {ème }}$ Conférence, le nombre des territoires ainsi représentés s'élevait à neuf. Or, sans être surestimées, les conséquences sur le plan politique d'une telle participation ne sauraient être tenues pour négligeables.

Il en va de même de tous les efforts entrepris par la C.I.S.L. en direction des pays sous-développés. En voici un cas. Dès le début de 1957, cette centrale réclame l'institution d'une commission consultative africaine (à l'image de la Commission Économique pour l'Afrique créée par l'O.N.U.): cette demande est prise en considération par le Conseil d'Administration à sa session de mars 1958 (la C.I.S.C. soutenant d'ailleurs une revendication identique). Observons à ce propos que l'O.I.T. a tenu à Lagos en décembre 1960 sa première Conférence régionale africaine à laquelle ont été invités à participer les États indépendants de ce continent, les puissances encore chargées de responsabilités coloniales (comme la Grande-Bretagne et le Portugal) et plusieurs territoires toujours dépendants (Kenya et Sierra Leone par exemple). L'objectif de la réunion est de procéder à un examen des questions que posent la prospérité économique et le progrès social de l'Afrique.

Mais la C.I.S.L. s'intéresse également à des questions purement professionnelles et tend à provoquer soit l'amélioration des dispositions existantes (développement des services permanents de santé sur les lieux du travail) soit l'institution de nouvelles règles motivée par certains aspects du progrès technique, par exemple protection des travailleurs contre les radiations ionisantes.

Du point de vue de cet ouvrage, l'une des réalisations les plus originales de l'O.I.T. a été la création d'un Comité de la Liberté Syndicale chargé de procéder à un examen préliminaire des plaintes reçues en la matière (comité tripartite élu par le Conseil d'Administration parmi ses membres). Toute dénonciation est d'abord transmise au gouvernement intéressé qui est prié de fournir ses observations. L'affaire est ensuite [p. 249] étudiée par le Comité qui en fait rapport au Conseil, celui-ci soumettant, le cas échéant, des remarques et suggestions à l'État responsable. Or les organisations syndicales ont présenté de très nombreuses requêtes. Sur le plan de la conceptualisation théorique, il s'agit à l'évidence d'un mécanisme de pression 
indirect : les travailleurs d'un pays pesant sur leur gouvernement par l'intermédiaire de l'internationale syndicale et de l'organisation intergouvernementale. Quel a été le résultat pratique de ce mécanisme?

Depuis sa création, le Comité s'est occupé d'environ deux cents réclamations. La C.I.S.C. a déposé des plaintes, par exemple, pour les motifs suivants : intervention du gouvernement polonais lors des grèves de Poznan; intervention des autorités chiliennes lors des grèves d'employés de banque et d'ouvriers dans les mines de nitrate ; répression de l'action des travailleurs hongrois lors de leur révolte d'octobre 1956 ; violation de la liberté syndicale dans une entreprise textile au Canada... La C.I.S.L. a émis plusieurs protestations contre le gouvernement français à propos de son action Outre-Mer et spécialement en Afrique du Nord : Tunisie d'abord, Maroc ensuite, Algérie enfin. Dans ce dernier cas, la première plainte formulée remonte à février 1957. Elle réclamait en particulier la reconnaissance par le gouvernement français du caractère représentatif de l'Union Générale de Travailleurs Algériens et le rétablissement d'une «complète liberté syndicale » en Algérie. D'autres ont suivi (notamment à propos de l'arrestation et de la mort d’Aïssat Idir) ${ }^{1}$.

Quel est l'effet de ces initiatives qui, très souvent, unissent de façon inextricable le social et le politique ? Si l'on en croit certains commentateurs, les résultats ne seraient pas négligeables, les suggestions faites à certains gouvernements ayant été suivies d'effets (modification de diverses dispositions de la législation syndicale ; libération de syndicalistes détenus). De fait, il n'est pas exclu que parfois la pression morale ainsi exercée par l'organisme intergouvernemental contribue à un renforcement de la liberté syndicale. Dans beaucoup d'autres cas, le Conseil se heurte à une mauvaise volonté systématique des gouvernants qui refusent de fournir les renseignements et sabotent la procédure tout en criant au «viol » de la souveraineté nationale. Nous retombons ici sur l'équivoque signalée tout à l'heure (selon la C.I.S.C., la liberté syndicale serait pratiquement supprimée dans une trentaine d'États membres de l'O.I.T.).

[p. 250] En dehors de cette introduction directe de certains intérêts dans ses structures $^{2}$, l'O.I.T. offre aux groupes internationaux divers mécanismes de consultation analogues à ceux qui seront examinés en détail dans les rubriques suivantes consacrées à l'O.N.U. et à ses agences spécialisées. Il s'agit là pour l'O.I.T. d'une pratique ancienne dont l'établissement fut, en une large mesure, l'œuvre d'Albert Thomas : le premier directeur général du B.I.T. pensait en effet que les associations

1 Pour les interventions de la C.I.S.L. sur l'Algérie, voir le Rapport du Cinquième Congrès Mondial, op. cit., pp. 94-96 et 101-103 ainsi que le Projet de rapport 1957-59, Bruxelles, 1960, pp. $96-98$ et 100-103.

2 L'exemple de l'O.I.T. est particulier au sens où l'introduction des intérêts privés dans la structure de l'organisation est officiellement admise. Il arrive que cette admission ait lieu de facto sans entraîner normalement les mêmes prérogatives. Soit par exemple, la Commission Économique pour l'Europe. Elle est aidée dans son travail par dix Comités (problèmes agricoles ; charbon, énergie électrique, habitat, etc.) qui sont, en principe, composés uniquement de délégués gouvernementaux. Mais cette règle souffre de multiples exceptions, plusieurs gouvernements tenant à inclure dans leurs délégations des représentants de l'industrie privée (Associations, décembre 1959, pp. 847-848). 
privées pouvaient rendre de grands services à l'organisation en la contrôlant, en la stimulant et si nécessaire en la critiquant. Ses rapports annuels (par exemple ceux de 1922 et 1925) témoignent de cette conception.

Le mécanisme des arrangements consultatifs devant être exposé à propos d'autres organismes, on se bornera ici à énumérer les catégories de groupements avec lesquelles l'O.I.T. est en relations ${ }^{1}$.

Un tout petit nombre d'entre eux jouissent du statut consultatif proprement dit, six en tout: Alliance Coopérative Internationale; Confédération Internationale des Syndicats Chrétiens ; Confédération Internationale des Syndicats Libres ; Fédération Internationale des Producteurs Agricoles; Fédération Syndicale Mondiale et Organisation Internationale des Employeurs. Les bénéficiaires du statut sont associés à l'activité de l'Organisation : il leur est loisible, par exemple, d'assister, sur invitation, à une séance déterminée du Conseil et d'y faire des déclarations orales ou des exposés écrits sur des questions à l'ordre du jour. Les autres organisations d'employeurs et de travailleurs ne bénéficient pas des mêmes avantages, mais elles occupent une position particulière au sein de l'institution qui entretient de facto avec elles (y compris plusieurs d'assiette nationale) des rapports suivis : on comprendra mieux le sens de ces relations si l'on n'oublie pas que les délégués non gouvernementaux sont normalement choisis parmi les membres de tels groupements.

Une seconde catégorie trouve son origine dans une décision du Conseil d'administration (juin 1956) approuvant l'établissement d'une «Liste spéciale des organisations non-gouvernementales » : pour y figurer, l'organisation doit avoir un intérêt évident dans un des domaines d'activité au moins relevant de la compétence de l'O.I.T. Les facultés qu'ouvre cette inscription paraissent restreintes. Actuellement une cinquantaine d'organisations ont déjà été inscrites sur cette liste assez éclectique (Commission des Églises pour les Affaires Internationales et Fédération Internationale des Fonctionnaires Supérieurs de Police, Organisation Internationale de Normalisation et Fédération Internationale des Sourds, etc.

[p. 251] Voici un exemple de participation d'une O.N.G. aux travaux de l'O.I.T. : lors de la $40^{\mathrm{e}}$ Conférence internationale, le Congrès juif Mondial, qui figure sur la liste, a été invité à s'associer comme expert technique aux travaux du comité d'études établi par la Conférence sur la discrimination dans le domaine de l'emploi et du travail. Le représentant du Congrès a demandé l'insertion d'un certain nombre de points dans tout projet de convention sur ce thème (par exemple droit de pétition auprès d'un organisme spécialisé fonctionnant dans le cadre de l'O.I.T.).

Au total, l'O.I.T. offre l'image d'une communauté très ouverte aux préoccupations des professionnels, employeurs et travailleurs. Cependant, même dans la perspective du tripartisme, ce libéralisme dans l'accueil ne signifie nullement une complète domination de l'organisation par des intérêts. Employeurs et travailleurs se surveillent et se restreignent naturellement: les délégués gouvernementaux adoptent

1 Le texte consultatif de l'O.I.T. et le règlement de la Conférence Internationale figurent tous deux dans une brochure publiée à Genève par le B.I.T. 
généralement des positions nuancées et suggèrent parfois des compromis. Ce n'est certes pas le Parlement Mondial du Travail, mais c'est plus qu'un pur organisme consultatif. Pourtant, l'O.I.T. ne pouvait éviter d'être impliquée dans la division idéologique du monde : si, de nos jours, elle présente une grande importance pour notre discipline c'est, en grande partie, comme illustration grandiose de la conjonction syndicalisme-politique.

\section{b) TECHNIQUE DES ARRANGEMENTS CONSULTATIFS}

$\underline{\text { Retour à la table des matières }}$

Le cas de l'O.N.U. sera examiné en premier lieu, celui des Agences spécialisées l'étant ensuite plus brièvement. Une étude systématique de ces problèmes exigerait à elle seule un gros volume (qui n'est malheureusement pas disponible). On ne pourra ici que situer le sujet, tout à fait différent d'ailleurs du problème abondamment discuté entre les deux guerres mondiales de l'accès direct de l'individu à la vie internationale (en particulier sous l'angle juridictionnel).

Nations Unies (O.N.U.) - Le système des consultations s'y fonde sur l'art. 71 de la Charte : «Le Conseil économique et social peut prendre toutes dispositions utiles pour consulter les organisations non gouvernementales qui s'occupent de questions relevant de sa compétence. Ces dispositions peuvent s'appliquer à des organisations internationales et, s'il y a lieu, à des organisations nationales après consultation du membre [p. 252] intéressé de l'Organisation ». Il semble qu'à San Francisco trois séries de forces aient joué dans l'élaboration de ce texte : la F.S.M. (qui d'ailleurs, aurait voulu bénéficier, au minimum, d'un siège au Conseil Économique et social) ; une quarantaine d'organisations américaines privées qui étaient associées aux activités de la délégation des États-Unis ; enfin, l’Alliance coopérative internationale.

En un sens, cette mesure apporta une légère satisfaction à ceux qui voulaient confier le destin du monde à une élite choisie pour sa compétence ou sa capacité de travail, et dégagée des contingences nationales ou des rivalités politiques. Prodigieuse utopie s'il en fût : on ne doit pas en tirer nécessairement un jugement défavorable sur le modeste système de consultation qui, idéologiquement, peut lui être rattaché.

À aucun moment de son existence, la S.D.N. n'avait institué un régime analogue à celui de l'art. 71. Cependant, elle avait coutume d'entrer de facto en relations avec les O.N.G. compétentes pour le problème considéré : de tels rapports furent noués à l'occasion de conférences sur divers sujets (trafic de stupéfiants et de femmes; désarmement, etc.) ainsi qu'en matière de coopération intellectuelle. De plus, la Ligue choisissait parfois ses experts (assessors) parmi les membres des organisations privées, ces techniciens intervenant pour donner un avis motivé tout en représentant les groupements considérés. 
Il semble toutefois que durant ses dernières années, la S.D.N. ait montré moins d'empressement à coopérer avec les organisations non gouvernementales, qu'il s'agisse de groupements d'affaires ou d'associations idéologiques. Il est difficile d'exposer les raisons de ce revirement: volonté de ne pas sortir des solutions de routine, effort pour éviter les poussées d'ordre politique pratiquées par de nombreuses O.N.G., ou peut-être, plus simplement, médiocrité des services rendus et des avis donnés...

L'idée n'est donc pas originale et l'on a vu que l'O.I.T. la mettait déjà volontiers en pratique. Cependant, le nouveau régime tranche par son caractère réglementaire et par son ampleur ${ }^{1}$.

Le régime des consultations a été fixé en premier lieu par une résolution du Conseil en date du 21 juin 1946. Il a été revu et amendé par une nouvelle résolution du 27 février 1950.

Le but de ces arrangements est double : permettre au Conseil ou à l'un de ses organes d'obtenir des renseignements ou des avis autorisés de la part d'organisations ayant une compétence spéciale et par ailleurs, [p. 253] donner à celles qui représentent des éléments importants de l'opinion publique, la possibilité d'exprimer le point de vue de leurs membres. Au total, on entendait confier aux O.N.G. une fonction d'expertise et une mission de porte-parole de l'opinion. Il semble que les Nations Unies aient surtout encouragé la première de ces missions, des réticences s'étant manifestées vis-à-vis de la seconde par suite des tensions politiques mondiales.

Le Conseil classe en trois catégories les organisations susceptibles de bénéficier d'arrangements consultatifs :

1 Pour les textes de base, voir la brochure de l'U.A.I., Commentary on Article 71 of the Charter of the United Nations and Official Basic Texts, Bruxelles, 1956. Les indications contenues dans cette brochure sont extraites du Répertoire de la pratique suivie par les organismes des Nations Unies, vol. 3, art. 55-72, New York, 1956, pp. 599-611. Pour les derniers aspects, se reporter au Supplément $\mathrm{n}^{\circ} 1$, vol. II, art. 55 à 111 publié à New York en 1959. Voir aussi le travail de HABICHT (A.), Consultation between the United Nations and Non-Governmental Organizations, Carnegie Endowment for International Peace, New York, 1949 ; la brochure de Edwin A. BOCK, Representation of Non-Governmental Organizations at the United Nations, Public Administration, Clearing House, 1955, et l'étude de WHITE (L.C.), « Les organisations non gouvernementales et leurs relations avec les Nations Unies », Revue Générale de Droit International Public, janvier-mai 1952, pp. 61-84. Pour un bref historique du problème au temps de la S.D.N., consulter Associations, septembre 1955, pp. 575-581 (Études de B. PICKARD et Janet ROBB). On pourra trouver aussi quelque profit à lire les observations (d'esprit journalistique) de Robert de TRAZ, L'esprit de Genève, Paris, 1929, passim. Mentionnons sans insister que la plupart des manuels se contentent d'effleurer la question, témoignant ainsi d'une parfaite indifférence - dont la validité est discutable - à l'égard de l'organisation privée. Par exemple, VANDENBOSCHI (Amy) et HOGAN (Willard N.) dans The United Nations. Background, organization, functions, activities. New York, 1952, consacrent une page au problème (sur 456). Voir toutefois GOODRICH (L.M.), HAMBRO (E.), Charter of the United Nations, 2e édition, Boston, 1949, pp. 397-405. Consulter enfin le Yearbook of the United Nations, 1958, New York, 1959. Encore que principalement consacré aux organes intergouvernementaux, l'ouvrage comprend un chapitre sur les O.N.G. et le fonctionnement des arrangements consultatifs. 
celles qui s'intéressent au premier chef à la plupart des activités du Conseil et qui ont des rapports étroits avec la vie économique et sociale des régions qu'elles représentent (catégorie A) ;

celles qui, s'assignant des objectifs spécialisés, s'intéressent spécifiquement à certains des domaines d'activité du Conseil (catégorie B) ;

celles qui, enfin, sans répondre aux précédents critères, paraissent néanmoins susceptibles d'apporter une contribution au travail du Conseil. Elles sont inscrites sur un Registre qui comprend, en particulier, les organisations bénéficiant du statut consultatif auprès d'une agence spécialisée sans figurer pour autant dans la catégorie À ou B.

En principe, le bénéfice de ces arrangements est réservé aux organisations internationales. Cependant, dans un petit nombre de cas, il a été octroyé aussi à des organisations nationales (qui jouissent dès lors ipso facto de la "capacité internationale »). Motif de ces exceptions : l'existence d'organisations nationales couvrant un domaine qui n'est du ressort d'aucune autre organisation internationale ou possédant une expérience particulière dont le Conseil pourrait avoir intérêt à se servir. En réalité, on ne saurait expliquer autrement que par un simple effet de domination, l'octroi du statut consultatif à des organismes américains aussi marqués sur le plan idéologique que la Chambre de Commerce des États-Unis, le Committee for Economic Development et la National Association of Manufacturers of the United States of America ${ }^{1}$. Il est en tout cas difficile de dire si l'action exercée par la Chambre de Commerce des États-Unis auprès de la Commission Économique pour l'Europe résulte de cette faveur ou en constitue la justification a posteriori.

Selon les dernières informations, 334 O.N.G. jouissent du statut consultatif auprès de l'Ecosoc : dix dans la catégorie A qui bénéficie des privilèges les plus larges : 119 dans la catégorie B (dont douze natio-[p. 254] nales) ; 205 sur le registre (deux nationales). Les secteurs les plus représentés dans la catégorie B sont les organisations religieuses (plus d'une vingtaine) et les associations féminines (une quinzaine). Les facultés des organismes placés sur le Registre sont limitées : envoyer des observateurs aux réunions publiques du Conseil et de ses comités ou encore présenter, mais seulement sur invitation du Secrétaire Général, des déclarations écrites ${ }^{2}$.

On ne comprend pas davantage d'ailleurs la présence en catégorie B de la Société belge d'étude et d'expansion ou de la Société de Législation comparée (encore que cette dernière, bien qu'association française, possède des membres et des correspondants dans de nombreux pays).

2 Chiffres extraits du rapport du Conseil Économique et Social, $1^{\text {er }}$ août $1959-5$ août 1960 , à l'Assemblée générale, document de la $15^{\mathrm{e}}$ session, supplément $\mathrm{n}^{\circ} 3(\mathrm{~A} / 4415)$ - Dans sa dernière édition le Yearbook International Organization fournit la liste arrêtée à mai 1958 de toutes les O.N.G. bénéficiant du statut consultatif auprès de l'O.N.U. et de ses agences spécialisées. Les dix organismes placés en catégorie A sont : Chambre de Commerce Internationale. C.I.S.L., Alliance Coopérative Internationale; Fédération Internationale des Producteurs Agricoles; C.I.S.C. ; F.S.M., Fédération Mondiale des Associations pour les Nations Unies ; Fédération Mondiale des Anciens Combattants ; Organisation Internationale des Employeurs ; Union Interparlementaire. 
Les consultations revêtent de multiples formes. Elles sont sous le contrôle de l'un des Comités permanents du Conseil, le Comité chargé des organisations non gouvernementales. Les membres des catégories A et B ont la possibilité de soumettre des déclarations écrites (d'étendue limitée) qui sont imprimées et distribuées comme des documents officiels aux délégations nationales. Ils ont aussi le droit d'exposer leurs vues oralement devant le Comité permanent qui en fera rapport au Conseil. Seules les organisations A peuvent, sur recommandation du Comité, faire des déclarations orales devant le Conseil lui-même: elles ont aussi la faculté, par l'intermédiaire du Comité, qui possède en fait un pouvoir de veto, de suggérer au Secrétaire Général l'inscription d'un problème à l'ordre du jour du Conseil. Mais c'est dans les commissions du Conseil que les échanges de vues sont les plus fournis : ces commissions ont, en effet, l'habitude d'entendre directement des représentants des organisations $\mathrm{A}$ et $\mathrm{B}$, encore qu'elles soient en droit de se décharger de cette tâche sur des comités spéciaux fondés à cet effet.

On achèvera cet exposé très rapide de la structure des arrangements consultatifs par deux observations. La première, pour rappeler les efforts de regroupement des O.N.G., soit de leur propre initiative, soit sur suggestion de l'Ecosoc (en particulier, la Conférence des organisations consultatives non gouvernementales). La seconde, pour signaler que le système des arrangements consultatifs fonctionne également auprès des commissions économiques régionales (aujourd'hui au nombre de quatre : Europe, Asie et Extrême-Orient, Amérique latine, Afrique). En considérant la nature du travail effectué par ces commissions et l'influence que cette activité est susceptible d'exercer sur les politiques gouvernementales, on ne s'étonnera pas de l'ample utilisation qui est faite de ces mécanismes par les O.N.G. qui ont une implantation dans la région.

Les règles adoptées sont généralement très voisines de celles en vigueur dans les autres organismes de l'Ecosoc avec toutefois certaines [p. 255] variations tenant aux caractéristiques propres de la situation (ainsi, par exemple, la Commission pour l'Europe a-t-elle admis à participer à ses travaux sur la base d'arrangements ad hoc, certaines organisations ne figurant pas dans les catégories A et B de l'Ecosoc) ${ }^{1}$.

Comme on l'a dit précédemment, ce sont les commissions et sous-commissions techniques du Conseil qui constituent la principale "voie d'accès » des groupes internationaux dotés de facultés consultatives ou, si l'on préfère, en forment la «cible» principale... ${ }^{2}$. Le seul intitulé de ces commissions suffit à établir l'importance de leurs travaux pour de nombreux groupes à travers le monde: transports et communications ; statistique ; population ; questions sociales ; droits de l'homme; lutte contre les mesures discriminatoires et protection des minorités;

1 On trouvera une bonne présentation générale de ces quatre Commissions dans un numéro spécial de Associations, décembre 1959, pp. 842-866. Voir aussi l'ouvrage très conformiste de WIGHTMAN (David), Economic Co-operation in Europe. A study of the United Nations Economic Commission for Europe, Londres, 1956.

2 L'ouvrage de base pour une présentation relativement détaillée de l'œuvre du Conseil est le livre déjà cité de la Brookings Institution, The United Nations and Promotion of the General Welfare, 1216 p. Il contient en particulier une foule d'informations sur les divers champs d'intervention des O.N.G. 
condition de la femme ; stupéfiants ; commerce international des produits de base. Certaines d'entre elles attirent davantage les organisations orientées vers les problèmes techniques; d'autres, aux débats plus bruyants, se préoccupent de questions d'une brûlante actualité ; la plupart sont susceptibles d'engendrer de vives querelles idéologiques. Ainsi s'expliquent l'étendue et l'intensité des pressions qui, à diverses époques et sur certains problèmes, se sont exercées sur ces organismes.

Considérons, par exemple, les questions inscrites à l'ordre du jour de la $14^{\mathrm{e}}$ session de la Commission de la Condition de la Femme (Buenos Aires, mars-avril 1960) : état des droits politiques des femmes dans les divers pays ; statut des femmes dans les territoires sous tutelle et dans les territoires non autonomes; accès des femmes aux carrières de la fonction publique; problème de l'égalisation des rémunérations («À travail égal, salaire égal »); perspectives économiques ouvertes aux femmes; accès des femmes à l'éducation; statut des femmes en droit privé ; nationalité des femmes mariées. Cette liste suffit à établir l'importance et la variété des intérêts impliqués dans les travaux de la Commission. Or ceux-ci ne sont pas purement académiques puisqu'ils ont abouti au vote de conventions dont les organisations féminines, nationales et internationales, peuvent ensuite tenter d'obtenir la ratification par les États.

La première en date a été la convention sur les droits politiques des femmes qui, adoptée par l'assemblée générale en décembre 1952, est entrée en vigueur le 7 juillet 1954, soit 90 jours après le dépôt de la sixième ratification. Son objet principal est de supprimer toutes différences entre les sexes pour l'électorat, l'éligibilité et l'accès à la fonction [p. 256] publique. Mentionnons aussi la convention sur la nationalité de la femme mariée (conçue pour lui éviter de perdre automatiquement, et même contre son gré, sa propre nationalité lors de son mariage). Enfin, la Commission de la femme s'intéresse de près à la ratification de certaines conventions de l'O.I.T. (en particulier celle de l'égalité des rémunérations qui, au $1^{\mathrm{er}}$ février 1960, était ratifiée par une trentaine d'États).

La liste des déclarations écrites, présentées par les O.N.G. à l'Ecosoc de mai 1958 à mai 1959, est révélatrice de la variété des préoccupations qui s'expriment par la voie consultative. Ce caractère d'ailleurs risque d'être un facteur de dispersion et un élément de faiblesse. On compte, au total, 75 déclarations (dont 13 adressées à la Commission de la Femme par 9 organisations internationales). Les sujets traités vont des «problèmes monétaires de la Communauté économique européenne » à la « délinquance juvénile dans le Sud-Est de l'Asie », des «fluctuations dans les prix des produits primaires » à « l'exploitation de la prostitution des autres », de la " charge de la preuve dans l'imposition sur le revenu » à « l'établissement d'une liste des parcs nationaux », etc. Finalement, le domaine potentiel de consultation des O.N.G. par les Nations Unies s'étend à toute la gamme des entreprises humaines dans le domaine économique et social, depuis des sujets d'un intérêt général, comme les Droits de l'Homme, jusqu'à des questions techniques et spécialisées comme les conditions de délivrance des permis automobiles et les signaux routiers. 
À la lumière de ces observations, on comprend mieux les difficultés d'une action commune des O.N.G. sur des problèmes de fond. Les essais tentés depuis une dizaine d'années ont abouti à des résultats assez négligeables. En dehors de leurs préoccupations propres, on ne peut guère susciter l'intérêt unanime des trois cents O.N.G. de l'O.N.U. qu'au niveau de vagues généralités ou de déclarations d'une réelle platitude. Il est douteux que l'affaire vaille les frais de voyage considérables qu'elle implique.

N'hésitons pas à écrire que le problème des rapports des organisations non gouvernementales avec l'O.N.U. et ses diverses agences doit être abordé sans hypocrisie ni naïveté. En leur attribuant la qualité de groupes de pression, qui est indubitablement la leur, on ne peut que contribuer à une vue plus réaliste des choses. Il est admis depuis longtemps sur le plan interne, qu'il n'existe pas de groupe de pression de [p. 257] l'intérêt général, même s'il arrive que des organismes défendent des positions telles qu'on puisse, conventionnellement, les assimiler au bien public. On sait de même que les possibilités de dialogue entre betteraviers, sidérurgistes, anciens combattants et témoins de Jéhovah, sont rares. À moins d'un miracle, on n'aperçoit pas comment ces vérités élémentaires devraient s'effacer quand on passe du plan national aux relations internationales.

Unesco - Venons-en maintenant à cette organisation qui a toujours attaché une grande valeur au système d'arrangements consultatifs. On dira quelques mots de leur régime qui vient de connaître diverses modifications.

La base juridique en est l'art. 11, par. IV, de la convention créant l'Organisation. Il est stipulé qu'elle "peut prendre toutes dispositions utiles pour faciliter les consultations et assurer la coopération avec les organisations internationales privées s'occupant de questions qui entrent dans son domaine ». Dès sa première session (octobre-novembre 1946), la Conférence générale formulait à cet effet des directives provisoires. Elles furent transformées par la deuxième session de la Conférence (décembre 1947) en un système durable qui a toutefois reçu, depuis, plusieurs amendements résultant des difficultés rencontrées ${ }^{1}$.

L'Unesco classe en trois catégories les O.N.G. entrant en relations avec elle. Un petit nombre bénéficie d'accord en « due forme ». Ce sont des organisations dont la collaboration est indispensable à la réalisation du programme et qui, en dehors de la faculté consultative, ont des avantages matériels appréciables. Une seconde catégorie, plus large, jouit d'arrangements consultatifs (envoi d'observateurs aux sessions de la Conférence générale ; présentation au Directeur Général de remarques concernant le programme ; participation, sur invitation, à des réunions techniques, etc.). Enfin, l'Unesco établit des relations non officielles avec des O.N.G. qui, sans être admises au niveau précédent, offrent néanmoins un intérêt du point de vue du programme : elles

Sur ce système, voir TRIPP (B.M.H.), « Unesco in Perspective », International Conciliation, mars 1954, pp. 322-383 (spécialement pp. 349-351). Voir aussi la note publiée dans Associations, décembre 1955, pp. 812-815. 
sont inscrites au Registre du Directeur Général et leur coopération avec l'Organisation revêt des formes souples.

Au début de 1960, le chiffre des organismes intégrés à ces catégories était de 10 pour les accords en due forme, 148 pour les arrangements consultatifs et 207 pour les relations non officielles, soit au total 365 . On observera que les différences entre les deux premières séries se [p. 258] sont atténuées, de nombreux membres de la seconde recevant un appui matériel sous des formes diverses (en particulier subventions de fonctionnement). Le seul privilège supplémentaire attaché à l'accord en « due forme » serait l'attribution gratuite de locaux au siège de l'Unesco ${ }^{1}$.

En dehors des relations individuelles, l'Unesco a mis au point certaines méthodes de consultations collectives: réunions ad hoc concernant une question précise et groupes de travail spécialisés (éducation de base ; droit à l'éducation ; conséquences sociales de l'industrialisation, etc.). Ces derniers sont généralement constitués dans le cadre de la Conférence des organisations non gouvernementales dont on a déjà signalé l'existence.

Sur de nombreux points, ce système vient d'être soumis à révision, un projet de nouvelles directives venant d'être approuvé par la Conférence générale de l'Unesco (session de 1960) ${ }^{2}$. Le système adopté comporte toujours trois catégories mais dont le contenu est quelque peu différent. D'abord, une catégorie dite « d'information mutuelle » (C) rassemblant les O.N.G. désireuses de coopérer avec l'Unesco et jugées par le Directeur Général capables d'apporter une aide à l'Organisation. Ensuite, une catégorie dite "d'information et consultation » (B) groupant les O.N.G. susceptibles de donner à l'Unesco une aide efficace (contribution par leurs activités à l'exécution de certaines parties du programme). Enfin, une troisième, plus restreinte, dite « consultation et association » (A) composée d'un nombre réduit d'O.N.G. qui, ayant une composition largement internationale et une compétence éprouvée dans l'un des domaines de l'Unesco apportent à celle-ci une contribution régulière ${ }^{3}$. Le système de directives, confirmant l'usage actuel, prévoit la possibilité et réglemente l'attribution éventuelle d'une aide financière (subventions) aux organisations qui seraient classées dans les catégories $\mathrm{A}$ et $\mathrm{B}$.

À plusieurs reprises l'Unesco a encouragé et même provoqué, la constitution d'associations susceptibles par la suite de l'aider à réaliser son programme. Citons par

1 Ce qui vaut parfois aux dirigeants de ces organismes diverses facilités matérielles annexes (par exemple, dans l'ordre des exonérations fiscales).

2 Ces directives avaient été approuvées par le Conseil exécutif dans sa 56e session (mars 1960) sous réserve d'un point à réexaminer au cours de la $57^{\mathrm{e}}$ session. Sous leur forme définitive, elles ont été présentées à la II ${ }^{\mathrm{e}}$ session de la Conférence générale qui les a adoptées le 13 décembre 1960.

3 La catégorie C paraît correspondre aux organismes actuellement inscrits au Registre. Les associations bénéficiant d'accords en due forme et d'arrangements consultatifs seraient redistribuées en fonction des services rendus, dans les catégories $B$ et A. Le nouveau régime prévoit des passages d'une catégorie à l'autre, en particulier de $\mathrm{C}$ à $\mathrm{B}$ (après une période probatoire d'au moins deux ans). Toutefois on a prévu la possibilité d'admettre directement une O.N.G. dans la catégorie A ou B si le Conseil Exécutif le juge utile à la réalisation des objectifs de l'Unesco ou à l'exécution de son programme. 
exemple la création en 1950 de l'Association Internationale des Universités dans le but d'assurer la coopération entre les universités et les institutions d'enseignement supérieur similaires (réalisation d'un centre de documentation universitaire à l'échelle mondiale; équivalence des grades universitaires; santé mentale à l'Université ; organisation de la recherche scientifique, etc.). Cette association, [p. 259] à laquelle l'Unesco a délégué plusieurs de ses compétences, semble lui avoir rendu en retour d'appréciables services. Il est beaucoup plus difficile (et probablement ne dispose-t-on pas pour cela des instruments d'évaluation nécessaires) de formuler un jugement sur la contribution globale des autres. De même, est-on mal informé de la part prise par ces organismes à la préparation du programme ${ }^{1}$.

Selon l'acte constitutif, la responsabilité de cette élaboration revient aux États membres et à la Conférence générale, d'une part, au Conseil exécutif et au Directeur Général de l'autre. Les États membres ont toujours été divisés quant au sens de l'activité de l'Organisation (les uns insistant sur le maintien de la paix, d'autres sur la réalisation du bien-être). La Conférence générale n'a jamais été très efficace dans la fixation de la ligne de conduite et des objectifs de l'organisme (trop grande ampleur du programme; rotation excessive des délégués; rôle des préoccupations politiques...). D'abord assez incertain, le Conseil exécutif paraît, depuis 1950, avoir gagné en solidité et influence. Mais c'est évidemment sur le Directeur Général, assisté des fonctionnaires du Secrétariat, qu'a toujours reposé l'essentiel de la tâche. Ce personnel, découragé dans les premières années par un recrutement assez désordonné et une grande instabilité de carrière, a peu à peu acquis, avec des garanties d'emploi, compétence et autorité : il joue un rôle considérable dans la préparation et l'exécution du programme (préfigurant l'avènement d'une véritable bureaucratie internationale qui obéirait à ses propres standards).

Les O.N.G., agissant comme groupes de pression, ont tenté en permanence de peser sur le programme pour l'infléchir dans un sens conforme à leurs idéologies ou à leurs intérêts. Le point d'application de cette action s'est situé, tantôt au sein de l'Organisation (Conférence générale durant ses sessions, membres du Conseil exécutif, Directeur Général et personnel du Secrétariat), tantôt au dehors (action directe sur les gouvernants des États-membres). Une voie d'accès particulière est fournie par les Commissions nationales (dont la structure et le mode de fonctionnement varient considérablement avec les États).

Selon certains observateurs, ces interventions auraient eu pour principal effet d'empêcher la concentration du programme sur quelque thème d'importance majeure : acharnés à poursuivre la réalisation de leurs desseins propres, ces groupes auraient

Voir sur ce point l'ouvrage, à plusieurs égards décevant, de LAVES (W.H.C.), THOMPSON (C.A.), Unesco Purpose, Progress, Prospects, Bloomington (Indiana), 1957. Consistant pour l'essentiel en une description, le livre n'apporte qu'une faible contribution à l'analyse théorique (le chapitre XIII, «Who makes Unesco's Program »), tout en fournissant des données utiles, ne va pas au fond du problème : ce qui serait une ambition peut-être prématurée...). Voir aussi ASCHER (Charles S.), Program-Making in Unesco 1946-51, Chicago, Public Administration Clearing House, 1951. Voir aussi AKZIN (Benjamin), op. cit., passim. 
provoqué une dispersion des efforts de l'Unesco, finalement préjudiciable à son rendement et [p. 260] à son efficacité. Mais, en l'état des connaissances, ce point de vue qui attribue peut-être aux O.N.G. une responsabilité excessive, demeure une simple hypothèse.

Autres organisations - Il serait sans beaucoup d'utilité pour ce travail de poursuivre l'étude des arrangements consultatifs dans d'autres organisations intergouvernementales qui lui accordent généralement une place moins considérable ${ }^{1}$. On voudrait seulement dire que le système se retrouve également dans les organismes voués à l'étude des problèmes techniques. Dans des cas de ce type, il n'est pas inconcevable que la consultation mettant en œuvre une compétence rare, et éventuellement unique, ait une grande portée. Mais, malgré les efforts accomplis en ce domaine par quelques spécialistes américains, nous manquons encore le plus souvent des travaux qui permettraient d'apprécier la valeur de cette hypothèse.

C'est ainsi, par exemple, que l'Union Internationale des Télécommunications collabore avec les organisations internationales ayant des intérêts et des activités connexes, les relations s'établissant surtout par la représentation des O.N.G. aux conférences administratives de l'Union et leur participation aux travaux des comités consultatifs. Le Conseil d'administration a attribué une position et des privilèges spéciaux à une vingtaine d'entre elles (par exemple Association Internationale des intérêts Radio-maritimes, Fédération Internationale des Radio-Télégraphistes, Organisation Internationale de Radiodiffusion, Commission Mixte Internationale pour les Expériences relatives à la Protection des Lignes de Télécommunication et des Canalisations Souterraines, etc.) ${ }^{2}$. Pour sa part, l'Organisation Météorologique Mondiale a accordé le statut consultatif à une dizaine d'organisations non gouvernementales (à buts pratiques comme la Fédération Internationale des Associations de Pilotes de Ligne, ou scientifiques comme l'Union Astronomique Internationale) : de plus, elle a conclu un arrangement de travail avec l'Union Géodésique et Géophysique Internationale visant à éviter tout double emploi.

Un dernier exemple enfin : celui de l'Office Central de Transports Internationaux par Chemins de Fer. Il coopère avec les O.N.G. s'occupant de ces questions, soit en les invitant aux conférences de révision (avec possibilité d'émettre un avis en séance sur les problèmes à l'ordre [p. 261] du jour), soit en les autorisant à participer avec

1 Pour de nombreuses informations sur d'autres organisations intergouvernementales, consulter Associations, numéros spéciaux sur le problème : décembre. 1955 et janvier 1956. Pour la F.A.O., voir HAMBIDGE (C.), The Story of the F.A.O., New York, 1955 ; pour l'I.C.A.O., SCHENKMAN (J.), International Civil Aviation Organization, Genève, 1955 (thèse de l'Institut Universitaire de Hautes Études Internationales); pour la W.H.O., BERKOV (R.), The World Health Organization, Genève 1957; pour l'I.T.U., CODDING (George Arthur) Jr, The International Telecommunication Union. An experiment in international cooperation, Leiden, 1952 (Thèse de l'Institut de Hautes Études Internationales de Genève).

2 Voir MULATIER (Léon), « Relations de l'Union Internationale des Télécommunications avec les Organisations Non Gouvernementales », Bulletin O.N.G., novembre 1952, pp. 422-424. 
voix consultative et sous condition de réciprocité, aux séances de commissions d'experts ${ }^{1}$.

Valeur $d u$ système - D'une façon générale, les organisations non gouvernementales sont très désireuses d'obtenir le statut consultatif auprès d'une ou plusieurs organisations intergouvernementales. On s'est demandé si elles ne voyaient pas dans l'opération une sorte de reconnaissance ou au minimum de consécration, leur apportant l'équivalent moral de la personnalité juridique internationale toujours inexistante.

Les grandes associations internationales jouissent généralement de facilités consultatives avec plusieurs organismes. Ainsi, C.I.S.L., C.I.S.C. et F.S.M. disposentelles du statut consultatif auprès de l'Ecosoc, de l'O.I.T, de l'Unesco, de la F.A.O. et de l'Unicef. La Chambre de Commerce Internationale étant absente de l'Unesco n'a d'accès direct qu'auprès de quatre de ces institutions, mais l'Union Catholique Internationale du Service Social et la Commission des Églises pour les Affaires Internationales possèdent chacune cinq affiliations (les mêmes d'ailleurs). Si plusieurs autres organisations sont dans une situation aussi favorable (Union Internationale des Organismes Familiaux, Fédération Mondiale des Anciens Combattants, Alliance Coopérative Internationale), trois seulement bénéficient de six affiliations (Organisation Internationale de Normalisation, Ligue des Sociétés de la Croix-Rouge, Union Internationale de Protection de l'Enfance), et une seule dispose de sept (Fédération Mondiale des Associations pour les Nations Unies: Ecosoc, O.I.T., Unesco, Organisation Mondiale de la Santé, F.A.O., Unicef et Organisation Météorologique Mondiale).

L'acquisition de ces facilités implique, en contre-partie, des obligations et des servitudes pour les bénéficiaires ${ }^{2}$. On a suggéré que, dans plusieurs cas, l'activité des

1 Il est intéressant de connaître la liste des premières O.N.G. qui ont demandé à recevoir le statut consultatif auprès de l'Agence Internationale de l'Énergie Atomique. Ce sont (avril 1959), Organisation Internationale de Normalisation ; F.S.M., Chambre de Commerce Internationale ; Fédération Mondiale des Associations pour les Nations Unies; Alliance Coopérative Internationale ; Conférence Mondiale de l'Énergie ; C.I.S.C. ; C.I.S.L., Fédération Mondiale pour la Santé Mentale. Au total, un bon mélange de préoccupations économiques, idéologiques, techniques... Sur la réglementation du statut auprès de l'Agence, voir Associations, février 1959, pp. 150-153.

2 Nous ne connaissons qu'une seule analyse monographique de ce type d'activité. Il s'agit de l'ouvrage déjà cité de Nehemiah ROBINSON, The United Nations and the World Jewish Congress. L'auteur expose systématiquement les efforts accomplis par le Congrès dans le domaine relevant de sa compétence : développement du droit international (Convention sur le Génocide; statut des réfugiés.); protection des communautés juives; sauvegarde des droits humains et des libertés fondamentales; lutte contre la discrimination et protection des minorités; soutien des Nations Unies... Durant la période de 1945-55, le Congrès a présenté 90 déclarations écrites (liste, pp. 148187) et 72 exposés oraux (liste, pp. 164-167). Du même auteur, voir The Genocide Convention. A Commentary, New York, 1960. L'octroi du statut consultatif implique en principe l'assistance aux réunions de l'organisme intergouvernemental. Voici, à titre d'exemple, celles auxquelles a participé le Bureau International Catholique (titulaire du statut auprès de l'Ecosoc, l'Unesco et l'Unicef) pour la période mai 1953-mai 1955 (d'après le rapport d'activité présenté au Conseil général le 6 mai 1955) $16^{\mathrm{e}}$ et $18^{\mathrm{e}}$ sessions du Conseil Économique et Social ; $6^{\mathrm{e}}$ session de la sous-commission de 
O.N.G. auprès de l'Organisation Internationale s'était révélée plus intense avant l'obtention du statut qu'après. Allégation qui n'est pas nécessairement inexacte et conduit à une évaluation globale du système.

Le spécialiste en science politique ne peut s'étonner du développement des arrangements consultatifs sur le plan des relations internationales. Depuis longtemps, le mouvement s'affirme au niveau interne, traduisant l'interdépendance, sans cesse plus poussée entre les secteurs public et privé : relations si étroites même, en vérité, que la séparation paraît artificielle. On y voit parfois le signe d'une subordination des [p. 262] initiatives privées aux autorités officielles, le témoignage d'un écrasement du citoyen par le pouvoir. D'autres considèrent ces arrangements comme un instrument d'asservissement des centres étatiques aux classes dominantes. Il n'est pas indispensable d'insister sur ces préconceptions doctrinales venues d'un temps où nul ne pouvait encore prévoir les résultats de la révolution technologique. Les formes actuelles de coopération, qui s'instituent entre les pouvoirs publics et les forces sociales, découlent du mouvement des faits et non de vieilles philosophies ; elles sont neuves et parfois déconcertantes. Le gouvernement français subventionne des mouvements de jeunesse qui combattent âprement sa politique. Dans la même perspective, quelques-uns des critiques les plus virulents de l'Unesco ne se trouventils pas dans les associations qui doivent aux subventions versées par l'organisation de poursuivre leurs activités?

À propos des arrangements consultatifs octroyés aux O.N.G. une question est souvent posée : les résultats acquis justifient-ils le temps, l'argent et les efforts dispensés pour les obtenir? Si l'on fait abstraction des flots d'éloquence ad hoc déversés dans les réunions inaugurales, ou les discours de clôture, il apparaît bien, qu'en cette matière, personne n'est sûr de rien.

Les reproches adressés par les O.N.G. aux organisations intergouvernementales sont nombreux, souvent excessifs, parfois contradictoires : dans l'ensemble pourtant, ils ne sont pas sans justification. Le plus fréquent, semble-t-il, traduit une accusation d'inconséquence: les organisations gouvernementales réclament le concours des O.N.G. pour l'élaboration de leurs programmes et la diffusion de leurs idéaux, mais, en même temps, elles multiplient les restrictions dont l'effet est de limiter l'influence

lutte contre les mesures discriminatoires et de la protection des minorités; $10^{\mathrm{e}}$ et $11^{\mathrm{e}}$ sessions de la Commission des Droits de l'Homme ; $8^{\mathrm{e}}$ et $9^{\mathrm{e}}$ sessions de la Commission de la Condition de la Femme ; $8^{\mathrm{e}}$ session de la Commission de la Population; $10^{\mathrm{e}}$ session de la Commission des Questions sociales ; Réunion en vue de la préparation du programme de l'Unesco pour l'année 5556 ; Réunion du Comité des O.N.G. ayant statut consultatif auprès de l'Unesco ; $4^{\mathrm{e}}$ Conférence générale des O.N.G. ayant statut consultatif auprès de l'Unesco; $8^{\text {e }}$ Conférence générale de l'Unesco ; Conseils d'administration de l'Unicef ; Réunions du comité des O.N.G. ayant statut consultatif auprès de l'Unicef ; Conférence des organisations consultatives non gouvernementales ; conférence latino-américaine des O.N.G.; conférence des organisations internationales non gouvernementales intéressées au problème de la réadaptation des handicapés ; conférence des organisations non gouvernementales intéressées à la lutte contre les mesures discriminatoires et les préjugés. On aperçoit vite la difficulté d'apporter une contribution intéressante à tant de manifestations (sans même évoquer le temps pris par la participation aux débats et la lecture, éventuelle, des documents de travail et rapports). 
des forces privées sur l'action internationale. En fait, on aurait monté un mécanisme lourd et complexe, fort coûteux de surcroît, sans pouvoir, ou sans vouloir, l'utiliser raisonnablement.

Les O.N.G. incriminent volontiers la rigidité bureaucratique des grandes organisations internationales (en particulier O.N.U., Unesco, F.A.O.) : il en résulterait une quasi-impossibilité de faire prévaloir des idées neuves, de rajeunir une structure, de rénover un programme. Cette imputation est excessive, d'autres reprochant à ces organismes leur versatilité et, assez curieusement, leur "manque de mémoire » (le départ d'un fonctionnaire faisant parfois tomber dans l'oubli les problèmes dont il était chargé ou, si l'on préfère, obligeant à tout repren-[p. 263] dre). Il est clair, au surplus, qu'aucune généralisation n'est possible, l'efficacité des secrétariats n'étant pas la même. Là où elle est très marquée, la rigidité bureaucratique des services internationaux dépasse tout ce que C.N. Parkinson a écrit sur les administrations nationales : elle rend les adaptations nécessairement lentes et risque de décourager les bonnes volontés extérieures.

Les organisations intergouvernementales ne sont pas réduites à la défensive et leurs critiques ne manquent pas de poids. Elles font ressortir que les O.N.G. ne nomment pas toujours auprès du siège (et spécialement celui de l'O.N.U.) des représentants capables d'assumer les charges du mécanisme. Dans certains cas, les groupements négligent de répondre, simplement par correspondance, aux demandes d'information ou d'assistance et évitent même d'envoyer au Secrétariat leurs publications ; ou des renseignements sur leurs activités : il leur arrive de réclamer des renseignements déjà fournis ou de présenter des requêtes traduisant une méconnaissance complète des règles statutaires de fonctionnement de l'Organisation.

Les O.N.G. se défendent le cas échéant en invoquant la médiocrité de leur situation financière qui, en bien des cas, les oblige à un travail bénévole. Ce resserrement financier les empêcherait de créer des moyens de communication effectifs avec l'O.N.U. ou ses agences. La défense est plausible, mais n'a-t-on pas en tort de solliciter un statut dont la mise en œuvre exigerait des ressources qui ne sont pas disponibles ? Et quelles protestations en perspective si la capacité administrative et financière devenait facteur de premier rang pour l'octroi du statut !

Un autre reproche fait aux O.N.G., en tout cas à plusieurs d'entre elles, est d'utiliser les facilités consultatives pour diffuser leurs propres idéologies, de façon en somme gratuite, auprès de l'opinion publique — du moins celle qui suit régulièrement les débats de l'Ecosoc, de l'Unesco et autres grandes organisations intergouvernementales. Cette objection n'est pas sans fondement: il est vrai que plusieurs associations non gouvernementales ont abusé de leurs privilèges, leurs membres ayant pris la parole et présenté des déclarations écrites beaucoup plus à des fins de propagande, qu'en vue de donner une consultation utile. Gardons-nous cependant d'oublier que l'une des idées qui ont présidé à la création du système était de donner à l'opinion publique la possibilité de s'exprimer sans passer par le « convertisseur» (souvent déformant) de délégations gouvernementales. En un sens, on l'a dit, le statut [p. 264] consultatif avait pour objet, dans l'esprit de ses promoteurs, 
d'affirmer la diplomatie du citoyen et éventuellement du producteur face aux diplomates traditionnels.

Mais qui souhaite entendre l'opinion doit être prêt à en écouter les diverses expressions, et qui veut maintenir les relations de voisinage doit accepter le voisin tel qu'il est. L'universalité et l'unité d'inspiration sont rarement compatibles en ce milieu du $\mathrm{XX}^{\mathrm{e}}$ siècle (l'ont-elles jamais été pleinement ?) Les auteurs de l'étude déjà citée de la Brookings Institution, évoquent en termes sévères, l'activité de la F.S.M. à l'Ecosoc : ils lui reprochent de réclamer des pouvoirs qui sont statutairement refusés aux gouvernements non membres du Conseil (par exemple, droit de procéder à la convocation du Conseil ou de participer à ses débats sur le même pied que les Étatsmembres). Ils l'accusent également d'abuser des facilités ouvertes en introduisant dans la discussion des questions politiques étrangères à l'ordre du jour.

Ces remarques reposent sur des faits indiscutables qui remettent en cause, on l'a dit, la distinction public-privé. Il n'est aucun phénomène de notre vie politique et sociale (y compris l'impressionnisme ou Picasso) que la dialectique marxiste ne soit capable de ramener à l'exploitation capitaliste. Il n'est aucune circonstance (y compris l'organisation de championnats sportifs) qui ne constitue, pour les communistes, une occasion valable de dénoncer l'« impérialisme » ou les «fauteurs de guerre ». Seuls manquent de logique ceux qui s'étonnent de ne pas trouver de neutralité dans de tels contacts. Au surplus, le monde communiste est-il le seul à afficher son point de vue et à lutter pour lui ?

La déformation idéologique des auteurs de la Brookings Institution est révélée par l'unicité de l'exemple. Il serait, en effet, facile de citer de multiples cas attestant que chacun, avec ses méthodes propres, pense à la glorification de son saint. C'est ainsi qu'à une certaine époque, le programme de l'Unesco a fait une place à des projets, d'origine quaker, sur la médiation et la « rencontre des esprits » que de nombreux syndicalistes européens tiennent pour un essai de diversion et de division sociales. Pourquoi ne pas parler aussi de la C.I.S.L. qui fait essentiellement de la politique, encore que selon une autre inspiration et d'autres méthodes que la F.S.M. ? Si on enlevait de ses rapports d'activité, les décisions et démarches (y compris auprès des Nations Unies) qui relèvent de la volonté de combattre le communisme, ou de le devancer, la lecture en serait très rapide. Et si l'on veut connaître la conception ca[p. 265] tholique du statut consultatif, on découvrira sans surprise que, pour les organisations internationales de cette confession, la raison d'être de l'institution est d'abord «la possibilité d'exprimer le point de vue de la morale chrétienne et de la doctrine de l'Église sur les différents points de l'activité des Nations Unies » ${ }^{1}$.

Au total, on a peine à croire que des spécialistes universitaires ne soient pas capables de dépasser les différences de style pour trouver l'unité de comportement, ou, si l'on préfère, de tactique. Les pratiques constatées, les déviations observées, les

1 Texte ronéoté d'une conférence sur Les relations des organisations internationales catholiques avec les organisations internationales officielles et les organisations non gouvernementales, Paris, 1955, p. 9 (Bureau International Catholique de l'Enfance). 
abus identifiés, n'étonneront plus, et surtout, ne provoqueront pas ces pudiques accès de morale dirigée, si l'on veut admettre, comme on l'a déjà suggéré, que les O.N.G. sont en fait des groupes de pression internationaux.

Elles ne sont pas que cela, beaucoup accomplissant leurs tâches propres par des moyens privés, sans se soucier d'un appel aux mécanismes étatiques, ou d'une pesée sur eux. Mais, à partir du moment où ces organisations se préoccupent d'agir par la voie gouvernementale, que ce soit sur le plan international ou national, ce sont, sous cet aspect, des groupes de pression et rien que cela.

Ainsi, tout devient simple. La notion d'« organisation annexe » et, plus généralement la distinction entre capacité autonome et dérivée aident à expliquer plusieurs des conduites incriminées. La référence a l'« intérêt commun », comme base et ciment du groupe, permet de comprendre, et l'aptitude de celui-ci à intervenir sur ce qui fait son objet, et son indifférence aux préoccupations d'ordre général. Il arrive que le désir de "placer » son association, ou une certaine disponibilité de temps, ou encore le goût invétéré de parler indéfiniment de choses abstraites, poussent le responsable exécutif d'une O.N.G. à se prononcer sur des problèmes hors de son ressort, ou à participer aux conférences spécialisées dans les problèmes généraux et, de préférence, mondiaux. Dans ce cas, et ici l'auteur parle d'expérience, il faudrait savoir si la position prise a le moindre rapport avec l'opinion du groupe qui, probablement, refuserait d'en exprimer une comme tel.

En définitive, le régime fonctionne quand le problème intéresse le ou les groupes considérés. Et cette évidence suffit à expliquer que, dans plusieurs cas, les O.N.G. aient fourni un appui aux Nations Unies. Il en a été ainsi, semble-t-il, dans le domaine des droits de l'homme, du statut de la femme, de l'aide aux réfugiés, des transports ${ }^{1}$. L'octroi de ce concours s'explique par l'existence de groupes qui ont vu dans [p. 266] l'O.N.U. un puissant moyen d'accélérer et d'amplifier la réalisation de leurs objectifs propres. Les juristes et moralistes risquent, il est vrai, d'alléguer qu'une expression comme "groupe de pression" ne saurait convenir à des activités essentiellement désintéressées. C’est oublier qu'il s'agit là d'une catégorie qui entend saisir les phénomènes d'intervention sur le pouvoir sans se prononcer sur leur légitimité ou leur qualité spirituelle. C'est oublier aussi que, si le terme « intérêt » est équivoque, l'un de ses sens, selon Littré, est simplement «ce qui importe aux personnes en quelque manière que ce soit ». Et cet intérêt peut être la recherche d'un avantage matériel égoïste ou la promotion d'une valeur.

Au total, l'art. 71 de la Charte (ou ses équivalents dans les autres organisations), se borne à transposer sur le plan international, la tendance à la consultation et à la coopération public-privé (la "démocratie fonctionnelle», selon certains) qui se manifeste au niveau national avec beaucoup d'ampleur. Sous des inspirations moralisantes et humanitaristes, on a tenté d'en faire un instrument de

Voir l'étude de HAMORI (Laszlo), "Le rôle des organisations non gouvernementales dans le programme de défense sociale des Nations Unies ", in L'avenir des organisations internationales gouvernementales, Bruxelles (U.A.I.), 1956. 
perfectionnement du genre humain. Et l'on a ainsi essayé de créer une mystique de l'organisation non gouvernementale qui ne pouvait naturellement résister à l'épreuve des faits.

Si les organisations intergouvernementales témoignent de vitalité et développent leurs fonctions, l'activité des O.N.G. s'étendra parallèlement ou, du moins, la part de leurs activités consacrée à des contacts gouvernementaux s'élargira. Ces relations se situeront naturellement sur le plan de l'avantage réciproque, les forces gouvernementales devant veiller à ce que le marché ne soit pas trop inégal. Mais l'on s'épargnerait bien des déboires en considérant que les êtres collectifs et individuels intéressés ne changent pas de préoccupations ou de comportement lorsqu'ils quittent les fonctionnaires britanniques ou français, pour trouver ceux de l'O.N.U. ou de l'Unesco.

\section{c) RELATIONS DE FAIT}

\section{$\underline{\text { Retour à la table des matières }}$}

On entend par là celles qui s'établissent entre les deux secteurs public et privé hors de toute référence à un cadre juridique quelconque. De tels contacts se nouent naturellement même dans les organisations que l'on vient d'étudier, le régime consultatif étant inapte à couvrir la totalité des rapports que peut entretenir, à un moment quelconque et [p. 267] parfois de façon épisodique, une organisation intergouvernementale. Cependant, les consultations libres sont la norme quand il n'existe pas de réglementation particulière, ce qui est encore largement le cas pour les communautés européennes. Par son exceptionnelle importance, pratique comme théorique, cette expérience vaut d'être évoquée dans l'optique de cet ouvrage.

Conseil de l'Europe et O.E.C.E. - Quelques mots d'abord des deux organisations les plus anciennes : le Conseil de l'Europe et l'O.E.C.E., leur attitude en la matière ayant été différente.

Au mois d'octobre 1951, le Comité des ministres du Conseil de l'Europe, s'inspirant du précédent des Nations Unies, a créé un régime d'arrangements consultatifs, destiné aux organisations non gouvernementales qui s'occupent de questions relevant de la compétence du conseil. Celles-ci sont réparties en trois catégories (A, B et C). Le classement s'effectue, compte tenu de l'étendue de la compétence des associations en cause, de leur représentativité et de leur vocation à envisager les problèmes dans le cadre européen. Chacune de ces classes jouit de facilités et de privilèges différents (les plus étendus allant aux O.N.G. de la catégorie A, qui, par exemple, sont seules à pouvoir discuter avec le Secrétariat général de l'inscription d'une question nouvelle à l'ordre du jour de l'Assemblée). Notons d'ailleurs que, ce faisant, le Comité des ministres n'a nullement voulu se priver, pour l'avenir, des relations de fait avec des organismes n'ayant pas demandé le statut consultatif. 
Parmi les premières O.N.G. bénéficiaires de ces facilités, on relève soit des groupes à vocation mondiale (C.I.S.C., C.I.S.L., Fédération Mondiale des Anciens Combattants...), soit des associations à compétence européenne (Confédération Européenne de l'Agriculture, Conseil des Communes d'Europe, Centre Européen d'Études de Population...). L'assoupissement du Conseil de l'Europe et, pour parler plus clairement, sa stérilité, ôte beaucoup de sa portée à ce dispositif ${ }^{1}$.

Bien que l'O.E.C.E. ait tenu de l'art. 20 (b) de la Convention Européenne de Coopération Économique le droit d'entretenir des rapports avec d'autres organisations internationales, elle n'a pas institué en ce qui la concerne de code des relations avec les organisations non gouvernementales. Toutefois, en juin 1949, le Conseil a émis un certain nombre de principes, en distinguant trois formes de liaison : relations [p. 268] officielles établies à la suite de décisions arrêtées par le Conseil ; relations entretenues directement par les Comités techniques ; contacts pris et maintenus par le Secrétaire général.

La reconnaissance officielle implique chez l'O.E.C.E. la volonté de tenir l'association considérée au courant des activités réalisées ou projetées et de solliciter ses observations. Très peu d'organisations en ont bénéficié. Citons entre quelques autres le Conseil des Fédérations Industrielles d'Europe et le Conseil Européen de l'Artisanat et des Petites et Moyennes Entreprises (respectivement créées en 1949 et 1953 pour servir d'organes de liaison avec l'O.E.C.E.). De leur côté, les comités techniques, qui ont joué un très grand rôle dans la vie de l'O.E.C.E., sont entrés en contact avec de nombreux organismes professionnels internationaux (les rapports pouvant aller du simple échange de documentation à la présence d'observateurs de ces organismes aux séances des Comités) ${ }^{2}$.

Communauté Européenne du Charbon et de l'Acier - Avec cette institution, nous entrons dans le domaine de l'intégration européenne dont l'objectif est de construire progressivement, par un cheminement de l'économique au politique, une communauté à la mesure des exigences du $\mathrm{XX}^{\mathrm{e}}$ siècle ${ }^{3}$. Première pièce du système, la

1 La référence de base est ROHNN (Peter H.), Relations between the Council of Europe and International Non-Governmental Organizations, Bruxelles, 1957. Sur le Conseil les ouvrages essentiels sont ROBERTSON (A.H.), The Council of Europe. Its structure function and achievements, Londres, 1956, et DUCLOS (Pierre), La réforme du Conseil de l'Europe, Paris, 1958. Voir aussi ROBERTSON (A.H.). European Institutions, Cooperation, Integration, Unification, Londres, 1959 (suggestions pour former la "Grande Europe »). Bonne présentation d'ensemble in DUCLOS (Pierre), Le Conseil de l'Europe, Paris, 1960 (Que sais-je? № 885).

2 Sur ces problèmes, et en particulier sur le rôle des comités techniques, voir les rapports publiés par l'O.E.C.E., Dix ans de coopération. Réalisations et perspectives, Paris, 1958 et Le rôle de l'Organisation Européenne de Coopération Économique, Paris, 1959. Voir aussi la note de Etienne-Sadi KIRSCHEN, "L'activité des comités verticaux de l'O.E.C.E. » in L'O.E.C.E. au service de l'Europe, $3^{\mathrm{e}}$ édition, Paris, 1956, pp. 77-82. Le mouvement d'idées né dans ces Comités (en liaison avec les Missions de productivité aux États-Unis) a parfois entraîné la création d'O.N.G. Ainsi, fondation en 1953 de la Fédération Européenne de la Manutention et de la Fédération Européenne des Constructeurs d'Équipement Pétrolier.

3 L'intégration économique européenne a donné lieu à une volumineuse littérature d'intérêt très inégal. L'ouvrage de MAURY (René), L'intégration européenne, Paris, 1958, constitue une utile 
C.E.C.A. a été dotée de pouvoirs propres d'intervention et d'orientation, dont elle n'a fait qu'un timide usage ${ }^{1}$. Ils lui donnent en tout cas un caractère hors série qui incite à évoquer, rapidement d'ailleurs, ses relations avec les organisations du secteur privé. Elles ont été de deux types.

D'abord des relations officielles par le moyen du Comité consultatif (art. 18 du traité), qui comprend aujourd'hui 51 membres (maximum statutaire), représentant en nombre égal trois sortes d'intérêts: producteurs, travailleurs, utilisateurs et négociants. Ils sont nommés, à titre personnel, par le Conseil. Toutefois, pour les deux premières catégories, le Conseil choisit les membres sur des listes établies par les organisations professionnelles entre lesquelles ont été répartis les sièges à pourvoir (chaque liste présentant un nombre de noms double de celui à retenir). Le Traité précise que les membres ainsi choisis ne sont liés par aucun mandat ou instruction des organisations qui les ont désignés. Cette formule correspond à l'introduction directe des intérêts dans la structure de l'institution. Cependant, la mission du Comité reste consultative (la Haute Autorité ayant la possibilité de demander l'avis de [p. 269] ce dernier quand elle le juge opportun et étant parfois tenue de le faire).

D'après certains observateurs, le Comité aurait pris sa fonction «très au sérieux ${ }^{2}$, donnant à son activité un caractère périodique, exigeant d'être mis au courant des mesures adoptées ou envisagées, exerçant même une initiative dans le choix des questions placées à son ordre du jour ${ }^{3}$. D'autres estiment pourtant que son rôle technique, en tant que chambre professionnelle si l'on veut, est médiocre : son action serait plus efficace sur le plan psychologique (notamment par la possibilité qu'il ouvre aux organisations de travailleurs d'être informées des grands problèmes

introduction au sujet. On trouvera aussi quelques éléments intéressants in HAINES (C. Grove) ed., European Integration, Baltimore, 1957.

1 Sur la C.E.C.A., voir DIEBOLD (William) Jr, The Schuman Plan. A study in economic cooperation 1950-1959, New York, 1959 (le meilleur bilan disponible) ; REUTER (Paul), La Communauté européenne du Charbon et de l'Acier, Paris, 1953 ; Institut de Relations Internationales de Bruxelles, La Communauté Européenne du Charbon et de l'Acier, Paris, 1953 ; VIGNES (Daniel), La Communauté Européenne du Charbon et de l'Acier. Un exemple d'administration économique internationale, préface de Paul GUGGENHEIM, Paris, 1956 ; L'application du traité instituant la C.E.C.A. au cours de la période transitoire, Luxembourg, 1958 (Assemblée Parlementaire Européenne). Bonne introduction in SOTO (Jean de), La C.E.C.A., Paris, 1958 (Que sais-je ? n 773), et GOORMAGHTIGH (John), «European Coal and Steel Community », International Conciliation, mai 1955, pp. 343-408. Voir aussi l'ouvrage (d'esprit très juridique) de PRIEUR (R.), Les relations internes et externes de la C.E.C.A., Paris, 1958.

2 Selon l'expression de Pierre WIGNY, Un témoignage sur la Communauté des Six. Luxembourg, 1957.

3 On trouvera dans le $8^{\mathrm{e}}$ Rapport général ( $1^{\mathrm{er}}$ février 1959-31 janvier 1960), Luxembourg, 1960, pp. 24-26, un bref exposé des activités du Comité qui s'est réuni onze fois dans la période considérée. Il a été effectivement consulté sur les problèmes les plus complexes et les plus graves pour la vie de l'institution (recommandation au gouvernement français dans le domaine des prix de l'acier; mesures à prendre pour faire face aux difficultés charbonnières...). Mais les termes du rapport n’éclairent en rien sur le sens et l'étendue du travail accompli. 
qui intéressent la vie de la Communauté) ${ }^{1}$. D'autres, enfin, n'hésitent pas à déclarer qu'il s'agit de l'organe de la C.E.C.A. ayant fonctionné avec le moins de succès et d'utilité : selon cette opinion qui ne manque pas de solidité, le Comité n'aurait occupé qu'une place secondaire dans l'élaboration de la politique de l'institution ${ }^{2}$.

Un point intéressant est de savoir si les diverses catégories figurant au Comité font abstraction des frontières nationales dans leur comportement habituel : on estime généralement que les travailleurs des six pays, du moins ceux qui les représentent (les organisations liées au Parti Communiste étant privées du droit d'envoyer des délégués) témoignent d'une plus grande cohésion d'idéologie que les producteurs ${ }^{3}$.

Mais le Comité consultatif n'offre qu'un aspect des relations entretenues par la Haute Autorité avec le secteur privé. L'art. 48 du traité, en des termes qui ne brillent pas par leur clarté, l'autorise à recourir aux associations pour en obtenir les informations qui lui sont nécessaires, ou pour faciliter l'exécution des missions qui lui sont confiées. Les associations se présentent donc à la fois comme les porte-parole des entreprises auprès de la Haute Autorité et comme les collaborateurs de cette dernière. Ce rôle est fort différent de celui des membres du Comité consultatif qui doivent se prononcer à titre personnel (au moins sur le papier, car, en réalité, ils épousent étroitement les solidarités professionnelles). En somme, l'art. 48 revient à légaliser, sur la base de l'avantage réciproque, le jeu des groupes de pression à l'égard des autorités de la C.E.C.A.

Deux points valent d'être mentionnés : d'une part la Haute Autorité n'a créé aucun mécanisme officiel de relations consultatives. Les contacts sont donc des rapports de fait, dans le cadre, bienveillant et compréhensif, de l'art. 48. En second lieu, le souci de «maximer» les [p. 270] pressions effectuées a conduit les professionnels européens à créer de nouvelles organisations. Déjà ébauchée à l'égard de l'O.E.C.E., la tendance que nous retrouverons encore plus intense dans le Marché Commun, a pris un vif essor dès la mise en œuvre de la C.E.C.A.

Selon E. Haas qui a fait une analyse minutieuse du problème, il aurait été créé en Europe occidentale, de 1949 à 1957, une soixantaine d'organisations internationales privées ayant comme base des intérêts économiques et commerciaux et dont l'essentiel du recrutement s'effectue dans les six pays de la Communauté (avec parfois une adjonction limitée de membres en provenance de Grande-Bretagne, Suisse, Autriche, Espagne, Portugal et Scandinavie). Si l'on déduit de ce chiffre les organismes se consacrant à des tâches de service (amélioration de la qualité, productivité, promotion des ventes), il reste une trentaine d'associations de producteurs qui constituent autant de forces de pression d'une réelle puissance.

J. de SOTO, op. cit., p. 44.

In European Organization, Londres, Political and Economic Planning, 1959, p. 239. Les développements fournis par ce volume sur la C.E.C.A. sont bons (pp. 229-294).

3 La seule étude approfondie de ce problème dont nous disposions est HAAS (Ernst B.), The Uniting of Europe, Political, Social and Economical Forces, 1950-1957, Londres, 1958, chap. 9 et 10. On recommande vivement la lecture de ces développements qui apportent des aperçus originaux sur le jeu des groupes autour de la C.E.C.A. 
Ces regroupements offrent un intérêt évident pour la théorie politique, car ils représentent l'une des ripostes du monde des affaires à l'instauration par les autorités publiques, d'un système tendant à modifier les comportements habituels. Les formules adoptées par les intéressés varient selon les cas. Les métallurgistes, par exemple, n'ont pas établi une nouvelle fédération pour rassembler les associations nationales : ils se contentent d'une sorte de " club » (siégeant à Bruxelles) aux activités discrètes. Les producteurs de charbon, par contre, ont éprouvé le besoin d'une structure plus ferme et ils ont créé à cet effet un comité d'étude. Les industries consommatrices d'acier des six pays sont désormais liées par un réseau de contact très souple (Comité de Liaison des Industries Métalliques, aujourd'hui renforcé dans le cadre du Marché commun).

Notons encore l'existence d'un Comité Européen de Liaison des Négociants et Utilisateurs de Combustibles (poussés à s'organiser par le désir de contrebalancer la cohésion et la force de pression des producteurs de charbon et des syndicats ouvriers) ainsi que d'une Union Européenne des Négociants Détaillants en Combustibles (qui comporte quelques noyaux extérieurs à la C.E.C.A.).

Quel est le niveau de cohérence interne de ces groupements ? Haas estime que la réalisation éventuelle d'un "consensus" au sein de ces organismes, serait d'ordre tactique et ne correspondrait que rarement à une idéologie commune et à des valeurs morales partagées. En som-[p. 271] me, l'accord se ferait par rapport à un problème spécifique, d'où l'absence d'un schéma unique de coopération, les modalités de la collaboration variant selon les cas.

L'une des tâches essentielles de ces groupements, quelle qu'en soit l'assiette, est de négocier avec les autorités de Luxembourg et, éventuellement, de faire pression sur elles selon les méthodes habituelles. Par ailleurs, n'oublions pas l'intervention directe de puissants groupes d'affaires à propos de divers problèmes et tout spécialement des opérations de concentration (du type charbon-acier ou acier-acier: Krupp, Thyssen...). Les organisations professionnelles de travailleurs de leur côté ne demeurent pas inactives : sur ce point pourtant le jeu est faussé en une large mesure par l'élimination systématique des syndicats communistes de France et d'Italie.

Ce processus est parfaitement connu de tous les spécialistes de la C.E.C.A. Plusieurs des organismes intéressés ont établi des bureaux de liaison à Luxembourg où se développe une politique d'information et de persuasion. Cependant, on en discerne mal les aspects concrets. On évoque parfois pour justifier cette ignorance, le respect du secret professionnel qui pèse sur la Haute Autorité (l'entreprise lésée par la divulgation d'informations pouvant obtenir une réparation pécuniaire devant la Cour de justice).

Mais, dans une large mesure, c'est à une insuffisance des recherches (axées presque exclusivement sur les problèmes juridiques et économiques) qu'il convient d'attribuer les lacunes de notre information sur le fonctionnement réel de la C.E.C.A.

Communauté Économique Européenne - Venons-en maintenant au Marché commun qui, selon le jargon consacré, comporte nettement moins de « supranationalité » que la C.E.C.A. L'institution, qui n'a pas beaucoup plus de trois 
ans d'existence, se trouve encore, quant à ses rapports extérieurs, dans une phase expérimentale. La tendance actuelle des responsables semble être de ne pas brusquer le mouvement, de ne pas l'« institutionnaliser » trop vite et de garder aux contacts une grande souplesse. Comme dans la C.E.C.A., ces relations sont de deux sortes : une participation officielle aux travaux de la Communauté, par le canal du Comité Économique et Social (ainsi que du Comité Monétaire et du Comité des transports) et un ensemble de liaisons officieuses, dont le Traité lui-même accepte le principe.

[p. 272] Le Comité Économique et Social (art. 193-198 du traité) se compose de 101 membres, répartis entre les six pays et nommés par le Conseil des ministres sur présentation des États, chacun fournissant une liste de candidats en nombre double de celui des sièges attribués à ses ressortissants. Les membres du Comité représentent les différentes catégories de la vie économique et sociale que l'on entend associer ainsi à l'œuvre entreprise. La compétence de cet organisme est purement consultative (la demande d'avis étant toutefois, dans un certain nombre de cas, obligatoire tant pour le Conseil que pour la Commission).

Le Comité a constitué sept commissions spécialisées pour préparer le travail : agriculture ; questions économiques ; transports ; questions sociales ; activités non salariées et services ; pays et territoires d'outre-mer ; problèmes nucléaires. Il a déjà rendu plusieurs avis (par exemple sur le Fonds social européen et la politique agricole commune). On envisage également de créer des sous-comités appelés à élaborer des projets d'avis sur des questions déterminées.

On ne saurait porter encore de jugement sur le Comité dont le président actuel estime qu'il devrait réaliser « la complémentarité nécessaire entre les technocrates qui imaginent une situation idéale et les praticiens plongés dans la réalité de tous les jours ${ }^{1}$. Bien qu'ils soient choisis par les États, il est évident que ses membres sont, pour la plupart, appelés à être sélectionnés parmi les dirigeants d'organisations professionnelles ${ }^{2}$. C'est donc là, pour ces derniers, une voie d'accès aux institutions du Marché commun. Mais il y en a d'autres.

Selon l'art. 229 du traité, la Commission est chargée d'assurer « les liaisons opportunes avec toutes organisations internationales ». La formule est riche de virtualités. L'une d'elles consiste dans l'européanisation du lobby. Et déjà l'on évoque précisément la formation d'un «lobby européen ». Essayons de dresser un bilan rapide des divers types de pressions susceptibles de s'exercer sur les institutions de Bruxelles.

1 Dans une interview donnée au journal L'Européen, nº 8, décembre 1959 janvier 1960. Sur certaines inquiétudes ouvrières notamment à l'égard du Comité, voir TESSIER (H.), (« Préoccupations des syndicalistes français face au Marché commun », Revue du Marché commun, Paris, septembre 1959, pp. 300-309. Consulter enfin BEEVER (R.C.), European Unity and the Trade Union Movements, Leyde, 1960.

2 L'actuelle délégation française (24 membres) comprend : 9 syndicalistes, 6 patrons de l'industrie, 5 représentants des exploitants agricoles, 1 artisan, 2 fonctionnaires et M. Émile ROCHE. La C.G.T. en est écartée (comme son homologue italienne). 
D'abord, à la base, l'intervention de forces nationales mécontentes des décisions prises ou envisagées. Soit, par exemple, la politique agricole commune. Dans une réunion tenue à Bonn le 14 décembre 1959, l'Union Nationale des Paysans Allemands critique et rejette plusieurs des propositions de la Commission, tandis que la Fédération Allemande des Commerçants en Vin lui reproche de songer à orienter toute l'économie viticole du Marché commun sur le modèle, ou selon la volonté, de la France. La Fédération des Syndicats Allemands (D.G.B.) s'oppose [p. 273] par avance à tout traitement de faveur, non justifié, de l'agriculture. De son côté, la Fédération Nationale des Syndicats d’Exploitants Agricoles s'élève contre les pressions exercées sur l'agriculture des pays d'Europe par le G.A.T.T. qui tente, selon elle, de favoriser les pays extra-européens et les États-Unis désireux d'écouler leurs surplus.

Autres problèmes: la Fédération des Industries Belges donne son accord à l'accélération des étapes cependant que la Fédération des Ingénieurs Techniciens et Agents de Maîtrise des Houillères de France réclame une politique coordonnée de l'énergie. Le commerce de gros et d'exportation allemand se plaint du caractère dirigiste de la C.E.C.A. et déplore l'insuffisance du contrôle parlementaire à son endroit. La Confinductria (Italie) émet des réserves sur l'accélération de la démobilisation douanière, tandis que l'Union des Travailleurs Italiens conteste certaines dispositions du Fonds social européen ${ }^{1}$.

Nous trouvons là le schéma classique des organisations nationales qui s'efforcent d'agir sur des organes extérieurs par l'intermédiaire de leur gouvernement. Une particularité toutefois : par suite de la concentration géographique, les autorités de Bruxelles connaissent immédiatement ces critiques et ne peuvent manquer d'en être affectées.

Deuxième palier: les organisations européennes qui, dès maintenant, interviennent directement à Bruxelles. L'agriculture d'abord: on peut en citer plusieurs, spécialement fondées à cet effet. En premier lieu, le C.O.P.A. (Comité des Organisations Professionnelles Agricoles) qui, constitué de façon formelle en septembre 1958, groupe les représentants des associations agricoles à vocation générale des six pays (pour la France Assemblée Permanente des Présidents de Chambre d'Agriculture; Confédération Générale de la Coopération Agricole; Confédération Nationale de la Coopération, Mutualité et Crédit Agricoles; Fédération Nationale des Syndicats d’Exploitants Agricoles). Le Comité a établi des contacts permanents avec les institutions de la Communauté. Il existe aussi des organisations spécialisées parmi lesquelles nous mentionnerons entre autres, le Comité des Associations Viticoles des Six et le Comité des Organisations des jeunes Agriculteurs, etc.

À ces organismes nouvellement créés s'ajoutent ceux qui existaient déjà dans le cadre européen, comme la Confédération Internationale des Betteraviers Européens et le Comité Européen des Fabricants de Sucre. Ces derniers, comptant quelques États

1 Exemples extraits pour la plupart des Cahiers Mensuels de Documentation Européenne (janvier, février, mars et juillet 1960) publiés par l'Assemblée Parlementaire Européenne. 
qui n'appartiennent pas aux Six, ont constitué en leur sein une Commission des pays du Marché com-[p. 274] mun. L'activité de celle-ci s'est très vite manifestée à propos du fonctionnement des marchés de la betterave et du sucre dans cette zone : notes et rapports ont déjà été remis aux autorités compétentes de la Commission ${ }^{1}$.

Il va sans dire que les secteurs industriels et commerciaux connaissent le même mouvement, avec sans doute plus de force et de systématisation. On observe chez les associations professionnelles des six pays une tendance à se grouper à tous les niveaux, les réalisations allant de la tenue de tables rondes occasionnelles à l'institution d'organismes régulièrement déclarés (avec personnalité juridique et secrétariat). Dans plusieurs cas, on s'est borné (formule déjà rencontrée) à fonder une commission ou un comité "Marché commun » au sein d'une organisation existant à l'échelle européenne ou internationale : méthode suivie par l'Association Européenne des Industries de l'Habillement, le Conseil des Fédérations Commerciales d'Europe, l'Union Internationale des Producteurs et Distributeurs d'Énergie Électrique, etc. Mais souvent, de nouveaux organes ont été créés : ainsi l'Unice (Union des Industries de la Communauté Européenne) qui rassemble les fédérations industrielles centrales des Six, l'Association des Industries Margarinières des pays de la C.E.E., le Comité de Liaison de l'Industrie Automobile pour les pays de la Communauté Européenne, etc.

Cet effort d'organisation professionnelle ne traduit cependant qu'un aspect (probablement pas le plus important) du puissant élan de concentration, au sens large du terme, qu'a suscité la mise en marche de l'unification européenne. Il n'existe encore aucune étude qui embrasse l'ensemble de ce mouvement, mais les éléments que l'on peut en connaître donnent l'impression d'un courant large et fort. Dans chaque État, un grand nombre d'entreprises — au besoin après avoir procédé à des réorganisations et des fusions sur le plan national - ont pris contact avec leurs concurrents des autres pays de la Communauté. De multiples accords en ont résulté ayant pour objet, soit la coordination et la spécialisation des programmes de fabrication, soit l'utilisation en commun de systèmes de vente, soit l'échange de connaissances techniques. À titre d'exemple, évoquons les relations établies entre les fédérations cotonnières des six pays pour élaborer une politique commerciale commune et réaliser un plan d'assainissement (analogue à celui déjà réalisé en partie par les « cotonniers »français).

[p. 275] Comme on pouvait s'y attendre, les industries les plus dynamiques emploient simultanément toutes ces formules. C'est le cas de la construction électrique où l'on observe des regroupements et ententes sur le plan intérieur, l'interpénétration de firmes appartenant à plusieurs pays du Marché commun, la création par des entreprises nationales de filiales dans les autres pays de la

Voir Betteraviers Européens, 1958 (1), pp. 26-32, « La culture de la betterave au sein du Marché commun » ; 1959 (1), pp. 13-36 (prises de position sur les marchés de la betterave et du sucre dans les six pays) ; 1959 (2), pp. 9-11, etc. 
Communauté. Encore que moins accentué, un mouvement de collaboration se dessine aussi sur le plan bancaire et financier ${ }^{1}$.

S'ajoutant à l'expansion des organisations professionnelles, ce phénomène a pour résultat immédiat d'accroître le nombre et la puissance des firmes capables de rayonner sur plusieurs pays et, finalement, de s'adresser directement aux autorités de la Communauté ${ }^{2}$. D'une façon générale, les syndicats de travailleurs, en raison de leur fragmentation idéologique, paraissent mal placés pour réaliser de tels regroupements. Il peut arriver que se dessine alors un déséquilibre sérieux entre les forces et cela expliquerait diverses craintes des syndicalistes ${ }^{3}$.

Une tendance à l'organisation s'observe aussi au niveau des professions libérales : par exemple chez les médecins (dont la libre circulation et la libre installation sont prévues à des dates relativement rapprochées). D’où un souci d'harmonisation qui porte sur de nombreux domaines (enseignement, organisation hospitalière, déontologie...). Le premier congrès européen, consacré aux «perspectives de la médecine dans les six pays du Marché commun » (Strasbourg, octobre 1960), a mis en lumière les difficultés de cette opération.

Enfin, les institutions de Bruxelles sont, bien entendu, soumises aux forces de pression internationales et l'installation de plusieurs grandes firmes étrangères dans les pays du Marché commun renforce cette éventualité (les seuls investissements américains y ayant pratiquement quadruplé depuis 1950).

Mentionnons entre parenthèses que lors de la dernière conférence des ministres des «Sept» (Association Européenne de Libre Échange), la décision a été prise d'établir un Comité consultatif. L'objet de cet organisme sera de formuler des avis sur tous les aspects de l'activité de l’Association : il sera composé (à concurrence de cinq délégués et de cinq suppléants par pays) de représentants qualifiés des milieux du commerce, de l’industrie, des syndicats et de l'agriculture. Ses promoteurs en attendent un large appui des milieux de l'économie privée à la politique de l'A.E.L.E.

[p. 276] Appréciation globale - S'agissant d'évaluer ce mouvement d'européanisation, on ne saurait encore que poser des questions. En voici deux :

$1^{\circ}$ Évaluation de la capacité de pression. On s'est demandé si, en passant du plan national au plan de la Communauté, les interventions ne perdraient pas une partie de leur intensité et de leur virulence. On fait valoir que les autorités de Bruxelles restent

1 Pour une évaluation des effets du Traité de Rome sur la branche de l'assurance, voir OBERSON (Jacques), L'assurance et l'Europe, Lausanne, 1959, pp. 111-142. Voir aussi dans le même esprit DUTOIT (Bernard), L'aviation et l'Europe, Lausanne, 1959.

2 Voir dans Réalités, juin 1959, pp. 111-115, le tableau des plus grandes banques de l'Europe et des 100 premiers groupes industriels.

3 En date du 25 avril 1960, les centrales syndicales d'inspiration socialiste ou socialisante ont publiquement émis de sérieuses réserves sur les projets d'accélération - qui tendent à avancer la démobilisation douanière sans réaliser l'unification économique. Les Centrales protestent aussi (référence donnée dans la deuxième note 1 p. 269), contre l'insuffisance du rôle attribué au Comité Économique et Social. 
beaucoup moins soumises à des contingences électorales que celles de n'importe quel pays membre. Ce détachement pourrait occasionner des déboires aux organisations agricoles que menacent au surplus, d'un pays à l'autre, de graves rivalités (d'où possibilité ouverte aux autorités publiques de neutraliser les interventions par compromis, manœuvres tactiques...). Il est vrai que les groupes de pression européens à Bruxelles ne paraissent aujourd'hui ni très ardents, ni très revendicatifs, beaucoup ne semblant être là que pour faire acte de présence. Mais cet assoupissement relatif n'estil pas le fait d'une période de " rodage » (au cours de laquelle l'essentiel, réserve faite de certaines échéances inéluctables, dépend encore des gouvernements nationaux) ?

En réalité, trop de facteurs nous échappent pour qu'on hasarde un pronostic. Tout d'abord l'évolution de la Communauté elle-même qui, selon les tendances politiques des gouvernements au pouvoir, peut s'effectuer au profit de la Commission ou du Conseil des ministres. Ensuite, le destin de l'Assemblée Parlementaire Européenne dont beaucoup souhaitent qu'elle devienne un véritable Parlement (ce qui provoquerait un large effort d'intervention des groupes à son encontre). Mais la réalisation de cette éventualité (que certains voudraient hâter en faisant élire l'Assemblée au suffrage universel) reste lointaine ${ }^{1}$.

Un autre élément pourrait modifier l'équilibre actuel : la fusion des trois exécutifs européens, proposée en particulier par le Comité d'action pour les États-Unis d'Europe. Parmi les arguments donnés à l'appui de cette thèse figure le souci de compenser la croissance du pouvoir économique, qui se réalise sous nos yeux, par une autorité dotée d'une puissance suffisante. Ce contrôle du pouvoir des affaires, qui est dans la ligne du Traité, implique des difficultés et suscite des controverses.

Admettons que l'essentiel des attributions des communautés reste d'ordre économique sans aboutir à la création d'un pouvoir politique commun. Certains groupes auraient probablement à souffrir d'une telle situation : en particulier ceux qui contrebalancent habituellement l'in-[p. 277] suffisance de leur puissance de marchandage, par le recours à une capacité d'influence politique. Au premier chef les paysans, qui, sauf en quelques secteurs limités, ne semblent pas en mesure d'instituer des dispositifs privés d'action collective dans le cadre des Six (trop de rivalités régionales, de discordances dans les rendements obtenus...) ; et aussi les travailleurs affaiblis par leurs querelles intestines et l'élimination des syndicats communistes,

Le cas de l'agriculture est net. Jusqu'à présent, la définition d'une politique agricole commune n'a pas beaucoup progressé. D'accord sur la procédure et les principes d'une telle action, les ministres des Six n'ont pas réussi à traduire en décisions concrètes ces données générales. La grande industrie aurait ainsi chance d'être partout bénéficiaire d'un vide politique, car elle peut d'elle-même arriver à l'accord — un accord que personne ne serait alors assez fort pour contrôler.

Bonne présentation du problème in GINESTET (Pierre), L'Assemblée parlementaire européenne, op. cit. Voir également LINDSAY (Kenneth), European Assemblies. The experimental problem, op. cit. 
$2^{\circ}$ Cadre de référence. Il est loisible d'utiliser le schéma national-international proposé au chapitre précédent : il suffit d'attribuer la qualité «international » à tout groupe susceptible de peser directement, et sans l'appui d'un ordre juridique particulier, sur les institutions de l'une ou l'autre des communautés (y compris Euratom, organisme sur lequel il n'y a encore, du point de vue de cette étude, que fort peu à dire). Cependant, l'étroitesse relative de la zone considérée et le rôle éminent joué par le Conseil des ministres (surtout dans le Marché commun) sont susceptibles, en de nombreuses occasions, de rendre aléatoire l'application d'un tel schéma.

On peut dès lors songer à un chaînon intermédiaire, " régional » ou " européen », qui serait défini selon la même démarche de pensée: serait réputé tel le groupe jouissant d'une capacité d'intervention européenne ou « capacité européenne », c'està-dire de la faculté d'exercer une poussée dans un cadre dépassant les frontières d'un seul État, mais comportant néanmoins des limites géographiques. Cette distinction, d'ordre théorique, rejoindrait l'effort accompli par certaines organisations intergouvernementales et non gouvernementales pour séparer les deux catégories d'intervention. Mais, jusqu'à maintenant, les essais de conceptualisation de ces tendances demeurent confus et hétérogènes.

À supposer que l'on accepte de considérer l'Europe des Six comme une « région », elle aurait sur plusieurs autres la supériorité d'une claire délimitation et d'une forte organisation. On se heurterait, il est [p. 278] vrai, à un nouvel obstacle : l'existence de groupes constitués à une échelle plus large et comportant en leur sein un organisme, au besoin sans personnalité spécifique, chargé des relations avec les Six. Où classer un tel organe si l'on souhaite conserver un principe de répartition simple?

En somme, l'idée de groupe « régional » (c'est-à-dire, dans notre cas, de groupe « européen ») paraît défendable et même raisonnable : elle ramènerait les institutions en cause à leurs véritables dimensions, des objections pouvant être faites à l'emploi du terme «international » pour désigner le rassemblement d'un petit nombre de pays. Mais la structure et le mode d'« accès » des groupes dans la Communauté Européenne est trop fluide pour que l'on puisse établir dès à présent un schéma abstrait: la question ne pourra être abordée avec profit qu'une fois la situation elle-même décantée et consolidée.

En annonçant ce tableau des interventions sur les organismes intergouvernementaux, on marquait le souci, dicté par l'état de la documentation, de se limiter aux manifestations ostensibles, Le lecteur est désormais en mesure d'apprécier l'étendue des lacunes qui en découlent.

Lacunes quant aux acteurs. Le Saint-Siège n'a pas été évoqué dans cet exposé. Il joue pourtant par divers procédés et notamment par le biais d'observateurs, un rôle important et discret dans plusieurs de ces organismes. Ce point a été récemment exposé par Mgr Paul Bertoli, nonce apostolique à Paris, dans une communication à l'Académie Diplomatique Internationale (Le Monde diplomatique, décembre 1960, p. 17). Pas plus qu'avec la S.D.N., le Saint-Siège n'a établi de liens officiels avec l'O.N.U., mais il suit de plusieurs manières un grand nombre des activités de cette 
institution. De plus, il entretient des rapports, officiels cette fois, avec quelques agences spécialisées. C'est ainsi que son influence reste forte à l'Unesco, auprès de laquelle il dispose justement d'un observateur permanent (en fait un prélat italien, membre du Tribunal de la Signature Apostolique) ainsi que d'un Centre Catholique International (dirigé par un religieux français) : sans être membre de cette institution, il fait partie des pays officiellement invités aux conférences générales et il y envoie une délégation. Même au temps [p. 279] où l'U.R.S.S. n'était pas membre de l'Organisation, on aurait sans doute rencontré des difficultés pour y promouvoir une étude objective du birth-control.

Le Saint-Siège est également représenté par un diplomate accrédité auprès de la F.A.O.

Sont également absentes de notre étude des collectivités (groupes d'affaires, mouvements de libération nationale...) qui, n'ayant pas le statut consultatif, agissent pourtant et éventuellement avec éclat, dans les organisations techniques ou idéologiques selon les cas.

Lacunes quant aux modalités de cette voie d'accès. L'octroi du statut consultatif s'accommode de bien des démarches différentes de celles énoncées dans les directives. À lire ces textes, on en vient à penser que les hommes ayant des responsabilités dans les organismes internationaux ne seraient sensibles qu'à l'argumentation écrite ou orale. Conception déconcertante par sa candeur: toutes sortes de facteurs peuvent intervenir pour perturber cette vision idéale (jeu des relations personnelles, liens nationaux, volonté de rendre un service, contre-partie d'un avantage précédemment reçu, ignorance ou préconception doctrinale, etc.).

Il serait facile d'allonger la liste de ces déficiences, mais l'opération relèverait alors d'un principe masochisme. Aucun perfectionnement de nos connaissances n'est désormais concevable sans recherches monographiques à conduire séparément pour chaque organisation intergouvernementale. Encore serait-il sage, pour les plus grandes d'entre elles, de prévoir une décomposition dont il ressortirait, peut-être, que les mêmes mots n'ont pas un sens identique d'un Département à l'autre. Dans les universités européennes, les moyens financiers considérables nécessaires à la conduite de telles recherches ne semblent pas disponibles. Sommes-nous donc condamnés au silence ou à l'approximation?

[p. 280]

\section{INSTITUTIONS NATIONALES}

$\underline{\text { Retour à la table des matières }}$

C'est le niveau d'application le mieux connu, au moins pour les principes. L'intervention des groupes internationaux se situe dans la même perspective et emprunte les mêmes voies que celles des groupements intérieurs. La différence qui, en pratique, n'est pas toujours apparente, tient à l'origine externe de la poussée. 
L'opération a parfois comme objet de déterminer ou de modifier la position du pays dans une organisation intergouvernementale quelconque. Les délégués d'un mouvement d'émancipation nationale, ou les porte-parole d'une minorité visiteront ainsi les capitales en prévision d'un débat aux Nations Unies. Cette tentative a aussi pour mobile d'agir sur la politique du gouvernement considéré, dans ses rapports directs avec les autres États et dans ses attitudes à l'égard des questions internes. Ce serait une erreur que de limiter aux affaires diplomatiques ou de nature connexe, les pressions des groupes internationaux : ceux-ci ont été, et demeurent, des facteurs parfois essentiels de la décision intérieure.

À ce point de l'exposé, on rencontre des notions traditionnelles et très en honneur dans le langage de notre temps: l'intervention ou, comme on préfère le dire, l'ingérence dans les problèmes d'un pays au nom d'intérêts étrangers. C'est la voie classique de l'impérialisme au sens politique du terme qui, tantôt supprime ostensiblement l'autonomie des centres décisionnels considérés, et tantôt la laisse subsister en la vidant de son contenu. L'action des groupes de pression internationaux est l'un des facteurs qui définissent le niveau réel d'indépendance d'un pays quelconque. L'écart entre le type idéal de souveraineté et la marge de manœuvre disponible est souvent considérable a-t-il existé un État qui soit parvenu à l'annuler complètement?

Une objection viendra immédiatement à l'esprit du lecteur : dans cette œuvre d'érosion des souverainetés nationales, les groupes internationaux sont rarement seuls. Les États jouent volontiers à leur égard le rôle de partenaires effectifs, sinon d'inspirateurs autoritaires. Dès lors, on peut s'interroger sur la validité d'un raisonnement qui, analysant les pressions venues de l'extérieur, distingue comme deux catégories différentes les groupes internationaux d'une part, les États étrangers de l'autre. Cette séparation heurtera l'opinion qui veut que, dans [p. 281] les relations internationales, démarches gouvernementales et action des milieux privés soient, notamment sur le plan économique, deux aspects d'une seule entreprise.

Il arrive même aujourd'hui que l'effort d'amalgame embrasse jusqu'à des organisations intergouvernementales. Décrivant l'action des «monopoles des U.S.A. » à l'égard des pays latino-américains, on réunira dans une même vue globale des banques nord-américaines, le gouvernement de Washington et les institutions de Bretton-Woods. L'ossature de cette analyse est simple. Elle repose sur l'idée que pour obtenir l'aide du gouvernement américain, ces pays sont obligés d'accepter des mesures d'orthodoxie financière que les «monopoles » des États-Unis leur imposent par le truchement du Fonds Monétaire International ${ }^{1}$.

Le refus d'admettre une telle position que l'on justifiera dans le chapitre suivant, n'est pas fondé sur un naïf optimisme faisant de l'État un appareil neutre et impartial, uniquement au service de l'intérêt général. La conjonction des préoccupations publiques et des soucis privés est patente, nationalement et internationalement. Mais,

1 ALBERDI (Paulino Gonzales), "Amérique latine et monopoles U.S.A.", Nouvelle Revue Internationale, décembre 1959, pp. 44-56. 
à moins de passer de la discussion scientifique à la polémique, on n'a pas le droit de fixer à ce rapport un contenu unilatéral et, encore moins, de le déclarer invariable.

Il est arrivé que l'économique domine le politique: de patientes recherches historiques ont pourtant établi que, dans des cas importants, les groupes financiers ont servi de levier de manœuvre à des ambitions idéologiques, religieuses, culturelles, etc. Le sens de cette conjonction a varié selon les époques : il n'est pas permis de postuler son identité dans deux pays aussi proches et aussi irréductiblement lointains que la France et le Royaume-Uni.

Même si, professionnellement, l'on est habitué à constater de tels écarts, le décalage qui existe en cette matière, entre l'affin-nation dogmatique et les acquisitions de la recherche, demeure surprenant.

Il n'est donc pas inutile de définir, en les distinguant des interventions accomplies par les États étrangers, les démarches réalisées de l'extérieur sur les autorités nationales par les groupes privés internationaux. Plusieurs étapes sont en effet indispensables à une explication complète: dissocier le bloc complexe de phénomènes dont on prétend rendre compte, décomposer chaque pièce du système en ses divers éléments ; pousser le processus de fragmentation jusqu'à la découverte des facteurs élémentaires dont la combinaison et l'interaction portent la responsabilité [p. 282] du mécanisme global observé. Dans l'état présent, encore primitif, de l'analyse politique, les démarches propres des groupes peuvent passer pour un tel facteur qui devra lui-même être soumis à de nombreuses ventilations à mesure des progrès de la connaissance.

Voici maintenant quelques remarques permettant de situer ces contacts dans le complexe des relations d'où découlent les décisions gouvernementales.

\section{a) MOTIFS DU CHOIX DE CE NIVEAU}

\section{$\underline{\text { Retour à la table des matières }}$}

En une large mesure, l'«accès » aux organisations intergouvernementales s’analyse comme l'établissement de contacts avec des autorités nationales. Or on peut saisir un ministre ou un fonctionnaire national dans les Salons d'une assemblée intergouvernementale exactement de la même façon que dans les couloirs d'un Parlement: et cela pour des affaires concernant l'organisation, mais aussi pour n'importe quelle autre question (dans ce cas l'agence intergouvernementale ayant comme seul rôle de fournir un point géographique de rendez-vous). Des contacts ébauchés dans le bâtiment des Nations Unies peuvent se poursuivre à Paris ou viceversa. Tant que l'organisation internationale ne sera pas véritablement un gouvernement mondial, la distinction entre les deux niveaux d'application de la pression restera arbitraire et incertaine.

Cette rubrique couvre les interventions effectuées sur les autorités nationales comme telles en tous endroits, mais généralement au siège naturel de leurs activités 
(leur présence dans des capitales étrangères étant épisodique et leur participation aux assemblées intergouvernementales simplement périodique, tandis que le déplacement n'affecte dans les deux cas qu'une infime partie de l'appareil gouvernemental). Ce niveau d'application, s'il demeure imprécis quant à ses limites, constitue, comme l'atteste l'expérience quotidienne, une solide réalité. Quels motifs particuliers poussent les groupes internationaux à l'utiliser de préférence à un autre ?

Une première série de mobiles tient justement à l'absence d'une autre faculté : le recours à une organisation intergouvernementale se révélant soit matériellement impossible, soit en opposition avec les objectifs visés, soit encore disproportionné à la cause. De telles situations ne sont pas rares. Le souci de rassembler en un faisceau explicatif des éléments que les analyses courantes dispersent à plaisir conduit à inclure dans [p. 283] notre catégorie des groupements de nature et de philosophie dissemblables et jouissant comme tels de facultés différentes. Les groupes d'affaires, par exemple, ne disposent pas du statut consultatif sinon indirectement par l'intermédiaire d'organisations professionnelles obligées, au titre d'associations sans but lucratif, à une prudence apparente, et mal outillées pour défendre des revendications individuelles : or tous les trusts internationaux ne sont pas également aptes à se ménager un accès auprès des fonctionnaires internationaux.

Au surplus, en dépit d'un penchant à étendre leur sphère d'action (compatible, en plusieurs cas, avec une réelle inaptitude à examiner sérieusement les domaines revendiqués) les organisations intergouvernementales ne peuvent se permettre d'aborder l'ensemble des affaires. La réserve aux États d'un très large secteur de compétence intérieure représente, entre plusieurs autres, un facteur de blocage de telles initiatives. Évoquons encore le cas où la situation, loin de concerner la totalité de la communauté internationale n'intéresse qu'un tout petit nombre de ses membres et relève dès lors, sauf aggravation ou extension, de contacts directs.

À ces motifs de choix de l'échelon national, déjà nombreux mais simplement indicatifs d'un ensemble plus vaste, s'ajoute une raison originale qui est parfois décisive : la volonté d'une négociation secrète avec un État dans la conviction qu'en portant le débat sur la place publique on n'obtiendrait aucun avantage sérieux. Cette préoccupation du secret peut s'attacher à des activités de nature différente, « intéressée » ou « désintéressée ». Discutant avec un État, un trust pétrolier obtiendra probablement un traitement meilleur si la question ne donne pas lieu à conflit ouvert : car, dans ce cas, le souci de leur position morale conduirait les gouvernants à plus d'intransigeance. Mais on sait que cette tactique caractérise également l'action du C.I.C.R. Dans l'ensemble, le fonctionnement des organisations intergouvernementales est rarement conciliable avec la discrétion sans laquelle l'ajustement, par concessions réciproques, de prétentions rivales reste difficile.

Une deuxième série de situations, dont les mobiles sont parfois très proches de ceux qui viennent d'être évoqués, correspond à la volonté d'utiliser d'abord la voie nationale et de ne se présenter sur le plan international qu'en cas d'échec de la première tentative. Elle suppose que l'organisme concerné dispose bien de ces deux 
types d'« accès » et [p. 284] n'éprouve aucune réticence à les utiliser l'un et l'autre (ce qui n'est pas le cas du C.I.C.R. pour la partie la plus délicate de ses activités).

On peut en trouver de nombreux exemples dans la lutte engagée par la C.I.S.L. pour la protection et la promotion des territoires non autonomes. Ainsi dans le compte rendu que donne l'organisation de son activité en faveur des syndicalistes algériens, il est bien précisé que l'intervention sur les instances internationales a consacré l'échec des tentatives faites auprès du gouvernement français lui-même. Parfois l'essai de passage par la voie nationale n'est qu'un geste de propagande ou une manière de couverture soit que l'on sache parfaitement dès le début l'inutilité de la démarche, soit que l'on n'ait pas l'intention d'engager une réelle discussion. Cependant la volonté d'épuiser toutes les possibilités de négociation avant d'aller sur le forum est une méthode caractéristique de certaines forces (celles, en particulier, pour qui le temps n'est pas un facteur pressant, l’Église catholique par exemple).

Enfin, dans une troisième série de situations, le retour à l'action sur les autorités nationales fait suite à une intervention (acte isolé ou campagne articulée) auprès des instances internationales. Plusieurs circonstances peuvent expliquer un tel phénomène. Le succès sur le plan intergouvernemental d'abord: si le vote d'une convention (génocide, droits des femmes, etc.) a été acquis, il faut ensuite en obtenir la ratification par les États. Ce sera souvent le fait exclusif des organisations nationales intéressées, mais il n'est pas impossible que la force internationale n'apporte son appui, par des moyens divers, à l'œuvre entreprise. L'échec constitue aussi un facteur d'éventuelle reconversion : n'ayant pas réussi à se faire entendre ou à mobiliser un nombre suffisant d'appuis, le groupement décide de se limiter à des secteurs plus réduits dès lors qu'une chance de succès y paraît subsister.

Le problème se pose en des termes particuliers pour les mouvements d'émancipation coloniale qui trouvent un écho de plus en plus sensible auprès des organisations intergouvernementales. Pourtant, même s'il bénéficie d'un retentissement très large, le verdict de celles-ci n'est pas toujours suivi d'effets pratiques et, à un moment donné, le mouvement peut avoir intérêt à se présenter à nouveau devant l'État responsable. On doit alors tenir compte du surcroît de prestige et d'influence que vaut au groupement le soutien reçu sur le plan international. La manœuvre consistant à se renforcer du dehors pour affronter avec plus de chances l'inéluctable interlocuteur est une tactique éprouvée : l'utilisation en ce [p. 285] sens de l'organisation internationale lui apporte une modalité nouvelle. Le déroulement du conflit à propos de l'Algérie illustre parfaitement ce système d'action.

Le schéma que l'on vient d'établir a le défaut de toutes les tentatives de classification: il donne une vision statique d'un problème que, pourtant, l'on ne saurait comprendre sans une interprétation essentiellement dynamique. Dans la réalité d'une discussion concrète, et en particulier quand il s'agit d'un conflit, les deux niveaux d'application que l'on s'est efforcé de séparer peuvent rarement être isolés. La pratique nous révèle des cas nombreux d'utilisation simultanée et surtout elle met en lumière l'extrême fluidité des passages de l'un à l'autre. 


\section{b) CARACTÉRISTIQUES DE L'INTERVENTION}

$\underline{\text { Retour à la table des matières }}$

Il serait difficile d'en dresser un inventaire complet en raison de leur extrême variété. Ce peut être l'envoi d'un émissaire pour informer ou exposer une argumentation, ou encore, plus modestement, un simple télégramme de protestation. Il est également vrai que de grandes entreprises capitalistes ont cherché à contrôler complètement les gouvernements de pays faibles : finançant des partis politiques et soudoyant des personnages officiels, elles ont, à l'occasion, soutenu (ouvertement ou dans la coulisse) des révolutions préfabriquées. L'intervention de plusieurs entreprises américaines dans les affaires des petites républiques d'Amérique centrale est trop connue pour qu'il soit nécessaire d'insister : encore faut-il préciser qu'il ne s'agit pas là d'un cas isolé (l'utilisation de la « cavalerie de Saint-Georges », par exemple, n'ayant rien de mythique).

La fréquence, plus encore peut-être la nature, de ces démarches dépendent de multiples facteurs dont les trois principaux sont : la position et la puissance de la force de pression elle-même; la qualité et les capacités de résistance de l'interlocuteur; l'état des conceptions sur les rapports entre les pays (ce dernier point étant étroitement lié à l'influence de l'opinion). Ces trois éléments permettent de comprendre à la fois le contour des situations particulières et les lignes générales de l'évolution. Voici quelques observations rapides sur chacun d'entre eux.

$1^{\circ}$ En ce qui concerne la force de pression, la situation ne sera pas la même selon que le groupement international possède ou non dans le pays un relais capable de lui servir de porte-parole, d'outil de pénétra-[p. 286] tion, d'instrument de diffusion. Ce seront pour les O.N.G. les associations affiliées; pour les groupes d'affaires, les filiales, succursales ou correspondants ; pour les Églises centralisées, les hiérarchies nationales; pour les mouvements de libération, les bureaux de représentation ou les organismes de soutien (parfois d'une grande importance : Irlandais et juifs installés aux États-Unis à l'égard de l'indépendance de l'Irlande et de la protection d'Israël).

On ne connaît pas de formule capable d'exprimer en peu de mots la totalité des relations susceptibles de s'établir entre le centre moteur ou inspirateur et les éléments nationaux capables ou désireux de l'aider. Les exemples donnés dans les chapitres précédents montrent que les divers types de rapport concevables et existants vont d'une hiérarchie strictement réglementée à un appui moral toujours révocable. On a déjà noté qu'en plusieurs cas, il est difficile de dire si l'organe national agit pour son propre compte et sous sa propre inspiration ou se borne à appliquer des consignes et suggestions de l'extérieur.

Qu'elle soit directe ou indirecte, l'action du groupe international peut tendre à convaincre le (ou les) gouvernement intéresssé : elle peut aussi s'exercer dans un sens hostile en vue de ramener à résipiscence. 
Au premier type appartiennent, par exemple, les démarches du Dr N. Goldman, président du Congrès Juif Mondial auprès du chancelier Adenauer après la vague d'antisémitisme de décembre 1959. Selon le Congrès, le problème de l'antisémitisme, d'ampleur encore limitée, redeviendrait particulièrement grave en Allemagne si celleci retrouvait sa puissance militaire. Or il ne lui semble pas qu'un effort suffisant soit fait en Allemagne occidentale pour enseigner systématiquement à la jeunesse la tolérance religieuse et raciale et la coopération internationale. D'où plusieurs suggestions au gouvernement de Bonn qui, évidemment, relèvent directement de l'action gouvernementale : élimination de la vie politique, sociale et culturelle de ceux qui furent d'actifs nazis ; interdiction des organismes qui se livrent à des activités nazies ou sont suspectés de tendances favorables à cette idéologie; surveillance étroite des groupements de réfugiés étrangers antisémites; révision des pensions accordées aux anciens fonctionnaires et dirigeants nazis et à leurs ayant-droits ; vaste programme d'éducation visant à inculquer aux jeunes la connaissance des méfaits du régime hitlérien et à encourager la fidélité à l’idéal démocratique, etc.

[p. 287] C'est au fond tout un programme de gouvernement. Cet exemple, à vrai dire peu ordinaire, est une nouvelle illustration de la thèse qui insiste sur la liaison entre l'activité des groupes de pression internationaux et la politique intérieure. Encore les propositions du Congrès juif ont-elles été présentées au gouvernement Fédéral sur le ton de la négociation. Mais l'acuité des oppositions idéologiques, l'importance des facteurs d'incompréhension, la dispersion géographique et culturelle des membres affaiblissent souvent la force de persuasion des organisations internationales privées. On en vient donc assez rapidement aux mesures de rétorsion : rarement efficaces, elles sont souvent critiquables en matière de droit des gens.

Soit par exemple le boycottage qui constitue une méthode de pression sur les individus ou les États : dans le cadre national, c'est la décision prise par un individu ou un groupe d'individus de ne pas acheter à un commerçant ou de ne pas acquérir tel produit. Cet art d'empêcher un tiers de travailler, comme dit le Dictionnaire des sciences économiques, est utilisé au niveau interne à titre de représailles politiques contre un négociant ou une affaire. Sur le plan international, il équivaut à interrompre les relations commerciales avec un pays ou, plus précisément avec les nationaux d'un État étranger ${ }^{1}$. Ce peut être le fait d'un État (attitude des pays arabes contre Israël, et de divers pays, Malaisie et Ghana notamment, contre l'Afrique du Sud) ou d'un groupement privé (par exemple, syndicats de dockers qui refusent de décharger ou de charger des marchandises en provenance ou à destination d'un pays déterminé).

Les juristes ont l'habitude de distinguer le boycottage régulièrement décidé par un organisme international compétent, et les autres formes de boycott qu'elles soient le fait d'États ou de particuliers. Seule la première forme, «boycottage-sanction », leur paraît légale. Ajoutons que les groupements privés n'ont que rarement les moyens de réaliser un véritable boycottage durant une période de temps appréciable. Depuis la fin de la guerre, on a observé bien des exemples d'une telle faiblesse dans les résultats

1 Voir ROUSSEAU (Ch.), «Le boycottage dans les rapports internationaux », Revue Générale de Droit International Public, janvier-mars 1958, pp. 5-25. 
obtenus, si bien qu'en somme la portée de l'opération est surtout morale (mise en alerte de l'opinion publique). Les États ont, certes, plus de facilités et de possibilités ; mais leurs désaccords rendent le déclanchement de l'action difficile et sa poursuite aléatoire (destin des sanctions contre l'Italie fasciste). Il est inutile d'épiloguer sur le fait que les gouvernements de l'époque prêtèrent peu d'attention à la de-[p. 288] mande du Congrès juif Mondial, en septembre 1933, d'organiser le boycott moral et économique de l'Allemagne nazie.

L'utilisation de cette méthode par des groupes privés peut, dans certaines situations, créer un imbroglio politique. En voici un exemple récent. Pour lutter contre la tactique des « listes noires » arabes (frappant les bateaux ayant fait escale en Israël ou transporté des marchandises israéliennes) les dockers américains (Seafarers International Union et Longshoremen Association) décident de refuser tous services aux navires arabes, le premier vaisseau atteint par ces mesures étant la " Cléopâtre » (13 avril 1960). Les dockers d'autres pays, Suède notamment, se déclarant d'accord avec cette initiative, laissent supposer qu'ils vont aussi entrer dans la lutte. C'est l'esquisse d'un mouvement international de pression.

Cependant, dès le début, le Département d’État marque sa surprise et son désaccord : il fait savoir publiquement qu'il ne veut pas donner suite aux demandes des syndicats tendant à renforcer l'opposition au boycott arabe (interdiction aux navires américains d'acheter du pétrole dans des ports où fonctionne le système des listes noires ; interruption immédiate de la livraison de surplus agricoles aux pays établissant des discriminations à l'encontre de la marine américaine...).

Ces prises de position (accompagnées, semble-t-il, de l'envoi à diverses capitales arabes de messages que l'on veut « rassurants ») ne suffisent pas à apaiser les remous créés dans tout le Moyen-Orient par le geste des dockers américains dont il est difficile de dire si leur action fut pleinement autonome. Dénonçant l'opération comme « une partie d'un grand complot politique dont les buts se ramènent à faire cesser le blocus d'Israël » ${ }^{1}$, la Confédération Internationale des Syndicats Arabes proclame un contre-boycott visant les bateaux américains qui entre en vigueur le 29 avril. Dès le 6 mai, les dockers américains capitulent.

Certes, le Sénat des États-Unis votera, dans un moment de colère, une résolution d'inspiration anti-arabe : mais ce geste, qui s'explique largement par des raisons de politique intérieure, suscitera l'opposition de l'Administration, bien décidée à n'en tenir aucun compte. Finalement, les dockers américains auront procuré une victoire à bon compte au nationalisme arabe et placé la diplomatie des États-Unis dans une situation dont elle ne se tirera qu'avec peine.

Autre erreur tactique des groupes internationaux: la surestimation des moyens dont ils disposent. On l'a déjà suggérée à propos du Réar-[p. 289] mement Moral, et la même tendance se fait jour parfois chez des hommes d'affaires, entraînés pourtant à une exacte appréciation des possibilités. Lors de la nationalisation du Canal, la

Nouvelles du monde arabe (Genève), 25 mai 1960. 
Compagnie de Suez tenait en réserve une arme suprême : le retrait de ses pilotes. Un tel battage publicitaire avait été fait autour d'eux qu'on les tenait pour irremplaçables. Par un premier communiqué en date du 6 août 1956, la Compagnie les incitait à demeurer au travail, afin de ne pas gêner la conférence qui allait s'ouvrir à Londres. Mais la menace demeurait suspendue sur les autorités égyptiennes. Le résultat visé n'ayant pas été atteint, un nouveau message du 11 septembre proclamait l'achèvement de la «période de travail supplémentaire imposée par la Compagnie ». Les pilotes sont partis, mais le canal est resté ouvert ${ }^{1}$.

$2^{\circ}$ Les caractéristiques de l'intervention sont également commandées du moins en une large mesure, par la personnalité et le comportement habituel de l'interlocuteur. À moins de présenter ici une théorie complète des structures politiques et de leur évolution, on ne saurait prétendre à une vue authentique de ce problème. On tentera malgré tout d'en dégager quelques aspects caractéristiques.

Partons d'un facteur simple: le niveau d'honnêteté et donc de résistance à la corruption des gouvernants (hommes politiques et fonctionnaires). Des habitudes de vénalité facilitent sans doute la pénétration de l'appareil étatique par les groupes intéressés, (spécialement, quoique non exclusivement il s'en faut de beaucoup, les internationales d'affaires). Or, jusqu'à une époque récente, il n'y avait que fort peu d'États dégagés de cette tare: hommes politiques ou fonctionnaires, ou les deux, voyant dans le service public un moyen plus ou moins rapide d'enrichissement personnel.

Gardons-nous sur ce point de toute interprétation pharisienne. L'évolution historique révèle des transformations considérables en la matière : aux environs de 1800 , la vie publique britannique était très corrompue cependant que vers la fin du siècle des changements décisifs s'étaient produits dans les mœurs. C'est dire que, contrairement à des vues bien simplistes, il n'existe probablement pas de tendance innée à la malhonnêteté chez certains peuples. L'un des facteurs-clé de la situation est le paiement par l'État de traitements décents et réguliers et ses serviteurs : c'est une condition, mais aussi un résultat du développement social.

[p. 290] Un point essentiel dans l'ordre économique est l'attitude de l'État vis-à-vis des capitaux étrangers. Or, même dans les pays les plus faibles, les autorités cessent de témoigner à leur égard, comme ce fut souvent le cas dans le passé, d'une entière passivité. Dans les régions sous-développées, une tendance se manifeste pour réserver an secteur gouvernemental (et au minimum à des entreprises nationales privées) les investissements dans les services publics. On souhaite de plus en plus introduire, perfectionner et étendre un contrôle national des ressources naturelles locales:

\footnotetext{
Un fait mérite d'être signalé à propos de l'affaire de Suez. Il existe une Chambre Internationale de la Marine Marchande dont les membres possédaient ou contrôlaient plus de $80 \%$ du trafic à travers le canal. Elle est inscrite sur le Registre des Nations Unies : c'est-à-dire que le Secrétaire général a la faculté de la consulter. Or, si l'on en croit le rapport pour 1956-57 de la Chambre de la Marine Marchande du Royaume-Uni, il ne semble pas que l'O.N.U. ait eu l'idée de demander à la Chambre Internationale son avis sur le règlement du problème.
} 
raidissement des gouvernements envers les capitalistes étrangers qui affecte même les concessions existantes.

Quelques pays sont allés jusqu'à exclure complètement les capitaux extérieurs de certaines branches (pétrole par exemple). D'autres limitent ou interdisent l'acquisition de terres par les étrangers (prohibition générale ou limitée à certaines régions). Une manière plus subtile de s'attaquer au problème est de réglementer (et éventuellement d'exproprier) les terres qui ne sont pas exploitées « directement » : encore qu'une telle disposition ne vise pas en apparence la propriété étrangère, on a tenté, en divers États d'Amérique centrale, de l'utiliser à son encontre (cas de la United Fruit Company).

De façon plus générale, l'action des groupes de pression internationaux dans un pays dépend de la philosophie dominante des rapports sociaux, éventuellement imposée d'en haut, qui y a cours. Le cas de l'Égypte mériterait ici un assez long examen, car il est assez caractéristique des positions que veulent prendre beaucoup de gouvernants, spécialement dans les nouveaux États, vis-à-vis des idéologies extérieures et des intérêts étrangers ${ }^{1}$. Encore que la politique de ce pays soit affectée de traits propres à l'Islam (en particulier, le sentiment très net chez le musulman de la supériorité de sa culture), elle comporte des éléments (position également négative envers les grands systèmes qui veulent se partager le monde) qui lui donnent une large audience dans les pays du tiers-monde. Elle s'appuie aussi sur une certaine xénophobie qui, le temps aidant, ira peut-être en s'atténuant.

Cependant, au-delà de manifestations spectaculaires qu'inspire encore le souvenir d'un très récent passé, il faut voir l'essentiel qui est la volonté d'apporter aux problèmes nationaux des solutions, morales et matérielles, proprement nationales. On aurait tort d'en déduire que l'ère des groupes de pression internationaux s'achève, car, selon un processus éternel, il peut justement résulter de cet état d'esprit la pro-[p. 291] pension à étendre ailleurs la nouvelle philosophie et donc à créer des instruments de diffusion adéquats. Mais les conditions de travail des groupes en sont transformées.

De telles dispositions s'observent aussi dans les pays développés à l'égard de la pénétration étrangère, économique ou idéologique. Citons, à titre d'exemple, les décisions prises en Suède contre le financement par des éléments étrangers de la propagande politique nationale. Bien que ne comportant aucune référence à un mouvement particulier, cette législation vise en réalité le parti communiste. Le Code pénal suédois punit d'une peine de prison ou de travaux forcés, pouvant aller jusqu'à deux ans, l'acceptation d'une aide financière étrangère destinée à influencer l'opinion publique quand il s'agit de problèmes se rapportant à la Constitution ou à la situation intérieure et extérieure. Une loi du 6 mars 1952 accorde à la police en certaines matières (présomption d'espionnage) le droit de saisir la correspondance et de

1 Sur ces questions, AUSTRUY (Jacques), Structure économique et civilisation. L'Égypte et le destin économique de l'Islam, Paris, 1960 (spécialement chap. III de la $\mathrm{II}^{\mathrm{e}}$ partie sur la politique économique du colonel Nasser). 
surveiller les conversations téléphoniques ${ }^{1}$. Inutile de souligner que des législations beaucoup plus restrictives existent également dans de multiples États.

$3^{\circ}$ On mentionnera un dernier point qui se rattache à des développements ultérieurs. Dans leurs rapports avec les différents États et spécialement les petits, les groupes de pression internationaux se heurtent à des règles non écrites capables de limiter leur pénétration et, surtout, de restreindre la gamme des procédés d'intervention, Quiconque néglige ces barrières risque de sérieux inconvénients. Écoutons A. Berle qui analyse l'intervention des firmes américaines dans les affaires intérieures de pays étrangers. "Depuis près de trente ans, chaque société américaine sait que participer à des évènements politiques de cette sorte ne rapporte aucun avantage, est forcément dangereux et équivaut à long terme à un suicide ${ }^{2}{ }^{2}$. C'est une vue probablement irénique dans son effort de généralisation, mais la tendance n'apparaît pas contestable.

On ne saurait à cet égard parler d'un " code de conduite ", sinon en un sens très souple. Une marge d'appréciation existe (d'où la formation d'une sorte de « service diplomatique » au sein des grandes affaires). Au surplus, ces tendances ne sont pas nées spontanément, d'une purification morale des intéressés par exemple : elles sont le résultat chèrement payé de multiples expériences. Aujourd'hui les groupes de pression internationaux agissent avec prudence : habileté et discussion, spécialement dans les rapports avec les petits pays, sont les mots d'ordre courants.

[p. 292] Il n'en a pas été toujours ainsi. Encore qu'on ait eu propension à en exagérer la noirceur (et plus encore peut-être la rigueur logique), le comportement des trusts pétroliers internationaux reste particulièrement intéressant à évoquer pour notre propos. La lutte entre les intérêts britanniques et américains au Mexique illustre, presque jusqu'à la caricature, la pénétration d'intérêts étrangers dans la vie politique d'un pays. Selon des dépositions officielles devant le Congrès américain, le combat ainsi livré devait à un moment devenir si aigu que le gouvernement des États-Unis consentit à ce que les compagnies pétrolières américaines opérant au Mexique paient simultanément des mensualités à des gouvernements établis, des insurgés, et des bandits (car, sinon, ces derniers coupaient les pipe-lines). Mais l'affaire devait se terminer en 1938 par l'attribution à l'État mexicain du monopole de l'extraction, du raffinage et de la distribution $!^{3}$

\footnotetext{
Selon R. FUSILLIER, «Les finances des partis politiques D, Revue politique et Parlementaire, octobre 1953.

Op cit., p. 105.

L'ouvrage de Pierre LESPAGNOL de LA TRAMERYE, La lutte mondiale pour le pétrole, $2^{\mathrm{e}}$ édition, Paris, 1922, reste intéressant à consulter, spécialement pour mesurer le chemin parcouru. Moins ancien (Paris, 1933), le livre d'A. ZISCHA, La guerre secrète pour le pétrole, ne dépasse guère le plan de la narration journalistique. L'ouvrage de Harvey O'CONNOR, L'empire du pétrole, Paris, 1958 (qui traite surtout de la politique du cartel) se réfère souvent au sujet évoqué ici (spécialement $\mathrm{VI}^{\mathrm{e}}$ partie, "L'industrie pétrolière américaine à l'étranger "): mais c'est essentiellement un travail de polémiste à vues unilatérales, et pas toujours attentif à la vérification des sources. Sur le Moyen-Orient, bonne présentation générale (déjà un peu ancienne) in
} 
Depuis la fin de la seconde guerre mondiale, la politique pétrolière internationale est devenue, par la force des choses, beaucoup plus voilée et subtile. L'attitude prise à l'égard de M. Bétancourt dont les revendications ont coûté cher aux sociétés, illustre bien cette nouvelle ligne de conduite : pas d'opposition ouverte, et, probablement, un réel souci d'éviter toute implication dans des complots; puis une pression, aussi discrète que possible, pour obtenir une modification des dispositions prises à fin 1958 (et l'on suggère l'adoption de correctifs techniques, par exemple, dans le calcul des amortissements, qui auraient chance de passer inaperçus); enfin, maintien en exploitation, sans aucune réserve, des puits ouverts mais, peut-être, tendance à quelque ralentissement des nouveaux forages et surtout des recherches (mouvement accompagné du transfert d'appareils de sondage en d'autres pays, provisoirement plus compréhensifs).

Au total, la pression subsiste, mais elle a changé de forme. L'opinion publique constitue, spécialement dans ce cas, un facteur important : il est nécessaire de lui consacrer quelques développements.

Il ne serait pas difficile de trouver des exemples analogues en bien d'autres pays d’Amérique Latine (Cuba, Guatemala, Venezuela, etc.).

[p. 293]

\section{OPINION PUBLIQUE}

$\underline{\text { Retour à la table des matières }}$

À une époque où l'image de l'« ingénieur des âmes » devient familière, on ne saurait s'étonner de la valeur attribuée par les groupes de pression, nationaux et internationaux, aux phénomènes de l'opinion publique. Psychologie et psychologues d'ailleurs, par le biais de la recherche motivationnelle, se mettent au service de la réclame qui d'ailleurs n'est et n'a jamais été confinée dans le seul domaine commercial $^{1}$. Il est vrai que les groupes ne s'appuyant pas sur une branche de production ou un ensemble de puissantes entreprises, disposent rarement (communistes exceptés) des ressources financières considérables exigées par de telles interventions.

LONGRIGG (S.H.), Oil in the Middle East, Londres, 1954, et SHWADRAN (Benjamin), The Middle East, Oil and the Great Powers, New York, 1955. Pour une présentation récente, consulter LENCZOWSKI (George), Oil and State in the Middle East, Londres, 1960 (étudie spécialement les relations entre les Compagnies pétrolières et les États dans cette région). Voir aussi LONGHURST (Henry), Adventure in Oil. The Story of British Petroleum, Londres, 1959, ainsi que HEWINS (Ralph), Mr Five per Cent, Londres, 1957, (histoire de C.S. Gulbenkian). Voir aussi l'importante étude de TEILHAC (Ernest), "Le pétrole dans l'économie du Moyen Orient », Économie Appliquée, octobre-décembre 1954, pp. 399-489.

On aura une bonne idée de cette extension en lisant ROSS (Irwin), The Image Merchants. The fabulous world of American public relations, Londres, 1959. 
L'action des groupes sur l'opinion se décompose en opérations de portée très variable. Parfois il s'agira seulement d'influencer la conduite d'un pays donné à propos d'un problème particulier. Dans d'autres cas, on envisagera ou on mettra en œuvre, une vaste campagne tendant à la promotion d'une "cause » à l'échelle mondiale. Un seul facteur est commun à toutes ces démarches: la volonté d'influencer le (ou les) gouvernement à travers l'opinion, en utilisant cette dernière comme un levier qui facilite aux intéressés l'attaque ou la défense.

Le but est toujours de rassembler les fidèles, de mobiliser les sympathisants, de convaincre et d'attirer les indifférents, de neutraliser les adversaires déclarés. Le calcul repose sur l'idée, juste en définitive, qu'aucun gouvernement, si autoritaire soitil, ne peut mépriser complètement les réactions de l'opinion et qu'en tout cas la propre propagande de ce gouvernement perd singulièrement de son efficacité dès que des voix dissidentes parviennent à se faire entendre ou, plus exactement, écouter.

Cette entreprise est plus ou moins facile à réaliser tant du fait des obstacles élevés par l'action gouvernementale (par exemple «brouillage des émissions ») qu'en raison des attitudes manifestées par les destinataires eux-mêmes. Dans certains cas privilégiés, l'appui d'un secteur de l'opinion publique sera spontanément acquis à un mouvement en raison de traditions morales ou de convergences idéologiques : il en va souvent ainsi à propos du sort des minorités ou des soulèvements nationaux. Mais d'autres fois, le soutien ou la neutralisation espérés ne sont obtenus qu'au prix d'une véritable campagne, souvent coûteuse et presque toujours aléatoire.

[p. 294] L'analyse du rôle de l'opinion dans la formation de la politique intérieure et extérieure est encore très insuffisante : en France, par exemple, le nombre d'études scientifiques consacrées à ce thème reste très réduit spécialement en matière de politique internationale ${ }^{1}$. Les clichés abondent. Au niveau international, la

Voir les études rassemblées dans la $3^{\mathrm{e}}$ section du volume déjà cité, La politique étrangère et ses fondements ; l'article de J.B. DUROSELLE, «L'opinion publique et la politique étrangère », dans le volume collectif Les affaires étrangères, Paris, 1959, pp. 212-234 ; l'étude de R. PELLOUX, "Les interférences de la politique intérieure et de la politique extérieure dans l'opinion française depuis 1919 », dans l'ouvrage collectif L'opinion publique, Paris, 1957, pp. 305-315 ; l'article de G. GORIÉLY, "L'opinion publique et le plan Schuman », Revue Française de Science Politique, juillet-septembre 1953, pp. 585-611. On signalera aussi dans l'ouvrage de BORELLA (François), L'évolution politique et juridique de l'Union française depuis 1946, Paris, 1958, les chapitres sur l'influence de l'opinion publique française et internationale (pp. 63-137). Pour la Grande-Bretagne on mentionnera deux thèses de l'Institut Universitaire de Hautes Études Internationales, TUCKER (William R.), The Attitude of the British Labour Party towards European and Collective Security Problems, 1920-1939, Genève, 1950, et NAGLE (Thomas W.), A Study of British Public Opinion and the European Appeasement Policy, 1933-39, Wiesbaden, 1957. Pour la Suisse, la seule étude disponible est une leçon donnée par Maurice BATELLI à l'Université de Nancy sous le titre L'opinion publique et la politique internationale en Suisse (texte ronéoté). Selon lui, l'accession à la Société des Nations fut le problème ayant le plus passionné l'opinion. Mais d'autres aussi mériteraient une analyse approfondie (ratification de la Convention du Gothard, affaires des zones franches...). Rappel de l'ouvrage publié sous la direction de Roy MACRIDIS, Foreign Policy in World Politics, où le problème du rôle de l'opinion publique est posé pays par pays. Pour une approche historique, voir DESCHAMPS (Henry-Thierry), La Belgique devant la France de juillet. 
connaissance du phénomène est presque inexistante : on ne saurait donc exprimer ici que des observations de portée très limitée et encore le fera-t-on avec la plus extrême réserve ${ }^{1}$. Dans le domaine que nous abordons, États et forces privées interviennent simultanément parfois pour s'épauler, parfois pour se combattre. Conformément à l'idée qui anime cet ouvrage, c'est essentiellement aux activités des secondes que seront consacrées ces pages.

\section{a) ASPECTS ET NATURE DE L'OPINION MONDIALE}

\section{$\underline{\text { Retour à la table des matières }}$}

Y a-t-il une opinion mondiale ? La question n'a de sens pour l'étude scientifique que si elle met en cause un concept sociologiquement maniable. Voici une manière de la poser : peut-on trouver et mesurer, à propos d'un problème ou d'un ensemble de problèmes déterminés, un public dont la composition s'étende à un groupe plus ou moins vaste de nations, un continent ou le monde tout entier ? Bien entendu, l'existence d'un public ne postule pas nécessairement l'unité de vue : connaître l'opinion publique, c'est en particulier déterminer la force respective des divers courants qui la composent. Pour qu'il y ait "public », il est indispensable que les sujets se réfèrent au même cas et le posent, approximativement au moins, dans les mêmes termes. Diversité des solutions et des points de vue certes, mais d'abord manifestation d'un minimum de concordance sur la constatation et la formulation du problème : sans cette convergence de base, l'opinion ne saurait se former.

Une telle situation existe certainement dans les milieux scientifiquement ou techniquement spécialisés (professeurs d'astrophysique ou champions d'échecs) pour les questions qui relèvent de leur pratique quotidienne. Mais le même phénomène s'observe-t-il au niveau des problèmes politiques généraux ? L'appel à la « conscience universelle » représente-t-il autre chose qu'une formule littéraire, très usée en définitive, ou une habileté tactique qui a d'ailleurs trop servi pour conserver son mordant?

La manipulation de ces concepts par des politiciens habiles produit inévitablement chez l'observateur un agacement qui pourrait conduire à [p. 295] contester la réalité même du phénomène. Ce recours à l'« opinion mondiale » vient trop à propos dans de nombreux discours pour ne pas susciter la méfiance. On en dira autant des représentations souvent mythiques que l'on classe sous la rubrique «amitié des

L'opinion et l'attitude française de 1839 à 1948, Paris, 1956, et CASE (Lyon M.), French Opinion on War and Diplomacy during the Second Empire, Philadelphie, 1954.

Pour les références nécessaires à une étude approfondie on ne peut que renvoyer à SMITH (B.L.), et SMITH (Chitra M.), International Communication and Political Opinion. A guide to literature, Princeton, 1956. La thèse de J.L. MARTIN signalée sous le $n^{\circ} 144$ de cette bibliographie a depuis été publiée en volume International Propaganda. Its legal and diplomatic control, Minneapolis, 1958. 
peuples ». Ce sont des formules utilisées à tout instant (par exemple l'« entente cordiale ») sans que l'on songe jamais à vérifier objectivement ce qu'elles signifient pour les citoyens des pays considérés. Les unes trouvent un fondement dans des combats ou des souffrances partagés. D'autres ne sont que des déclarations creuses ou littéraires (ainsi la « latinité » : l'Italie « sœur latine » et autres approximations). On ne saurait dès lors aborder ce sujet sans établir une distinction entre l'état réel de l'opinion et le contenu qu'on lui prête arbitrairement pour défendre une thèse ou appuyer une position idéologique.

Ce phénomène de l'opinion mondiale, bien des attitudes de notre temps le postulent comme une indiscutable réalité. Le Conseil Mondial de la Paix, par exemple, s'y réfère quand il déclare avoir reçu dans ses campagnes plus de 500 millions de signatures (656 millions en 1955 pour l'appel de Vienne contre la préparation de la guerre atomique). M. Eisenhower l'admet aussi dans l'ordre des intentions quand il propose (juillet 1960) d'organiser un référendum mondial sous le contrôle des Nations Unies et sur le thème : régime communiste ou système de liberté tel qu'on le trouve aux États-Unis (idée que M. Gomulka, bon tacticien communiste, proposera de transformer en un plébiscite mondial sur « le désarmement »).

Plus modestement, quoique non sans prendre position avec clarté, le tome XI de l'Encyclopédie française, La vie internationale, consacre un chapitre à la « formation de l'opinion mondiale ». Mais justement, une déception guette le lecteur : on lui fournit de belles images assorties de légendes que, selon l'humeur, il trouvera touchantes ou ridicules («Déjà les mêmes jeux rassemblent les hommes,... les mêmes images nourrissent leurs rêves,... les mêmes voix les excitent ou les rassurent au fond du désert et au cœur des forêts... »). Cependant, de l'opinion mondiale on ne parle pas ou presque : le texte traite en réalité de la formation des opinions nationales (française surtout) et c'est bien différent. Cette lacune tient-elle au choix des auteurs ou à l'inexistence du sujet?

Quiconque a eu la charge de diriger une classe de relations internationales dans une Université groupant des élèves venus des diverses parties du monde sera probablement tenté de pencher pour le second [p. 296] terme de l'alternative. Dès que l'on entend sortir des plus banales généralités pour aborder les vraies questions qui se posent dans chaque partie du monde, on note sans peine, chez la plupart, ignorance et indifférence à ce qui ne concerne pas sa province. On s'aperçoit alors du vide complet de certains thèmes à succès, disons de «slogans » popularisés par les organisations internationales: le monde uni, plus exactement le monde un... ou encore la complémentarité de l'Occident et de l'Orient. On saisit mieux le caractère utopique des projets somptueusement financés, en général, sur le développement culturel de l'humanité.

Pour qui intervient sur le terrain même, le problème reste de conduire les intéressés à surmonter un provincialisme tenace, de les amener à considérer leur sort respectif (profondément, sincèrement, et non pour obtenir une place d'expert de l'assistance technique). Il est, au total, difficile de dépasser le stade de la seule entente sur les mots, sinon sur les mythes : les accords de ce type étant simples à obtenir, car 
chacun interprète les concepts en cause et en tire des implications, selon son propre souhait.

Si l'on passe des bancs de l'Université au plan du citoyen, les enquêtes d'opinion publique, quand on a pris la peine d'en faire sérieusement, révèlent, selon le mot d'un auteur américain, de «sombres zones d'ignorance " ${ }^{1}$. S'agissant de problèmes de politique étrangère vitaux pour l'avenir du pays, on s'aperçoit que les sujets, dans une proportion variant entre un et deux tiers selon le cas, en ignorent les données les plus élémentaires. Au fur et à mesure que la question s'éloigne du centre d'intérêt national, le "public » fléchit pour ne plus représenter finalement qu'une minorité des plus réduites. On serait tenté de dire que l'opinion publique existe mais traduit seulement la rencontre de milieux restreints (certains les définissant alors comme des couches « élitaires »). Une telle position est-elle nécessairement en contradiction avec les statistiques du Conseil de la Paix et le messianisme de M. Eisenhower ? Ce n'est pas sûr.

Les phénomènes auxquels on se réfère en général pour établir la réalité d'une opinion mondiale correspondent davantage à des attitudes collectives touchant des problèmes généraux qu'à des opinions portant sur des faits précis et limités, raisonnablement étayés et vérifiés. Ces attitudes sont, au fond, très proches de l'idéologie : la dégradation qui atteint toute idée ou système d'idées, dont l'aire de diffusion s'élargit, [297] est ici particulièrement forte. Encore que le terme manque par trop de précision, c'est peut-être d'« aspirations » qu'il conviendrait de parler à cette occasion. Aspirations relatives aux valeurs suprêmes de l'humanité : paix, fraternité, bien-être... et par conséquent refus, plus ou moins cohérent et violent, de tous les facteurs capables de retarder ou d'empêcher la satisfaction de ces valeurs, ou du moins des facteurs jugés tels (exploitation économique, colonialisme et discrimination raciale, sans oublier, pour une bonne partie de l'humanité, la présence du monde occidental).

Il arrive que ces sentiments diffus se cristallisent brusquement sur une question déterminée, engendrant alors un puissant mouvement de protestation que l'on observe effectivement d'un bout à l'autre de la terre : l'affaire de Suez semble avoir provoqué une coalition de ce type, d'autant plus puissante qu'elle était le résultat d'un élan spontané des esprits. On n'aurait probablement trouvé dans le monde entier que fort peu d'auditoires susceptibles d'approuver l'action anglo-française. Le point de cristallisation disparu, les tendances ayant engendré la lame de fonds retrouvent leur état diffus et inorganisé : elles demeurent prêtes à une nouvelle flambée de révolte si la conjoncture vient à la justifier.

Même sur cette base, l'opinion mondiale n'est pas l'humanité tout entière. Beaucoup parmi les hommes vivent encore dans un état d'isolement moral et de

KRIESBERG (Martin) in Public Opinion and Foreign Policy, New York, 1949 (ouvrage collectif publié par le Council on Foreign Relations), pp. 49-64. Une évaluation de l'exemple français contemporain doit partir du numéro spécial de Sondages (1958, n 1-2), « La politique étrangère de la France et l'opinion publique, 1954-1957 ». 
décrépitude physique qui les tiennent à l'écart de tels courants : la réflexion sur le destin collectif de l'homme, plus modestement la prise de conscience de l'appartenance à l'univers humain, exigent un niveau minimum de santé et de culture dont une fraction considérable du monde reste privée. Combien de pays (par exemple en Amérique latine) dans lesquels, pour un grand nombre, parfois, la majorité, l'intégration à la vie sociale n'est pas faite. Cependant, les grands thèmes que l'on vient d'évoquer ont déjà un large public — beaucoup plus large que celui qui se détermine à partir de la connaissance des phénomènes particuliers. Voici quelques exemples de ces prises de position.

La crainte des radiations provenant du développement de l'énergie atomique constitue certainement l'une d'entre elles. Cette peur assure une audience considérable aux discussions tendant à l'arrêt des essais. Il est probable que l'on n'a pas encore évalué à leur juste mesure les conséquences de la bombe atomique et de la menace d'une guerre nucléaire sur l'esprit humain. Il en résulte que, même si l'on parvenait à [p. 298] réserver son utilisation à des œuvres de paix, l'emploi de l'énergie atomique soulèverait, au moins durant une période, des préoccupations sérieuses pour l'équilibre spirituel et moral du monde. Ce danger a conduit l'Organisation Mondiale de la Santé à convoquer un groupe international d'experts pour étudier les « questions de santé mentale que pose l'usage de l'énergie atomique à des fins pacifiques »; le rapport issu de ces travaux décrit longuement les « réactions affectives pathologiques résultant directement de l'avènement de l'énergie atomique ${ }^{1}$.

Cette menace a été assez fortement ressentie aux États-Unis pour conduire le Président à créer un Fédéral Radiation Council composé du président de la Commission de l'Énergie Atomique, du secrétaire d'État à la Défense, du secrétaire d’État au Commerce et du secrétaire d’État à la Santé Publique. Ce conseil, dont la nature politique a fait l'objet de vives critiques, est chargé de préparer les règlements qui assureront la protection du public contre les effets biologiques nocifs des radiations et, en particulier, contre les conséquences de la radio-activité sur l'eau et les aliments. Le cas du poisson, par exemple, a suscité de vives inquiétudes à la suite d'une proposition de l'Académie des Sciences tendant à effectuer l'immersion sousmarine des déchets radioactifs plus près des côtes que par le passé.

Mais l'Amérique n'a pas le monopole de telles appréhensions qui ont aujourd'hui, il est permis de le dire, gagné le monde entier et, en particulier, la Grande-Bretagne. Lors du dernier Congrès du Parti Travailliste (Scarborough, octobre 1960), il s'est trouvé une majorité, très faible il est vrai, pour réclamer la renonciation unilatérale à l'arme atomique. Rappelons qu'il existe dans ce pays un organisme dit « Campagne, pour le désarmement nucléaire » dont certains membres envisagent d'exécuter, par

Rapport publié à Genève par l'O.M.S. en 1958 sous le $n^{\circ} 151$. Sur les problèmes de la bombe voir McALLISTER (G.) ed., The Bomb Challenge and Answer. Londres, 1955 (aboutit à un plaidoyer pour le gouvernement mondial). Comme ouvrage d'ensemble BLOERKLUND (Admiral Elis), International Atomic Policy During a Decade. An historical political investigation onto problems of atomic weapons during the period 1945-1955, Londres, 1956. 
des moyens non violents, un programme de désobéissance civile contre l'armement atomique.

Cette prise de conscience résulte, certes, de l'immensité du péril et du caractère apocalyptique des destructions dues aux deux premiers envois de bombe sur le Japon. Elle a été évidemment renforcée par une puissante action protestataire dans laquelle des groupes internationaux ont joué un rôle primordial : spécialement, mais non exclusivement, Conseil Mondial de la Paix, Fédération Mondiale des Travailleurs Scientifiques, F.S.M. En plusieurs pays, les techniciens sont entrés dans l'arène en publiant des manifestes susceptibles d'émouvoir le public ${ }^{1}$. Au moins dans les États occidentaux, divers savants ont refusé, pour des rai-[p. 299] sons idéologiques et morales, de collaborer à l'exécution des programmes militaires gouvernementaux.

L'explosion française au Sahara a constitué l'un de ces points de cristallisation précédemment signalés. Sans doute beaucoup des protestations émises ou des réserves effectuées avaient-elles un fondement purement politique. D'autres, par contre, reposaient sur la crainte que ces essais ne viennent remettre en question la trêve péniblement maintenue grâce à la Conférence de Genève et ne contribuent à déclencher, par une réaction en chaîne, des actes défavorables à la paix comme à la santé du monde. Cependant, l'ampleur du mouvement protestataire n'a pas dissuadé le Président de la République de réaliser une seconde explosion.

On voudrait mentionner un deuxième phénomène qui constitue un point de ralliement de vaste audience: l'anti-américanisme. À des degrés divers, on le rencontre dans de nombreux pays géographiquement et culturellement éloignés les uns des autres : chez les alliés des États-Unis comme chez leurs adversaires, dans les pays développés et sous-développés, en Asie et en Amérique latine... En plusieurs milieux européens, ce sentiment est pour ainsi dire devenu une manière de conformisme (qui, le cas échéant, n'empêche pas d'encaisser des subsides venus des fondations américaines ou d'accepter les invitations du Département d'État à visiter le pays). On a même vu des écrivains proclamer à la fois leur amitié pour les États-Unis et la nécessité d'établir un barrage à l'américanisme ${ }^{2}$.

Cette attitude n'est pas sans rapport avec la volonté de neutralisme affichée aujourd'hui par tant de pays sous-développés. Position surprenante si l'on considère que les États-Unis furent les premiers après la guerre, spécialement dans le cadre de l'O.N.U., à proclamer l'urgence d'une promotion du tiers-monde par le moyen d'une aide massive ${ }^{3}$ et si l'on ne méconnaît pas l'appui, ouvert ou discret, apporté à tant de mouvements de lutte anticolonialiste. Apparemment, tout cela est bien oublié et la violence des manifestations d'hostilité à l'égard de leur politique a conduit les Américains à en rechercher les causes: le Département d'État, par exemple, a consulté plusieurs spécialistes sur les motifs de l'antagonisme exprimé par de

\footnotetext{
Voir l'ensemble des données fournies in («Explosions nucléaires et retombées radioactives », Recherches Internationales à la Lumière du Marxisme, n 16, novembre-décembre 1959.

Par exemple ARNAVON (C.), L'américanisme et nous, Paris, 1958.

Voir FAUVEL (LUC), « L'O.N.U. et les pays insuffisamment développés », Annales Africaines.
} 
nombreux milieux latino-américains et, fait exceptionnel, il a publié le résultat de ses études ${ }^{1}$.

On n'entreprendra pas de rechercher ici les causes de la situation qui paraît inquiéter les hommes d'affaires américains eux-mêmes ${ }^{2}$. Elle est, [p. 300] dans une large mesure, le résultat d'une action de longue haleine du communisme international, mais cette propagande n'est pas l'unique facteur du mouvement observé. On voudrait, dans l'optique de cet ouvrage, esquisser certaines des conséquences qui en découlent et pèsent actuellement sur la politique mondiale.

D'abord une sous-estimation globale de l'aide américaine (et plus généralement de l'aide occidentale) ; non seulement les motifs en sont suspectés, mais l'ampleur même en est systématiquement contestée. Il est vrai que les transferts de capitaux n'ont pas atteint les montants suggérés par les experts ; cependant, même si l'on effectue une ventilation pour mettre à part l'aide militaire, on constate que le concours total du monde occidental est encore très supérieur à celui du monde communiste. Les ÉtatsUnis sont pourtant mal placés dans la compétition : si les mouvements de capitaux sont trop faibles, eu égard aux besoins, on accusera leur égoïsme; s'ils se développaient sur une très large échelle, le schéma léniniste de l'impérialisme financier ferait rapidement l'objet d'utilisations supplémentaires ${ }^{3}$.

1 WASHINGTON (S. Walter), A study of the Causes of Hostility toward the United States in Latin America... Washington, Department of State, 1956, 2 vol. Plusieurs spécialistes réputés (LIPPMANN, KENNAN...) ont effectué des analyses sévères, véritables examens de conscience de l'action américaine à l'extérieur. Voir également SULZBERGER (C.L.), What's Wrong with U.S. Foreign Policy, New York, 1959 (l'ouvrage étant, curieusement, muet sur l'Amérique latine). Sur ce sujet, consulter une intéressante chronique bibliographique « Autocritique américaine dans les rapports extérieurs ", in Développement et Civilisation, juin 1950, pp. 72-82. Voir aussi CLEVELAND (Harlan), MANGONE (Gerald J.), ADAMS (John Clarke), The Overseas Americans, Syracuse (N.Y.), 1960. Selon les auteurs le principal facteur d'incompréhension ne serait pas l'obstacle linguistique mais le "choc culturel " (anxiété des Américains envoyés à l'extérieur en ne retrouvant pas, ailleurs, les symboles et les traits de leur vie sociale courante : d'où, en conséquence, attitudes de raideur et de chauvinisme excessif).

2 Voir en particulier, la brochure Public Opinion. Achilles heel of U.S. business overseas ? due au vice-président d'une importante affaire de «relations publiques» (Hill and Knowlton International). Qualifiant cette tendance de «castroism», l'auteur la déclare beaucoup plus répandue qu'on ne l'envisage communément. Soulignant qu'on l'observe même au Canada, il esquisse un programme d'action sur l'opinion qui devrait permettre de la combattre. Il apparaît toutefois douteux que les 58\% des Français et les 49\% d'Allemands de l'Ouest - qui selon l'auteur sont défavorables à l'installation d'usines américaines dans leur pays - se laissent séduire par un programme, si élaboré soit-il, de « relations publiques ». Comme indice de cette tendance, voir les remous qu'a suscités en Grande-Bretagne l'offre d'achat par la société Ford de la fraction du capital de sa filiale anglaise qu'elle ne détenait pas encore (opération finalement autorisée par la Trésorerie). L'émotion soulevée par cette affaire est d'autant plus inattendue que le prix proposé était très généreux et que de toute façon, la Ford américaine détenait déjà un contrôle majoritaire (54,6\%) de la Ford anglaise.

3 Deux rapports récents (juillet-août 1960), du Département d'État s'efforcent de présenter des «mises au point » sur le problème de l'aide extérieure : Economic Assistance as a Cooperative Effort of the Free World et Communist Economic Policy in the Less Developed Areas. Il est douteux que la démonstration renverse le courant. L'aide soviétique possède d'ailleurs, 
En second lieu, une sous-estimation globale de la puissance américaine. Le lancement d'engins spatiaux constituait évidemment le type d'événement capable de créer une opinion mondiale : le résultat a probablement dépassé les évaluations les plus vastes faites à l'Occident ${ }^{1}$. Cette dévalorisation du facteur américain, tant militaire qu'économique, correspond, pour la période présente, à une erreur de calcul considérable, fondamentale même; cependant, elle possède, comme thème de propagande, un remarquable pouvoir de persuasion.

En publiant une étude intitulée L'impérialisme et tous les réactionnaires sont des tigres en papier, Mao-Tsé-Toung se situe en plein centre de ce courant dont l'affirmation est l'un des dogmes du communisme chinois actuel. Quand un journal chinois écrit : " Il y a encore des personnes qui estiment que la puissance de l'Ouest n'est pas à mépriser, c'est aussi une superstition », il lance une thèse dont on est porté, de ce côté du monde, à sous-estimer la résonnance ${ }^{2}$.

La baisse du prestige américain au profit de l'U.R.S.S. paraît peu contestable. En l'absence d'études sérieuses, on est peut-être porté à l'exagérer (les « adversaires » étant dans un tel cas, plus bruyants que les « amis »). On ne saurait pourtant ignorer qu'elle se manifeste aujourd'hui chez les alliés de ce pays (encore que la Maison Blanche ait refusé de divulguer les documents qui, selon la déclaration de M. [p. 301] Kennedy, lors de la campagne présidentielle, établiraient clairement les dimensions du phénomène) ${ }^{3}$.

L'aspect le plus grave de cette situation est qu'elle conduit les intéressés euxmêmes à douter de la puissance et de la capacité qu'ils possèdent, en particulier sur le plan économique. Le problème, il est vrai, s'avère plus complexe pour l'avenir. Un ajustement du système américain permettrait probablement de réduire, notamment dans le domaine scientifique ${ }^{4}$ les facteurs défavorables à la croissance américaine. Il est douteux que de légers aménagements dans la machine administrative, du type de ceux réalisés depuis l'automne 1957, suffisent pour redresser la situation. Pourtant, faute d'accepter immédiatement ces transformations, les États-Unis risquent de connaître plus tard des moments difficiles.

spécialement dans les conditions de sa mise en œuvre, certaines supériorités intrinsèques que met bien en lumière KNORR (Mans E.), Rubber Diplomacy Challenge in American Foreign Aid, Princeton, 1956 (Center of International Studies). Pour une présentation d'allure plus passionnée, voir LUBRANO-LAVADEBA (Michel), L'ours dans la bergerie. La pénétration soviétique dans les pays sous-développés, op. cit. (spécialement pp. 131-186).

1 Par exemple HAMUY (E.), SALCEDO (D.), SEPULVEDA (O.), El Primer Satélite Artificial. Sus efectos en la opinion publica, Santiago du Chili, 1958. Voir aussi BERKNER (LV.), "Earth satellites and foreign policy », Foreign Affairs, janvier 1958, pp. 221-231 et HEALEY (D.), « The sputnik and Western Defence », International Affairs, avril 1958, pp. 145-156.

2 Le texte de MAO-TSE-TUNG, (accompagné de divers documents et commentaires) a été publié en français par les Éditions en langues étrangères, Pékin, 1959.

3 Cependant la presse d'information a publié de larges extraits de ces documents. Voir en particulier dans le New York Times, International Edition, 2 novembre 1960, une section d'un rapport établi en date du 29 août 1960 par la United States Information Agency.

4 Voir sur ces problèmes un numéro intitulé « Perspectives on Government and Science » des Annals of the American Academy of Political and Social Science, janvier 1960. 
Les phénomènes que l'on vient de rappeler illustrent l'existence d'une opinion publique mondiale à condition de prendre l'expression en un sens très souple. Sous certains de leurs aspects (spécialement ceux d'inspiration anti-...), ils peuvent être utilisés par une politique nationale assez puissante pour séduire les protestataires, assez habile pour conserver leur sympathie: à ce jeu, l'U.R.S.S. a marqué de nombreux points durant les récentes années ${ }^{1}$. Mais l'on peut aussi tenter de placer ces courants au service d'intérêts collectifs, par exemple, l'Année mondiale du Réfugié, ou encore la Campagne contre la Faim que la F.A.O. envisage de mener à une échelle massive durant les cinq prochaines années (projet dont il est intéressant de rapprocher la décision des Rencontres internationales de Genève de mettre au programme de leur $\mathrm{XV}^{\mathrm{e}}$ session — septembre 1960 — le thème de la Faim).

Cet appel à l'opinion internationale est déjà ancien : le préambule de la Quatrième convention de La Haye, par exemple, précise que, en dehors des dispositions réglementaires adoptées, les populations des belligérants restent sous la protection de divers principes et des «exigences de la conscience publique ». Selon Paul de La Pradelle, certaines dispositions du pacte de la. S.D.N. (en particulier le système du moratoire de guerre de l'art. 12) n'ont de sens que si on les suppose appuyées par un fort courant d'opinion, capable de déclencher une violente réprobation morale à l'encontre du contrevenant. De même, cet auteur signale plusieurs reconnaissances «spectaculaires » de l'opinion publique internationale, dans cet après-guerre (préambule de la Charte [p. 302] de l'O.N.U. : « Nous les peuples des États-Unis »; jugement de Nuremberg ; Déclaration universelle des Droits de l'Homme...) ${ }^{2}$.

En définitive, le concept « opinion mondiale » couvre bien, à l'Université comme dans le grand public, deux séries de phénomènes : des aspirations générales, confuses et puissantes, capables d'intervenir spontanément dans la politique internationale, mais susceptibles aussi d'être " capturées » au profit de l'une des grandes forces en présence ; une connaissance commune de problèmes déterminés suscitant des publics spécialisés, quoique de dimensions infiniment plus restreintes. Bien entendu, tout ce que les sociologues nous ont appris sur la nature et la structure de l'opinion interne (dispersion des "publics »; part respective des éléments irrationnels et extrarationnels ; alliages de constance et de versatilité, etc.) demeure valable au niveau de l'opinion internationale.

On n'entrera pas ici dans l'analyse du mode de circulation des opinions à l'échelle mondiale. En un sens, le problème est dominé par l'importance de l'analphabétisme (l'Unesco évaluait en 1957 le nombre des adultes analphabètes dans le monde à

1 Voir sous cet angle les trois volumes publiés sur les récents voyages de M. Khrouchtchev à travers le monde: Confrontation. Récit du voyage de Khrouchtchev aux États-Unis ; Khrouchtchev en France ; Le séjour de N. Khrouchtchev en Inde, en Birmanie, en Indonésie et en Afghanistan. Encore que la lecture en soit monotone, ces ouvrages sont des documents importants pour l'étude des mécanismes de formation de l'opinion publique internationale et l'explication des succès de la propagande soviétique.

Sur les manipulations de l'opinion en U.R.S.S. même, voir INKELES (Alex), L'opinion publique en Russie soviétique. Une étude sur la persuasion des masses. Traduit de l'américain, Paris, 1956.

2 In « L'opinion publique internationale », L'Opinion publique, op. cit., pp. 431-444. 
quelque 700 millions, soit environ $44 \%$ de la population âgée de quinze ans et plus) ${ }^{1}$. D'où, spécialement dans les pays sous-développés, l'extrême pouvoir de la radio qui libère la transmission des idées et des nouvelles, des servitudes du texte écrit ${ }^{2}$. Il semble que la télévision soit susceptible d'accroître considérablement cette « internationalisation de l'événement » (voir, par exemple, le système Eurovision qui permet de diffuser dans plusieurs pays le reportage d'une cérémonie quelconque survenue dans l'un d'entre eux), mais à l'échelle mondiale, la télévision est encore le luxe des pays développés ${ }^{3}$.

En dehors de l'activité propre des groupes de pression internationaux, qui est le thème de cette rubrique, l'opinion publique provoque sur le plan international, une série d'efforts d'inspirations différentes. En raison des liens qu'ils ont nécessairement avec notre propos, il paraît indispensable d'en faire une brève énumération.

D'abord, l'action des États eux-mêmes visant à enrôler l'opinion au service d'une politique, d'une « cause », d'une idéologie, d'une conception morale. C'est là un souci permanent auquel le développement des moyens d'information de masse confère une dimension encore jamais atteinte : les techniques modernes de transmission donnent à chaque gouvernement le moyen d'obtenir une vaste audience internationale, [p. 303] mais, par un effet complémentaire, rendent difficile la mise en garde contre les entreprises de l'adversaire. La guerre radiophonique, en particulier, illustre parfaitement une telle interdépendance ${ }^{4}$.

Cette activité se place volontiers sous le pavillon des « relations culturelles » qui, comme on l'a dit, représentent bien souvent un prolongement des stratégies nationales ou, si l'on préfère, un moyen de leur assurer une résonnance favorable dans le monde ${ }^{5}$. Il suffit d'observer à cet égard la lutte qui se livre pour la formation des élites dans les pays sous-développés. Cet effort s'appuie sur la production nationale en matière artistique, littéraire, scientifique, etc. ; production qui, selon les cas, constitue une activité sous contrôle public, ou relève de l'inspiration privée.

1 Voir la documentation considérable rassemblée dans l'étude de l'Unesco, L'analphabétisme, dans le monde, au milieu du $X X^{e}$ siècle, Paris, 1957.

2 Voir GODDING (George A.) Jr, La radiodiffusion dans le monde, Paris, Unesco, 1959 (en particulier chapitre 3, « La radiodiffusion dans les régions sous-développées »).

3 L'ouvrage de l'Unesco, La télévision dans le monde, Paris, 1954, est déjà très ancien, compte tenu du sujet. Mais il confirme bien l'inégalité entre les pays. À ce moment où les Américains possédaient 139 stations en service et un nombre de récepteurs de l'ordre de 21500000 (mars 1953), le gouvernement indien se préoccupait d'installer à New Delhi un laboratoire expérimental de télévision.

4 Le phénomène a été particulièrement étudié du point de vue des activités américaines. Voir HOLT (Robert T.), Radio Free Europe, Minneapolis, 1958; BARRETT (Edward W.), Truth is Our Weapon, New York, 1953 (étude de «La voix de l'Amérique » depuis la guerre) ; DAVISON (W. Phillips), "Voices of America » dans l'ouvrage collectif déjà cité, Public Opinion and Foreign Policy, pp. 156-179.

5 Rappel de l'ouvrage déjà cité de DOKA (Carl), Les relations culturelles sur le plan international, qui fournit une assez abondante documentation, mais ne s'attache guère à exposer l'emploi de ces relations comme élément des stratégies nationales. 
Dans l'ensemble, l'analyse politique n'a jamais accordé à ces phénomènes une attention proportionnée à leur importance. Soit, par exemple, le problème des traductions d'auteurs nationaux en langue étrangère. Dans les régions communistes, celles qui sont à l'usage des autres pays sont souvent assurées (spécialement pour les œuvres de nature politique) par des services nationaux eux-mêmes, généralement dit « éditions en langue étrangère ». Ailleurs, l'opération relève normalement du secteur privé, l'éditeur vendant les "droits » à son collègue étranger ; mais nombreux sont les cas dans lesquels une intervention officielle, ou la promesse d'un subside public, en facilite la réalisation ou tente de le faire. En tout état de cause, il n'est pas indifférent à la science politique que, parmi les auteurs traduits plus de cent fois de 1948 à 1955, figurent: Lénine (en tête avec 968 traductions publiées), Staline (troisième rang, 689), Marx (dixième rang, 415) ${ }^{1}$. Même si une bonne part de ces traductions a trait aux diverses langues de l'Union soviétique, le fait n'en reste pas moins significatif.

Une seconde contribution, d'un esprit différent, sinon entièrement opposé, est celui des organisations intergouvernementales (tout particulièrement l'Unesco). On peut la décomposer en plusieurs éléments. D’abord, un effort pour la suppression des obstacles à la libre circulation des informations et, plus généralement, de tous les instruments culturels : il s'agit de repérer ces obstacles qui sont nombreux et parfois subtils ; ensuite d'en obtenir l'élimination au moins partielle, et enfin de mettre en œuvre des programmes d'aide ou d'échange qui donnent un contenu concret à ces tentatives ${ }^{2}$. Une autre activité, plus délicate encore, tend à la suppression ou à l'atténuation des facteurs [p. 304] d'incompréhension : l'action de l'Unesco dans le domaine des manuels scolaires, par exemple, est trop connue pour qu'il soit besoin de l'évoquer longuement ${ }^{3}$. Il arrive que des organisations internationales privées accomplissent des travaux se situant exactement dans cette perspective, ainsi, le $\mathrm{V}^{\mathrm{e}}$ Congrès du Bureau International Catholique de l’Enfance consacré à « l'éducation du

$1 \quad$ Voir le tableau présenté dans Le Courrier de l'Unesco, février 1957, page 8. L'Unesco vient de publier (1960) le II $^{\mathrm{e}}$ volume de l'Index Translationum, répertoire international de traductions qui en signale 30 000, effectuées dans 64 pays. Sans nul doute, le dépouillement systématique de cette énorme documentation apporterait des éléments sérieux pour l'analyse de la formation de l'opinion publique.

2 On aura une juste idée des efforts entrepris par l'Unesco en la matière par la lecture du volumineux rapport que son directeur général vient de présenter aux Nations Unies sous le titre International Relations and Exchanges in the Fields of Education, Science and Culture (dans la numérotation de l'Ecosoc, E/3352, 7 avril 1960).

3 Cette tentative aboutit à des conseils pratiques comme le montre en particulier la série de brochures publiées sous le titre "Vers la compréhension internationale » : voir en particulier LAUWERGS (J.A.), Les manuels d'histoire et la compréhension internationale; L'enseignement de la géographie. Petit guide à l'usage des maîtres ; Les Nations Unies et le civisme international... Il n'y a pas lieu ni de surestimer ni de déprécier systématiquement de tels efforts Voir aussi BRIGGS (Asa), «L'éducation des travailleurs pour la compréhension internationale », Études et Documents d'Éducation, septembre 1954. 
sens international chez l'enfant ${ }^{1}$. Il en va de même aujourd'hui de plusieurs centres de recherche privée ${ }^{2}$.

Enfin, on notera l'action déjà signalée dans un précédent chapitre, des organisations internationales non gouvernementales, qui rassemblent, sur le plan international, les groupements nationaux des "professionnels » occupés dans les divers secteurs de l'information ${ }^{3}$. Leur activité a souvent eu pour objet la défense et l'extension de la liberté de l'information et de la diffusion des nouvelles. Plus récemment, les professionnels en sont eux aussi venus à l'analyse scientifique de leur métier et des conséquences de leur activité sur l'esprit public. On vise ici la fondation à Paris, en 1957, d'une Association Internationale des Études et Recherches sur l'Information dont la première session d'études a été consacrée au secret professionnel des journalistes ${ }^{4}$.

\section{b) MODALITÉS D’ACTION DES GROUPES}

\section{$\underline{\text { Retour à la table des matières }}$}

L'intervention sur l'opinion tient une place variable dans l'action des groupes dont les uns (spécialement milieux bancaires et financiers) font du secret l'aspect premier de leur activité. Une large partie des organisations sans but lucratif (en particulier les organismes à recrutement scientifique) attache peu d'importance à la publicité et même s'en défie. Cependant, l'extension de la technique dite des «relations publiques » tend, sinon à supprimer la différence, du moins à en réduire le développement. Les pages achetées dans la presse mondiale par le Réarmement Moral, précèdent, ou suivent, celles acquises par la Standard N.J. ou la British Petroleum.

Quand il tente d'orienter l'opinion, tout groupe a en fait deux objectifs. Le premier, rarement énoncé comme tel, n'est pourtant que rarement absent des préoccupations :

Dont les actes ont été publiés à Paris en 1957.

On mentionnera à titre de spécimen le cas du Center of International Studies rattaché au Massachusetts Institute of Technology (M.I.T.). Signalons parmi ceux de ses travaux ayant trait directement à l'opinion publique internationale: ISAACS (H.R.), Scratches on Our Minds : American images of China and India, New York, 1958 ; COELHO (G.V.), Changing Images of America : a study of Indian students' perceptions, Glencoe (Ill.,), 1958 ; PERLMUTTER (H.V.), BRUNER (J.S.), " Compatriot and Foreigner : a study of impression formation in three countries ", The Journal of Abnormal and Social Psychology, septembre 1957, pp. 153-260 ; PERLMUTTER (H.V.), SHAPIRO (D.), «Stereotypes about American and European who make Specific Statements », Psychological Reports, 1957, pp. 131-137, etc. Bien entendu, ces titres ne sont présentés que comme des exemples tendant à illustrer le sens d'un très vaste courant de la recherche socio-culturelle contemporaine.

3 Voir sur ces organisations le répertoire établi par l'Unesco, Professional Association in the Mass Media. Handbook of press, film, radio, television organizations (en particulier pp. 11-54: les organisations internationales).

4 Sur cette institution, voir l'étude de Jacques KAYSER in Associations, août 1960, pp. 481-484. 
renforcer la cohérence des membres, dissiper les causes de pessimisme, améliorer le «moral». Le second est de gagner des sympathies à l'extérieur: il s'agit éventuellement d'augmenter le nombre des adhérents et, en tout cas, de créer dans le pu-[p. 305] blic des images favorables au mouvement. L'ajustement de ces deux plans pose souvent des problèmes subtils; les motifs capables d'exciter le zèle et de provoquer l'enthousiasme des membres n'étant pas toujours de nature à plaire en dehors d'eux. Les responsables essaient parfois de s'en tirer en instituant deux séries de publications dont l'une est strictement réservée à leurs adeptes.

On s'attachera surtout ici aux organismes pour lesquels la conquête d'un public sans cesse élargi, représente en somme l'objectif prédominant, sinon unique. Ce n'est qu'un aspect du problème, mais son étude ouvre des perspectives originales. Nous dirons quelques mots des techniques elles-mêmes et présenterons ensuite quelquesuns des mouvements qui en font un emploi systématique.

Techniques d'intervention sur l'opinion — Un premier mode d'emploi général, est la convocation de réunions. Les modalités en sont nombreuses allant de la manifestation de masse, largement « ouverte » à la réalisation d'entretien de type « fermé ». Voici quelques exemples tirés de la pratique.

Et d'abord le grand rassemblement destiné à influencer les participants et à frapper l'opinion. Relèvent de ce genre les Festivals de la jeunesse organisés par les mouvements para-communistes (spécialement la Fédération Mondiale de la jeunesse Démocratique), avec l'appui, habituellement non dissimulé, du gouvernement soviétique. Il y en a eu déjà sept : Prague (1947), Budapest (1948), Berlin-Est (1951), Bucarest (1953), Varsovie (1955), Moscou (1957), Vienne (1959). Celui de Moscou a revêtu une importance certaine en mettant l'accent sur la « neutralité idéologique » de la manifestation. L'appel à la jeunesse lancé à cette occasion spécifiait : « Le Festival est ouvert à tous les jeunes sans distinction de race, de croyance religieuse ou de nationalité ; aucune tendance idéologique, politique, philosophique ou religieuse ne devra y prévaloir ».

La même profession de foi est intervenue pour celui de Vienne, le premier de ces festivals à se tenir au-delà des frontières du monde communiste. On notera que l'accord du gouvernement autrichien a été obtenu pour des raisons purement diplomatiques et en dépit de 1'opposition quasi-unanime des organisations de la jeunesse autrichienne ${ }^{1}$.

L'un des traits caractéristiques des festivals de Moscou et de Vienne a été l'intérêt porté par les organisateurs aux jeunes des pays afro-asia-[p. 306] tiques. Pour beaucoup d'entre-eux, l'assistance à celui de Vienne a été suivie de circuits touristiques en divers pays du bloc communiste. C'est dire que la lutte contre le

\footnotetext{
L'Union Fédérale de la Jeunesse Autrichienne, qui regroupe toutes les associations de la jeunesse autrichienne (à l'exclusion des Jeunesses Communistes dont l'importance dans ce pays est très réduite), a vivement pris position contre le Festival dénommé comme " parfaitement communiste ». Critiquant «l'écrasement des organisations libres de jeunesse dans les pays de démocratie populaire », l'Union a décliné toute participation à ce Festival.
} 
colonialisme a constitué l'idée force de ces manifestations. Mais le programme comportait aussi une partie culturelle d'une grande richesse (participation de grandes vedettes de la scène, de la chanson, du cirque; philatélie comme moyen de rapprochement entre les peuples ; bals, carnavals, séances de chant...). Ces festivals font l'objet d'une préparation soigneuse qui est du ressort d'un comité où les éléments communistes occupent une large place, sans se réserver le monopole. La F.M.J.D. lui fait un chaleureux accueil dans sa revue jeunesse du Monde publiée en plusieurs langues, cependant que le comité préparatoire de la réunion de Vienne a diffusé, également en plusieurs langues, un journal intitulé Festival.

Naturellement, de telles manifestations entraînent des frais considérables qui sont réglés sur un « fonds monétaire commun » dont la majeure partie des ressources est d'origine gouvernementale (les comités africains et asiatiques en particulier n'assurant qu'une contribution purement nominale). Il n'est guère possible d'en évaluer le retentissement : on a l'impression que, notamment à l'égard des jeunes venus des pays sous-développés, les efforts des organisateurs sont d'une véritable efficacité.

Quelques mots maintenant sur la technique du congrès qui constitue un procédé de travail usuel des organisations internationales. Ce n'est certes pas une nouveauté. L'Union des Associations Internationales fait partir son fichier de 1681, année où se serait réuni à Rome un premier congrès médical international : pour la période allant de 1681 à 1899, l'Union en a repéré 1414 embrassant les activités les plus diverses ${ }^{1}$. En fait, le mouvement, qui débuta réellement au milieu du siècle dernier n'a cessé de s'intensifier depuis lors : tout d'abord proche de l'unité, la cadence annuelle est passée à une cinquantaine vers la fin du siècle dernier, et elle atteint à présent plusieurs centaines (un calendrier préparé par l'U.A.I. et nécessairement incomplet recense 587 manifestations de ce type pour la seule année 1960).

On ne s'étonnera donc pas que les villes, soucieuses de leurs intérêts commerciaux, aient construit des «palais » ou « maisons » destinés à accueillir ces réunions que les agences de voyage et compagnies de transport observent d'un œil vigilant. En même temps, on attache de plus en plus d'importance aux problèmes de leur organisation administrative : non sans quelque erreur terminologique on parle de constituer une [p. 307] une "science des congrès » et l'on réunit des congrès...d'organisateurs de congrès (dont la tenue doit sans doute réjouir C.N. Parkinson) ${ }^{2}$

Voir sa brochure Les Congrès internationaux de 1681 à 1899. Liste complète, Bruxelles, 1960.

Sur ces problèmes, la revue de l'U.A.I., Associations, apporte un matériel d'une grande richesse dont voici, à titre indicatif, quelques éléments. Tout d'abord, voir dans le $\mathrm{n}^{\circ} 1$ de 1954, pp. 21-22, une liste des études publiées sur ce sujet dans le Bulletin O.N.G. accompagnée d'un certain nombre d'éléments de bibliographie générale. Voir également les numéros suivants: octobre 1960, « Congrès internationaux »; avril 1960, "La science des Congrès " (compte rendu du $\mathrm{II}^{\mathrm{e}}$ Congrès des Organisateurs et techniciens de Congrès internationaux, Lausanne, mars 1960) ; janvier 1959 et mars 1959, «Aspects et problèmes de l'organisation d'un Congrès international » (compte rendu du premier des Congrès organisés par l'U.A.I. » ; mai 1957, pp. 273-284, « Conference Interpreting » ; octobre 1956, pp. 620-628, NEILSON (M.J.), «International Congresses. Building up the organization from small beginning». Ajouter un «manuel» publié par le Conseil des 
Encore que la définition de ce terme soit assez fluide on la réserve généralement aux manifestations d'une assez vaste ampleur, à caractère relativement ouvert mais, dans les faits, le mot couvre des rassemblements allant de 100 participants (et parfois moins) à 2000 (et parfois plus). Selon une estimation, soigneusement établie, depuis le début du mouvement, environ 5 millions de personnes se seraient rencontrées en quelques 19000 congrès. Encore qu'il soit difficile d'indiquer un coût moyen, on imagine sans peine les frais entraînés par de telles réunions ${ }^{1}$. Les résultats acquis justifient-ils les sommes dépensées et l'énergie ainsi mise en œuvre ?

Beaucoup en doutent aujourd'hui et l'on évoque volontiers la crise des congrès ${ }^{2}$. Si le rôle de ces manifestations est bien, comme l'estiment presque tous les promoteurs, d'assurer la coopération dans l'action et la coordination du savoir, il apparaît douteux que des gains sérieux soient réalisés sous un quelconque point de vue. Plus exactement, ces objectifs officiels sont, pour une bonne part, compromis par l'aspect « foire aux vanités » ou « récréation touristique » que revêtent le plus souvent les congrès (dont près de $70 \%$ se tiennent en Europe). Cependant il serait excessif de conclure à la totale inutilité de ce mode d'échange. Quand, par exemple, la jeune Chambre Économique Internationale réunit à Paris pour une semaine 2000 jeunes chefs d'entreprise et cadres, représentant 300000 membres répartis dans 58 pays, il n'est pas concevable qu'une telle assemblée soit sans aucune influence sur les esprits. Il semble permis notamment de considérer que ces rencontres contribuent, de façon d'ailleurs très lâche, à la formation d'une opinion publique internationale, éventuellement sur des sujets spécialisés : on ne saurait déplacer chaque année 200 à 300000 personnes sans escompter au moins un résultat de cet ordre. Réserve faite, peut-être, d'un certain effet éducatif des congrès scientifiques, cette appréciation modeste convient probablement à la moyenne des cas.

On en arrive enfin à des réunions d'audience matérielle plus réduite et à participation le plus souvent «fermée » pour lesquelles le langage courant propose une variété déconcertante de termes: colloque, entretien, symposium, séminaire, session, ou stage d'étude, ou table ronde, etc. ${ }^{3}$. Depuis la fin de la guerre, la technique du séminaire fait l'objet d'une utilisation croissante ${ }^{4}$. On a déjà mentionné dans le chapitre [p. 308] premier l'emploi de cette formule par diverses organisations comme le Congrès pour la Liberté de la Culture.

Organisations internationales des sciences médicales, L'organisation des réunions internationales, Paris, 1957 ; World Federation for Mental Health. Communication or Conflict, Conferences : their Nature, Dynamics and Planning, Londres, 1960 ; Union des Associations Internationales, Théorie et pratique de l'Organisation des Congrès internationaux, Bruxelles, 1960.

Voir les chiffres avancés par P. VASSEUR in Associations, janvier 1959, pp. 5-6.

Voir SPEECKAERT (G.P.), «La crise des Congrès internationaux », Bulletin O.N.G, avril 1953, pp. 159-172. Nous avons beaucoup apprécié les remarques caustiques, mais finalement réalistes de J. BARENTS, "Vanity Fair? Or International Congress Reconsidered », American Political Science Review, décembre 1959, pp. 1090-1094.

3 Pour un essai de différenciation terminologique, voir Associations, mai 1958, pp. 371-374.

4 Pour un essai d'évaluation de cette technique, voir NIJKIERK (K.J.), Evaluation of International Seminars. A report for Unesco, Cologne, Institut de l'Unesco pour les Sciences sociales, 1957. 
De façon générale, on attribue à ce genre de rencontres une double supériorité sur les congrès : nombre restreint des participants qui permet un travail en profondeur, désignation de ceux-ci à titre individuel et non comme représentants d'organisation, système qui réduit les clivages nationaux. Si les membres de la réunion sont choisis parmi les personnes influentes dans leurs pays respectifs, ou susceptibles de le devenir, il peut en résulter la pose de jalons intéressants pour la formation de l'opinion.

Il arrive que les organisations internationales mettent en œuvre successivement les divers types de réunions, parfois en quelque sorte de façon simultanée. Pax Romana par exemple, a organisé à Manille (fin 1959-début 1960) toute une série de manifestations de plus ou moins grande envergure (ainsi, pour la seule branche « Étudiants », assemblée annuelle interfédérale qui réunit, au niveau mondial, les membres de l'Association ; séminaire sur « la responsabilité sociale de l'universitaire d'aujourd'hui »; réunion des dirigeants des fédérations asiatiques...).

Une seconde technique d'action, d'emploi également universel, est le recours aux moyens ordinaires d'information (mass-communications). Pendant longtemps la presse en a été le seul véhicule disponible, mais au cours des dernières décennies les procédés audio-visuels ont fait leur apparition (encore que beaucoup de groupes ne soient pas en mesure de s'en servir à cause de leur prix).

Comme les groupes nationaux, les associations internationales disposent, en de nombreux cas, de leur propre presse, qui, dans l'ensemble, représente une source de documentation encore très peu exploitée. On a déjà pu recenser environ un millier de périodiques couvrant pratiquement toutes les activités humaines; mais le dépouillement, en dépit des précautions prises, ne saurait être tenu pour exhaustif ${ }^{1}$. Les statistiques préparées à cette occasion établissent que l'importance numérique de cette presse spécialisée va croissant et que, si l'Europe demeure en tête par le nombre des périodiques publiés, la contribution des autres continents augmente peu à peu. Ces périodiques sont principalement, et parfois exclusivement, réservés aux membres : d'où la relative franchise de certains d'entre eux qui en rend l'analyse scientifique assez fructueuse.

[p. 309] Pour atteindre le reste du public, les groupes internationaux doivent se servir de la grande presse ou presse d'information, ce qui n'est pas sans poser à beaucoup de difficiles problèmes, spécialement d'ordre financier. La tenue d'une conférence de presse (par exemple à l'issue d'une réunion) est un procédé peu coûteux, mais ses résultats sont souvent décevants. Par ailleurs, les grandes agences de presse sont rarement "réceptives » à des nouvelles d'un caractère spécialisé ou technique.

Répertoire des périodiques publiés par les Organisations internationales, $2^{\mathrm{e}}$ édition, Bruxelles, 1959. Pour un commentaire, voir DOLO-ANDRE (Éliane), "International Periodicals », Associations, octobre 1959, pp. 704-710. 
On peut en dire autant de la Radiodiffusion : il ne semble pas que l'effort réalisé à Genève au profit des organisations non gouvernementales ait été imité ailleurs ${ }^{1}$. L'« accès » sera donc plus difficile et restera épisodique.

Ces observations ne sont valables, ni pour les très grandes organisations qui disposent de larges facilités, ni pour celles qui parviennent à un moment donné à éveiller un vif intérêt dans le public. Les unes en permanence, les autres de façon temporaire, reçoivent un traitement de faveur dans les journaux ou les émissions radiophoniques: mais ce n'est pas le cas le plus fréquent. Quant aux forces de pression du type "groupes d'affaires ", les moyens financiers dont elles disposent sont loin de toujours suffire à leur assurer l'«accès » aux leviers de l'information (ceux-ci étant désormais, dans un grand nombre de pays, à la disposition ou sous le contrôle des services gouvernementaux qui les gèrent souvent dans un esprit défavorable aux intérêts économiques).

Nous signalerons enfin un troisième moyen d'action que l'on pourrait appeler : technique des activités simultanées ou coordonnées. Elles s'adressent à des individus isolés, mais dans le cadre d'un programme d'ensemble et généralement sous une direction centralisée. On y rangera le procédé déjà évoqué à plusieurs reprises, de la recherche des signatures en vue d'appuyer un manifeste ou une pétition. Obtenir un résultat appréciable à l'échelle mondiale exige une structure et des liaisons de qualité, dont dispose seulement un petit nombre de groupes internationaux. On y ajoutera le système de l'« invitation au voyage » qui, depuis la fin de la seconde guerre mondiale, se déploie sur une large échelle spécialement mais non exclusivement, dans le monde communiste. De telles libéralités — probablement plus rentables qu'on n'est porté à l'admettre — sont surtout le fait des gouvernements: il arrive parfois à ceux-ci d'associer à la préparation ou à l'exécution du programme soit une association internationale alliée ou sympathisante, soit la branche nationale d'une telle organisation (ainsi, en Europe, les associations pour [p. 310] l'établissement de rapports amicaux avec le monde communiste du type France-U.R.S.S.).

Étude de quelques cas - Parmi les organismes qui attachent une importance essentielle à l'action sur l'opinion publique, on peut citer, en premier lieu, la Fédération Mondiale des Associations pour les Nations Unies dont, aux termes de ses statuts, le premier but est de constituer « un mouvement des peuples pour les Nations Unies ». C'est le type même du mouvement international consacré à la défense d'une cause : « promouvoir la tolérance, la compréhension, la solidarité et la coopération... ; contribuer à éliminer les obstacles à la paix... et aider à l'extension de la coopération pacifique entre les nations...». L'organisation possède actuellement des membres adhérents (ou simplement associés) dans une cinquantaine de pays. Il existe également, dans le cadre de la Fédération, un Mouvement International des Étudiants pour les Nations Unies (dont, au cours des dernières années, l'activité a été très réduite en raison de la médiocrité des ressources financières disponibles).

1 Voir SUES (Marcel W.), «La radio et les grandes institutions internationales », Bulletin O.N.G., février 1953, pp. 51-52. 
Le travail de base est assuré par les Associations membres dont la structure et les modalités d'action varient d'un cas à l'autre. Les interventions les plus fréquentes sont : organisation de séries de conférences sur des sujets se rapportant aux Nations Unies; préparation d'émissions à la radio et à la télévision ; projection de films ; publication de revues et bulletins d'information; tenue de stages d'études... Plusieurs attachent une attention particulière à l'action dans le milieu des enseignants et des étudiants. Toutes ces associations ne semblent pas déployer le zèle souhaité, de nature le plus souvent bénévole et s'acquitter exactement de leurs obligations financières à l'égard de l'organisme central (une procédure ayant dû être adoptée lors de la $62^{\text {ème }}$ session du Comité exécutif pour mettre fin à l'affiliation de membres inactifs et endettés envers la Fédération).

Cette dernière ne se borne pas à orienter et à coordonner les actions de ses membres. Elle réalise un programme particulier avec l'aide de diverses organisations intergouvernementales, notamment l'Unesco. Ses procédés de travail usuels sont: séminaires ou stages d'études, conférences régionales, cours sur l'O.N.U. et ses agences spécialisées (par exemple de 1959, cours sur le Fonds des Nations Unies pour l'enfance, l'Organisation Mondiale de la Santé, la Commission Économique pour l'Europe et l'Organisation Internationale du Travail). La Fédération tient [p. 311] également à manifester son point de vue sur les questions mondiales en suspens : après beaucoup d'autres, elle réclame des mesures économiques pour élever le niveau de vie des pays encore insuffisamment développés.

Conformément à la mission qui lui est impartie, elle se préoccupe aussi du désarmement. Lors de la $14^{\text {ème }}$ Assemblée plénière, deux décisions ont été prises à l'unanimité sur ces problèmes : la première, pour réclamer l'adoption d'un traité de désarmement général, la seconde pour exprimer le souhait d'une cessation permanente des expériences d'armes nucléaires.

L'activité de la Fédération repose sur la supposition que l'O.N.U. constitue la seule organisation mondiale capable de procurer la paix, la justice, la sécurité et la prospérité : dans cette perspective, il lui apparaît évidemment souhaitable que des milieux de plus en plus larges, ayant pris connaissance de 1'œuvre des Nations Unies, poussent les gouvernements à les épauler. C'est exactement le principe de l'action indirecte. Est-il possible de considérer que l'activité de la Fédération a renforcé l'audience de l'O.N.U. dans le monde ?

Il n'existe aucune donnée qui autorise à se prononcer dans un sens ou dans l'autre ; dès lors, toute évaluation ne serait qu'une simple impression, ou, pire encore, un pur jugement de valeur. Nous dirons seulement ici que l'action susceptible d'être exercée par la Fédération dans sa structure présente et ses moyens actuels, ne semble guère capable, compte tenu de l'immensité du problème en cause, d'atteindre le quantum lui permettant de modifier la situation.

L'efficacité d'une propagande quelle qu'elle soit, dépend de l'existence d'une certaine relation entre les dimensions de l'organisme, ou de la cause que l'on veut défendre, et celle de l'organe chargé de cette mission ; or, ici, la disproportion est écrasante à tous les points de vue. Autrement dit, la Fédération peut certes rendre des 
services aux Nations Unies, mais elle n'est pas à la mesure qu'aurait exigée la mission considérée. C'est là un vice de construction qui paraît difficilement réparable et affecte d'ailleurs un grand nombre, la plupart peut-être, des groupements à vocation idéologique. Est-ce le cas des mouvements dits européens, qui, depuis la fin de la guerre, ont combattu pour promouvoir l'unification de l'Europe ?

Faut-il remonter jusqu'à Pierre Dubois et son traité, De recuperatione terrae sanctae (publié au début du $\mathrm{XVI}^{\mathrm{e}}$ siècle), pour trouver l'origine de [p. 312] l'idée européenne moderne ? Laissons les spécialistes en discuter ${ }^{1}$ et partons simplement du discours de Zurich par lequel Churchill "dédouana» en quelque sorte l'idée européenne, compromise comme tant d'autres par le régime nazi. Depuis lors, on a vu s'épanouir toute une floraison de mouvements dont on voudrait esquisser les principaux traits ${ }^{2}$.

Le premier est la multiplication des organisations qui entendent promouvoir cet objectif : diversité tenant certes à des oppositions de personnes, mais reflétant aussi la variété des conceptions sur les moyens de faire l'Europe. Voici quelques-uns des rassemblements les plus caractéristiques. D'abord, l'Union Européenne des Fédéralistes, constituée à la fin de 1946. Fédérant des mouvements implantés dans huit pays, l'Union veut hâter la création d'une Fédération Européenne disposant de pouvoirs effectifs et susceptible d'adhérer, par la suite, à une confédération mondiale. Au cours des dernières années, son « radicalisme » s'est accentué. En juin 1959, elle est devenue le Mouvement Fédéraliste Européen, ce changement de dénomination correspondant à une modification de structure : le groupe est désormais fondé non sur des sections nationales, mais sur des sections régionales à discipline européenne.

Diverses associations se sont formées à partir, ou en fonction, d'une orientation politique déterminée. Ainsi, le Mouvement Socialiste pour les États-Unis d'Europe (créé sous un autre nom au début de 1947). Ce mouvement, dont le nom indique l'objectif, compte aussi parvenir à la réalisation d'un travaillisme à l'échelle de ce continent. Il ne regroupe pas des partis socialistes comme tels, mais vise à réunir en les rassemblant dans des sections nationales, « les partisans de l'unification fédérale de l'Europe de tendance de gauche ». Quant aux Nouvelles Équipes Internationales (dont on a déjà parlé), elles sont le pendant du Mouvement Socialiste dans la sphère

Voir CARAVALE (G.), « Considerazioni sul concetto di 'Europeismo' », Comunità internazionale, avril-juillet 1959, pp. 311-326 ; DUCLOS (Pierre), «L'Idea d'Europa, Fattore di Organizzazione Internazionale », Rivista Internazionale de Scienze Sociali, septembre-octobre 1958, pp. 397-412 ; HITCHENER (D.C.), "Supranational Organization and Democracy in Western Europe ", Parliamentary Affairs, été 1958, pp. 273-286 ; LEONI (B.), « Attualità del Federalismo », Politico, mars 1958, pp. 98-115.

2 Pour un tableau des mouvements européens (sur lesquels il n'y a pas encore d'étude approfondie), lire : VOYENNE (Bernard), Petite histoire de l'idée européenne, $2^{\mathrm{e}}$ édition, Paris, 1954, pp. 173199 ; SAINTE-LORETTE (L. de), L'idée d'union fédérale européenne, Paris, 1955, pp. 110-144 et aussi ROQUETTE (Marlise), in "Méthodes et mouvements pour unir l'Europe », Bulletin du Centre Européen de la Culture, mai 1958, pp. 43-80. Voir aussi un résumé commode in " Construction européenne. Mouvements privés et institutions officielles », Nouvelles Européennes et Mondiales, supplément au $\mathrm{n}^{\circ} 108$. 
de la démocratie chrétienne. Cet organisme, que d'aucuns présentent comme l'internationale des partis sociaux-chrétiens, ou démocrates chrétiens (supra), s'est rapproché des tendances fédéralistes au fur et à mesure du renforcement des oppositions à l'idée européenne ${ }^{1}$. Citons encore dans cette perspective, le Mouvement Libéral pour l'Europe Unie dont les activités semblent assez limitées (information des membres).

Très différente des trois formations précédentes est la Ligue Européenne de Coopération Économique. Cette association se donne offi-[p. 313] ciellement comme but de travailler au regroupement des États Européens sur le plan économique et culturel ; en fait, elle tend à jouer le rôle d'un intermédiaire officieux entre le grand patronat d'Europe Occidentale et les institutions de coopération économique européenne. Elle se cantonne généralement dans les études économiques réalisées au sein de commissions spécialisées (formule permettant d'éviter la « cristallisation » des points de vue nationaux) ${ }^{2}$. La Ligue, d'inspiration proche de celle de la Chambre de Commerce Internationale, constitue une force de pression efficace et passe pour avoir joué un rôle appréciable dans les travaux préparatoires à la C.E.E. aussi bien que dans l'institution, de l'Union Européenne des Paiements.

Mentionnons enfin la constitution en 1947, sous l'impulsion de M. CoudenhoveKalergi, d'une Union Parlementaire Européenne visant à promouvoir l'Europe (avec constitution européenne de caractère fédéral ou confédéral) par une action au sein des différents Parlements nationaux. C'était chez M. Coudenhove la continuation d'un vieux dessein remontant à 1923, date où fut établie à Vienne une Union paneuropéenne qui, entre les deux guerres, inspira plusieurs projets d'union. Après une phase d'interruption due au dernier conflit mondial, l'Union pan-européenne allait reprendre son activité en octobre 1954 (réunion du $6^{\text {e }}$ Congrès Pan-européen).

Tous les groupes que l'on vient d'évoquer ont été créés autour de 1947 (d'autres devant l'être par la suite : par exemple, le Congrès du Peuple Européen fondé en avril 1956 et le Centre d'Action Européenne Fédéraliste mis sur pied en juillet de la même année par un groupe d'anciens adhérents à l'Union Européenne des Fédéralistes). Ce sont tous des groupes de pression que l'on peut qualifier d'européens ou d'internationaux, selon que l'on désire ou non retenir l'échelon régional: en les baptisant ici d'européens, conformément à un usage bien établi, il ne s'agit pas de

1 Sur les tendances fédéralistes ou si l'on préfère sur les principaux thèmes de l'École fédéraliste, voir l'ouvrage collectif L'ère des fédérations, Paris, 1958 (Tribune libre, 36).

2 Les préférences économiques de la Ligue sont bien spécifiées par le thème de quelques-unes de ses toutes premières publications : Un système de convertibilité des monnaies européennes entre elles $\left(\mathrm{n}^{\circ} 1\right)$; Vers la liberté des transferts internationaux de devises $\left(\mathrm{n}^{\circ} 3\right)$; La démobilisation tarifaire intra-européenne $\left(\mathrm{n}^{\circ}\right.$ ), etc. Ce groupement a toujours été très attaché au maintien des liens de l'Europe avec le Commonwealth. Voir en particulier le compte rendu de la Deuxième Conférence Économique de Westminster, janvier-février 1954, organisée par le Mouvement européen : la résolution générale esquissait les conditions d'une union économique plus étroite entre l'Europe continentale, les pays d'Outre-Mer qui lui sont associés, et le Commonwealth britannique « comme une étape utile vers la création d'un système universel d'échanges et de paiements » : c'est là une conception européenne pour le moins extensive ! 
prendre parti sur le problème théorique fort délicat qu'ils soulèvent. Cette multiplicité d'efforts isolés, si elle était un signe de la vitalité de l'idée européenne, n'allait pas sans provoquer un certain malaise. Réclamant l'unification au niveau gouvernemental, les groupes semblaient au départ incapables d'entreprendre eux-mêmes une action coordonnée.

Cette conjoncture explique la formation, en décembre 1947, d'un Comité International de Coordination des Mouvements pour l'Unité Européenne qui décida d'organiser une série de congrès en faveur de l'Eu-[p. 314] rope Unie, dont le premier et le plus « spectaculaire » devait avoir lien à La Haye du 7 au 10 mai 1948, avec la participation de 800 personnes de toutes tendances. Compte tenu du scepticisme général concernant l'efficacité de telles rencontres, il est frappant d'observer l'importance décisive que beaucoup attachent à cette manifestation : ils estiment en particulier que la signature à Londres, le 5 mai 1949, du statut du Conseil de l'Europe, en fut, dans une large mesure, le résultat.

L'essentiel du travail du Congrès se fit en trois commissions (politique, économique et culturelle) qui émirent une série de revendications précises : réunion d'une Assemblée européenne délibérative; rédaction d'une charte des droits de l'Homme assortie d'une Cour de justice pour en obtenir le respect ; union économique de l'Europe ; création d'un Centre européen de la culture. Cependant le Congrès révéla aussi la division des forces européennes sur les moyens et modalités de l'unification, les « unionistes » demeurant opposés à toute limitation de souveraineté des États, tandis que les «fédéralistes » réclamaient l'institution d'un pouvoir central. Dès lors, la fusion complète des mouvements s'avérait impossible et seule une formule de type confédéral, laissant à chacun sa liberté dans une sphère bien déterminée, se révélait acceptable. Telle fut l'origine du Mouvement Européen, créé en 1948, pour coordonner et, par là, renforcer l'action des organisations isolées.

Le Mouvement a une structure assez complexe. Comme il ne recrute pas de membres individuels, sa force repose sur les six organismes définis comme fondateurs : Ligue Européenne de Coopération Économique ; Mouvement Libéral pour l'Europe Unie ; Mouvement Socialiste pour les États-Unis d'Europe ; Nouvelles Équipes Internationales; Mouvement Fédéraliste Européen; Centre d'Action Européenne Fédéraliste. De plus, il s'appuie sur des Conseils nationaux au nombre de quinze, qui, dans chaque pays membre, regroupent, également sous une forme confédérale, les sections nationales des associations que l'on vient de citer. Ainsi, l'organisation française du Mouvement Européen couvre-t-elle cinq de ces sections (le Mouvement Libéral n'ayant pas de filiale en France) ${ }^{1}$.

Le Mouvement Européen a toujours soutenu l'idée que les pays actuellement privés de liberté devraient appartenir, dès que possible, aux structures exprimant l'unité européenne. À ce titre, il possède des comités nationaux (en exil), pour les pays suivants: Albanie, Bulgarie, Espagne, Estonie, Hongrie, Lettonie, Lithuanie, Pologne, Roumanie, Tchécoslovaquie, Yougoslavie. Même observation pour certains de ses membres associés : ainsi Union Internationale Paysanne, groupant les partis de pays passés sous contrôle communiste et Union Démocrate-chrétienne de l'Europe centrale qui réunit des représentants exilés de partis chrétiens-démocrates. 
Il reste à signaler l'existence : $1^{\circ}$ d'une organisation " adhérente », le Conseil des Communes d'Europe, qui groupe en une structure fédérative des municipalités de neuf pays européens (le "jumelage » des villes étant l'aspect le mieux connu de l'activité du Conseil). $2^{\circ}$ de plusieurs organisations associées parmi lesquelles le Mouvement Paneuropéen (de-[p. 315] puis 1952), l’Association Européenne des Enseignants et l'Union des Résistants pour une Europe Unie.

Il s'agit là, de prime abord, d'une force de pression considérable. Comment les dirigeants de ce groupe ont-ils cherché à remplir leur mission ?

Dans une première phase de son histoire (1947-1950), le Mouvement a été taxé d'anglomanie et de conservatisme: puis, il s'est largement ouvert aux influences socialistes et «continentalistes ». On l'a accusé de servir les desseins de la politique vaticane (en raison de la place qu'y tient M. R. Schuman). En réalité, il a toujours éprouvé des difficultés à tenir l'équilibre entre les tendances et les susceptibilités nationales : d'où l'obligation de créer une lourde structure administrative faisant leur part à ces divers éléments. Cette coexistence est devenue plus complexe à partir d'août 1954 (rejet de la C.E.D. par le Parlement français) : les divisions idéologiques se sont renforcées, contribuant à rendre difficiles les prises de position collectives.

Depuis 1948, le Mouvement Européen a tenu de nombreux congrès et conférences dans l'ordre politique, économique, culturel. L'une des plus importantes de ces manifestations fut celle de Hambourg (septembre 1951) qui se prononça en faveur de l'intégration de l'Allemagne dans une communauté européenne. Le Mouvement a également convoqué, conjointement avec l'Union Parlementaire Européenne, plusieurs conférences parlementaires. Parmi ses créations citons le Centre Européen de la Culture, fondé en exécution de l'une des résolutions du Congrès de La Haye ${ }^{1}$, et la Campagne Européenne de la jeunesse (lancée en 1951) pour coordonner et renforcer, avec d'ailleurs des méthodes d'une grande souplesse, les diverses associations de jeunesse européennes.

Mais, en liaison avec toute cette activité, l'Europe commençait de s'organiser, spécialement sur la base de la Communauté des six pays. Dès 1952, le Comité exécutif du Mouvement Européen, en vue d'adapter son action aux données politiques nouvelles, fondait le Comité d'Action pour la Communauté Supra-nationale Européenne groupant les seuls représentants de ces six pays. Son objectif était de créer un pouvoir politique central qui subordonne les souverainetés nationales à une souveraineté supérieure : en somme un véritable gouvernement européen, responsable devant des assemblées européennes (ambition qui, vers la fin de 1953, n'était pas, plus exactement ne paraissait pas, tout [p. 316] à fait utopique). Désormais, le Mouvement Européen, conformément à son manifeste du 8 janvier 1958, soutient l'idée d'une élection au suffrage universel direct de l'assemblée prévue au traité de Rome et d'une coordination de la politique extérieure des Six : cependant les vues de ses membres sur la construction européenne continuent à être différentes.

1 Voir le rapport fait par le Centre de ses dix premières années d'activité in Bulletin du Centre Européen de la Culture, 1959-1960, nº 6. 
Il reste à évoquer la création, au mois d'octobre 1955, du Comité d'Action pour les États-Unis d'Europe qui avait pour ambition de susciter l'élan politique capable de redonner force à l'idée européenne, après l'échec des plans d'intégration militaire. La lettre adressée par M. Jean Monnet aux personnalités pressenties pour former le Comité, spécifie bien le but visé : délégation par les États de certains de leurs pouvoirs à des institutions fédérales européennes mandataires de l'ensemble des pays participants ; pour cela intervention du Comité et des organisations groupées en son sein auprès des gouvernements, des parlements et des opinions publiques; efforts pour assurer une étroite association de la Grande-Bretagne aux institutions nouvelles.

Pour fonder le Comité, M. Monnet a fait appel à des éléments dirigeants des six pays, représentatifs des forces politiques et syndicales (à l'exclusion du secteur communiste). Au total, quatre catégories partis socialistes; partis démocrateschrétiens; partis libéraux et autres syndicats ouvriers. Le Parti Social Démocrate allemand accepta d'entrer dans le Comité en la personne de son président M. Erie Ollenhauer (point important si l'on considère l'hostilité dont ce parti avait témoigné à l'égard du plan Schuman et de l'armée européenne). La lettre d'invitation précisait que les personnalités participant à la constitution du Comité (une trentaine au total) demanderaient chacune à leur organisation d'y adhérer.

Le point de départ de son action a été la volonté de faire passer dans les faits la résolution de Messine du 2 juin $1955{ }^{1}$. Il a choisi d'exercer son influence par une série d'interventions concrètes et précises. L'effort a d'abord porté sur la création d'une communauté atomique européenne (« déclaration commune » du 18 janvier 1956). Le Comité a demandé que, parallèlement à la négociation du traité, soient définis les éléments d'un programme de réalisations : d'où la mission confiée aux « trois Sages » tendant à déterminer l'objectif de production d'énergie nucléaire réalisable dans le cadre de l'Euratom ${ }^{2}$. Il s'est également employé, par une action soutenue, à faciliter les négociations relatives aux deux nou-[p. 317] velles Communautés et a ensuite poussé à la ratification des traités (intervention que sa composition même lui permettait aisément).

Depuis, le Comité a agi pour soutenir et renforcer les communautés naissantes. Il déclare attacher une valeur exceptionnelle aux accords conclus entre l'Euratom et les États-Unis qui, selon lui, ouvrent la voie à une coopération de grande importance réalisée sur un pied d'égalité. L'ordre du jour de sa huitième session (juillet 1960), caractérise bien les préoccupations actuelles du Comité qui concernent cinq points : fusion des trois exécutifs européens (C.E.C.A., Euratom, Marché commun) ; élection au suffrage universel de l'Assemblée Parlementaire Européenne ; contrôle, par les institutions du Marché commun, des ententes et des «abus de puissance économique »; adhésion de la Grande-Bretagne et des autres pays européens à

1 Dans l'été 1955, peu après son départ de la C.E.C.A., M. MONNET publiait Les États-Unis d'Europe ont commencé. La C.E.C.A., Discours et allocutions, 1952-54, Paris, 1955.

Voir DOLLFUSS (Daniel F.), RIVOIRE (J.), Euratom, Paris, 1959, pp. 96-110 et passim. 
l'ensemble de la Communauté européenne ; contribution de la communauté à la mise en valeur des régions sous-développées ${ }^{1}$.

Le Comité ne perd pas de vue l'unification politique européenne qui constitue son objectif majeur. Mais il estime qu'actuellement l'essentiel est de renforcer le mouvement général vers l'unité économique. On observera qu'il a toujours été partisan d'un élargissement des perspectives : dans sa $4^{\text {ème }}$ session (mai 1957), il réclamait l'établissement d'une « zone de libre échange entre le Marché commun, la Grande-Bretagne et les autres pays de l'O.E.C.E. ». Au cours de la $8^{\text {ème }}$ session, il a émis le vœu que la Grande-Bretagne et les autres pays européens deviennent simultanément membres des trois communautés ${ }^{2}$.

Les quelques notions présentées sur les mouvements européens n'épuisent pas le sujet. En particulier on aurait dû évoquer le rôle de multiples centres d'enseignement ou de recherche (comme le Collège de Bruges ou le Centre de Recherches Européennes de l'Université de Lausanne) ${ }^{3}$. Il semble toutefois que l'essentiel de l'action entreprise a été exposé. Peut-on se prononcer sur les résultats obtenus ?

Contrairement à la Fédération des Associations pour les Nations Unies, les mouvements européens semblent avoir été dans l'ensemble proches des conditions nécessaires pour exercer une véritable influence. On ne trouvera pas entre leurs facultés d'action et l'objectif visé cette disproportion si frappante dans le cas de la Fédération. Une preuve très nette en est donnée par l'interpénétration étroite des milieux dirigeants responsables et des organisateurs ou doctrinaires des mouvements. Des hommes ayant été, ou devant devenir, ministres par exemple, ont été [p. 318] aussi des membres parfois très actifs de ces organisations. Cette conjonction, que l'on observe particulièrement à l'échelon des Six, a joué un rôle considérable dans ce processus d'unification. Mais selon quelles modalités ?

Nous manquons toujours en 1960 d'une étude de l'intégration européenne sous l'angle essentiel, celui de la science politique ${ }^{4}$. Cette carence, peu surprenante pour

1 Le Monde, 9 juillet 1960. Comme pour chacune des précédentes sessions, le Comité a rendu public le texte de la « Déclaration commune » adoptée à l'issue des débats.

2 Voir MONNET (Jean), La Communauté Européenne et la Grande-Bretagne, Lausanne, 1958 (texte d'un discours adressé aux industriels anglais du textile). Le Centre de Documentation du Mouvement a publié de nombreux rapports sur le problème. Voir en particulier Considérations sur les rapports entre le Marché commun et les pays tiers (janvier 1959) et les relations du Marché commun avec le reste du monde. Sur la question, voir aussi EUROPEUS, La crise de la zone de libre-échange, Paris, 1959 (Tribune libre, 43).

3 Les établissements ou centres d'enseignement et de recherches spécialisés sur l'Europe ont été groupés, pour la plupart, par le Centre Européen de la Culture en une Association des Instituts d'Études Européennes. Voir l'Annuaire 1957 de l'Association dans le Bulletin du Centre, octobre 1957. Pour les aspects les plus récents, consulter l'Annuaire 1960-61 qui vient de paraître.

4 Nous avions écrit ces lignes avant d'avoir pu consulter l'ouvrage collectif récent du Collège de l'Europe, Sciences humaines et intégration européenne, préface de Robert Schuman, Leyde, 1960. Ce livre comporte plusieurs contributions excellentes, mais il n'oblige pas à revoir le diagnostic formulé. Rassemblement de points de vue divers et parfois hétéroclites, il ne saurait tenir lieu d'une analyse politique de l'intégration européenne qui reste à faire. On regrettera au surplus qu'au lieu d'adopter des formules neuves, les responsables de cet effort s'en soient tenus à une banale 
qui connaît l'état réel de cette discipline en Europe, s'étend même à la phase déjà ancienne de l'effort d'unification (par exemple le Congrès de La Haye, la formation du Mouvement Européen et la fondation du Conseil de l'Europe). Entreprise avec des moyens suffisants, une telle recherche (que seule une paresse intellectuelle invétérée pourrait conduire à déclarer irréalisable) ouvrirait des perspectives sur la consistance et la hiérarchie des influences qui se sont exercées dans le processus. En l'absence de tels travaux on hésite à répéter ici les sempiternels lieux communs.

Action des groupes? C'est peu douteux : le Mouvement Européen dans la première phase, le Comité d'Action pour les États-Unis d'Europe ensuite, ont émis des revendications et accompli des interventions que l'on peut directement relier à des décisions ultérieures des autorités responsables. En certains cas, on l'a vu, la concordance est si forte que la notion d'un lien de causalité paraît s'imposer. Mais aussi action des hommes: le Comité d'Action, c'est d'abord un instrument d'intervention pour M. Monnet dont beaucoup d'anciens collaborateurs (ceux des missions d'achat aux États-Unis et du Commissariat au Plan) occupent, ou ont occupé, des situations importantes, parfois dominantes, dans les communautés.

Action aussi des circonstances : la « satellisation » des pays d'Europe orientale a fait beaucoup pour susciter la conscience européenne et la politique des successeurs immédiats de Staline, a contribué à détendre l'effort. Il n'est pas sûr que le Parlement français eut ratifié, avec la même majorité, les deux traités de Marché commun et d'Euratom (et surtout celui d'Euratom), si les positions prises à l'extérieur sur l'affaire de Suez (en particulier par les États-Unis) n'avaient conduit les parlementaires à quelques réflexions amères. Mais peut-on aussi faire abstraction du jeu de facteurs plus profonds comme la conscience de l'irrémédiable déclin que subiraient les puissances européennes en ne s'unissant pas face aux nouvelles puissances mondiales ${ }^{1}$.

Si l'on se place dans le cadre de l'Europe des Six, un fait apparaît : le dynamisme de l'intégration économique, spécialement dans les secteurs industriels. De nombreux facteurs expliquent ce mouvement dont il n'existe encore aucun inventaire systématique. Parmi les variables qui ont probablement exercé une influence, on peut citer, pour la France : le souci, très puissant, de faire pièce à la zone de libre-échange ; le remplacement, intervenu en diverses branches, des dirigeants anciens par des éléments plus jeunes qui ont mieux compris les avantages de la production à large échelle et redoutent beaucoup moins la concurrence étrangère ; la situation favorable aux exportations qu'ont créée les mesures monétaires de décembre 1958 (en somme, la première dévaluation réussie... depuis 1936). Autre élément: l'influence de la décision politique comme telle dès qu'elle est tenue par les intéressés comme

répartition disciplinaire. Le poids des traditions rend certes difficile aux Universités de s'en évader, mais il est incompréhensible qu'un organisme nouveau se situe d'emblée au niveau d'une routine qui ne trouve plus guère de défenseurs.

1 Voir l'intéressante étude d'Émile GIRAUD, « De la cité à l’État continental », qui marque bien les étapes de l'évolution et dégage avec pertinence les conditions nécessaires à l'union in Sciences humaines et intégration européenne, op. cit., pp. 127-155. 
irréversible. À partir de là, les responsables d'une activité se demandent quelles seront les réactions des concurrents (nationaux et extérieurs) et agissent pour ne pas être dépassés. Ce type de raisonnement fondé sur le comportement hypothétique que l'on prête au rival est générateur d'un processus de contagion.

Sous ces diverses influences (dont, sans aucun doute, le contenu a varié d'un pays à l'autre) des éléments, jadis hostiles ou réticents, poussent aujourd'hui à l'accélération des procédures. On a précédemment parlé du vaste mouvement de concentration qui en constitue l'un des aspects essentiels et qui, se développant de manière incontrôlée, n'est pas sans soulever des problèmes pour l'équilibre des intérêts dans la Communauté (travailleurs, consommateurs...). Certains sont tentés de croire qu'aujourd'hui la pression principale pour l'unification de l'Europe (une Europe d'ailleurs beaucoup plus « libérale » que ne l'indique le traité de Rome) vient des milieux d'affaires. En somme, les mouvements européens auraient achevé leurs tâches, les hommes de la pratique se chargeant de traduire dans les faits les consignes de l'idéologie, du moins ce qu'il leur parait souhaitable d'en retenir. Les groupes économiques représenteraient désormais les vrais et seuls groupes de pression européens, poussant à l'unité et s'efforçant de la modeler à leur convenance (avec toutefois des divergences quant à l'esprit et aux modalités des rapports à établir entre les Six et les Sept).

La tendance ne paraît pas contestable et la substitution est déjà partiellement réalisée. Mais faut-il pousser le raisonnement jusqu'à dire : «L'Europe des affaires ? elle est faite. L'Europe politique ? elle se [p. 320] fait " ${ }^{1}$. Il ne le semble pas. Ce serait d'abord une abdication du politique à l'égard de l'économique car une formule de ce type sous-entend que, se dégageant de la poussée des affaires, la construction à venir serait à leur mesure et dans la ligne de leur comportement. Mais à supposer que l'on admette ce risque, rien ne garantit que le passage d'un plan à l'autre se ferait automatiquement, grâce à une sorte de processus continu. En réalité, la construction d'un pouvoir politique européen suppose une mutation, un changement de nature qualitative, une discontinuité. Comme l'écrit parfaitement Pierre Duclos, il s'agit de franchir le cap qui sépare le diplomatique du politique, de passer « le seuil de la politification ${ }^{2}$. On ne saurait attendre un tel résultat d'une transition insensible, d'une sorte d'accoutumance indolore.

Aujourd'hui, qu'on s'en réjouisse ou le déplore, l'action des autorités françaises ne semble pas s'exercer dans cette direction. Encore que les responsables évitent d'exprimer publiquement leurs intentions réelles, on a le sentiment que leur souhait de

1 Titre sous lequel Entreprise, 28 novembre 1959, présente une interview de Walter HALLSTEIN. Sur le sens de l'accélération, voir Communauté Européenne, avril 1960. (Il s'agit du Bulletin Mensuel d'Information des Communautés.) On notera que le mouvement suscite, particulièrement en France, de nombreuses appréhensions au sens où il tend à accélérer la démobilisation douanière sans comporter l'institution d'une politique économique et sociale commune. Appliquée brutalement, une accélération de ce type ruinerait l'esprit du Traité.

2 Dans un texte très dense, «L'Europe et la science politique », publié dans l'Annuaire 1959 de l'Institut Universitaire d'Études Européennes. 
base serait de ramener les trois communautés à une sorte de coopération intergouvernementale, laissant quasi-intact le pouvoir de décision national.

Les programmes d'ordre politique sont encore plus vagues. On fait allusion à l'institution d'un conseil régulier des gouvernements et à la création d'un secrétariat politique qui permettraient d'établir des procédures de consultations périodiques et d'ajuster les positions par voie de négociations. Ou encore à une consultation des peuples par voie de référendum (du moins dans les pays où la Constitution le permet) complétée, d'ici deux ou trois ans, par des élections européennes au suffrage universel direct. Assez curieusement le Mouvement Européen, dans une conférence récente (Luxembourg, novembre 1960), semble avoir donné son accord à de telles propositions qui, dans leur contenu actuel ne comportent aucun élément susceptible de favoriser l'intégration politique des Six. Faut-il y voir la renonciation à un idéal ou une simple adaptation tactique?

La seconde hypothèse est plus vraisemblable. Mais cette attitude est critiquée par les fédéralistes intransigeants c'est-à-dire logiques avec leur idéal qui redoutent que de tels atermoiements ne créent un processus irréversible de dégradation de l'unification européenne dans le cadre de l'Europe des Six (construction qu'avait déjà sérieusement compromise l'échec de la C.E.D.).

[p. 321] Admettons que cette dégradation soit seulement passagère et que la construction d'un pouvoir politique unifié puisse être reprise un jour. En cette éventualité, qui semble douteuse, on retrouverait le problème du seuil de politification. Et par là, celui de l'opinion publique, au sens où toute fédération suppose chez ceux qu'elle rassemble, à la fois la volonté d'être unis et le souci de rester distincts. Nous sommes ainsi ramenés au problème de l'influence exercée sur l'opinion par les mouvements européens.

\section{c) DIMENSIONS DE L'INFLUENCE SUR L'OPINION}

\section{$\underline{\text { Retour à la table des matières }}$}

Deux facteurs compliquent l'étude de cette question. En premier lieu, l'insuffisance des données théoriques relatives au mode de formation et de transformation des opinions et, plus profondément, des attitudes. En dépit d'un certain nombre d'études expérimentales (réalisées principalement aux États-Unis), il n'existe aucun corps de principes applicables en la matière: les techniques utilisées pour vérifier les phénomènes - par exemple, résistance des esprits à la propagande, en sont encore au stade du laboratoire ${ }^{1}$. Deuxième difficulté : la médiocrité et, dans

Pour une vue d'ensemble de la perméabilité des individus à l'information, voir HOVLAND (Carl I.), « Effects of the Mass Media of Communication », in Handbook of Social Psychology, vol. II, 1954, pp. 1062-1103 (avec une importante bibliographie). Lire aussi HOVLAND (C.I.), JANIS (I.L.), KELLEY (H.H.), Communication and Persuasion, New Haven, 1953. Pour une analyse 
quelques cas, l'inexistence des données relatives à l'évolution de l'esprit public européen durant la période considérée.

Si l'on se réfère aux expériences réalisées - en particulier celles conduites durant la seconde guerre mondiale par S. Stouffer et ses associés sur les soldats américains ${ }^{1}$, une constatation se dégage assez aisément: la possibilité d'améliorer les connaissances objectives, mais la difficulté de transformer les attitudes (le résultat obtenu se limitant souvent à renforcer la conviction de ceux déjà convaincus). Toutes les études de sociologie électorale font ressortir la faiblesse des changements dans les opinions au cours, et en dépit, des campagnes électorales.

L'Unesco a mené, voici quelques années, une vaste expérience dans le cadre des efforts entrepris pour diffuser la Déclaration des droits de l'Homme. Trois villes universitaires (Cambridge, Upsal, Grenoble) furent soumises à une campagne d'information intense utilisant tous les moyens concevables. En comparant les données recueillies avant l'ouverture de la campagne et après son achèvement, on n'aperçoit pas que cette tentative de persuasion ait entraîné un progrès considérable dans la connaissance de la Déclaration ${ }^{2}$.

[p. 322] Ces enquêtes aboutissent donc à des conceptions assez restrictives sur la possibilité de modifier les représentations collectives. Il n'est pas sûr que cette persistance ne s'attache même aux données objectivement vérifiables. En voici un exemple tiré de notre expérience immédiate.

Pour beaucoup de gens, l'Europe est encore un continent ravagé et amoindri par la guerre. Sa décadence par rapport aux forces neuves du reste du monde est un thème qui trouve une large audience, non seulement auprès des Africains et des Asiatiques, mais des Européens eux-mêmes. Sous l'influence de publicistes et de journalistes qui franchissent un peu trop vite et au moindre coût intellectuel la frontière séparant le reportage de la philosophie de l'histoire ce masochisme est bien porté dans nos pays. La vérité est différente ; même si l'on s'en tient au plan économique (particulièrement compromis par les deux guerres mondiales), l'Europe occidentale est l'une des régions du monde qui, actuellement, possède le plus grand dynamisme et le taux d'expansion le plus élevé.

Observons en particulier la Communauté Économique Européenne pour laquelle on dispose désormais de quelques statistiques d'ensemble. Le grand économiste néerlandais J. Tinbergen vient de lui consacrer une étude dont plusieurs éléments sont à retenir ${ }^{3}$. Tout en signalant que le produit national brut de la Communauté reste très inférieur à celui des États-Unis (légèrement au-dessus de la moitié), il affirme que,

d'ambition pratique, ABELSON (Herbert I.), Persuasion. How opinions and attitudes are changed, Londres, 1960 (donne une importante bibliographie).

Studies in Social Psychology in World War II, 4 vol., Princeton, 1949-1950.

«Trois expériences de diffusion de la déclaration universelle des droits de l'homme: Cambridge, Grenoble, Upsal », Bulletin International des Sciences Sociales, 1953 (3), pp. 624-644.

3 Publiée (sous forme ronéotée) par le Centre de Documentation du Comité d'Action pour les ÉtatsUnis d'Europe. 
sur le plan industriel, celle-ci en tant que telle, occupe encore pour certains postes la deuxième position dans le monde.

Il est significatif d'examiner le taux de croissance des pays du Marché commun par rapport à d'autres. Selon le Bulletin de Statistiques de l'O.N.U. (août 1960) la hausse de la production industrielle réalisée de 1953-1960 dans les trois grands pays de la Communauté (Allemagne, France et Italie) serait de l'ordre de 60\%. Ce pourcentage est certes sensiblement inférieur à celui atteint ailleurs (par ordre décroissant: Chine, Japon, U.R.S.S., Allemagne de l'Est...), mais il est très notablement supérieur à celui obtenu par les États-Unis et la Grande-Bretagne au cours des dernières années. Sans atteindre les chiffres allemands ou français, les PaysBas et même la Belgique se situent au-dessus des pays anglo-saxons.

On observe un mouvement d'expansion analogue dans l'ordre des échanges commerciaux : selon le dernier Rapport de la Banque des Règlements Internationaux, les exportations de la Communauté Euro-[p. 323] péenne ont augmenté de 11\% entre 1958 et 1959, alors que celles de l'ensemble des pays industriels en dehors du bloc soviétique ne s'élèvent que de $6 \%$.

Sans doute, le propre des données statistiques est-il qu'elles soient contestables. Celles de Tinbergen ont naturellement été critiquées. Cependant, on ne saurait sans injustice discréditer systématiquement celles qui attestent la vitalité des Six pays de la Communauté ainsi que de plusieurs pays voisins. Ces chiffres en tous cas ne confirment nullement le jugement de décrépitude, émis de façon apitoyée ou agressive que l'on porte volontiers sur notre continent, du dedans et du dehors.

En fait, le principal élément de fragilité économique de l'Europe provient de l'absence d'un pouvoir politique stabilisateur. Une volonté d'unification — qui pourrait ne pas comporter les mêmes obligations pour tous les pays — vaudrait probablement à ce continent une amélioration de ses taux de croissance. Mais nous savons aujourd'hui (exemple récent de la crise charbonnière dans la C.E.C.A.) que cette unification - bien différente d'une coordination intergouvernementale — ne se fera pas sans unification politique préalable. Or, on peut légitimement douter qu'en dépit des efforts d'information et de propagande, les esprits soient préparés à intervenir activement dans la politique pour la promouvoir.

Une action résolue des gouvernements en cause, devançant et accélérant le cours de l'évolution, pourrait, peut-être, autoriser le franchissement du seuil de la politification et créer une situation irréversible. Il s'agirait en somme de gagner de vitesse une opinion sinon hostile du moins indifférente. Mais une telle initiative, à laquelle on ne saurait assimiler un vague référendum, apparaît peu vraisemblable.

En définitive, même dans le cadre limité des Six, les mouvements européens ne semblent pas avoir réussi à susciter un vaste courant en faveur de la Fédération. Sans doute, ont-ils contribué à réduire les tensions traditionnelles et les préjugés habituels. Un tel résultat est déjà considérable, surtout si l'on tient compte de l'ensemble des forces et des groupements qui s'attachent à «contrer» systématiquement le rapprochement franco-allemand. Il n'est pas suffisant pour susciter une poussée provenant de la « base ». 
Admettons franchement que cette vue, dont beaucoup contesteront le pessimisme relatif, est impressionniste. Il n'existe aucun ensemble de données, scientifiquement vérifiables, qui permette de la démontrer. Cer-[p. 324] tes, divers travaux ont été effectués dans ce domaine (dont tous ne sont pas encore publiés : en particulier, ceux du sociologue américain Daniel Lerner sur l'évolution des attitudes à l'égard de l'unification européenne dans les «milieux influents » d'Allemagne, de France et de Grande-Bretagne) ${ }^{1}$. Il y a, sans aucun doute, beaucoup à prendre dans plusieurs d'entre eux : ainsi dans les expériences d'éducation européenne réalisées par le Centre Européen de la Culture ${ }^{2}$. De nombreux sondages ont été effectués qui éclairent convenablement quelques aspects du problème : par exemple, ampleur et qualité des informations possédées par le public sur les diverses modalités de la construction européenne ${ }^{3}$. Cependant, la connaissance du phénomène reste fragmentaire et superficielle.

Les attitudes collectives et les courants d'opinion qui les expriment se transforment indubitablement, mais d'une part ces transformations sont presque toujours lentes, et d'autre part, rien ne permet d'affirmer que l'utilisation, même massive, des moyens de communication suffise pour assurer cette modification. Peutêtre, après tout, l'art suprême des groupes de pression idéologiques est-il d'aller dans le sens du courant: mais reconnaissons les lacunes et les imperfections de la recherche sociologique pour l'étude des facteurs de tels courants.

Il est aisé de comprendre qu'en bien des cas, les difficultés d'agir sur l'opinion se multiplient et s'intensifient quand on se place au plan international : la diversité des traditions, la variété des cultures, la force des tendances nationalistes, constituent des obstacles considérables, parfois presque insurmontables. Plus exactement, la réalisation d'une propagande apte à franchir les obstacles exige des moyens qui sont rarement à la disposition des forces privées.

Ces difficultés grandissent à mesure que se développe la sphère d'action. Le lancement d'une propagande «européenne » est concevable au prix d'adaptations tenant compte des nuances nationales. Par contre le problème change d'échelle s'il s'agit d'être entendu à la fois des Français et des Birmans. D'où l'effort de régionalisation accompli par plusieurs grandes O.N.G. spécialement les internationales syndicales. Cependant, rares sont celles qui ont les moyens d'une telle démultiplication.

1 On trouvera un premier spécimen de ces recherches in « French Business Leaders look at E.D.C. A Preliminary Report », Public Opinion Quarterly, printemps 1956, pp. 212-221.

2 «Neuf expériences d'éducation européenne », Bulletin du Centre Européen de la Culture, décembre 1959.

3 HERBERICHS (Gérard), « L'Europe sans opinion ? », Internationale Spectator, 8 juillet 1959, pp. 353-368. 
Une conclusion, modeste quoique significative, se dégage de cette analyse. Quand un groupe de pression (et sur ce point il en va de même [p. 325] aux deux niveaux national et international) agit dans le sens d'un courant puissant ou dominant, son action est facilitée parfois dans des proportions considérables. Il importe peu d'ailleurs que cette base idéologique repose sur des données objectives solides ou exprime des réactions émotionnelles. Par contre, si le groupe intervient en sens inverse d'un tel courant, son activité est difficile et aléatoire. Dans ce cas, la tactique qui s'impose est, ou bien d'agir et de revendiquer dans le secret, ou bien d'intervenir pour transformer l'opinion. Mais la première éventualité n'est pas toujours praticable et se révèle parfois dangereuse ; la seconde reste d'un rendement incertain.

Observation revenant à affirmer l'importance de la culture politique ou idéologique qui nourrit les membres de la communauté considérée : on ne la perdra pas de vue en essayant d'évaluer les résultats ${ }^{1}$. On n'oubliera pas non plus que la cohésion nationale apporte une sévère limitation aux tentatives d'intervention venues de l'extérieur : la propagande étrangère trouve aisément son chemin quand elle est soutenue par de puissants éléments du pays considérés. Il en va ainsi particulièrement quand le concours est spontané. Sur ce fondement, les deux courants, international et national, qui tendent au même but, se renforcent réciproquement.

Mentionnons à ce propos la lutte menée depuis, la première guerre mondiale contre les "marchands de canons », soit par des individus isolés, soit par de grandes forces collectives. Sans doute les fabricants d'armes et les munitionnaires ont-ils riposté avec de puissants moyens financiers (la contre-attaque comportant la prise de contrôle de journaux, le lancement de campagnes d'esprit nationaliste, le financement de partis ou de ligues, etc.). Cependant la dénonciation des «marchands de mort »parfois exprimée en termes discutables et s'appuyant sur des sources contestables - a trouvé un vaste écho dans l'opinion. En bien des pays l'octroi aux industries d'armement d'une large part de responsabilité dans les conflits internationaux est devenu un trait significatif de la culture politique.

Une telle évolution est-elle susceptible de diminuer la force de pression des industries d'armement ou, plus largement, joue-t-elle au profit de la paix ? On manque certes du recul nécessaire à une formulation réaliste. Au surplus, de nos jours, le problème a été transformé par la multiplication des secteurs dont le niveau d'activité

L'importance de cette culture apparaît clairement si l'on étudie par exemple un événement comme l'affaire Finaly (voir l'ouvrage, plutôt polémique d'ailleurs, que lui a consacré M. KELLER, Paris, 1960). Inutile de rappeler les faits qui sont encore proches. En apparence, les parties en présence étaient des particuliers sans importance spéciale mais bientôt, de puissantes forces allaient être impliquées dans l'affaire : la hiérarchie catholique française et le judaïsme français (avec leurs inévitables prolongements internationaux, ainsi, envoi d'une lettre au Souverain Pontife par l'Alliance Israélite Universelle) ; des éléments religieux assez organisés pour tenter de soustraire les enfants à la famille en les cachant dans un couvent à l'étranger, etc. Dans le succès final remporté par les thèses juives, on ne peut négliger l'appui apporté par une large fraction de l'opinion publique pour laquelle un tel rapt était, à notre époque, inadmissible (courant assez fort pour conduire très vite la hiérarchie catholique à négocier avec le rabbinat et à s'entremettre pour assurer le retour des enfants). 
est fonction des commandes de guerre. Il n'est pas certain que les notions et critères [p. 326] valables pour les armes anciennes (dites " conventionnelles ») restent utilisables à propos des nouveaux engins.

Au total on a le sentiment que la question a, depuis les années 1930, subi de sérieuses modifications. Les activités directement intéressées à la guerre sont plus nombreuses et diversifiées. Mais elles semblent moins bien placées que par le passé pour se livrer aux intrigues et manœuvres classiques. Si ce phénomène est exact, il apparaît difficile de l'interpréter sans tenir compte du puissant mouvement protestataire qui, depuis une quarantaine d'années s'efforce d'éveiller et de mobiliser l'opinion. 
[p. 327]

\section{CHAPITRE IV}

\section{PREMIER BILAN}

$\underline{\text { Retour à la table des matières }}$

LE LECTEUR qui aura suivi jusqu'ici notre effort admettra sans doute que l'établissement d'un tel bilan est, à tous égards, prématuré. Si, au surplus, il lui est arrivé de lire l'un des nombreux manuels de « relations internationales » écrits pour le public de langue anglaise (et a fortiori, s'il en a lu plusieurs), son impression se transformera en certitude. N'est-il pas contestable, même en ayant recours à toutes les précautions d'usage, de porter un jugement sur les forces qui animent la vie internationale, alors qu'il n'existe encore aucun cadre solide, et unanimement accepté, pour en effectuer le classement?

Il serait tentant de suivre les voies de la prudence, qui sont souvent celles de la commodité, en évitant de prolonger l'analyse. Mais ce serait justement l'arrêter au point où son utilité peut se révéler la plus grande : la recherche sinon de véritables fils conducteurs, du moins de lignes de repère pour l'explication des événements contemporains. On tentera donc l'aventure, sans dissimuler que les développements de ce chapitre trop court pour le sujet abordé, et pourtant sans doute trop long eu égard au savoir disponible) constituent le résultat de réflexions personnelles et non le produit d'un plan systématique d'évaluation.

Deux séries de problèmes vont être évoquées. D'abord, l'examen des résultats de l'action des groupes sur la politique internationale et la vie intérieure des différents États. Il ne s'agit certes pas à ce stade de mettre en œuvre l'approche complexe et subtile du decision making, mais simplement de présenter quelques hypothèses préparatoires à l'introduction [p. 328] des forces étudiées dans le processus d'analyse. En second lieu, un essai d'intégration à la théorie politique des acquisitions encore modestes réalisées an cours de notre étude.

Ce thème final ne sera traité, en réalité, que «pour ordre ». La connaissance des groupes est médiocre, parfois purement nominale, cependant que la formalisation théorique reste fluide et sur bien des points inexistante. Une défaillance de cet ordre (et la similitude n'est pas l'effet du hasard) frappe l'étalon de mesure et le phénomène 
à apprécier. Ce livre traitant seulement des groupes de pression internationaux, on ne saurait étendre son domaine aux insuffisances de la formulation théorique proprement dite: on se bornera donc à suggérer diverses recherches capables d'améliorer les notions que nous possédons sur les groupes eux-mêmes.

\section{PLACE DANS LA VIE POLITIQUE}

$\underline{\text { Retour à la table des matières }}$

Comment ne pas tout d'abord se poser une question : les forces évoquées dans ce livre ont-elles en définitive le moindre poids sur le comportement des États ? Prenons quelques-unes de celles dont la capacité à s'organiser et à exercer des pressions semble la plus évidente : il serait facile de multiplier les exemples d'échecs d'une gravité exceptionnelle. Toute la puissance du judaïsme mondial s'est brisée sur le national-socialisme : des actions partielles pourront être menées à bien grâce à un combat sans relâche, mais le plan hitlérien d'extermination systématique trouvera sa mise en œuvre à l'échelle que l'on sait ${ }^{1}$. Aujourd'hui, Israël et l'Organisation Sioniste Mondiale ne parviennent pas à imposer la liberté de navigation dans le canal de Suez au profit des navires et des intérêts israéliens : le Département d'État, on l'a vu, se donne beaucoup de mal pour oublier et faire oublier une affaire qui accuse son indétermination fondamentale. Les grands trusts pétroliers réalisent chaque année un chiffre d'affaires bien supérieur au budget de nombreux États souverains: en plusieurs points du monde, l'Irak par exemple, ils sont réduits à une défensive sans panache. Le répit provisoire dont ils bénéficient résulte davantage de l'encombrement du marché (et de la survivance de quelques féodalités) que de leur capacité intrinsèque d'influence. Le mouvement catholique international est puissant, certes : mais le Maroc [p. 329] n'a pas hésité à refuser à Pax Romana l'autorisation de tenir un congrès sur son territoire (interdit à toute manifestation confessionnelle autre que islamique...).

Observons le problème d'un autre point de vue. L'action de dizaines de groupes, adossés à de puissantes forces gouvernementales, n'a pas conduit les autorités soviétiques à reculer d'un pouce dans la liquidation de la révolution hongroise. Les démarches d'une grande quantité d'associations, vigoureusement soutenues par tous les États communistes et d'innombrables éléments neutralistes n'empêche pas le réarmement de l'Allemagne occidentale — qui intervient d'ailleurs à la suite de celui de l'Allemagne de l'Est — de s'effectuer lentement mais inexorablement. Au cours des années récentes, de larges secteurs de l'opinion internationale ont pris position contre des exécutions capitales dont la légitimité morale paraissait contestable : rares pourtant sont les cas où la campagne (parfois doublée de l'intervention discrète de très hautes personnalités) parvint à imposer la commutation de la peine.

1 Voir le bilan dressé, année après année, par Isaac I. SCHWARZBART, 25 années au service du peuple juif. Une chronique des activités du Congrès Juif Mondial, août 1932-février 1957, op. cit. 
Faut-il donc en conclure que, sur le plan international, les États sont les seuls acteurs d'importance, que les seules pressions efficaces sont celles exercées par les gouvernements les uns sur les autres et que, dès lors, la seule voie ouverte à un groupe pour agir à un tel niveau, est de confier à un ou plusieurs gouvernements la défense de ses droits ou la promotion de ses vœux ? L'objectif de cette section est de montrer que cette présentation comporte des éléments de vérité et que, prise à la lettre, elle minimise à l'excès le rôle des forces privées.

Un aspect souvent oublié de cette fonction concerne les pays qui, pour des raisons diverses ne sont pas, ou pas encore, membres des Nations Unies : on peut admettre qu'ils y ont un certain accès par le canal de groupes privés internationaux auxquels sont affiliées les organisations nationales.

Il n'existe probablement aucun groupe de pression international dont on puisse dire, selon l'approximation littéraire connue, qu'il «mène le monde ». Mais ce serait verser dans une affabulation aussi répréhensible que de ramener à un rôle tout à fait auxiliaire, ou simplement dérive, les forces internationales de nature privée ou assimilées.

Voici dès maintenant, un fait remarquable : en bien des cas, les forces privées, on que nous tenons pour telles, se révèlent plus souples et surtout plus rapides que les appareils gouvernementaux à s'adapter aux changements de la situation. Dans les précédents chapitres, plusieurs cas [p. 330] de semblables «reconversions » ont été cités, particulièrement à propos de la «décolonisation". Les Églises ont généralement pris de vitesse les autorités politiques. Les centrales syndicales mais aussi des internationales d'affaires ont souvent devancé les gouvernements « atlantiques ». Dans le monde communiste lui-même, les organisations non-étatiques ont parfois précédé la diplomatie soviétique ou sont apparemment allés plus loin qu'elle.

Ce phénomène n'est pas nouveau. Il n'est pas inexact de faire remonter les origines de l'Organisation Internationale du Travail aux efforts d'un groupement privé : l'Association Internationale pour la Protection des Travailleurs. Créée à Paris en 1900 par des hommes venus de milieux divers (économistes, sociologues, fonctionnaires), cette organisation se proposait de favoriser par une action sur les gouvernements l'expansion unifiée de la législation sociale. Autre exemple : le Bureau International d'Éducation. C'est aujourd'hui un important organisme intergouvernemental ; mais il trouve sa source dans une O.N.G. fondée à Genève en 1925 et transformée en service officiel par un accord signé au mois de juillet 1929.

Cette situation s'explique par divers facteurs: lourdeur des administrations publiques ; soucis de politique étrangère qui conduisent à des ménagements (parfois de type acrobatique) ; existence de traités d'alliance... Il est vrai qu'en divers cas on peut présumer une sorte de division du travail entre le secteur officiel et les groupements et, au minimum, une connivence tacite (rappel de la classification suggérée entre capacité autonome et dérivée).

Avant d'entreprendre l'analyse du problème, il paraît souhaitable de spécifier un certain nombre de mises en garde. 


\section{a) EXIGENCES D'UNE ANALYSE POSITIVE}

\section{$\underline{\text { Retour à la table des matières }}$}

Compte tenu des déformations et polémiques qui s'attachent couramment à l'examen d'un tel sujet, il ne sera pas inutile de faire quelques remarques à cet effet.

$1^{\circ}$ La première observation aura trait à l'impartialité. Nul, à commencer par l'auteur de ce livre, ne saurait se targuer d'une réelle objectivité. On doit pourtant éviter d'ériger la vision partisane en principe d'explication. Or, beaucoup d'esprits n'abordent le domaine étudié ici que pour y chercher des arguments contre une force particulière (l’Église [p. 331] catholique ou le communisme international, par exemple) ou encore contre le système social dans son ensemble.

Il n'est pas rare, dans des cas de ce type, que le propos de l'enquête détermine à la fois l'énoncé de la question et le contenu de la réponse : de plus, pour peu qu'un grain de philosophie de l'histoire ou une ébauche de systématisation doctrinale s'en mêle, l'enquêteur aura l'avantage de connaître a priori le mécanisme conduisant de la question à la réponse. La démarche revient donc, finalement, à remplir un cadre entièrement prédéterminé et n'autorisant aucune échappatoire, en sélectionnant dans les faits et déclarations disponibles, ceux qui corroborent le schéma accepté.

Sur cette base, un avocat habile parviendrait à donner à n'importe quelle thèse un minimum de vraisemblance : si ce procédé est le support naturel de la polémique, on aurait tort d'en croire le travail universitaire pleinement exempt.

Dans cette perspective, l'usage des concepts doit être surveillé avec une vigilance particulière. Parmi les abus les plus courants, citons l'extension d'un qualificatif à des individus ou catégories n'entrant pas dans l'acception normale du concept - et se trouvant, au besoin, en opposition complète avec les éléments figurant déjà sous le pavillon. L'emploi du terme «communiste» pour disqualifier un adversaire est aujourd'hui de pratique courante, notamment sur le plan international. Toute appellation étant de nature conventionnelle, rien n'interdit a priori de dire « communiste » tout individu qui recommande l'extension de la sécurité sociale, se prononce pour l'union libre, ou considère qu'il revient aux autorités civiles de commander aux militaires. Cependant, le terme " communiste » ayant déjà un sens propre dans le vocabulaire politique, cette désignation est illégitime, à moins de bien spécifier qu'on entend lui donner un second sens, embrassant la ou les caractéristiques retenues. C'est justement ce que l'on se garde de faire, l'habileté consistant à étendre l'emploi du qualificatif sur la base de l'une des caractéristiques, d'une seule en vérité, qui constituent l'attitude du parti. Ainsi les partisans non communistes de la sécurité sociale seront-ils «amalgamés » aux communistes parce que ceux-ci revendiquent aussi l'extension du mécanisme. Ajoutons également que le caractère imprécis de nombreux concepts politiques (libéralisme, radicalisme, socialisme, etc.) facilite de telles opérations. 
[p. 332] Un procédé plus subtil est de forger un concept qui, sous une façade d'abstraction et de neutralité, se trouve construit de manière à définir, ou qualifier, les mêmes actes de façon différente selon leurs auteurs ou leurs destinataires. Il s'agit en somme d'une spécification ad hoc, voulue dès l'origine, ou adoptée par la suite. Pour un communiste orthodoxe, par exemple, aucun acte de l'U.R.S.S. ne saurait être de nature impérialiste puisque, selon la définition de Lénine, le terme s'attache exclusivement à une étape du capitalisme : d'où il suit que les conduites impérialistes ne peuvent venir que d'un certain nombre de puissances, localisées dans l'espace et le temps.

Cette tactique procure évidemment une grande tranquillité d'âme, en permettant de ranger dans des cadres différents des actes qui paraissent, pourtant, d'inspiration voisine. Ainsi, l'établissement d'une influence politique par la signature de contrats de livraison à long terme : technique utilisée par le national-socialisme pour saper la présence anglo-française en divers pays balkaniques et par l'U.R.S.S. pour miner la position occidentale en plusieurs pays sous-développés.

Observons que la science politique, quand elle emploie la catégorie « groupe de pression ", suit une direction exactement opposée. Elle part d'un critère qui est la constatation d'une certaine ligne de conduite : pression, directe ou indirecte, sur le gouvernement. Mais ensuite, elle rassemble dans cette classe et sans idée préconçue, tous ceux qui se livrent à une telle activité. L'inclusion dans la catégorie soulève chez quelques-uns des protestations, généralement fondées sur un facteur moral. Pourtant, même si cela doit lui valoir l'accusation, assez ridicule en vérité, de tendances technocratiques, notre discipline range sous cette rubrique, syndicats ouvriers et associations patronales, forces spirituelles et intérêts matériels... les uns et les autres ayant désormais l'habitude d'agir par la voie gouvernementale. Un tel concept apporte ainsi, et c'est un immense avantage, un facteur d'interprétation uniforme.

Voici un dernier aspect de ces déformations : la justification idéologique des moyens utilisés par référence aux fins ou, si l'on préfère, la sanctification inconditionnelle des fins. Pour le chercheur, des problèmes complexes découlent de cette pratique devenue habituelle. L'analyse politique n'a pas pour règle d'ignorer les fins. Elle s'efforce de les identifier sans tomber dans le piège des prétextes ou des alibis : mais elle laisse au moraliste et, le cas échéant, au citoyen, le soin de porter sur elles un jugement éthique. Les buts étant déterminés par les instances [p. 333] compétentes, il revient au spécialiste d'apprécier l'efficacité des moyens envisagés ou utilisés : il ne sort pas de son rôle en déclarant tels objectifs irréalisables ou, ce qui revient au même, en montrant qu'ils exigeraient des instruments que les autorités ne veulent ou ne peuvent employer. Il lui revient aussi d'énoncer la règle de la spécialisation des moyens ou, si l'on préfère, d'établir l'existence de relations exclusives entre certains moyens et certaines fins : ce qui revient à dire que ces mesures échoueront si on les applique à des objectifs différents. Mais aucune de ces démarches n'oblige à admettre qu'un moyen ou un instrument change de sens simplement parce qu'il plaît à son utilisateur de se réclamer d'une fin idéale (dont l'excellence est généralement matière à interprétation subjective). 
Pour les juristes soviétiques, la nécessité première est de distinguer l'État « socialiste » de l'État « exploiteur ». On ne comprendrait rien selon eux à la situation si l'on refusait d'admettre cette opposition radicale de principe. Le raisonnement serait plus convaincant si tous les régimes, totalitaires ou autoritaires, ne se réclamaient au départ du même postulat. Il reste au surplus troublant d'observer que, dans la mesure où un effort de restauration de la légalité a été accompli en U.R.S.S. ce pays s'est borné à mettre en œuvre des procédures et garanties connues de longue date dans les vieilles démocraties de l'Occident.

$2^{\circ}$ Deuxième écueil à éviter dans cette analyse de l'influence des groupes : le dogmatisme, c'est-à-dire une position rigide et imperméable à l'expérience, ou encore, l'attachement inflexible à des conceptions qui ont cessé de correspondre à la situation et sont devenues des schémas périmés. Cette attitude, cause ou conséquence du sectarisme, est une position très courante dont il est nécessaire d'exposer quelques aspects ${ }^{1}$.

N'ayons pas peur d'écrire que l'on se rend certainement coupable de quelque dogmatisme en attaquant le sujet par grandes catégories : internationales syndicales, internationales d'affaires,... auxquelles même en connaissant l'hétérogénéité d'un tel regroupement, on est insensiblement porté à attribuer un comportement uniforme. La thèse de l'unité du monde des affaires à l'égard de la politique n'est pas soutenable sans une certaine candeur, moins rare qu'on ne le suppose, ou un vigoureux désir de polémique. Sur le plan international, des divergences s'observent d'une firme à l'autre et même entre les filiales d'un grand trust réparties [p. 334] entre plusieurs pays. Elles tiennent, soit à l'équation personnelle des dirigeants, soit à une diversité d'appréciation des facteurs objectifs.

On peut faire une observation analogue à propos de l'expression «tiers monde » qui rassemble des éléments hétérogènes de niveau économique et culturel fort inégal. Unis sur quelques grands thèmes de signification morale, ces pays se séparent dès que surgissent des difficultés politiques concrètes. Il est improbable que l'accès généralisé à l'indépendance n'accentue pas ces clivages.

$\mathrm{Au}$ surplus les relations changent. Si l'on considère l'évolution des rapports politiques et singulièrement l'éveil des nationalités, il serait pour le moins curieux que les schémas politico-économiques forgés à la fin du siècle dernier demeurent valables aujourd'hui. Or, en matière d'analyse sociale, il existe souvent un important retard de l'explication sur les faits, cultural lag disent les Américains, qui conduit à garder en service de vieilles notions dépassées.

\footnotetext{
Pour une intéressante critique du dogmatisme marxiste, voir LUTHY (H.), « L'impérialisme ou les martyres posthumes de Karl Marx ", Preuves, juillet 1960, pp. 39-52. Le prétexte en était le volumineux ouvrage de Fritz STERNBERG, Le conflit du siècle, capitalisme et socialisme à l'épreuve de l'histoire, traduit de l'allemand. Paris, 1958. L'ouvrage, particulièrement dogmatique, souffre beaucoup du traitement caustique infligé par Luthy. Mais les remarques de ce dernier ont une portée générale en dehors de l'objet, auquel elles s'appliquaient directement.
} 
Sans doute le perfectionnement de l'outillage statistique rend-il assez vite apparents les changements réalisés dans les éléments quantifiables, mais aucun dispositif ne permet de saisir directement les transformations survenues dans les mentalités, parfois à l'insu des intéressés eux-mêmes. On ne saurait les appréhender qu'au prix d'une importante recherche socio-psychologique susceptible de faire ressortir de temps à autre, les grandes lignes d'une modification éventuelle, mais encore incapable de démonter le processus même de la mutation.

À cette explication, somme toute honorable, de la situation s'ajoutent d'autres facteurs de conservatisme intellectuel : attachement aux données acquises, poids des traditions, souci de garder une interprétation dont la valeur polémique est éprouvée. Nous en trouvons un exemple dans les attaques volontiers lancées contre les prêteurs de fonds à l'étranger, surtout dans les pays ayant reçu ces apports. Or, depuis la première guerre mondiale, les porteurs de telles créances n'ont cessé de subir des avatars graves qui sont allés dans plusieurs cas (y compris en des pays développés ou semi-développés) jusqu'à une spoliation complète ${ }^{1}$.

Autre aspect de ces changements : le rôle pris ou repris par les étudiants dans la politique au cours des dernières années. Sous l'effet d'un intense bombardement idéologique, nous avons fini par considérer que les révolutions du $\mathrm{XX}^{\mathrm{e}}$ siècle seraient prolétariennes, les travailleurs organisés formant en somme le mouvement de pointe et fournissant les colon-[p. 335] nes d'assaut. Or, en de nombreux cas récents, ce sont les étudiants qui ont pris la tête de l'agitation ou même ont été seuls à la créer : phénomène qui nous plonge en fait dans l'atmosphère des révolutions libérales du $\mathrm{XIX}^{\mathrm{e}}$ siècle. Est-ce là un épisode ou une modification durable ?

Un trait caractérise l'époque actuelle, même s'il ne lui appartient pas en propre : la possibilité pour un « petit » de tenir tête à un " grand, voire même à un très grand en se fondant sur une meilleure position morale dans la société internationale. On peut observer dans la pratique des combinaisons diverses : petit État contre un plus grand ou, encore groupe à faibles ressources (par exemple, mouvement d'émancipation coloniale) contre un grand État ou, enfin, petit État contre un groupe international très puissant. Il est probable que des oppositions de ce type ont toujours existé mais il n'est pas certain que le phénomène ait déjà revêtu dans l'histoire occidentale son acuité actuelle.

1 Citons, sans insister, la liste des «déboires » de l'épargne française dans le recouvrement des créances sur l'étranger telle qu'elle figure dans le dernier rapport de l'Association de Porteurs Français de Valeurs Mobilières : emprunts russes dette extérieure grecque ; emprunts brésiliens; anciens emprunts allemands emprunts autrichiens ; litiges avec l'Argentine; emprunts de l'Europe centrale ; emprunt 4\%-or 1901 au Congo ; service des obligations norvégiennes ; emprunt ville de Tokyo. Les difficultés sont plus ou moins graves selon les cas : elles vont d'une carence totale à de simples problèmes en voie de règlement. Mais l'Association souligne les faibles progrès enregistrés, au total, dans le recouvrement de ces créances: ce qui la conduit à souhaiter l'établissement d'une " charte des crédits extérieurs ». Ailleurs, les capitalistes, avant de s'engager dans des pays comportant des risques politiques ou monétaires exceptionnels, demandent des garanties à leur propre gouvernement (rôle considérable joué aux États-Unis par l'International Cooperation Administration). 
On verserait dans la tendance apologétique en prétendant que, désormais, le « petit» est toujours en mesure de résister au "grand»: le temps des annexions discrètes et des étranglements silencieux n'est pas révolu. Et, par ailleurs, le " petit » est mieux armé pour se défendre contre une attaque expresse, que contre la supériorité dont dispose le " gros » par ses dimensions mêmes et, éventuellement, hors de toute visée agressive. Pourtant il n'est pas impossible que des changements considérables se soient produits au cours des dernières années, le plus important paraissant être l'espèce de réprobation universelle qui entoure certains actes ou qui interdit divers procédés.

Ce phénomène qui aboutit, en plusieurs cas, à une dévalorisation relative de la puissance matérielle, tient à des causes multiples: jeu de l'opinion publique internationale ; transformation, qui joue en faveur des petits et des pauvres, dans la composition de l'O.N.U. et de ses Agences spécialisées; mauvaise conscience, inconnue dans le passé, des peuples ayant acquis un statut privilégié ${ }^{1}$; concurrence entre les États-Unis et l'U.R.S.S., pour la domination mondiale, etc.

Nul ne saurait prédire s'il s'agit là d'un renversement définitif des perspectives, ou d'un phénomène transitoire appelé à se résorber avec telle ou telle des causes qui expliquent son succès (la seconde éventualité si l'on considère l'expérience historique étant tout de même plus vraisemblable que la première). Pour l'immédiat en tout cas, c'est un facteur avec lequel on doit compter : l'effet « réducteur » de l'influence jouant [p. 336] aussi bien pour les grands États que pour les groupes importants (spécialement les internationales d'affaires).

$3^{\circ}$ Troisième écueil à éviter enfin : la tendance à faire de l'action des groupes de pression le facteur exclusif de l'action politique. Explicable si, dans le prolongement de la pensée de Bentley on ramène à la catégorie "groupes » toutes les institutions publiques, cette surestimation n'a plus de sens dès que l'on conserve en gros, comme on l'a fait ici, la distinction public-privé. Les groupes sont, à tous les niveaux, l'un des éléments du combat politique : ils contribuent à façonner le déroulement de cette lutte qui, par un choc en retour, modèle leur dispositif d’action.

Les organismes de pression occupent en définitive une place dont on peut s'efforcer de délimiter les contours, mais qu'il est impossible de mesurer avec exactitude : encore cette évaluation approximative est-elle difficile à établir, compte tenu de l'action propre de facteurs extérieurs aux groupes dont voici quelques-uns.

Mentionnons comme éléments caractéristiques le rôle des événements, le poids des forces matérielles, l'influence des rapports entre les choses. Il ne s'agit pas de réintroduire par ce biais un déterminisme géographique que, sous sa forme primitive, les plus brillants esprits n'ont cessé de dénoncer. Pourtant, il est des évolutions liées

\footnotetext{
Mauvaise conscience que créent ou entretiennent les critiques parfois extrêmement dures de la politique occidentale faites par les Occidentaux eux-mêmes. Voir sous cet angle, l'ouvrage de L.J. LEBRET, Suicide ou survie de l'Occident, Paris, 1958. Voir également, à titre de test, la mise en accusation de son pays que vient de faire, le sociologue américain C. WRIGHT MILLS, Listen Yankee. The revolution in Cuba, New York, 1960.
} 
notamment à des facteurs technologiques, qui prennent naissance et se précipitent hors de la volonté des parties en présence : ces dernières ayant seulement les moyens, à condition de disposer des ressources indispensables, de lancer une manœuvre pour tenter de renverser, ou au moins de modérer, le courant constaté.

La remarque a une portée évidente quand il est question de déterminer les facultés et responsabilités propres d'un groupe à l'égard de ses interlocuteurs: il s'agit, notamment, de ne pas lui imputer les conséquences de phénomènes échappant à sa juridiction. La surproduction pétrolière actuelle oblige les États arabes à composer avec les firmes du cartel. Situation due à l'impérialisme de ces firmes ? Peut-être, mais ne résulte-t-elle pas aussi de l'impuissance présente de ces trusts à contrôler une conjoncture dont le déroulement leur est favorable ? Le répit politique qui leur est ainsi offert découle moins d'un complot que d'un mouvement du marché extérieur à leur volonté. On rencontrera plusieurs cas du même ordre attestant que, sous tous les régimes, l'élément matériel continue d'exercer une incontestable influence.

[p. 337] Autre point : le rôle des hommes. On l'a déjà envisagé sous ses aspects généraux et on se bornera donc ici à quelques remarques supplémentaires concernant la politique internationale. Il est souvent possible d'intégrer le facteur humain à la théorie des groupes. Avec quelle pondération toutefois ? Voici un exemple simple, mais intéressant, tiré des discussions intervenues entre les commerçants américains installés au Maroc et les autorités françaises, dans le courant des années 1950.

Il semble que l'affaire ait été particulièrement poussée par l'un des 37 commerçants en cause, qui était alors président de l'American Trade Association of Morroco : affirmant l'existence de discriminations à l'égard d'intérêts américains, il en vint à revendiquer l'adjonction d'un amendement à la loi d'aide qui aurait privé la France de tout concours des États-Unis. Or il fut assez fort et habile pour intéresser à sa cause deux sénateurs américains qui parvinrent à pousser l'affaire au point où le gouvernement français, inquiet et excédé, annonça son intention de présenter le dossier à la Cour Internationale de Justice ${ }^{1}$. Il n'est pas douteux que l'énergie déployée par le président de l’Association ait pesé sur le cours de la discussion. Mais, précisément, il agissait au nom d'un groupe et une telle situation relève alors de la formule selon laquelle celui qui lutte c'est l'homme social, c'est-à-dire une collectivité plus ou moins volumineuse ${ }^{2}$. Est-ce toujours vrai, en particulier dans l'ordre de la politique extérieure?

On peut se poser la question à deux niveaux. D'abord, celui de l'homme ordinaire qui n'exerce pas de fonction gouvernementale et n'ambitionne pas de jouer un rôle politique. Deux auteurs américains ont tenté de préciser l'influence exercée par l'individu de ce type sur la politique étrangère en dehors de toute affiliation de groupe

COHEN (B.C.), The Influence of Non-Governmental Groups on Foreign Policy-Making, op. cit., p. 10.

2 Dans la terminologie reproduite par G. PLEKHANOV, Essai sur le développement de la conception moniste de l'histoire, Moscou (Éditions en langue étrangère 1956, p. 267. 
(au sens de groupement organisé et non de milieu social, bien entendu) ${ }^{1}$. Dans l'état présent de la méthodologie, il apparaît difficile de donner un tour opérationnel à cette distinction (qui, poussée jusqu'à son fondement, reviendrait à tenter d'évaluer la part respective de la démocratie représentative et de la démocratie fonctionnelle dans la conduite de la politique étrangère). Il y a un second niveau : celui de l'homme promu, par ses qualités et les circonstances, à occuper une place exceptionnelle tout en demeurant extérieur, au besoin temporairement, à la sphère gouvernementale.

Est-il possible d'admettre, par exemple, que le général de Gaulle, n'ait pas joué un rôle particulier dans le rejet de la C.E.D. (dépassant [p. 338] de beaucoup les simples consignes données aux anciens députés du R.P.F. qui continuaient à lui être fidèles) ? Sa conception négative n'a-t-elle pas contribué à cristalliser dans la résistance au traité un secteur de l'opinion modérée qui, sans cela, aurait pu adopter, soit une position de soutien réticent, soit une attitude de neutralité résignée?

L'étude de ces problèmes sortirait du cadre de notre livre puisque nous avons entendu, dès le départ, établir une séparation entre l'action collective et l'action proprement individuelle. Ces remarques, insistant à nouveau sur des points déjà considérés, n'avaient d'autre but que de rappeler la nécessité d'une vision pluraliste qui n'est pas forcément un pur éclectisme.

\section{b) INTÉRÊTS ÉCONOMIQUES ET POUVOIR POLITIQUE}

\section{$\underline{\text { Retour à la table des matières }}$}

Sans oublier les réserves exposées sur le dogmatisme d'une telle question, on peut tenter de rechercher, à titre d'orientation générale, les relations qui unissent ces deux secteurs de l'activité humaine, spécialement dans l'ordre des relations internationales. Une réponse complète vient à l'esprit: la conception léniniste de l'impérialisme formulée voici une quarantaine d'années sur la base de faits antérieurs à la première guerre mondiale. Or, les marxistes considèrent, semble-t-il, qu'en dépit des grands changements intervenus dans la situation internationale, les principes posés à la base de cette construction restent valables pour le monde contemporain. Est-on tenu d'accepter ce verdict?

Rappel de la thèse léniniste - On ne saurait expliciter ici, même de façon schématique, la thèse soutenue par Lénine qui, par sa vaste diffusion, relève aujourd'hui du domaine le plus commun et le mieux connu de la pensée politique. Elle est d'ailleurs assez claire et solidement construite, pour se laisser réduire à quelques propositions principales : concentration de la production et des capitaux qui transforme peu à peu le capitalisme fondé sur la libre concurrence en capitalisme

1 ADLER (K.P.), BOBROW (D.), «Interest and Influence in Foreign Affairs », Public Opinion Quarterly, Spring 1956. 
monopoleur ; conquête d'une importance toute spéciale par les banques : domination de l'économie par le capital financier et l'oligarchie de l'argent ; exportation intensive des capitaux, aussi bien dans les colonies que dans les États juridiquement indépendants ; partage du monde entre les sociétés capitalistes (cartels internationaux, accords entre les trusts); répartition [p. 339] du monde entre les Puissances capitalistes pour de nouveaux débouchés et de nouvelles sources de richesses naturelles.

De ces cinq indices ou chaînons, le plus important peut-être pour les tenants de cette conception, est le second : fusion du capital bancaire et du capital industriel et création, sur la base de ce « capital financier », d'une oligarchie financière. Concluons ce bref rappel avec une citation de Lénine lui-même : "L'impérialisme est : $1^{\circ}$ le capitalisme monopoliste; $2^{\circ}$ le capitalisme parasitaire ou pourrissant; $3^{\circ}$ le capitalisme agonisant ${ }^{1}$.

Tout spécialiste est en droit de donner sa définition personnelle du concept utilisé, l'opération aboutissant selon le cas, nous l'avons dit, soit à en réserver l'usage exclusif à une catégorie déterminée de phénomènes (concept fermé qui suppose la mise en œuvre de spécifications ad hoc), soit à proposer une notion permettant d'accueillir au fur et à mesure qu'ils se présentent ou qu'on les découvre, tous les faits objectivement rattachables au critère choisi (concept de type ouvert). Or, avant Lénine ou en même temps que lui, d'autres avaient utilisé le terme « impérialisme » en un sens large : par exemple Schumpeter, dans son Essai sur la sociologie de l'impérialisme (1919). Pour lui, la poussée impérialiste trouve en elle-même sa propre justification : elle est indépendante, en particulier des conditions économiques et, à ce titre, est le fait aussi bien de l'ancienne Égypte que de l'Angleterre du XIX ${ }^{\mathrm{e}}$ siècle ${ }^{2}$. Et les analystes des idées politiques n'ont aucun mal à trouver les racines de ce concept chez d'anciens

1 Euvres complètes, Tome 23, p. 116 de l'édition française. Pour une étude de la pensée léniniste, voir naturellement L'impérialisme, stade suprême du capitalisme, Paris, 1952. Ajouter VARGA (E.), MENDELSOHN (L.), Données complémentaires à «L'Impérialisme » de Lénine, Paris, 1950 et STALINE (J.),

Les questions du léninisme, 2 vol., Paris, 1946-47 (spécialement tome I, pp. 9-86). Pour une application intégrale de la doctrine, consulter Histoire moderne, cours d'histoire, enseignement secondaire, traduit du russe, Leningrad, Éditions scolaires d'État, 1959 (spécialement chapitres 3032). Voir également Manuel d'économie politique (de l'Académie des Sciences de l'U.R.S.S.), Paris, 1956, pp. 247-289. Se reporter enfin à DRAGUILEV (M.), La crise générale du capitalisme, Moscou, Éditions en langues étrangères, 1960. On y trouvera un parfait exemple des difficultés considérables qu'impose la volonté d'appliquer un système doctrinal rigide à une réalité en pleine évolution.

2 Voir SCHUMPETER (J.), Imperialism and Social Classes, traduit de l'allemand, édité et précédé d'une introduction de Paul M. SWEEZY, Oxford, 1951. Autre conception ouverte: celle développée par TERLINDEN (Vicomte), Impérialisme et équilibre. La politique internationale depuis la Renaissance jusqu'à la fin de la seconde guerre mondiale, Bruxelles, 1952 (entend démontrer que de Charles Quint à nos jours deux principes seulement ont dominé la vie internationale : l'impérialisme générateur de guerres et les politiques d'équilibre, d'abord empiriques et puis systématiques, dont le but est de maintenir la paix). 
auteurs, tel Bacon qui préconisait un retour à l'idée romaine de grandeur, fondée cette fois sur un support naval, et considérait l'expansion comme un devoir ${ }^{1}$.

La conception de Lénine établit une solution de continuité entre les phénomènes du passé (comme le dit H. Luthy : « Les Colomb, Pinzon, Pizarre, chercheurs d'or et bâtisseurs d'empire... les condottières de la Renaissance ou les marchands aventuriers du Haut Moyen-Âge ou n'importe quel organisateur de conquête et de chasse d'esclaves de l'antiquité »). On lui reproche aussi de suggérer que le capitalisme a engendré l'impérialisme alors que sans le second, qui a créé une accumulation financière primitive et ouvert, à une large échelle, le cycle sources d’approvisionnement-débouchés, le premier n'aurait probablement pas vu le jour.

Ces reproches ne sont peut-être pas décisifs, la science sociale contemporaine nous invitant à étudier les déterminismes sociaux dans chaque [p. 340] société globale avant de procéder à une quelconque extension. Dès lors, il n'est pas illégitime pour commencer de limiter le modèle explicatif à la période 1890-1920 effectivement observée par Lénine et caractérisée, au moins dans les sociétés industrialisées, par une relative uniformité des conduites économiques. Mais, dans ces conditions, pour avoir le droit d'étendre ce schéma à notre époque, il faudrait établir, autrement que par une profession de foi, que 1960 prolonge exactement 1910 et qu'entre temps, la société globale, de type occidental, n'a pas subi de modification qualitative (la volonté de ranger en un seul type des sociétés aussi variées que celles d'Amérique du Nord, de Scandinavie, de Grande-Bretagne, d'Europe occidentale, du Japon... étant d'ailleurs une manifestation typique de dogmatisme).

Un point est frappant : l'âpreté avec laquelle les marxistes défendent la conception léniniste de l'impérialisme et le mépris dont ils accablent ceux qui la remettent en cause. Une controverse récente permet de saisir le sens et les motifs de cette attitude.

Partant du phénomène de la conquête, un auteur britannique vient de définir l'impérialisme «comme le processus par lequel certains peuples et nations conquièrent, soumettent, puis dominent de façon permanente (de jure ou de facto) d'autres pays et nations $"{ }^{2}$. L'entreprise qui, de façon ambitieuse veut définir un concept valable pour toutes les formes de société est-elle légitime ?

Tel n'est pas l'avis de M. Palme Dutt qui y voit, non sans raison d'ailleurs, un essai de justification d'une thèse particulière : le caractère post-impérialiste de l'Angleterre contemporaine. Il lui reproche d'oublier que l'impérialisme déborde de loin le cadre des empires coloniaux proprement dits, et de ne pas comprendre que seuls les pays faisant actuellement partie du camp socialiste sont parvenus à s'affranchir de toutes les formes d'impérialisme ${ }^{3}$. La première réserve se situe au niveau de la réflexion scientifique : on peut toujours discuter de la valeur d'un concept comme instrument de

\footnotetext{
WHITE (H.B.), « Bacon's Imperialism », American Political Science Review, juin 1958, pp. 470489.

Il s'agit de John STRACHEY (ancien ministre du Labour), The End of Empire, Londres, 1959.

In « Lénine, l'impérialisme et M. Strachey », Nouvelle Revue Internationale, avril 1960, pp. 22-40.
} 
regroupement des faits dont la similitude ou l'homogénéité rendent un traitement unifié souhaitable.

La seconde remarque, par contre, nous fait brusquement passer du plan de la science à celui de la croyance. Mais comme la croyance ne se démontre pas, il n'existe qu'un moyen de tenir les curieux en respect : éviter que la question litigieuse ne soit posée. Et pour cela il faut repousser systématiquement et catégoriquement, toute définition de l'impérialisme qui ne s'applique pas aux seuls pays auxquels on a décidé, dès le [p. 341] départ, de réserver ce terme, devenu par la force de la propagande l'injure élémentaire à l'égard d'une partie du monde. Mais dès lors, quiconque n'accepte pas le dogme ne saurait être contraint d'adopter un tel point de vue.

Un historien anglais a renversé le problème en soulignant la fausseté des déclarations selon lesquelles, une fois abolie la propriété privée des moyens de production, il ne peut y avoir d'impérialisme, d'asservissement ou d'exploitation d'une nation par une autre ${ }^{1}$. Nuançons un peu sa pensée en disant qu'aucun facteur n'autorise à absoudre d'emblée les États collectivistes d'une telle imputation. Admettre a priori semblable prétention reviendrait simplement à céder au vertige de la propagande $^{2}$ : en d'autres termes, la situation doit être examinée cas par cas sur la base de faits prouvés et non en fonction d'idéologies préconçues.

La thèse léniniste de l'impérialisme se présente avant tout comme une arme de combat, la pensée chez Lénine n'ayant jamais été séparée de l'action ${ }^{3}$. Notons que, même si les observations sur les États attaqués se révélaient exactes, rien n'obligerait à considérer, sinon un pur tabou idéologique, que ceux-ci ont été et restent nécessairement les seuls à pratiquer les actes en cause. Mais, dans la sphère dont il entend rendre compte, le modèle de Lénine correspond-il aux faits ?

Évaluation de cette thèse - Sans prétendre à l'originalité, nous nous bornerons à évoquer, entre autres objections disponibles, trois points sur lesquels le schéma proposé ne semble pas pleinement en harmonie avec certains phénomènes de la période 1890-1914.

Soit d'abord la colonisation. Est-il légitime de porter un jugement d'ensemble et, par exemple, de définir catégoriquement l'expansion coloniale française ? $\mathrm{H}$.

1 SETON-WATSON (Hugh), Neither War nor Peace. The struggle for power in the post-war world, Londres, 1960, pp. 264.

2 En dépit de son évidente partialité, un ouvrage comme celui de Walter KOLARZ, La Russie et ses colonies, traduit de l'anglais, Paris, 1954, apporte des matériaux que l'on ne saurait récuser d'emblée. Il reste à savoir si, en particulier, les termes de "colonie » ou «colonialisme » conviennent pour caractériser les faits d'exploitation relevés dans la Zone soviétique, spécialement dans les années ayant suivi le second conflit mondial (phénomène dont quelques-uns ont disparu depuis lors). C'est là un simple problème de conceptualisation. Disons, sans insister, que, sur le plan scientifique, l'emploi d'un vocabulaire différencié serait préférable : ce qui revient à dire que le colonialisme traditionnel n'est pas la seule forme de domination politico-économique.

3 SMITH (D.G.), "Lenin's Imperialism : a study in the unity of theory and practice ", Journal of Politics, novembre 1955, pp. 546-569. 
Brunschwig souligne exactement la difficulté d'une telle démarche en disant que, sur aucune des questions qui se posent dans le cas français, il n'y a de bonne monographie ${ }^{1}$. En d'autres termes, la généralisation doctrinale précède l'élucidation des faits. Il est vrai qu'en diverses occasions, le schéma colonialiste usuel trouve une application facile; en Indochine, notamment, le régime colonial, imposant des charges aux contribuables indo-chinois et métropolitains, a principalement fonctionné au profit de quelques groupes financiers et de la population française, assez peu nombreuse d'ailleurs, installée dans le pays ${ }^{2}$. De même, il serait aisé de trouver des cas illustrant parfaitement les traits que l'on prête à l'exploitation coloniale (dilapidation des [p. 342] ressources, blocage du progrès économique...) ${ }^{3}$. Ces faits, qui sont loin d'exprimer toute la réalité, autorisent-ils à penser que l'expansion coloniale de la France fut d'essence économique et que ce pays fut contraint de trouver des colonies pour y déverser un excédent d'hommes et de capitaux ?

Il est permis d'en douter. Si l'on se place dans les années 1930, on constate que la mise en œuvre des territoires coloniaux acquis dans le dernier quart du $\mathrm{XIX}^{\mathrm{e}}$ siècle, spécialement l'Afrique noire, était à peine entamée. Les capitaux investis en Afrique par l'épargne française, publique et privée, sont demeurés jusqu'à une époque bien récente à un niveau très bas. Il serait difficile de croire que le capitalisme français d'alors ait dû son salut aux phénomènes d'exploitation, du type pacte colonial, enregistrés en divers points de cet immense Empire. À la veille de la première guerre mondiale, l'économie française, comme aussi l'économie anglaise, étaient stagnantes malgré la possession de vastes territoires d'outre-mer et l'économie allemande en pleine expansion (alors que l'Allemagne n'avait recueilli qu'une faible part des « dépouilles »).

À la base de l'expansion coloniale, on reconnaît des mobiles autres qu'économiques. C'est incontestable pour le cas français et on a peine à penser qu'il soit unique. Encore que non écrite, la règle qui a prévalu à cette époque est que la possession d'un empire ultra-marin constituait l'attribut indispensable d'une grande puissance, cette clé permettant de forcer l'entrée du club des États dominants. Des considérations stratégiques sont intervenues et, pour la France, un certain dynamisme militaire a constitué un facteur essentiel. À ce point, on est contraint de renverser le schéma habituel : les intérêts économiques ne sont plus le moteur, mais un prétexte

1 Voir son intéressant ouvrage Mythes et réalités de l'impérialisme colonial français, 1871-19.14, Paris, 1960 : l'auteur souligne les aspects chauvins et même racistes que le colonialisme a revêtus chez certains hommes politiques de la $\mathrm{III}^{\mathrm{e}}$ République (Jules Ferry en tête). Se reporter aussi à l'intéressant ouvrage d'Aimé Césaire TOUSSAINT-LOUVERTURE, La Révolution française et le problème colonial, Paris, 1960.

2 Voir CHESNEAUX (Jean), Contribution à l'histoire de la nation vietnamienne, Paris, 1955. Si plusieurs chapitres de ce livre semblent appeler de fortes réserves, l'interprétation donnée des résultats de la présence française ne paraît pas fondamentalement contestable.

3 Voir par exemple KALKC (Pierre), Réalités oubanguiennes, Paris, 1958. Pour une étude plus large de conception marxiste, voir SURET-CANALE (J.), Afrique Noire occidentale et centrale, tome I, Paris, 1958 (s'arrête à l'année 1950). L'auteur a publié un chapitre du Tome II en préparation, « Le régime des grandes concessions au Congo français (1899-1914) et ses conséquences " in La Pensée, septembre-octobre 1960, pp. 10-23. 
couvrant l'action politique (phénomène très net dans le cas des interventions allemandes à l'égard du Maroc) ${ }^{1}$.

Cette importance attribuée au mobile politique n'exclut nullement que financiers et spéculateurs ne s'intéressent à l'affaire, ne poussent à sa réalisation et n'en tirent avantage. Comme l'a montré $H$. Brunschwig, le colonialisme français d'abord « patriote » dans la période 1870-1890 s'imprégna progressivement de tendances mercantiles. Ce que l'on a appelé en France le «parti colonial » (on parlerait aujourd'hui de lobby), associait des hommes politiques, des intellectuels, des milieux militaires et navals, des missions religieuses : il comprend aussi, bien sûr, des hommes d'affaires. La recherche historique contemporaine nous met seulement en garde contre les dangers d'une interprétation unilatérale (ainsi, [p. 343] selon l'expression de Brunschwig, celle qui ramènerait l'impérialisme colonial, à une « curée de capitalistes avides de riches territoires »).

Observons maintenant l'exportation des capitaux dans les États juridiquement indépendants. Les conséquences économiques de la pénétration financière sont bien connues: exploitation des ressources naturelles du pays d'accueil au profit de l'expéditeur ; élargissement des marchés d'exportation grâce à la technique dite des prêts liés ; conquête de positions stratégiques (services publics, chemins de fer...) dans les pays visés par cette forme de l'impérialisme, etc. On pourrait sans doute avancer des centaines d'exemples d'intervention de ce type, plus rémunératrices au total que l'exploitation coloniale classique. Mais, encore une fois, ces soucis d'enrichissement et de spéculation expliquent-ils tout le mouvement des capitaux ?

Considérons encore le cas de la France. Compte tenu de l'esprit d'épargne de la population, le marché financier français disposait d'une quantité considérable des capitaux privés dont, au cours des quinze à vingt années qui ont précédé la première guerre, le quart environ fut consacré à des investissements à l'étranger. Il s'agit d'une masse de manœuvres importante, plus d'un milliard de francs-or par an. Or, il est désormais bien connu que la politique extérieure française a été en mesure d'employer cette arme financière et ne s'en est pas fait faute. À l'époque d'ailleurs, cette propension aux investissements étrangers a été vivement critiquée en divers milieux qui lui reprochaient d'aboutir à une négligence dans la mise en valeur du patrimoine national.

Deux facteurs ont facilité cette utilisation: la nécessité d'une autorisation gouvernementale pour les émissions de valeurs étrangères et le penchant des épargnants français pour les titres à revenu fixe ${ }^{2}$. Les gouvernements français de

Voir les remarques de Jacques GRUNEWALD, op. cit., pp. 21-22.

On estime qu'à la veille de la première guerre mondiale, le portefeuille de valeurs coloniales et étrangères appartenant à des épargnants français, était de l'ordre de 40 milliards. Les deux tiers environ couvraient des pays européens (plus de 10 pour la seule Russie), un tiers seulement allant au reste du monde. Dans les évaluations classiques (NEYMARK, FEIS), le poste « Tunisie et colonies » compte pour environ 3 milliards (le minimum d'estimation étant de 2 milliards et le maximum de 4). O. MOREAU-NÉRET, auquel nous empruntons ces données (Les Valeurs mobilières, op. cit., tome II, pp. 298-302), attribue cette carence à l'égard de l'empire colonial à « la 
cette époque ont agi de manière à interdire aux États considérés comme hostiles l'accès au marché : ils sont ainsi parvenus à bloquer toutes les tentatives d'introduction en France de titres allemands. Par contre, les gouvernements ne cessèrent d'appuyer les demandes présentées par les États amis et spécialement par le gouvernement russe à partir du moment où fut signé l'alliance avec ce pays : ils y voyaient un moyen de renforcer la position diplomatique du pays. Il est clair que cette préoccupation n'allait pas jusqu'à l'ignorance des intérêts économiques : en certaines occasions, les négociateurs s'efforceront d'obtenir, en contrepartie des autorisations accordées, divers avantages matériels (commandes d'équipement à passer aux industriels fran-[p. 344] çais). Mais en de pareilles occasions, ce souci commercial ne fut pas le mobile dominant.

Le fonctionnement de l'alliance franco-russe illustre bien l'emploi de la puissance financière d'un pays à des fins politiques. Par exemple, l'appui de la diplomatie russe en diverses circonstances (ainsi, Conférence d'Algésiras) paraît avoir été acquis grâce à la promesse française d'autoriser de substantielles émissions sur le marché financier. Sans aucun doute, ces opérations ont rapporté des bénéfices considérables aux banques émettrices et la publication de nombreux documents par le gouvernement soviétique a laissé peu de doutes sur l'inimaginable climat de vénalité qui entoura les emprunts. Mais ces constatations restent accessoires par rapport au fait principal : l'utilisation de l'épargne nationale comme ciment des relations diplomatiques ${ }^{1}$. Et l'on pourrait étendre cette remarque à bien d'autres, en France et à l'étranger.

Troisième observation : le partage des marchés mondiaux entre les grandes firmes privées n'a jamais été aussi complet et durable que les schémas léninistes entendent l'établir. Bien souvent, une lutte, véritablement acharnée, a précédé l'établissement d'un accord : c'est seulement en 1928 que les trusts pétroliers ont enterré la hache de la guerre. L'étude des cartels internationaux est surtout celle des difficultés de tels accords, perpétuellement voués à des dissidences internes et externes. Comme l'a bien montré J. Freymond, les exemples donnés par Lénine, et choisis dans les branches se prêtant le mieux à la démonstration, sont loin d'être convaincants ${ }^{2}$.

crainte de l'aventure ». Il ajoute «les variations de l'histoire diplomatique ont eu une influence constante et considérable sur la constitution du portefeuille français de valeurs étrangères ». Il rappelle aussi qu'à l'époque, les valeurs à revenu fixe composaient plus des deux tiers des titres cotés en bourse. Pour l'aspect actuel des exportations de capitaux français, dans les territoires d'Outre-Mer, voir avec des réserves PICQUEMAL (M.), «Les exportations de capitaux français dans les colonies ", Économie et Politique, août-septembre 1957, pp. 66-75. Pour une étude approfondie, consulter naturellement les rapports annuels du Comité Monétaire de la Zone Franc (première année couverte 1953).

1 Voir les remarques suggestives du correspondant du Temps en Russie, Charles RIVET, in Le dernier Romanof, Paris, 1917, $3^{\mathrm{e}}$ partie. Une fraction seulement de l'argent prêté aux Russes était réemployée en France.

2 In Lénine et l'impérialisme, op. cit. Les chap. 4 et 5 fournissent une excellente interprétation de la thèse léniniste, les réserves émises apparaissant solidement fondées. Voir aussi MORGENTHAU (H.J.), Politics among Nations. The struggle for power and peace, $2^{\mathrm{e}}$ édition, New York, 1954, pp. 41-66, et HYVÄRINEN (Risto), Monistic and Pluralistic Interpretations in the Study of International Politics, Helsinki, 1958, pp. 79-94. 
Lénine a raison d'insister sur la disparition de la concurrence de type classique, celle des petites unités. Ainsi que l'établit a contrario l'exemple agricole, cette transformation est heureuse, la compétition de type classique excellant à produire gaspillages et chaos. Mais l'évolution s'est rarement poursuivie jusqu'à la création de monopoles proprement dits, (par fusion définitive ou entente durable). Ces régimes de petit nombre, comme disent les économistes (competition among the few) ont leurs propres règles qui comportent tantôt l'accord, exprès ou tacite, tantôt la lutte.

Au total, l'ouvrage de Lénine, s'il se ressent de la militance qui présida à son établissement, a souligné des phénomènes que l'on ne saurait négliger sans renoncer à comprendre l'évolution. Son principal apport reste d'avoir clairement établi la possibilité d'un impérialisme [p. 345] sans drapeau : l'expansion coloniale n'a pas été la seule forme de l'exploitation des peuples. En bien des occasions et des endroits (Amérique latine), la pénétration des grandes affaires britanniques et surtout américaines a réduit à une pure fiction les souverainetés locales ${ }^{1}$. Pourtant, l'interprétation proposée par Lénine ne couvre pas toutes les conduites (spécialement, mais non exclusivement, les comportements français). Parfaitement fondé à souligner l'interpénétration des secteurs public et privé, celui-ci a toutefois eu tort de donner à la liaison une direction unilatérale.

Dans la préface de la première édition russe (éditée à Petrograd en avril 1917), Lénine soulignait que, compte tenu de la censure tsariste, il avait dû s'en tenir à une analyse surtout économique en ne traitant des aspects politiques qu'avec la plus grande prudence et par la seule voie d'allusions. Les événements ne lui ont pas laissé le loisir de s'attaquer à nouveau à ces aspects non économiques de l'impérialisme et, comme c'est souvent le cas, ses disciples ont cristallisé plutôt que nuancé l'interprétation initiale. La thèse est devenue un dogme sacré : dès lors, elle suscite la confusion plus qu'elle n'informe.

En définitive la doctrine léniniste de l'impérialisme, qu'il n'est pas injuste de définir comme " un grand effort dialectique pour édifier une théorie du fait acquis » ${ }^{2}$, ne crée pas un cadre général pour l'interprétation des rapports entre l'économique et le politique. Elle repose sur des concepts construits de manière à n'accueillir qu'une catégorie de phénomènes localisés dans le temps et l'espace. Dans le cadre même qu'il prétend embrasser, ce système ne rend qu'imparfaitement compte des phénomènes exposés. Comme l'a noté Henri Chambre, il décrit, sans employer un appareil critique très exigeant, un certain nombre de faits bien connus: exploitation des peuples de

1 Voir par exemple PINTO SANTA CRUZ (Francisco A.), Hacia Nuestra Independencia Economica, Santiago du Chili, 1953, ou encore ANAYA (Ricardo), Nacionalizacion de las Minas de Bolivia, Cochabamba (Bolivie), 1952. Voir aussi GREENE (Th.P.), American Imperialism in 1898, Boston, 1955. Se reporter également aux publications de HAYA de la TORRE, (V.R.), en particulier El Antimperialismo y el APRA, Santiago, 1936 et Treinta Años de Aprismo, Mexico, 1956. Sur le même problème, KANTOR (H.), The Ideology and Program of the Peruvian Aprista Movement, Berkeley (Cal.), 1953. Sur l'interférence des problèmes économiques et des positions diplomatiques, consulter entre beaucoup d'autres, OWSLEY (F.L.), King Cotton Diplomacy. Foreign relations of the Confederate States of America, $2^{\mathrm{e}}$ édition, Chicago, 1959.

2 Selon l'expression de C.-J. GIGNOUX, Lénine, Paris, 1952, p. 97. 
couleur par les Européens, exportation de capitaux, guerres coloniales. Beaucoup des faits avancés ont correspondu à la réalité. Et il est probable que sur le plan des conséquences sociales (désagrégation des structures traditionnelles ; introduction de fléaux de type européen : alcoolisme, par exemple, etc.) le commentateur moderne serait porté à plus de sévérité encore que n'en traduit l'analyse léniniste. Mais pour avoir négligé ou réduit à un rôle dérivé les aspects politiques, cette thèse n'explique pas totalement les phénomènes considérés ${ }^{1}$. Par ailleurs, sur le plan du raisonnement économique où Lénine a voulu se placer, on constate que les formules théoriques de base [p. 346] (entièrement empruntées à l'économie politique du temps dont la médiocrité n'est contestée par personne) restent très rudimentaires.

La thèse de l'impérialisme, par son monisme même, est devenue un merveilleux instrument de combat. Lénine a gravement sous-estimé la capacité de résistance des capitalismes européens; il a par contre procuré aux peuples sous-développés, colonisés ou non, un instrument qui permet d'expliquer d'un seul coup tous les retards, toutes les souffrances, toutes les servitudes. Pour des centaines de millions d'êtres affamés et humiliés, l'impérialisme des peuples de l'Occident suffit à rendre compte de la situation (ce qui permet de passer sous silence, en particulier, l'un des plus grands parmi les fléaux qui menacent aujourd'hui l'humanité : une natalité sans frein).

Dans la déclaration finale de la Conférence de solidarité des peuples d'Asie et d’Afrique (Le Caire, décembre 1957), on lit: «L'existence de l'impérialisme est inadmissible à l'étape actuelle de l'histoire de l'humanité " ${ }^{2}$. Le comportement des groupes de pression à buts économiques ou financiers justifie-t-il aujourd'hui le maintien de cette accusation?

Les transformations dans les rapports internationaux - Les modifications que l'on peut relever de 1914 à 1960 sont, sans aucun doute, importantes. Mais une bonne part de celles observées dans notre domaine est tout à fait indépendante de la volonté des groupes intéressés. La création d'une vaste zone régie par les principes de l'économie collectiviste est le plus apparent de ces bouleversements et l'influence de ce phénomène déborde largement le cadre dans lequel il se déroule. Ayant valeur d'exemple, il inspire à un degré saisissant, le gouvernement de nombreux États non communistes (voire d'États se disant anti-communistes). Autre aspect, encore plus considérable, de ce poids du monde communiste : la compétition fort active des deux blocs pour se gagner la sympathie des peuples non engagés. On ne saurait interpréter correctement le comportement des intérêts économiques sans référence à ce contexte.

1 De Karl Marx à Mao Tsé-Tung, Paris, 1959, p. 203. Henri LEFEBVRE (in La pensée de Lénine, Paris, 1957) présente une interprétation fort séduisante de la pensée de Lénine sur l'impérialisme (pp. 234-248) en tentant de lui restituer des dimensions politiques. "Dans l'impérialisme, écrit-il (p. 237), la politique l'emporte sur l'économique : elle le contient... ». Mais il semble bien, comme le note H. CHAMBRE, que le commentateur ait ajouté à la pensée qu'il analyse.

2 Le texte des exposés présentés à cette conférence a été publié en langue française par les Éditions en langue étrangère de Moscou, 1958. Voir en particulier un rapport égyptien sur « L'impérialisme et le soutien des droits des peuples à l'indépendance et à la souveraineté », pp. 71-86. 
Il est devenu courant aujourd'hui d'attribuer aux firmes installées à l'étranger, spécialement dans les pays sous-développés, une attitude d'extrême prudence à l'égard de la politique locale. Elles s'abstiendraient désormais de toute ingérence dans les luttes partisanes, se bornant à intervenir auprès des gouvernements intéressés (et encore avec un grand souci de compréhension) dans le seul domaine des problèmes techniques. [p. 347] Une telle conduite expliquerait que ces affaires parviennent à conserver leurs positions dans des circonstances difficiles alors que les gouvernements auxquels elles sont rattachées renoncent à exercer une influence ou sont contraints de le faire.

Ce phénomène permettrait aussi de comprendre qu'en certaines occasions les autorités publiques aient voulu instituer une diplomatie dite des hommes d'affaires (expression signifiant la volonté de s'attacher à des questions économiques pour atténuer les tensions politiques). Ce souci de "présence » des industriels peut aller très loin et avoir des répercussions politiques : lors de la dernière foire de Leipzig, un journal allemand n'a pas hésité à parler du défaitisme des grands industriels, convaincus de l'idée qu'on peut régler les problèmes pendants avec les Soviets sur la base de fourniture de tubes (selon Le journal de Genève, 16 mars 1960).

Laissons ces cas extrêmes : on a depuis longtemps souligné que les grandes organisations d'affaires sont plus habiles à réaliser une coopération, entre elles ou avec des appareils gouvernementaux, que les gouvernements eux-mêmes. Il est par exemple banal de souligner l'activité accrue des firmes britanniques en Inde et au Ghana après l'accession de ces pays à l'indépendance. Est-il même impossible que de telles entreprises témoignent d'un esprit de prévision en apportant un concours ou, au moins, un élément de reconnaissance à des mouvements de révolte dont elles estiment qu'ils ont une chance de devenir le gouvernement de demain ? À plusieurs reprises, on a dénoncé en France l'existence d'une collusion entre le F.L.N. et certains grands trusts pétroliers, américains en particulier : aucune preuve de ces rapports n'a jamais été fournie (ce qui, si l'on observe divers exemples étrangers déjà cités, ne doit pas inciter à nier, par principe, leur existence).

À condition de considérer ce phénomène comme un mouvement général et une tendance récente, l'observation ainsi émise peut être tenue pour vraisemblable. Mouvement général, c'est-à-dire compatible avec des exceptions (dont on pourrait penser qu'elles se manifestent aussi bien à l'encontre de pays avancés que de pays sous-développés). Tendance récente au surplus: les affaires de l'Iran (essai de nationalisation du pétrole) et du Guatemala appartiennent tout de même à un proche passé. Il est d'ailleurs douteux que les puissances intéressées soient aujourd'hui en mesure de leur donner la même conclusion.

[p. 348] Cette constatation n'implique pas que les firmes étrangères (spécialement quand elles agissent par le canal de filiales ayant la nationalité du pays considéré), renoncent à obtenir des autorités compétentes les décisions nécessaires au maintien et à la prospérité de leurs affaires. La transformation entraîne simplement une absence d'immixtion ou une forte diminution de l'ingérence dans la sélection des gouvernants et le choix des grandes options politiques. Au surplus, n'oublions pas les 
aménagements pratiques qui peuvent intervenir, une fois les grands principes déclarés.

C'est ainsi qu'en Argentine, sous la magistrature de M. Frondizi, des entreprises étrangères ont été admises, en échange d'un versement substantiel, à « donner leur concours » à l'organisme d'État chargé de la production, l'exploitation et la distribution du pétrole. Or il ne semble pas que les contrats de service ainsi passés par les filiales de la Standard Oil et de la Royal Dutch avec l'État argentin soient pour elles une mauvaise affaire. Ils leur permettent, en tout cas, de retrouver un certain contrôle des richesses pétrolières du pays. Ce système ayant d'ailleurs suscité l'inquiétude des forces armées, le gouvernement argentin a adopté une réglementation nouvelle qui, semble-t-il, renforce la situation de la Compagnie nationale (à laquelle serait donnée désormais la préférence, mais dans des limites dites raisonnables, pour la mise en valeur des zones non exploitées).

Un second trait caractéristique des transformations survenues de 1914 à nos jours, spécialement depuis 1945, est l'intervention directe des gouvernements qui prennent peu à peu en charge, isolément ou par le truchement d'agences intergouvernementales, des problèmes ou activités jadis du ressort des seules organisations privées. Cette intervention peut s'effectuer occasionnellement pour faciliter une évolution : ainsi, le traité franco-éthiopien signé le 12 novembre 1959 à Addis-Abeba a-t-il modifié le statut de la Compagnie du Chemin de Fer FrancoÉthiopien. La Compagnie ancienne était de nationalité française et la France détenait les trois quarts du capital social : la nouvelle est éthiopienne, le capital doit être partagé à égalité entre les actionnaires français et étrangers, le Conseil d'administration comprend 5 membres pour chacune des deux nationalités. Cette évolution est susceptible d'empêcher ou de retarder une nationalisation ${ }^{1}$.

Parmi les changements d'allure permanente dans la répartition entre les activités publiques et privées, citons les efforts accomplis dans le [p. 349] domaine des matières premières pour substituer aux cartels privés des accords intergouvernementaux. En dépit de sa tendance libérale, la Charte de La Havane ne pouvait ignorer qu'en un pareil domaine le libéralisme concurrentiel conduit rapidement au chaos. Elle a donc admis la possibilité d'ententes en ce qui concerne les produits de base, mais sous plusieurs conditions: nature intergouvernementale, inclusion des principaux pays intéressés, égalité entre producteurs et consommateurs, recherche, d'une expansion de la demande, efforts pour régulariser les fluctuations... Comme on pouvait le prévoir, la conclusion de tels accords a été difficile et malgré un gros travail d'élaboration, trois seulement ont vu le jour : sucre (contingentement des exportations) ; blé (contrats multilatéraux) étain (stock régulateur) ${ }^{2}$. Ce dernier est

Pour quelques détails supplémentaires, voir L'Économie, 4 février 1960, pp. 14-15.

Auxquels il faut ajouter aujourd'hui, l'Accord international sur le café qui, renouvelé à Washington le 28 septembre 1960, couvre 93\% de la production de café dans le monde (l'entente consistant dans une restriction volontaire des exportations sur la base de contingents). Pour une bonne présentation d'ensemble, voir GOETSCHIN (P.), « Accords internationaux de matières premières et sous-développement », Revue Économique et Sociale, septembre 1959, pp. 80-94. Voir aussi les 
caractéristique en raison de la position de l'U.R.S.S. qui, ayant d'abord entravé et pratiquement annulé par des ventes massives l'activité du stock régulateur, a pris l'engagement de ne pas dépasser un certain maximum pour ses ventes à l'Ouest.

Autre aspect de cette vaste substitution de responsabilités : la prise en charge par les États et les organisations étatiques de tout l'effort d'assistance technique, qui représente d'ailleurs, pour une très large part un développement neuf ${ }^{1}$. De nombreuses conventions bilatérales ont été signées à cet effet (États-Unis au titre du point IV, U.R.S.S., France avec les États de la Communauté...). Dès le mois de décembre 1946, l'Assemblée générale de l'O.N.U. s'occupait du problème et en 1949, l'Ecosoc adoptait le principe d'un programme élargi.

Deuxième élément, d'ailleurs très vaste, de cette évolution : les changements survenus dans les mouvements de capitaux et les investissements internationaux. D'une part, sur bien des points et en de nombreuses occasions, les États ont dû se substituer aux capitalistes et institutions privées, d'autre part, diverses institutions intergouvernementales ont été fondées pour rassembler des moyens et proposer des solutions à l'échelle mondiale. On se limitera ici à citer quelques faits caractéristiques.

Les mouvements de capitaux privés, certes, n'ont pas disparu ${ }^{2}$. Dans certains cas, ils ont augmenté au cours des dernières années : ainsi, pour les États-Unis, depuis 1956, l'accroissement ayant spécialement profité aux pays sous-développés d'Amérique latine. De même, les exportations allemandes de fonds privés se sont accrues rapidement dans les années récentes. Mais chacun s'accorde à trouver les envois insuffisants. Cette situation découle des transformations dans la structure des marchés financiers et la constitution de l'épargne, des besoins financiers de plus en plus [p. 350] considérables des pays industrialisés eux-mêmes et aussi des risques courus par les prêteurs ${ }^{3}$.

rapports du G.A.T.T. (spécialement celui paru en octobre 1958) et les Études sur les produits de base publiées par l'O.N.U. Voir aussi WILKINSON (H.F.). Étude des initiatives internationales en vue de la stabilisation des marchés des produits de base, Genève, 1959 ; CAINE (S.), « Stabilizing Commodity Prices », Foreign Affairs, octobre 1958, pp. 130-143 ; NEGRI (G.), « Aspetti degli Accordi Intergovernativi per Prodotti », Rivista di Politica Economica, mars 1950, pp. 278-292 ; MASON (E.S.), Controlling Word Trade. Cartels and commodity agreements, New York, 1946.

1 Pour une bonne présentation d'ensemble voir Dupuy (Michel), L'assistance technique et financière aux pays insuffisamment développés, Paris, 1956.

2 Sur ces problèmes, voir les deux brochures de l'O.N.U., Les courants internationaux de capitaux privés, 1948-1952, New York, 1954, et Le courant international de capitaux, 1956-1958, New York, 1959.

3 Ils sont bien résumés par ANSELME-RABINOVITCH (L.), « Les investissements internationaux privés », Banque, juillet 1959, pp. 416-421. On notera que la Ligue Européenne de Coopération a proposé une défense en commun des investissements européens à l'étranger par les huit pays membres selon une formule assez originale mais qui, dans l'état actuel de la politique mondiale, ne semble pas promise à un grand avenir (voir le rapport établi à l'occasion de la réunion du Conseil central, Londres, 30 mars 1957, point 2 de l'ordre du jour). On trouvera des notions intéressantes sur plusieurs aspects de ces problèmes in Rippy (J. Fred), British Investments in Latin America, 1822-1949. A case study in the operations of private enterprise in retarded region, Minneapolis, 
On a préconisé diverses solutions pour renforcer le sentiment de sécurité, en particulier l'octroi d'une garantie de bonne fin de l'opération par le gouvernement à ses propres nationaux prêteurs du type de celle instituée, aux États-Unis par la section 413 de la Mutual Security Act de 1954 (certificat de transfert et compensation des pertes). Les réticences à l'égard de nombreux pays restant solides, une situation paradoxale en résulte. Beaucoup de dirigeants de pays sous-développés, de formation plus ou moins marxisante, attendaient de pied ferme l'assaut du capitalisme international (« impérialisme »). L’attaque n'ayant pas eu lieu, ce sont aujourd'hui les mêmes responsables qui songent à appeler de tels capitaux en prodiguant des assurances sur la pureté de leurs intentions, sans oublier l'offre de faveurs fiscales et de garanties (régimes d'imposition de longue durée ; conventions économiques à long terme qui stabilisent les conditions existant à l'origine, etc.). Il n'est pas certain que ces affirmations, dont la mise en œuvre reconstituerait les privilèges différentiels si âprement critiqués, fassent disparaître la défiance.

Il y a d'ailleurs une contradiction, spécialement perceptible au niveau des pays déjà développés, entre l'appel aux capitaux étrangers et la volonté d'ordonner l'emploi des ressources nationales suivant un plan. Le capital entend trouver, de lui-même, son point d'application tandis que l'existence d'un programme gouvernemental d'expansion risque de lui en imposer un. La réception de fonds privés sur une vaste échelle et la réalisation d'une planification nationale ne sont pas aisément compatibles. Ajoutons que, dans plusieurs pays, les autorités soumettent à des réglementations spéciales l'activité des capitaux d'origine extérieure (limitation des sphères d'activités ouvertes, transfert des produits, rapatriement...) ${ }^{1}$, C'est aujourd'hui une tendance générale. Le Maroc agira ainsi dans ses rapports avec la France, mais la France fera de même avec les États-Unis. La reprise de la convertibilité monétaire en Europe y a un peu atténué plusieurs de ces préoccupations: mais la volonté de surveiller la pénétration des capitaux dans le pays subsiste. Dès lors, les faveurs envisagées risquent de ne pas séduire les détenteurs de monnaie.

L'insuffisance de l'investissement privé a conduit au développement des opérations gouvernementales effectuées soit directement par la Trésorerie, soit par des organismes spécialisés (du type de l’Export-Import Bank aux États-Unis dont les prêts, en 1958, ont atteint le milliard de [p. 351] dollars). Il arrive que ces opérations soient conclues avec des affaires on groupements privés (ainsi pour l'Export-Import Bank), mais elles sont souvent réalisées de gouvernement à gouvernement (ce qui,

1959 (surtout chap. 17 et 18 qui établissent le contraste entre les vues anglaises d'une part, latinoaméricaines, de l'autre). De façon générale, rappel des travaux cités dans la note 2 p. 202.

1 Très significative à cet égard est la lecture du rapport de l'O.E.C.E., Les investissements privés américains en Europe et dans les territoires d'outremer, Paris, 1954. Voir aussi, toujours de l'O.E.C.E., Rapport sur les investissements internationaux, Paris, 1950, et Les investissements dans les territoires d'outre-mer en Afrique, au Sud du Sahara, Paris, 1951. Le Conseil Économique vient d'étudier le problème des investissements étrangers en France métropolitaine. Voir Journal Officiel, avis et rapports du Conseil Économique et Social, 17 janvier 1960, pp. 1-31. Voir aussi BLANCHAERT (M.C.), "Les investissements directs privés des États-Unis dans le Marché commun », Annales de Science Économique Appliquée, mai 1959, pp. 183-218. 
évidemment, cadre mieux que les mouvements privés avec le souci d'un développement planifié).

On a également créé des agences intergouvernementales pour ce type d'activité : la Banque Internationale pour la Reconstruction et le Développement (B.I.R.D.) et plus récemment la Société Financière Internationale, qui a pour objet d'encourager l'essor d'entreprises privées dans les États membres ${ }^{1}$. Mentionnons aussi la Banque Européenne d'Investissement dans le Marché commun.

Plusieurs de ces formules se ramènent à des relations "public-privé (cas du prêt entre gouvernements), d'autres sont du type "privé-public ». Ce dernier, qui traduit l'interdépendance des secteurs à notre époque, a provoqué la création d'organismes permanents (dont la Société Financière) et il a aussi inspiré de nombreuses combinaisons d'affaires dont voici un exemple: l'association à l'Organisation Iranienne du Plan de banques privées (Lazard frères de New York et Chase International, filiale de la Chase Manhattan), de la B.I.R.D. et de l'I.C.A. (Administration de Coopération Internationale du gouvernement des États-Unis). La Société Iranienne met ainsi à la disposition des industries agréées par elle-même et par les banques étrangères les crédits reçus de ces dernières. Citons un autre cas : le crédit ouvert par cinq banques européennes (sous la direction du Comptoir National d'Escompte) à Pemex, organisme étatique des pétroles mexicains ${ }^{2}$.

On sortirait du cadre de ce livre en examinant si les solutions ainsi retenues et d'autres que l'on n'a pas évoquées (par exemple la récente entrée en fonction de l'Association Internationale de Développement) sont susceptibles d'aider, de façon appréciable, le développement du tiers monde ${ }^{3}$. Notre propos était seulement de signaler les changements dans les formules d'action depuis Lénine. Beaucoup, spécialement dans les pays sous-développés, trouvent ces changements superficiels et trompeurs. Ils y voient simplement de nouvelles tactiques de l'impérialisme ou la manifestation d'un néo-impérialisme dont un des principaux aspects serait le renforcement, par des subventions économiques, de gouvernements à la dévotion des exploiteurs. Ainsi la «doctrine Eisenhower» pour le Moyen-Orient était-elle présentée comme une incitation aux pays de cette zone à céder leur indépendance à Washington et à accepter de lui [p. 352] être assujettis. Il n'est pas besoin de dire que l'U.R.S.S. appuie cette interprétation par toutes les voix de sa propagande.

Ces déclarations ne sont pas totalement dépourvues de fondement, sous réserve d'admettre que les concours soviétiques s'inspirent eux aussi d'une conception de l'intérêt national russe et d'une stratégie politique à long terme. Le point qui nous

1 Sur la société, voir Roux (R.), « La constitution de la société financière internationale », Revue de Science Financière, avril-juin 1957, pp. 202-245. Pour une étude générale, voir SALMON (Jean), Le rôle des organisations internationales en matière de prêts et d'emprunts. Problèmes juridiques, Paris, 1958.

2 Exemples tirés de Maximilien CHARRIER, Aspects et problèmes du capitalisme contemporain, Aix-en-Provence, 1960, pp. 59-61.

3 Pour une bonne synthèse, voir L'HUILLIER (J.), « L'aide aux pays sous-développés par la voie des placements de capitaux », Revue économique et sociale, septembre 1959, pp. 126-136. 
importe est d'observer qu'en de nombreux cas (et pas seulement dans le monde communiste) les gouvernements ont pris la relève des groupes privés, de façon plus ou moins complète. Si impérialisme il y a encore, l'affaire se situe directement au niveau suprême et échappe au cadre limité de ce volume dont le propos est précisément d'analyser l'action des groupes capables d'agir au plan international sans passer par un ordre juridique de rattachement.

Il serait sans aucun doute très utile d'étudier, et si possible, d'évaluer globalement, à diverses époques, la part respective des forces privées et des appareils gouvernementaux dans les relations internationales. Bien des éléments permettent de penser que les services étatiques jouent, un rôle considérable et probablement en expansion (au moins par rapport à la situation de 1914): mais il s'agit là d'impressions plus que d'affirmations prouvées. On en déduit parfois de vastes conclusions et, en particulier, celle d'une extension de la lutte des classes à l'échelle internationale ou, plus exactement, dune superposition aux conflits internes d'un combat entre les nations selon leur état de développement économique. Dans cette perspective, les travailleurs des pays industrialisés seraient aussi les bénéficiaires de l'impérialisme (cette thèse venant d'ailleurs à point pour expliquer une assez grande imperméabilité au marxisme). Sur cette base, le recours à la notion d'un «État bourgeois », agent direct de l'impérialisme, ne surprend pas.

La discussion de cette thèse ne saurait être entreprise ici. Disons qu'elle présente certains éléments de valeur. Elle néglige pourtant des faits essentiels : l'expansion des échanges entre les pays développés eux-mêmes et les avantages qu'en tirent les deux parties. Les partenaires essentiels des États industrialisés sont les pays industriels euxmêmes. De telles lacunes sont graves et se trouvent à la base des erreurs commises dans l'appréciation des chances d'une révolution marxiste au sein des pays développés.

Mais les analyses habituelles suffisent-elles à rendre compte du problème ?

[p. 353] De l'« exploitation » à la «domination» - Nous avons la conviction qu'il n'en est rien. Ces positions ont le tort de laisser croire que l'impérialisme, l'exploitation ou plus généralement le fait d'occuper une position meilleure que l'interlocuteur résulte d'un propos délibéré. Il est vrai que l'exploitation découle souvent d'une volonté bien arrêtée. Mais le même phénomène ne peut-il être la conséquence aussi de la différence de moyens ou de situation? C'est le lieu d'évoquer le concept de la domination désormais connu des économistes à la suite des travaux de F. Perroux. En voici une présentation simplifiée ${ }^{1}$.

L'unité économique dominante peut être caractérisée par l'exercice sur les autres unités d'une influence unilatérale, irréversible ou seulement partiellement réversible. Elle le doit à ses dimensions, à son pouvoir de négociation, à la nature des activités

1 Nous l'empruntons à Raymond BARRE, Économie politique, tome I, Paris, 1956, pp. 108-109. Pour l'exposé initial de la théorie, se reporter à PERROUX (François), «Esquisse d'une théorie de l'économie dominante », Économie Appliquée, avril-sept. 1948, pp. 243-300. 
qu'elle accomplit ou contrôle (secteurs-clefs). La notion s'applique en premier lieu à la firme privée, mais on peut l'étendre à des unités plus complexes : des villes, des zones industrielles, des places financières, des nations. Pour ces dernières, le degré de domination dans l'ordre des rapports internationaux s'exprime par l'intensité plus ou moins grande de l'influence asymétrique et irréversible manifestée sur les autres.

Firmes dominantes : les grandes concentrations d'affaires précédemment évoquées comme Unilever, Krupp ou encore l'United Fruit Company. Nations dominantes : l'Angleterre au XIX ${ }^{\mathrm{e}}$ siècle et les États-Unis aujourd'hui, mais aussi, dans sa sphère, l'U.R.S.S. La supériorité, sur tant d'autres, du concept de domination est sa neutralité à l'égard des conduites considérées : il s'applique dès que certains effets de puissance sont reconnus, indépendamment de toute controverse idéologique. Sur le plan scientifique, ce concept a le grand mérite d'expliquer la survenance de certains phénomènes non systématiquement recherchés. S'il arrive à la Suisse de bénéficier d'entrées massives de capitaux, spéculatifs et donc indésirables, c’est qu'elle exerce dans l'ordre financier spécialement Zurich) un effet de domination.

Ce concept convient parfaitement à l'analyse des rapports entre les nations ${ }^{1}$. Considérons la France et le Gabon. Même si la première veut travailler sur un pied d'égalité avec le second, elle est incapable d'annuler sa supériorité : voulant l'égalité, elle ne pourra s'évader de l'inégalité. Il en va exactement de même dans les relations entre le monopole du commerce extérieur soviétique et les États moyens et petits avec les-[p. 354] quels il conclut des accords (plusieurs d'entre eux ayant déjà subi des déboires notables de ce fait).

Il semble permis d'étendre la confrontation à des unités de nature différente : par exemple, un grand trust économique et un petit État. Ce dernier possède certes sur le plan des principes le pouvoir souverain : il a faculté légale de chasser le trust ou de le nationaliser. $\mathrm{Si}$, pour des raisons quelconques, cette voie n'est pas praticable et que l'État accepte ou tolère les groupes d'affaires, alors la disproportion se manifeste inévitablement, De nos jours, un État, même petit, trouvera à se protéger contre des tentatives ouvertes de mainmise et de conquête, tandis qu'il risque d'être plus ou moins désarmé contre les séquelles silencieuses de l'inégalité des forces. Ce déséquilibre serait mieux marqué si les hommes d'affaires avaient les qualités d'audace et d'intrépidité, le goût du risque et de la puissance que leur attribuent... généreusement ceux qui n’en ont jamais vu agir.

Bien entendu, la domination n'exclut en elle-même ni la pression ni aucune forme d'intervention. À la puissance peut s'ajouter la volonté de l'utiliser au maximum et jusqu'au bout. Mais le point important reste qu'il ne suffit pas de le désirer et même de le vouloir pour annuler cette supériorité. Autrement dit, la « décolonisation » - sauf si elle s'accompagnait d'une table rase économique - en laisse subsister de nombreux

Sur le déclin de la «domination anglaise », voir COTTA (Alain), Revue d'Économie Politique, janvier-février 1960, pp. 35-68. L'article de P. LANGLOIS et J. DESSAU, «Recul de la domination américaine », Économie et Politique, novembre 1959, pp. 6-22, conçoit le terme de domination en un sens beaucoup plus proche du langage courant. 
effets. Et ces conséquences sont acquises dans tous les cas, y compris ceux où il n'y a pas eu au préalable colonisation proprement dite. L'observation est essentielle : même si par la force des choses ou une meilleure compréhension du problème, la grande firme ou la combinaison d'affaires s'efforcent d'écarter de leur comportement tout ce qui pourrait déplaire aux États, spécialement aux nouveaux, l'effet de domination demeure inéluctablement.

Serait-il possible de parvenir à une réglementation internationale qui permette d'améliorer la situation ? On a beaucoup parlé, par exemple, du contrôle des cartels internationaux : les tribunaux américains ont tendance à aller très loin dans cette voie (ainsi ont-ils, en 1909, déclaré le Sherman Act applicable à un accord exécutoire en Grande-Bretagne, qu'avaient conclu l'American Tobacco et son concurrent britannique). Pour justifier l'existence d'une surveillance, on a souligné que les intérêts économiques dépassant désormais les limites d'un État, la législation devait devenir elle-même internationale. Réserve faite des dispositions de la Charte de la Havane, largement restées lettre morte, on n'a fait [p. 355] jusqu'ici que peu de chose pour promouvoir une telle réglementation ${ }^{1}$. La transformation des ententes privées en accords intergouvernementaux n'a été, on l'a vu, que rarement possible.

Le problème se pose avec acuité en Europe si l'on considère le grand mouvement de concentration auquel ont donné lieu la fondation de la C.E.C.A. et l'institution du Marché commun. Il risque d'aboutir, à moins qu'une réglementation compensatrice n'intervienne rapidement, au renforcement des éléments de domination dans le marché européen. Une réglementation a été stipulée par le traité de Rome, mais sa mise en œuvre se révèle difficile ${ }^{2}$ : aucun accord n'a encore pu se réaliser sur des points aussi essentiels que la procédure de notification des cartels ou les pouvoirs propres de l'Exécutif de Bruxelles. Comme l'a remarquablement montré André Marchal, deux conceptions s'affrontent dans ce débat : celle d'une Europe libérale attendant son salut de la seule création d'un grand marché et donc proscrivant les ententes (ce qui est d'ailleurs presque impossible à réaliser) ; celle d'une Europe aboutissant à l'intégration par une collaboration volontariste des groupes organisés,

1 Voir JESSUP (Philip C.), LANDE (A.), LISSITZYN (Oliver J.), International Regulation of Economic and Social Questions, New York, Carnegie Endowment, 1955. Dans ce même volume, voir l'importante étude International Organization de Joseph CHAMBERLAIN. Sur les efforts accomplis par le G.A.T.T., voir SEYID MAHAMMAD (V.A.), The Legal Framework of World Trade, Londres, 1958 (contient également une analyse du processus de négociation dans cet organisme).

2 Sur ce problème, HOUSSIAUX (Jacques), Concurrence et Marché commun, Paris, 1960 ; PLAISANT (Robert), LASSIER (J.), Ententes et Marché commun, Paris, 1959 ; MARCHAL (A.), "Les ententes et les concentrations dans le Marché commun », Revue du Marché Commun, Paris, octobre 1959, pp. 357-368; AUSTRUY (Jacques), ( La réglementation des ententes et les pouvoirs compensateurs dans le Marché commun », Revue Économique, septembre 1960, pp. 770802. SCHUMACHER (H.), «La politique de la C.E.E. en matière d'ententes », Revue du Marché Commun, mai 1959, pp. 207-214. Sur la C.E.C.A., RIEBEN (H.), « La C.E.C.A. et les Cartels », Cartel, janvier et avril 1957, pp. 7-16 et 46-55. Pour une vue globale du problème se reporter à l'étude du G.A.T.T., Les pratiques commerciales restrictives, Genève, mai 1959 (mémoire établi par J. LHUILLIER). 
mais admettant la nécessité d'un contrôle de ces combinaisons. Reste l'éventualité d'une troisième solution laissant les ententes et la concentration se développer sans contrôle suffisant. On aurait ainsi, à l'échelle du Marché commun, la solution que les hommes d'affaires nomment «libérale » et qui se situe juste à l'opposé d'un tel courant : le dirigisme professionnel.

En tout état de cause, il est nécessaire de montrer qu'un certain nombre de faits reprochés aux entreprises économiques de l'Occident résultent en réalité d'une situation objective et se trouvent dès lors relativement indépendants des modes d'organisation économique: l'infériorité d'un pays agricole vis-à-vis d'un pays industriel demeure quel que soit le régime économique adopté par le second. À cette remarque doit être rattachée la question des termes de l'échange.

On souligne, volontiers que, réserve faite des périodes de pénurie ou de stockage spéculatif, l'évolution de ces termes (terms of trade) s'effectue au détriment des pays fournisseurs de denrées agricoles et de matières premières. Ce serait, toutes choses égales, un phénomène du même ordre que celui qui affecte la position des paysans dans les nations industrialisées.

La question est loin d'être aussi claire et indiscutable que diverses présentations polémiques voudraient l'établir, l'évaluation même des déca-[p. 356] lages étant très difficile et l'accord ne régnant pas quand il s'agit des techniques à utiliser à cet effet ${ }^{1}$. Beaucoup estiment que le pouvoir l'achat des produits de base a considérablement diminué de 1850-60 à 1930-40. D'autres pensent que la situation ne s'est pas beaucoup modifiée de 1928-30 à 1955-56. Cependant la thèse prédisant une évolution défavorable pour le prix de ces biens et surtout les matières premières agricoles n'est pas sans défenseurs. Serait-il facile de renverser la tendance ?

Il y a aujourd'hui bien des obstacles à une valorisation. Le progrès technique permet de tirer un meilleur parti des éléments utilisés (économies d'énergie), de déceler par endroits des gisements inconnus et d'introduire dans le circuit productif des sources jugées jusqu'alors inexploitables. Notons aussi la concurrence de plus en plus rapide faite aux matières naturelles par les produits de remplacement, plastiques, fibres synthétiques, etc. Les pays industrialisés s'efforcent de diminuer leur dépendance à l'égard de l'outre-mer de deux manières : développement en priorité de leurs propres ressources et expansion des marchés de la récupération. En définitive, la part des matières premières dans le commerce mondial va en décroissant et, si l'on en croit un organisme de la qualité du National Institute of Economic and Social Research (Londres), les pays industrialisés dépendent moins aujourd'hui qu'hier des

Pour l'aspect théorique du problème, voir ATALLAH (M.K.), The Long Term Movement of the Terms of Trade Between Agricultural and Industrial Products, Rotterdam, 1958 et KINDLEBERGER (C.P.), The Terms of Trade : a European case study, New York, 1956. Voir aussi INSEE, «L'évolution des termes de l'échange dans le commerce extérieur de la France », Études et Conjoncture (Econ. fr.), juillet-août 1952, pp. 300-320 ; BALDWIN (R.), AUBREY (H.), «Long-term Trends in International Trade », American Economic Review, mai 1955, pp. 259-295; BRUTON (H.J.), "Productivity, the Trade Balance and the Terms of Trade», Economia Internazionale, août 1955, pp. 503-521. 
matières premières en provenance des pays à production primaire ${ }^{1}$. Ce ne sont pas là, on en conviendra, les conditions idéales d'un effort de valorisation ${ }^{2}$.

Pour l'immédiat, il est vrai, la question de la stabilisation du prix de ces produits reste essentielle. En 1957-58, les cours des matières premières ont baissé de 10\%, et les prix des produits finis monté de $1 \%$, tandis que la perte en découlant pour les pays à productions primaires s'élevait à 2 milliards de dollars. Or, jusqu’à présent, les États occidentaux n'ont pas été en mesure de proposer une solution positive à ces problèmes (la Russie au contraire garantissant dans certaines limites la stabilité par la signature de contrats à long terme). La question est d'autant plus grave qu'il suffit souvent d'un écart minime entre la production et la consommation pour provoquer une variation substantielle du prix de vente. En une large mesure, cette instabilité (qui interdit ou, du moins, rend difficile aux pays producteurs primaires un effort de développement planifié reposant sur les recettes d'exportation) n'est pas le résultat d'un plan préconçu des États ou groupes industriels : elle cons-[p. 357] titue pourtant l'une des accusations les plus graves portées contre l'Occident ${ }^{3}$.

\section{c) POIDS DES CONTRAINTES MATÉRIELLES}

\section{$\underline{\text { Retour à la table des matières }}$}

Dans les précédents développements, on a insisté sur des sujets qui en l'état actuel de l'analyse sociale, sont plutôt réservés d'habitude aux économistes. Figurant aujourd'hui au centre des préoccupations gouvernementales, ces thèmes ne sauraient pourtant être exclus de l'analyse politique que par la réduction de celle-ci à un point de vue purement formel. Il est également indispensable de prendre de tels phénomènes en considération quand il s'agit d'évaluer la position de tel élément du marché mondial : tel que, par exemple, le Cartel des Pétroles dont on sait qu'il rassemble depuis 1928 les «sept grands » du pétrole (cinq sociétés américaines : Standard Oil N.J., Gulf, Texas, Standard Oil of California, Socony Mobil Oil ; le groupe Royal Dutch ; la British Petroleum).

Selon The Economist, 3 octobre 1959, p. 77.

Sur la politique des matières premières des États-Unis, dont on sait l'importance pour le reste du monde, voir BIDWELL (P.W.), Raw Materials. A study of American Policy, New York, 1958. Pour une vue globale du problème, VERMOT-GAUCHY, «Relations économiques internationales et problèmes des matières premières », Bulletin Sedeis, supplément aux n ${ }^{\text {os }}$ 726, 728, 730 et 731 (le dernier fascicule étant consacré à la régularisation des cours et de la production des matières premières).

3 Sur l'ensemble des problèmes évoqués dans cette rubrique voir MYRDAL (G.), Une économie internationale, Paris, 1958, ainsi que Théorie économique et pays sous-développés, Paris, 1959. Sur un secteur particulier du monde, CAPET (M.), Traité d'économie tropicale. Les économies d'A.O.F., Paris, 1958. Pour un point de vue d'une autre inspiration, on n'oubliera pas de lire RÖPKE (W.), L'économie mondiale aux XIX $X^{e}$ et $X X^{e}$ siècles, Genève, 1959. Voir aussi IMLAH (Albert H.), Economic Elements in the Pax Britannica. Studies in British foreign trade in the nineteenth century, Cambridge (Mass.), 1958. 
Avant de commencer cet exposé, il faut dire que le gouvernement des États-Unis a entrepris en 1953 un procès pour violation de la loi antitrust contre les firmes américaines membres du Cartel. L'affaire vient de se terminer (au moins à l'égard de la Standard Oil N.J. et de la Gulf qui ont accepté un arrangement à l'amiable) par un jugement prohibant tout accord futur entre les firmes pour fixer les prix, partager les marchés, répartir la production... La Standard N.J. et la Socony ont annoncé leur décision de dissoudre l'organisme commun qu'elles avaient créé sous le nom de Standard-Vacuum Oil Company pour produire, raffiner et distribuer le pétrole dans une cinquantaine de pays: les actifs de la Vacuum sont partagés entre les deux affaires selon des critères géographiques. Quant à la Gulf, elle a accepté de mettre chaque année à la disposition des compagnies indépendantes une fraction du tonnage extrait dans ses concessions. Selon certains commentateurs, les aménagements ainsi conclus (surtout la dislocation de la Vacuum) ne seraient pas sans rapport avec les difficultés d'ordre commercial que connaît aujourd'hui l'industrie pétrolière.

On ne sait pas encore si ces mesures sonnent définitivement le glas du Cartel des Pétroles. Il est possible que l'ensemble ainsi désigné dans la suite de l'exposé n'ait plus qu'une signification historique et que ses membres doivent affronter en ordre dispersé la situation présente. Pour-[p. 358] tant, il semble prudent d'attendre un peu avant de conclure à une disparition définitive de l'organisme et à un abandon total des pratiques suivies.

Le Cartel — plus exactement peut-être les firmes qui le composaient — subit aujourd'hui de sérieuses menaces. Les unes sont d'ordre nettement politique tenant à des initiatives gouvernementales qui s'en prennent directement aux conditions d'activité et à la capacité de profit de ses membres. D'autres sont essentiellement économiques, relevant de l'allure actuelle de l'offre et de la demande. La distinction entre les deux séries de troubles n'est pas toujours évidente. Elle a cependant un intérêt, car on peut dire que la situation du marché jointe à certains traits de domination procure, provisoirement peut-être, une sécurité au Cartel contre le risque d'éviction.

En somme, l'étude de la position du Cartel montre les limitations que les faits sont susceptibles d'imposer aux idéologies, en l'espèce l'idéologie nationaliste, pourtant aujourd'hui la plus puissante de toutes. Sans entrer dans une analyse détaillée, nous allons essayer d'esquisser les principaux facteurs de la question ${ }^{1}$, le propos étant

\footnotetext{
Bonne présentation d'ensemble in DURAND (D.), La politique pétrolière internationale, Paris, 1960 (Que sais-je ? n 891). Voir aussi FRANKEL (P.H.), L'économie pétrolière, Paris, 1948 ; LAUDRAIN (M.), Le prix du pétrole brut, Paris, 1958 ; LEVEQUE (Maurice), Le pétrole et la guerre, Paris, 1958 ; VASSEUR (L.V.), Pétrole et gaz naturel dans le monde, Paris, 1958. Rappel (sans oublier les réserves faites) du livre de O'CONNOR, L'Empire du pétrole. Pour un exposé historique, voir le monumental ouvrage MAC LEAN (John), HAIGH (Robert W.), The Growth of Integrated Oil Companies, Cambridge (Mass.), 1954. Pour une étude approfondie des pratiques du Cartel, il faudrait naturellement se reporter au fameux rapport présenté en 1952 au Sénat des ÉtatsUnis par la Federal Trade Commission. Le Rapport de la Commission Économique pour l'Europe, Le prix des produits pétroliers en Europe occidentale, ne donne aucun élément vraiment neuf eu égard au document américain.
} 
d'établir que la force de marchandage ne résulte pas toujours d'un calcul ou, plus exactement, que les circonstances et la structure de la situation (présence de régimes féodaux en divers pays du monde arabe), renforcent singulièrement les résultats d'un calcul quel qu'il soit.

Les menaces d'ordre politique concernent directement notre sujet, car elles affaiblissent le pouvoir de pression des trusts pétroliers sur les gouvernements considérés. La plus grave est sans doute la nationalisation des sources de pétrole. Réserve faite du monde communiste, elle est intervenue à de nombreuses reprises mais dans des conditions, différentes. Il s'agit parfois d'une position de principe visant une exploitation future (décision d'exclure de l'industrie à créer les capitaux étrangers par exemple). Il est arrivé aussi que le transfert de propriété porte sur des activités en état de marche : en 1938, le Mexique, qui n'est pas revenu sur sa décision et dont les ventes ont considérablement décliné ; en 1951, l'Iran, qu'un blocus pétrolier et diverses manœuvres politiques ont contraint de modifier la sienne ${ }^{1}$.

L'Indonésie vient de se livrer à une opération de ce type. Dans ce pays, la production était presque entièrement réalisée par trois des compagnies: Shell, Standard Vacuum ( «Stanvac ») et Royal Dutch (sous réserve de champs dans le Nord de Sumatra qui auraient été récemment [p. 359] concédés à une société japonaise). L'apport total sur le marché demeurait faible, de l'ordre de $2 \%$ du brut mondial. La nouvelle loi (novembre 1960) déclare que désormais seules les firmes de l'État peuvent procéder aux différentes opérations de l'industrie pétrolière. Cependant le texte prévoit la possibilité pour les compagnies étrangères de continuer leur activité en signant des contrats avec les entreprises étatiques.

La nationalisation peut aussi porter sur un réseau de raffinage et de distribution (la dernière en date étant celle réalisée à Cuba en juillet 1960, à l'encontre des installations de la Shell, de l'Esso Standard et de la Texaco, filiales des trusts internationaux). En principe, l'opération est moins grave: cependant le principal avantage de ces affaires étant de réaliser une intégration verticale parfaite, elles sont vulnérables en tous les points du circuit.

Les menaces peuvent ne viser que les conditions de l'exploitation. Au niveau des pays producteurs, la question est d'obtenir le maximum de droits et redevances. Les termes du problème sont bien connus. Les premières concessions en pays orientaux furent obtenues moyennant des sommes énormes pour les bénéficiaires, mais dérisoires eu égard aux bénéfices acquis. Puis, la règle du partage des bénéfices à égalité (dite du fifty-fifty) instituée au Venezuela en 1943, connut à partir de là une

Pour l'affaire iranienne, il existe une volumineuse littérature. On pourra consulter ELWELLSUTTON (L.P.), Persian Oil. A study in power politics, Londres, 1953 ; VECCIA VAGLIERI (L.), " Storia del Petrolio di Persia », Communità Internazionale, octobre 1956, pp. 595-619 ; SABLIER (E.), « La signification de l'affaire du pétrole iranien », Politique Étrangère, mars-avril 1953, pp. 16-22 ; RAZWY (A.A.), « The Anglo-Iranian Oil Dispute », Pakistan Horizon, juin 1953, pp. 7585 ; X. « La nationalisation de l'Anglo-Iranian Company », Annales de l'Économie collective, aoûtdécembre 1951, pp. 253-272. Voir aussi sur un secteur latéral HAY (R.), « The Impact of the Oil Industry on the Persian Gulf Shaykdoms », Middle East Journal, automne 1955, pp. 361-372. 
extension considérable. Bientôt d'autres affaires indépendantes du cartel offrirent des avantages plus appréciables. On a beaucoup parlé du 75\% accordé par M. Mattei : en définitive, il n'est pas certain que pour l'État propriétaire cette formule soit, compte tenu des stipulations du contrat, supérieure au partage classique. Mais cette fraction a une valeur propre, indépendante de ses conditions d'établissement.

Un autre aspect de cette pression gouvernementale sur les trusts internationaux consiste à leur imposer la création d'une industrie de raffinage dans le pays même. Telle fut la politique de la France dans l'entre-deux-guerres. Le régime douanier institué en 1928 pour ce produit, autorisait l'entrée du brut presque en franchise, les produits finis étant lourdement taxés à leur introduction sur le territoire. D'où la création en France, d'une puissante industrie de raffinage (avantages : diminution des dépenses de change ; amélioration des facilités de stockage stratégique ; possibilités de réexportation...).

Les revendications tombent actuellement sur un marché saturé. La situation s'exprime en quelques chiffres. Selon les spécialistes américains, la capacité présente des puits dans le monde est de l'ordre de 26 millions [p. 360] de barils par jour (un baril équivalant à 159 litres), la demande courante s'élevant seulement à 19. L'excès quotidien serait donc de 7 millions de barils, ou encore, d'après d'autres déclarations, s'établirait à 5 seulement. Au cours des quatre dernières années l'offre, telle que disponible aux puits, a augmenté de 6 millions de barils par jour, tandis que la demande ne s'élevait que de 3. Le déséquilibre initial est donc allé en s'aggravant. Même si les pronostics optimistes concernant l'élévation future de la consommation se vérifient, cette surabondance de brut risque de créer des difficultés sérieuses à l'industrie pendant une encore assez longue période.

Les causes de cette situation sont faciles à discerner. Du côté de la demande, le pétrole a sans doute gagné sa bataille sur le charbon : encore son expansion est-elle freinée par des mesures restrictives visant à protéger l'industrie charbonnière en déclin. Par ailleurs, il se heurte à de nouvelles sources nettement compétitives : le gaz naturel en particulier. Des efforts sont faits pour étendre les débouchés (pétrochimie) : mais les utilisations du pétrole comme matière première des produits (plastiques) n'absorbent que des quantités très faibles. L'expansion de l'offre, surtout, est le point noir. Due à l'action des États propriétaires des gisements qui, pour d'évidentes raisons financières, poussent les sociétés concessionnaires, et spécialement celles du Cartel, à développer l'extraction à tout prix, elle résulte aussi — et de plus en plus — de l'action de producteurs extérieurs au Cartel.

Il s'agit en premier lieu des producteurs américains que l'on appelle les « indépendants ». Désireux de se procurer un approvisionnement à des conditions financièrement meilleures que celles de l'extraction aux États-Unis, les compagnies américaines indépendantes ont recherché et obtenu des concessions en plusieurs pays pétroliers. Mais pour se procurer des périmètres de prospection et de production, ces affaires ont dû souvent consentir aux États intéressés des avantages supérieurs à ceux accordés par le Cartel. Le gouvernement américain ayant pris entre temps la décision de contingenter les importations pétrolières, ces compagnies doivent désormais 
écouler leur production sur des marchés extérieurs, ce qui les conduit à livrer une guerre de prix aux grands trusts internationaux.

Le second facteur est l'U.R.S.S., qui a beaucoup accru sa production et entend la développer davantage : possédant dès maintenant de gros surplus exportables, elle tente de les placer avec ténacité et parfois habileté. Sans aller aussi loin, plusieurs autres pays s'efforcent de couvrir [p. 361] leurs besoins avec des ressources nationales : c'est en particulier le cas de l'Argentine qui serait désormais en mesure de se passer d'importations.

Évoquons enfin à une échelle plus réduite, les efforts de M. Mattei en divers pays d'Afrique du Nord, en Égypte et en Iran, etc. Et n'oublions pas la capacité du Sahara ni celle en pleine expansion de la Lybie.

Le cas de l'U.R.S.S. est fort préoccupant pour les sociétés du Cartel ${ }^{1}$. Il est probable que dans ce pays la production va augmenter beaucoup plus vite que la consommation. Certes, les Russes connaissent un handicap sérieux par rapport aux sociétés internationales, n'ayant pas l'extraordinaire réseau commercial de ces dernières à travers le monde et ne disposant que d'une flotte pétrolière insuffisante (faiblesse que les armateurs " capitalistes », s'ils en étaient sollicités, ne laisseraient probablement pas subsister longtemps). Citons ici le projet en cours de réalisation d'un " conduit international » du pétrole soviétique, partant de Kouibychev (région Volga-Oural) et qui, au terme d'un trajet de 4500 kilomètres, aboutirait à un point sur l'Oder où un grand complexe chimique est en cours de construction. Divers embranchements permettraient d'approvisionner, au meilleur coût, les autres pays communistes (l'un en particulier desservant Hongrie et Tchécoslovaquie). Il est possible qu'un tel pétrole raffiné près de la Baltique puisse entrer victorieusement en concurrence sur les marchés nordiques avec celui d'autres régions.

Au surplus, les Russes n'hésitent pas à compenser leur retard commercial actuel en offrant des prix systématiquement moins élevés (quoique encore fort rémunérateurs). On a longtemps parlé de rabais de l'ordre de $10 \%$ et il semble que, actuellement, le sacrifice, soit nettement plus grand. L'U.R.S.S. et les grands trusts entrent déjà en compétition sur plusieurs marchés (ainsi, récemment en Inde, où les trois compagnies installées - Burmah-Shell, Standard Vacuum et Caltex - ont dû consentir ellesmêmes une réduction de $12 \%$ environ pour combattre les offres russes). L'une des armes disponibles pour les sociétés du Cartel est de refuser le raffinage du pétrole d'origine soviétique : on sait que M. Fidel Castro s'est fondé sur cette attitude pour nationaliser le réseau de raffinage et de distribution à Cuba.

L'état du marché, mondial aide certainement à comprendre la situation de l'exploitation pétrolière au Moyen-Orient ${ }^{2}$. Elle explique en particulier la modération

1 Voir HASSMANN (H.), Oil in the Soviet Union. History geography problems, Princeton, 1953 (apporte beaucoup d'informations mais paraît s'être trompé sur le sens de l'évolution) et LEVEQUE (M.), L'essor pétrolier de l’U.R.S.S., Paris, 1954.

2 Sur le Moyen-Orient, en dehors des travaux déjà cités de LENCZOWSKI, LONGRIGG. SHWADRAN et TEILHAC, voir HAMILTON (Daniel C.), Competition in Oil. The Gulf Coast 
dans le ton dont a témoigné en définitive le Congrès arabe du pétrole tenu au Caire en avril 1959 (l'Irak et Qatar ne participant pas à la réunion pour des raisons politiques, et l'Iran, pays non [p. 362] arabe, y étant représenté par des observateurs) ${ }^{1}$. Deux traits caractérisèrent cette manifestation : pas de Russes à la conférence et un effort évident pour écarter les discussions idéologiques. Les débats furent volontairement situés à un niveau d'affaires, les termes de « colonialisme » et d'« impérialisme » étant soigneusement évités et celui de « nationalisation » pratiquement exclu.

Les principales revendications exprimées furent les suivantes: hausse sur des bases raisonnables et équitables, des redevances versées et développement de l'intégration de l'industrie pétrolière. Par cette expression, les États arabes entendent la participation à toutes les opérations de l'industrie, de la production à la distribution : ils demandent ainsi que $30 \%$ au moins du pétrole arabe soit raffiné sur leur sol, et qu'à côté des entreprises privées existantes soit assurée la création de sociétés nationales (à prépondérance étatique). Ils revendiquent également des consultations préalables à tous changements dans le système de fixation des prix et les cours effectivement pratiqués. Autre proposition faite au Caire : la construction d'un pipe-line appartenant aux pays arabes qui drainerait dans l'avenir la production pétrolière de l'Arabie, de Bahreïn, de Qatar, de Koweït, d'Irak et même d'Iran. Enfin, la conférence a étudié des projets tendant à établir une certaine péréquation des revenus pétroliers entre les États qui en possèdent et ceux qui n'en ont pas ou peu.

Plusieurs de ces demandes soulèvent des problèmes considérables (par exemple, où trouver les capitaux indispensables ?). Leur mise en œuvre exigerait chez les États concernés un souci d'unité politique qui, au fond, ne s'est pas encore manifesté et dont l'insuffisance reste plutôt un atout pour les «pétroliers ». Il est pourtant douteux, compte tenu de la situation internationale et de la présence soviétique, que ces demandes demeurent à l'état de vœux platoniques. Il n'en est pas moins curieux d'observer que le Congrès a paru considérer comme un fait inéluctable, au moins pour un certain temps, la présence des grandes compagnies au Moyen-Orient. Habileté simplement tactique ? Peut-être, mais l'état du marché et la capacité des sociétés (facteur de domination) n'ont certainement pas été étrangers à cette attitude.

L'industrie du pétrole est l'une de celles qui permettent le mieux de vérifier l'étendue, mais souvent aussi la subtilité, des relations entre l'économie et la politique. En voici trois exemples récents.

D'abord l'intervention soviétique sur le marché qui est probablement d'inspiration surtout économique. Disposant d'un produit dont le prix, [p. 363] grâce aux efforts du Cartel, reste avantageux, les Russes veulent en profiter et se gardent bien de provoquer un effondrement des cours par l'offre de tarifs inconsidérés. En plusieurs

refinery market, Cambridge (Mass.), 1958 ; BERREBY (J.J.), Le golfe Persique, mer de légende, réservoir de pétrole, Paris, 1959 ; BESANÇON (J.), «L'année pétrolière 1958 au Moyen-Orient », Revue de Géographie de Lyon, 1960 (2), pp. 183-212 ; LUBELL (II.), « Middle East Crises and World Petroleum Movements », Middle Eastern Affairs, novembre 1958, pp. 338-348 ; KOJANEC (C.), « Politica petrolifera » Medio Oriente », Communità Internazionale, juillet 1958, pp. 471-487.

Voir les remarques présentées sur le Congrès par The Economist, 18 avril 1959. 
circonstances, la motivation politique reste proche et peut, à l'improviste, devenir prépondérante (affaire de Cuba). Les Russes savent aussi qu'un affaiblissement des positions pétrolières occidentales au Moyen-Orient serait pour ces puissances et spécialement la Grande-Bretagne, sinon absolument catastrophique, du moins grave : on s'étonnerait que cette constatation n'ait engendré chez eux aucun désir d'action. Entre plusieurs signes de cette attitude citons l'intérêt porté par l'U.R.S.S. à la politique de M. Mattei, d'esprit si l'on peut dire « neutraliste », et l'accord conclu avec lui lors du voyage à Moscou de M. Gronchi : opération dont l'objectif à long terme est de faciliter la pénétration de l'U.R.S.S. sur les marchés d’Europe occidentale ${ }^{1}$.

Autre zone de contacts : l'exploitation des richesses pétrolières du Sahara. Le conflit algérien dans son déroulement et sa prolongation ne saurait en être dissocié. La venue de ce pétrole sur le marché va poser des problèmes considérables, aussi bien pour les sociétés internationales que pour les pays arabes déjà producteurs.

Les remous provoqués en France par la création finalement sans éclat d'un second groupe pétrolier illustrent bien cette interaction du politique et de l'économique. L'affaire vient d'aboutir, après deux ans de négociations, à la création de l'Union Industrielle des Pétroles (dont le capital est réparti entre Caltex pour $40 \%$ et les six producteurs nationaux groupés dans l'Union Générale des Pétroles pour 60\%). Son objectif est de développer les activités de transport, de raffinage et de distribution précédemment exercées en France par Caltex.

Les dimensions de départ attribuées à l'institution sont faibles, les milieux officiels parlant d'un « réseau-témoin ». Cependant, les groupes pétroliers internationaux, et aussi la Compagnie Française des Pétroles que, d'après des déclarations ministérielles, l'on aurait écartée de l'opération simplement pour ne pas favoriser le « gigantisme »... restent inquiets des intentions gouvernementales (ce qu'on a pu appeler en termes polémiques un « national-pétrolisme ») ${ }^{2}$.

Dernier exemple : la tendance à la baisse généralisée des prix du pétrole brut au Moyen-Orient. À vrai dire, depuis longtemps diverse à compagnies vendaient audessous du «tarif affiché » (des rabais de 30\% ayant été signalés) pour deux motifs : l'abondance du produit sur le [p. 364] marché et la pression russe. Dès lors, la décision d'Esso-Standard (9 août 1960) de réduire les prix du brut (de 2,5 à 6\% selon les cas) constituait une régularisation partielle. Mais les redevances versées aux États étant calculées sur les cours officiels, ces derniers verront leurs encaissements

L'essentiel de l'accord dont l'initiative paraît revenir à M. Mattei consiste dans la fourniture par l'U.R.S.S. à l'Italie, au cours des cinq années à venir, de 12 millions de tonnes de pétrole. En contrepartie, l'Italie fournit du caoutchouc synthétique et surtout des tubes en acier et divers matériels pour l'installation du « conduit pétrolier » international (supra).

2 Voir le débat au Conseil Économique sur « Politique pétrolière et problèmes posés par les pétroles et le gaz saharien », Journal Officiel, 21 juin 1960, pp. 428-450. L'affaire ne paraît pas avoir tourné finalement à la satisfaction des pétroliers internationaux: voir les réserves présentées par le Président directeur général d'Esso-Standard lors de la dernière Assemblée générale de la société, $L e$ Monde, 19-20 juin 1960. Pour une documentation de portée générale, voir PIERRE (Bernard), Pétrole français, Paris, 1960 et CHAMMARD (Paul de), Problèmes pétroliers de la France et de la Communauté, Paris, 1959. 
diminuer ou, au minimum, ne pas augmenter, la tendance à la baisse absorbant le supplément attendu de la hausse de la production. Aussi la British Petroleum et la Shell ont-elles décidé de suivre Esso, en donnant à la baisse des modalités qui, semble-t-il, soient moins préjudiciables aux intérêts des États producteurs.

La décision des Américains a vivement mécontenté les Anglais qui l'ont trouvée fort inopportune à la veille de difficiles conversations avec l'Irak. L'affaire montre, selon un schéma d'ailleurs classique, qu’États arabes et sociétés pétrolières, opposés entre eux, ont des intérêts communs vis-à-vis du reste du monde. Or la surproduction du marché est, pour partie, l'œuvre des Russes (même s'il s'agit d'un facteur encore marginal), qu'ils se bornent à chercher des devises comme nous le pensons, ou qu'ils tentent de désorganiser le marché mondial, comme d'autres le croient. Il est vrai qu'une interprétation absolvant l'U.R.S.S. de toute faute a prévalu dans divers milieux arabes : selon une thèse, les compagnies internationales se serviraient des ventes de pétrole russe à bon compte comme d'un prétexte pour réduire les prix officiels et diminuer les redevances à verser, ou encore pour réaliser de telles baisses dans un dessein de propagande politique.

On a insisté sur cette affaire pour suggérer l'ampleur des implications politiques d'un simple affaissement des prix. Or, sauf reprise importante et inattendue de la hausse de la consommation, de nouvelles baisses pourraient intervenir. Encouragé par les premiers avantages consentis, le gouvernement indien en a immédiatement réclamé de nouveaux. Qu'allait-il en résulter dans les rapports Trusts pétroliers États producteurs?

Les réactions ont été en fait très vives. Ce furent d'abord une double série de revendications : augmentation des taxes et royalties pour compenser la réduction des prix et approbation préalable des pays producteurs à toute mesure de compression des tarifs ou de diminution de la production. Mais les États producteurs sont parvenus à une dérision plus significative, en créant une Organisation des Pays Exportateurs de Pétrole (Moyen-Orient et Venezuela) qui entend désormais peser (renversement de la pression) sur les sociétés pétrolières. Il est clair que la capacité d'action de cet organisme - dans lequel certains voient déjà, un peu [p. 365] vite semble-t-il, le successeur du Cartel — dépendra surtout de son aptitude à constituer un front commun et à imposer aux membres une politique globale ou au moins coordonnée : elle sera finalement fonction de la solidarité des producteurs qui, jusqu'à présent, a été purement verbale. Tout pronostic sur la vitalité future de cet organisme (et par exemple, sur sa capacité à obtenir des différents pays intéressés une réduction concertée de la production vu un partage des marchés), serait prématuré. Par ailleurs, la réussite de telles tentatives soulèverait le problème de la protection des consommateurs.

La seconde Conférence arabe des pétroles qui s'est tenue à Beyrouth en octobre 1960 a été caractérisée par un ton beaucoup plus vif que celui du Caire. Les compagnies internationales y ont été accusées de vouloir s'assurer le maximum de profits au détriment des producteurs. D'autre part, il semble bien que les intéressés ressentent désormais le danger des exportations soviétiques, les attaques lancées 
contre la politique de M. Mattei (lequel se présentait volontiers comme l'ami, sinon le sauveur, des pays sous-développés) en sont un signe sans équivoque.

À tous égards, la situation actuelle est particulièrement fluide. Solide en termes politiques, la position des États gros exportateurs se heurte à de sérieuses difficultés économiques. Au surplus, il n'est pas acquis que ses accusations rituelles contre les grandes compagnies délivrent l'U.R.S.S. aux yeux des Arabes de toute responsabilité : déjà manifeste, le conflit pourrait s'aggraver si l'exportation soviétique (sans oublier la réalité du Sahara) s'accomplissait au rythme prévu.

En de nombreux milieux, gouvernementaux et privés, le Cartel des pétroles n'a pas bonne presse. Il est vrai que, durant des années, les sociétés qui le composent et leurs filiales communes (ainsi l'Aramco pour l'Arabie saoudite) ont réalisé des bénéfices considérables. Les " pétroliers » se défendent contre de telles allégations en faisant valoir que l'appréciation de leurs activités doit être effectuée d'une manière globale. Ils signalent que les bénéfices réalisés dans une région du monde ont servi souvent à balancer les pertes enregistrées ailleurs par suite d'insuccès dans la prospection et les forages. Cette observation n'est pas dépourvue de fondement: l'industrie pétrolière est aléatoire. Cependant, on ne saurait contester que les grands trusts pétroliers ont réalisé des profits confortables fondés sur un mode de tarification ignoré du public.

Pour que ce régime de prix (golfe du Mexique comme point de base) ait été, entamé, il a fallu attendre-la protestation de l'Amirauté britannique [p. 366] ellemême en 1943. Aujourd'hui, ces sociétés, qui comptent parmi les plus puissantes du monde, négocient sans être trop sûres du lendemain avec des gouvernements dont les exigences tendent à être aussi grandes que les moyens matériels sont réduits.

Durant toute une période, environ de 1930 à 1950, le Cartel a constitué une sorte de gouvernement mondial du pétrole : justification contre Lénine, au moins sur un point, de la thèse de l'« ultra impérialisme de Kautsky » (exploitation en commun par le capital financier réuni au plan international). Le sens de l'unité — joint, il est vrai, à des changements dans les rapports de puissance — a été si fort que l'implantation accrue des intérêts américains au Moyen-Orient, jadis fief britannique exclusif, s'est effectuée sans entraîner de rupture majeure. La situation n'est désormais plus la même. Cependant l'effort de régulation assuré par le Cartel, tout en ayant été compromis ces dernières années par plusieurs dissensions entre les membres sur la question des prix pratiqués, demeure encore le facteur principal de la politique pétrolière internationale. L'avenir reste incertain.

Un seul point est hors de doute : on ne pourrait laisser un marché comme celui du pétrole aux déchaînements de la libre concurrence sans qu'il en résulte un chaos fondamental capable d'engendrer des conséquences politiques aussi sérieuses qu'imprévisibles. Les cyniques diront peut-être que l'état de choses actuel (intérêts privés "pressurés » par les gouvernants de pays producteurs et soumis à une forte pression extérieure : Russie...) représente la solution la moins dangereuse. Il est vrai que la gamme des possibilités concevables en la matière ne paraît pas très étendue : le caractère extrêmement mouvant de la conjoncture suffisant, en pratique, à empêcher 
la conclusion de tout accord capable de tenir compte des intérêts actuels et de ceux, tout aussi légitimes, de demain.

On a voulu dans ce paragraphe montrer que le maintien d'un statu quo dépend parfois, souvent peut-être, des conditions objectives de la situation (dans lesquelles s'insèrent les particularités du régime politique). Le point est capital : la plupart du temps, lorsqu'il s'agit d'interpréter les résultats obtenus par un groupe, on néglige ce facteur et l'erreur est courante en cas de succès. Il arrive alors que, méconnaissant l'appui que vaut au groupe l'état des structures ou de la conjoncture, on se trouve obligé de supposer des interventions, voire des machinations ima-[p. 367] ginaires. L'évaluation du rôle propre de la pression politique ne pourrait être entreprise sans un essai pour apprécier la portée du contexte. La position de l'Aramco serait aujourd'hui probablement différente si l'Arabie saoudienne était devenue province de la République arabe unie.

Prenons un autre exemple: la reconcentration (verticale et horizontale) de la sidérurgie allemande. On comprend que, sur le plan politique, certains noms ne soient pas sans susciter quelque appréhension ou protestation. Voyons les faits. L'idée, entrevue à un moment, de limiter à 1,5 ou 2 millions de tonnes la capacité de l'unité sidérurgique, s'est révélée pure utopie. À l'échelle américaine, de telles entreprises sont microscopiques. Or le but de l'intégration européenne n'est-il pas de créer un marché à la taille de celui des États-Unis ? Et dans ces conditions, la concentration se poursuivra inéluctablement en Allemagne, mais aussi en France et en Belgique.

Est-ce à dire que le rôle de la C.E.C.A. doit s'amenuiser jusqu'à disparaître ? Certainement pas. Il lui revient d'accepter ce phénomène et de le contrôler. Et cette opération devrait être d'autant plus stricte que les limites des dimensions de l'entreprise optimale (selon le jargon à la mode) s'élèvent elles-mêmes. Sans entrer dans le détail, disons qu'en cette matière (la C.E.C.A. l'a parfaitement compris), le point essentiel est la supervision des investissements, qui devrait aller jusqu'à la nécessité d'une autorisation préalable pour les nouveaux. Il s'agit en somme d'éviter qu'une situation semblable à celle qui s'est créée sur le marché américain ne prévale en Europe : nous sommes encore loin d'une telle concentration.

Ces considérations ne reviennent point à taxer d'impuissance Krupp, Thyssen, Klöckner et quelques autres. Ce sont des groupes forts et solides dont les avis comptent en Allemagne et à Luxembourg, mais leur combat pour la reconcentration a été facilité par les exigences de l'évolution technique qui, selon d'éminents spécialistes, rendraient insuffisantes les combinaisons à 2 millions (taille française) et souhaitables des formules à 5-7 (les trois groupes allemands cités atteignant déjà, ou devant bientôt y parvenir, 4 millions) ${ }^{1}$.

\footnotetext{
Autre exemple de cette puissance. On sait que les Alliés en 1954 avaient décidé que M. Alfred Krupp devrait renoncer à ses entreprises charbonnières et sidérurgiques. Le délai fixé pour la vente (cinq ans) a été prorogé deux fois (en raison, notamment de l'incapacité des alliés de s'entendre sur la destination finale de ces propriétés) ; la position finalement arrêtée serait l'octroi d'un nouveau délai d'un an. Selon des informations officieuses, la Commission internationale chargée de se
} 
[p. 368]

\section{d) RÔLE DES ORGANISATIONS NON GOUVERNEMENTALES}

\section{$\underline{\text { Retour à la table des matières }}$}

En les traitant à part, et postérieurement à l'étude des grandes entreprises économiques, on n'entend pas, comme c'est le cas dans les présentations courantes, dévaloriser a priori leur faculté d'intervention et leur capacité d'influence. On se propose seulement de ne pas négliger certaines caractéristiques de leur « accès » à la vie internationale: absence de but lucratif; arrangements consultatifs avec des organisations non gouvernementales; présence de sections nationales assurant à l'organisme central un caractère représentatif de l'opinion mondiale (du moins d'une fraction plus ou moins large de celle-ci). Quels résultats ces facteurs permettent-ils d'obtenir?

On a déjà insisté sur la diversité des organisations non gouvernementales, qui s'affirme sous tous les aspects et en particulier quant à la nature de l'objectif. Les possibilités de regroupement sont diverses, mais en général approximatives et contestables. Ainsi, par exemple, en considérant la portée du but visé distingue-t-on volontiers trois séries d'associations ; celles qui défendent des intérêts matériels et professionnels au sens large du terme ; celles qui groupent des savants se préoccupant d'échanges scientifiques; celles qui ont pour souci la promotion d'activités humanitaires, d'idéologies morales... Il n'est pas impossible de ramener la seconde catégorie, en vérité assez diversifiée, à la troisième et de retrouver ainsi la division fondamentale déjà signalée : défense d'un intérêt (en prenant le mot dans l'acception d'un avantage matériel) — promotion d'une cause (ce que les Anglo-saxons appellent volontiers des groupements civiques).

La critique de ce principe de classification est facile à faire. Beaucoup d'organismes, et on en a déjà cité des exemples, se vouent à une activité de nature dualiste impliquant la protection d'intérêts privés et une référence à l'intérêt général ou à une conception de la société. Bien des groupes se servent de l'idéologie pour masquer l' «égoïsme » de leurs revendications. Cependant, la pratique montre que cette distinction n'est pas dépourvue de portée opérationnelle. Nous l'emploierons ici sans y voir autre chose qu'un instrument de travail à usage limité.

L'une des grandes difficultés que l'on rencontre en étudiant l'influence éventuelle des O.N.G. est de faire la discrimination entre ce qui revient au centre, ce qu'il apporte en propre et ce qui appartient aux composantes nationales. Certaines

prononcer sur les modalités d'application aurait conclu qu'elle n'était pas exécutable (Times, 7 octobre 1960). Pendant ce temps la firme Krupp étend ses relations internationales (Inde par exemple) : son directeur général est reçu avec de grands honneurs à Varsovie. 
associations internationales sont en réalité de simples modes de contact entre les membres qui se réunissent pour [p. 369] s'informer de leurs activités, de leurs projets, de leurs progrès. L'organisation centrale facilite de tels échanges, mais ce n'est pas dire pour autant qu'elle pourrait exercer une action par elle-même. Ce sont les organisations «boîte à lettres » ou " agence de voyages ». Encore qu'on n'ait pas le moyen d'en établir le recensement, il semble qu'elles soient nombreuses. On ne saurait les tenir comme des facteurs directs de la décision. Autrement dit, de tels organismes n'ont qu'en apparence la « capacité internationale ».

Sous l'angle de la décision, l'O.N.G. n'a de réalité que si elle apporte, une capacité supplémentaire à chacun de ses membres. Ce complément s'analyse, au fond, en un renforcement de la cause ou de l'intérêt défendu qui résulte de la mobilisation des forces réalisées par l'association considérée. Mais en bien des occasions il est difficile d'en constater l'existence et, plus encore, d'en mesurer la portée.

Quand l'organisation agit directement au niveau intergouvernemental, il est relativement aisé d'apercevoir et, dans certaines limites, d'évaluer ce qu'elle apparaît susceptible de réaliser. À tout le moins peut-on retenir comme un point caractéristique la volonté d'exercer un rôle. L'organisation intervient aussi au plan simplement gouvernemental, soit en l'absence d'une section nationale, soit, s'il en existe une, pour appuyer son action. C'est évidemment dans cette dernière hypothèse que la répartition des responsabilités est la plus délicate.

Il est possible que l'on parvienne un jour à exprimer de telles formules en un modèle d'allure rigoureuse actuellement, compte tenu de la rareté des observations disponibles, l'opération n'occasionnerait vraisemblablement que des déboires. On se bornera donc à quelques remarques de type littéraire, en insistant sur les associations les plus puissantes et les plus influentes (spécialement à l'O.N.U.): Chambre de Commerce Internationale ; groupements religieux ; internationales syndicales.

Groupements à buts économiques ou professionnels - Il est hors de doute que plusieurs des organismes rattachables à cette catégorie ont été en mesure d'exercer une action sur le plan mondial. La Chambre de Commerce Internationale, dont on a déjà parlé plusieurs fois, est l'un d'entre eux.

Pour la période de l'entre-deux-guerres, de nombreux commentateurs ont souligné le rôle de la Chambre dans l'élaboration et la mise en œuvre du plan Dawes (c'est elle qui aurait lancé la première [p. 370] l'idée de créer un comité d'experts pour traiter du problème des réparations). Armée de sa compétence et du poids des intérêts représentés, elle aurait aussi tenu une place considérable dans l'établissement du moratoire Hoover en 1931 : selon ses propres déclarations, ce serait une illustration des possibilités qui sont ouvertes à un organisme international de modifier les positions gouvernementales par une action sur l'opinion (le facteur de changement ayant été en l'occurrence la publicité faite par la presse aux déclarations des leaders mondiaux des affaires lors du Congrès de Washington au début de mai 1931). De même, on relève de nombreuses actions couronnées de succès dans des domaines plus spécialisés : lutte contre la double imposition, par exemple. 
Voici un cas typique d'intervention limitée. En 1936, les autorités compétentes envisageaient une hausse des tarifs télégraphiques pour 1938. La Chambre réagit vigoureusement : elle se livra à une vaste enquête auprès de ses membres et déposa un rapport affirmant que toute augmentation de ce genre forcerait les affaires à réduire le nombre et la longueur des messages téléphoniques et à utiliser d'autres moyens de communication. Les gouvernements se le tinrent pour dit et ce projet fut abandonné ${ }^{1}$.

Le rapport du Secrétariat général de la Chambre montre bien l'étendue des problèmes abordés par l'organisme. Notons, spécialement, l'activité des commissions techniques où se fait la synthèse des opinions nationales et se prépare l'établissement d'un point de vue international. Voici l'objet de quelques-uns de ces instruments de travail : politique commerciale et monétaire; placements à l'étranger et développement économique; questions fiscales; produits de base et matières premières; ententes économiques internationales; protection internationale de la propriété industrielle, etc. La simple lecture de ce document montre qu'il ne s'agit pas là de discussions académiques, mais de débats concrets au cours desquels, en particuliers, sont fixées les positions à défendre. Les rapports indiquent aussi, à l'occasion, le sens des interventions et les résultats obtenus ${ }^{2}$.

Citons quelques exemples pour la période 1955-57: effort en vue de susciter l'intérêt de l'opinion publique et des gouvernements pour les marchés à terme (l' « accès » étant la Commission du Commerce International des Produits de Base) ; intervention auprès des gouvernements pour l'abrogation du plus grand nombre possible des réglementations affectant la commercialisation internationale des produits ; action conti-[p. 371] nue pour promouvoir la convertibilité des monnaies sur une base mondiale; protestation contre certains termes employés dans les instruments relatifs aux droits de l'Homme et susceptibles d'ébranler la confiance des bailleurs de fonds privés («droit de souveraineté permanent des peuples sur leurs richesses et leurs ressources naturelles ») ; protestation contre le boycottage effectué par certains pays à l'encontre des firme; étrangères, sous le prétexte d'une appartenance raciale ou religieuse des dirigeants de ces sociétés. Même en se limitant aux interventions ouvertes, on pourrait aisément allonger la liste.

La Chambre possède pleinement la capacité internationale. Elle est organisée pour intervenir directement auprès des instances intergouvernementales (y compris,

Exemples tirés des ouvrages de LYMAN (White) et RIDGEWAY (déjà cité). Voir aussi DELAISI (François), Les contradictions du monde moderne, $3^{\mathrm{e}}$ édition, Paris, 1932, chap. XVII.

2 Sur certains points, il serait facile de pousser plus loin l'analyse de l'influence de la Chambre. Celleci, par exemple, n'a jamais fait mystère de ses opinions libérales sur les placements à l'étranger. À diverses reprises, elle a élaboré des recommandations pratiques visant notamment à l'octroi d'avantages fiscaux destinés à encourager les investissements internationaux. Or la S.D.N comme l'O.N.U. ont plusieurs fois pris publiquement position en la matière. Voir, par exemple, la brochure publiée en février 1950 par le Département des Affaires économiques des Nations Unies, Les effets de l'impôt sur le commerce et les investissements internationaux (où revient plusieurs fois, dans les références, le nom de la Chambre). Une simple comparaison de textes permettrait déjà de poser d'utiles jalons. 
naturellement, les institutions européennes). En même temps, la qualité des membres et la position qu'ils occupent dans l'économie de leur pays lui assurent une voie de pénétration efficace auprès des autorités nationales. Sous tous ces aspects, peu de groupes de pression internationaux peuvent lui être comparés.

Il ne semble pas possible de présenter des constatations analogues pour l'Agriculture. Certes, on peut faire remonter assez haut les premiers efforts de coopération internationale en cette matière (signature d'une convention sur le phylloxéra en 1878) ${ }^{1}$. Par la suite furent fondées quelques associations spécialisées (volailles en 1912 ; betteraves en 1932 ; oléiculture en 1934, etc.). Enfin, il existait avant la seconde guerre mondiale, une Commission internationale de l'Agriculture qui, en 1938, rassemblait 86 associations (nationales ou internationales) ${ }^{2}$. Il ne paraît pas qu'elle ait exercé une action très efficace auprès des autorités intergouvernementales avec lesquelles ses rapports furent plutôt médiocres (cas, notamment, de l'Institut International de l'Agriculture). Quant à la S.D.N., elle s'occupa peu en fait de l'agriculture. Quoi qu'il existe aujourd'hui, on l'a vu, une Fédération Internationale des Producteurs Agricoles (F.I.P.A.), on hésiterait pourtant à écrire que la situation s'est complètement modifiée.

La F.I.P.A. est d'ailleurs consciente de cette faiblesse dont elle attribue la cause à l'incapacité de la F.A.O. de jouer le rôle d'un organisme international où les gouvernements élaborent leur politique (ou, du moins, puisent certains éléments d'inspiration commune). Soulignant le nombre restreint d'activités multilatérales dans ce domaine, la Fédération relève des différences spectaculaires entre les politiques suivies par les diverses nations et les débats internationaux à l'intérieur et à l'extérieur de la [p. 372] F.A.O. Mais il est possible que cette particularité tienne davantage encore à la nature des problèmes qu'à la carence de la F.A.O. Plus que celles de l'industrie et surtout du commerce, les questions agricoles, on l'a dit, dépendent de structures et de circonstances nationales - particularisme accru aujourd'hui par la volonté des États, spécialement en Europe, de réduire au minimum leur coefficient de dépendance alimentaire vis-à-vis de l'extérieur.

Ainsi s'expliquerait le décalage entre la puissance des groupes agricoles sur le plan national et leur faiblesse au niveau international ; celle-ci étant susceptible de s'atténuer quand il s'agit de productions spécialisées et géographiquement concentrées. Mais il est douteux que, même dans le cadre réduit de l'Europe des Six, la capacité professionnelle de l'agriculture comme un bloc, rejoigne celle de l'industrie.

Le caractère largement international des problèmes de transport explique naturellement l'activité des associations internationales en cette matière. On en trouve déjà de nombreux exemples entre les deux guerres. L'un des plus connus est celui de

HOUILLIER (F.), L'organisation internationale de l'agriculture. Les institutions agricoles internationales et l'action internationale en agriculture, Paris, 1935.

2 RIEUL PAISANT (Marcel), «La Commission internationale d'agriculture et son rôle dans l'économie européenne », Annales de la Commission Internationale d'Agriculture, 1936 (XV). 
l'Association du Trafic Aérien International (devenu aujourd'hui l'Association du Transport Aérien International). On a pu dire de cette organisation que, sans son concours et son activité, la réglementation publique de la navigation aérienne aurait été considérablement retardée ${ }^{1}$ (certains affirmant même que c'est son travail qui a rendu possible, après la dernière guerre, la création de l'Organisation Internationale de l'Aviation Civile).

Fondée en 1919 en vue de grouper les compagnies de transport, l'Association du Trafic Aérien a joué un rôle considérable dans l'élaboration du droit international aérien public et privé. En matière de droit public, par exemple, elle a entretenu des rapports étroits avec l'officielle Commission Internationale pour la Navigation Aérienne (dont le secrétaire général assistait régulièrement à ses réunions) : sur des points précis que l'on a pu repérer (par exemple la question des déclarations douanières pour les marchandises transportées), ses demandes ou réclamations sont directement entrées dans la réglementation internationale. Dans le domaine du droit privé, on relève un fait exceptionnel : les compagnies membres de l'Association décidèrent d'appliquer la convention de Varsovie dès son entrée en vigueur, même dans les États qui n'avaient pas ratifié la convention.

Autre exemple significatif : celui de l'Association Internationale des AutomobileClubs reconnus (devenue Fédération Internationale de l'Auto-[p. 373] mobile) et de l'Alliance Internationale du Tourisme. Bien qu'ayant des missions différentes, ces organisations ont toujours partagé des préoccupations dont témoigne la fondation, en 1947, de l'Organisation Mondiale du Tourisme et de l'Automobile qui assure la représentation commune de deux organes (plus celle de la Fédération Internationale des Clubs d'Automobile) auprès de l'Ecosoc. Ces associations se sont notamment préoccupées de faire adopter les réglementations facilitant le passage des voitures à travers les frontières. Ainsi l'introduction, dès 1913, du "carnet de passage en douanes » (accepté en 1936 par 45 pays) et, entre les deux guerres l'acceptation généralisée dans les pays européens, du "tryptique », chacune des deux associations revendiquant d'ailleurs la responsabilité exclusive d'avoir obtenu cette remarquable facilité.

Dernier exemple : l'Union Internationale de Radiodiffusion (reconstituée après la guerre sous le nom d'Organisation Internationale de Radiodiffusion et devenue, depuis 1949, une institution de type paracommuniste). Entre les deux guerres, l'Union a joué un rôle très important dû à l'incapacité où se trouvèrent d'abord les États de légiférer en pareille matière : en particulier elle aida ceux-ci dans leur effort pour parvenir à une distribution rationnelle des longueurs d'onde entre les divers postes d'émission, sans laquelle ce nouveau mode d'information aurait engendré un véritable chaos international.

De telles organisations ont également exercé une fonction notoire auprès de l'O.N.U. (l'une des commissions de l'Ecosoc s'occupant des transports et

1 Voir COLEGROVE (K.W.), International Control of Aviation, Boston, 1930, et TOMBS (Lawrence C.), International Organization in European Air Transport. New York, 1936. 
communications). Parmi les O.N.G. qui semblent s'être le plus intéressées à cette activité, on peut citer (en dehors de la Chambre de Commerce Internationale) : la Fédération Routière Internationale (qui possède des secrétariats autonomes à Washington, Londres et Paris) ; l'Association Internationale du Transport Aérien ; la Fédération Internationale des Armateurs ; la Fédération Internationale des Ouvriers du Transport (l'un des secrétariats professionnels rattachés à la C.I.S.L.) ; l'Union Internationale des Chemins de, Fer (qui joue en particulier le rôle d'organe d'études de la Conférence internationale pour l'unité technique des chemins de fer) ${ }^{1}$; l'Union Internationale des Organismes Officiels de Tourisme ${ }^{2}$, etc. Un aspect caractéristique de cette activité a été le concours apporté par les O.N.G. à la réorganisation des transports européens (tâche assurée par un comité spécialisé de la Commission Économique pour l'Europe) ${ }^{3}$.

Considérons maintenant un domaine spécialisé : celui de l'Organisation Mondiale de la Santé qui entretient, on l'a dit, des relations consultatives [p. 374] avec une cinquantaine d'O.N.G. De tels organismes existaient évidemment bien avant la guerre : par exemple la Fédération Dentaire Internationale qui s'est efforcée à la fois de défendre l'intérêt de ses membres auprès des gouvernements et de constituer un centre de documentation sur les questions spécifiques de la profession. Entre les deux guerres, l'Organisation Internationale du Travail s'occupait directement des problèmes de la santé par l'intermédiaire d'un service particulier qui avait des contacts directs avec plusieurs associations (notamment celles concernées par les accidents professionnels et les maladies industrielles). Plusieurs conférences sur la santé des marins furent organisées par diverses O.N.G. en coopération étroite avec l'O.I.T. Mais la fondation de l'O.M.S. a donné un élan nouveau à ces relations ${ }^{4}$.

L'O.M.S. collabore particulièrement avec l'Association Médicale Mondiale (par exemple organisation en commun en 1953 d'une conférence sur l'enseignement de la médecine) et avec le Conseil des Organisations Internationales des Sciences Médicales. Elle déclare avoir reçu un concours actif de plusieurs organisations :

1 La Conférence est un organe intergouvernemental qui groupe 19 pays. L'Union internationale des chemins de fer assure la représentation commune des organismes suivants : Comité International des Transports par Chemins de Fer; Conférence Européenne des Horaires des Trains de Marchandises; Union Internationale des Voitures et des Fourgons; Union Internationale des Wagons et Union des Services Routiers de Chemins de Fer Européens.

2 Cet organisme rassemble, en particulier, 9 organisations internationales : Association Internationale des Skal Clubs ; Centre d'Information des Chemins de Fer Européens ; Comité International pour la Diffusion Artistique et Littéraire par le Cinéma; Fédération Internationale des Agences de Voyage; Association Internationale de l'Hôtellerie; Union Internationale d'Organisations nationales d'Hôteliers Restaurateurs et Cafetiers ; Fédération Internationale pour les Auberges de la jeunesse ; Association Mondiale des Agences de Voyage; Union Internationale des Transports Routiers.

3 Voir sur la question «European Inland Transport since the End of the War ", Transports and Communications Review, octobre-décembre 1948, pp. 14-26; MANCE (H. Osborne), " International Inland Transport in Europe ; Recent Developments in Organization », Journal of the Institute of Transport, mars 1954, pp. 337-342.

4 Voir Les dix premières années de l'Organisation Mondiale de la Santé, Genève, 1958, pp. 141-145. 
Comité International de la Croix-Rouge et Ligue des Sociétés de la Croix-Rouge ; Fédération Mondiale pour la Santé Mentale ; Conseil International des Infirmières ; Société Internationale de la Lèpre ; Organisation Internationale contre le Trachome, etc. On notera qu'une partie de ces relations ne semble entrer que difficilement dans le schéma "groupes de pression" (ainsi participation à une campagne antituberculeuse organisée par l'O.M.S.). Pourtant, dans la mesure où l'objectif final reste d'obtenir une aide ou une réglementation gouvernementale, l'application du cadre général reste légitime, sous réserve de transposer le cas au niveau de la défense des causes.

Plusieurs des organismes groupés autour de l’O.M.S. sont justement de ceux qui contredisent la formule simpliste protection d'un intérêt-promotion d'une cause. On a déjà signalé que la défense professionnelle de catégories, telles que médecins, dentistes, pharmaciens, s'effectue davantage, au plan national qu'au niveau international. Sans doute, l'ancienne Association Professionnelle Internationale des Médecins et l'actuelle Association Médicale Mondiale ont-elles inscrit dans leurs objectifs la protection des intérêts des médecins. La première, en particulier, accordait une place considérable à des questions comme le libre choix du médecin par le malade, les modes de paiement des services médicaux, le contrôle du médecin par la profession elle-même, etc. Cependant, au cours des dernières années, les solutions gouvernementales à cet égard ont beaucoup [p. 375] varié d'un pays à l'autre. Si l'on prend quelques cas typiques (service de santé en Grande-Bretagne, résistance à toute forme de médecine sociale aux États-Unis, solution de compromis en France...), des influences internationales ne semblent pas être intervenues au cours de la querelle et de son règlement.

Les cas cités jusqu'à présent permettent une double observation. L'action des groupes de pression internationaux trouve sa sphère de prédilection dans les questions impliquant une responsabilité mondiale, ou se posant de façon identique dans plusieurs pays, ou exigeant des solutions uniformes qui minimisent le rôle, généralement perturbateur, des frontières nationales. On pourrait dire en somme, et ce serait banal, que la pression internationale s'exerce quand il y a matière à une telle activité. Cependant de nombreuses O.N.G., malgré une mission d'apparence internationale, ont pour objectif certaines questions qui se posent en termes nationaux ou «nationalisés» (volonté d'autarchie agricole): il est possible qu'alors, leur influence soit limitée.

La possession de sections nationales composées de personnalités représentatives dans leur propre pays (Chambre de Commerce Internationale) ou d'une clientèle nombreuse (Clubs d'automobile) est un facteur éminent de puissance. Un groupement bénéficiant d'une telle composition verra, toutes choses égales, son influence s'affirmer dans les organisations intergouvernementales : tandis qu'en même temps il dispose d'une voie d' "accès » efficace auprès des autorités gouvernementales de chaque pays-membre. Le rôle des personnalités reste, comme partout, spécialement important, cette identité des dirigeants ou des inspirateurs, à travers des structures qui se situent à des niveaux différents, étant l'un des facteurs essentiels du sujet. 
L'analyse des groupes internationaux attachés à la promotion de causes confirmet-elle ces remarques ou exige-t-elle qu'on leur apporte retouches, nuances, complément?

Internationales religieuses et idéologiques - À première vue, l'action de ces multiples groupements aux objectifs si divers et souvent opposés semble défier une présentation systématique, au moins dans l'état actuel de nos connaissances. En ce qui concerne les nombreuses organisations constituées sur la base d'une confession religieuse, d'aucuns y verront essentiellement des éléments de discorde (effervescence pan-islamique, appui de l'Église romaine à la constitution d'un bloc anti-soviétique) : d'autres [p. 376] insisteront sur l'action pour la paix menée par tant de ces organismes, sur leur contribution aux institutions internationales (œuvre de philanthropie, appel à la fraternité...). Si l'on s'en tient au niveau de la pression en son sens le plus strict, quelle peut être à notre époque la force de l'excommunication ou de l'anathème ou encore la portée d'un mot d'ordre de guerre contre les infidèles ? À propos de l'excommunication, rappelons seulement qu'aux termes du code de droit canon (art. 2234), elle frappe automatiquement «tous ceux qui émettent des lois, mandats ou décrets contre la liberté et les droits de l’Église et tous ceux qui empêchent directement ou indirectement l'exercice de la juridiction ecclésiastique ».

Dans la perspective de cet ouvrage, il est évident que l'Église romaine constitue de nos jours l'une des plus importantes organisations internationales ou même mondiales. Cependant, on a déjà montré que les Protestants, loin de négliger la formule de l'association, avaient témoigné au cours des dernières décennies d'une remarquable aptitude à l'utiliser (ce qui est peut-être à l'origine d'un renforcement des organisations catholiques elles-mêmes et en tout cas d'un souci de coordonner plus étroitement leurs activités). En bien des secteurs et de bien des façons, catholiques et protestants semblent en tête de l'organisation internationale privée.

On a déjà souligné, à de nombreuses reprises, les liaisons qui s'établissent nécessairement entre l'activité de ces organismes et les problèmes de la politique, nationale et internationale. Certains, (par exemple le Conseil International des Missions) ont témoigné d'une prescience des événements que bien des gouvernements auraient pu leur envier ${ }^{1}$.

Ces groupes interviennent pour obtenir l'octroi de conditions favorables à l'accomplissement de leurs tâches : par exemple, effort du Conseil des Missions pour que la liberté de l'apostolat missionnaire soit reconnue dans les traités de paix après la première guerre mondiale et dans le système des mandats. Ils agissent aussi pour promouvoir un règlement des problèmes politiques conformes à leurs principes : tentatives d'organisations protestantes après la première guerre pour encourager un

Publication à Londres dès 1933 des résultats d'une enquête (conduite avec des fonds Rockefeller), Modern Industry and the African. En 1935, le Conseil présentait les résultats d'une autre enquête sur l'application du cinéma à l'éducation des Bantous. 
traitement des minorités conformes aux exigences de la morale chrétienne (action qui est allée jusqu'à un essai de réconciliation entre la Bulgarie et la Yougoslavie) ${ }^{1}$.

Mais la puissance de ces organisations religieuses ne leur vient-elle pas de s'appuyer sur une force plus large et plus haute, dont elles sont les porte-parole et même les mandataires ? Il nous semble que cette [p. 377] observation éclaire plusieurs aspects du problème étudié ici ; sa répercussion, en tout cas, déborde du cadre de l'exemple donné.

Pour l'appréciation globale de l'influence des groupes qui défendent des causes, on peut faire quelques suggestions. Un petit nombre d'entre eux seulement semblent constituer des forces directes de pression, c'est-à-dire capables d'inspirer ou de corriger par elles-mêmes les comportements gouvernementaux. Quant aux autres, s'ils ont finalement une influence, c'est au titre de l'audience éventuelle dont ils peuvent jouir auprès de l'opinion. En bien des cas, au surplus, ces groupes sont l'émanation de forces supérieures auxquelles il convient en définitive de rapporter le bénéfice des succès, mais aussi la responsabilité des erreurs : ils représentent en somme des pions, plus ou moins habilement maniés dans l'immense bataille d'influence que se livrent l'Est et l'Ouest. Essayons, sinon de prouver ces propositions, du moins d'en montrer l'intérêt comme hypothèse de travail.

Certains estimeront que ce jugement minimise le rôle joué par les O.N.G. d'inspiration idéologique. En témoignage de leur puissance et de leur efficacité, on place volontiers en avant le vote par les Nations Unies de la Déclaration Universelle des Droits de l'Homme. Voici, selon L. White, les techniques par lesquelles les O.N.G. auraient réussi à imposer l'adoption de cet instrument ${ }^{2}$.

Tout d'abord, ce sont des organisations non gouvernementales (la première dès 1929) qui auraient eu l'idée d'un tel document et en auraient dressé les ébauches initiales. Ensuite, les O.N.G., un grand nombre d'entre elles du moins, ont envoyé des mandataires aux réunions de la Commission des Droits de l'Homme pour y présenter des exposés oraux (à la seule session allant du 9 mai au 20 juin 1949, onze organisations firent, en tout, une vingtaine de déclarations). En troisième lieu, 28 organisations ont établi une centaine de communications écrites. En se fondant sur de telles activités, on a pu dire que beaucoup de groupes (spécialement les O.N.G. confessionnelles : catholiques, protestantes, juives) avaient contribué à la rédaction du texte final. Quatrième technique d'intervention: les O.N.G., par le canal de leurs branches nationales, ont exprimé directement leurs vues aux gouvernements et obtenu leur soutien. Enfin, on signale le gros effort de propagande réalisé par ces organismes pour faire pénétrer dans l'opinion publique le concept de «droits de l'homme ». Dans le même ordre d'idées, on insiste sur le [p. 378] travail (précédemment signalé) de plusieurs organisations féminines auprès de la Commission du statut de la Femme.

1 Sur ces efforts, voir MACFARLAND (Charles S.), International Christian Movements, New York, 1924, pp. 188-189. Le problème du Pacte d'amitié Yougoslavie-Bulgarie est évoqué dans le rapport pour 1936-37 de la World Alliance for International Friendship through Churches.

2 International non Governmental Organizations, pp. 262-264. 
Nous ne voudrions commettre aucune injustice pour juger de tels efforts qui constituent au moins pour partie, (car il y a eu beaucoup de «touristes » des Droits de l'Homme) une somme de dévouement parfaitement désintéressé dans son principe. Il semble cependant que l'on tende en divers milieux à exagérer l'action propre des O.N.G. Et le seul fait que la Déclaration ait été votée par 48 voix contre 0 (avec 8 abstentions) pourrait être tenu pour une preuve de cette surestimation : si personne n'a osé s'opposer à la Déclaration - y compris les États dont la conduite est en complète contradiction avec le texte signé - c'est tout de même un signe que la résistance gouvernementale n'a pas été aussi sévère qu'on serait tenté de le croire à la lumière de certains comptes rendus d'activité.

Il n'apparaît pas d'ailleurs que, depuis 1948, l'ensemble des États, anciens et nouveaux, se soient particulièrement souciés de la protection des Droits de l'Homme : des camps de travail ou de concentration se sont fermés en quelques coins du monde alors que d'autres s'ouvraient ailleurs. Dira-t-on qu'après tout la Déclaration a renforcé le vaste mouvement d'émancipation des peuples colonisés ? Ce serait peut-être prendre l'effet pour la cause.

D'autres estimeront au contraire que notre thèse accorde trop d'importance aux organisations de ce type. Et l'on peut, sous cet angle, citer des cas d'échec démontrant que les meilleurs efforts et les intentions les plus pures sont inutiles quand certains éléments se déchaînent. Il s'agit des insuccès subis à diverses reprises par les organisations vouées à la défense de la paix et au désarmement. Certes, entre les deux guerres, le mouvement pacifiste a parfois bénéficié d'une large audience : il n'est même pas impossible qu'il ait compromis la défense nationale de certains États (Grande-Bretagne) face à des voisins moins enclins à de telles conceptions ${ }^{1}$. Mais, comme force d'arrêt de la guerre, son impuissance fut manifeste. Voici quelques éléments d'information sur cette activité ${ }^{2}$.

On peut faire remonter de telles organisations au Bureau International de la Paix fondé à Genève en 1892 pour donner une structure permanente aux divers congrès pour la paix tenus depuis $1843^{3}$. On cite également dans cette perspective les efforts considérables accomplis par l'Union Interparlementaire qui, dès ses origines en 1888, entreprit [p. 379] de jouer un rôle important dans la promotion d'un règlement pacifique des conflits. Si l'on en croit certains auteurs, c'est à l'Union que fut due la

1 Voir par exemple les observations de J. TCHERNOFF sur les courants pacifistes en GrandeBretagne autour des années 1930 in Les démagogies contre les démocraties, Paris, 1947, pp. 275290. Rappel du succès du peace ballot de 1935 sur lequel on pourra lire LIVINGSTON (V.), The Peace Ballot, Londres, 1935.

2 Comme tableau d'ensemble, se reporter à l'énorme livre de GOUREVITCH (Boris) The Road to Peace and to Moral Democracy. An encyclopaedia of peace, 2 vol., New York, 1955 (peu enthousiaste sur la contribution éventuelle des O.N.G. à l'organisation mondiale).

3 Sur cette organisation et sur d'autres, on trouvera des informations in BEALES (A.C.F.), The History of Peace, Londres, 1931. 
décision de Nicolas II de proposer la tenue de la Conférence de La Haye (1899) ${ }^{1}$. L'Union qui, selon les mêmes sources, aurait eu une large part de responsabilités dans la convocation de la Conférence de 1907, devait ensuite déployer de grands efforts pour obtenir la ratification des conventions adoptées. Ces tentatives n'ont jamais cessé et en avril 1915 par exemple, était constituée à La Haye, l'Organisation Centrale pour une Paix Durable (dont le programme aurait, dit-on, inspiré les « Quatorze points » de Wilson).

En 1919, était fondée à Genève une Union internationale visant à rassembler les associations dont le but était de promouvoir la compréhension et la mise en œuvre des principes du Covenant. Beaucoup de travail fut accompli dans ce cadre, mais sans empêcher le monde d'aboutir finalement aux années noires que l'on sait. Sans doute, la fédération avait-elle acquis une certaine influence sur la S.D.N. Pourtant, dès 1935, l'enthousiasme du début était en voie d'effondrement. Cependant on doit signaler un dernier effort pour rétablir la situation : la création à Genève en 1932 du Groupement Consultatif International pour la Paix et le Désarmement.

Il s'agit d'une tentative d'action directement liée à la Conférence de Genève sur le désarmement de 1932. Cette réunion provoqua un vaste mouvement d'opinion publique sur lequel de nombreuses organisations essayèrent de s'appuyer pour orienter les débats dans un sens favorable à la paix. Quatre comités spéciaux pour le désarmement établirent des pétitions et résolutions dont les promoteurs affirmaient qu'elles traduisaient la volonté de plus de deux cents millions de personnes (la simple pétition établie par les associations féminines comportant plus de neuf millions de signatures). En juillet 1932, toutes les organisations s'unirent pour faire de grandes démonstrations de masse (ainsi, présentations au président de la Conférence, en octobre 1933, de cinq mille messages venus du monde entier à l'époque où l'Allemagne décidait de s'en retirer) ${ }^{2}$.

On sait qu'après la seconde guerre mondiale le mot d'ordre de la paix a été repris par de nombreux groupes directement rattachés au mouvement communiste international: ils ont tenté, non sans succès d'ailleurs, de décrire le monde communiste comme le camp de la paix. Le mouvement a largement utilisé le sentiment d'horreur qu'inspire aux peuples [p. 380] l'éventualité d'un conflit nucléaire : il n'a d'ailleurs pas craint d'ajouter à la dénonciation de périls qui ne sont pas imaginaires des accusations sans fondement (celle faite aux États-Unis d'avoir livré une guerre «biologique » en Corée). À ce plaidoyer pour la paix on peut en plusieurs sens rattacher l'expansion du neutralisme.

1 Selon Christian LANGE, «Histoire de la doctrine pacifique et de son influence sur le développement du droit international », Académie de Droit international. Recueil des Cours, 1926, Vol. III, Paris, 1927, pp. 403-404.

2 En 1936, toujours à Genève, était organisée une Campagne internationale pour la Paix en vue de coordonner les activités de toutes les organisations directement ou indirectement intéressées par les questions de la paix et de la compréhension internationale. Son premier Congrès de la Paix, (Bruxelles, septembre 1936) fut suivi par 4000 personnes représentant 750 organisations. Elle devait aussi construire le Pavillon de la Paix à l'Exposition Universelle de Paris en 1937. 
Un grand nombre d'O.N.G., au premier rang desquelles la F.S.M., ont eu comme préoccupation principale, depuis 1947-48 surtout, de diffuser cet ensemble de thèmes dans le monde entier et spécialement dans les pays du tiers-monde. Encore que toute estimation précise des résultats soit impossible, il semble que l'audience ainsi gagnée ait été immense et ne cesse de croître. Mais derrière ces O.N.G. il y a une force puissante, inspiratrice et coordonnatrice, qui dispense les moyens nécessaires à une telle propagande et nous sommes ramenés par là aux considérations initialement présentées sur les O.N.G. vouées à des causes. Cependant, nous avons, entre temps, acquis assez de matériaux pour faire des remarques positives.

En premier lieu, il semble possible d'appliquer, mutatis mutandis, à cette catégorie de groupes, les observations dégagées à propos des associations de nature économique ou professionnelle. Ces hypothèses soulignent l'importance de deux facteurs dans l'acquisition de l'influence: l'audience dont bénéficie le (ou les) problème évoqué et la qualité des moyens disponibles pour forcer l'attention et obtenir l'acquiescement des autorités responsables.

Un groupe de pression idéologique ou humanitaire ne pourrait guère parvenir à des résultats si la thèse qu'il tente de faire prévaloir ne rencontre que l'indifférence. Autrement dit, l'action de ces organismes sur le plan international, plus exactement leur faculté d'action, s'améliore au fur et à mesure de leurs progrès dans la formation de l'opinion publique internationale. Le cas de la Croix-Rouge est exceptionnel : le symbole qui la représente est connu même dans les milieux dont les idées sur cette organisation restent vagues. Voir aussi sur un autre plan, et encore qu'aucune comparaison avec la Croix-Rouge ne soit de mise, les « casques bleus » de l'O.N.U. L'effort pour créer un public exige beaucoup de patience et des moyens considérables : s'il est possible en effet de réaliser éventuellement, notamment par une action de presse massive, un climat passager (souvent éphémère) d'attention ou de sympathie, il est infiniment plus compliqué d'«accrocher" l'opinion de façon durable ${ }^{1}$.

[p. 381] Ainsi s'explique la difficulté qu'éprouvent certains groupes à se faire entendre sur une large échelle : par exemple, la notion de « moralité publique » n'est pas de celles qui commandent le rassemblement d'un vaste public. Divers problèmes ont plus de résonance dans un pays que dans un autre. Les hiérarchies de valeurs varient selon les continents; beaucoup d'Africains, la plupart peut-être, voient aujourd'hui dans l'apartheid un phénomène bien plus dangereux que le communisme. Cependant, on a déjà évoqué dans le cours de ce volume, quelques-uns des thèmes qui exercent de nos jours une attraction quasi-universelle : relèvement de la condition

On notera qu'en dépit des échecs subis, le thème du pacifisme continue de former un pôle d'attraction : ainsi par exemple tenue récente (août 1960) à Bâle (sous les auspices du Comité de liaison des organisations pour la paix) d'une semaine d'études consacrées aux répercussions d'un désarmement général sur la politique, l'économie et l'individu. L'un des membres du séminaire a proposé de créer avec les objecteurs de conscience (plus de 30000 dans la République fédérale ?) la « grande année de lutte contre la misère ". 
des pays sous-développés, émancipation des peuples dépendants... Quand il se situe dans un tel courant, un groupe est assuré, au départ, d'un atout sérieux.

L'autre carte maîtresse à la réussite est commune à tous : possession d'un « poids » suffisant à l'égard des autorités abordées et constitution d'un réseau de personnalités capables d'assurer l'exploitation des victoires de principe remportées. Ce fut le cas, dans certaines limites, des mouvements européens au sein desquels se trouvaient à la fois des militants et des hommes de gouvernement ou hauts fonctionnaires.

L'échec de la C.E.D. en France montre d'ailleurs que la faculté de transformation des idéologies dominantes connaît des limites. En dépit de ce qu'il leur en a coûté dans l'histoire, les peuples européens restent, comme tous les autres en ce monde, dominés par le nationalisme. À l'époque actuelle, il n'apparaît pas que les solidarités sociales s'élèvent au-dessus des solidarités nationales: ou alors la promotion n'intervient que sur le papier et s'évanouit à la première rencontre des faits. Peut-être, après tout, y aurait-il quelque optimisme à trop compter, pour imposer la paix, sur les centaines de millions de signatures réunies par le Conseil Mondial de la Paix. Les précédents conseillent la prudence.

On a le sentiment que peu de groupes disposent, à titre autonome, des deux atouts que l'on vient d'énoncer. Mais pour beaucoup d'entre eux, le mot autonomie est plus ou moins dépourvu de sens. C'est le cas de tous les groupements qui ont une attache avec une force supérieure dont ils tirent inspiration, soutien moral et, souvent aussi, subsides financiers (Saint-Siège, communisme international...). L'effet de l'aide accordée par ces forces sur la puissance du groupe est variable. Ce peut être un facteur d'amélioration et de consolidation (réseau de relations, financement, etc.). Il arrive aussi que cette intervention provoque une fragmentation, c'est-à-dire la constitution de plusieurs groupes pour [p. 382] défendre la même cause, chacun le faisant sous une certaine optique idéologique. C'est le cas, en particulier, pour le syndicalisme.

Internationales syndicales — À la lumière des développements précédents, nous pouvons maintenant examiner le problème des centrales syndicales, écarté jusqu'à maintenant en raison de sa complexité. En 1936, Alexandre Berenstein situant les organisations ouvrières par rapport à la S.D.N., y voyait les organisations numériquement les plus fortes et aussi, à beaucoup d'égards, les plus représentatives (spécialement la Fédération Syndicale Internationale disposée à accueillir les travailleurs du monde entier sans considération de foi religieuse ou d'opinions politiques) ${ }^{1}$. Un observateur se risquerait-il aujourd’hui à faire la même proposition pour le syndicalisme international dans ses rapports avec l'O.N.U. ? Nous hésiterions à prononcer un tel jugement. D'où vient, si elle existe, la différence ?

1 Les organisations ouvrières, leurs compétences et leur rôle dans la société des Nations, Bruxelles, 1936. Voir aussi WILSON (Francis Graham), Labor in the League System. A study of the International Labor Organization in relation to international administration, Stanford, 1934. 
En divers milieux, on répondra tout de suite que le syndicalisme contemporain fait trop de politique et cela au détriment des questions professionnelles. Ainsi exprimée, la réponse manquerait de pertinence. En réalité, spécialement dans les années qui ont suivi la fin des hostilités, la Fédération Syndicale Internationale prit des positions et engagea des actions nettement politiques. On en a déjà mentionné quelques-unes : en particulier, tentatives d'embargo ou de boycott à l'encontre des gouvernements dont il lui paraissait légitime d'arrêter ou de gêner l'action. La Fédération s'efforça d'exercer une influence sur le règlement des problèmes comme l'occupation de la Ruhr, les réparations, le désarmement, l'aide aux réfugiés. Lors de la guerre civile espagnole, elle n'hésita pas à aider les syndicats ouvriers républicains. On ne saurait avoir d'hésitation sur le fait que cet organisme prit une attitude positive à l'égard de la politique. Allons plus loin : syndicalisme et politique sont indissociables même sur le plan de la législation professionnelle. Si la réglementation du travail dépend des autorités gouvernementales, alors les syndicats doivent intervenir auprès d'elles et le faire en suivant la règle du jeu.

Cependant deux considérations nuancent ce tableau. D'une part, la Fédération plaça au centre de ses préoccupations la promotion de la législation sociale (protection du travail, extension des droits et des compétences des syndicats, assurances sociales...). De ce point de vue, certains ont pu y voir un facteur indispensable au fonctionnement de [p. 383] l'O.I.T. dans l'entre-deux-guerres. Quant à son activité disons extraprofessionnelle, la Fédération tout en s'inspirant des idées et des positions de l'Internationale socialiste, ne semble pas avoir été vis-à-vis d'elle en situation de vassalité ni même d'alignement inconditionnel.

La F.S.M. ne correspond certainement pas à cette image. Tirant l'essentiel de sa force de pays situés dans le monde communiste, elle est indissolublement liée à celuici. L'interprétation de la C.I.S.L. est plus complexe (ne serait-ce qu'en raison des dissensions internes qui la caractérisent depuis le début). Sur de nombreux points, elle a épousé étroitement et fidèlement les thèses du bloc occidental, plus exactement les thèses soutenues par les États-Unis au nom du bloc occidental. En d'autres domaines, elle a adopté des attitudes «en flèche », à l'égard notamment des pays sousdéveloppés et spécialement vis-à-vis de l'Afrique. Sur l'Afrique du Nord, la C.I.S.L. a pris des positions que le gouvernement des États-Unis ne pouvait soutenir lui-même (au moins de façon ostensible) : nul ne sait si cette division du travail fut et demeure totalement spontanée ou quelque peu concertée.

Abstraction faite de la C.I.S.C. (dont la «capacité internationale » est réduite), nous avons le sentiment que les deux grandes centrales internationales sont mues aujourd'hui par une seule pensée : la conquête des masses industrielles (actuelles et surtout futures) des pays sous développés. Nous n'avons pas à critiquer ce choix, mais à observer que, sur un tel terrain, l'internationale syndicale ne saurait être qu'un facteur d'une stratégie plus vaste et, dès lors, finalement un instrument au service de cette stratégie. Au total, dans le domaine syndical, le combat idéologique de ce temps a provoqué la fragmentation des forces et inspire, à chaque instant, la lutte que se livrent les adversaires: ce ne sont probablement pas les conditions idéales pour 
l'établissement et le renforcement d'une puissance qui appartienne en propre à ces organismes.

Parmi les problèmes insuffisamment analysés dans ce paragraphe, figure l'action des O.N.G. à l'égard du secteur administratif des collectivités publiques. C'est un point que l'on a signalé tout au long de cet ouvrage. Dépourvues de l'aspect passionnel et souvent dramatique de la politique, ces questions sont volontiers négligées par les spécialistes de l'organisation internationale. Il serait vain d'exagérer les perspectives qui découlent de telles interventions pour l'union des hommes: l'harmonisation des horaires des chemins de fer ou l'unification de la largeur des voies ne [p. 384] suffit pas à éliminer les conflits entre les peuples. Cependant ce sont là des aspects de la politification qu'il serait préférable de mieux connaître

Cette action est particulièrement sensible dans les domaines où il est soit possible, soit même indispensable de mettre en œuvre des solutions uniformes: ainsi, par exemple, les problèmes de la circulation et de la sécurité routière. Ils concernent au premier chef l'Organisation Mondiale du Tourisme et de l'Automobile, mais plusieurs autres O.N.G. sont également intéressées à leur solution (Association Internationale Permanente des Congrès de la Route, Fédération Routière Internationale, etc.).

Ces questions soulèvent des difficultés qui ne cessent de croître. L'Organisation Mondiale du Tourisme et de l'Automobile a organisé à leur propos de nombreuses manifestations (par exemple: Semaine internationale d'étude de la technique de la circulation routière, qui vient de tenir sa $5^{\text {ème }}$ session ; congrès internationaux de la sécurité routière, etc.). Il est intéressant d'observer que l'Organisation a l'habitude de faire participer à ses réunions des membres d'administration qui ont la charge de régler ces problèmes aux divers échelons de l'action gouvernementale (représentants des organisations intergouvernementales comme la Division des Transports de la Commission Économique pour l'Europe ; membres de la Fédération Internationale des Fonctionnaires Supérieurs de Police; fonctionnaires nationaux remplissant des tâches équivalentes à celles des ingénieurs des Ponts et Chaussées français, etc.

Il est évidemment difficile d'évaluer a priori l'importance de tels contacts. On peut admettre qu'ils ne sont certainement pas sans conséquence pratique. L'un des aspects de cette coopération est l'échange d'expériences pouvant conduire à la généralisation de pratiques qui ont fait leurs preuves (par exemple dans l'ordre des pertes économiques dues à la congestion de la circulation).

Or, en bien des cas, de tels dispositifs ne peuvent être mis en œuvre que par le moyen de «décisions autoritaires ». Dès lors, l'action de l'organisation gouvernementale privée est facteur direct de semblables mesures, qu'elles soient prises au niveau intergouvernemental avec ratification ultérieure par les États, ou qu'elles soient adoptées directement par plusieurs de ces derniers. Il semble qu'actuellement ces remarques conviennent bien au secteur de la « défense sociale » et de la protection des « handicapés » — secteur dans lequel les O.N.G. ont joué un rôle important. 
[p. 385]

\section{e) DÉVELOPPEMENT DE LA COMPRÉHENSION INTERNATIONALE}

$\underline{\text { Retour à la table des matières }}$

On prend l'expression en un sens très large : capacité d'entente et de travail en commun, en d'autres termes renforcement de l'organisation internationale comme un tout. Ne serait-ce pas là le résultat spontané du travail de ces multiples organismes dont beaucoup, sur le plan des réalisations concrètes, ne témoignent pas d'un dynamisme notable ? En définitive, toutes ces organisations grandes ou petites, riches ou pauvres, efficaces ou inutiles, n'engendreraient-elles pas sans le chercher une vaste pression en faveur de la " politification » (tendance au gouvernement mondial) de la société internationale?

Certains n'hésitent pas à répondre « oui » et de façon chaleureuse. Pour eux, les O.N.G. constituent un mode nouveau d'aménagement des rapports internationaux, une sorte d'alternative à la formule faisant reposer ceux-ci sur des États souverains. On aboutit ainsi à la notion d'un Parlement mondial des individus qui a déjà partiellement inspiré l'article 71 de la Charte des Nations Unies. Les organisations non gouvernementales seraient-elles donc appelées (comme d'aucuns le voudraient) le « sixième grand »?

Le fonctionnement présent de ces institutions, tel que nous l'avons décrit ne justifie guère un tel optimisme. Admettons que des améliorations soient possibles : doit-on pour autant accepter cette vision grandiose de l'activité et du rôle des O.N.G. ?

Au fil des précédents développements, le lecteur s'est sans doute posé un problème qu'il est souhaitable d'aborder avant de répondre à cette question. Ces organisations, gouvernementales et non gouvernementales, n'y en a-t-il pas trop ? Un auteur français évoquait il y a quelques années " l'associationite » ou tendance à une multiplication effrénée de groupements, s'accompagnant pour beaucoup du désir de jouer un rôle officiel, voire politique ${ }^{1}$. Il paraît difficile d'ignorer cette observation quand on étudie l'organisation internationale.

En un sens, l'expansion numérique des O.N.G., qui correspond à un mouvement spontané, traduit une tendance à la défense en commun de "causes » et à la satisfaction collective des besoins. C'est un mouvement que l'on découvre aussi sur le plan national. L'évolution est trop profonde, pour qu'on puisse la taxer d'artificielle. Cependant, n'est-elle pas accusée et, dès lors, aggravée par des facteurs parasitaires ? Nous ne saurions le nier.

[p. 386] Quelques mots d'abord de la prolifération des organismes intergouvernementaux qui a été dénoncée par plusieurs organismes sérieux, en

VIRTON (P.), « L'associationite », Travaux de l'Action Populaire, novembre 1947, pp. 801-812. 
particulier la Chambre de Commerce Internationale ${ }^{1}$. C'est ainsi que, selon elle, les mêmes problèmes de transport européen, par exemple, sont traités par la Commission Économique pour l'Europe, la C.E.C.A., la C.E.E., la Conférence Européenne des Ministres des Transports, la Conférence Européenne de l'Aviation Civile. Or les usagers ne peuvent rester indifférents à ces collèges qui discutent, plus ou moins ouvertement, du sort réservé à leurs instruments de travail, d'où le souhait d'une coordination des efforts et si possible d'une suppression des doubles emplois ${ }^{2}$. On serait bien étonné qu'un tel vœu fut entendu.

De telles situations ne sont pas rares. En matière de lutte contre le trafic des stupéfiants, plusieurs organismes existent dont les fonctions se chevauchent : Comité Central Permanent de l'Opium et Organe de Contrôle des Stupéfiants à l'O.N.U. ; Bureau Anti-Stupéfiants de la Ligue Arabe ; services de la Commission Internationale de Police Criminelle, etc. Le secteur de l'assistance technique est typique d'une telle confusion : il n'est pas excessif d'écrire que les agences spécialisées s'y livrent une lutte aussi farouche que les États souverains représentés aux Nations Unies. Il semble difficile de parvenir à une réelle coordination des efforts tant que le secrétaire général de l'O.N.U. n'aura d'autres prérogatives que celles du primus inter pares vis-à-vis des chefs de ces agences ${ }^{3}$.

Voyons par exemple l'énergie nucléaire qui, en raison de sa nouveauté et de l'ampleur des moyens nécessaires, exige un effort particulier. Il y a déjà une organisation intergouvernementale à l'échelle mondiale et quatre organisations, également intergouvernementales, pour la seule Europe. Ce sont: l'Agence Internationale pour l'Énergie atomique qui, créée le 4 décembre 1953 à l'initiative et dans le cadre des Nations Unies, comprend, aujourd'hui plus de 70 États-membres et constituerait selon certains auteurs un établissement public international ; l’Organisation Européenne pour les Recherches Nucléaires (C.E.R.N.) fondée le $1^{\text {er }}$ juillet 1953 à l'initiative de l’Unesco ; la Communauté Européenne de l'Énergie Atomique (Euratom) instituée le 25 mars 1957 ; l’Agence Européenne pour l'énergie nucléaire aménagée sous l'impulsion de l'O.E.C.E. le 20 décembre 1957 ; l'Institut Central pour les Recherches Nucléaires mis sur pied par l'U.R.S.S. à l'intention des pays communistes le 26 mars 1956.

[p. 387] De leurs côtés, les Nations Unies ont créé en leur sein plusieurs organes qui s'occupent de ces problèmes : Comité Consultatif des Applications de l'Énergie Atomique; Sous-Comité de l'Énergie du Comité Administratif de Coordination, destiné à mettre en harmonie les politiques suivies par l'O.N.U., l'Unesco, la F.A.O., le B.I.T. et la nouvelle Agence Internationale ; Comité Scientifique pour l’Étude des

Voir Nouvelles de la C.C.I., juin 1957, p. 13.

On aura une idée de la complexité du problème en consultant HUSSON (Georges). « Les usagers des transports devant les instances internationales D, Revue du Marché Commun, février 1959, pp. 59-65.

3 Voir sur ce point les observations de Andrew SHONFIELD, « Opportunity for U.N. », Observer, 23 octobre 1960. Pour une étude plus détaillée, voir son ouvrage The Attack on World Poverty, Londres, 1960 (spécialement la $3^{\mathrm{e}}$ partie). 
Effets des Radiations ionisantes. L'Union de l'Europe Occidentale et le Conseil Nordique ont également procédé à la création de services particuliers. On trouve aussi dans ce domaine des O.N.G. : les unes nouvelles et entièrement spécialisées (Société Européenne d’Énergie Atomique, Fédération Européenne des Industries Nucléaires), d'autres ayant étendu leur activité à ce secteur (ainsi, Union Internationale des Producteurs et Distributeurs d’Énergie Électrique qui a fondé un Comité d’Étude des Centrales nucléaires...).

C'est déjà un ensemble imposant: encore s'agit-il là d'un bilan provisoire, les techniciens ayant la certitude que l'effort d'organisation en cette matière n'en est qu'à la phase initiale.

En d'autres termes, les éléments de gouvernement mondial dont nous disposons ne sont pas agencés en vue de l'efficacité. On ne peut dès lors accueillir qu'avec réserve les propositions visant à lui ajouter de nouvelles branches : ainsi, celle de 1'Alliance Coopérative Internationale tendant à créer une Organisation des Nations Unies pour l'Habitation (problème auquel s'intéressent déjà plusieurs organes intergouvernementaux et privés). Mais la tendance ne cesse de s'affirmer: ainsi, signature récente (décembre 1960) entre une dizaine de pays européens, d'une convention pour la réalisation d'un programme commun de recherches sur l'espace.

Les organisations non gouvernementales suivent, dans l'ensemble, le même rythme d'expansion que le secteur public. Voici, à titre de spécimens, les noms de quelques-unes des associations fondées au cours des dernières années. Association des Bibliothèques de Judaica et Hebraica en Europe (1955) ; Alliance Européenne des Agences de Presse (1957) ; Fédération Internationale des Bureaux d'extraits de Presse (1953) ; Union Internationale pour l'Éducation Anti-alcoolique de la jeunesse (1954) ; Société Européenne de Sociologie Rurale (1957); Association Internationale pour l'Histoire des Religions (1950); Institut International de la Paix (1957); Communauté Européenne de Crédit Communal (1954); Association Internationale des juristes Espérantistes (1957) ; [p. 388] Association Mondiale de la Lutte contre la Faim (1957); Fédération Internationale des Cadres de la Chimie et des Industries Annexes (1956); Société Internationale des Écrivains de l'Aviation (1956); Organisation Européenne pour le Contrôle de la Qualité (1956); Fédération Internationale de Luge (1957), etc.

Pour achever de situer le problème, mentionnons quelques organismes dont la création vient d'être décidée ou est envisagée : Conseil International pour l'Éducation Physique et Sportive; Société Ibéro-américaine de Philosophie; Association Européenne des Éditeurs de Publications pour la jeunesse ; Alliance Atlantique des Anciens Combattants; Académie Internationale de Médecine Aéronautique ; Association Internationale des Photographes de la Fédération Naturiste Internationale ; Association Européenne des Agences de Publicité Directe... Il serait facile, mais sans portée, de multiplier les exemples.

Le trait caractéristique de la situation est la volonté de créer un cadre nouveau ou bien de se servir, au besoin en le diversifiant, d'un organisme existant. Cette « associationite » serait difficilement explicable si l'on ignorait les satisfactions de 
vanité et les possibilités de tourisme gratuit qu'apportent souvent de tels groupements à leurs dirigeants : même s'ils restent "marginaux » en plusieurs cas ces mobiles portent partiellement la responsabilité de l'«associationite » qui, cela va sans dire, sévit aussi au plan national.

Les quelques exemples choisis concernent des groupements qui, de prime abord, ne semblent pas représenter des facteurs de pression très significatifs. Doit-on considérer qu'instituant des relations d'ordre privé ils n'appartiendraient qu'exceptionnellement à notre recherche ou, au contraire, qu'ils en constituent un aspect important par l'influence exercée sur la compréhension internationale ? ${ }^{1}$.

Certains le contestent a priori. Seule l'organisation intergouvernementale leur paraît capable de susciter un véritable esprit international et, surtout, de créer les conditions d'une réelle coopération pacifique. Ce type d'organisation fournit en effet un point d'accrochage solide et permanent aux efforts faits en vue de développer la compréhension: en son sein se forme progressivement une élite de bureaucrates internationaux qui s'habituent à analyser les problèmes sans référence à des consignes ou exigences nationales. La formule des O.N.G. serait en définitive trop fluide pour autoriser de tels espoirs : ce n'est pas en quelques jours de congrès, par exemple, que se créent des éléments d'un esprit [p. 389] international. Au surplus, les secrétariats des O.N.G. ne sont qu'exceptionnellement des machines puissantes et efficaces ; en dépit d'une tendance récente à la bureaucratisation ils reposent encore, pour une large part, sur un travail bénévole. En plusieurs cas les sections nationales des O.N.G. n'existent guère que sur le papier : il arrive qu'elles se ramènent à quelques personnes, éventuellement peu représentatives.

L'opposition ainsi établie, si elle n'est pas toujours formulée avec cette rigueur, traduit le sentiment de nombreux milieux issus en particulier des secrétariats des organisations intergouvernementales. Les partisans des O.N.G., d'ailleurs, ne restent pas insensibles à un tel débat et leurs arguments méritent d'être énoncés. Ils soulignent en particulier l'indépendance des O.N.G. à l'égard des influences gouvernementales et des changements d'ordre politique (que ceux-ci se produisent à l'intérieur des pays membres ou dans les organismes internationaux officiels); la souplesse, la liberté d'action et la marge de manœuvre dans le choix du personnel : toutes facultés dont les associations privées disposeraient à un plus haut degré que les organismes officiels; la possibilité pour les organisations internationales privées d'entrer en contact avec les autorités provinciales et locales ainsi qu'avec des institutions ou des personnes privées sans nécessairement passer par les gouvernements nationaux: l'importance que présentent pour les institutions intergouvernementales la compréhension, la critique positive et le soutien offerts par de libres rassemblements de citoyens. Conclusion : malgré le prestige et l'ampleur des

Voir l'ouvrage déjà cité Foundations of World Organizations : a political and cultural appraisal, passim. Certaines sections de l'ouvrage tentent d'apprécier la contribution de diverses organisations et mouvements à la création d'un gouvernement mondial : l'ouvrage comporte quelques éléments intéressants, mais la conception d'ensemble (et par conséquent l'appréciation globale) est particulièrement faible. 
ressources financières des organes gouvernementaux, l'activité des O.N.G. est indispensable. Ou, si l'on préfère, l'action publique et privée sont complémentaires sur le plan international aussi bien que national ${ }^{1}$.

Les défenseurs les plus solides des O.N.G. ne sont d'ailleurs pas sans apercevoir les faiblesses actuelles de ce secteur et les énumérer avec lucidité. Ils soulignent le décalage qui s'institue, et probablement s'approfondit aujourd'hui entre un secteur intergouvernemental doté de moyens d'action de plus en plus puissants et une sphère non gouvernementale dont l'évolution reste très lente. Les O.N.G. leur semblent constituer des forces sociales négligées qu'il faudrait vivifier en leur accordant les concours nécessaires. Ils réclament que les rapports entre ces deux éléments soient placés sous le signe d'une réciprocité d'appui ${ }^{2}$.

Ce débat ne manque pas d'intérêt, mais on omet en général de signaler un fait que nous avons déjà noté : le rétrécissement du secteur privé non gouvernemental à mesure des progrès de la zone communiste et plus [p. 390] généralement de formules autoritaires de gouvernement qui, en particulier, caractérisent tant de nouveaux États. Si le compte était fait des pays où les membres des groupes privés peuvent prendre position librement, à l'écart de toutes directives officielles, on aboutirait probablement à un chiffre dont la faiblesse surprendrait. Dans beaucoup de pays, les délégations nationales envoyées aux O.N.G. constituent simplement un instrument, parfois très docile, des autorités gouvernementales. Ailleurs la dépendance est moins marquée et, surtout, reste occasionnelle : cependant, même là, l'action non gouvernementale ne se ramènerait pas, en totalité, à l'expression spontanée des positions et des vœux des citoyens ${ }^{3}$.

1 Sur la possibilité pour les O.N.G. d'exercer un contrôle démocratique des organisations gouvernementales, voir l'étude de MITRANY (David), « Un progrès en matière de représentation démocratique », Associations, octobre 1954, pp. 469-472. Du même auteur, dans la même revue « International Cooperation in Action », septembre 1959, pp. 644-648. La thèse de D. Mitrany ne nous paraît pas sans utopisme. Encore une fois le schéma "groupe de pression » rend mieux compte du phénomène : les groupes surveillent avec attention le secteur - et celui-là seul - qui les intéresse (c'est d'ailleurs un aspect du pluralisme démocratique).

2 Voir l'étude de G.P. SPEECKAERT, «L'évolution de la structure internationale », Associations, septembre 1958, pp. 571-584. De nombreuses études publiées dans la même revue abordent aussi cette question ou s'en rapprochent. Ainsi, à titre d'exemple, WHITE (L.C.), « Peace by Pieces. The role of non-governmental organizations ", The Annals of the American Academy of Political and Social Science, juillet 1949, pp. 87-97 (également reproduit in Bulletin O.N.G., juillet 1949, pp. 103-107) et «Non-governmental Organization and Democracy », Bulletin, novembre 1953, pp. 437-441; REES (Dr J.R.), "L'autorité et l'efficacité des organisations internationales non gouvernementales », Associations, septembre 1958, pp. 585-588. Voir aussi, RICHARDS (Haydn), «Local Government's Contribution to International Understanding », Associations, novembre 1959, pp. 770-774. Ajouter la brochure de l'U.A.I. (série d'exposés), L'avenir des organisations internationales non gouvernementales, déjà citée.

3 Pour certains auteurs, l'efficacité du travail d'une organisation privée dépend du degré de coopération de chacun des membres nationaux avec son gouvernement. En ce sens, Joseph CHAMBERLAIN dans l'essai «International Organization » (volume déjà cité de la Dotation Carnegie). Pour lui, l'organisation privée doit être strictement modelée sur les organisations étatiques et dès lors consacrer les compartimentages nationaux. Sur cette base, il apparaît à J. 
Cette situation pose un problème grave pour les O.N.G. Avec leur critère de la représentation géographique, qui est devenu presque une manie, (le succès d'un congrès s'apprécie principalement au nombre de pays participants), les organisations intergouvernementales conduisent les associations à s'assurer des membres dans un nombre d'États aussi grand que possible : il s'agit là du souci de l'universalité qui, en particulier, pousse les organisateurs de Congrès à rechercher avec frénésie les « nationalités rares » (même si les éléments ainsi recrutés sont foncièrement ignorants du thème discuté). Tendance compréhensible certes et, à quelque égard, louable : mise en œuvre à l'extrême, elle aboutit pourtant à faire des O.N.G. des machines hétérogènes et divisées contre elles-mêmes dont les membres, pleins d'arrière-pensées les uns à l'égard des autres ne sont capables de s'entendre que sur les banalités les plus creuses et les plus éculées. En bien des cas un dilemme s'impose : ou la concentration de l'O.N.G. sur un secteur du monde et une baisse de sa faculté de négociation auprès des autorités compétentes, par absence d'universalité : ou l'extension au monde entier et alors l'amoindrissement, voire la destruction de cette faculté par le dedans ${ }^{1}$.

D'un point de vue scientifique, il n'existe aucun moyen de mesurer et même d'apprécier sommairement la contribution du secteur non gouvernemental à la compréhension internationale. Si l'on exigeait ici un jugement global, nous ne l'énoncerions qu'avec les plus grandes réserves, comme l'expression d'un seul point de vue subjectif : mais, celles-ci émises, nous, n’hésiterions pas à déclarer que pour l'instant, cette contribution reste médiocre. Peut-être exprimerons-nous plus clairement ce jugement en distinguant deux plans.

[p. 391] L'organisation non gouvernementale peut susciter à travers les frontières des solidarités spécialisées et limitées. Comme on l'a noté précédemment, elle provoque la constitution de publics particuliers d'ampleur souvent limitée (voir quelques-unes des associations nouvelles que l'on vient de mentionner). Ces regroupements de contenu homogène peuvent éventuellement devenir des instruments de pression efficaces et assurer la conquête des avantages que permet une action bien conduite auprès des autorités publiques. Encore faut-il ne pas oublier que la

Chamberlain que la société internationale forme un tout et que les organisations privées s'inscrivent en son sein comme une nécessité vitale.

1 Voir l'intéressante étude de Vladimir HERCIK, «Vers l'universalité des organisations internationales non gouvernementales », Associations, octobre 1958, pp. 639-676. Tout en insistant sur les facteurs favorisant l'universalisation et sans peut-être marquer avec assez de force les contradictions qu'ils recèlent, l'auteur énonce avec lucidité d'indispensables réserves. À qui émet des réticences sur le sens de telle confrontation la propagande communiste décerne volontiers le titre d'« ennemi de la paix ». La charge serait mieux fondée si les voix les plus autorisées du monde soviétique ne présentaient la "coexistence pacifique » comme une simple force de combat pour l'extension du régime communiste au monde entier. Pour un modèle de cette attitude, voir REIMANN (Max), "Coexistence pacifique et lutte de classes », Nouvelle Revue Internationale, octobre 1960, pp. 1-20 (ainsi la déclaration suivante : « Tout d'abord, la coexistence pacifique est elle-même une forme particulière de la lutte des classes. Ensuite, non seulement elle ne supprime pas les autres formes de la lutte menée dans les pays capitalistes, mais encore elle suppose qu'elles se développent », p. 4). À partir de là, il est aisé de comprendre le sens des efforts accomplis par les soviétiques dans les O.N.G. 
possibilité de telles conjonctions est aujourd'hui limitée par la division idéologique du monde et la poussée nationaliste qui s'affirme partout.

Mais l'action des O.N.G. va-t-elle jusqu'à engendrer une sorte de solidarité globale, le sentiment d'appartenir à un même monde, le souci de l'organiser comme tel ? Écartons les clichés sur le prétendu « rôle commun » des O.N.G. (amélioration des relations entre les peuples; participation au progrès humain ; élimination des préjugés raciaux). Ce ne sont là, pour utiliser une expression bienveillante, que de simples affirmations de tribune : les points que l'on tient ainsi pour acquis avec une grande complaisance n'ont encore donné lieu à aucune vérification digne de foi. En définitive, la seule hypothèse de travail admissible est de considérer que les O.N.G. s'insèrent, selon des mécanismes que nous connaissons mal, dans le courant de formation de l'opinion publique internationale. Avec quelle efficacité ?

Nous avons cité précédemment le cas des millions de gens qui, à l'époque contemporaine, ont quitté leur pays et souvent traversé les mers pour participer à un congrès. Solidarités restreintes et préoccupations touristiques expliquent le mouvement pour l'essentiel. Mais de tels rapprochements ne facilitent-ils pas la diffusion des idées et des valeurs ? Témoigner d'un optimisme inconditionnel serait s'abuser : de tels échanges, en effet, laissent généralement chacun sur ses positions et rien ne serait plus utopique que de voir un facteur de compréhension dans le seul fait de confronter des thèses opposées.

Au total, les O.N.G. sont l'un des véhicules des opinions. Il est probable que, dans une mesure limitée, elles contribuent à leur formation; et, de la sorte, certaines proclamations (même platoniques) sont capables d'exercer une influence insoupçonnable sur le moment. Pourtant, ne nous y trompons pas : cette action est d'autant plus sensible que l'association considérée s'insère dans un courant déjà puissant (anticolonialisme, par exemple) ou parvient à trouver le concours d'une force dominante : [p. 392] par là, nous sommes ramenés à l'un des thèmes fondamentaux de cette analyse. En d'autres termes, les O.N.G. restent des éléments de la société internationale, subordonnés en quelque sorte aux rivalités nationales ou partisanes. Pour la période prévisible et en dépit d'un foisonnement quantitatif qui est partiellement de mauvais aloi, c'est pure utopie que de les déclarer susceptibles d'engendrer de manière autonome une idéologie mondiale ou de servir de fondement à un nouvel ordre national.

Peut-être faudrait-il réserver une place particulière aux organismes qui agissent dans le domaine de l'éducation au sens large du terme. Les efforts de l'Unesco sur ce plan touchent évidemment un secteur primordial. Mais, au moins jusqu'à nouvel ordre, on ne saurait postuler que ces associations sont elles-mêmes exemptes des traits qui rendent l'établissement de la compréhension internationale si difficile. En divers pays le corps enseignant, surtout primaire et secondaire, témoigne d'une propension nationaliste sans défaut et d'un engagement sans faille au service d'une idéologie particulière. Cet exemple privilégié par son contenu même va d'ailleurs nous permettre d'entrevoir les grandes lignes d'une analyse globale. 


\section{f) GROUPES INTERNATIONAUX ET VIE POLITIQUE}

$\underline{\text { Retour à la table des matières }}$

Nous allons maintenant tenter de rassembler en quelques propositions les remarques faites dans les précédents paragraphes. Ce serait une bien grande prétention que de revendiquer le titre de "modèle » pour caractériser cet essai : le niveau des connaissances disponibles oblige, certes, à plus de réserve. Ces observations ne sont donc offertes que comme « jalons de route ».

Groupes et politification - Le premier facteur global qui détermine le comportement et délimite l'influence des groupes internationaux est l'absence ou du moins la faiblesse de la politification à l'échelle internationale. Au moins sur le plan des principes juridiques, la souveraineté des États - qu'ils agissent à titre isolé ou rassemblés dans des organisations internationales - continue d'être le seul régulateur de la vie internationale. Le rêve du gouvernement mondial semble, en apparence, aussi pleinement utopique et peut-être davantage qu'au début du $\mathrm{XX}^{\mathrm{e}}$ siècle. Cependant la communauté mondiale comporte, dès maintenant, certains [p. 393] éléments de politification partielle qui, demeurant souvent à l'état de tendances, sont difficiles à repérer. En voici quelques-uns.

D'abord la pression de l'opinion publique internationale. Sensible au niveau des affirmations de principe, elle réduit la marge de souveraineté réelle des États : même si on en conteste la légitimité, les décisions de l'O.N.U., dès qu'elles s'appuient sur de tels courants, ne sont pas nécessairement vaines. Le fonctionnement des organisations internationales aboutit, en fait, à susciter des éléments contraignants de portée variable selon la situation et la puissance des États intéressés. Divers éléments (notamment le perfectionnement des moyens d'information) renforcent ce mouvement.

En second lieu, on doit compter avec l'activité encore mal connue de la bureaucratie internationale. Admettons qu'au niveau des instances dominées par les querelles idéologiques cette influence soit encore limitée: cette observation demandant toutefois un contrôle qui demeure toujours à faire. Reste le cas des organes dans les travaux desquels les aspects techniques jouent un rôle prépondérant. Pensons, par exemple, à des institutions comme l'Organisation Météorologique Mondiale, l'Union Postale Universelle, l'Union Internationale de Télécommunications, voire l'Organisation Mondiale de la Santé. En bref, tout ce que l'on pourrait appeler l'administration internationale. Or l'analyse de ce vaste secteur sous l'angle de la science politique est fragmentaire et dans l'ensemble insuffisante. Assez poussée en quelques universités américaines, cette étude est presque totalement négligée en Europe. 
On ne saurait écarter a priori l'idée que le travail de ces services, auxquels s'associent généralement les autorités nationales de compétence administrative, pèse quelque peu sur les agencements et comportements internes.

Citons enfin les essais de politification au plan régional dont l'intégration européenne demeure un cas privilégié. Sans doute s'est-on un peu trop pressé, à propos de la C.E.C.A., de pronostiquer l'avènement d'une technocratie internationale capable de surmonter, voire de domestiquer, les souverainetés nationales. Sans doute aussi la Communauté Économique Européenne marque-t-elle un net retour au procédé diplomatique traditionnel : on ne saurait tenir pour invraisemblable la thèse qui veut qu'aujourd'hui l'Exécutif du Marché commun fonctionne comme un simple bureau technique aux ordres de gouvernements nationaux. Mais des formules nouvelles ont été esquissées dont il n'est pas absolument certain [p. 394] que le revirement actuel annule entièrement l'effet. On pourrait évoquer aussi le cas de l'OTAN et, bien que le contexte en soit très différent, les efforts du Conseil d'Assistance Mutuelle pour spécialiser et coordonner les économies des pays communistes.

Revenons, sous cette perspective particulière, au cas de l'Assemblée Parlementaire Européenne. On a déjà noté l'importance qu'y prend le rassemblement des membres par groupes politiques et non par nationalité. De plus, le Règlement : adopté par cette Assemblée (le 23 juin 1958) traduit clairement un souci de politification dans le cadre de l'Europe des Six. Ainsi l'organisation et le fonctionnement des Commissions (articles 38 à 43) qui s'inspirent largement de la procédure parlementaire française, par exemple secret des délibérations. Ou encore le choix du procédé des questions (art. 44) et des pétitions (art. 45).

Encore que sa portée soit actuellement limitée, la tendance au contrôle des institutions européennes qui se dégage des travaux de l'Assemblée traduit un net souci de politification, susceptible — c'est l'autre face du phénomène — de concentrer l'attention des groupes de pression sur l'activité exercée. Quand la Commission de l'Agriculture de l'Assemblée prépare et diffuse des rapports en matière de politique commune dans les secteurs, du vin, du lait, du sucre, des céréales, des fruits et légumes, des œufs et volailles, etc., tout porte à croire que les secteurs intéressés n'ont pas dû rester à l'écart de telles délibérations ${ }^{1}$.

Sous toutes ces réserves, la marche des relations internationales demeure à composantes étatiques. Ce sont les États qui restent les meneurs du jeu. La vie internationale est faite des positions qu'ils adoptent les uns à l'égard des autres (négociations, interventions et pressions de tous types, agressions...). Une large partie de ce que l'on peut appeler 1'impérialisme au sens compréhensif du terme (effort conscient pour imposer sa volonté à un plus faible), leur est directement imputable. L'appétit territorial de certains États nouveaux atteste que cette soif de conquête est

Une source commode de documentation sur l'Assemblée est fournie par les fascicules (ronéotés) qui résument périodiquement son activité. Il existe naturellement un Journal Officiel des Communautés Européennes avec diverses annexes. 
indépendante du système d'organisation économico-sociale. Des effets de domination compliquent et, généralement, renforcent cette propension naturelle à l'expansion.

Mais les États sont en fait des hommes qui se déterminent eux-mêmes sous des influences diverses et en particulier sous celle des groupes de pression. Certes, il serait aujourd'hui simpliste d'expliquer le comportement public, national et international, par l'effet des seules forces organisées, notamment d'ordre économique. Nous avons déjà dit et tenons à le [p. 395] répéter, qu'en de nombreuses occasions les forces de la production et de la finance ont constitué les instruments d'un dessein stratégique ou diplomatique, même si, par la suite, elles devraient tirer parti de sa réalisation ${ }^{1}$. Cependant, cette poussée est l'un des facteurs de la décision. À l'action des groupes nationaux s'ajoute, éventuellement, celle des organisations à « capacité internationale ». Quelle est l'influence de la non-politification sur cette faculté ?

En un sens on peut admettre que cette fragmentation des souverainetés a grandement facilité l'action des groupes de pression internationaux, du type « internationales d'affaires », souvent portés à exercer leur activité dans des pays à faibles possibilités défensives. On ne saurait d'ailleurs s'en tenir uniquement en cette matière aux dimensions territoriales et humaines des sociétés politiques considérées. D'immenses pays (Inde et Chine) furent les victimes de l'impérialisme de type léniniste cependant que de très petits y échappaient ou en étaient les bénéficiaires. La valeur de la structure politique et le niveau technologique ont joué un rôle essentiel.

Ne tombons pas dans l'explication préfabriquée, voulant que la division ou la «balkanisation » soient nécessairement le résultat de complots «impérialistes » puisque cette situation passe pour être favorable et l'est en fait, aux grands intérêts économiques et financiers. Il conviendrait alors d'attribuer aux publicitaires la responsabilité de la crédulité humaine dont ils tirent, pour le compte de leurs mandants, un si fructueux parti. Il eût été fort étonnant que l'œuvre centralisatrice accomplie par les puissances coloniales à partir d'un découpage artificiel et en plusieurs cas contraire aux réalités humaines, résiste à la poussée de forces centrifuges qui, même un peu soutenues de l'extérieur, n'en gardent pas moins une réalité autonome. Sur un autre plan, ce ne sont pas les groupements industriels et bancaires qui s’opposent à l'intégration européenne.

Quelques mots maintenant des groupes du type O.N.G. qui affichent une vocation à l'universalité ou, au moins, à un recrutement de vastes dimensions. L'absence de politification constitue, évidemment, un obstacle à leurs ambitions. Si elle permet des succès limités dans des zones favorables à l'action entreprise, elle rend l'accomplissement de desseins de portée générale plus difficile. Après le vote d'une Convention au sein d'une instance intergouvernementale, il faut aussi en obtenir la ratification par chacun des gouvernements.

Le lecteur qui voudrait étudier le problème pourra se reporter à la bibliographie donnée par Jacques FREYMOND in Lénine et l'impérialisme, op. cit., pp. 132-133 : en particulier FEIS (H.), Europe the World Banker, New Haven, 1930 ; RUDIN (H.R.), Germans in the Cameroon 1884-1914. A case study in modern imperialism, New Haven, 1938; STALEY (H.), War and the Private Investor, New York, 1936. 
[p. 396] La division du monde en États souverains accentue l'hétérogénéité des préoccupations (déjà favorisée par la diversité des conditions culturelles et naturelles) et accroît la variété des solutions possibles à des problèmes en apparence communs (alimentation et agriculture, par exemple). Ainsi s'explique, on l'a vu, la relative incapacité, au plan international, d'intérêts qui sont puissants dans le cadre national (paysans).

En réalité, si l'on raisonne en termes d'extension géographique, la plupart des groupes n'ont qu'une capacité internationale réduite. Pour beaucoup d'entre eux, cette faculté n'est guère plus que régionale ou, si l'on préfère, limitée à une zone du monde. Les internationales syndicales l'ont si bien compris qu'elles ont décidé de régionaliser leur activité : mais il est possible que cette opération, bien qu'elle permette en apparence de sauvegarder l'unité, aboutisse en fait à fragmenter la capacité internationale.

Au cours des dernières années, plusieurs organisations se sont constituées sur la base d'un recrutement asiatique ou latino-américain. Encore que moins accentuée, la tendance s'observe déjà dans le cadre de l'Afrique. Ces formules de régionalisation (de droit ou de fait, peu importe) constituent certes un recul à l'égard du rêve de l'unité mondiale : elles ont cependant pour avantage de faciliter la cohésion et la cohérence des groupes qui s'en inspirent pour leur politique de recrutement.

En définitive, on peut se demander si dans un cadre encore dominé par les solidarités nationales (et éventuellement, régionales), le seul facteur de regroupement universel ne se trouverait pas dans la défense et la promotion de ces courants idéologiques dont on a reconnu la présence en étudiant l'opinion publique internationale. Le plus souvent, il est vrai, la force de ces courants leur vient de rester à l'état d'aspirations vagues et confuses: ils peuvent dans certaines circonstances, favoriser ou contrarier l'action des groupes existants, sans pour autant être en mesure d'inspirer la fondation d'un organisme durable qui se chargerait de leur propagation. Mais cette remarque suggère un autre facteur d'appréciation globale de l'action collective internationale.

Groupes et politisation - Ce second facteur atteint beaucoup des rapports qui se nouent entre individus et groupes à l'échelle internationale. Le propre d'un tel processus, sur ce plan comme sur les autres, est d'atteindre des secteurs où les comportements et les choix sont censés relever d'un autre principe que celui du combat idéologique. La lutte [p. 597] ouverte que se livrent aujourd'hui les puissances pour assurer la formation des cadres scientifiques et techniques des pays sousdéveloppés en est un exemple saisissant. L'octroi des prix Nobel ne semble pas à l'abri de telles tendances. Aucune manifestation sportive ou culturelle n'est dépourvue de certains éléments de compétition partisane. En bien des cas, relations commerciales et mouvements de capitaux sont placés au service de stratégies politiques, offensives ou défensives : et cela reste vrai, même si des soucis tactiques conduisent les responsables à proclamer expressément le contraire.

Cette situation fait périodiquement l'objet de dénonciations plus ou moins violentes. On évoque le funeste «politique d'abord» dont la conséquence serait de 
subordonner toutes les valeurs à la raison d'État et qui formerait le péril majeur de notre époque ${ }^{1}$. Mais à la vérité, pour la période actuelle, le choix n'est plus ouvert. La distinction privé-public qui, à condition de n'être pas la simple justification ou sauvegarde de privilèges aurait pu constituer l'une des grandes conquêtes de la civilisation moderne, est peut-être en voie de s'effondrer. Sur le plan international en tout cas, deux facteurs contribuent à l'affaiblir. D'une part, l'extension des responsabilités gouvernementales qui rétrécit constamment an sein de chaque État la sphère des rapports purement privés : elle est plus marquée dans les États autoritaires ou dictatoriaux qu'au sein des sociétés pluralistes, mais en cette matière les effets de contagion sont évidents. D'autre part, l'intensité du combat entre les systèmes rivaux ; même dans la zone d'autonomie qui leur est considérée, les esprits ne sauraient s'évader des grandes discordes idéologiques. Réserve faite d'hypothétiques périodes d'unification spirituelle il en fut toujours ainsi : les oppositions ne sont peut-être pas plus vives dans leur principe que celles d'autrefois (guerres de religion), mais elles engagent plus profondément la totalité du destin social et elles s'étendent à toute la terre.

Il est de mode à cet égard, de raisonner sur une «bipolarisation » du monde. Ce mot doit son succès au fait d'apporter une vision ultra-simplifiée des hommes et des événements. Le système des pôles tend à suggérer l'image d'une humanité s'orientant autour de deux centres ou en voie de se répartir selon une combinaison dualiste. Et sur cette base l'on pourrait, appliquant une propriété précédemment établie, dire que l'influence et l'efficacité des groupes de pression dépendent de leur aptitude, sincère ou simulée, à défendre les intérêts et valeurs de l'une des combinaisons ou du moins à, s'en réclamer.

[p. 398] Qu'il y ait une sorte de relation entre la capacité d'un groupe quelconque et la position du milieu, dans lequel il opère, à l'égard de ses thèses ou revendications semble peu contestable. Mais aujourd'hui la distribution des idéologies ne se ramène pas à une opposition de type manichéen. Il est facile de montrer que la situation à laquelle se heurtent les groupes est différente de celle qui résulterait d'une simple fragmentation dualiste. Les échecs subis pour avoir adopté des notions aussi simplistes en sont la preuve.

En premier lieu, la réduction des points de vue en présence à une telle opposition est arbitraire et ne traduit pas la réalité. Le contenu positif de la «troisième force » est certes assez pauvre : mais cette attitude représente souvent, une force puissante de refus dont les groupes en rapports avec l'un ou l'autre camp doivent tenir compte. Si le souci de la régionalisation se rattache à la nécessité de démultiplier l'action pour l'appliquer à un complexe de problèmes relativement homogènes, il relève aussi du souhait d'atténuer, au moins en apparence, la liaison idéologique avec l'un des blocs. En d'autres termes, cette tendance déjà favorisée par l'absence de politification est renforcée par l'état du combat idéologique et la volonté d'une large partie du tiersmonde d'adopter des solutions originales. Plusieurs groupes occidentaux se font

1 A côté de l'apolitique, il y a aussi l'antipolitique. Voir, en ce sens, SIMOND (Daniel), Antipolitique, Lausanne, 1941. 
volontiers les missionnaires de la démocratie et s'étonnent des réticences que manifestent les destinataires de la croisade. On éviterait facilement de telles déconvenues en observant que les principes de notre organisation politique correspondent à un état des relations humaines et des progrès technologiques qui, sauf exception, n'a pas son équivalent outre-mer. Il conviendrait aussi de ne pas oublier que, dans le passé, nous avons rarement admis ces principes comme matière d'exportations ${ }^{1}$.

La vision manichéenne a un second inconvénient: elle surestime l'unité et l'homogénéité de chacun des pôles. À l'Est, même au seul plan des déclarations officielles, l'accord sur les bases idéologiques de la politique ne semble pas parfait. $\mathrm{Au}$ surplus, les sentiments populaires ne coïncident pas nécessairement avec les déclarations officielles. En plusieurs pays, l'Église romaine demeure un puissant facteur de pression que l'on s'efforce de désagréger soit de l'extérieur (campagnes pour l'athéisme), soit de l'intérieur (ralliement au régime d'une partie du clergé, sur la base de la défense de la paix). L'Ouest ne constitue un "camp », d'ailleurs assez lâche, qu'au niveau des stratégies militaires. En diverses zones, la propagande des groupements communistes ou para-commu-[p. 399] nistes y possède une profonde résonance. Le neutralisme est puissant en quelques secteurs. En voici un exemple : il y a quelques années, des milieux de l'extrême-gauche socialiste en Norvège ont apporté quelque attention à une thèse voulant que leur pays quitte l'O.T.A.N. et remplace l'alliance par une position de non-violence de type gandhien. Aujourd'hui, les syndicats de Grande-Bretagne mettent en cause l'unité d'inspiration de la politique extérieure britannique (qui, au moins dans ses grandes lignes pouvait être considérée comme bi-partisane).

Mais le concept de «bipolarisation » a un défaut plus grave encore il dissimule que certaines positions idéologiques bénéficient d'une audience qui déborde les frontières des deux blocs pour affecter l'opinion mondiale dans son ensemble. Ainsi aujourd'hui la lutte anti-colonialiste ou la dénonciation de l'impérialisme. L'extrême prudence manifestée par plusieurs grandes puissances occidentales, lors des récentes difficultés congolaises notamment sur le problème du Katanga, illustre cette tendance : sans l'ingérence ostensible et à beaucoup d'égards maladroite de l'U.R.S.S. en ce secteur, elles auraient probablement persévéré dans cette tendance. Admettons que cette attitude soit davantage le résultat d'une manœuvre tactique que le produit d'une conviction sincère (la même observation étant également valable pour les attitudes soviétiques) : le fait montre que ces puissances, dites pourtant impérialistes, ont témoigné d'une réserve qui a suscité en Belgique une vive amertume. À propos de

Il y a sur ce point une vaste littérature de qualité inégale. L'un des meilleurs témoignages disponibles pour caractériser cet état d'esprit reste BOER (Hans A. de), Aux carrefours du monde, traduit de l'allemand, Paris, 1959. L'ouvrage reste intéressant à lire malgré l'extrême naïveté de plusieurs passages et une tendance à l'affabulation. 
telles propensions présentes dans tous les secteurs de l'opinion mondiale il serait plus juste de parler de « polarisation » que de « bipolarisation » ${ }^{1}$.

Au total, l'évaluation de la capacité internationale, de son extension et de sa profondeur, doit s'attacher à deux phénomènes: absence (ou faiblesse) de la politification, présence (ou éventualité) de la politisation. À bien des égards les courants idéologiques et les attitudes morales ont une portée transnationale : d'où une possibilité d'extension de la zone d'influence des groupes qui s'en réclament. La politisation compenserait ainsi les lacunes de la politification.

Cependant cette remarque doit être interprétée avec prudence. D'une part, les schémas usuels («bipolarisation» par exemple) ne rendent pas compte de la répartition réelle des forces. D'autre part, la capacité d'un groupe à mobiliser l'attention, voire la sympathie, sur le plan mondial n'entraîne pas nécessairement pour lui une force matérielle correspon-[p. 400] dante (des considérations stratégiques pouvant intervenir pour annuler l'action des préférences morales).

Position propre des groupes - Un troisième facteur déjà analysé doit être pris en considération à propos de l'influence des groupes : leur autonomie (on pourrait dire leur isolement) ou, au contraire, leur participation à un ensemble plus ou moins étroitement coordonné dont ils tirent inspiration et directives, d'une part, soutien sous des formes variées, de l'autre. À partir de là, nous retrouvons la distinction déjà ébauchée entre capacité internationale autonome ou dérivée. Il est maintenant possible d'en traiter avec plus de détails.

Tout au long de cet ouvrage, nous avons rencontré de telles constellations: communisme international, sionisme, Église romaine, mouvement œcuménique, et si l'on en croit diverses présentations, sociétés secrètes comme la maçonnerie. Certaines de ces combinaisons s'appuient si étroitement sur un ou plusieurs États, qu'il est à la vérité difficile de les en distinguer. Par ailleurs, le mode de combinaison des efforts est plus ou moins rigide ; s'il traduit une heureuse utilisation de l'action collective le Conseil Ecuménique des Églises ne ressemble, ni en fait, ni en intention, à une seconde Rome.

Pour qu'un tel regroupement devienne possible, il est indispensable qu'un centre unique d'inspiration et d'impulsion existe et s'impose. Dans certains cas, ce principe d'unification est simplement absent : si les affaires capitalistes s'inspirent en gros de la même philosophie (réaliser une différence positive entre recettes et dépenses) il est patent que leur rassemblement comme instrument de combat ou de pénétration n'a jamais dépassé les limites d'une branche professionnelle ou de quelques-uns des milieux financiers. On compte un grand nombre d'internationales d'affaires, mais il n'y a d'internationale économique que sur le plan des consultations et négociations avec des organismes internationaux (S.D.N., O.N.U.), ou d'un front commun pour modérer les revendications sociales (O.I.T.). En ce qu'ils ont de plus dynamique, les

1 Encore que très discutable à beaucoup d'égards, l'ouvrage de Jacques MENETRIER, Le monde polarisé, Paris, 1958, ouvre des perspectives. 
intérêts d'affaires restent séparés et souvent rivaux. La défense d'une idéologie globale, et spécialement d'une confession religieuse, constitue un facteur d'unification beaucoup plus puissant : cependant la religion orthodoxe, par exemple, est largement demeurée dans le cadre national (ce qui explique la relative facilité avec laquelle elle a pu être « nationalisée » par divers gouvernements dont les régimes communistes ne sont pas les premiers).

[p. 401] On a évoqué à plusieurs reprises les rapports institués entre des groupes internationaux et nationaux et les instances américaines publiques ou privées. La liste de ces groupements, qui n'a jamais été établie sur des bases sérieuses, serait sans doute impressionnante. Sur le papier on pourrait y voir les éléments d'une véritable internationale, mais en fait, si l'on inclut dans ces termes un minimum de direction cohérente et de sujétion hiérarchique, celle-ci n'a jamais vu le jour. Deux éléments ont fait défaut pour tirer le parti optimum des efforts engagés : une inspiration de contenu positif qui comporte un message idéologique commun à tous les éléments de la combinaison et une coordination des activités des membres selon une vue d'ensemble comportant un programme à long terme. S'il est un point qu'illustre l'action des ÉtatsUnis depuis 1945, c'est la faiblesse du moyen financier à l'état pur, que son emploi résulte d'un calcul ou d'un acte de générosité ${ }^{1}$.

Les groupes ainsi touchés ou aidés par l'action américaine se situent entre ceux dont l'autonomie reste entière et ceux réellement intégrés à une force plus large. Il s'agit d'une sorte de nébuleuse aux contours imprécis et de contenu éventuellement changeant. Il est à la fois difficile d'en préciser la nature et les dimensions, et impossible de la passer sous silence. Bien entendu, d'autres pays ont adopté un comportement analogue, mais généralement avec des moyens trop limités pour espérer plus que des victoires locales.

Quand il existe un centre d'impulsion unifié, on peut envisager l'emploi de plusieurs moyens, alternatifs ou simultanés, en vue d'assurer le triomphe de la cause. La formation d'organisations non gouvernementales constitue seulement l'une des techniques utilisées par le communisme et le catholicisme dans leur lutte pour la conquête des esprits. Un autre sera, par exemple, la formation d'un ensemble de partis nationaux sans oublier l'existence de réseaux de communication et d'information qui, pour avoir quelque efficacité, ne doivent pas faire l'objet de publicité. D'autres forces n'ont pas une telle disponibilité d'instruments.

Il est essentiel de distinguer l'idéologie politique, culturelle, religieuse, qui inspire le mouvement, de l'organisation qui se fonde sur elle et tente d'en assurer l'expansion. Le développement dune idéologie est, jusqu'à un certain point, indépendant de l'organisation. Mais l'histoire du monde moderne montre le poids considérable des méthodes d'encadrement et d'administration. Si l'on veut évaluer les influences qui

Dans un ouvrage où l'imagination prédomine sur l'observation, La paix du dollar, Paris, 1957. M. André KOSTOLANY a soutenu qu'en réalité l'Amérique aurait, depuis la guerre, suivi une ligne unique : assurer la prospérité toujours croissante des nations libres. Admettons que cette prospérité a été considérée par les États-Unis comme l'un des moyens de freiner l'expansion du communisme : mais la manière dont l'aide a été apportée est souvent allée à l'encontre du but visé. 
s'exercent sur la politique, il est important d'analyser l'aptitude comparée des diverses [p. 402] idéologies à engendrer une structure et d'examiner chacune des formules mises en œuvre (en particulier sous l'angle de la qualité de la coordination).

Généralement, l'objectif global de la constellation des groupes ne fait aucun doute. Les Catholiques, par exemple, visent à assurer l'expansion de l'Église et l'application de ses enseignements à la vie publique. Une question se pose quand le mouvement s'appuie sur un État ou un ensemble d'États. Ceux-ci veulent-ils en réalité le développement de l'idéologie pour elle-même ou la mise de celle-ci au service d'une politique nationale ? La situation exige le plus souvent des formules nuancées. Dans un précédent chapitre on a refusé d'assimiler le communisme international à la défense de l'impérialisme russe traditionnel. En de nombreux cas, les faits relèvent d'une interprétation ambivalente. Quand Staline, en mai 1935, déclare approuver la politique française de défense nationale, il se préoccupe sans doute de la sécurité soviétique, mais en même temps il ouvre la voie qui permettra au Parti Communiste Français d'entrer dans une majorité gouvernementale ${ }^{1}$.

La discussion reste ouverte de savoir si de tels centres d'impulsion, lorsqu'ils ont une structure propre, doivent être considérés comme des groupes de pression ou s'il convient de leur appliquer un autre qualificatif, laissant celui de "groupes » aux associations chargées de propager la doctrine dans le siècle. En tout état de cause, comme on l'a dit, il est souhaitable de distinguer une capacité internationale propre ou autonome (indépendance d'une instance supérieure) et une capacité seconde ou dérivée. La répartition entre les deux séries ne manquera d'ailleurs pas de soulever des controverses. Ainsi les marxistes, à tort selon nous, contestent-ils cette autonomie à diverses religions dans lesquelles ils voient des "serviteurs du capitalisme ». En définitive, ont une capacité autonome tous les groupes qui puisent leur propre fonds, c'est-à-dire, ressources et inspirations chez leurs membres: en particulier, les combinaisons d'affaires, les confessions religieuses, les mouvements d'émancipation nationale (lorsque leur combat trouve en lui-même son inspiration sans se rattacher à une stratégie plus vaste) et aussi de multiples O.N.G. comme l'Alliance Coopérative Internationale, la Chambre de Commerce Internationale...

Bien entendu, il n'y a pas de relation directe entre l'autonomie et la capacité internationale. Un groupe autonome peut n'exercer qu'une influence réduite cependant qu'un autre, à puissance dérivée, jouira, du fait [p. 403] de ce rattachement, d'une large audience. Mais dans le second cas, le bénéficiaire retransmet en quelque sorte les résultats acquis au responsable principal ou, du moins, est censé agir en ce sens.

Ces observations, établies principalement à la lumière des événements de ce temps, ne sont sans doute que de simples suggestions destinées à orienter des recherches ultérieures. Or un sentiment assez répandu est que nous vivons aujourd'hui une phase de transition dont les caractéristiques ne présenteraient dès lors qu'une signification passagère. L'objection a-t-elle de la valeur? Évoquer une telle période

1 On ne saurait imaginer d'interprétation de cet acte plus erronée et partiale que celle donnée par TIROTSKY, Journal d'exil, 1935, traduit du russe, Paris, 1960, pp. 143-148. 
n'a de sens que par rapport à un état plus durable qui pourrait être aussi bien le retour aux normes du passé que l'adoption de nouveaux modes de conduite. La première de ces orientations néglige l'irréversibilité de nombreuses évolutions, la seconde le poids des attitudes traditionnelles. L'une et l'autre opposent le « durable » au « transitoire », le « normal » à l'« anormal », l'« équilibre » au « déséquilibre ».

L'analyse économique a fait un réel progrès en découvrant que les situations qualifiées de "normales » ou "d'équilibrées » consistent en une série, mieux une succession, de déséquilibres assez faibles pour s'annuler réciproquement : surtout, les économistes ont montré qu'en matière économique le déséquilibre est le principe même du mouvement, que ce soit expansion ou contraction. En prévoyant le « retour à une situation normale » on ne fait qu'exprimer une préférence morale pour le passé et témoigner d'une incompréhension de la vie des affaires. Malheureusement, la science politique en est encore demeurée, chez la plupart des auteurs, au stade de la conception statique qui voit dans les bouleversements de toute nature l'introduction d'un déséquilibre appelé à se résorber tôt ou tard.

Dans une interprétation dynamique, notre période ne semble pas très différente des précédentes sinon, peut-être, par l'accélération des évolutions et l'amplification des tendances. On ne saurait poser a priori que les principes régissant cette série de déséquilibres d'où sort le mouvement politique ou, si l'on préfère, que le complexe de facteurs responsables de ces changements diffèrent fondamentalement d'une époque à l'autre. Pour énoncer sur ce point un jugement valable, il n'y a pas d'autres moyens que d'instituer une coopération entre Histoire et la science politique et cette suggestion conduit directement à la seconde partie de ce chapitre.

[p. 404]

\section{INTÉGRATION À LÀ THÉORIE}

Retour à la table des matières

Pour les raisons qu'on a dites, le sujet ne sera qu'effleuré. Les problèmes de la formulation théorique dominent de très haut la recherche empirique. Mais, à moins de confondre la théorie avec l'expression d'un système d'interprétations personnelles (qui peuvent être brillantes mais aussi banales), on admettra volontiers l'impossibilité de progresser autrement que de façon lente, presque pas à pas. Si le lecteur connaît l'état actuel de la question, il acceptera aisément cette attitude réservée.

\section{a) DIVERSITÉ DES NIVEAUX DE L'ANALYSE POLITIQUE}

Telle qu'on l'a conçue, la catégorie "groupes de pression internationaux », est utilisable au double niveau de la politique intérieure et de la politique internationale. En tout état de cause, les conduites qu'elle exprime interviennent sur l'action 
gouvernementale : même si l'on repousse la formule proposée, il reste à tenir compte des faits qu'elle recouvre. Or il n'en est pas toujours ainsi.

Cette lacune de l'analyse est particulièrement visible au niveau de la vie politique interne. Trop souvent, les études qui en sont faites négligent des influences venues de l'extérieur ou ne leur accordent qu'une place insuffisante. Plusieurs facteurs en sont responsables. D'abord, le formalisme qui dans de nombreux pays continue de caractériser la majeure partie des études sur le système de gouvernement : on néglige les forces qui actionnent les gouvernants, simplement parce que la Constitution les ignore ou par souci de préserver de toute atteinte l'image conventionnelle des institutions.

Supposons cette étape franchie : il est significatif d'observer que l'examen portera essentiellement sur les groupes nationaux. Il y a une sorte de répugnance à admettre que sur tel ou tel point, le comportement des autorités est susceptible de refléter les vœux de forces étrangères ou l'impulsion reçue d'elles. Pour un peu, on déclarerait volontiers que de tels procédés caractérisent seulement les États mineurs. Dès lors, l'action des forces étrangères est abandonnée aux observations et divagations des polémistes ou aux impressions nécessairement vagues de l'opinion publique.

[p. 405] L'étude des groupes de pression internationaux est également indispensable au niveau de la politique étrangère. Si la politification de la société internationale se développait, l'effort de ces groupes porterait naturellement sur les nouvelles unités de commandement (rappel des observations présentées sur les institutions européennes de Luxembourg et de Bruxelles). Aujourd'hui, l'objectif essentiel reste de modifier la conduite des États nationaux en un sens favorable aux intérêts ou idéologies défendus. L'influence éventuelle de ces groupes constitue donc un élément à introduire dans les analyses consacrées à l'élaboration de la politique extérieure et au fonctionnement des organisations intergouvernementales. Quiconque est un peu familiarisé avec les ouvrages traitant de ces matières reconnaîtra qu'il reste encore beaucoup à faire sur ce point.

À ce stade, une question pourrait être abordée : la position de l'étude des relations internationales dans l'analyse politique. Mais on veut éviter de revenir, une fois de plus, sur ce débat irritant et vain. Tout au long de cet ouvrage on a montré les liaisons étroites qui unissent l'action interne et externe des gouvernants. Et c'est au moment où ces rapports apparaissent indissociables que l'on propose de constituer une discipline des relations internationales distincte de la science politique: ce qui postule l'établissement d'un critère permettant de répartir l'activité gouvernementale en deux secteurs ayant chacun leur principe d'inspiration et possédant chacun un contenu homogène. Or, un tel critère personne ne l'a fourni.

Nous admettrons avec S. Hoffmann que cette étude constitue un secteur largement autonome dans le champ encore confus et mouvant de l'analyse politique ${ }^{1}$. Mais ce sera à une condition : que cette autonomie soit considérée comme une insuffisance de

Dans Contemporary Theory in International Relations, op. cit., p. 1. 
l'analyse et non comme la réalisation d'un idéal intellectuel. Si les diverses branches du secteur étatique sont traitées comme des pièces détachées, c'est simplement par impuissance de notre discipline à trouver des concepts globaux (celui de pouvoir n'ayant qu'une faible capacité opérationnelle). Évitons, comme c'est si souvent le cas, de faire d'insuffisance vertu.

On admettra, également sans discussion particulière, que dans ce secteur de l'analyse politique comme dans tous les autres, le recours à la connaissance historique présente une importance essentielle: cette discipline est susceptible, à la fois, d'apporter des matériaux à la construction théorique et de fixer les limites éventuelles d'application dans le temps des schémas construits pour l'époque contemporaine (ce qui est une [p. 406] autre manière de différencier les déterminismes en fonction des sociétés globales). Ces résultats seront mieux et plus vite acquis si le spécialiste en science politique sait coopérer avec l'historien.

À vrai dire l'Histoire, du moins la grande Histoire, a toujours tenu le plus grand compte des phénomènes dont nous venons de parler. Pierre Renouvin, en particulier, a admirablement évoqué le rôle dans le déroulement des relations internationales des forces sous-jacentes, des mouvements profonds, des passions collectives : en même temps, il s'est refusé à y voir le moteur exclusif des événements et des décisions ${ }^{1}$. L'objet spécifique de ce livre est simplement de forger un instrument qui permette de mieux saisir et interpréter l'action de ces forces profondes, économiques ou morales. Les historiens ont beaucoup à dire quant à la valeur, logique et pratique, de l'instrument de travail proposé.

Raymond Aron a montré, en des termes qui semblent échapper à la contestation, le rôle de la comparaison historique dans l'analyse politique (par exemple, pour l'étude de l'influence de la politique intérieure sur la politique extérieure) ${ }^{2}$. Il va jusqu'à énoncer que «seul un sociologue qui suivrait la méthode historique aurait chance de devenir le conseiller du prince ». Nous ne sommes en désaccord avec lui que sur un point: pourquoi rétablir un contraste, même implicite, entre cette « sociologie historique » et la science politique ? Cette discipline, pas plus que la science économique, ne saurait fournir de résultat concluant si elle ne s'attache à exploiter la dimension historique, cette dernière lui ouvrant, notamment, les perspectives de l'analyse comparative, substitut de l'expérience. Raymond Aron signale justement que les expressions « science politique » et « sociologie politique » recouvrent exactement les mêmes phénomènes. Cependant si l'on admet d'utiliser les termes «science politique », la notion de «sociologie historique » apparaît contestable : du moins le serait-elle si l'on voulait en déduire que la science politique peut négliger la composante historique.

1 Voir son introduction à l'Histoire des relations internationales, tome I, Paris, 1953, pp. IX-XVII, et aussi la définition des «forces profondes » données dans le tome V, Paris, 1954, p. 9, « esquisse générale du milieu social, économique et des tendances de la pensée politique ».

Voir son étude, "Les tensions et la guerre du point de vue de la sociologie historique », dans l'ouvrage collectif De la nature des conflits, Paris, Unesco, 1957, pp. 201-226. 
Reste le problème des rapports entre le sujet de ce volume et le droit international public. L'analyse de ces relations exigerait une prise de position sur le fondement et la nature du droit des gens que nous n'avons pas compétence pour formuler: disons seulement trouver fondées les positions juridiques dont Paul Guggenheim résume parfaitement l'inspiration en refusant de faire de ce droit « une construction politicosociologique des relations internationales ${ }^{1}$. La lecture d'ouvrages récents où l'on voit tout ce que le juriste perd dans de telles tentatives sans que [p. 407] le sociologue ait quoi que ce soit à y gagner, confirme bien la valeur de cette préférence ${ }^{2}$.

Dans cette conception, le droit et la politique internationales relèvent d'analyses certes distinctes, mais en relation l'un avec l'autre. P. Guggenheim a raison d'écrire que « l'analyse du droit positif conduit à l'étude des phénomènes du monde extérieur : ils forcent à examiner les faits politiques en tant que faits soumis au principe de causalité et non à titre de problèmes normatifs ${ }^{3}$. Par contre, nous éprouvons quelques réticences à l'égard des observations qu'il présente sur la science des relations internationales dont, selon lui, l'objet « reste cependant fonction du contenu du droit positif ... C'est ... la validité personnelle, spatiale et matérielle de l'ordre juridique international qui détermine le champ des recherches de la science explicative des relations internationales $»$.

Il semble qu'une telle définition risquerait, au moins en fait, d'appauvrir le domaine des recherches d'inspiration sociologique. L'exemple des phénomènes internes est de nature à renforcer cette réserve : tous les essais partant du droit constitutionnel pour rejoindre la vie politique ne sont jamais parvenus à rendre la richesse et la complexité de cette dernière.

Il nous paraît donc souhaitable de prendre pour fondement de la discipline l'autonomie de la recherche politique, interne et externe, vis-à-vis de la technique du droit : ce qui n'entraîne aucune indifférence à l'égard du cadre juridique et des règles du droit positif dans la mesure où elles influencent, et parfois dictent entièrement, le comportement des acteurs du jeu.

In Traité de droit international public, 2 vol., Genève, 1953-54, tome I, p. II.

Ainsi par exemple, ALVAREZ (Alejandrô), Le droit international nouveau dans ses rapports avec la vie actuelle des peuples, Paris, 1959. Dans cette perspective, consulter l'intéressante étude de YAKEMTCHOUK (Romain), "Droit des gens positif et sociologie des relations internationales ", Revue de l'Institut de Sociologie (Solvay), 1958 (2), pp. 335-390. L'auteur s'efforce d'établir les limites du droit international positif et de montrer qu'il laisse place à une sociologie des relations internationales. Mais on n'en saurait tirer, selon nous, aucun argument contre la conception positive du droit: en fait, l'argumentation n'a de sens que si elle recommande la distinction des plans d'analyse ayant chacun leur inspiration propre.

Op. cit., p. 28. 


\section{b) CARACTÉRISTIQUES DE L'APPROCHE SUGGÉRÉE}

\section{$\underline{\text { Retour à la table des matières }}$}

Les développements présentés dans cet ouvrage ne constituent pas une théorie proprement dite. Cependant ils sont l'expression de préférences théoriques que l'on voudrait tenter de clarifier, au moins partiellement. On ira du plus évident qui est aussi le plus simple au plus complexe.

Le premier trait est le refus délibéré de toute interprétation monistique. À de multiples reprises, nous avons déclaré que la totalité des conduites qualifiées «groupes de pression internationaux», forme seulement l'un des facteurs du problème. A fortiori apparaît-il impossible d'attribuer à l'un quelconque de ces éléments le rôle d'une variable causale universelle.

[p. 408] En dépit de ses faiblesses intrinsèques, l'interprétation monistique correspond à une pente de l'esprit humain. C'est du moins l'impression que laisse l'effort poursuivi, d'une génération à l'autre, en vue de dégager le facteur unique capable d'indiquer à lui seul le sens de l'évolution et de donner la clé de toutes les situations. Sur le plan scientifique, de telles tentatives n'ont pas été sans utilité. Elles ont conduit, parfois contre leur gré, les spécialistes à examiner des phénomènes négligés ou sous-estimés: rôle des facteurs économiques ou encore poids des conditions géographiques et biologiques. L'analyse théorique a ainsi beaucoup reçu des conceptions monistiques, mais en les dépassant et en faisant éclater leur caractère partiel.

Il demeure que ces positions sont d'admirables instruments de propagande. Encore que les spécialistes de la "persuasion» en discutent, il semble bien que, dans beaucoup de cas, le propagandiste n'ait pas intérêt à exposer le pour et le contre : confusion et hésitation dans l'auditoire seraient le prix d'un essai d'objectivité. Les explications monistes présentent l'avantage d'une grande simplicité et il est facile de leur donner une tournure "émotionnelle » susceptible d'exalter les esprits. C'est l'un des moyens les plus efficaces d'influencer les masses (en liaison étroite avec l'emploi de slogans, de « boucs émissaires », de mythes...).

Le comble du succès est atteint quand de telles interprétations impressionnent et influencent ceux-là mêmes contre lesquels elles sont dirigées : ainsi aujourd'hui, certaines thèses du marxisme réduites il est vrai à leurs aspects les plus élémentaires. Cette utilisation quasi inconsciente, ne constitue nullement une conversion : en bien des cas, les intéressés seraient fort étonnés d'apprendre l'origine des mots qu'ils emploient ou des arguments qu'ils utilisent. L'audience de ces concepts dépend, en une large mesure, de l'ampleur et de l'intensité du bombardement idéologique auquel est soumise la communauté.

Cette tendance à l'acceptation des conceptions monistes est l'un des faits dont l'analyse théorique doit se saisir : il n'est pas inexact d'y voir l'une des sources de 
conflits, dans le monde moderne, entre catégories sociales ou entre nations ${ }^{1}$. Mais le monisme comme tel n'est pas une base valable pour l'explication scientifique.

Ce refus implique dès lors un recensement préalable, très méticuleux, et à prétention exhaustive, de tous les facteurs susceptibles d'influencer les comportements gouvernementaux. À l'égard du secteur qu'il avait pour ambition d'explorer, ce livre reste indicatif : cependant, on n'a pas [p. 409] hésité à inclure dans le tableau présenté des éléments dont il est probable que l'influence reste limitée. N'oublions pas que le perfectionnement de l'analyse sociale conduit à insister sur le rôle des petites variations ou, en d'autres termes, sur l'action des éléments d'importance réduite dans le passage d'un état à l'autre (analyse à la marge).

Dans ce recensement, une difficulté surgit : la validité de la distinction, longtemps pratiquée et encore parfois recommandée, entre les "facteurs constants » et les « variables ». Sous un certain angle, très rudimentaire d'ailleurs, la différence revient à opposer les facteurs dits physiques ou naturels aux comportements humains : on en tire inévitablement l'idée d'une malléabilité plus grande des seconds aux projets et directives des autorités.

Cependant, il est devenu clair que l'opposition est simplement relative. Sur une période assez longue, il arrive que les facteurs naturels se modifient spontanément ou fassent l'objet de changements «volontaires ». Dans la courte période la résistance des mentalités humaines constitue parfois un obstacle infranchissable. D'où l'introduction dans la notion de "structure » des états d'esprit ou des modes de conduite, dès lors qu'il s'agit de traits suffisamment stables. Mais l'idée même de structure est encore trop controversée pour fournir une base satisfaisante à une construction théorique qui en reste à la phase initiale.

Faute d'un accord sur cette question, on peut continuer à utiliser l'expression de « variables » pour désigner tous les éléments du processus politique qui, à un moment donné, apparaissent susceptibles de transformation soit par un mouvement interne, soit à la suite d'une pression ou intervention externe. Mais cet emploi n'est légitime que sous deux réserves qui, tout en jouant dans un sens opposé, ne sont pas contradictoires.

La première est de considérer que, si les réactions humaines sont des « variables », la fixation de leur valeur dans l'équation de la politique n'est jamais à l'entière disposition des gouvernants ou de qui que ce soit. Pour les groupes de pression, c'est à la fois une protection contre les risques de désagrégation sous l'effet d'une propagande adverse et une limitation aux facultés d'influence, notamment par le canal de l'action sur l'opinion. Cette propriété s'accentue quand augmente la diversité, mieux l'hétérogénéité du milieu culturel : ce qui est normalement le cas pour l'activité internationale.

[p. 410] La seconde est de noter que les conduites humaines, sans exception aucune, sont susceptibles de transformation. Bien ne serait plus dangereux que de

Voir ELLWOOD (Charles A.), A History of Social Philosophy, New York, 1953, p. 341. 
figer, à un moment quelconque, la constellation des « variables » avec la valeur alors acquise. Les groupes de pression internationaux relèvent tout particulièrement de cette observation : sous des influences diverses, ils se transforment en eux-mêmes, dans leurs rapports respectifs, dans leur relation avec les autorités. Quiconque ignore cette plasticité de "variables » se condamne à soutenir des positions dépassées par l'évènement. Pourtant ceux-là mêmes qui admettent la validité de cette observation n'arrivent pas toujours à en tirer les conséquences. Sera-t-il jamais possible de bâtir une théorie capable de s'adapter à ces transformations incessantes, au fur et à mesure de leur survenance?

Ces remarques aboutissent à la question capitale que pose l'introduction de la catégorie « groupes de pression » dans la vie politique : l'évaluation de la capacité des groupes organisés à restreindre la liberté de manœuvre gouvernementale et cela qu'il s'agisse de promouvoir une action critiquée par les autorités ou de s'opposer à une disposition souhaitée par elles. Bien entendu, l'activité des organisations n'est que l'un des facteurs qui limitent les facultés d'intervention des gouvernants : ceux-ci doivent également compter avec des réactions spontanées, parfois extrêmement puissantes (vagues d'indignation ou d'enthousiasme, éventuellement éphémères). Cependant la tendance à l'expansion et à la rationalisation de l'activité collective, dans tous les secteurs des relations humaines, impose d'accorder une attention particulière à ce type de participation.

Sur ce problème notre ouvrage apporte quelques indications : le lecteur aura pourtant noté leur rareté et leur imprécision. Rien ne permet encore de dire s'il sera possible d'en arriver un jour à une véritable mesure, éventuellement de type qualitatif.

L'analyse des groupes internationaux n'a de sens que si elle prépare la formulation d'une théorie générale des relations internationales, capables de s'intégrer plus tard à une théorie générale de la politique. On ne possède aucune certitude que l'établissement d'une telle conceptualisation, même limitée à la seule politique internationale, soit proche. Et les éléments ne font pas défaut qui, jusqu'à nouvel ordre, conduisent à admettre le caractère prématuré de toute tentative en ce sens.

On n'insistera pas ici sur les ambitieuses synthèses présentées au cours des dernières années à propos des relations internationales. Le propre de [p. 411] ces systèmes qui se veulent explicatifs est d'être tout au plus descriptifs : encore ne détient-on aucune garantie véritable que le tableau fourni corresponde à la réalité (ainsi en va-t-il par exemple de la doctrine du "réalisme » dont Hans J. Morgenthau demeure l'exposant le mieux connu). Les essais d'explication disponibles se ramènent soit à des approximations de type plus littéraire que scientifique, soit à de hasardeuses spéculations mathématiques (dont la signification est faible si l'on traduit en langage clair les montagnes d'équations utilisées).

À vrai dire, nul ne connaît encore très bien le type de théorie qu'il serait souhaitable de formuler. En exprimant, malgré le discrédit philosophique actuel de la notion de causalité, une indestructible préférence pour la théorie causale, nous n'ignorons ni le caractère proprement nébuleux d'une telle expression, ni les incertitudes qui s'attachent à l'élucidation du contenu même de la recherche. Tout au 
plus s'agit-il de suggérer une orientation aux travaux à entreprendre et de leur fixer un but assez attirant pour justifier les immenses efforts qu'exige le projet.

Admettons que la difficulté majeure d'une explication causale réside dans la «pondération» des facteurs (probablement impossible à réaliser dans le cadre, finalement assez pauvre, de la statistique purement quantitative). Mais ce serait déjà un grand résultat que d'obtenir un tableau du sens des rapports, c'est-à-dire des modalités selon lesquelles les facteurs dégagés agissent les uns sur les autres. On ne pourrait y parvenir sans une connaissance suffisamment précise de ces facteurs sur bien des points, cette condition nécessaire n'est pas remplie ${ }^{1}$.

\section{c) SUGGESTIONS POUR UNE ÉTUDE APPROFONDIE}

\section{$\underline{\text { Retour à la table des matières }}$}

Les auteurs encore très rares qui ont évoqué ce sujet se retrouvent d'accord sur une difficulté essentielle du problème : la variété des phénomènes à observer et leur extrême diffusion géographique. Il n'est pas exagéré d'écrire qu'idéalement, la recherche serait en quelque sorte illimitée ${ }^{2}$. Rien n'empêche pourtant d'envisager des travaux qui, tout en ramenant cette ambition à des proportions humaines, fassent progresser considérablement la connaissance du sujet. On se bornera ici à présenter quelques suggestions pour le choix de thèmes spécifiques de recherche.

Il ne sera pas inutile auparavant d'indiquer les caractéristiques de la documentation dont on dispose actuellement pour l'étude des groupes [p. 412] internationaux. Sauf omission importante de notre part dans le recensement bibliographique, les services que l'on en peut attendre pour l'analyse de la vie politique sont limités.

Une partie de cette documentation est, certes, conforme aux exigences de l'étude scientifique. Mais plusieurs traits restreignent sa valeur pour notre propos : elle ne concerne que certains éléments du sujet et les étudie de façon généralement isolée, sans référence à une interprétation d'ensemble : elle est étonnamment dispersée dans son inspiration et sa méthodologie, émanant de disciplines aux préoccupations hétérogènes (histoire, science économique, sociologie religieuse...), elle fait presque complètement abstraction du point de vue propre à la science politique ou ne s'en inspire que de façon incidente ou superficielle. Quand des sources documentaires sont disponibles, la difficulté essentielle est de passer de l'une à l'autre en vue de rapprocher et de comparer les résultats acquis: on aboutira souvent à constater l'impossibilité de l'opération.

La meilleure introduction à la théorie des relations internationales dans son état actuel est l'ouvrage déjà cité, HOFFMANN (Stanley H.), ed., Contemporary Theory in International Relations.

2 BLAISDELL (Donald C.), « Unofficial Group in International Relations. Some Thoughts or Scope and Method of Study », Associations, juin 1959, pp. 436-438. 
Mais une très large partie de l'information disponible n'est pas d'ambition et de faculté universitaires. En bien des cas pourtant, elle présente une grande importance : c'est le cas du matériel préparé ou inspiré, par les intéressés eux-mêmes. On en dira autant de certains ouvrages de caractère ouvertement polémique dont il existe un grand nombre sur certains aspects du sujet. Dans l'un et l'autre cas, il s'agit d'éléments bruts pour l'analyse desquels on ne dispose pas toujours de critères objectifs de tri et d'interprétation.

Plusieurs des forces considérées ont l'habitude de travailler et d'intervenir de façon discrète, sinon clandestine. Il en résulte une propension à l'établissement d'interprétations romancées et à la construction de mythes que les gouvernements favorisent en refusant de rendre publics les renseignements ou rapports dont ils disposent. Il en découle également une tendance à la présentation manichéenne. Enfin, il $\mathrm{v}$ a des secteurs ignorés aussi bien de l'analyse sociologique que de la discussion polémique : l'activité de beaucoup d'organisations non gouvernementales entre sous cette rubrique. En dépit des efforts de l'Union des Associations Internationales — dont émane la plus large partie de la documentation existante — la connaissance de ce vaste réseau demeure très rudimentaire.

Sur cette base nous voudrions suggérer trois orientations de recherche.

[p. 413] $1^{\circ}$ La première direction de travail est l'établissement de monographies portant sur la structure et le fonctionnement des groupes. Ce conseil correspond à souligner une nécessité, sinon à émettre une évidence. Pourtant, sa mise en œuvre soulève un problème de répartition du travail dont voici les termes.

À l'égard des forces non exclusivement et parfois non principalement politiques, l'analyse politique se trouve, du fait de la séparation disciplinaire, dans une situation équivoque. Procédant à leur étude monographique, elle empiète manifestement sur le terrain d'autres branches : l'expérience établit pourtant que les travaux conçus par les spécialistes de ces matières répondent rarement au type de question que se pose notre discipline.

Soit par exemple l'analyse des cartels internationaux. Sur plusieurs d'entre eux on dispose de bonnes études économiques. Mais l'économiste s'intéresse davantage au contenu des mesures prises qu'aux circonstances de leur adoption : il a tendance à considérer les rapports des dirigeants de l'entente avec les pouvoirs publics ou les instances internationales comme un terrain d'étude semé d'embûches dont le défrichage ne s'impose pas. Avec ce mode de recherche on connaît finalement le diptyque : position du problème - solution adoptée, et on dispose généralement d'une évaluation de la cohérence des conduites choisies. Mais le plus souvent on ignore à peu près tout des démarches et discussions ayant suggéré et parfois imposé la ligne adoptée.

Remarquons d'ailleurs que la présente concentration des études économiques sur des préoccupations macroscopiques ne peut qu'encourager cette tendance: elle aboutit, comme nous l'avons exposé ailleurs, à présenter une vision tronquée et parfois fallacieuse de la politique économique. Il en résulte l'obligation pour le 
spécialiste en science politique, sinon de refaire le travail sous l'angle de ses préoccupations, du moins de le revoir et de le compléter.

Ces monographies devraient naturellement porter sur des organisations non gouvernementales sans but lucratif. Il serait certes souhaitable que les recherches couvrent des organes représentatifs de divers types d'association (dimension, nature de l'implantation, structure et mode d'organisation). Il est douteux qu'une certaine coordination des travaux entre les chercheurs des divers pays (et même d'un seul) puisse être envisagée. Cette situation risque de provoquer une concentration excessive sur certaines catégories, jointe à une absence complète de données sur d'au[p. 414] tres. En matière scientifique, comme en d'autres domaines, la concurrence pousse plutôt à l'exploitation des sentiers battus qu'à la découverte de nouveaux champs.

En bien des cas les O.N.G. accepteront au moins en principe de telles enquêtes (l'insuffisance des secrétariats réduisant d'ailleurs la quantité et la qualité des éléments documentaires susceptibles d'être communiqués au chercheur). Mais il faudrait étendre aussi la recherche politique aux relations internationales des grandes affaires. Inutile d'insister sur les obstacles, éventuellement infranchissables, qui risquent d'entraver le travail des enquêteurs peu préparés à donner une vue apologétique. L'expérience montre d'ailleurs que le simple dépouillement des journaux professionnels et financiers, s'il s'accompagne d'une bonne connaissance du milieu en cause, donne plus de renseignements qu'on ne serait tenté de le supposer a priori.

$2^{\circ}$ Un autre pôle de la recherche pourrait être l'analyse des organisations intergouvernementales comme des unités politiques ou politico-administratives soumises à des pressions dans l'exercice de leur activité quotidienne. Le choix des points d'étude devrait être assez large pour embrasser les divers types de missions accomplies par ces organismes : idéologique, humanitaire, proprement technique, etc. Peut-être ne donne-t-on pas une vue équitable du travail accompli par les institutions internationales (ou de l'efficience qu'elles peuvent obtenir) en se limitant à l'Ecosoc ou à la F.A.O.

Le travail de ces organismes est complexe et aucune recherche ne saurait être significative sans se concentrer sur certains aspects de leurs interventions: par exemple, l'étude détaillée des relations extérieures d'un département ou d'une commission, ou encore le fonctionnement effectif des relations consultatives dans une hypothèse déterminée. Il serait tentant d'entreprendre l'étude sur le terrain d'une assemblée générale (comme d'autres ont étudié les «couloirs » des parlements nationaux) : mais une telle démarche exigerait le concours d'une équipe spécialement entraînée à cet égard.

Une recherche significative serait l'étude des arrangements consultatifs. Nous ne savons presque rien du fonctionnement pratique de ce système, si ce n'est que les bénéficiaires en font un usage fort inégal. Il donne lieu à de nombreuses, et parfois vives, polémiques qui ne permettent cependant pas d'apprécier l'efficacité réelle du mécanisme, peut-[p. 415] être variable selon la nature des questions abordées. Ces lacunes persisteront tant qu'on n'aura pas transposé l'approche dite du decision making 
aux instances internationales (en particulier aux commissions du Conseil Économique et Social qui constituent pour les groupes l'une des principales « voies d'accès »).

$3^{\circ}$ Une troisième approche pourrait être l'analyse des problèmes à la solution desquels il est évident que les groupes internationaux ont pris part ou tenté de le faire. La liste potentielle de tels sujets serait immense: mais les difficultés de l'analyse varient considérablement d'un cas à l'autre (atteignant probablement leur maximum quand les intérêts financiers sont en cause).

L'analyse du processus de « décolonisation » (terme dont il convient de souligner après d'autres auteurs l'extrême imprécision) offrirait probablement d'intéressantes perspectives à cet effet. Il serait souhaitable, mais opérationnellement difficile, d'étudier le rôle des groupes internationaux dans la fondation de nouveaux États ou le retour à l'indépendance de structures étatiques placées sous protectorat.

On pourrait sans difficulté, allonger la liste des points d'application éventuels d'une telle activité. En tout état de cause, un aspect revêt une importance spéciale : la présentation de ces phénomènes comme un système de relations liant les organismes privés (ou semi-publics) aux instances officielles soit directement soit par l'intermédiaire de l'opinion. La formulation et la systématisation de ces rapports constituent la tâche propre de la science politique : l'expérience établit qu'elle n'est presque jamais accomplie si un spécialiste de cette discipline ne la prend en charge.

$\mathrm{Au}$ cas où la proximité de ces événements inspirerait des appréhensions sur l'objectivité de la recherche et l'accès aux sources, il serait aisé de trouver dans l'entredeux-guerres, période encore si peu connue, une vaste série de cas significatifs: l'action des groupes à propos de quelques-uns des problèmes majeurs abordés par la S.D.N. (minorités nationales, démobilisations douanières, stabilité monétaire, désarmement) se révélerait probablement pleine d'enseignements. Et, bien entendu, il n'y aurait que des avantages à remonter plus haut en analysant, de ce point de vue, quelques-unes des questions dont eurent à débattre les grands Congrès diplomatiques ayant fonctionné du début du $\mathrm{XIX}^{\mathrm{e}}$ siècle au déclanchement de la première guerre mondiale.

[p. 416] S'attachant à examiner de tels problèmes, l'enquêteur rencontrera nécessairement des intérêts dont il essaiera d'évaluer l'influence à leur juste mesure. Il se heurtera aussi à des idéologies qui, souvent, fournissent une estimation dogmatique de l'intervention de diverses forces. Si le souci de «démythification » n'est pas une attitude à sens unique, on doit en témoigner à l'égard des doctrines pour établir l'écart qui les sépare de la réalité et souligner l'exploitation qui en est réalisée. Ce point est important. Les idées sont si puissantes sur l'esprit des hommes qu'elles en viennent à tenir lieu de faits ou à changer complètement la signification des événements. Il est fréquent qu'un maniement subtil du raisonnement dialectique permette d'invoquer à l'appui dune cause des phénomènes qui lui sont étrangers ou totalement opposés. On aboutit ainsi à une présentation des affaires mondiales où le même acte change de sens selon celui qui l'accomplit. 
Si le spécialiste en science politique, fidèle aux exigences élémentaires de l'esprit scientifique, se refuse à verser dans le moralisme, il lui devient par là même impossible de proposer ou même d'accepter la justification des moyens par les fins : établissant la substance des actes, ce mode d'analyse met en lumière les comportements effectifs sans tenir compte des proclamations idéologiques destinées à brouiller le jeu. Dans cette perspective et sur ce fondement, l'étude des groupes de pression internationaux peut apporter d'utiles matériaux à la connaissance des sociétés politiques ou en voie de politification. 
[p. 417]

\section{CONCLUSION}

$\underline{\text { Retour à la table des matières }}$

IL N'EST PAS dans le rôle de l'auteur de mettre son ouvrage en cause. On voudrait pourtant signaler en terminant quelques-uns des points qui semblent, dès l'abord, sujets à controverse. L'objectif de ces remarques n'est pas de tenter une justification anticipée, mais d'indiquer au lecteur que ce livre n'a pas été écrit sans inquiétudes ni doutes. Existe-t-il beaucoup de spécialistes qui n'éprouvent pas un tel sentiment quand ils livrent le résultat de leur effort ? Pourquoi alors ne pas exprimer avec simplicité divers motifs d'insatisfaction...

Le premier tient au risque d'erreur sur les faits et sur les intentions : telle est l'immensité du domaine exploré (singulièrement dans le premier chapitre), qu'il serait puéril de prétendre à une totale et parfaite exactitude. Ce travail sera donc discuté, en quelque sorte, par fragments, chacun admettant les observations qui concernent le voisin, ou l'adversaire, mais trouvant aisément de judicieuses raisons pour contester ce qui se rapporte à lui-même.

Sur les faits, ce livre soulèvera probablement des objections de la part de divers milieux. Dans les conditions présentes de l'organisation universitaire, un tel danger est pratiquement inévitable. Un chercheur isolé ne peut remplacer l'équipe qui serait indispensable pour rassembler et vérifier la documentation. Quoi qu'on en dise, le mode artisanal n'est pas le procédé idéal de la recherche scientifique.

Certains s'étonneront peut-être de la multiplicité et de la variété des phénomènes qu'il est nécessaire d'évoquer en tentant d'étudier le gouvernement des hommes. À une époque encore proche, on en a voulu tirer la conclusion que la science politique était une discipline impraticable [p. 418] ou qu'elle constituait une vague connaissance de synthèse: de telles considérations s'effacent à mesure que l'on comprend la nature et les exigences de l'analyse sociale.

La fragmentation disciplinaire, résultant de notre impuissance intellectuelle à organiser l'examen positif de la société comme un tout, oblige chaque branche à envisager, sous un certain point de vue, la totalité du social. À moins de se résigner à 
n'être qu'une scolastique formelle, aucun secteur des sciences humaines n'échappe à cette servitude. Elle ne prendra fin que par la réunification de la sociologie.

Quant aux intentions on pourra aussi ouvrir divers procès à l'auteur. La science politique ne peut éviter de spécifier les motifs des conduites analysées. À cet effet, il convient d'examiner les déclarations officielles, mais aussi de les apprécier. Il existe aujourd'hui des "slogans" dont l'acceptation est si large et totale que des gouvernants peuvent les utiliser à coup sûr, pour couvrir les actes les plus variés et faire servir à leur gloire jusqu'à leurs propres erreurs.

Dans les jugements portés on s'est efforcé d'éviter la partialité systématique et on a tenté de montrer le « pour » et le « contre ». Attitude dictée certes, par la complexité des phénomènes, mais également par le souci de modération dont témoignent volontiers les représentants des vieilles cultures trop expérimentées (trop usées diront les cyniques) pour ne pas faire du doute l'instrument primordial de la réflexion.

Avouons pourtant que les conséquences de cet état d'esprit peuvent prêter à l'irritation. On finit par voir une preuve de sa propre sagacité, de sa propre honnêteté intellectuelle, dans le fait de recevoir des critiques des points opposés de l'horizon politique : en somme, on est porté à tenir pour vrai — ou vraisemblable — ce qui ne contente personne. La recherche de la voie et de l'appréciation moyennes constitue une sorte de protection, sinon une manière de titre de noblesse. Or il n'est pas sûr qu'on se rapproche alors d'une vue exacte des problèmes en cause.

Notre ouvrage n'a pas échappé à ce piège. Ainsi donne-t-il sans doute une vue trop «balancée » et par là inexacte, de la pénétration du communisme international en plusieurs milieux des pays sous-développés (milieux souvent en opposition avec les hommes actuellement au pouvoir : par exemple, la Fédération des Étudiants d'Afrique Noire en France dont les dirigeants ne cachent pas en général leur sympathie pour l'Union soviétique et la cause du communisme).

[p. 419] Tant de gens ont abusé de l'épithète " communiste », simplement pour déconsidérer un adversaire, qu'il en est résulté nécessairement des scrupules à l'étendre à des individus qui ne la réclament pas expressément. C'est là une sauvegarde indispensable pour éviter de fâcheux excès pouvant aller jusqu'à l'hystérie. Cependant on ne doit pas ignorer que, dans certaines situations, le meilleur service à rendre à une organisation est de nier, au moins provisoirement, qu'on lui appartient. De même, en dehors d'une volonté d'aveugler, ou de s'aveugler, il est impossible de passer sous silence tant d'alignements et de convergences systématiques, sous le prétexte d'un neutralisme positif, devenu commode en raison de la haute franchise et de l'exceptionnelle dignité morale de plusieurs de ses porteparole.

La politique soviétique elle-même facilite et peut-être s'efforce systématiquement de provoquer des assimilations contestables. À l'égard des pays non industrialisés, les dirigeants communistes ont pris l'habitude de soutenir des mouvements nationaux, même si ceux-ci font profession de lutter contre la diffusion du communisme, Un exemple particulièrement clair de cette tactique est l'aide apportée à la République arabe unie dont les chefs actuels ne font pas mystère de leur opposition à l'idéologie 
communiste et répriment sévèrement toute tentative pour en organiser l'expansion. Aujourd'hui, l'Union Soviétique apporte son aide au Maroc (fourniture d'avions, veto sur l'admission de la Mauritanie à l'O.N.U...) ; or, le gouvernement marocain est composé d'éléments conservateurs qui s’opposent avec vigueur aux forces tenues pour progressistes.

On peut certes discuter la valeur de cette tactique. Elle revient à postuler que l'évolution se fera finalement au profit des éléments attachés à réaliser la révolution sociale. Mais en attendant, elle aboutit à encourager et à consolider des gouvernements ou des mouvements opposés au communisme. Encore que l'on manque sur ce point d'éléments sérieux de connaissance il n'est pas impossible que la validité de cette tactique soit l'un des sujets de controverse entre Russes et Chinois, ces derniers étant au contraire partisans d'un soutien direct des mouvements révolutionnaires.

Quoi qu'il en soit, il faut se garder de la tendance qui voudrait classer parmi les communistes tous ceux qui acceptent l'aide de l'Union Soviétique. Peut-être en définitive, le calcul de celle-ci se révèlera-t-il fondé. On ne saurait pourtant exclure que dans l'esprit de plusieurs des béné-[p. 420] ficiaires l'acceptation de ce concours ait justement pour objet d'entraver l'expansion du communisme en améliorant le niveau de vie. Il se joue là certainement une partie très délicate dont nul ne peut dire à l'avance quel sera le vainqueur. On ne s'étonnera pas que, dans ce combat, l'U.R.S.S. s'efforce de mettre le maximum d'atouts dans son jeu : l'un d'entre eux est d'exprimer ostensiblement sa sympathie ou de promettre son concours (éventuellement militaire) à des gouvernements qui, pourtant, ne sont pas décidés à passer dans le camp communiste.

Il est possible qu'en diverses occasions, les hommes d'État de l'Occident soient tombés dans le piège ainsi ouvert par la propagande soviétique. C'est là un danger que ne devraient pas oublier ceux qui attribuent, inconsidérément, la qualité de communiste à tous les chefs d'État de pays sous-développés faisant le voyage de Moscou. Cette position sans nuance comporte un double risque : détourner l'attention des véritables points d'appui de la politique soviétique à travers le monde et aussi, rapprocher finalement de l'U.R.S.S. les éléments que l'on voudrait en éloigner.

$\mathrm{Au}$ total, un phénomène complique l'appréciation des attitudes politiques spécialement sur le plan international : l'absence d'un critère objectif de répartition.

Si ce livre se caractérise par la modération - ce qui entraîne des perspectives de déformation - il est difficile de faire la part de ce qui tient au goût de l'explication pluraliste et au souci du confort moral. Cette ambiguïté n'est pas l'une des moindres hésitations que l'on éprouve en achevant ce travail.

Un second reproche nous sera certainement adressé : l'absence systématique de différenciation, selon le but visé, entre les multiples organismes dont nous avons parlé. Est-il légitime de classer dans la même catégorie d'analyse des combinaisons 
d'affaires, des mouvements d'émancipation, des sociétés de pensée, des groupements humanitaires, etc. ? Cette critique est si courante qu'elle devient rituelle. On voudrait y répondre une fois de plus.

Admettons que l'on se préoccupe de tracer une ligne acceptable sur le plan moral : où la tirer ? Il ne serait pas raisonnable de se borner à distinguer entre les groupes qui cherchent directement le profit, au sens économique du terme, et ceux qui s'affirment sans but lucratif. La tech-[p. 421] nique de l'association est un instrument de défense et de promotion d'intérêts extrêmement variés. Les entreprises, on l'a dit, agissent par de nombreux moyens dont le groupement professionnel. À l'inverse, si les coopératives font du commerce, ce n'est pas, au moins en principe, pour réaliser des bénéfices dans l'acception usuelle du terme. La forme de l'organisme n'est d'aucune utilité pour un tel classement.

On a mentionné à plusieurs reprises la distinction entre l'action pour la défense d'un intérêt matériel et celle pour la promotion d'une cause. Cette répartition que nous avons éprouvée en diverses occasions n'est pas dépourvue de valeur opérationnelle, mais elle laisse de nombreux cas sans solution et oblige à des interprétations subjectives. Une certaine aspiration morale sous-jacente se trouve satisfaite par cette séparation : la contre-partie en est l'établissement d'évaluations contestables et qui se révèlent vite polémiques.

On a proposé un autre critère pour sortir de l'impasse : la nature générique du motif poussant les hommes à s'unir. Le groupe se fonderait soit sur l'existence de caractéristiques objectives communes, soit sur la constatation d'une communauté d'attitudes. En principe, le motif des premiers serait «intéressé », celui des seconds « désintéressé ». Cette distinction soulève les mêmes difficultés que la précédente. De plus, elle comporte un obstacle supplémentaire: la présence dans un même organisme, de sujets mus par des sollicitations différentes.

Aucune des formules que livre l'immense littérature sur les pressure-groups ne dispense d'un effort d'interprétation qui, dans les cas douteux (et ils sont multiples), donne des résultats différents selon son auteur. Au surplus, même si l'on parvenait à dégager un facteur précis de classification, encore faudrait-il, après l'avoir mis en œuvre, procéder au regroupement qu'impose la similitude, sinon l'identité parfaite, de l'action entreprise. Là réside la raison d'être de la catégorie " groupe de pression » sur le plan national ou international : l'objectif est, en particulier, d'analyser le mode de formation de la décision dans les diverses situations gouvernementales et, de ce point de vue, les « bons » empruntent la même voie que les « mauvais ».

À dire vrai, de tels reproches, parfaitement compréhensibles et respectables quand ils proviennent du public, surprennent de la part de spécialistes en sciences sociales. Il s'agit, pour partie, d'une maladie infantile que des disciplines mieux assurées que la nôtre ont déjà surmontée. Quand l'économiste considère objectivement les conditions de fonction-[p. 422] nement et d'expansion du « marché noir », nul ne lui demande de porter l'anathème contre ce type de rapport : quelle philosophie imposerait donc une attitude différente à la science politique, quand on étudie le fascisme ou les camps de concentration? 
La formulation, éventuellement non-volontaire, de jugements d'ordre moral représente un défaut d'ordre professionnel, peut-être inévitable en de telles matières. Ce n'est pas un trait à exalter, mais une faute que doivent s'efforcer de réduire ou d'éviter ceux qui s'arrogent la faculté de s'occuper de science politique.

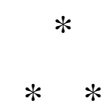

Mais il y a plus. Cet ouvrage traite de problèmes à l'échelle mondiale. Or, il a été écrit par un homme attaché à une certaine civilisation qui ne pouvait rester sans influence sur la forme donnée à cet essai et aussi son inspiration profonde. Dès lors, ce travail ne risque-t-il pas de manquer de signification pour les membres d'autres civilisations? Ne témoigne-t-il pas à leur égard d'une incompréhension fondamentale?

Une telle situation est le résultat d'insuffisances ou de lacunes dans la connaissance qu'un perfectionnement de notre discipline permettrait d'éviter ou de réduire. Il en va ainsi par exemple, à propos des religions de l'Inde et plus généralement, de l'Asie. Que représente, par exemple, en termes d'influence politique, la tenue d'une session du Conseil Mondial du Bouddhisme (comme celle organisée à Rangoon en 1953) et que veut dire sur le plan de la convergence des esprits l'effort missionnaire dont témoigne cette confession jusqu'en Europe semble-til ? Or, une telle activité ne saurait être négligée par la science politique si l'on considère que l'un des points essentiels du programme bouddhiste est le travail en faveur de la paix (auquel il semble même qu'une fondation américaine ait apporté un substantiel concours).

Signalons un problème en apparence plus simple : le nombre des adeptes de cette confession. Il est troublant d'entendre certains spécialistes déclarer qu'en raison de la superposition du bouddhisme du Grand Véhicule à d'autres religions qui ont subsisté (cas de la Chine où coexistent confucianisme, taoïsme et bouddhisme) on se trouve devant une masse flottante de 500 millions d'hommes plus ou moins bouddhistes, les évaluations faites différant dès lors selon les cas, de plusieurs centaines de millions.

[p. 423] Jusqu'à présent, la science politique a été, comme disent les Anglosaxons, " parochial » : elle a pris le monde occidental comme sa paroisse et n'en est pas sortie. Les efforts pour étudier le monde non-occidental ont été presque exclusivement l'œuvre d'anthropologues dont les préoccupations ne coïncident pas avec les nôtres. À une époque très récente, des efforts ont été tentés, spécialement aux États-Unis, pour combler ces lacunes : les premières données recueillies doivent être interprétées avec prudence.

Considérons par exemple le facteur religieux. Nous sommes loin, en Europe, d'être d'accord sur les répercussions politiques et économiques de nos vieilles religions (en particulier sur leur influence spontanée dans le comportement humain). Or, il ne manque pas en France et ailleurs d'auteurs qui, pour avoir passé un an dans un pays musulman, et sans même connaître l'arabe, se croient autorisés à émettre des vues tranchantes, entre autres sur le rôle économique de l'Islam. Il est souhaitable que 
l'analyse politique évite de telles erreurs, mais, alors, comment se livrer à une analyse de la politique internationale ?

Le tort le plus grave de ce travail est peut-être de laisser supposer que la formule « groupe de pression» est applicable à toutes les civilisations. En fait, nous avons considéré ici des groupes fondés dans le monde occidental, ou créés ailleurs sur ce modèle (par exemple, les multiples O.N.G. asiatiques). Observons que l'extension du marxisme, dont la logique profondément rationaliste ne saurait être mise en doute, accroît le secteur géographique où un tel mode de raisonnement conserve sa légitimité. Mais ailleurs?

Pour prendre un type de généralisation (dont on a déjà donné des exemples) il n'est pas impossible d'énoncer que l'évolution de l'Afrique dépend de trois forces ascendantes: le communisme international, la poussée de l'Islam et le réveil nationaliste africain. Or il est clair que cet ouvrage donne tout au plus des indications sur la première de ces forces. L'annuaire des O.N.G. ne comporte pas, dans son index analytique, de rubrique "Islam » ou " musulman ». Comment cette confession agitelle dans le siècle (à supposer que la distinction spirituel-temporel ait réellement acquis un sens pour elle) et comment le problème religieux se soude-t-il à la politique?

Soit, par exemple, des partis comme le Pan-Malayan Islamic Party en Malaisie ou le Nahdatul Ulama en Indonésie. Ils représentent un mé-[p. 424] lange de nationalisme, de conservatisme et de progressisme difficilement explicable par référence à nos divisions politiques. L'un et l'autre se font les avocats du neutralisme sur la scène internationale, d'un renforcement de l'Islam dans les structures nationales, de réformes économiques et sociales, etc. En termes occidentaux, la combinaison est difficile à expliquer (rappel des observations présentées sur l'Association des Frères Musulmans).

On dit volontiers que la race blanche doit aujourd'hui se résigner à vivre en groupe minoritaire sur la planète (idée d'ailleurs différente du prodigieux masochisme vouant cette section du monde à une décadence inévitable et à la destruction plus ou moins proche). Cette constatation peut nous inciter à établir, en coopération avec les intéressés, la science politique du «monde non occidental»; à défaut d'une connaissance parfaite, nous y gagnerons au moins l'avantage d'une présentation moins incomplète et plus homogène que celle offerte dans ce livre.

L'un des risques majeurs d'une telle démarche est d'aborder l'étude des phénomènes non occidentaux avec des échelles d'appréciation, au besoin implicites, qui ne leur conviennent pas. Notre civilisation a une tendance manifeste à valoriser la puissance économique et la force matérielle et l'U.R.S.S. augmente plutôt qu'elle ne restreint la force de ce comportement. Un fait pourtant devrait nous donner à réfléchir: aujourd'hui, ce ne sont pas ceux qui donnent le plus aux pays sousdéveloppés qui y bénéficient, surtout auprès de la jeunesse, de la cote morale la plus élevée. Et ce n'est pas là probablement le résultat de maladresses dans la distribution de l'aide, comme des explications vraiment simplistes tentent de nous en persuader. 
Mais où trouver le principe de la hiérarchie d'influence qui inspire déjà une partie du monde et marquera demain une fraction encore plus grande ?

L'auteur de ces pages n'a aucune compétence pour répondre à une question de telle envergure. Actuellement, le mirage de l'industrialisation universelle possède assez de force pour annuler la portée de semblables observations. Mais, dans les faits, l'industrie ne touche qu'une part réduite de l'humanité et nul ne saurait garantir la permanence du courant actuel.

S'attaquant à l'explication du monde - une explication qu'il veut plus complète et surtout plus systématique que celle léguée par ses devanciers - le spécialiste du $\mathrm{XX}^{\mathrm{e}}$ siècle ne peut faire autrement, surtout au départ, [p. 425] que d'utiliser les instruments forgés au sein de sa propre culture. N'oublions pas les dangers de cette transposition.

On ne manquera pas d'assurer que point n'est besoin d'aller si loin pour trouver matière à critique. Après tout, même pour le monde occidental, le concept « groupe de pression » est-il sans reproche ? La réponse est simple à formuler : cette notion est un outil imparfait, l'une des tâches primordiales de la science politique est d'entreprendre sa révision et son fonctionnement; l'auteur de cet essai espère se trouver en mesure de contribuer à cet effort. Mais, en attendant, c'est le moins mauvais des instruments dont nous disposions pour décomposer le jeu des influences autour des centres décisionnels.

Ce souci de fragmentation constitue d'ailleurs en un sens, le plus grave des reproches qui puissent être adressés à la formule. N'aboutit-on pas, sous prétexte de clarté et de précision, a provoquer la confusion en dissociant des réalités étroitement unies et tirant peut-être leur sens de cette association même. N'est-ce pas ouvrir la porte à la mystification ?

En réalité, tout au long de ce travail, on a tenté de limiter le contenu de la catégorie "groupe de pression international ». D'où l'établissement de distinctions souvent arbitraires et artificielles, avec des phénomènes voisins sinon semblables. D'où la volonté aussi d'énoncer une possibilité de différenciation entre le secteur public et le secteur privé, alors que l'évolution conduit à une interprétation sans cesse plus poussée.

Mais l'ambiguïté a une autre origine. La pression est un processus d'intervention absolument généralisée : l'ouvrier fait pression sur son patron pour en obtenir un supplément de salaire et aussi divers milieux espèrent que l'O.N.U. fera pression sur le gouvernement sud-africain pour l'amener à réviser sa politique à l'égard des Noirs. En baptisant certaines organisations (plus exactement d'ailleurs certains aspects de l'activité de ces organisations) " groupes de pression » ne tend-on pas, même de façon inconsciente, à leur attribuer le monopole des pressions effectuées dans la vie politique ? Là est probablement l'argument le plus décisif que l'on puisse émettre contre la terminologie usuelle. 
Il est vrai que la vie politique, nationale et internationale, résulte des interventions et pressions réciproques des participants dont nos groupes ne sont qu'un élément. On peut se refuser à dissocier l'ensemble de ma-[p. 426] nière, par exemple, à ne pas dénaturer l'état réel des relations, mais il semble qu'aucune discipline scientifique ne saurait se développer sans un effort préalable de décomposition. La difficulté d'une telle opération, en sciences sociales, est l'absence de critères objectivement fondés.

Autrement dit, il ne semble pas que l'on puisse critiquer le souci qui a poussé à créer la rubrique " groupes de pression », mais seulement la nature et les dimensions des catégories qui en ont résulté.

À partir de là, il devient évident que la notion même en devra être revue. Dans le sens d'une modulation, plus proche des faits de la relation public-privé, mais aussi sur le plan du rapport réactions individuelles-actes collectifs, et éventuellement, sous l'angle des nuances, extrêmement subtiles parfois, qui rassemblent ou séparent les manifestations spontanées de l'opinion publique et les opérations organisées des groupes. En somme, un grave sujet de préoccupation théorique domine le débat: tracer une ligne de démarcation valable et cohérente entre actions purement privées et actions purement gouvernementales, interventions proprement individuelles et proprement collectives, manifestations organisées et spontanées (avec en arrière-plan les problèmes de la diffusion des idéologies).

Tant que ces points resteront entourés d'une zone d'incertitude, on rencontrera des difficultés à exposer et défendre cette notion.

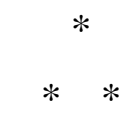

Une dernière source d'inquiétudes : nous avons voulu partir des faits pour aller à un schéma. Dans quelle mesure le cadre proposé permet-il d'embrasser les faits retenus ? Ou, si l'on préfère, dans quelle mesure le schéma proposé offre-t-il un instrument correct de regroupement et d'interprétation des matériaux bruts fournis dans le chapitre premier?

C'est là une question dont la réponse relève bien plus du lecteur que de l'auteur. Il nous semble que le concept de « capacité internationale » (éventuellement doublé de celui de « capacité régionale ») couvre valablement les cas relevés et que son emploi apporte des facilités supplémentaires d'interprétation, mais un chercheur est rarement le meilleur juge de la portée de son travail.

En tout état de cause, on s'est efforcé d'appeler l'attention sur des phénomènes et des comportements trop souvent absents des analyses courantes. Et même ceux qui seront tentés de repousser le schéma sug-[p. 427] géré considèreront peut-être que ce rappel de l'existence d'un domaine ignoré, ou négligé, justifie le présent livre. 
Ce n'est pas sans de sérieuses réticences que l'on envisage de mettre ce volume à la disposition du public. Et bien sûr, tout permet de croire que d'autres réserves ou critiques seront faites. De tels risques sont pris en parfaite connaissance de cause. Qui, en nos matières, oserait aujourd'hui avancer un point de vue définitif ? Il faudrait tout ignorer de leur complexité et, par surcroît, n'avoir aucune idée des exigences de la vérification scientifique : au niveau universitaire, de telles caractéristiques, si on les rencontre parfois, sont néanmoins rares. La contribution personnelle de la plupart d'entre nous est nécessairement partielle et fatalement destinée à être absorbée, plus ou moins vite, dans un progrès ultérieur de l'analyse.

Puisse cet ouvrage, en suscitant des recherches, connaître bientôt l'anonymat des œuvres dont le destin se réduit à éveiller l'attention.

[p. 428, sans texte.] 
[p. 429 à 496, notes bibliographiques.]

\section{OBSERVATIONS PRÉLIMINAIRES}

\section{$\underline{\text { Retour à la table des matières }}$}

Après des hésitations, on a pris le parti de ne pas établir de bibliographie proprement dite. Cette décision est dictée par l'état de la documentation.

Il n'existe, du moins à notre connaissance, aucun ouvrage qui traite exactement et complètement du sujet de ce livre. Quelques travaux portent directement sur certains aspects du problème (par exemple les remarquables travaux de White sur les O.N.G.) : ils sont rares. Pour l'essentiel, le long recensement effectué a procuré des données, souvent importantes et originales, sur des points particuliers. Or la conception que nous avons choisie du thème abordé a conduit à multiplier les " coups de sonde » dans de très nombreuses directions.

On n'a pas jugé opportun de rassembler en un instrument méthodique le matériel accumulé dans les notes : il en aurait résulté un alourdissement considérable de ce volume sans grand profit pour le lecteur. Par ailleurs, une bibliographie limitée aux quelques titres qui donnent une vision cohérente, mais partielle du sujet, aurait seulement pour résultat d'accuser la pauvreté de la recherche dans ce secteur des rapports internationaux.

La consultation directe des notes bibliographiques est certes impraticable. Mais on peut s'y livrer sans difficulté à partir des index que l'on a voulu détaillés. Le lecteur intéressé par une question quelconque trouvera donc dans les listes (et surtout l'index des matières) les références aux pages du texte qui lui sont consacrées. À partir de là, il accèdera aisément aux indications bibliographiques correspondantes. 
[p. 467]

\section{APPENDICE DOCUMENTAIRE}

$\underline{\text { Retour à la table des matières }}$

Établi lors de la correction des épreuves, cet appendice comporte quelques références qui, pour des raisons diverses (date de parution des ouvrages, lacunes dans les bibliothèques utilisées, oublis de l'auteur), étaient absentes du dépouillement initial. C'est un simple complément d'information dont les données ont été intégrées dans les index.

\section{INTERNATIONALES DE PARTIS}

Sur l'état présent du communisme international voir l'étude de George MODELSKI The Communist International System, Center of International Studies, Princeton University, 1961. Consulter également le numéro de janv.-fév. 1961 de Problems of Communism, "Coexistence, Communism and Latin America ». Voir enfin MORRIS (B.), "Soviet policy toward national communism : the limits of diversity », American Political Science Review, mars 1959, pp. 128-137.

L’élément le plus important en cette matière reste, bien entendu, la Conférence des 81 partis. L'interprétation du document que le Times a qualifié de «nouveau manifeste » continue de susciter des controverses. Pour une présentation officielle, voir Khrouchtchev (Nikita S.), « Perspectives du mouvement communiste mondial. À propos de la Conférence des partis communistes et ouvriers », Nouvelle Revue Internationale, janvier 1961, pp. 1-62.

Le point le plus discuté demeure celui des rapports entre partis chinois et soviétique. La presse de l'Occident a publié divers textes, d'origine soi-disant communiste, qui font état de graves désaccords (à titre d'exemple voir celui commenté par l'Observer du 12 février 1961) : cependant de nombreuses expériences conduisent à n'accueillir de telles « révélations » qu'avec les plus expresses réserves. Observons pourtant qu'en diverses occasions (notamment déclarations à des journalistes américains : voir les commentaires de Harry [p. 498] SCHWARTZ dans le New York Times, international edition, 18 janvier 1961) ; les plus hautes autorités chinoises, tout en contestant l'existence de «différences », ont admis la présence de « dissimilarités ».

La Conférence des 81 partis a suscité diverses réactions dans les milieux opposés à l'expansion du communisme : en particulier chez les socialistes lors de la réunion " privée » tenue à Salzbourg au début de janvier et qui rassemblait les chefs des partis socialistes de dix pays européens. Il semble que l'Internationale Socialiste envisage d'émettre son propre manifeste à l'occasion du congrès qui doit grouper à Rome, en 
octobre 1961, les partis socialistes du monde entier. Un point complique l'établissement d'un tel document : l'absence d'unanimité entre les partis membres de l'Internationale sur l'appropriation collective des moyens de production. Autre question difficile : les relations avec les pays sous-développés. Sur ce problème voir l'article, toujours actuel, de SAPOSS (D.J.), « The Split between Asian and Western Socialism », Foreign Affairs, juillet 1954, pp. 588-594. L'Internationale vient de créer un fonds destiné à assurer la construction et le renforcement du socialisme en Afrique, en Amérique latine et en Asie.

On a souligné à plusieurs reprises l'importance de l'Assemblée Européenne. Consulter sur cette question STEIN (E.), "The European Parliamentary Assembly : technique of emerging " "political control" », International Organization, printemps 1959, pp. 233-254. Voir aussi Les élections européennes au suffrage universel direct (colloque des 14 et 15 avril 1960), Bruxelles, Institut de Sociologie Solvay, 1960.

Mentionnons enfin, sur le plan historique, l'ouvrage de STEPANOVA (E.), Friedrich Engels, Moscou, Éditions en langues étrangères 1958 (en particulier le chapitre VII, « Engels pendant la période de la $1^{\text {ère }}$ Internationale et de la Commune de Paris »).

\section{INTERNATIONALES SYNDICALES}

Nous signalons d'abord deux ouvrages importants du Bureau International du Travail : Les problèmes du travail en Afrique (Genève, 1959) et Les problèmes du travail en Afrique du Nord (Genève, 1960). Ces volumes fournissent, en particulier, quelques notions sur les organisations de travailleurs et d'employeurs dans chacun des pays considérés. Ajouter POUPART (R.), Première esquisse de révolution du syndicalisme au Congo, Bruxelles, Institut de Sociologie Solvay, 1960.

Voici maintenant quelques indications sur la Confédération Internationale (les Syndicats Arabes dont, faute de renseignements adéquats, nous nous étions borné jusqu'à présent à signaler l'existence. Cette organisation dont le siège [p. 499] est au Caire réunit plusieurs fédérations syndicales appartenant aux pays suivants : Égypte et Syrie (R.A.U.), Jordanie, Liban, Libye, Soudan (pays dans lequel l'activité syndicale paraît avoir été assez réduite au cours des dernières années). En 1958 la Confédération déclarait posséder six millions de membres (chiffre que certains experts estiment supérieur aux effectifs réels). La Confédération n'est affiliée à aucune des grandes centrales internationales: cependant elle entretient des contacts avec la Fédération Syndicale Mondiale. Elle ne dispose pas du statut consultatif auprès de l'Organisation Internationale du Travail, mais elle a des rapports officieux avec le B.I.T. et envoie des observateurs à la Conférence depuis 1958.

Sur le plan documentaire signalons la publication par la F.S.M. du compte rendu de la $\mathrm{XI}^{\mathrm{e}}$ session de son Conseil général tenue à Pékin en juin 1960 (supplément au n 7 pour 1960 du Mouvement Syndical Mondial). 
Sur les problèmes du syndicalisme canadien, déjà évoqués à propos de la C.I.S.C., voir FORSEY (E.), " The movement towards Labour Unity in Canada », Canadian Journal of Economics and Political Science, février 1958, pp. 70-83.

Renvoyons enfin à l'article de GREEN (L.C.), «The International Labour Organization under Pressure », Current Legal Problems, 1957, n 10, pp. 57-84.

On a noté à plusieurs reprises les interventions effectuées par la C.I.S.L. dans des territoires encore placés sous le contrôle politique de la France. Des phénomènes du même ordre se sont produits dans les secteurs africains dont la Grande-Bretagne continue de porter la responsabilité. Sous l'impulsion des autorités britanniques des accords tendant à un partage des tâches ont été conclus entre la C.I.S.L. et le Conseil des syndicats britanniques : si l'on en croit des informations récentes, il ne semble pas que les stipulations en aient été scrupuleusement appliquées par les Américains.

\section{INTERNATIONALES D'AFFAIRES}

On trouvera quelques informations intéressantes sur le fonctionnement d'une grande affaire capitaliste in DOWAN (Max), Dupont de Nemours. De la poudre au nylon, Paris, 1961 (avec une bibliographie).

Pour une analyse approfondie de la dispute entre le gouvernement français et les négociants américains installés au Maroc sous le protectorat (sujet évoqué dans le cours du volume), voir FAMCHON (Yves), Le Maroc. D'Algésiras à la souveraineté économique. Analyse du statut juridique de l'économie marocaine, Paris, 1957.

Sur certains phénomènes d'action collective liés au Marché commun, voir LACAN (Roger-Adolphe), Pour la création d'une société anonyme de type euro-[p. 500] péen, Paris, 1960, ainsi que MAURY (L.), « Les sociétés internationales dans le Marché commun », Revue du Marché Commun, Paris, octobre 1958, pp. 353-360. Voir aussi CAZE (L.), «Vie d'un comité syndical de liaisons et d'études dans le cadre du Marché commun », même revue, novembre 1959, pp. 409-416. Il s'agit d'un organisme instauré par les fabricants de chaussures des six pays pour la défense de leurs intérêts communs et l'unification de leurs revendications. Le Comité qui prend ses décisions à la majorité simple (une voix par Fédération) a déjà joué en quelques cas un rôle d'arbitre entre ses membres. Il exprime ses vœux aux gouvernements et aux organes de la Communauté en vue de protéger les exportations des «Six » contre la fermeture des marchés étrangers et d'empêcher les importations à vil prix.

Nous signalerons un dernier point: l'évolution récente du marché pétrolier où s'accuse et, à quelques égards, s'accentue l'interaction du politique et de l'économique. Au mois de janvier dernier s'est tenue à Caracas la deuxième session de l'Organisation des Pays Exportateurs de Pétrole (qui groupe désormais Arabie Saoudienne, Koweït, Iran, Irak, Qatar et Venezuela). L'organisation qui a décidé d'installer à Genève le siège de son secrétariat paraît avoir pour premier objectif d'obtenir la remontée des prix à leur niveau antérieur mais ce souhait reste difficile à 
réaliser sans un certain contingentement de la production. Il semble que quelques-uns des intéressés (Venezuela en particulier) aient proposé de mettre sur pied un système restrictif reposant sur l'attribution de quotas de production à chacun des État s en présence : cependant ce projet a soulevé des objections de la part d'autres membres (surtout Iran et Koweït). Il existe donc une volonté commune de tirer le parti maximum de cette ressource, non exclusive, d'ailleurs, de graves divergences au plan de la mise en œuvre. On a pu, dès lors, se demander si les consommateurs ne seraient pas appelés à faire les frais des marchandages entre compagnies pétrolières et pays producteurs. M. Mattei a déclaré récemment que pour un pays consommateur la recherche de sources d'énergie à bas prix est un problème très important. Comment concilier ce souci avec le désir des producteurs d'accroître l'ampleur de leurs encaissements sans gaspiller les ressources disponibles?

Les six pays de l'O.P.E.C. assurent aujourd'hui 85\% des exportations de pétrole. Leur position semble donc très forte. Mais dès maintenant, sans parler des « nouveaux venus », il faut compter avec le naphte soviétique. Retrouvant une vieille tradition d'exportatrice de ce produit l'U.R.S.S. ne cesse d'accroître ses ventes (spécialement à l'Europe, premier centre mondial de consommation) en proposant des prix «attractifs». Les spécialistes estiment que l'on entendra beaucoup parler du pétrole russe dans les années à venir. Quelle sera dès lors la position de l'U.R.S.S. à l'égard de l'O.P.E.C. ?

[p. 501]

\section{INTERNATIONALES RELIGIEUSES}

Voici d'abord une liste d'ouvrages documentaires sur le catholicisme publiés au cours des derniers mois. Ils apportent dans l'ensemble une vaste information sur plusieurs des problèmes abordés dans cet ouvrage :

Bilan du Monde 1960. Tome II (Encyclopédie du Monde Chrétien). Tournai-Paris, 1960 : étudie la situation du catholicisme dans les différents pays. FALCONI (Carlo), La Chiesa e le organizzazioni cattoliche in Europa, Milan, 1960. Du même auteur: La Chiesa e le organizzazioni cattoliche in Italia (1945-1955), Turin, 1956, ainsi qu'un ouvrage d'intention nettement polémique, Il Pentagono Vaticano, Bari, 1958. Dans la même perspective, voir ROSAPEPE (Giacomo), Inquisizione addomesticata, Bari, 1960.

CREUSES (J.), S.J., Religieux et religieuses d'après le droit ecclésiastique, $8^{\mathrm{e}}$ éd., Bruxelles, Paris, 1960.

DELMASURE (A.), Les catholiques et la politique. Préface de Mgr Pierre Tiberghien, Paris, 1960. Voir aussi DESQUEYRAT (R.P.A.), S.J., L'enseignement « politique » de l'Église. Tome I, L'État, Paris, 1960.

GRAHAM (Robert A.), Vatican diplomacy. A study of Church and State on the international plane, Princeton, 1959. 
COSTANTINI (Cardinal Celso), Réforme des missions au $\mathrm{XX}^{\mathrm{e}}$ siècle, traduit de l'italien, Tournai-Paris, 1961. On trouvera un ensemble d'études sur l'encyclique Princeps Pastorum (28 novembre 1959) in Les Missions Catholiques, janvier-mars 1961, pp. 1-72.

Sur la préparation du second concile du Vatican, voir le numéro spécial en date du $1^{\mathrm{er}}$ janvier 1961 des Informations Catholiques Internationales : " l'Église en état de Concile ».

Pour un aspect du combat mené par le catholicisme contre le communisme, voir TRUMAN (T.), "Catholics and Politics in Australia », Western Political Quarterly, juin 1959, pp. 527-534. Mentionnons également la création par les soins du cardinal Ottaviani, qui en sera le directeur, de l'Institut de Saint-Pie V (qui ne paraît pas avoir de lien de filiation directe avec l'ancien mouvement de la Sapinière) : cet organisme qui disposera d'une grande autonomie (n'étant pas, en particulier, sous la dépendance du Saint Office) a pour mission la défense et la consolidation des valeurs chrétiennes. L'inspiration de l'Institut, dont les fondateurs envisagent de travailler à une échelle réellement internationale, sera, certes, religieuse et morale mais aussi politique au sens le plus général du terme.

Dans le domaine du protestantisme, mentionnons l'important ouvrage de NEILL (Stephen), L'anglicanisme et la communion anglicane, traduit de l'anglais, Paris, 1961 (on rappelle que la «communion anglicane » regroupe quinze Églises de pays différents comprenant trois cent trente et un diocèses et districts missionnaires).

[p. 502] Évoquons enfin le problème de la situation des Églises dans les pays communistes. Sur les possibilités de "coexistence » entre le communisme et le bouddhisme voir l'étude, plutôt optimiste, d'André MIGOT, «Situation des religions en Chine Populaire. Bouddhisme et Marxisme » dans l'ouvrage collectif Le régime et les institutions de la République populaire chinoise, Bruxelles, Institut de Sociologie Solvay, 1960, pp. 39-55 (pour un point de vue totalement différent voir dans le même volume l'exposé de l'Abbé A. SOMER, pp. 139-151, «La religion en Chine Populaire »). On trouvera dans le Guide de Chine, Pékin, Éditions en langues étrangères, 1958, pp. 121-124, la liste des « organisations populaires » constituées en matière religieuse (notamment "Association des Catholiques Patriotes de Chine »). Sur la situation dans la République Démocratique du Viet-Nam, voir les observations de Bernard FALL in Le Viet-Minh, Paris, 1960, pp. 164-169.

Ces derniers mois ont été marqués par un très net durcissement des autorités polonaises à l'égard du catholicisme (en particulier récente décision — janvier 1961 - du Comité central du Parti ouvrier polonais de supprimer l'enseignement religieux dans les écoles publiques). En Russie même les autorités communistes trahissent quelques inquiétudes dues au développement de la pratique religieuse dans certains milieux de jeunes. Selon des informations, actuellement incontrôlables, l'Église orthodoxe russe ne serait finalement pas défavorable, au moins en principe, à un rapprochement des Églises chrétiennes (que des dirigeants communistes n'hésitent pas à présenter comme l'essai de création d'un « Nato ecclésiastique sous leadership du Vatican »). 


\section{MOUVEMENTS DE REVENDICATION NATIONALE}

Sur l'organisation des Frères Musulmans, plusieurs fois évoquée dans cet ouvrage, voir BERTHIER (F.), "L'idéologie politique des Frères Musulmans », Orient, $4{ }^{\mathrm{e}}$ trimestre 1958, pp. 43-57, et JOMIER (J.), «Les Frères Musulmans et leur influence », Études, mars 1959, pp. 317-331.

Pour une bonne mise au point sur le bloc afro-asiatique voir GUITTARD (O.), Bandoeng et le réveil des peuples colonisés, Paris, 1961 (Que sais-je ? n 910).

La Conférence des chefs d'États africains, tenue à Casablanca du 3 au 7 janvier 1961, constitue la manifestation la plus récente du mouvement neutraliste : on sait qu'elle s'est achevée par l'adoption d'une «Charte Africaine ». La Conférence de Brazzaville organisée en décembre 1960 par les État s africains d'expression française a témoigné d'une inspiration différente. Mentionnons enfin l'activité du Mouvement Panafricain pour l'Indépendance de l'Afrique centrale et orientale qui, actuellement, s'intéresse surtout aux problèmes des Rhodésies et du Tanganyika.

L'appui apporté par les autorités du Caire à l'expansion de la confession [p. 503] islamique illustre la relation entre politique et religion: C'est ainsi que le Département religieux du gouvernement égyptien vient d'annoncer le prochain établissement d'un nouvel émetteur intitulé « La Voix de l'Islam ». Il semble que la compétition avec le christianisme doive d'abord porter sur les Africains fidèles aux religions ancestrales (le nombre de ceux-ci étant estimé à une quarantaine de millions).

Sur la situation actuelle des minorités dans les pays arabes, voir RONDOT (P.), "The minorities in the Arab Orient to-day », Middle Eastern Affairs, juin-juillet 1959, pp. 214-228.

Sur le sionisme et son activité à l'échelon intergouvernemental, voir GLICK (E.B.), «Zionist and Israeli efforts to influence Latin America: A case study in diplomatic persuasion », Western Political Quarterly, juin 1956, pp. 329-343. Certains aspects de l'histoire du mouvement viennent de faire l'objet d'un important ouvrage : SYKES (Christopher), The Balfour Declaration, Londres, 1961 (livre dont l'une des originalités est d'insister sur les négociations germano-sionistes qui intervinrent durant la première guerre mondiale).

Dernière indication bibliographique : on trouvera un exposé complet de la thèse polonaise sur la frontière Oder-Neisse dans l'ouvrage collectif Les terres polonaises de l'Ouest, Poznan, Institut Occidental, 1959. 


\section{AUTRES GROUPEMENTS}

Signalons en premier lieu la publication d'une nouvelle édition, en français cette fois, de l'irremplaçable annuaire de l'Union des Associations Internationales, Annuaire des Organisations Internationales, 1960-1961, $8^{\mathrm{e}}$ édition, Bruxelles, 1961. Pour un bref commentaire des données contenues dans cet ouvrage, voir TEW (E.S.), « The Organizational World », Associations, décembre 1960, pp. 732-737.

Pour une histoire des essais d'unification européenne, se reporter à ALBONETTI (Achille), Preistoria degli Stati Uniti d'Europa, Milan, 1960. Sur le Congrès de La Haye, Voir WALTON (C.C.), The Hague Congress of Europe: A case study of public opinion », Western Political Quarterly, septembre 1959, pp. 738-752.

On notera que la première conférence des Femmes afro-asiatiques s'est tenue au Caire en janvier 1961. Le Congrès a adopté soixante résolutions parmi lesquelles des textes réclamant l'interdiction du mariage forcé, la fixation d'un âge minimum pour le mariage des jeunes filles. L'abolition de la polygamie, la restriction des droits arbitraires du mari en matière de divorce, la reconnaissance aux femmes du droit de vote et d'éligibilité. D'autres résolutions protestent contre la discrimination raciale en Afrique du Sud, appuient les résolutions de la Conférence de Bandoeng, etc.

Février 1961 
[p. 504, sans texte, p. 505 à 517, Index]

\section{INDEX DES AUTEURS}

Retour à la table des matières

ABELSON, H.I.

ABRAHAM, R.

ACKERMAN, N.W.

ADAM, H.T.

ADAMS, J.C.

ADLER, K.P.

AGAR, $\mathrm{H}$.

AGOSTINI, R.

AHMAD, I.

AHMED, J.M.

AITKEN, H.G.J.

AKZIN, B.

ALBERDI, P.G.

ALBONETTI, A.

ALEM, J.P.

ALESSANDRINI, F.

ALEXANDER, R.J. ALEXANDROWICZ,

C.H.

ALLEN, R.L.

ALMOND, G.

ALVAREZ, A.

ANAYA, R.

ANDRÉ, P.J.

ANDREWS, F.E.

ANSELME-RABINOVITCH, L.

ANWANDER, A.

ANWAR EL SADAT

ARAGON, L.

ARENDT, $\mathrm{H}$.

ARKEMA, N.

ARMSTRONG, H.F.

ARMSTRONG, J.A.

ARNAVON, C.

ARON, R.

ARVON, H.

ASCHER, C.S.

ASFOUR, E.

ATALLAH, M.K.
ATANIAN, S.

AUBERY, P.

AUBREY, $\mathrm{H}$.

AUSTRUY, J.

BABEL, A.

BABOULÈNE, J.

BACHELET, V.

BACON, F.

BAHADUR, L.

BALDWIN, R.

BALL, W.M.

BALLANDE, L.

BARCENA Y GUZMAN, J. DE.

BARENTS, J.

BARNETT, A.D.

BARNETT, C.

BARRE, R.

BARRETT, E.W.

BARRIA TRELLES, C.

BARRUEL, Abbé

BARTON, P.

BARUCH, B.M.

BARUK, $\mathrm{H}$.

BASS, R.H. 434.

BASTID, S.

BATELLI, M.

BAUDIN, L.

BEALES, A.C.F.

BEARN, J.

BEATTY, C.

BEAU DE LOMÉNIE, E.

BEDJAOUI, $\mathrm{M}$.

BEEVER, R.C.

BEGUIN, B.

BELL, G.K.A.

BELL, J.

BEN-GOURION, D. 
BENNABI, M.

BENOIST-MÉCHIN, J.

BENTLEY, A.F.

BERENSTEIN A.

BERKNER, L.V.

BERKOV, B.

BERKOVITS, E.

BERLE, A., Jr.

BERNSTEIN, M.H.

BERQUE, J.

BERREBY, J.J.

BERTIER, F.

BERTRAND, A.N.

BESANÇON, J.

BETH, L.P.

BIDWELL, P.W.

BIGO, R.

BINDER, L.

BLAISDELL, D.

BLANCHAERT, M.C.

BLOERKLUND, E.

BLYTH, C.D.

BOBROW, D.

BOCK, E.A.

BOCKSTAEL, G.

BOEHMER, $\mathrm{H}$.

BOER, H.A. DE.

BOERSNER, D.

BOFFA, G. 435.

BOITEL, M.

BOLLI, J.J.

BONNE, A.

BOOTH, D.A.

BORELLA, F.

BORKENAU, F.

BOUCHAUD J.

BOUDET, R.

BOULGAKOFF, $\mathrm{S}$.

BOURDON, A.

BOUSCAREN, A.T.

BOUVIER, J.

BOZZOLA, G.B.

BRADEN, C.S.
BRAUNTHAL, A.

BRAUNTHAL, J.

BRIGGS, A.

BRIMMEL, J.H.

BRINTON, C.

BRODRYCK, J.

BROMBERGER, S.

BRUNNER, J.S.

BRUNSCHWIG, $\mathrm{H}$.

BRUTON, H.J.

BRYSON, L.

BRZEZINSKI, Z.K.

BUCHMAN, F.

BUTTERFIELD, $\mathrm{H}$.

BYRD, R.O.

BYRNES, R.F.

CARIER, P.

CAINE, S.

CALBRETTE, J.

CALVERT, $\mathrm{H}$.

CAMPAIGNE, C.

CAMPBELL, $P$.

CAMUS, A.

CANALS, S.

CANDELORO, T.

CANU, J.

CAPET, M.

CARAVALE, G.

CAREW HUNT, R.N.

CARR, G.

CARRÈRE D'ENCAUSSE, H.

CARRINGTON, C.E.

CARTY, E.B.

CASE, L.M.

CASORIA, G.M.

CATTEL, D.T.

CAZE, L.

CESAIRE, A.

CHAMBERLAIN, J.

CHAMBRE, $\mathrm{H}$.

CHAMMARD, P. de

CHARLES, R. 
CHARMOT, F.

CHARRIER, M.

CHEJNE, A.G.

CHELHOD, J.

CHESNEAUX, J.

CHEVALIER, J.

CHOURAQUI, A.

CHOWDHURI, R.N.

CLARK. G.

CLAUDE, I.L., Jr.

CLEVELAND, $\mathrm{H}$.

CLEWS, J.

CLONMORE, Lord.

CODDING, G.A., Jr.

COELHO, G.V.

COHEN, B.C.

COHEN, M.

COLE, G.D.H.

COLEGROVE, K.W.

COLINON, M.

COLLIARD, C.A.

COLLINET, M.

COLOMBE, $\mathrm{M}$.

CONZE, E.

COORNAERT, E.

CORTI, E.C. Comte

COSTANTINI, C.

COSTON, H.

COTTA, A.

COURSIER, $\mathrm{H}$.

COURTADE, P.

COURVOISIER, J.

CRAGG, $\mathrm{K}$.

CRAIPEAU, Y.

CRANKSHAW, E.

CREAC'H, J.

CREUSEN, J.

CRISTIANI, L.

CROZIER, B.

DAULTE, $P$.

DAVID, R.

DAVISON, W.P.
DECRAENE, P.

DELAISI, F.

DELAVIGNETTE, R.

DELMASURE, A.

DESCHAMPS, H.T.

DESCOLE, J.

DESQUEYRAT, R.P.A.

DESSAU, J.

DESSAZZE, E.

DEUTSCH, K.W.

DIB, G.M.

DIEBOLD, W.

DIENNE, J.

DJILAS, M.

DOBRY, G.

DOKA, C.

DOLLÉANS, E.

DOLLFUS, D.F.

DOLO-ANDRÉ, E.

DONATH, D.

DORIAN, M.

DRACHKOVITCH, M.M.

DIRAGUILEV, $\mathrm{M}$.

DRAPER, G.I.A.D.

DROZ, J.

DRUHE, D.N.

DRUON, M.

DUBOIS, P.

DUBUIS, S.

DUCLOS, Paul.

DUCLOS, Pierre.

DUFF, E.

DUMONT, P.

DUPUY, M. 489.

DURAND, D.

DUROSELLE, J.B.

DÜRRLEMAN, F.

DUSCHINSKI, E.

DUTORR, B.

EAGLETON, C.

EBENSTEIN, W.

EDGAR-BONNET, G.

EDINGER, L.J. 
EDMONDS, C.J.

EGIDO, J.P.

EHLER, S.Z.

EHRENBERG, R.

EHRMANN, $\mathrm{H}$.

EINZIG, P.

ELDERSVELD, S.

ELIOT, T.S.

ELLIOT, W.Y.

ELLWOOD, C.

ELWELL-SUTTON, L.P.

ERRERA, J. 467.

EUROPEUS.

EVELY, R.

FAKHRY, M.

FALCIONELLI, A.

FALCONI, C.

FALL, B.

FAMCHON, Y.

FAUVEL, L.

FAVROD, C.H.

FAY, B.

FEIS, $\mathrm{H}$.

FEJTO, F.

FELDMANN, C.

FELLER, A.H.

FERLE, $\mathrm{T}$.

FERNANDO, C.

FERNAU, F.W.

FESSARD, G.

FINER, $\mathrm{H}$.

FICHHER, G.

FISHER, S.N.

FITZSIMONS, M.A.

FLORY, M.

FODA, E.

FOLLIET, J.

FORSEY, E.

FRANCO, V.

FRANKEL, P.H.

FREYMOND, J.

FRIED, A.H.
FRIEDMANN, W.

FRIEDMANN, W.G.

FROHMAN, $\mathrm{H}$.

FROLA, E.

FROSSARD, A.

FRYE, R.N.

FUCHS, L.H.

FUSILIER, R.

FYZEE, A.A.A.

GABBAY, R.

GALTER, A.

GANNAGE, J.

GARDET, L.

GARRIGOU-LAGRANGE, M.

GARRIGUE, K.C.

GATHORNE-HARDY, G.H.

GAUDEMET, P.M.

GAVALDA, B.

GAVAN, S.S.

GAXOTTE, P.

GERTH, $\mathrm{H}$.

GHEDDO, P.

GRIGNOUX, C.J.

GILLE, B.

GINESTET, P.

GIOLITTI, A.

GIRAUD, E.

GLASENAPP, H. de

GLEDHILL, A.

GLICK, E.B.

GOETSCHIN, P. 489

GOITEN, S.D.

GOODMAN, N.M.

GOODRICH, L.M.

GOODWIN, G.L.

GOORMAGHTIGH, J.

GORIELY, G.

GOTTMANN, J.

GOUILLY, A.

GOUREVITCH, B.

GRABER, D.A.

GRAHAM, R.A. 
GREEN, L.C.

GREENAWALT, K.W.

GREENE, T.P.

GREENIDGE, C.W.W.

GROSSER, A.

GROUSSET, R.

GRUNEWALD, J.

GUERRY, Mgr.

GUGGENHEIM, P.

GUITTARD, O.

GURIAN, W.

GYGES

HAAS, E.B.

HABICHT, A.

HAIGH, R.W.

HAINES, C.G.

HALES, E.E.Y.

HALL, H.D.

HALL, W.H.

HALLSTEIN, W.

HAMBIDGE, G.

HAMBRO, E.

HAMILTON, D.C.

HAMILTON, T.J.

HAMM, G.

HAMON, L.

HAMORY, L.

HAMUY, E.

HASSMANN, H.

HASSOUND A.K.

HAY, R.

HAYA DE LA TORRE, V.R.

HEALEY, D.

HEBERLE, R.

HEILBRUNN, O.

HENDERSON, W.

HERBERICHS G.

HERZIK, V.

HERON, LEPPER, J.

HESCHEL, A.J.

HESTON, E.L.

HEWINS, R.
HEXNER, E.

HEYDECKER, J.J.

HITCHENER, D.G.

HOBALLAH, M.F.

HOBSBAWN, E.J.

HODGKIN, T.

HOFFET, F.

HOFFMANN, S.H.

HOGAN, W.N.

HOLBORN, L.W.

HOLT, R.T.

HOMO, L.

HOUART, P.

HOUILLIER, F.

HOURS, J.

HOUSSIAUX, J.

HOVLAND, C.I.

HOWARD, P.

HUBER, M.

HUET, P.

HUSSON, G.

HUTIN, S.

HYVARINEN, R.

IMLAH, A.H.

INGRAM, A.

INKELES, A.

ISAAC, J.

ISAACS, H.R.

ISRAËL, G.

ITURRIAGA ROMERO, J.

IUNG, J.

IVANYI, N.G.

JACKSON, E.

JACOBSON, H.R.

JAHODA, $M$.

JAMES, A.M.

JANIS, I.L.

JEHOUDA, J.

JENSEN, A.E.

JESSUP, P.C.

JOLL, J. 
JOMIER, JOSEPH-BARTHELEMY.

JOYCE, J.A.

JOYE, P.

JUNOD, M.

KABES, V.

KALKC, P.

KANTOR, H.

KARUMAKARAN, K.P.

KAUTSKY, J.H.

KAYSER, J.

KELLER, M.

KELLEY, H.H.

KENNAN, G.

KENNEDY, S.

KERTESZ, S.D.

KINDLEBERGER, C.P.

KIRKPATRICK, E.M.

KIRISCHEN, E.S.

KISS, A.C.

KNORR, K.E.

KOHN, $\mathrm{H}$.

KOJANEC, G.

KOLARZ, W.

KOSKINER, A.A.

KOSTOLANY, A.

KRIESBERG, M.

KRI PALANI, A.J.B.

KHROUCHTCHEV, N.S.

KRUTH, A.

KUNZ, J.L.

LABEYRIE-MENAHEN, C.

LABIN, S.

LACAN, R.A.

LACOUTURE, J.

LACOUTURE, S.

LADAME, P.A.

LADOR LEDERER, J.J.

LA FOURNIÈRE, M. de.

LAGROUA WEILL-HALLÉ

LAJUGIE, J.

LALLY, J.
LAMBERT, P.

LANDE, A.

LANDES, D.S.

LANGE, C.

LANGER, P. 433.

LANGLOIS, P.

LANGROD, G.

LANTERNARI, V.

LAPIERRE, J.W.

LA PRADELLE, P. Geouffre de

LA PRADELLE, R. Geouffre de

LAQUEUR, W.Z.

LASSALLE, C.

LASSIER, J.

LA TRAMERYE, P. Lespagnol de

LATREILLE, A.

LATTRE, J.M. de

LAUDRAIN, $\mathrm{M}$.

LAEWERGS, J.A..

LAVES, W.H.C.

LAWRYMENKO, J.

LAZITCH, B.

LEAKEY, L.S.B.

LEANHOFF, E.

LE BRAS, G.

LEBRET, L.J.

LECLER, J.

LEDERMANN, L.

LEDRÉ, C,

LEEB, J.

LEENHARDT, F.J.

LEFEBVRE, $\mathrm{H}$.

LEFEBVRE, J.

LEFRANC, G.

LEMBERG, $\mathrm{H}$.

LENCZOWSKI, G-512 -

LÉNINE, V.

LÉONARD, E.G.

LONI, B.

LEPAGE, $\mathrm{M}$.

LEPOINTE, G.

LERNER, D.

LEVÊQUE, M. 
LEWIN, I.

LEWINSOHN, R.

LEWIS, B.

LEWIS, G.

LEWIS, W.H.

L'HUILLIER, J.

LIALINE, C.

LICHTBLAU, G.E.

LIE, Trygve

LILLI, V.

LIMBERT, P.A.

LINDSAY, K.

LIPPMANN, W.

LISSITZYN, O.J.

LITTRÉ, E.

LIVINGSTON, V.

LOEWENSTEIN, R.

LOMBARDI, R.

LONDON, K.

LONGHURST, $H$.

LONGRIGG, S.H.

LORWIN, L.L.

LORY, M.J.

LOVEDAY, A.

LOVSKY, F.

LOWENTHAL, R.

LOX, F.

LUBELL, $\mathrm{H}$.

LUBRANO-LAVADERA, $M$.

LUCHAIRE, F.

LUGON, C.

LISIGNAN, G. de

LUTHY, H.

MACFARLAND, C.S.

MACKAY, J.A.

MACLEAN, J.

MACRIDIS, R.C.

MAKLAKOFF, G.

MANCE, H.O.

MANDELSTAM, A.N.

MANGONE, G.J.

MAO-TSÉ-TUNG
MARABUTO, P.

MARCEL, G.

MARCHAL, A.

MARCUS, A.

MARCUS, J.T.

MARGALITH, I.

MARTIN, J.L.

MARTIN-CHAUFFIER, L.

MARX, K.

MASANI, M.R.

MASON, E.S.

MASSE, $\mathrm{H}$.

MASTERS, R.D.

MATIP, B.

MAURY, L.

MAURY, R.

Mc ALLISTER, G.

Mc KNIGHT, J.P.

Mc LANE, C.B.

Mc VICKER, C.P.

MEHDEN, F. von der

MEJAN, F.

MENDELSOHN, L.

MENETRIER, J.

MENSCHING, G.

MERCENIER, F.

MEYENDORFF, J.

MEYER, P.

MEYRIAT, J.

MIGOT, A.

MILLIOT, L.

MILLS, C.W.

MITRANY, D.

MITTERRAND, J.

MOCH, J.

MODELAKI, G.

MONESTIER, M.

MONNET, J.

MONTAGNE, R.

MONTANI, G.B.

MONTCEAU, M.

MONTCHEUIL, Y. de

MONTEIL, V. 
MOODY, J.N.

MOREAU, E.

MOREAU-NÉRET, O.

MORGENTHAU, H.J.

MORRALL, J.B.

MORRIS, B.S.

MOSCA, R.

MOSKOWITZ, M.

MOURIN, M.

MOUTET, M.

MUHLER, N.

MULATIER, L.

MULENZI, J.

MURRAY, A.V.

MURRAY, J.C.

MURRAY J.N.

MURY, G.

MYRDAL, G.

NAGLE, T.W.

NAJJAR, F.M.

NANTET, J.

NASH, K.

NASSER, G.A.

NEGRI, G.

NEILL, S.

NEILSON, M.J.

NEUMANN, R.

NEUVECELLE, J.

NEWMAN, P.C.

NEYMARCK, A.

NIAZ AHMED ZIKRIA

NICOLAS, H.G.

NOEL-BAKER, Ph.

NIJKERK, K.J.

NIKITINE, B.

NORMANDIN, A.

NORTHROPP, F.S.C.

NUCCITELLI, N.

NUSEIBEN, H.Z.

OBERSON, J.

O'CONNOR, H.

OGRODZINSKI, P.
OLLIVIER, G.

OREN, M.

ORMESSON, W. d'

OWSLEY, F.L.

PACKARD, V.

PADELLARO, N.

PADMORE, G.

PALME DUTT, M.

PARAF, P.

PARIS, E.

PARIZEAU. J.

PARTNER, P.

PATRICK, D.G.M.

PEASLEE, A.J.

PELLOUX, R.

PERETZ, Don

PERKINS, D.

PERLMUTTER, H.V.

PERRIN, G.

PERROUX, F.

PEYREGA, J.

PHILLIPS, W.T.

PICHON, C.

PICKARD, B.

PICKLES, $\mathrm{W}$.

PICQUEMAL, M.

PICTET, J.S.

PIERONI, A.

PIERRE, B.

PINTO SANTA CRUZ, F.A.

PIRENNE, J.

PLAISANT, R.

PLEKHANOV, G.

POCHON, R.

POIRIER, J.

POLIAKOV, L.

POLITIS, N.

POLK, W.R.

POTTER, L.D.

POTTER, P.B.

POUPART, R.

POURICHKIEVITCH, de 
PRIBRAM, K.

PRIEUR, R.

PRIOURET, R.

PRITZKOLEIT, F.

PROUDFOOT, M.J. 457.

QUEGUINER, M. 445.

RAPACKI, Z.

RATCLIFFE, T.A.

RAZWY, A.A.

RECORD, W.

REES, J.R.

REIMANN, M.

RENOU, L.

RENOUVIN, P.

REUTER, P.

REYNAUD, P.

RICE, A.V.

RICHARDS, H.

RIDGEWAY, G.L.

RIEBEN, $\mathrm{H}$.

RIEUL PAISANT, M.

RINGGREN, H.

RIPERT, G.

RIPPY, J.F.

RISTELHUEBER, R.

RIVET, C.

RIVOIRE, J.

ROBB, J.

ROBERTSON, A.H.

ROBINSON, N.

ROGIU, G.S.

ROH, $\mathrm{H}$.

ROHN, P.H.

ROLLAND, $\mathrm{M}$.

ROLLIN, H.

RONDOT, P.

ROPKE, W.

ROQUETTE, M.

ROSAPEPE, G.

ROSE, A.M. 460.

ROSS, I.
ROTH, C.

ROUILLER, J.F.

ROUSE, R.

ROUSSEAU, C.

ROUSSET, D.

ROUX, J.P.

ROUX, R.

RUDIN, H.R.

SABLIER, E.

SAINT-GERMAIN, J.

SAINT-SIMON.

SAINTE-LORETTE, L. de

SALCEDO, D.

SALMON, J.

SALOMON, J.

SALVIN, M.

SAPOSS, D.J.

SARTRE, J.P.

SAUVY, A.

SAVARY, A.

SAVATIER, R.

SAVORI, R.

SAWICKY, J.

SCALAPINO, R.A.

SCELLE, G.

SCHAPER, B.W.

SHAPIRO, L.D.

SCHENKMAN, J.

SCHEVENELS, W.

SCHICK, L.

SCHLESINGER, R.

SCHMID-AMMAN, P.

SCHNEIDER, R.M.

SCHRAM, S.R.

SCHUMACHER, $\mathrm{H}$.

SCHUMAN, R.

SCHUMPETER, J.A.

SCHWARTZ, H.

SCHWARZ, L.W.

SCHWARZ, W.

SCHWARZBART, I.I.

SCHWEBEL, S.M. 
SCOPPOLA, P.

SCZANIECKI, $M$.

SEPULVEDA, O.

SERAPHIM, M.

SERGOT, A.

SETON-WATSON H.

SEYID MAHAMMAD, V.A.

SHARP, W.R.

SHEDD, C.P.

SHONFIELD, A.

SHUSTER, G.N.

SHWADAN, B.

SIEGFRIED, A.

SIMOND, D.

SIMMONNET, R.

SIMPSON, G.E.

SIOTIS, J.

SLATER, $\mathrm{H}$.

SLOVES, $\mathrm{H}$.

SMITH, B.L.

SMITH (C.M.)

SMITH, D.G.

SOHIER, A.

SOHN, L.B.

SOTO, J. de

SPECTOR, I.

SPEECKAERT, G.P.

SPINKA, $M$.

SRIVASTANA, A.K.

STACKELBERG, G.A. von

STALEY, $\mathrm{H}$.

STALINE, J.

STAMLER, D.M.

STEIN, E.

STEINBACH, A.L.

STEPANOVA, E.

STERNBERG, F.

STEVENS, G.S.

STOCKING, G.W.

STOESSINGER, J.

STOUFFER, S.

STRACHEY, J.

STRAUSZ-HUPÉ, R.
STROKE, P.

STURMTHAL, A.

STZÖM, A.V.

SUES, M.W.

SUFFERT, G.

SUCATANANDA, A.

SULNES, L.J.

SULZBERGER, C.L.

SURET-CANALE, J.

SWEARINGEN, R.

SWEEZY, P.

SYLVAIN, N.

SYKES, C.

SZCZESNIAK, B.

TCHERNOFF J.

TEILHAC, E.

TERLINDEN, Vicomte

TESSIER, G.

TESSIER, $\mathrm{H}$.

TESSON, E.

TEW, E.S.

THAYER, P.W.

THIBERGHIEN, P.

THOMAS, M.R.

THOMSON, C.A.

THOROSSIAN, $\mathrm{H}$.

TIENNE, P. de

TILLON, G.

TIMSHEFF, N.S.

TINBERGEN, J.

TOLEDANO, A.D.

TOMA, P.A.

TOMBS, L.C.

TOUSSAINT, C.E.

TRAGER, F.N.

TRAZ, R. De

TRIPATHI, K.D.

TRIPP, B.M.H.

TROTSKY.

TRUMAN, $\mathrm{T}$.

TUCKER, W.R.

TUNSTALL, B. 


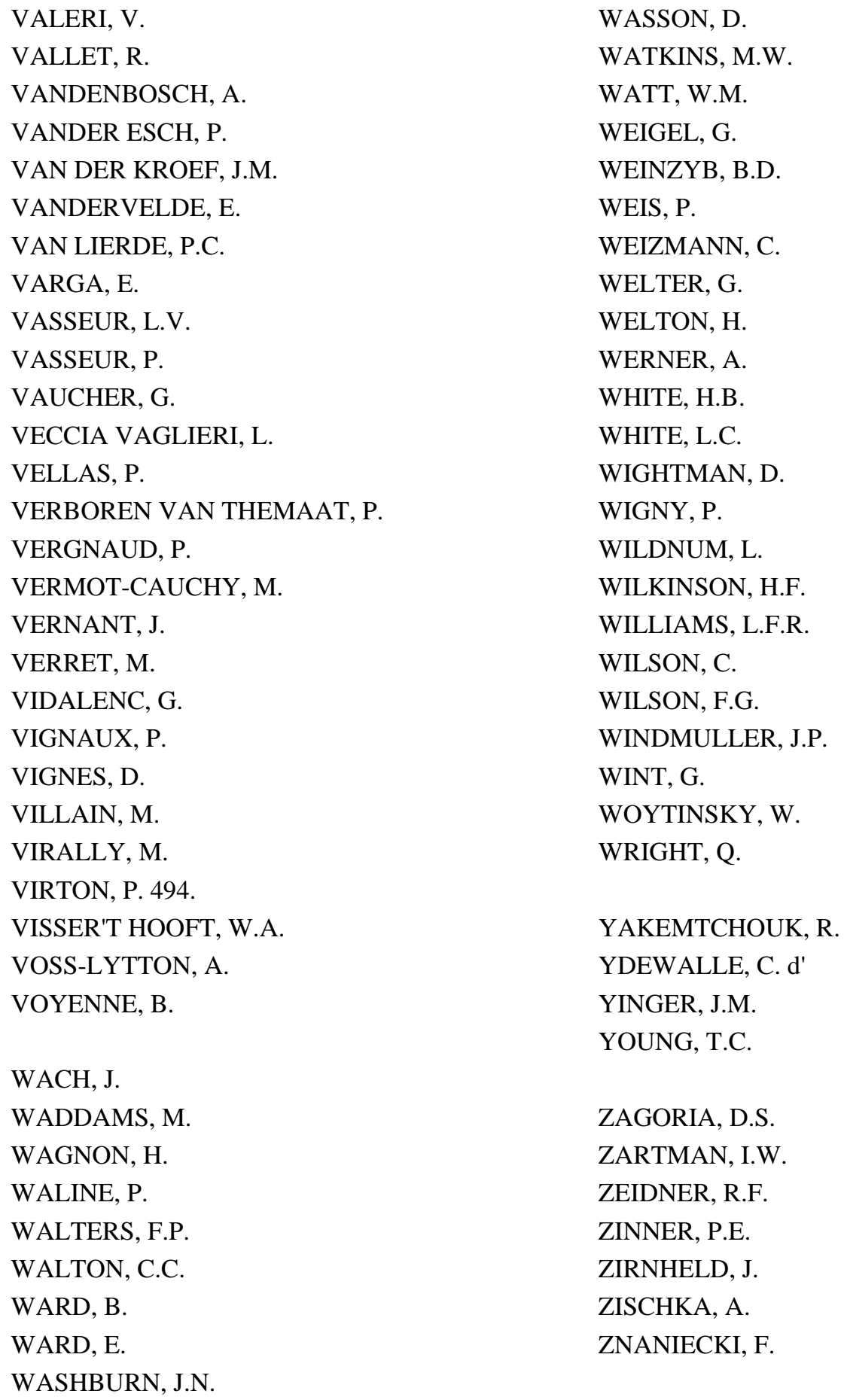


[p. 518]

\section{LISTE DES ORGANISATIONS CITÉES}

$\underline{\text { Retour à la table des matières }}$

Académie Internationale de Médecine Aéronautique. 388.

Académie Pontificale Ecclésiastique. Voir Saint-Siège.

Action Française. 238.

Aéroport International de Bâle-Mulhouse. 69.

Agence Européenne pour l'Énergie Nucléaire. 70, 386, 444.

Agence Internationale de l’Énergie Atomique. 69, 386, 387, 475.

Agence juive pour la Palestine. Voir Organisation Sioniste Mondiale.

Alliance Atlantique des Anciens Combattants. 388.

Alliance Coopérative Internationale. 143, 144-145, 149, 179, 250, 252, 261, 387, 402, 474, 475.

Alliance Européenne des Agences de Presse. 387.

Alliance Évangélique Universelle. 90.

Alliance Française. 157.

Alliance France-Israël. 203.

Alliance Internationale des Femmes - Droits Égaux - Responsabilités Égales.

Alliance Internationale du Tourisme. 185, 373.

Alliance Israélite Universelle. 95, 96, 106, 451, 485.

Alliance Réformée Mondiale. 91.

Alliance Universelle des Unions Chrétiennes de Jeunes Filles (Y.W.C.A.) 90, 451.

Alliance Universelle des Unions Chrétiennes de Jeunes Gens (Y.M.C.A.). 90, 185, 450-451.

Aluminium Company of America (ALCOA). 56.

Aluminium Company of Canada (ALCAN). 56.

Aluminium Industrie Aktiengesellschaft. 56.

Amants de Sion. 106.

American Jewish Committee. 96, 218, 452.

American Tobacco. 354.

[p. 519]

American Trade Association of Morocco. 337, 499.

Anglo-Jewish Association. 96.

Arabian American Company (ARAMCO). 163, 365, 367.

Armée du Salut. 75, 92. 
Assemblée Ecuménique de la jeunesse Européenne. 92.

Assemblée Parlementaire Européenne. 30-31, 216, 276, 316, 317, 394, 437, 495.

Assemblée Permanente des Présidents de Chambre d'Agriculture. 273.

Association Belge pour la Défense des Détenteurs de Fonds Publics. 201.

Association Catholique Internationale des Euvres de Protection de la jeune Fille. 83.

Association Catholique Internationale pour la Radiodiffusion et la Télévision. 83

Association des Bibliothèques de Judaïca et Hébraïca en Europe. 387.

Association des Catholiques Patriotes de Chine. 501.

Association des Instituts d’Études Européennes. 484.

Association des Frères Musulmans. 99-100, 424, 502.

Association des Hommes de Couleur (Brésil). 129.

Association des Industries Margarinières des pays de la C.E.E. 274.

Association du Trafic Aérien International, voir Association du Transport Aérien International.

Association du Transport Aérien International. 179, 372.

Association Européenne de Libre-Échange. 275.

Association Européenne des Agences de Publicité Directe. 388.

Association Européenne des Éditeurs de Publications pour la jeunesse. 388.

Association Européenne des Enseignants. 315.

Association Européenne des Industries de l'Habillement. 274.

Association France-U.R.S.S. 310.

Association Générale des Hygiénistes et Techniciens Municipaux. 209.

Association Internationale de Développement. 351.

Association Internationale de la Sécurité Sociale. 126, 153, 460.

Association Internationale de l'Hôtellerie. 493.

Association Internationale de Recherches sur la Qualité des Plantes Alimentaires. 68.

Association Internationale des Assureurs contre la Grêle. 68.

Association Internationale des Automobile-Club. Voir Fédération Internationale de

l'Automobile.

Association Internationale des Dames de Charité de Saint-Vincent de Paul. 83.

[p. 520]

Association Internationale des Études et Recherches sur l'Information. 304, 482.

Association Internationale des Intérêts Radio-maritimes. 260.

Association Internationale des juges des Enfants. 125, 459.

Association Internationale des juristes Démocrates. 434.

Association Internationale des juristes Espérantistes. 387.

Association Internationale des Lions Clubs. 139. 
Association Internationale des Photographes de la Fédération Naturiste Internationale. 388.

Association Internationale des Producteurs de l'Horticulture. 68.

Association Internationale des Recherches Hydrauliques. 209.

Association Internationale des Skals-Clubs. 493.

Association Internationale des Travailleurs. Voir Première Internationale.

Association Internationale des Universités. 258-259.

Association Internationale du Calendrier. 185.

Association Internationale du Transport Aérien. 373.

Association Internationale Permanente des Congrès de la Route. 384.

Association Internationale pour la Protection de la Propriété Industrielle. 186.

Association Internationale pour la Protection des Travailleurs. 330.

Association Internationale pour l'Histoire des Religions. 387.

Association Médicale Mondiale. 127, 374.

Association Mondiale de la Lutte contre la Faim. 388.

Association Mondiale des Agences de Voyage. 493.

Association Mondiale des Femmes Rurales. 185.

Association Nationale des Porteurs français de Valeurs Mobilières. 201, 202, 486.

Association Parlementaire du Commonwealth. 30.

Association Polonaise Pax. 80.

Association pour un Parlement Mondial. 30.

Association Professionnelle Internationale des Médecins. Voir Association Médicale Mondiale.

Association Sociale Chrétienne Internationale. 83.

Association Soroptimiste Internationale. 139.

Association Universelle des Parlementaires pour un Gouvernement Mondial. Voir

Association pour un Parlement Mondial.

Association Universelle pour l'Espéranto. 186.

[p. 521]

Banque d'Angleterre. 61.

Banque de France. 61.

Banque des Règlements Internationaux. 69.

Banque Européenne d'Investissement, 351.

Banque Internationale pour la Reconstruction et le Développement. 351.

Boeing Airplane. 441.

British Aluminium. 56, 58.

British Council. 156. 
British Petroleum. 156, 304, 364.

Bureau Anti-stupéfiants de la Ligue Arabe. Voir Ligue Arabe.

Bureau d'information des Partis communistes. Voir Kominform.

Bureau d'information et de liaison de la Conférence socialiste Internationale Voir Internationale Socialiste.

Bureau Hydrographique International. 210.

Bureau International Catholique de l'Enfance. 83, 124, 304, 475-476.

Bureau International contre l'Alcoolisme. 185.

Bureau International d'Éducation. 210, 330.

Bureau International de la Paix. 378.

Bureau International des Étalons Physico-chimiques. 185.

Bureau International des Unions de Consommateurs. 144.

Bureau International du Travail. Voir Organisation Internationale du Travail.

Bureau International pour la Répression de la Traite des Personnes. 125, 459.

Caisse commune des Porteurs des Dettes publiques autrichiennes et hongroises. 470.

Caltex. 361, 363.

Campagne Européenne de la jeunesse. 315.

Campagne pour le Désarmement nucléaire. 298.

Cartel Français d'Action Morale et Sociale. 127, 460.

Cartel International des Pétroles. 65, 223, 357-366, 491-493.

Centre Catholique des Intellectuels français. 449.

Centre Catholique International. 278.

Centre d'Action Européenne Fédéraliste. 313, 314.

Centre d'Information des Chemins de Fer Européens. 493.

Centre Européen de la Culture. 314, 315, 316, 484.

Centre Européen d'Études de Population. 267.

Centre International des Syndicalistes Libres en exil. 42, 438.

Centre International d'Études pour une Formation religieuse. 83.

[p. 522]

Centre National de la Cinématographie. 230.

Chambre de Commerce des États-Unis. 253.

Chambre de Commerce Internationale. 66-67, 162, 238, 261, 313, 369-371, 373, 375, 386, 402, 443, 474, 492, 494.

Chambre Internationale de la Marine Marchande. 478.

Comisco. Voir Internationale Socialiste.

Comité central permanent de l'Opium. Voir Organisation des Nations Unies.

Comité Consultatif des Applications Pacifiques de l'Énergie Atomique. 387. 
Comité d'Action pour la Communauté supra-nationale européenne. 315.

Comité d'Action pour les États-Unis d'Europe. 276, 316-317, 318.

Comité de la Liberté Syndicale. Voir Organisation Internationale du Travail.

Comité de Liaison de l'Industrie Automobile pour les pays de la Communauté Européenne. 274.

Comité de Liaison des Grandes Organisations Féminines Internationales. 139, 190.

Comité de Liaison des Industries Métalliques. 270.

Comité de Liaison des Organisations pour la Paix. 494.

Comité de Liaison des Secrétariats Professionnels Internationaux. 189.

Comité des Associations Viticoles des Six. 273.

Comité des Délégations juives. Voir Congrès juif Mondial.

Comité des Organisations des Jeunes Agriculteurs. 273.

Comité des O.N.G. auprès du Fonds des Nations Unies pour l'Enfance (Unicef). 124, 190, 468.

Comité des Organisations professionnelles agricoles. 273.

Comité des renseignements relatifs aux territoires non autonomes. Voir Organisation des Nations Unies.

Comité Européen de Liaison des Négociants et Utilisateurs de Combustibles. 270.

Comité Européen des Fabricants de Sucre. 273.

Comité inter-gouvernemental du Droit d'Auteur. 210.

Comité International Catholique des Infirmières et Assistantes médico-sociales.83.

Comité International de Coordination des Mouvements pour l'Unité européenne. 313.

Comité international de la Croix-Rouge. Voir Croix-Rouge Internationale.

Comité International de l’Apostolat de la Mer. 83.

Comité International des Transports par Chemins de Fer. 493.

Comité International Olympique. 142.

Comité International pour la Diffusion artistique et littéraire par le Cinéma. 493.

[p. 523]

Comité International pour l'Hygiène Mentale. Voir Fédération Mondiale pour la Santé Mentale.

Comité International Spécial des Perturbations Radio-Électriques. 191.

Comité Mixte C.I.S.L. - Groupe Ouvrier. Voir Confédération Internationale des Syndicats Libres.

Comité National Tchèque. 111.

Comité Scientifique pour l'étude des Effets des Radiations Ionisantes. 387.

Comité Technique International de Prévention et d'Extinction du Feu. 209.

Commission de Coopération Technique en Afrique du Sud au Sahara. 103.

Commission de la Condition de la Femme. Voir Organisation des Nations Unies. 
Commission des Droits de l'Homme. Voir Organisation des Nations Unies.

Commission des Églises pour les Affaires Internationales. Voir Conseil Ecuménique des Églises.

Commission des Instituts séculiers. Voir Saint-Siège.

Commission Économique pour l'Afrique. Voir Organisation des Nations Unies.

Commission Économique pour l'Europe. Voir Organisation des Nations Unies.

Commission Internationale Catholique pour les Migrations. 83.

Commission Internationale contre le Régime concentrationnaire. 132, 461.

Commission Internationale de Juristes. 131-132, 445, 461-462.

Commission Internationale de l'Agriculture. 371, 492.

Commission Internationale de la Moselle. 69.

Commission Internationale de Police Criminelle (Interpol). 182, 386.

Commission Internationale des Éditeurs de Journaux Catholiques. Voir Union Internationale de la Presse Catholique.

Commission Internationale du Peuplier. 210.

Commission Internationale pour la Navigation Aérienne. 372.

Commission Internationale pour la Prévention de l'Alcoolisme. 125, 185.

Commission mixte internationale pour les Expériences relatives à la Protection des Lignes de Télécommunication et des Canalisations souterraines. 260.

Commission pour l'Église persécutée des Organisations internationales catholiques. 449.

Committee for Economic Development. 253.

Communauté Économique Européenne. 110, 271-275, 277, 313, 317, 318, 319, 355, 386, 393, 466, 477-478, 490.

Communauté Européenne de Crédit Communal. 387.

Communauté Européenne de Défense. 40, 82, 315, 320, 337, 381, 448.

Communauté Européenne de l'Énergie Atomique (Euratom). 69, 177, 277, 316, 317, 318, 386, 467.

Communauté Européenne du Charbon et de l'Acier (C.E.C.A.). 66, 268-271, 273, 317, 323, 355, 367, 386, 393, 470, 476-477, 484, 490.

[p. 524]

Compagnie de Jésus. 77, 217, 447.

Compagnie Française des Pétroles. 156, 363.

Compagnie Générale d'Électricité. 201.

Compagnie Hollandaise des Indes. 57.

Compagnie Industrielle des Travaux. 220.

Compagnie Internationale pour la Fabrication de l'Aluminium Kaiser-Seichimé. 56.

Compagnie Internationale pour la Fabrication de l'Aluminium (FRIA). 56. 
Compagnie Universelle du Canal Maritime de Suez. 175-176, 289, 465, 466.

Confédération Internationale des Syndicats Arabes. 45, 288, 498-499.

Confédération des Syndicats Chrétiens d'Allemagne. 438.

Confédération des Travailleurs Catholiques du Canada. 44, 499.

Confédération Européenne de l'Agriculture. 267, 443.

Confédération Française des Travailleurs Chrétiens. 43, 47, 148.

Confédération Générale de la Coopération Agricole. 273.

Confédération Générale des Travailleurs Africains. 49.

Confédération Générale du Travail. 38, 47, 48, 211.

Conf édération Générale du Travail Force-Ouvrière. 42, 47, 223.

Confédération Interalliée des Étudiants. Voir Confédération Internationale des Étudiants.

Confédération Internationale des Anciens Prisonniers de Guerre. 122.

Confédération Internationale des Betteraviers Européens. 273.

Confédération Internationale des Cadres. 46.

Confédération Internationale des Éudiants. 51.

Confédération Internationale des Syndicats Chrétiens. 36, 38, 43-45, 46, 49, 84, 148, 246, 247, 248, 249, 250, 261, 267, 383, 438, 439, 474, 475.

Confédération Internationale des Syndicats Libres. 38, 40-43, 45-46, 47-48 49, 50, 148, 209, 211, 223, 246, 247, 248, 249, 250, 261, 264, 267, 284, 373, 383, 438. 439, 472, 473, 474, 475.

Confédération Internationale du Crédit Agricole. 68.

Confédération Latino-américaine des Syndicats chrétiens. 44.

Confédération Mondiale des Organisations de la Profession Enseignante. 142, 464.

Confédération Nationale de la Coopération, mutualité et crédit agricoles. 273.

Confédération Régionale Asienne. Voir Confédération Internationale des Syndicats Libres.

Confederazione Generale Italiana del Lavoro (C.G.I.L.). 88.

Conférence des Organisations Consultatives non gouvernementales auprès de l'O.N.U. 190, 254, 468.

Conférence des Organisations Internationales Catholiques. 84, 190.

[p. 525]

Conférence des Organisations juives. 97.

Conférence des Organisations mondiales intéressées à l'Adaptation des Handicapés. 190.

Conférence des Organisations non-gouvernementales intéressées au Problème de la Migration. 190, 468.

Conférence des Présidents. Voir Conférence des Organisations Internationales Catholiques. 
Conférence des Représentants des Organisations internationales non gouvernementales bénéficiant des arrangements consultatifs auprès de l'Unesco. 190, 468.

Conférence Européenne de l'Aviation civile. 386.

Conférence Européenne des Horaires des Trains de Marchandises. 493.

Conférence Européenne des Ministres des Transports. 386.

Conférence Internationale de la Croix-Rouge. Voir Croix-Rouge Internationale.

Conférence Internationale de la Mutualité et des Assurances sociales. Voir Association Internationale de la Sécurité Sociale.

Conférence Internationale des Charités Catholiques. 83.

Conférence Internationale des Étudiants. 52-53, 439-440.

Conférence Internationale du Travail. Voir Organisation Internationale du Travail.

Conférence Internationale pour l'Unité technique des Chemins de Fer. 373.

Conférence Mondiale de l'Énergie. 475.

Conférence Permanente des Agences bénévoles travaillant pour les Réfugiés 117.

Conférence Permanente des Leaders des Communautés juives d'Europe. 97.

Conférence Socialiste d'Asie. 20.

Conférence Socialiste Internationale. Voir Internationale Socialiste.

Confindustria. 273.

Congrès des Organisations Industrielles (C.I.O.). 37, 38.

Congrès des Peuples Africains. 50.

Congrès des Peuples d'Orient (Japon). 129.

Congrès du Peuple européen. 313.

Congrès international des Herbages. 68.

Congrès islamique. 101.

Congrès juif Mondial. 95-96, 97, 191, 251, 286, 287, 288, 328, 451-452, 455.

Congrès pour la Liberté de la Culture. 136-137, 308, 463.

Conseil Britannique des Églises. 93.

Conseil consultatif d'Organisations juives. 96.

Conseil d'Assistance Économique Mondiale (Comecon). 21, 215, 394.

Conseil de l'Europe.176, 216, 267, 314, 318, 437, 444, 461, 466.

[p. 526]

Conseil de Tutelle. Voir Organisation des Nations Unies.

Conseil des Communes d'Europe. 276, 314.

Conseil des Étudiants Néerlandais. 53.

Conseil des Fédérations Commerciales d'Europe. 274.

Conseil des Fédérations Industrielles d'Europe. 224, 268.

Conseil des Organisations internationales des Sciences médicales.186, 374, 483. 
Conseil des Porteurs de la dette publique répartie de l'Ancien Empire ottoman. 470.

Conseil Économique et Social (Ecosoc). Voir Organisation des Nations Unies.

Conseil Européen de l'Artisanat et des Petites et Moyennes Entreprises. 268.

Conseil International de la Philosophie et des Sciences Humaines. 186.

Conseil International des Femmes. 128, 139.

Conseil International des Femmes social-démocrates. 17.

Conseil International des Infirmières. 374.

Conseil International des Missions. 91, 92, 376, 493.

Conseil International des Sciences Sociales. 190.

Conseil International pour l'Éducation Physique et Sportive. 388.

Conseil Mondial de la Paix. 16, 22, 39, 52, 86, 295, 296, 298, 381, 434, 435.

Conseil Mondial des Rabbins. 96.

Conseil Mondial du Bouddhisme. 422.

Conseil Mondial pour l’Assemblée Constituante des Peuples. 138.

Conseil National du Patronat français. 224.

Conseil National Géorgien. 112.

Conseil Nordique. 387.

Conseil Ecuménique des Églises. 88, 91-94, 250, 261, 400, 451.

Conseil Parlementaire du Mouvement européen. 30.

Council of Foreign Bond-Holders. 201.

Croix-Rouge Internationale. 119-121, 179, 283, 284, 373, 380, 459-460.

Deuxième Internationale. 11-12, 14-15, 34, 431.

Douglas Aircraft. 441.

Dupont de Nemours. 162, 441, 499.

Entente Internationale de l'Acier. 64-65, 443.

Ente Nazionali Idrocarburi (E.N.I.). 156, 158, 160, 161, 359, 361, 365.

Esso Standard. 359, 364.

[p. 527]

Federal Radiation Council. 298.

Fédération Abolitionniste Internationale. 125.

Fédération Allemande des Commerçants en vin. 272.

Fédération Américaine du Travail (A.F.L.). 37, 38, 211.

Fédération Démocratique Internationale des Femmes. 22, 179.

Fédération Dentaire Internationale. 127, 374. 
Fédération des Associations Internationales établies en Belgique. 189.

Fédération des Cheminots autonomes de l'A.O.F. 48.

Fédération des Étudiants d'Afrique Noire en France. 418.

Fédération des Industries belges. 273.

Fédération des Ingénieurs Techniciens et Agents de maîtrise des Houillères de France. 273.

Fédération des Institutions internationales semi-officielles et privées établies à Genève. 189.

Fédération des Syndicats allemands (D.G.B.). 272.

Fédération Européenne de la Manutention. 476.

Fédération Européenne des Constructeurs d'Équipement Pétrolier. 476.

Fédération Européenne des Industries nucléaires. 387.

Fédération Générale des Clubs de Femmes. 140.

Fédération Internationale Catholique d'Éducation Physique. 83.

Fédération Internationale de Laiterie. 68.

Fédération Internationale de l'Automobile. 372.

Fédération Internationale de la Jeunesse Catholique masculine. 83.

Fédération Internationale de Luge. 388.

Fédération Internationale des Agences de Voyages. 493.

Fédération Internationale des Anciens Combattants. 122.

Fédération Internationale des Armateurs. 162, 373.

Fédération Internationale des Associations de Pilotes de Ligne. 260.

Fédération Internationale des Bureaux d'extraits de Presse. 387.

Fédération Internationale des Cadres de la Chimie et des Industries annexes. 46, 388.

Fédération Internationale des Cheminots anti-alcooliques. 125.

Fédération Internationale des Clubs d'Automobile. 373, 375.

Fédératior, Internationale des Droits de l'Homme. 461.

Fédération Internationale des Femmes de Carrières libérales et commerciales. 147.

Fédération Internationale des Femmes diplômées des Universités. 147.

Fédération Internationale des Fonctionnaires supérieurs de Police. 250, 384.

Fédération Internationale des Hommes catholiques. 83.

[p. 528]

Fédération Internationale des journalistes. 133, 149.

Fédération Internationale des Journalistes catholiques. Voir Union Internationale de la Presse Catholique.

Fédération Internationale des Mineurs. 46.

Fédération Internationale des Ouvriers des Transports. 45-46, 373, 472.

Fédération Internationale des Pen-clubs. 137. 
Fédération Internationale des Producteurs agricoles. 68, 250, 371-372, 443, 474.

Fédération internationale des Radio-Télégraphistes. 260.

Fédération Internationale des Résistants. 22.

Fédération Internationale des Sourds. 250.

Fédération Internationale des Syndicats de Mineurs chrétiens. 46.

Fédération Internationale des Universités catholiques. 83.

Fédération Internationale d'Oléiculture. 68.

Fédération Internationale du Bâtiment et des Travaux publics. 220.

Fédération Internationale Pharmaceutique. 127.

Fédération Internationale pour le Contrôle des Naissances. 126.

Fédération Internationale pour les Auberges de la jeunesse. 493.

Fédération Internationale Syndicale de l'Enseignement. 22.

Fédération Luthérienne Mondiale. 91.

Fédération Mondiale de la jeunesse démocratique. 22, 50, 305, 306, 434.

Fédération Mondiale des Anciens Combattants. 122-123, 261, 267, 459, 474.

Fédération Mondiale des Associations pour les Nations Unies. 133, 261, 310, 311, 317, 474, 475.

Fédération Mondiale des Congrégations Mariales. 83.

Fédération Mondiale des jeunesses Féminines Catholiques. 83.

Fédération Mondiale des Travailleurs Scientifiques. 298.

Fédération Mondiale pour la Santé Mentale. 127, 374, 460, 475, 483.

Fédération Nationale des Combattants Républicains. 463.

Fédération Nationale des Syndicats d'Exploitants Agricoles. 273.

Fédération Postale autrichienne. 35.

Fédération Probibitionniste Internationale. 125.

Fédération Routière Internationale. 373, 384.

Fédération Syndicale Internationale. 34-35, 36, 37, 45, 246, 382-383.

Fédération Syndicale Mondiale. 22, 37, 38-40, 43, 45, 46, 50, 52, 148, 179, 211, 246, 250, 252, 261, 264, 298, 380, 383, 438, 474, 475.

Fédération Universelle des Associations Chrétiennes d'Étudiants. 90.

Fondation Ford. 137.

Fonds Monétaire International. 153, 281.

Fonds des Nations Unies pour l'Enfance (U.N.I.C.E.F.). 180, 261, 310, 459.

Franc maçonnerie.27-29, 436-437.

[p. 529]

Fraternité Mondiale. 139.

Front de Libération Nationale (F.L.N.).54, 114, 218, 347, 457. 
General Dynamics. 441.

General Electric. 441.

General Motors. 56, 193.

Grande Loge Nationale de Tchécoslovaquie. 28.

Grand Orient de France. 29.

Groupement consultatif International pour la Paix et le Désarmement. 379.

Guilde Internationale des Coopératrices. 464.

Gulf Oil. 357.

Haut-Commissariat pour les Réfugiés. 117.

Hill and Knowlton International. 480.

Hindu Mahasabha. 73.

Institut central pour les Recherches nucléaires. 386.

Institut de Droit International. 185, 187.

Institut de Saint Pie V. 501.

Institut Interaméricain de Défense sociale. 126.

Institut International de l'Agriculture. 371.

Institut International de la Paix. 387.

Institut International de la Presse. 132-133, 461.

Institut International de la Soudure. 209.

Institut International de l'Épargne. 126, 460.

Institut International des Civilisations Différentes. 460.

Institut International des Classes moyennes. 68.

Institut International pour l'Unification du Droit privé. 176.

Interhandel. 175.

International Education Exchange Service. 157.

Internationale communiste. Voir Troisième Internationale.

Internationale de la jeunesse Socialiste. Voir Union Internationale de la jeunesse Socialiste.

Internationale de la Porte Ouverte pour l'Émancipation Économique de la Travailleuse. 128.

Internationale Féminine Socialiste. Voir Conseil International des femmes socialdémocrates.

[p. 530]

Internationale Libérale. 19.

Internationale Néo-Nazie. 31-33, 437.

Internationale Socialiste ouvrière. 13. 
Internationale Socialiste. 16-17, 18, 19-21, 41, 160, 434.

Internationale Syndicale rouge. 35-36, 40.

Jan Sangh. 73.

Jeune Chambre Économique Internationale. 307.

Jeunesse Ouvrière Chrétienne Internationale. 83.

Jeunesses Fédéralistes Mondiales. 138.

Kominform. 16, 215.

Komintern. Voir Troisième Internationale.

Krupp. 58, 162, 271, 353, 367, 492.

La Maffia. 28.

La Main Noire 27.

La Sapinière, [dite Société de Saint Pie V]. 238.

Ligue Arabe. 109-111, 218, 386, 455.

Ligue Catholique Internationale contre l'Alcoolisme. 83.

Ligue de la Patrie Arabe. 109.

Ligue des Sociétés de la Croix-Rouge. 119, 179, 261, 374.

Ligue Européenne de Coopération Économique. 312-313, 314, 483.

Ligue Internationale contre le Racisme et l’Antisémitisme. 129, 130, 460.

Ligue Internationale des Droits de l'Homme. 130, 461.

Ligue pour la Tolérance (Danemark). 129.

Ligue pour les Peuples (Grande-Bretagne). 129.

Ligue Yougoslave pour la paix, l'indépendance et l'égalité des peuples. 457.

Lockheed Aircraft Corporation. 441.

Longshormen Association. 288.

Martin Company. 441

Mission Laïque française. 157.

Motion Picture Export Association of America. 230.

Mouvement communiste International. Voir Troisième Internationale.

Mouvement contre le Racisme et l'Antisémitisme pour la Paix.130, 460-461.

[p. 531]

Mouvement Européen. 18, 314-316, 318, 320, 484.

Mouvement Fédéraliste Européen. 312, 313, 314.

Mouvement International des EÉudiants Catholiques. Voir Pax Romana 
Mouvement International des Étudiants pour les Nations Unies. 310.

Mouvement International des Intellectuels Catholiques. Voir Pax Romana

Mouvement International pour l'Union Atlantique. 133.

Mouvement International pour l'Union Fraternelle entre les Races et les Peuples. 138.

Mouvement Libéral pour l'Europe Unie. 312, 314.

Mouvement Mondial des Mères. 124, 459,

Mouvement Panafricain pour l'indépendance de l'Afrique centrale et orientale 502.

Mouvement socialiste pour les États-Unis d'Europe. 312, 314.

Mouvement Synarchique d'Empire. 28.

Mouvement Universel pour une Fédération Mondiale. 138, 463.

Nahdatul Ulama. 423.

National Association of Manufacturers of the United States of America. 253.

National Science Foundation. 157.

Nestlé 173, 225, 226, 466.

North American Aviation. 441.

Nouvelles Equipes Internationales (N.E.I.). 17-19, 312, 314.

Office Catholique International du Cinéma. 83.

Office Central de Transports Internationaux par chemins de fer. 260.

Office Central des Associations internationales. 435, 468.

Office de Secours et de Travaux des Nations Unies pour les Réfugiés de Palestine dans le Proche-Orient (U.N.R.W.A.). 117.

Office International de l'Enseignement Catholique. 83.

Olin Mathieson Chemical Corporation. 56.

Opus Dei 77-78, 447.

Ordre International des Bons Templiers. 125.

Organisation Centrale pour une Paix Durable. 379.

Organisation Démocrate-chrétienne d'Amérique Latine. 18.

Organisation des Nations Unies (O.N.U.). 43, 45, 67, 96, 103, 114, 121, 124, 125, 130, 138, 180, 182, 184, 190, 198-199, 208, 221, 222, 250, 251-257, 261, 262, 263, 264, 266, 278, 282, 310, 311, 349, 373, 377, 380, 384-, 386 387, 393, 400, 414, 415, 419, 461, 468, 469, 473-474, 492.

[p. 532]

Organisation des Nations Unies pour l'Alimentation et l'Agriculture (F.A.O.). 148, 153, 261, 262, 279, 301, 371, 372, 387, 414, 415. 
Organisation des Nations Unies pour l'Éducation, la Science et la Culture (Unesco). 43, 84, 153, 180, 190, 199, 221, 222, 227, 257-260, 261, 262, 266, 278, 302, 303, 304, 310, 321, 387, 461, 468, 474-475, 481, 482.

Organisation des Pays Exportateurs de Pétrole. 364-365, 500.

Organisation du Traité de l'Atlantique Nord. 394.

Organisation Européenne de Coopération Économique. 267-268, 270, 476, 489.

Organisation Européenne pour le Contrôle de la Qualité. 388.

Organisation Européenne pour la Recherche Nucléaire (C.E.R.N.). 386.

Organisation Intergouvernementale consultative de la Navigation Maritime. 471.

Organisation Internationale contre le Trachome. 374.

Organisation Internationale de l'Aviation Civile. 182, 372.

Organisation Internationale de Normalisation. 144, 149, 250, 261, 475.

Organisation Internationale de Radiodiffusion. 22, 260, 373.

Organisation Internationale des Employeurs. 245-246, 250, 474.

Organisation Internationale des Employeurs Industriels. Voir Organisation Internationale des Travailleurs.

Organisation Internationale des Femmes chefs d'entreprises. 147.

Organisation Internationale des journalistes. 22, 149.

Organisation Internationale du Travail. 34-35, 42, 43, 84, 126, 155, 221, 245251, 252, 261, 310, 330, 374, 383, 387, 400, 437, 457, 473.

Organisation Internationale pour les Réfugiés. 117, 458.

Organisation Météorologique Mondiale. 260-261, 393.

Organisation Mondiale Agudas Israël. 96, 452.

Organisation Mondiale de la Santé. 127, 153, 261, 298, 310, 373-374, 393, 460, 475, 493.

Organisation Mondiale du Tourisme et de l'Automobile. 373, 384.

Organisation Régionale Interaméricaine des Travailleurs (O.R.I.T.). Voir

Confédération Internationale des Syndicats Libres.

Organisation Sioniste Mondiale. 95, 106-109, 171, 328.

Pacte de Varsovie. 21.

Pan-Malayan Islamic Party. 423.

Pax Christi. 84.

Pax Romana. 83, 84-85, 191, 308, 329.

Péchiney. 56, 57, 162.

Pemex (pétro1es mexicains). 351.

Philipps G.F. 5\&

[p.533]

Première Internationale. 11, 431. 
Prévention Routière Internationale. 384.

Pro Helvétia. 157.

Pugwash 166.

Quakers. Voir Société des Amis.

Quatrième Internationale. 432-433.

Rassemblement International des Anciens Combattants. 122.

Réarmement Moral (R.A.M.). 133-136, 180, 214, 288, 304, 461-462.

Régie Renault. 202-203.

Registre International des Citoyens du Monde. 138.

République des Citoyens du Monde. 138, 186.

Reynolds Metal. 57-58.

Rhodesian Anglo-American. 140.

Rhodesian Selection Trust. 140.

Rotary International. 139.

Royal Dutch Shell. 56, 58, 156, 348, 358, 359, 364.

Saint-Gobain. 162.

Saint-Siège. 75, 76, 79-85, 93, 135, 171, 209, 211, 216, 231, 239, 265, 278-279, 284, 331, 376, 446-450, 485.

Scandinavian Airlines System. 69.

Schneider et $C^{\text {ie }} .220$.

Seafarers International Union. 288.

Secrétariat de coordination des Unions nationales d'Étudiants (COSEC). 52-53, 439440.

Smithsonian Institution. 157.

Société Anti-esclavagiste. 125.

Société belge d'Étude et d'expansion. 474.

Société de Législation comparée. 474.

Société de Saint Pie V. Voir La Sapinière.

Société de Saint-Vincent de Paul. 83.

Société des Amis. 75, 92, 264, 445-446.

Société des Forges et Ateliers du Creusot. 220.

Société des Nations. 66, 125, 148, 252, 278, 371, 400, 415, 434, 457, 468, 472, 492.

Société du Lion et du Soleil Rouges. 119.

[p. 534]

Société Eurochemic. 70, 444. 
Société Européenne d'Énergie Atomique. 387.

Société Européenne de Sociologie rurale. 387.

Société Européenne pour le Financement du Matériel Ferroviaire (EUROFIMA). 69, 177.

Société Féminine de Saint-Vincent de Paul. 83.

Société Financière Internationale. 69, 351.

Société générale française des Mines. 220.

Société ibéro-américaine de philosophie. 388.

Société Internationale de Défense Sociale. 126.

Société Internationale de la lèpre. 127.

Société Internationale de la Moselle. 69.

Société Internationale de Mécanique des Sols et des Travaux de Fondation. 191.

Société Internationale des Écrivains de l'Aviation. 388.

Société Internationale pour la Protection des Invalides. 127.

Société Internationale pour la Recherche sur l'Alimentation et les Recherches vitales. 144.

Société Métallurgique luxembourgeoise (Arbed). 220.

Société pour la Liberté de la Science. 186.

Sociétés du Croissant Rouge. 119.

Sociétés Nationales de la Croix-Rouge. 119.

Socony Mobil Oil. 357.

Sohyo (centrale syndicale japonaise). 38.

Sous-comité de l'énergie du Comité administratif de coordination. 387.

Standard Oil of New jersey. 56, 156, 211, 230, 304, 348, 357.

Standard Vacuum Oil. 357, 358, 361.

Texaco. 359.

Thyssen. 162, 271, 367.

Trade Unions britanniques. 37, 399.

Troisième Internationale. 13-16, 21-27, 36, 215, 331, 431-436.

Tube Investment. 58.

Ugine. 56.

Unilever. 55-56, 58, 162, 353, 440.

Union Astronomique Internationale. 260.

Union Catholique Internationale de Service Social. 83, 261.

[p. 535]

Union Chrétienne Démocrate d'Europe Centrale. 18. 
Union Cycliste Internationale. 142.

Union de l'Europe Occidentale. 387.

Union Démocrate-chrétienne de l'Europe Centrale. 18, 484.

Union des Associations Internationales. 142, 179, 180, 181, 189, 306, 412, 434, 440, 444, 467, 468, 473, 482, 483, 495.

Union des Industries de la Communauté Européenne. 274.

Union des Populations du Cameroun. 105.

Union des Résistants pour une Europe Unie. 315.

Union des Services routiers de chemins de fer européens. 493.

Union des Travailleurs Italiens. 273.

Union Économique Arabe. 110.

Union Européenne des Fédéralistes. Voir Mouvement Fédéraliste Européen.

Union Européenne des Négociants Détaillants en Combustibles. 270.

Union Européenne des Paiements. 317.

Union Fédérale de la Jeunesse Autrichienne. 482.

Union Fédéraliste Mondiale. 463.

Union Française des Associations de Combattants et des Victimes de Guerre. 122.

Union Générale des Étudiants Musulmans Algériens. 53, 54, 440.

Union Générale des Pétroles. 363.

Union Générale des Travailleurs Algériens. 50, 249.

Union Générale des Travailleurs de l'Afrique Noire. 48-49, 50, 51, 439.

Union Générale des Travailleurs Tunisiens. 48.

Union Générale. 61.

Union Géodésique et Géophysique Internationale. 260.

Union Industrielle des Pétroles. 363.

Union Internationale Antiraciste. 129, 460.

Union Internationale contre l'Alcoolisme. 125.

Union Internationale contre la Tuberculose. 127.

Union Internationale contre le Cancer. 127.

Union Internationale de la Jeunesse Socialiste. 17.

Union Internationale de la Presse Catholique. 83, 149.

Union Internationale de l'Humanisme et de l'Éthique. 133.

Union Internationale de Protection de l'Enfance. 124, 261.

Union Internationale de Radiodiffusion. Voir Organisation Internationale de Radiodiffusion.

Union Internationale de Secours aux Enfants. Voir Union Internationale de Protection de l'Enfance.

Union Internationale d'Études Sociales. 83. 
[p. 536]

Union Internationale des Architectes. 149.

Union internationale des Associations patronales catholiques. 83.

Union Internationale des Associations pour la Société des Nations. 379.

Union Internationale des Chemins de Fer. 373, 493.

Union Internationale, des Étudiants. 22, 51-52, 434, 439-440.

Union Internationale des Instituts de Recherches forestières. 68.

Union Internationale des Jeunes démocrates chrétiens. 18.

Union Internationale des Organismes Familiaux. 123, 155, 261, 459.

Union Internationale des Organismes officiels de tourisme. 373.

Union Internationale des Producteurs et distributeurs d'énergie électrique. 274, 387.

Union Internationale des Sciences de la Nutrition. 144.

Union Internationale des Syndicats des Mineurs. 46.

Union Internationale des Télécommunications. 182, 260, 393, 475.

Union Internationale des Transports Routiers. 493.

Union Internationale des Villes et des Pouvoirs locaux. 156, 464.

Union Internationale des Voitures et des Fourgons. 493.

Union Internationale des Wagons. 493,

Union Internationale d'Organisations nationales d'hôteliers, restaurateurs et cafetiers. 493.

Union Internationale Paysanne. 484.

Union Internationale pour la Protection de la Moralité Publique. 126-127, 460.

Union Internationale pour l'Éducation Anti-alcoolique de la Jeunesse. 125, 387.

Union Interparlementaire. 29-30, 149, 378-379, 437, 474.

Union Libérale Mondiale. Voir Internationale Libérale.

Union Marocaine du Travail. 439.

Union Minière du Haut-Katanga. 441.

Union Mondiale de la Femme pour la Concorde Internationale. 140.

Union Mondiale des Enseignants catholiques. 83.

Union Mondiale des Femmes Rurales. 128, 460.

Union Mondiale des Organisations féminines catholiques. 83, 185, 460.

Union Mondiale des Organismes pour la Sauvegarde de l'Enfance et de l'Adolescence. 124, 459.

Union Mondiale des Sociétés Catholiques de Philosophie. 83.

Union Mondiale O.R.T. (Organisation, reconstruction, travail). 96.

Union Nationale des Associations Régionales pour la Sauvegarde de l'Enfance et de l'Adolescence. 459.

Union Nationale des Étudiants de France. 53. 
Union Nationale des Étudiants de Suisse. 440.

Union Nationale des Paysans allemands. 272.

[p. 537]

Union Panafricaine des Travailleurs croyants. 44, 49.

Union pan-européenne. 313, 314.

Union Parlementaire Européenne. 313, 315.

Union Postale Universelle. 76, 199, 393.

Union Radio-scientifique Internationale. 185.

Union Routière. 70.

Union Syndicale Autonome de Côte d'Ivoire. 48.

Union Syndicale suisse. 221.

Union Territoriale des Syndicats C.G.T. du Sénégal et de Mauritanie. 48.

United Aircraft 441.

United Fruit Company. 41, 57, 290, 353.

United States Information Agency. 157.

Vereinigte Aluminium-Werke A.C. 56.

Vickers. 150

Voks [UR.S.S.]. 157. 
[p. 538]

\section{INDEX DES SUJETS}

$\underline{\text { Retour à la table des matières }}$

« Abus de puissance économique ». 317.

Achnacarry Agreement. Voir Pétrole.

Acier. 64-65, 268-271.

Action catholique internationale. 82-85, 145, 265.

Adenauer (C). 18, 73, 135.

Administration de Coopération Internationale (I.C.A.) des États-Unis. 351.

Administration Internationale. Voir Bureaucratie internationale.

Afrique 20, 26, 38, 44, 47-51, 56, 102, 103, 105, 115, 148, 154, 198, 248, 383, 423, 457, 498, 502.

Afrique du Sud. Voir Union Sud-Africaine.

Afro-asiatiques (États). Voir Bandoeng (monde de).

Agriculture (défense de l'). 68, 147-148, 272-274, 276-277, 371-372, 394, 396.

Aide aux pays sous-développés. 22, 41, 42, 137, 299, 300, 311, 434.

Alcoolisme (lutte contre l'). 125.

Alexis (Patriarche). 87.

Algérie (guerre d'). 53, 54, 114, 115, 121, 208, 218, 249, 284, 285, 347, 363, 383, 439, 440, 448, 458.

Algésiras (Conférence d'). 334, 499.

Alleg (H.). 138.

Allégeance des sociétés commerciales. 177-178.

Allemagne (redressement de l'). 135.

Alliance atlantique. 133.

Alliance franco-russe. 334.

Aluminium. 56-57, 58, 195.

Amérique centrale. 42, 285, 292.

Amérique latine. 32, 41-42, 44, 50, 71, 297, 299, 345, 349, 396, 498.

« Amitié des peuples ». 295.

Analphabétisme. 302.

Anarcho-syndicalisme. 36.

Anglicanisme. 75, 87, 91, 445, 501.

[p. 539]

Année mondiale du réfugié. 117, 301. 
Anti-américanisme. 299, 301.

Anti-colonialisme. 14-16, 20, 36, 40, 42, 48, 49, 52, 53, 90, 284, 299, 305-306, 378, 391.

Antisémitisme. 32-33, 93, 97, 109, 129-130, 286, 452, 455, 461.

Apartheid. Voir Union Sud-Africaine.

« Apatridie » économique. 195.

Apatrides (statut des). 458.

« Apostolat intellectuel ». 82-83.

Arabisme. 102, 109-111, 288, 361-362, 365, 455, 498-499.

Armateurs grecs. 57, 194-195, 471-472.

Armement maritime. 226, 361, 471-472.

Arménie (affaire d'). 112.

Armes atomiques (interdiction des). Voir Paix (lutte pour la).

Asie. 16, 20, 89, 168, 299, 396, 498.

Assistance technique. 296, 349, 386, 489.

« Associationite ». 385, 388.

« Associations étrangères ». 186-187.

Associations scientifiques. 154, 166, 304, 307.

Assyriens. Voir Minorités chrétiennes d'Orient.

Attitudes à l'égard du capital étranger. Voir Capital étranger (pénétration du).

Attitudes (transformation des). 321-325.

Auriol (Vincent) 122.

Autocéphalie. Voir Orthodoxie.

Autonomie (des groupes). 158-159, 238-239, 265, 377, 381, 391-392, 400-403.

Bagdache (Khalib). 456.

Bagdad (chemin de fer de). 60.

Bagdad (pacte de). 110.

Bahrein Voir Pétrole.

Balfour (déclaration). Voir Sionisme.

Bandoeng (monde de). 16, 20, 24, 114, 121, 168, 198, 290, 305-306, 346, 418-420, 502, 503.

Bardo (traité du). 61.

Battista. 132.

Bazzani (Mustapha al). 456.

Beck (colonel). 208.

Benès (Ed.). 129.

Ben Gourion (D.). 108. 
[p. 540]

Bernard (Samuel). 60.

Betancourt. 292.

Betterave. 274.

Bèze (Th. de). 88.

Bipolarisation du monde. 397-399.

Birth control. Voir Prévention des naissances.

Blé. 349

Blum-Byrnes (accord). 230.

Blum (L.). 129.

Bontoux (E). 61.

Bouddhisme. 74, 422, 445, 502.

Boycottage. 202-203, 287-288, 371, 382.

Brookings - Institution. 264, 457, 474.

Brouillage des émissions. 293.

Brown (I.). 37.

Bruges (collège de). 317.

Bureaucratie internationale. 141, 199-200, 222, 241, 244, 262-263, 266, 388, 393, 469-470.

Café. 489.

Califat. Voir Doctrine musulmane de l'État.

Campagne mondiale contre la faim. 301.

Camps de concentration. 132.

Camps d'internement. 121, 132.

Camps de personnes déplacées. 32.

Canal de Suez (restrictions à la navigation sur le). 46, 288, 328.

Canterbury (archevêque de). Voir Anglicanisme.

« Capacité européenne ». Voir « Capacité régionale ».

« Capacité internationale ». 206, 207, 210, 218, 220, 221-225, 228, 231, 253, 369, 396, 399.

« Capacité nationale ». Voir « Capacité internationale ».

«Capacité régionale ». 277-278, 313, 396, 467-468.

Capital étranger (pénétration du). 61-62, 290-291, 350, 440.

— dans les pays développés. 57-58.

— dans les pays sous-développés. 57, 227, 351.

Capital financier. Voir Impérialisme.

Carbonari. 27. 
« Carnet de passage en douane » (création du). 373.

Cartels (contrôle des). Voir Ententes (contrôle des).

Castes (Régime des). 73.

[p. 541]

Castro (F.). 361.

« Castroïsm ». 480.

Catherine II 87.

Catholicisme. 76-85, 87, 134, 209, 264, 284, 331, 375, 376, 377, 398, 402, 446-450.

« Cavalerie de St-Georges ». 285.

Center of International Studies (M.I.T.). 482.

Centre de recherches européennes de l'Université de Lausanne. 317.

Chamberlain (N.). 208.

Charbon. 268-271.

Charles-Quint (élection de). 59.

« Charte africaine » (Casablanca). 502.

Charte de la Havane. 349, 354.

Charte de Saint-Sébastien. 449.

Chase international. 351.

« Chatam House ». 432.

Chemin de fer franco-éthiopien. 348.

China Lobby. 205.

Chine communiste (admission aux Nations Unies). 93.

Chine (rapports avec l'U.R.S.S.). 24-26, 138, 419, 497-498.

Churchill (W.). 312.

Cinéma américain. 230.

Circulation routière. Voir Transports (problèmes des).

Citrine (Sir W.). 37.

Classes moyennes. 68.

«Cléopâtre » Affaire de la). 288.

Cocom. 201.

Cœur (Jacques). 60.

Coexistence (Doctrine de la). 25, 134-136, 497.

Colonialisme. Voir anti-colonialisme.

Colonisation. 341-344.

Colonisation juive. 106, 455.

Combat contre les préjugés raciaux. Voir Discriminations raciales.

Comité Mac Carran. 199. 
Commission européenne des Droits de l'homme. 461.

Commissions nationales de l’U.N.E.S.C.O. 259.

Communauté française. 49, 349.

Commune (échec de la). 11.

Communisme. 13-16, 81, 133-136, 154, 239, 264, 291, 293, 300, 305-306, 331, 346, 419, 431-435.

[p. 542]

Communisme et religion. 74, 85-88, 98, 502.

Communisme et sionisme. 108-109, 110.

Complaisance. Voir Législations et Pavillons de complaisance.

Compréhension internationale (Facteur de la). 385-392.

Comptoir national d'escompte. 351.

Concile du Vatican. 85, 88.

Concordat (méthode du). 78-79.

Conférence économique de 1927 (action de la C.I.I.). 66-67.

Conférence de Lambeth. Voir Anglicanisme.

Conférences de La Haye. 379.

«Conflits internes » (victimes des). Voir Victimes des conflits (protection des).

Confucianisme. 422.

Congrégation de la Propagande. Voir Missions catholiques.

Congrès arabes du pétrole. 361-362, 365.

Congrès de La Haye (7-10 mai 1948). 314, 318, 503.

Congrès des peuples de l'Orient (Bakou, 1920). 15.

Congrès (rôle et technique des). 306-307, 391.

«Conscience publique ». 301.

« Conscience universelle ». 294-295.

Consensus européen. Voir Europe (unification de l’.)

Consommateurs (défense des). 143-145, 235.

Construction électrique. 275.

Contrats de livraison à long terme. Voir Matières Premières.

Contre-boycottage. Voir Boycottage.

Contre-pression (phénomènes de). 218.

Contrôle (critère du). Voir « Nationalité » des sociétés commerciales.

Contrôle des naissances. Voir Prévention des naissances.

Convention

- sur la nationalité de la femme. 256.

— sur la protection de la maternité des travailleuses. 124. 
— sur l'égalité des rémunérations. 256.

— sur les droits politiques des femmes. 255.

Conventions de Genève. 119-120.

Coopération. 143, 144-145, 184.

Corps gras. 55.

Corruption de la presse. 344.

Corruption des autorités. 212, 290.

Costa-Rica. Voir Pavillons de complaisance.

Coudenhove-Kalergi. 313.

[p. 543]

Croix-Rouge (« fuite » d'un rapport de la). 121.

Curzon (ligne). 116.

Déclaration des droits de l'enfant. 124.

Déclaration des droits de la famille. 123.

Déclaration de Genève. Voir déclaration des droits de l'enfant.

Déclaration Universelle des Droits de l'Homme. 130, 139, 265, 302, 321, 371, 377379.

« Décolonisation » (attitudes à l'égard de la). 20, 76-77, 82, 89, 105, 140-141, 198, 223, 248-249, 299, 330, 347, 354, 415, 448.

Démocratie-chrétienne. 17-18, 31. Voir aussi Partis Démocrates chrétiens.

« Démocratie fonctionnelle ». 266.

Département d'EÉat. 32, 225, 288, 299.

Déportations. Voir camps de concentration et d'internement.

Désarmement. Voir Paix (lutte pour la).

Désarmement idéologique. 136, 149, 208.

« Désengagement » (plans de). Voir Paix (lutte pour la).

Deterding (Sir H.). 160.

« Deux-cents familles ». 213, 442.

Diallo (A.). 49.

Diplomatie des hommes d'affaire. 347.

Direction générale des Relations Culturelles. 157.

Discriminations raciales (lutte contre les). 16, 32-33, 54, 90, 93, 124, 129-130, 141, 223, 235, 236.

Dispersion orthodoxe. Voir Orthodoxie.

Divini Redemptoris (Encyclique). 81.

Doctrine Eisenhower. 352.

Doctrine musulmane de l'État. 97-98, 100-101. 
Dolci (D.). 137.

Doubles impositions. 67, 370.

Droit international public et Science politique. 406-407.

Droits de l'homme. Voir Déclaration Universelle des Droits de l'Homme.

Eaton (C.). 166.

Échanges universitaires. 51.

Économie mixte. Voir Sociétés d'économie mixte.

Eden (Sir Anthony). 160, 433.

«Éditions en langue étrangère » (dans les pays communistes). 303.

Église autocéphale de Serbie. Voir Orthodoxie.

[p. 544]

Église catholique. Voir Catholicisme.

Église (dans les pays communistes). 74, 85-88.

« Église du silence ». 80.

Église orthodoxe. Voir Orthodoxie.

Église synodale de Grèce. Voir Orthodoxie.

Église unie de l'Inde du Sud. 89.

Ehrardt (L.). 18.

Einstein (A.). 129.

Eisenhower (D.D.). 295.

El Tiempo, Bogota (suspension). 137.

Émigration juive vers Israël. Voir Sionisme.

Énergie atomique (dans le monde). 386-387.

Énergie atomique (dans l'Euratom). 316-317.

Enfance inadaptée. Voir Enfant (protection de l').

Enfant (protection de l'). 124-125, 236.

Engins spatiaux (lancement d'). 300.

Entente cordiale. 295.

Ententes (contrôle des). 317, 354-355.

Entreprises publiques. 214.

Esclavage. 118, 125, 459.

Étain. 349.

« Etablissements publics internationaux ». 69-71, 177, 214.

«État bourgeois ». Voir Impérialisme.

«État économique » (notion de l'). 64.

État islamique mondial. Voir Pan-islamisme. 
Étudiants. 51-54, 310, 334-335, 439-440.

Europe (unification de l') 20, 30, 31, 40, 82, 135, 143, 177, 178, 201, 235, 267-278, 312-321, 355, 393-394, 476-478, 483-485, 498, 500.

« Europe vaticane ». 73.

Eurovision (portée du système d'). 302.

Evanston (réunion d', 1954). Voir Ecuménisme.

Excommunication. 376.

Exilés. 18, 19, 117, 458, 464.

Exploitation coloniale. Voir Impérialisme.

Explosions nucléaires. Voir Paix (lutte pour la).

Exportation de capitaux. Voir impérialisme.

Expulsés. 116-118.

[p. 545]

Fascisme. 13, 14, 35, 37.

Fédéralisme mondial. Voir Gouvernement mondial.

« Fédéralistes ». Voir Europe (unification de l').

Femmes (droits des). 255-256, 265, 284, 503.

Femmes (organisations de). 128, 139-140, 146-147, 378, 460.

Ferry (Jules). 487.

Festivals de la Jeunesse. 305-306.

Fidei Domum (Encyclique). 82.

Finaly (Affaire). 485.

Finance internationale. 59-63, 442-443.

Financial Times. 194.

Fléaux sociaux (lutte contre les). 125-126.

Flotte grecque (rapatriement de la). Voir Armateurs grecs.

Fonctionnaires internationaux. Voir Bureaucratie internationale.

Fonction publique européenne. 470.

Fondations américaines. 128, 146, 157, 299.

Fonds social européen (utilisation du). 272, 273.

Fouquet (N.). 60.

Foyer National juif. Voir Balfour (Déclaration).

Franco (N.). 78, 117.

Frondizi (Président). 348.

Front national (tactique du). 14, 434.

Front populaire (tactique du). 14, 434. 
Fugger (J.) 59.

Fugger (Tharzo) 59.

Fusion des Trois Exécutifs. Voir Europe (unification de l').

Gandhi. 161.

Gasperi (A. de). 18, 73.

Gaulle (de). 116, 136, 203, 232, 338.

Géorgie (affaire de). 112.

Germanisme. 102.

Goerlitz-Zgorzeled (Conférence de, mai 1959). 39, 208.

Goldmann (N.). 286.

Gomulka. 295.

Gouvernement mondial. 30, 138-139, 220, 233.

Gouvernements en exil. 464.

Grève générale (utilisation de la). 12.

[p. 546]

Gronchi (Président). 363.

« Groupe de pression virtuel » (notion de). 165.

Groupe et mouvement (comparaison de notions). 166-167.

Groupes économiques et politiques (terminologie). 162.

Groupes parlementaires (dans l'Assemblée Parlementaire Européenne). 30-31.

Guaranis (République Chrétienne des). 471.

Guatemala (affaire du). 347, 434.

Guérilla. 121.

Guerre biologique. 380.

Guerre (lutte contre la). 12, 122, 431.

Guerre radiophonique. Voir Radiodiffusion (rôle de la). Guillaume II. Voir Germanisme.

Gulbenkian (C.S.). 478.

Haganah. 107.

Hammarskjoeld (Dag). 198.

Hassound (Abdel Khalek). 456.

Haut-Comité Arabe (Palestine). 107.

Haute Silésie (plébiscite de 1921). 35, 80.

Herriot (E.). 129.

Herzl (T.). 106. 
Hillmann (S.). 37.

Hindouisme. 73.

Histoire et Science Politique. 405-406.

Hitler. 14, 35, 78, 117, 208.

Hommes d'affaires. 354.

Honduras. Voir Pavillons de complaisance.

Horthy (boycott du gouvernement). 35.

« Idéal de service ». 139.

Idée européenne. Voir Europe (unification de l').

« Idéologie et coexistence » (Réarmement Moral). 134. Idéologies (Diffusion des). 167-169, 426.

Impérialisme. 15, 281, 300, 332, 338-357, 394, 395.

Incompréhension (Lutte contre les facteurs d'). 304. Voir aussi Compréhension internationale (facteurs de la).

Industrie pétrolière. Voir Pétrole.

Industries d'armement. 58-59, 150, 325-326, 441, 450.

[p. 547]

Infaillibilité Pontificale (dogme de l'). Voir Vieux catholiques.

Influence (hiérarchie d'). 11.

Information (professionnels de l'). 304.

Instituts séculiers. 77-78.

Institut Universitaire de Hautes Études Internationales. 6, 445, 451, 475, 479.

Intégration européenne. Voir Europe (unification de l').

« Intérêt commun ». 236, 265.

« Intérêt substantiel » (doctrine de l'). 178.

« Internationale américaine ». 26-27, 146, 401.

« Internationale noire ». 73.

« Internationale occidentale ». Voir « Internationale américaine ».

« Internationale vaticane ». 146.

Intervention des affaires dans la vie politique. 291-292, 346-348.

Intervention des États. 213, 280-281.

Investissements internationaux. Voir Prêts internationaux.

Invitations à des voyages. 22, 27, 50, 306, 309.

Islam et démocratie. Voir Islamisme.

Islamisme. 97-103, 109-110, 137, 290, 329, 375, 423-424, 452-454, 502.

Islamistan. Voir Islamisme.

Israël (fondation de l'État d'). 107, 286. 
Iran (nationalisation des pétroles de l'). 347, 358, 491.

Irlande (indépendance de l'). 111, 286.

Jean XXIII. 85, 88.

Jeunes Églises protestantes. Voir Protestantisme.

Jeunesse du Monde. 306.

Jésuites. 77, 217, 447.

Jouhaux (L.). 129.

Judaïsme. 79, 94-97, 328, 377.

Juifs (projet de création d'une Union mondiale des journalistes). 96.

Juifs (situation des). Voir Antisémitisme.

Jumelage des villes. 314.

Kautsky (Ultra-impérialisme). 366.

Kennedy (J.). 301.

Kerala (renversement du régime communisme au). 135.

Koweit Voir Pétrole.

Kreuzer (I.). 441.

[p. 548]

Khrouchtchev (N.S.). 109, 481.

Kurde (mouvement). 112-113, 456.

Kurdistan. Voir Kurde (mouvement).

Laïcat. Voir catholicisme.

Laïcisation de l'État. Voir Doctrine musulmane de l'État.

La Marsa (convention de). 61.

Lambeth (conférence de). Voir Anglicanisme.

« Latinité ». 295.

Lazard. 62, 351.

Légalité (respect de la). 131-132, 333.

Législations de complaisance. 64, 192, 193, 194-195, 226.

Léon XIII. 238.

Lesseps (F. de). 161.

Libéralisme. 19, 31, 153, 313, 331.

Libération (guerres de). 15, 54.

Libéria. Voir Pavillons de complaisance.

Liberté de la presse. 132, 304. 
Liberté d'opinion. 136-137.

Liberté syndicale. 40, 48, 247, 248-249.

Libre circulation des informations. 132, 303.

Lie (Trygve). 198.

« Listes noires » arabes. Voir Boycottage.

Littérature sur les groupes internationaux (Trait de la). 412.

Livanos. Voir Armateurs grecs.

Livre sterling (pression sur la). Voir Zurich (banquiers de).

Lloyd George (D.). 161.

« Lobby européen », 272, 276-277.

Maghreb (Fédération du). 111.

Malmoë (Congrès de juillet 1951). 31.

Mandats (système des). 457.

Manifeste aux hommes libres ». 136.

Marchands de canons ». Voir Industries d'armement.

Marché Commun. Voir Europe (Unification de l').

Marché Commun Arabe. 110.

Marché international du Blé. Voir Blé.

Marché international du Café. Voir Café.

[p. 549]

Marché international de l'Étain. Voir Étain.

Marché international du Pétrole. Voir Pétrole.

Marxisme. 154, 231, 264, 303, 340, 350, 352, 408.

Masaryk (T.G.). 129.

Matières premières. 42, 65, 332, 349, 355-357.

Matteï (Е.). 156, 160, 359, 361, 363, 365, 492, 500.

Mau-Mau. 105.

Mauritanie (veto russe sur la). 419.

Mayer (D.). 455.

M'Boya (Tom). 50.

Médecine (défense de la). 275, 374-375.

Médiation (action en faveur de la). 75, 264.

Messine (résolution de). Voir Europe (unification de l').

Milieu (notion de). 164-165, 215.

« Milieux financiers ». 62.

Minorités chinoises dans le Sud-Est asiatique. 104. 
Minorités chrétiennes d'Orient. 104.

Minorités ethniques. 103-104, 203-204, 231, 376, 415.

Missions catholiques. 76-77, 140, 217, 501.

Missions protestantes. 91, 376, 493.

Mollet (G.). 17, 20, 202.

Monnet (J.). 316, 318.

Monopoles (action des). Voir Impérialisme.

Moralité publique (protection de la). 127, 381.

Moratoire Hoover. 370.

Mussolini (B.). 78.

Mutual Security Act, 1954. 350.

Mythes. 19, 129, 295, 296, 408.

Nasser (G.A.). 100.

National Institute of Economic and Social Research (Londres). 356.

Nationalisme. 102, 104, 139, 210, 358, 381, 454.

Nationalisme africain. Voir Afrique.

Nationalisme arabe. Voir Arabisme.

Nationalisme irlando-américain. 111.

Nationalisme ukrainien. 456.

« Nationalité » des personnes morales. 171-172.

« Nationalité » des sociétés commerciales. 172-178, 192, 193.

« Nationalités rares ». 390.

[p. 550]

National-socialisme. 28, 31-33, 204, 226, 286, 288, 328.

Nation arabe. Voir Arabisme.

Nations Unies (propagande pour les). 310-311.

Nazisme. Voir National-socialisme.

Négociations secrètes. 120-121, 283.

Néo-malthusianisme. 126.

Neutralisme. 50, 53, 167-169, 299, 329, 399, 424, 465.

Neutralité. 168

Niarchos (S.). Voir Armateurs grecs.

Nicolas II. 379.

Nuremberg (procès de). 58, 302.

Oder-Neisse (Frontière de l'). 39, 116-117, 208. 
Ecuménisme. 85, 87, 88, 90, 91-94, 451.

« Officiers libres » (Égypte). 453.

Ollenhauer (E.). 316.

Onassis (A.). Voir Armateurs grecs.

Ordres religieux. 77, 217.

Organisation Commune des Régions Sahariennes. 173.

Organisation des Nations Unies pour l'habitation (proposition de création). 387.

Organisation iranienne du Plan. 351.

« Organisations annexes ». 22, 145, 265.

Organisations « en exil ». Voir Exilés.

Orthodoxie. 85-88, 92, 102, 502.

Observatore Romano. 81.

Oulemas. 101, 217, 454.

Pacelli (E.). Voir Pie XII.

Pacte Atlantique (lutte contre le). 201.

Paix et Liberté 136.

Paix (lutte pour la). 21, 39-40, 52, 75, 76, 89, 90, 166, 252, 295, 311, 376, 378, 380, 398, 493-494.

Palestine (mandat britannique sur la). 106-107, 198.

Palmerston. 201.

Pan-Africanisme. Voir Afrique.

Panama. Voir Pavillons de complaisance.

Pan-Arabisme. Voir Arabisme.

Pan-Germanisme. Voir Germanisme.

[p. 551]

Pan-Islamisme. Voir Islamisme.

Pan-Maghrébisme. Voir Maghreb (Fédération du).

Pan-Slavisme. Voir Slavisme.

Papauté Voir Catholicisme.

Parkinson (C.N.). 263, 307.

Parlement Mondial. Voir Gouvernement Mondial.

Parlement Ouvrier International. 34, 251.

Partage de la terre. Voir Impérialisme.

« Parti colonial ». Voir Colonisation.

Parti communiste français. 402.

Parti communiste syrien. 456. 
Parti ouvrier polonais. 502.

Parti social-chrétien de Belgique. 18.

Parti social-démocrate (Allemagne). 316.

Parti travailliste (G-B.). 17, 299.

Partis communistes. 13, 14, 21, 23, 25, 204, 497.

Partis démocrates chrétiens. 18, 81, 312, 316.

Pasternak (B.). 137.

Patriarcat d'Alexandrie. Voir Orthodoxie.

Patriarcat d'Antioche. Voir Orthodoxie.

Patriarcat de Jérusalem. Voir Orthodoxie.

Patriarcat Ecuménique de Constantinople. Voir Orthodoxie.

Patriarche de Serbie. Voir Orthodoxie.

Pavillons de complaisance. 46.

Pays afro-asiatiques. Voir Bandoeng (monde de).

Pays colonisés. Voir Anti-colonialisme.

Peine de mort (lutte contre la). 236.

Pereire. 62.

Personnalité morale des sociétés commerciales. 178.

Pétitions au Conseil de Tutelle. 114-115.

Pétrole. 65, 113, 140, 156, 195, 223, 227, 228, 292, 328, 347, 357-366, 491, 492, 500.

Picasso 264.

Pie X. 76

Pie XI. 80.

Pie XII. 77, 80.

Pildsuski. 80.

Pilotes de Suez (retrait des). 289.

Pineau (Ch.) 175, 202.

Plan Dawes. 369.

[p. 552]

Plan Marshall. 37.

Plan Schuman. Voir Europe (Unification de l'.)

Polarisation idéologique. 399.

Politique pontificale. Voir Catholicisme.

Porteurs de fonds russes (indemnisation des). 202.

Pour une paix durable, pour une démocratie populaire. 16.

Presse des groupes. 308.

Presse (situation et rôle de la). 133, 214, 304, 308-309. 
Pressions sur la presse. Voir Presse.

Prestige américain. Voir Anti-américanisme.

Prêtres ouvriers. Voir Catholicisme.

Prêts internationaux

— privés. 67, 343-344, 349-350, 488, 489.

- gouvernementaux et intergouvernementaux. 350-351.

Prévention des naissances. 81, 126, 141, 279.

Primauté du droit. Voir Légalité (respect de la).

Princeps Pastorum (Encyclique). 501.

Prisonniers de guerre. Voir Victimes des conflits (protection des).

Prix Nobel. 397.

Procès politiques. 131.

Produits alimentaires. Voir Matières Premières.

Produits de substitution. Voir Matières Premières.

Profits de guerre. 58.

Prostitution. Voir Traite des personnes.

Protection des créanciers nationaux. 201-202.

Protection diplomatique. 470.

Protestantisme. 79, 88-94, 376, 377, 450.

Public (notion de). 165-166, 204-205, 215.

Quai d'Orsay. 157.

Qatar. Voir Pétrole.

Racisme. Voir Discriminations raciales (lutte contre les).

Radiations nucléaires (crainte des). 297-299.

Radiodiffusion (rôle de la). 302-303, 309, 502.

Raffinage (du pétrole). Voir Pétrole.

Raison d'État. 132, 397.

Rapports de force dans la société internationale. 335-336.

Rapprochement franco-allemand.135, 204-205, 323.

[p. 553]

Rassemblement du peuple français (R.P.F.). 232, 338.

Rassemblements, Voir Congrès (rôle et technique des), Festivals de la Jeunesse, Séminaire (technique du).

Ratti (A.) Voir Pie XI.

Réarmement allemand. 329. 
Recherche motivationnelle. 293.

Réfugiés allemands. 116, 117.

Réfugiés arabes. 116, 117.

Réfugiés des pays communistes. 116, 117.

Réfugiés (statut des). 458.

Régionalisation de l'action des groupes. 41, 44, 47, 51, 323, 396, 438.

Relations culturelles. 157, 303.

« Relations internationales » (définition des). 197.

« Relations publiques ». 304.

Religion. Voir Anglicanisme, Bouddhisme, Catholicisme, Confucianisme, Hindouïsme, Orthodoxie, Protestantisme, Vieux Catholiques.

Religions (histoire des). 444.

Religions (sociologie des). 444.

Rencontres internationales de Genève. 301.

Répression de la traite des personnes. Voir Traite des personnes (Abolition de la).

Républicains espagnols. Voir Exilés.

République Arabe Unie. Voir Arabisme.

Réveil de la Nation Arabe (Le). 109.

Révélation (dépôt de la). Voir Islamisme.

Révisionisme. Voir Communisme.

Révolution d'Octobre. Voir Révolution soviétique.

Révolution égyptienne. 100. Voir aussi « Officiers Libres ».

Révolution française (rôle de la maçonnerie dans la). 28.

Révolution hongroise. 45, 122, 137, 208, 247, 249, 329, 463.

Révolution soviétique. 13, 21, 85, 216.

Roche (E.). 477.

Rolland (R.). 129.

Rothschild 60, 61, 62, 106, 442.

Sahara. 209, 299, 361, 363, 365.

Salafiya (doctrine de la). Voir Islamisme.

Sanctions (contre l'Italie fasciste). 287.

Santé mentale. 127.

[p. 554]

Santé (protection de la). 127, 143-144, 373-375.

Sarre. 80, 117.

Sartre (Jean-Paul). 455. 
Schuman (R.). 18, 73, 135.

Science. Voir Associations scientifiques.

Secrétaire général de l'O.N.U. 198-199, 254, 386, 469.

Secrétariats professionnels internationaux. 34, 45-46.

Secret (dans les négociations). Voir Négociations secrètes.

Secret professionnel des journalistes. Voir Liberté de la Presse.

Sectes religieuses. 75 .

Section Française de l'Internationale Ouvrière (S.F.I.O.). 20.

Sécurité routière. Voir Transports (problèmes des).

Sécurité sociale (renforcement de la). 118.

Ségrégation. Voir Discrimination Raciale.

Séminaire (technique du). 307-308.

Séverine. 129.

Sèvres (Traité de). 113.

Sherman Act. 354.

Sidérurgie allemande (reconcentration). 367.

Siège social (critère du). Voir « Nationalité » des sociétés commerciales.

Signatures (campagnes de). 295, 309, 379.

Sionisme, 33, 105-109, 181, 204, 218, 328, 503.

Slavisme. 27, 102-103.

Socialisme, 16-17, 19-21, 31, 247, 331.

Socialistes allemands. Voir Exilés.

« Sociétés internationales ». 70, 172, 175, 176, 177, 500.

Sociétés d'Économie Mixte. 156.

Sociétés religieuses et Sociétés politiques. 72, 78, 216-217.

Soustelle (J.). 203.

Sport (rapports avec la politique). 141-142, 397.

Stabilisation des cours. Voir Matières premières.

Staline. 14, 318, 402.

Streit (Cl.). 133.

Structure (notion de la). 409.

Stupéfiants (lutte contre les). 252, 386.

Succession d'Espagne (guerre de). 60.

Sucre. 274, 349.

Suez (opération de). 20, 297, 318, 433, 478.

Synarchie. 28, 73. 
[p. 555]

Taoïsme. 422.

Télévision (rôle de la). 302.

Termes de l'échange. Voir Matières premières.

Thomas (A.). 35, 250. Tibet (affaire du). 74, 115, 208.

« Tiers-Monde ». 334.

« Titisme ». 24.

Tito. 123.

Togo (sous administration britannique). 115.

Totalitarisme. 136-137.

Touré (Sekou). 49.

Toynbee. 451.

Traduction en langues étrangères. 303.

Traite des personnes (abolition de la). 125, 252.

Traité franco-éthiopien. Voir Chemin de fer franco-éthiopien.

Transcaucasie (République de). 456.

Transférés. Voir Expulsés.

Transports (problème des). 69, 372-373, 384, 386.

Travail forcé. 462, 473.

Tribunal de la Signature Apostolique. 278.

Trieste (affaire de). 123.

« Trois sages ». Voir Énergie atomique.

« Tripartisme » (O.I.T.). 155, 245, 246-247.

Trusts pétroliers. Voir Pétrole.

« Tryptique ». (création du). 373.

Tunisie (établissement du protectorat sur la). 60-61.

Tunnel sous la Manche (étude du). 70.

Tunnel sous le Mont-Blanc (constitution du). 69-70.

Tyrol du Sud (affaire du). 104, 122.

Ulster (Comtés de l'). 111.

Unification de l'Europe. Voir Europe (unification de l').

« Unionistes ». Voir Europe (unification de l’Union Sud-Africaine. 32, 93, 133, 208, 381.

Universalité (dans le recrutement).40, 144, 148-149, 182, 264, 390, 467.

[p. 556] 
Van Kol. 14.

Van Zeeland (P.). 18.

Vatican (État du). 76, 216.

Versailles (Traité de). 104.

Vichy (gouvernement de). 28.

Victimes des conflits (protection des). 119-123.

Vieux Catholiques. 92.

Zaharoff (Sir B.). 161, 465.

Zimmerwald (Conférence de). 13.

Zurich (banquiers de). 62. 